1989

\title{
Petrological and maturation characteristics of organic matter from the middle proterozoic McArthur Basin, Australia
}

Ian H. Crick

University of Wollongong

\section{Recommended Citation}

Crick, Ian H., Petrological and maturation characteristics of organic matter from the middle proterozoic McArthur Basin, Australia, Doctor of Philosophy thesis, Department of Geology, University of Wollongong, 1989. http://ro.uow.edu.au/theses/1399 


\section{NOTE}

This online version of the thesis may have different page formatting and pagination from the paper copy held in the University of Wollongong Library.

\section{UNIVERSITY OF WOLLONGONG}

\section{COPYRIGHT WARNING}

You may print or download ONE copy of this document for the purpose of your own research or study. The University does not authorise you to copy, communicate or otherwise make available electronically to any other person any copyright material contained on this site. You are reminded of the following:

Copyright owners are entitled to take legal action against persons who infringe their copyright. A reproduction of material that is protected by copyright may be a copyright infringement. A court may impose penalties and award damages in relation to offences and infringements relating to copyright material. Higher penalties may apply, and higher damages may be awarded, for offences and infringements involving the conversion of material into digital or electronic form. 
PETROLOGICAL AND MATURATION CHARACTERISTICS OF ORGANIC MATTER FROM THE MIDDLE PROTEROZOIC MCARTHUR BASIN, AUSTRALIA.

A thesis submitted in fulfilment of the requirements for the award of the degree of

DOCTOR OF PHILOSOPHY

from

THE UNIVERSITY OF WOLLONGONG

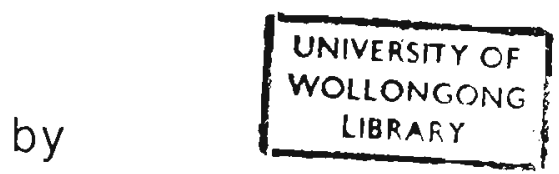

IAN H. CRICK

(B.Sc.(Hons), University of Melbourne, 1967)

Department of Geology 
Except where otherwise acknowledged in the text, the contents of this thesis are the result of original research by the author. The work has not been previously submitted for a degree to any other university or similar institution.

I. H. Crick 


\author{
ABSTRACT \\ ACKNOWLEDGEMENTS \\ LIST OF FIGURES \\ LIST OF TABLES
}

Page

CHAPTER 1. INTRODUCTION AND AIMS

CHAPTER 2. GEOLOGY OF THE MCARTHUR BASIN

2.1 Introduction

2.2 Stratigraphy

2.3 Intrusives

8

2.4 Age

2.5 Depositional framework and tectonics

2.6 Depositional environments

2.7 Occurrence of hydrocarbons

\title{
CHAPTER 3. METHODOLOGY
}

3.1 Samples

3.2 Measurement of geothermal gradients

3.3 Screening of samples: Rock-Eval and Total Organic Carbon analyses

3.4 Preparation of specimens for microscopic examination 25

3.5 Microscopic examination 25

3.6 Reflectance measurements

3.7 Fluorescence measurements

3.8 Statistical analysis and graphing of reflectance and fluorescence measurements

3.9 Preparation of macerates

3.10 Scanning electron microscopy and X-ray mapping

3.11 Extracts

3.12 Elemental analyses

3.13 Photographic film and processing 
CHAPTER 4. CLASSIFICATION AND NOMENCLATURE OF ORGANIC MATTER IN GEOLOGICAL FORMATIONS

4.1 Introduction 36

$4.2 \quad$ "Global" classification schemes 37

4.3 Bitumen associated with radioactive elements 45

$\begin{array}{lll}4.4 & \text { Kerogen } & 47\end{array}$

$4.5 \quad$ Coal and oil shales 48

4.6 Classification of Precambrian organic matter 49

4.7 Conclusions 52

CHAPTER 5. NOMENCLATURE AND PETROGRAPHIC

DESCRIPTIONS OF THE ORGANIC MATTER IN PROTEROZOIC SEDIMENTARY ROCKS OF THE MCARTHUR BASIN

5.1 Introduction 52

5.2 Nomenclature and definitions 52

5.2.1 Lamalginite 52

5.2.2 Oncalginite (new name) 53

5.2.3 Bitumen 54

5.2.4 Thucholite 55

5.3 Organic matter in sedimentary rocks in the McArthur Basin $\quad 55$

5.3.1 McArthur Group $\quad 59$

$\begin{array}{ll}\text { 5.3.2 Nathan Group } & 67\end{array}$

$\begin{array}{lll}\text { 5.3.4 Roper Group } & 67\end{array}$

CHAPTER 6. REFLECTANCES OF THE ORGANIC MATTER TYPES

$\begin{array}{lll}6.1 & \text { Introduction } & 71\end{array}$

6.2 Reflectances of lamalginite and bitumen 71

$\begin{array}{ll}6.2 .1 & 71\end{array}$

6.2.2 Bitumen 72

6.2.3 Ranges of mean maximum reflectances 74

6.2.4 Relationships between mean maximum and mean minimum reflectances $\quad 74$ 
6.3 Reflectances of thucholite

6.4 Changes to reflectances with increasing depths

CHAPTER 7. ASSESSMENT OF MATURATION LEVELS 82

7.1 Introduction

7.2 Tmax

7.3 Reflectance

7.4 Methylphenanthrene Index

7.5 Tmax versus extractable hydrocarbon yields

93

7.6 Reflectance versus extractable hydrocarbon yields

7.7 Calculated vitrinite reflectances derived from $\mathrm{MPI}-1$ indices versus extractable hydrocarbon yields

CHAPTER 8. LEVELS OF MATURATION WITHIN THE MCARTHUR BASIN

8.1 Introduction

8.2 Maturation levels in the Roper Group

CHAPTER 9. GEOLOGICAL MODELLING AND TIMING OF OIL GENERATION

9.1 Introduction

9.2 Thermal history of the McArthur Basin

9.3 Present geothermal gradients

9.4 Geological models 
10.3 Origin of the organic matter types in the McArthur Basin

Lamalginite

CHAPTER 11. CONCLUSIONS AND SIGNIFICANCE TO PETROLEUM AND MINERAL EXPLORATION IN THE PRECAMBRIAN

11.I Introduction

11.2 Organic matter types

11.3 Origin of the organic matter

11.4 Reflectances of the organic matter types

11.5 Assessment of maturation levels

11.6 Maturation patterns and history of the McArthur Basin

11.8 Significance for petroleum and mineral exploration

\section{REFERENCES}

\section{REPRINT}

Petroleum Geology and Geochemistry of Middle Proterozoic McArthur Basin, northern Australia II: Assessment of Source Rock Potential, by I. H. Crick, C. J. Boreham, A. C. Cook, and T. G. Powell. The American Association of Petroleum Geologists Bulletin, v. 72, no. 12 (December 1988), pp. 1495 - 1514. 


\section{ABSTRACT}

Organic matter in middle Proterozoic sedimentary rocks of the McArthur Basin occurs predominately within finegrained clastic sediments and is made up of the petrographically discernable entities, lamalginite, bitumen, thucholite and oncalginite. With increasing maturation, fluorescence in lamalginite diminishes from bright yellow to dull brownishorange and eventually ceases. Disaggregation of nonfluorescent lamalginite may have led to the formation of some types of bitumen. The lamalginite probably formed from a variety of micro-organisms but few are preserved in the lamalginite.

Reflectances of discrete maceral types generally show systematic increases with increasing depth, but discontinuities occur where fluorescent lamalginite gives way to nonfluorescent lamalginite and bitumen. The relationships of reflectance and Tmax indices to the oil window, and of observed reflectances to calculated vitrinite reflectances, derived from methylphenanthrene indices, are established.

Maturation levels in the McArthur Basin range from marginally mature to overmature. Contact metamorphism in the Roper Group and hydrothermal activity, associated with base metal mineralisation in places, in the McArthur Group, have locally increased maturation levels. Maturation levels in the Roper Group that are unaffected by contact metamorphism, display a pattern consistent with the concept that the Roper Group formed during the sag phase of the basin's development and that there has been subsequently a relatively uniform geological history. Maturation levels in the McArthur Group that are 
unaffected by hydrothermal activity, show a different pattern resulting from variable subsidence rates and geothermal gradients during the final phase of extension in the basin which preceded the sag phase.

Comparisons between modelled vitrinite reflectances and observed reflectances, recalculated to equivalent vitrinite reflectances, suggest that the Roper Group was up to about 1000 $m$ thicker than its observed maximum thickness and that sedimentary cover overlying the McArthur Group was less than $2000 \mathrm{~m}$ in places.

Hydrocarbon generation occurred from organic-rich units within the Roper and McArthur Groups, particularly from the Velkerri and Barney Creek Formations which contain up to $7 \%$ total organic carbon. Oil generation from these formations commenced before $1000 \mathrm{Ma}$ but low rates of oil generation may have continued, at low temperatures, for a considerable period of time extending well into the Phanerozoic. 


\section{ACKNOWLEDGEMENTS}

My thanks go to Amoco Australia Ltd., BHP Exploration, CRA Exploration and Carpentaria Exploration Companies for samples, and for allowing me to sample from stratigraphic, petroleum and mineral exploration holes, and to Jim Jackson and Ken Plumb for additional samples. My thanks are also due to the Bureau of Mineral Resources, Geology and Geophysics, Australia, Organic Geochemical Laboratory under the direction of Drs. T. Powell and C. Boreham, for most of the organic geochemical analyses.

I gratefully acknowledge the encouragement and advice given to me by my supervisors, Prof. A. C. Cook and Dr. T. G. Powell.

The work was assisted by a grant from the Australian National Energy Demonstration and Development Program, and by the Bureau of Mineral Resources, Geology and Geophysics, Australia. 


\section{LIST OF FIGURES}

Figure

Page

1-1 Locality map of the McArthur Basin, Australia.

2-1 Structural map of the McArthur Basin showing the 6 major tectonic units.

2-2 Geology of the southern McArthur Basin.

2-3 Schematic and interpretative NW-SE section showing the main stratigraphic and structural elements in the southern McArthur Basin.

2-4 Schematic cross-section of the southern McArthur Basin at the close of Roper Group sedimentation.

3-1 Location of drill holes in the McArthur Basin sampled in this study.

3-2 Location of drill holes (GR1-5, GR7-11) in the Glyde River Subbasin together with the surface geology of the region.

3-3 Signals emitted by a specimen by interaction with incident electron beam in a scanning electron microscope. 
Figure

5-1 Histograms showing total organic carbon contents for some formations in the Nathan and McArthur Groups.

5-2 Histograms showing total organic carbon contents for formations of the Roper Group.

5-3 Measurements of fluorescence intensity (I) at $546 \mathrm{~nm}$ and the red/green quotient "Q" $(650 / 500 \mathrm{~nm})$, plotted against depth, for lamalginite in the Barney Creek Formation, DDH GR10, Glyde River Subbasin.

5-4 Alteration of fluorescence intensity at $546 \mathrm{~nm}$ of lamalginite (Ai) from DDH GR10, Barney Creek Formation, after 30 minutes of irradiation.

5-5 Histogram of diameters of thucholite grains from DDH GR10, Barney Creek Formation.

6-1 Mean maximum reflectances for fluorescent and nonfluorescent lamalginite from the same specimens, Roper and McArthur Groups.

6-2 Histogram of mean maximum reflectances for the various organic matter types (excluding thucholite) in the McArthur Basin. 
Figure

6-3 Histogram of mean maximum reflectances in the range $0.0-1.59 \%$ for various organic matter types (excluding thucholite) in the McArthur Basin. 73

6-4 Relationship between maximum and minimum mean reflectances for all organic matter types, excluding thucholites, but including means of mixed maceral populations.

6-5 Relationship between maximum and minimum mean reflectances up to a maximum mean reflectivity of $1.5 \%$ for all organic matter types, excluding thucholites, but including means of mixed maceral populations.

6-6 Relationship between maximum and maximum minus minimum mean reflectances for all organic matter types, excluding thucholites, but including means of mixed maceral populations.

6-7 Relationship between maximum and minimum mean reflectances for all organic matter types, excluding thucholite, including means of mixed maceral populations together with vitrinite trend lines and semi-graphite range. 
Figure

6-8 Relationship between maximum and minimum mean reflectances for thucholites from DDH GR10.

6-9 Relationship between maximum and minimum mean reflectances for all organic matter types, including thucholite, and also means of mixed maceral populations.

6-10 Relationship between maximum minus minimum mean reflectances versus mean maximum reflectances for thucholites from DDH GR10.

6-11 Mean maximum reflectance values showing the range, mean and $95 \%$ confidence limits of the mean, versus depth for thucholites of all sizes (A) and for thucholites whose maximum sizes are less than $50 \mu(B)$ from DDH GR10 in the Barney Creek Formation, Glyde River Subbasin.

6-12 Maximum reflectances of lamalginite and bitumen showing the range, mean and 95\% confidence limits of the mean versus depth for DDH GR10, Barney Creek Formation, McArthur Group.

7-1 Van Krevelen diagram showing differences in the atomic $\mathrm{H} / \mathrm{C}$ and $\mathrm{O} / \mathrm{C}$ ratios of kerogen in selected samples. 
Figure

7-2 Tmax values and production indices (PI) versus depth for DDH GR7, Barney Creek Formation, McArthur Group.

7-3 Maximum reflectances of lamalginite and bitumen showing the range, mean and 95\% confidence limites of the mean, and reflectances calculated from MPl-1 indices versus depth for DDH GR7, Barney Creek Formation, McArthur Group.

7-4 Tmax values and production indices (PI) versus depth for DDH GR10, Barney Creek Formation, McArthur Group.

7-5 Maximum reflectances of lamalginite and bitumen showing the range, mean and $95 \%$ confidence limits of the mean, and reflectances calculated from MPl-1 indices versus depth for DDH GR10, Barney Creek Formation, McArthur Group.

7-6 Tmax values and production indices $(\mathrm{PI})$ versus depth for DDH GR11, Barney Creek Formation, McArthur Group. 
Figure

7-7 Maximum reflectances of lamalginite and bitumen showing the range, mean and $95 \%$ confidence limits of the mean, and reflectances calculated from MPI-1 indices versus depth for DDH GR11, Barney Creek Formation, McArthur Group.

7-8 Tmax values and production indices (PI) versus depth for DDH Urapunga 3, Velkerri Formation, Roper Group.

7-9 Maximum reflectances of lamalginite and bitumen showing the range, mean and $95 \%$ confidence limits of the mean, and reflectances calculated from $\mathrm{MPl}-1$ indices versus depth for $\mathrm{DDH}$ Urapunga 3, Velkerri Formation, Roper Group.

7-10 Tmax values and production indices (PI) versus depth for DDH Urapunga 4, McMinn Formation $(0-42 m)$, Velkerri Formation $(42-372.5 m)$ and Corcoran Formation (397.6-532m TD).

7-11 Maximum reflectances of lamalginite and bitumen showing the range, mean and $95 \%$ confidence limits of the mean, and reflectances calculated from MPI-1 indices versus depth for DDH Urapunga 4. 
Figure

Page

7-12 Methylphenanthrene indices (MPI-1) versus the measured mean maximum reflectances of organic matter from the same samples in the McArthur Basin.

7-13 Measured mean maximum reflectances for lamalginite and bitumen plotted against their calculated vitrinite reflectances from methylphenanthrene indices (MPI-1). Superimposed are the limits of measured reflectances for vitrinite and liptinite (after Murchison et al., 1985) and trend lines for telalginite and lamalginite (A.C. Cook, unpublished data), from the Phanerozoic.

7-14 Hydrocarbon yield plotted against Tmax values where $\mathrm{S} 2 \geq 0.20 \mathrm{~kg} /$ tonne.

7-15. Hydrocarbon yield to $250 \mathrm{mg} / \mathrm{gm}$ TOC plotted against Tmax values where $S 2 \geq 0.20 \mathrm{~kg} /$ tonne, in the range $400-5000 \mathrm{C}$.

7-16 Hydrocarbon yield plotted against Tmax values where $S 2 \geq 0.20 \mathrm{~kg} /$ tonne, for the various organic matter types within the Tmax range 400-5000 C and yield range $0-250 \mathrm{mg} / \mathrm{g}$ TOC. 
Figure

7-17 Yield of extractable hydrocarbons versus mean maximum reflectances in the range $0-2 \%$.

7-18 Calculated vitrinite reflectances from MPI-1 indices plotted against hydrocarbon yields.

8-1 Maturation levels for organic matter in core from DDH's examined within the McArthur Basin. 100

8-2 Reflectances of nonfluorescent lamalginite and/or bitumen, and Tmax, versus depth for the wild-cat oil well, Broadmere 1, Roper Group.

8-3 Mean maximum reflectances of nonfluorescent lamalginite and/or bitumen except where indicated, and Tmax, versus depth for DDH's B8, Urapunga 3 and 4, and 82/3, Roper Group.

8-4 Mean maximum reflectances for fluorescent lamalginite or nonfluorescent lamalginite and/or bitumen (mean maxRo\%) plotted against depth, for formations in the Roper Group. The outlined reflectance values have been affected by contact metamorphism.

8-5 Tmax values plotted against depth for formations of the Roper Group. 
Figure

Page

8-6

Measured reflectances, calculated reflectances

from MPI-1 indices and Tmax values versus

depth for DDH M17/08, HYC lead-zinc deposit,

Barney Creek Formation.

107

8-7 Measured reflectances, calculated reflectances from MPI-1 indices, and Tmax values versus depth for DDH N27/63, H.Y.C. lead-zinc deposit, Barney Creek Formation.

8-8 Mean maximum reflectances of fluorescent lamalginite, nonfluorescent lamalginite and/or bitumen, and Tmax versus depth for three drill holes (GR4, 10 and 11) in the Barney Creek Formation, Glyde River Subbasin.

8-9 Mean maximum reflectances for fluorescent lamalginite, nonfluorescent lamalginite and/or bitumen, and Tmax values versus depth for the Barney Creek Formation.

8-10 Mean maximum reflectances (mean maxRo\%) for fluorescent lamalginite, nonfluorescent lamalginite and/or bitumen, and Tmax values versus depth for formations in the McArthur Group and the Balbarini Dolomite in the Nathan Group in the central and northern areas of the Batten Trough. 
Figure

9-1 Temperature versus depth for DDH 82/5 showing

all data (a) and data from about $150 \mathrm{~m}$ depth

downwards (b) where temperatures are unaffected

by near-surface perturbations.

9-2 Temperature versus depth for DDH $82 / 7$ showing all data (a) and data from about $150 \mathrm{~m}$ depth downwards (b) where temperatures are unaffected by near-surface perturbations.

9-3 Burial history for the Barney Creek Formation, DDH GR7, Glyde River Subbasin, from the depositonal-erosional model 5 .

9-4 Burial history for the Barney Creek Formation, DDH GR7, Glyde River Subbasin, from the depositonal-erosional model 7.

9-4 Depth versus reflectance (Ro\%) for lamalginite and/or bitumen and stratigraphy of Broadmere 1 .

9-5 Burial history for Broadmere 1 well, assuming that $3000 \mathrm{~m}$ of Maiwok Subgroup sediments were deposited. 
Figure

9-6 Diagram showing main oil generation periods and possible low-temperature (less than $70^{\circ} \mathrm{C}$ ) oil generation periods (dashed line) for the base of the Velkerri Formation, and the base of the Barney Creek Formation at DDH GR7 in the Glyde River Subbasin.

10-1 Outline drawings, perpendicular to bedding, of a large body of lamalginite from GR10, $37.4 \mathrm{~m}$, showing normal dimensions (A) and decompacted shape given a 4 times decompaction (B).

10-2 Outline drawings, perpendicular to bedding, of a large body of lamalginite from GR10, $37.4 \mathrm{~m}$, showing normal dimensions (A) and decompacted shape given a 15 times decompaction (B). 


\section{LIST OF TABLES}

Table

2-1 Stratigraphy of the Roper Group, southern McArthur Basin.

2-2 Stratigraphy of the Tawallah, McArthur and Nathan Groups, southern McArthur Basin.

4-1 Classification of naturally occurring organic matter after Abraham (1963).

4-2 Terminology and clasification of naturally occurring bituminous substances, after Hunt et al. (1954).

4-3 Terminology and classification of naturally occurring bitumens and related substances, after Wen et al. (1978).

4-4 A classification scheme of sedimented organic matter and derived products, after Louis et al. (1959).

4-5 Classification scheme for organic matter in geological formations after King et al. (1963).

4-6 Classification of natural bitumens and coals after Hunt (1979). 
Table

Page

5-1 Organic matter types identified in some formations within the McArthur Basin.

8-1 Ranges of Tmax, reflectances and calculated vitrinite reflectances derived from the $\mathrm{MPl}-1$ indices (Rc\%) for each formation examined in the McArthur Basin.

9-1 Thicknesses and ages of sedimentary units that probably overlaid the Barney Creek Formation in the Glyde River Subbasin.

9-2 Thicknesses and depositional times used in models for the Glyde River subbasin.

9-3 Depositional-erosional models for the Glyde River Subbasin, assuming maximum thicknesses of the McArthur and Nathan Groups above the Barney Creek Formation in the Glyde River subbasin, together with calculated vitrinite reflectance (Rv) derived from Lopatin-Waples' and Price's (1983) methods assuming a constant geothermal gradient of $30 \mathrm{c} / \mathrm{km}$ with a zero intercept of $20^{\circ} \mathrm{C}$; and the observed equivalent vitrinite reflectances. 
Table

9-4 Depositional-erosional models for the Glyde River Subbasin, assuming minimum thicknesses of the McArthur and Nathan Groups above the Barney Creek Formation in the Glyde River Subbasin, together with calculated vitrinite reflectance percentages (Rv\%) derived from Lopatin-Waples' and Price's (1983) methods assuming a constant geothermal gradient of $30 \mathrm{C} / \mathrm{km}$ with a zero intercept of $20^{\circ} \mathrm{C}$; and the observed equivalent vitrinite reflectances. 124

9-5 Depositional-erosional models at Broadmere 1, Roper Group, together with calculated vitrinite reflectance percentages (Rv\%) derived from Lopatin-Waples' and Price's (1983) methods assuming a constant geothermal gradient of $30 \mathrm{C} / \mathrm{km}$ with a zero intercept of $20^{\circ} \mathrm{C}$, and the observed equivalent vitrinite reflectances. 



\section{CHAPTER 1}

\section{INTRODUCTION AND AIMS}

Australian crude oil will become an increasingly rare commodity with production probably falling to about $25 \%$ of total requirement by the year 2000 after having been at $100 \%$ in 1985 (McEvoy, 1987). Exploration for oil in Australia and worldwide has concentrated on Phanerozoic basins with only minor attention being given to Precambrian Basins (Murray et al., 1980; Hatch and Morey, 1985) yet carbonaceous rocks are known from the Archaean (McKirdy, 1974; Hunt, 1979). The Russians discovered in 1962 commercial quantities of oil and gas in the giant Markovo field near Irkutsk in Cambrian and Proterozoic formations (Vassoevich, 1971, quoted from Hunt, 1979) and since then further commercial quantities of hydrocarbons have been discovered in Late Proterozoic sediments in Siberia (Meyerhoff, 1980) and Oman (Al-Marjeby and Nash, 1986). In Australia, a significant but non-commercial gas flow from Late Proterozoic sediments in Exoil's wildcat well, Ooraminna 1, in the Amadeus Basin (Siller et al., 1963) was the first indication that commercial quantities of hydrocarbons might be discovered in the Australian Precambrian. Since then, an economic, but as yet undeveloped gas field, Dingo, was discovered in 1981 within Late Proterozoic sediments of the Amadeus Basin (Gorter et al., 1982). 
Precambrian rocks are exposed over large areas in Australia but in many places have had thermal and tectonic histories that preclude any possibility of finding hydrocarbons. However, in the middle Proterozoic McArthur Basin, which is exposed over an area of $170,000 \mathrm{~km}^{2}$ in northern Australia (Figure 1), there are reports of organic-walled microfossils showing low levels of thermal alteration (Croxford et al., 1973; Muir, 1974, 1976; J. H. Oehler, 1977; J. H. Oehler and Logan, 1977; D. Z. Oehler, 1978; Peat et al., 1978; Peat, 1979). In addition, shows of gas and bitumen have been reported from this basin (Muir et al., 1980) and some geochemical evidence presented suggesting that the McMinn Formation contains lowmaturity rocks with moderate organic carbon concentrations (McKirdy, 1977; Peat et al., 1978).

There was clearly some interest in finding hydrocarbons in the McArthur Basin by Amoco Australia Ltd. who were actively assessing its potential during the course of this study and drilled a dry wildcat well. The potential of the basin was confirmed by the discovery of a small amount of oil in the Velkerri Formation during stratigraphic drilling by the Bureau of Mineral Resources, Geology and Geophysics (Jackson et al., 1986).

The exploration for hydrocarbons in the McArthur Basin and in other sub-greenschist facies Precambrian basins was hampered by the lack of certainty over the level of maturation of the organic matter. Indices which are used to determine 


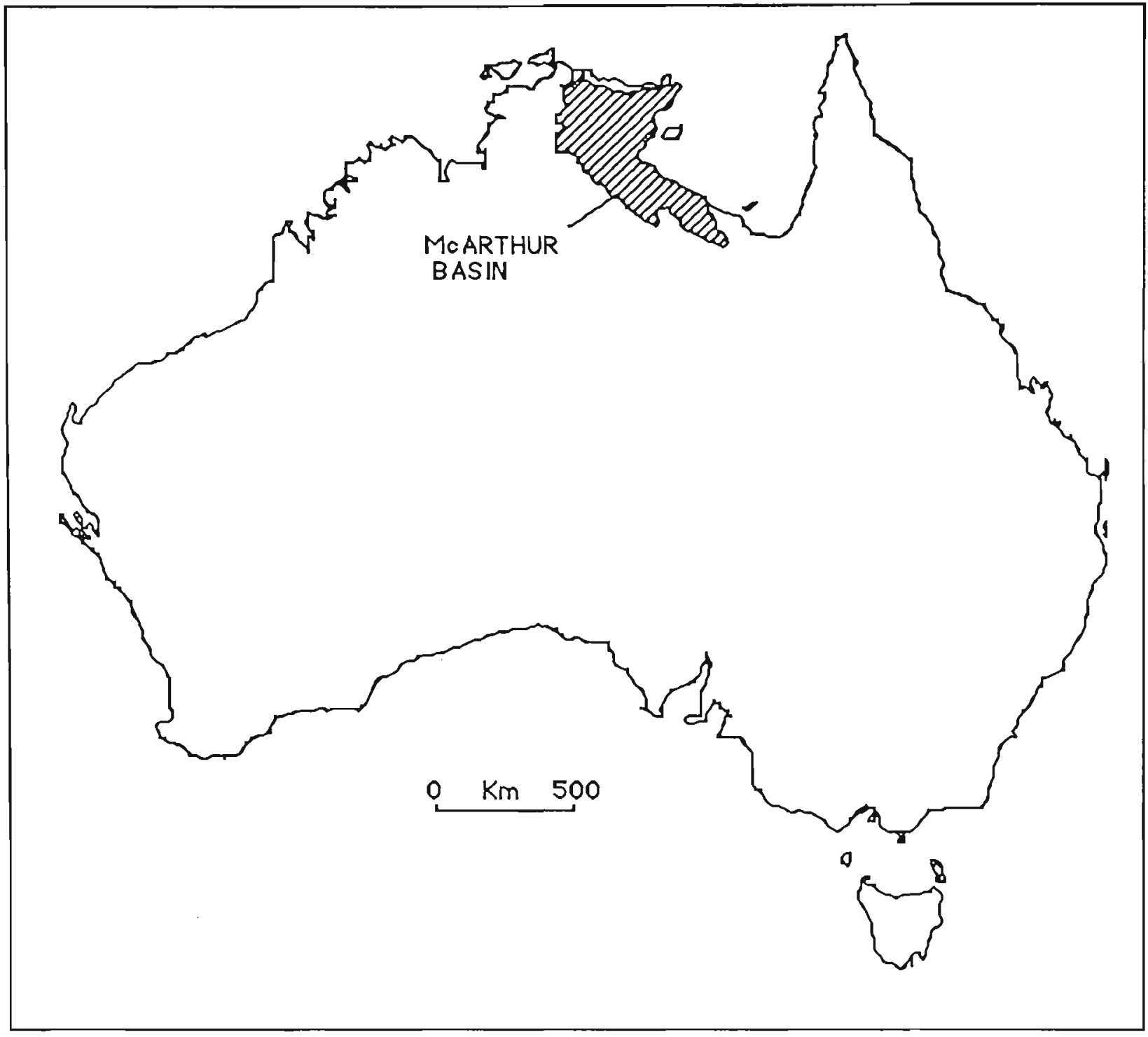

Figure 1. Locality map of the McArthur Basin, Australia.

maturation levels of organic matter in Phanerozoic rocks may behave quite differently in Precambrian rocks given the enormous amount of time between deposition and the present day, and the primitiveness of the source biota. Therefore, in order to improve the exploration effort for hydrocarbons in the McArthur and other Precambrian basins, an assessment of the two most commonly used maturation indices, reflectance and Tmax, and their relationship to the oil-window in the McArthur Basin was needed. Accordingly, the aims of this thesis are: 
1) to petrologically characterise the organic matter within the McArthur Basin;

2) establish whether reflectances of this organic matter and the geochemical maturation index "Tmax", derived from RockEval analysis, can be used to determine the maturity of the organic matter; and if so, to ascertain their relationship to the "oil-window" as conventionally defined in terms of vitrinite reflectance;

3) to assess the geological factors affecting its maturity, and 4) to compare modelled vitrinite reflectances derived from models of the geological history of the region with observed reflectances recalculated to equivalent vitrinite reflectances, and comment on the timing of hydrocarbon generation in the basin.

The area of study was restricted to the southern half of the McArthur Basin where all drill holes are located. The northern half is within the Aboriginal Reserve of Arnhem Land and access to this area is difficult due to its terrain and probems of gaining permission to enter from tribal elders. 


\section{CHAPTER 2}

\section{GEOLOGY OF THE MCARTHUR BASIN}

\subsection{Introduction}

The Middle Proterozoic McArthur Basin unconformably overlies the Early Proterozoic rocks to the west and north and the Early Proterozoic Murphy Tectonic Ridge to the east (Plumb et al. 1981). The basin is unconformably overlain to the north by sediments of the Palaeozoic Arafura Basin and to the south and east by the Palaeozoic Georgina and Daly River Basins (Figure 21). Scattered remnants of Cambrian volcanics and sediments and Cretaceous sediments unconformably overlie parts of the basin.

\subsection{Stratigraphy}

Sediments within the McArthur Basin are sub-greenschist facies and have a total thicknesss of up to $16.5 \mathrm{~km}$ (Plumb et al, 1981). Four major subdivisions are recognised in the southern McArthur Basin (Jackson et al., 1987a) - the Tawallah, McArthur, Nathan and Roper Groups, which are separated by regional unconformities (Figures 2-2, 2-3; Tables 2-1, 2-2). The Tawallah Group contains quartz-rich arenites with subordinate volcanics, carbonates, and lutites, and is up to $5.5 \mathrm{~km}$ thick. The McArthur Group is up to about $4 \mathrm{~km}$ thick and consists of interbedded carbonates and lutites with subordinate arenites and tuffaceous sediments. It is subdivided into two subgroups, the Umbalooga and Batten Subgroups, which are separated in 


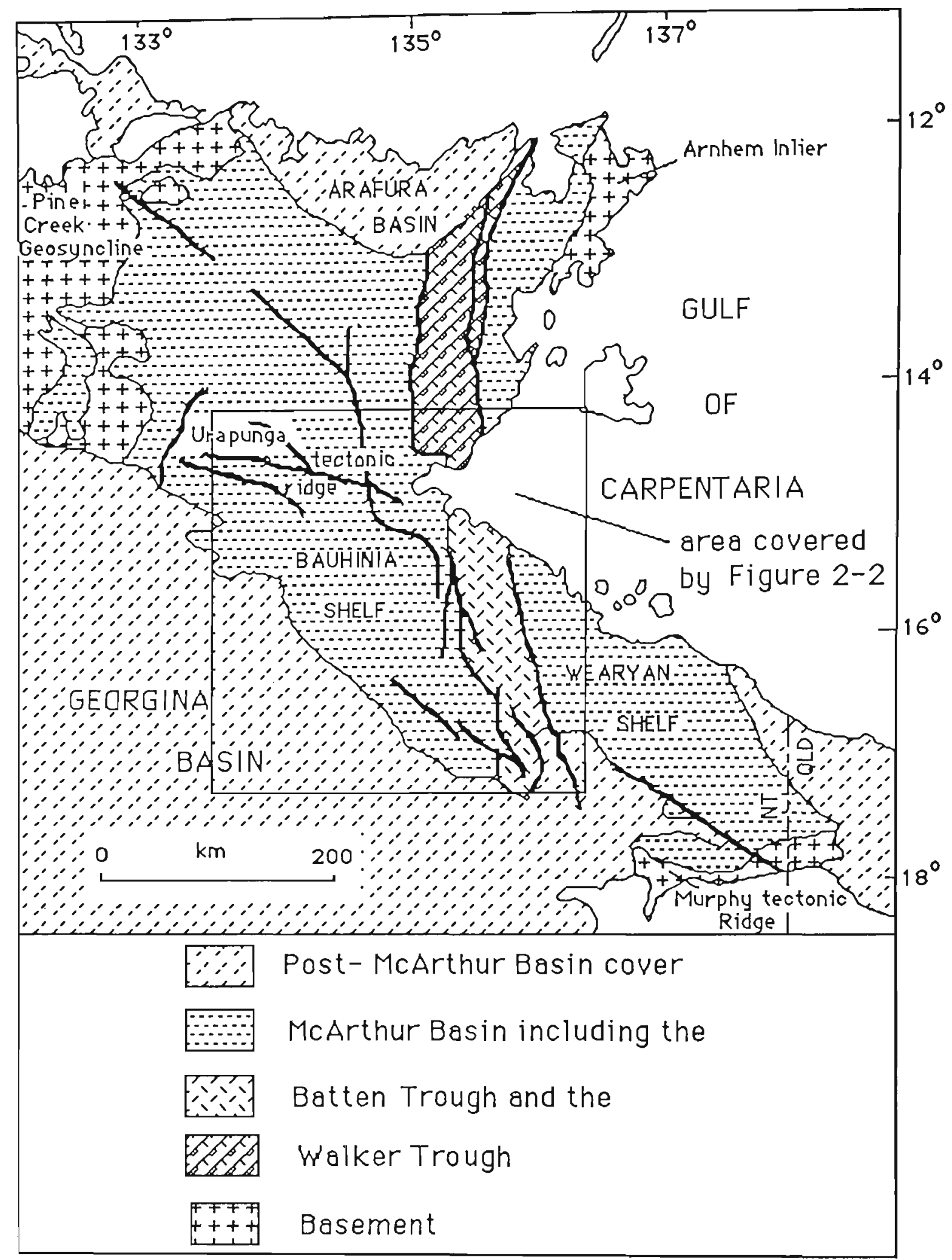

Figure 2-1. Structural map of the McArthur Basin showing the major tectonic units (after Plumb and Derrick, 1975; and Plumb and Wellman, 1987). 


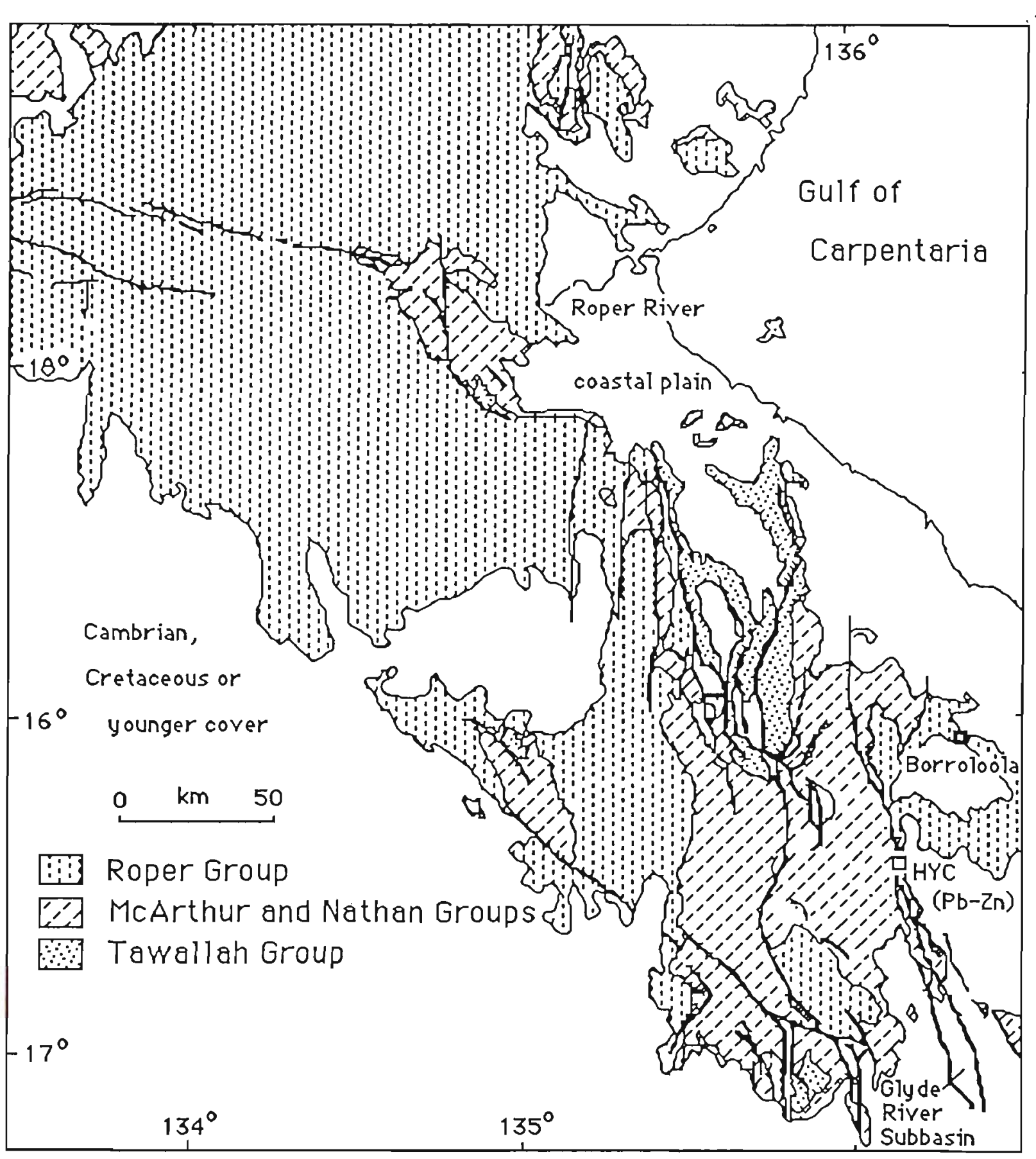

Figure 2-2. Geology of the southern McArthur Basin (after Jackson et al., 1987a)

places by an unconformity which is developed adjacent to and within major fault zones of a graben-like palaeogeographic feature, the Batten Trough.

The Nathan Group is up to $2 \mathrm{~km}$ thick and consists mainly of carbonates with minor lutites, arenites, rudites and volcanics. 
The Roper Group is the youngest of all the groups and is up to 5 $\mathrm{km}$ thick. It consists of interbedded arenites and lutites with subordinate carbonate and oolitic iron formation. Jackson et al (1987b) comment that the type of sediments in the Roper Group is very different from the McArthur and Nathan Groups and that it may be appropriate to describe them as belonging to a different, as yet unnamed basin.

\subsection{Intrusives}

Laterally extensive dolerite sills consisting in places of five different sills with an aggregate thickness of $300 \mathrm{~m}$ intrude the Roper Group (Dunn, 1963). Tucker and Boyd (in press), interpreting aeromagnetic anomalies, conclude that elongate and widely spaced dykes occur over much of the McArthur Basin. Outcrop of one such transgressive dyke occurs along a minor fault line in the Roper Group (Dunn, 1963).

\subsection{Age}

Volcanics and granites in the Murphy Tectonic Ridge, which form the basement to the McArthur Basin, have yielded minimum radiometric ages of $1733 \pm 20 \mathrm{~m} . \mathrm{y}$. for the Cliffdale Volcanics (Webb, in Plumb and Derrick, 1975) and about 1800 m.y. on the intrusive granites (McDougall et al., 1965). Page et al. (1984) comment that these igneous suites probably belong to the same magma generation event in the Kalkadoon-Leichardt Block to the south which yielded ages of between 1850-1870 m.y. 


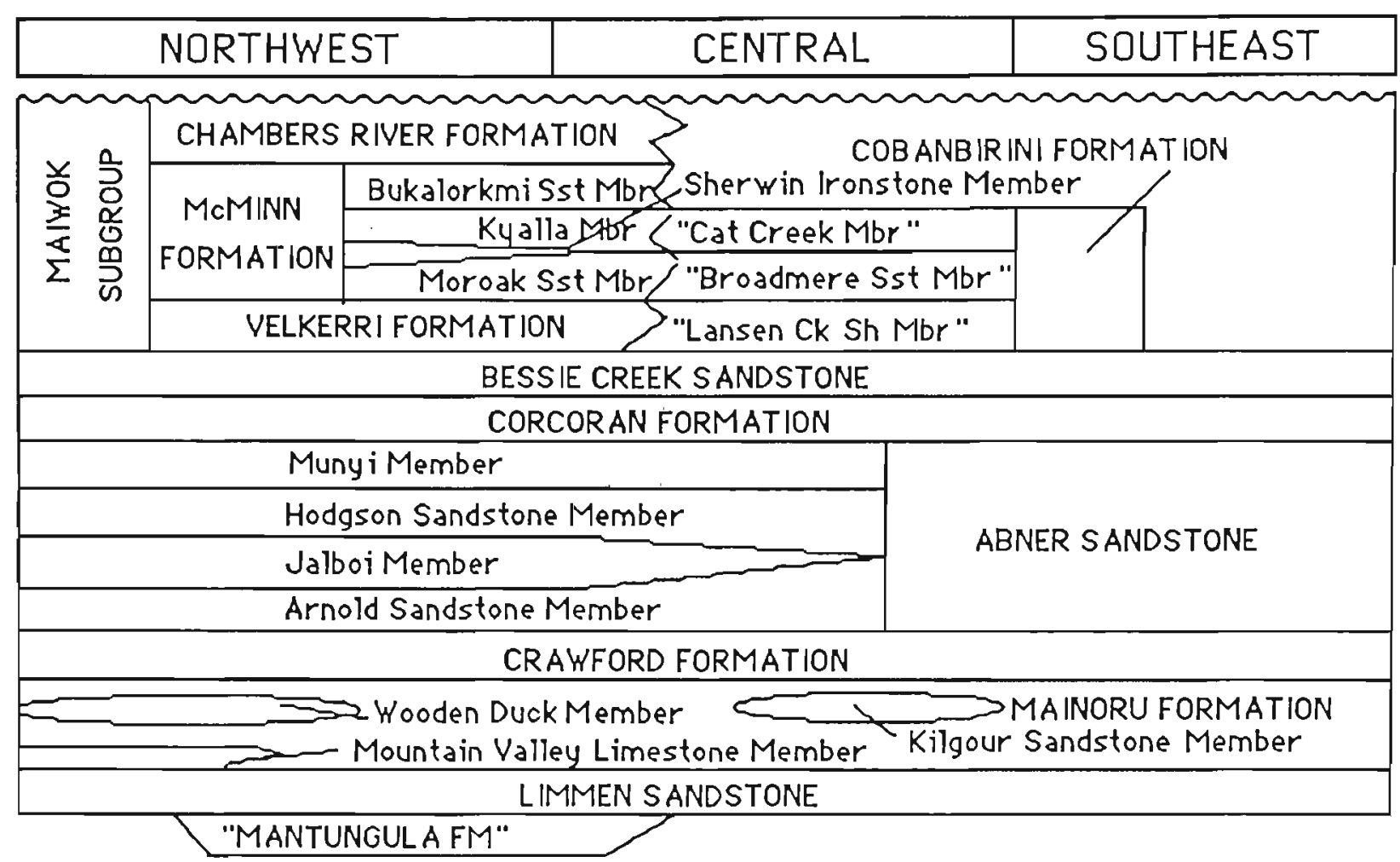

Table 2-1. Stratigraphy of the Roper Group, southern McArthur Basin (after Jackson et al., $1987 a, b)$.

K-Ar dating on sedimentary glauconites in the Tawallah Group gave minimum ages of 1,580 m.y. (Webb et al., 1963) and 1,590 m.y. (McDougall et al., 1965).

A model lead age of 1560 Ma from galena in the McArthur Group is given by Richards (1963) but because a model lead age is dependent on several parameters and assumptions, such an age has a margin of error of about 10 per cent (McDougall et al., 1965). A more precise age of $1690 \pm 27 \mathrm{Ma}$ has been derived from U-Pb zircon dating of tuffs in the Barney Creek Formation of the McArthur Group by Page (1981). Kralik (1982) gave a younger depositional age of $1537 \pm 52$ Ma for the Barney Creek Formation based 


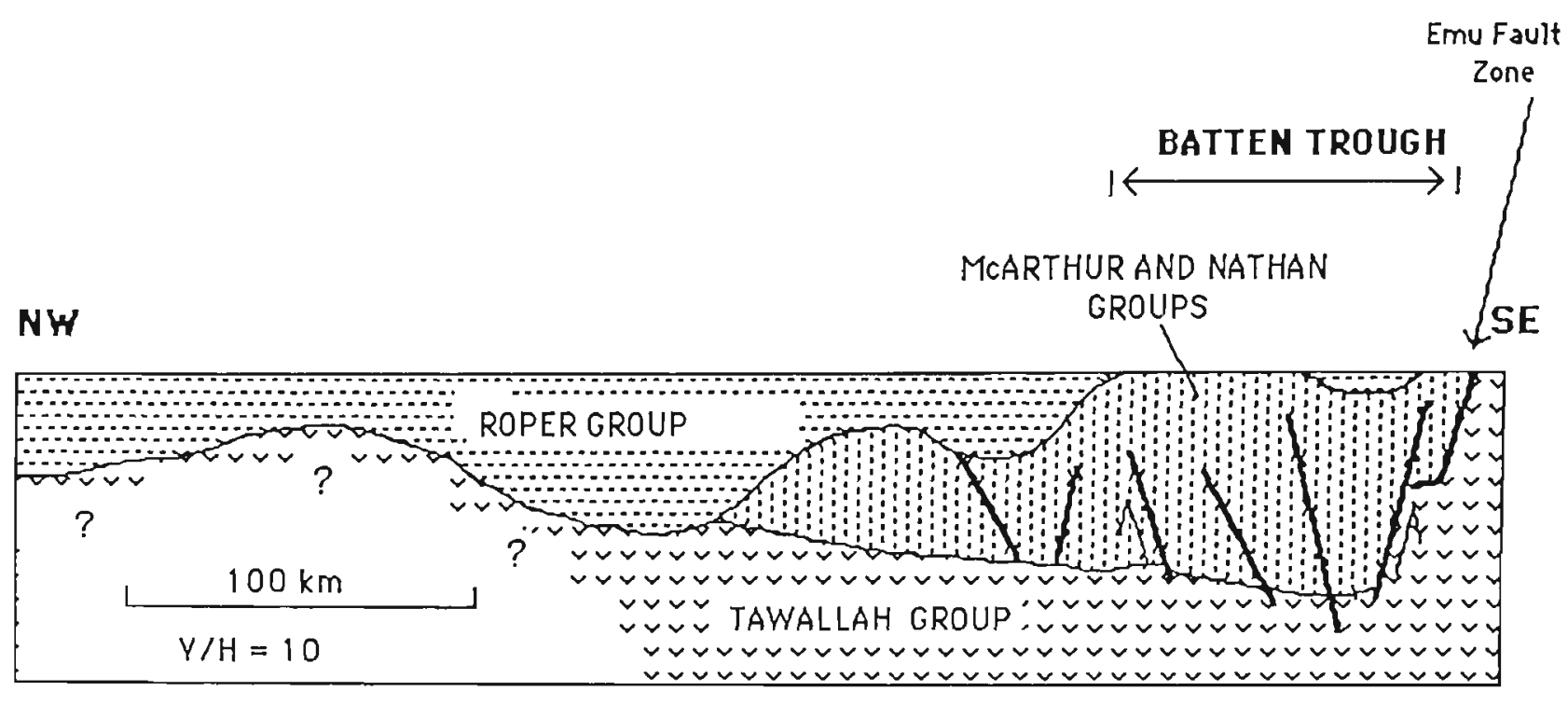

Figure 2-3. Schematic and interpretative NW-SE section showing the main stratigraphic and structural elements in the southern McArthur Basin (after Jackson et al., 1987a).

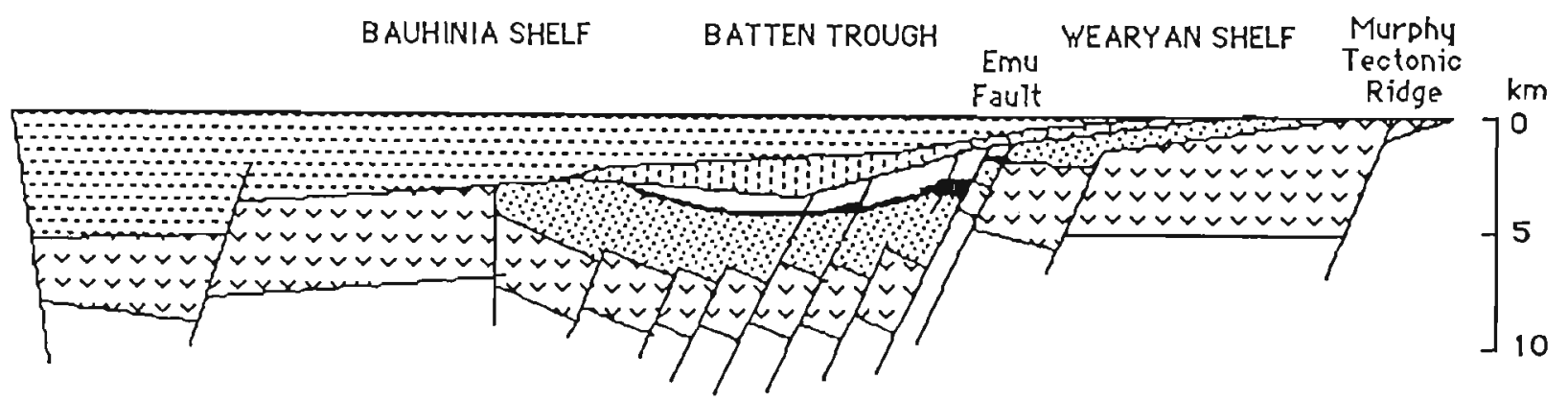

$\therefore$ Roper Group

Nathan Group

$\square$ Batten Subgroup

Barney Creek Formation $\quad$ - McArthur Group

lower Umbolooga Subgroup

Ẽ Tawallah Group

Figure 2-4. Schematic cross-section of the southern McArthur Basin at the close of Roper Group sedimentation (after Plumb, 1987). 


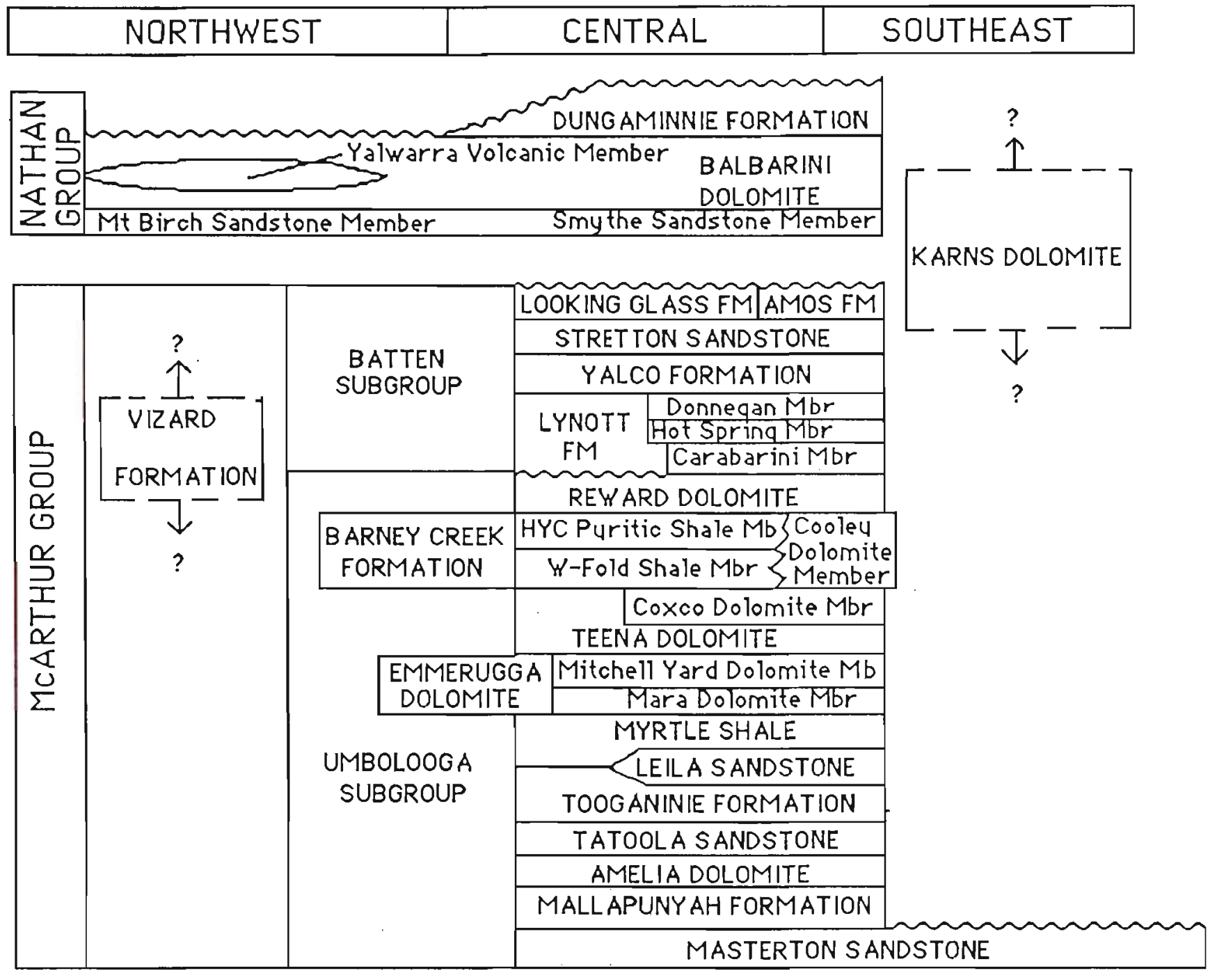

HOBBLECHAIN RHYOLITE

\begin{tabular}{|c|c|}
\hline \multirow{6}{*}{ 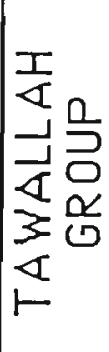 } & GOLD CREEK VOLCANICS \\
\hline & WUNUMANTYALA SANDSTONE $Z$ WOLLOGORANG FM \\
\hline & SETTLEMENT CREEK VOLCS \\
\hline & SLY CREEK SANDSTONE \\
\hline & SEIGAL VOLCANICS \\
\hline & WESTMOREL AND CONGLOM \\
\hline
\end{tabular}

Table 2-2. Stratigraphy of the Tawallah, McArthur and Nathan Groups, southern McArthur Basin (after Jackson et al., 1987b).

on $\mathrm{Rb}-\mathrm{Sr}$ measurements on $<2$ um illites and carbonate leachates but Page et al (1984) would interpret Kralik's data as a minimum age. Kralik (1982) also refers to unpublished data of his which suggest a Rb-Sr age of $1589 \pm 28$ Ma from tuffs in the McArthur Group. 
A minimum age of $1390 \mathrm{Ma}$ was obtained from glauconites in the uppermost unit in the Roper Group (Crawford Formation) using the Rb-Sr method (McDougall et al., 1965). Kralik (1982) derived an age of $1429 \pm 31 \mathrm{Ma}$ from a $\mathrm{Rb}-\mathrm{Sr}$ isochron of illites in the McMinn Formation of the Roper Group, an age which Page et al. (1984) consider to be a minimum age.

Dates of 1220 and $1280 \mathrm{Ma}$ were obtained from plagioclase in two dolerite sills in the Roper Group using the K-Ar method whereas co-existing pyroxene from one of the samples gave an age of $1150 \mathrm{Ma}$ (McDougall et al., 1965). However, as McDougall et al. (1965) point out, the difference between the measured ages for co-existing plagioclase and pyroxene shows that some argon loss has occurred and these ages are therefore minimum ages.

In broad terms then, the McArthur Basin was formed after $1870 \mathrm{Ma}$ and deposition was completed before $1280 \mathrm{Ma}$. More specifically, using the best available ages, the Barney Creek Formation in the McArthur Group has a depositional age of 1690 $\pm 27 \mathrm{Ma}$ (Page, 1981) and the Roper Group has a minimum depositional age of $1429 \pm 31$ Ma (Kralik, 1982).

\subsection{Depositional Framework and Tectonics}

The depositional framework of the basin was dominated by a northerly-trending intracratonic graben, the Batten Trough (Plumb and Derrick, 1975), which was 50 - $80 \mathrm{~km}$ wide by 600 $\mathrm{km}$ long. In this graben very much thicker successions (up to 12 $\mathrm{km}$ ) accumulated than on the stable shelves on either side (Plumb et al., 1980). About $4 \mathrm{~km}$ of sediments accumulated on 
the Bauhinia and Wearyan Shelves and up to $9 \mathrm{~km}$ on the far western Bauhinia Shelf (Jackson et al., 1987a). An even thinner sediment cover accumulated over a westerly trending basement high, the Urapunga Tectonic Ridge, which separates the Arnhem Shelf from the Bauhinia Shelf. Later tectonic activity resulted in deformation and uplift of the Batten Trough to produce the presently observed Batten Fault Zone (Plumb et al., 1980). Similarly, later tectonic activity occurred along the Urapunga Tectonic Ridge and formed the Urapunga Fault Zone (Plumb et al., 1980). The southern part of the Batten Trough was probably a half-graben (Jackson et al.,1987a) in which maximum subsidence was near its eastern margin, which is poorly defined by the Emu Fault Zone, and there is good sedimentological evidence of fault movement near this zone during deposition of the Barney Creek and Lynott Formations and the Stretton Sandstone (Jackson et al., 1987a).

Muir (1983a) comments that the sediments of the McArthur Basin were deposited in a number of northerly trending halfgrabens with the greatest subsidence during deposition taking place in the western areas of the half grabens, but that the overall pattern as given by Plumb et al. (1980) remains essentially correct. Complex block-faulting has resulted in locally steeply dipping strata adjacent to faults whereas elsewhere dips are generally very shallow (Plumb et al., 1980; Muir, 1983a) Plumb and Wellman (1987), in interpreting regional gravity and magnetic anomalies in the basin, consider the Batten Trough is separated by the Urapunga Tectonic Ridge and have redefined the northern part of the trough as the Walker 
Trough. They propose an east-west extension model, related to block rotation and accommodation by north-west transfer faults to explain the development of the Batten and Walker Troughs.

The McArthur Basin, therefore, probably formed in response to lithospheric stretching, in a manner similar to the model proposed by McKenzie (1978). Such rift basins are unconformably overlain by gently dipping, more laterally continuous strata of the post-extension, thermal subsidence or sag phase (McKenzie, 1978) The Roper Group clearly was deposited during this phase as it contains generally shallow dipping strata and as Plumb et al. (1980) point out, many of its units show a remarkable lithological consistency over hundreds of kilometres. In contrast, the older McArthur and Nathan Groups show marked rapid facies changes, with few formations showing lithological consistency over tens of kilometres (Jackson et al., 1987b). The Roper Group's depocentre is in the southwest, the Beetaloo Sub-basin (Plumb and Wellman, 1987), where over $3 \mathrm{Km}$ of the lower Roper Group were deposited. The sequence thins eastwards on to the Wearyan Shelf, and northwards on to the Urapunga Tectonic Ridge; further north the sequence thickens, and probably exceeded $2 \mathrm{~km}$ prior to the erosion of the Maiwok Subgroup (Jackson et al., 1987b).

\subsection{Depositional Environments}

The Tawallah Group sediments were deposited in a variety of environments ranging from shallow marine to continental (Jackson et al., 1987a). Lava flows and pyroclastics are relatively common on the Wearyan and Arnhem Shelves, but 
decrease significantly in the southern Batten Trough (Plumb et al., 1981).

The McArthur Group is characterised by sediments containing evidence of having formed under evaporitic conditions which are mostly interpreted as being continental (lacustrine), although sediments formed in shallow marine to sabkha-like environments are present in lesser amounts (Jackson et al., 1987a). One formation in particular, the Barney Creek Formation has been intensively studied as it hosts a number of base-metal deposits including a major Pb-Zn deposit, the H.Y.C. deposit (summary in Jackson et al., 1987a). Latest studies of the Barney Creek Formation in the vicinity of the H.Y.C. deposit, indicate deposition in a saline lake or nearshore lagoon complex that was developed on the eastern shore of the Batten Trough, at a time when the major eastern bounding fault zone, the Emu Fault Zone, was active, resulting in deeper water turbidites to shallowwater to emergent sediments similar to those found in sabkhas and saline lakes (Williams and Logan, 1981; Logan and Williams, 1984).

To the south of the H.Y.C., the Barney Creek Formation was deposited in a 20 by $7 \mathrm{~km}$ trough (the Glyde River subbasin, Figure 2-2) whose dimensions were controlled mainly by northerly faults which together with cross-cutting easterly faults were also active at the time of deposition (Dashlooty and Davidson, 1986). Abundant air-fall and detrital volcanic material, up to about $50 \mathrm{~m}$ in thickness, occurs at the base of the Barney Creek Formation which grades upwards over an interval of less than $10 \mathrm{~m}$ into up to $70 \mathrm{~m}$ of carbonacous shale 
(Dashlooty and Davidson, 1986). Overlying this sequence are up to ca. $800 \mathrm{~m}$ of mainly carbonate-rich turbidite beds, generally less than $10 \mathrm{~cm}$ thick and commmonly comprising fine-grained dolarenite grading into dolutite. Coarser-grained dolarenites and lithic dolarenites (containing clasts up to $1 \mathrm{~cm}$ long) are less common, and comprise less than ca. $20 \%$ of this sequence. Tuffaceous material is present within this sequence and its proportion increases markedly to the south until $17 \%$ of the total sequence is volcanoclastic, implying a proximal volcanic source (Dashlooty and Davidson, 1986).

The Nathan Group sediments have mostly formed in a playalake type environment (Balbarini Dolomite) but sediments at the top of this group (Dungaminnie Formation) may have been deposited in tidal to deeper marine conditions (Jackson et al., 1987b).

The basal unit of the Roper Group (Limmen Sandstone) was formed in fluvial conditions whereas most of the remaining units were formed in marginal to deeper marine conditions (Jackson et al., 1987b). The predominately fine-grain units (Mainoru, Corcoran and Velkerri Formations) are considered by Jackson et al. (1987b) to have formed in deeper open marine conditions whereas sulphur isotope values of pyrite from the upper half of the Velkerri Formation indicate that sulphate in the depositional waters was commonly limited and therefore the sediments could not have formed in open marine conditions where there is an unlimited supply of sea water sulphate (Donnelly and Crick, 1988). Such an environment may have been a barred marine basin that was occasionally breached. 
Millimetre-sized calcareous and/or pyritic discoidal shapes, randomly orientated in silty mudstone, and occasionally displaying cruciform twinning occur in one bed within the Velkerri Formation (Plate 30,e) and similar forms, displaying, in places, rosettes, occur also in one bed in the "Lansen Creek Shale" (Plate 39; $A, B$ ) which is stratigraphically equivalent to the Velkerri Formation (Jackson et al., 1987b). These discoidal shapes and their rare cruciform twins and rosettes, are typical of gypsum which has formed interstitially in pre-existing sediments (Muir, 1979), and were later replaced by carbonate and/or pyrite. These early diagenetic pseudomorphs after gypsum indicate that the depositional environment was hypersaline for at least part of the time. The pseudomorphs were observed in two drill holes (Urapunga 3 , and 82/1), which are separated by about $250 \mathrm{~km}$, indicating a widespread hypersalinity event consistent with the suggested depositional environment being, at times, a barred basin.

\subsection{Occurrences of hydrocarbons}

There is abundant evidence of the presence of hydrocarbons in a number of formations in the Roper and McArthur Groups (summarised in Jackson et al., 1987b).

The first report of the presence of hydrocarbons is given by Wade (1926) who found bitumen, which probably emanated from the Roper Group, impregnating vesicular basalt (Cambrian Antrim Plateau Volcanics) at its junction with quartzites, shales and flags (Roper Group) near the Waggon Lagoon on the Roper River. 
Bitumen was found in intergranular pores, vugs, microfaults, joints and stylolites within silicified carbonates of the Looking Glass Formation of the McArthur Group together with a dark brown viscous liquid which was probably liquid hydrocarbon (Muir et al., 1980). The bitumen in the vugs occured as globules which were mainly shiny and black on the outside but dark brown and crumbly when freshly broken and were not soluble in trichloroethelyne, or black, hard and shiny with a conchoidal fracture and were soluble in trichlorethylene.

Bitumen also occurs in the Yalco Formation, Stretton Sandstone and the Looking Glass Formation of the McArthur Group and in the Broadmere Sandstone in the Roper Group (Womer, 1986). In the Yalco Formation the bitumen formed thick coatings lining vuggy pore walls and in places was in contact with euhedral crystal terminations of authigenic quartz lining the vug suggesting the bitumen post-dated the growth of the secondary quartz. A similar relationship was observed in the Stretton Sandstone but the bitumen was also cracked in places and the cracks filled with sparry dolomite. The cracking was probably caused by loss of light ends from the bitumen and the circulating waters deposited the sparry dolomite after the reservoir was breached. Bitumen partly fills primary pore spaces in the Broadmere Sandstone and in places has also formed shrinkage cracks that are filled by dolomite, but secondary quartz crystal faces in the pore spaces are commonly curvilinear where in contact with the bitumen suggesting that the hydrocarbons inhibited crystal growth. Womer (1986) considers that the bitumen in the Broadmere Sandstone Member 
of the Cobanbirini Formation had formed from hydrocarbons that migrated into the formation and was degraded following breaching of the reservoir and subsequent flushing with meteoric waters.

Oil bled from drill core of the Barney Creek Formation exposed to sunlight from a Kennecott mineral exploration hole (Gallagher and MacKay, 1981). Gas, composed mainly of methane $(74.25 \%)$ and ethane $(10.25 \%)$, and probably sourced from the Coxco Dolomite Member which contained degraded crude oil trapped in fractures, also flowed from the same drill hole (Gallagher and MacKay, 1981). Oil bubbled from thin laminae of siltstone enclosed in black mudstone over a $0.1 \mathrm{~m}$ interval in the Velkerri Formation of the Roper Group (Jackson et al., 1986). 


\section{CHAPTER 3}

\section{METHODOLOGY}

\subsection{Samples}

All rock specimens examined in this study came from diamond drill core and in one case, from rock chips derived from the unsuccessful wildcat oil-exploration well, Broadmere 1 (Appendix A). There is an abundance of diamond drill core from the southern McArthur Basin particularly from the Batten Trough which has been intensively drilled in places by mineral exploration companies mostly looking for base-metal mineralisation of the kind found at the HYC deposit (Figure 3-1). This stratiform deposit has 227 million tonnes of ore with an average grade of $9.2 \% \mathrm{Zn}, 4.1 \% \mathrm{~Pb}$ and $41 \mathrm{~g} / \mathrm{t} \mathrm{Ag}$ but has yet to be exploited as no commercially viable process has been developed to extract the metals (Buchanan, 1984). In addition, Amoco Oil Exploration, commenced a regional survey of the McArthur Basin in 1980 which resulted in their drilling a number of stratigraphic holes and culminated with the wildcat dry oil-well, Broadmere 1, in 1984. Six shallow stratigraphic wells were drilled by the BMR in 1983 and 1984 as part of a project to examine the sedimentology of the Roper Group.

\subsection{Measurement of geothermal gradients}

In 1982 Amoco Australian Petroleum Company drilled eight stratigraphic holes (82/1 - 82/8) in the McArthur Basin, one of which (82/8) had to plugged upon abandonment due to strong artesian flow. I measured the downhole temperatures of two of these $(82 / 5,82 / 7)$ in August, 1983, by which time the 
downhole temperatures had stabilized (Plate 1b). Equipment failure prevented any more holes being measured.

The equipment used was a water-tight probe containing a thermistor (Fenwal, type UUA33J1) attached to about $500 \mathrm{~m}$ of cable on a portable drum. The probe was lowered down the drill hole and measurements made at $10 \mathrm{~m}$ intervals. A BMR-designed Wheatstone bridge was used to measure the change in resistance of the thermistor which was calibrated in the laboratory. Calibration errors and subsequent thermistor drift can contribute uncertainties of $0.01^{\circ} \mathrm{C}$ in absolute readings of temperature but, for determinations of thermal gradient, only the relative values are important (Cull and Sparksman, 1977). The performance and water-tightness of the equipment was checked down a test well prior to going into the field. A maximum thermometer was attached to the probe as a back-up and further in-field check of the equipment. Once the probe had reached the bottom of the $\mathrm{DDH}$ it was left there for 5 minutes to allow sufficient time for the maximum thermometer to equilibrate before the probe was hauled up.

\subsection{Screening of samples: Rock-Eval and Total Organic} Carbon analyses

Rock-Eval and total organic carbon (TOC) analyses were done in the Organic Geochemistry Laboratory, Bureau of Mineral Resources, Geology and Geophysics (BMR), Canberra, on all specimens collected from the McArthur Basin. The results were used initially as a guide to selecting specimens for petrographic analyses. 
Approximately 100 milligrams of rock powder was loaded into a stainless steel crucible and a series of samples (up to 18 at one time) was then automatically run through the machine (Rock-Eval II), starting each run with a standard followed by a blank.

Each sample was initially heated at $300^{\circ} \mathrm{C}$ for 5 minutes and the amount of hydrocarbon released recorded as the S1 value in milligrams per gram of sample. The $S 1$ value indicates the amount of free hydrocarbons below about $\mathrm{C}_{30}$ (Espitalie et al., 1986). The sample was then heated further at $25 \mathrm{C} / \mathrm{min}$. up to $550^{\circ} \mathrm{C}$ where it was left for 1 minute. The amount of hydrocarbon generated during this cycle from kerogen cracking and from the volatilization and cracking of heavy extractable compounds such as resins and asphaltenes (Espitalie et al., 1986), was recorded as the $S 2$ value $(\mathrm{mg} / \mathrm{gm})$. The amount of $\mathrm{CO}_{2}$ generated from the cracking of kerogen (Espitalie et al., 1986) whilst the sample was at $300^{\circ}$ to $390^{\circ} \mathrm{C}$, was recorded as the S3 value $(\mathrm{mg} / \mathrm{gm})$. During pyrolysis, water, carbon monoxide and carbon dioxide is generated from organic matter but the amount of water given off is completely masked by water set free by the thermal decomposition of a number of minerals (Espitalie et al., 1986). Only carbon dioxide is measured as carbon monoxide is difficult to trap and then only up to a maximum temperature of $390^{\circ} \mathrm{C}$ as carbon dioxide can be generated from the thermal decomposition of siderite at temperatures above $400^{\circ} \mathrm{C}$ (Espitalie et al., 1986). 


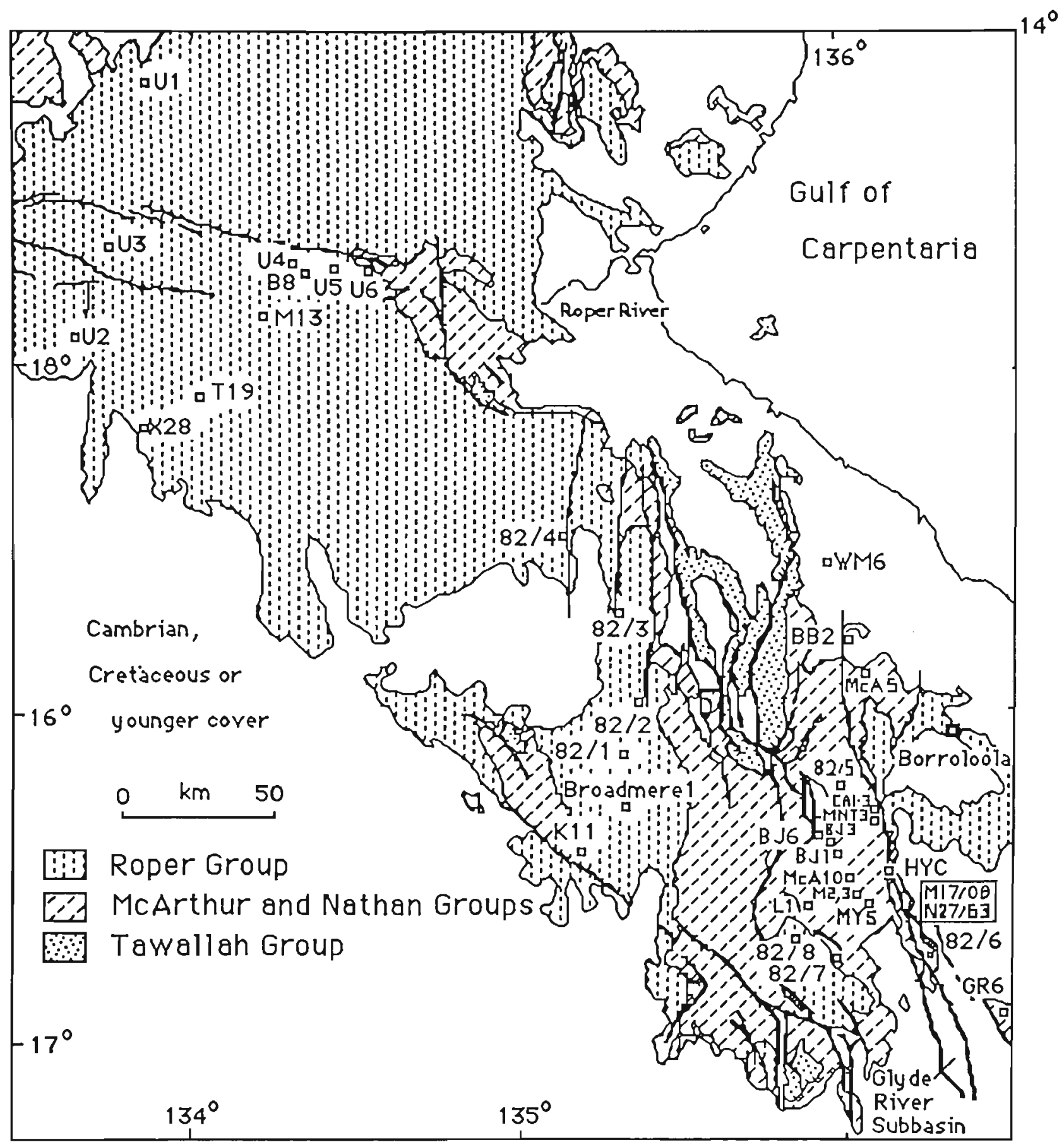

Figure 3-1. Location of drill holes in the McArthur Basin sampled in this study. For location of drill holes in the Glyde River Subbasin, see Figure 3-2. 


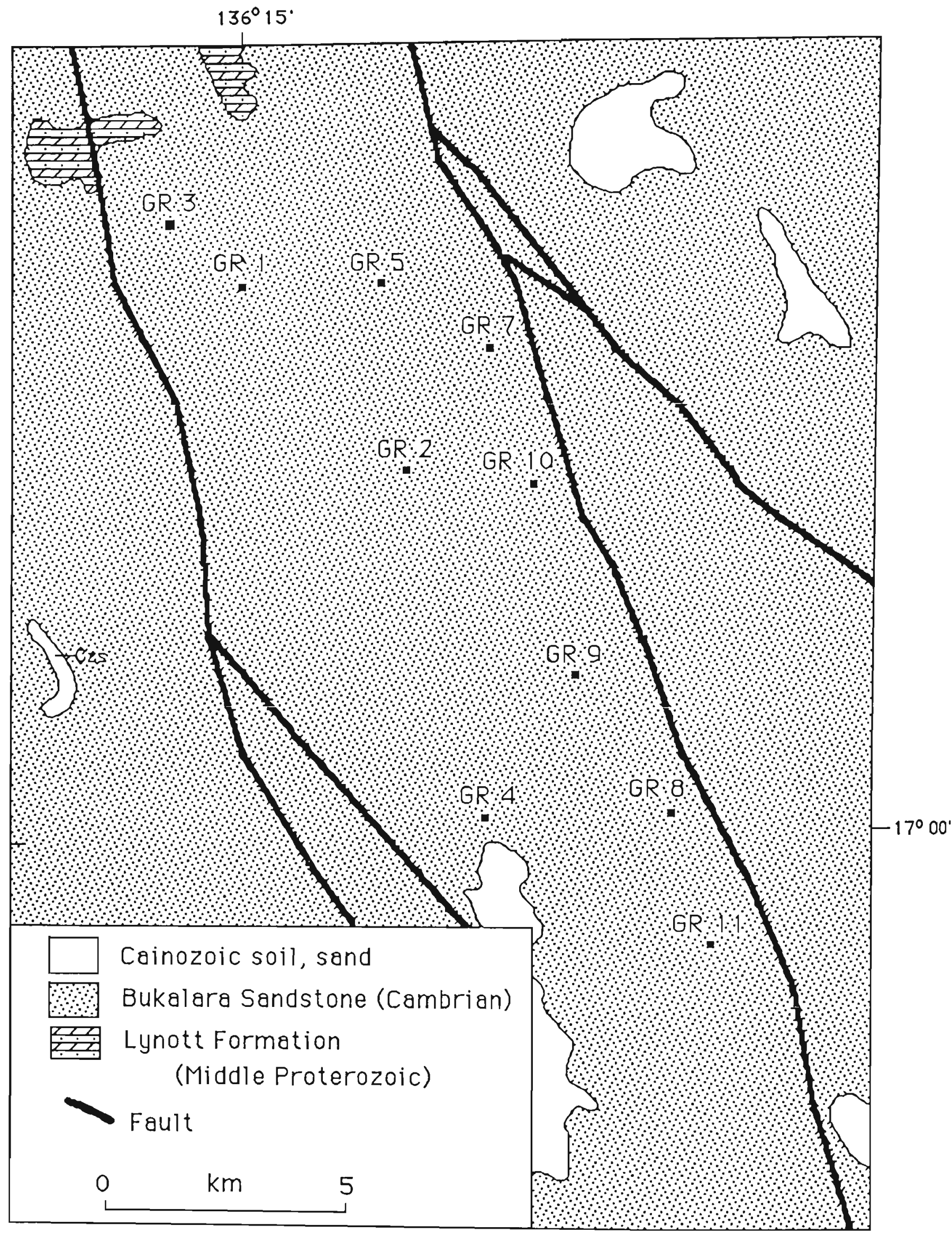

Figure 3-2. Location of drill holes (GR1-5, GR7-11) in the Glyde River Subbasin together with the surface geology of the region (after Smith, 1964; and Plumb and Rhodes, 1964) 
For TOC analyses, a 50:50 mixture of conc. $\mathrm{HCl}$ and distilled water was slowly added to $200 \mathrm{mg}$ of rock powder until effervescence ceased and the mixture was heated at $60^{\circ} \mathrm{C}$ for 1 hour and allowed to cool. The mixture was then filtered, washed with distilled water until neutral and dried at $60^{\circ} \mathrm{C}$ for 12 hours. The amount of TOC was determined using a Leco DC12 analyser.

\subsection{Preparation of rock specimens for microscopic} examination

Rock specimens were prepared for microscopic examination by mounting in cold-setting polyester resin mixed with one and a half to two percent hardener. Polished surfaces were then produced by a number of steps:

1) water-wet grinding using 120 then 180 size grit on rotary laps,

2) water-wet grinding using 320, 400 and finally 600 grit by hand,

3) polishing on rotary laps first with chromium sesquioxide (7 micron) and then with polishing grade magnesium oxide,

4) a final buff with a wet selvyt cloth and the specimen was rinsed with distilled water before drying.

\subsection{Microscopic examination}

The specimens were initially examined using a binocular (up to $x 40$ magnification) to assist in lithological description and to check the location of any organic matter. A drop of dilute $\mathrm{HCl}$ acid was placed on the edge of specimens as a matter of course to check for the presence of carbonates. A modified Leitz 
Panphot microscope mounted with a Wild MPS45 automatic 35 $\mathrm{mm}$ camera was also used for low magnification observations $(x 10$ to $\times 100)$ of polished blocks using oblique incident white light (tungsten bulb with blue filter) and normally incident blue/ultraviolet light from a $150 \mathrm{~W}$ Zenon lamp with a BG12 filter. Observations and photographs in fluorescence mode were made through a TK400 dichroic mirror and a K510 barrier filter.

High magnification observations (x320, x500, x1250) and photographs were made through a Leitz Orthoplan Pol microscope in both reflected white and blue/ultraviolet light modes. The ultra-violet light source was a $100 \mathrm{w}$ mercury vapour lamp and the light was passed through a BG3 (UV) filter and a BG38 (Blau) red-suppression filter. Observations and photographs in fluorescence mode were made through a TK400 dichroic mirror and initially through a K490 barrier filter but mostly with a K510 barrier filter. Photographs were taken with a manual $35 \mathrm{~mm}$ Leica mounted on an MPV1 photometer which was initially used to measure light intensities after taking some calibration films, but most light readings were obtained by use of a Leitz light-meter which could be mounted on the eye-tube, after removing the eye-piece.

A mirror housing attached to the rear of the microscope allowed easy switching from three light sources: 1) a 100 watt quartz-iodide lamp for general white-light observations, 2) a 100 watt quartz-iodide lamp that had a stabilized power source, for reflectance measurements and 3) a 100 watt mercury vapour lamp which had a stabilized power source, for general observations in fluorescence mode and for intensity and spectral measurements. 


\subsection{Reflectance measurements}

Reflectance measurements were made with a Leitz MPV-1 photometer, mounted on a Leitz Orthoplan Pol microscope, using monochromatic light at $543 \mathrm{~nm}$ (band-width $=22 \mathrm{~nm}$ ) and calibrated by McCrone Specular Reflectance Standards (spinel $0.416 \%$, yttrium aluminium garnet $-0.916 \%$, and gadolinium gallium garnet - $1.710 \%$ reflectance). Starting procedures, microscope adjustment, illumination, alignment and the degree of stability of the apparatus were done in accordance with the standards laid down by the International Committee of Coal Petrology. The MPV-1 photometer, which had only about 5 hours use prior to this study (D. Burger, pers. comm.) was initially checked for performance before being used, and was found to perform within the manufacturer's specifications.

Maximum and minimum reflectance measurements were made at a room temperature of $230 \mathrm{C} \pm 10 \mathrm{C}$ by rotating the stage through $360^{\circ}$ and recording the two maxima and minima provided the two maxima or minima readings were within $\pm 5 \%$ relative of each other. All measurements were made through a $x 50$ oil objective using Leitz Immersionsoel (DIN 58884), $\mathrm{n}^{23}=$ 1.5180. An illuminated field of $0.03 \mathrm{~mm}$ square was used and the measuring field was set at $0.001 \mathrm{~mm}$ square.

Reflectance measurements made on thucholites were taken one micron inside a well-defined edge of the thucholite and a maximum of four measurements taken about 90 degrees apart were made on each thucholite.

A $\times 120$ objective was initially experimented with for taking reflectance measurements, as much of the organic matter in the 
McArthur Basin presents very small areas suitable for measuring, but the results were not acceptable as the centering and levelling accuracy of the stage during rotation, even after the most careful adjustment, was poor. Even so, the process of keeping the measuring field over the same area whilst rotating, using a $\times 50$ objective, was time-consuming and required patience and delicate manipulative skills. Manfred Look, Chief Technician from Wild-Leitz (Australia), checked the levelling of the stage on two occasions, and could offer no solution for improving the centering or levelling of the stage as it appears that both features are, in the final analysis, a function of the accuracy tolerances in the manufacture of the stage and its support.

\subsection{Fluorescence measurements}

Measurement of the intensity of fluorescence (I) was made using a $543 \mathrm{~nm}$ interference filter (band-width $=22 \mathrm{~nm}$ ) on the MPV1 photometer, and the red-green quotient ( $Q$ ) was made using a $643 \mathrm{~nm}$ (band-width $=23 \mathrm{rm}$ ) and $504 \mathrm{~nm}$ (bandwidth $=20 \mathrm{~nm}$ ) interference filters. A Leitz fluorescence standard (uranyl-glass) which emits a yellow-green fluorescence was used for calibration and measured using the $543 \mathrm{~nm}$ filter. Although it would have been desirable to do reflectivity and fluorescence measurements together, the aperture of the measuring field used for reflectance measurements generally did not allow sufficient light through to the photometer from the uranyl-glass standard. Increasing the high-voltage supply to the photometer to increase its sensitivity and using the same measuring field as for 
reflectance measurements, resulted in unacceptably high darkcurrent fluctuations from the photometer, so the measuring field was increased to $0.01 \mathrm{~mm}$ square. Calibration of the photometer against the standard was done regularly, at least every 15 minutes as the higher voltage needed for the photometer resulted in some drift. In the case of measuring the alteration of intensity at $546 \mathrm{~nm}$ with time, the standard was measured at the begining and end of the 30 minute period and the intensity values obtained from the standard at the beginning and at the end were those used to calculate the organic matter intensity. In all measurements of fluorescence the barrier filter was removed but the TK400 dichroic mirror left in. Alignment of the measuring aperture was made initially with the barrier filter in and a final alignment made with it out, as removal of the barrier filter resulted in a slight shift of position of the the area to be measured.

\subsection{Statistical analysis and graphing of reflectance and} fluorescence measurements

Measurements of reflectance and fluorescence were statistically analysed using a Hewlett-Packard Statistical Analysis Pac, Series 80, on a Hewlett-Packard 86 bench-top computer. The mean value, $95 \%$ confidence limits of the mean, and range were plotted using a Maclntosh personal computor and associated software. Showing the $95 \%$ confidence limit of the mean on graphs of reflectance or fluorescence for individual drill holes provides some constraint on the plotting of trendlines and gives an indication of how significantly one data set varies from another (at the $95 \%$ confidence level). 


\subsection{Preparation of macerations}

A number of maceration procedures have been proposed (e.g. Staplin et al., 1960) but the choice of procedures depends largely on how quickly one requires maceration to take place; the quicker it is, the more likely the process will destroy delicate organic structures. Crushing the initial rock samples will obviously destroy large specimens and using hot or boiling reagents to speed up solution of the mineral matter may lead to carbonisation (Peat, 1979).

The procedure used in this study was similar to that used by Peat (1979) who developed the gentlest possible method to conserve most of the organic matter for his micropalaeontological study of the Roper Group.

The procedure used was:

1. Samples of core without any fractures were cut to about a 1 $\mathrm{cm}$. size cube and the surfaces hand ground to remove surface contamination.

2. The cube of rock was washed with distilled water and placed into a clean polypropylene beaker and then covered with concentrated HF. The beaker was then covered with a clean polypropylene dish.

3. The HF was topped up every few days and maceration was complete after about 3 weeks.

4. The macerate was washed in distilled water and placed in a polypropylene centrifuge tube and given a gentle centrifuge for about 5 minutes. After centrifuging, the distilled water was decanted and more distilled water added. The tube was gently shaken, and then gently centrifuged for another 5 minutes. After 
repeating this process about 5 times until the solution was neutral to litmus paper, the macerate and some of the distilled water was placed in a small clean glass container and a few drops of formalin added to prevent fungal growth ( $M$. Owen, pers. comm.), and sealed with a plastic snap-top.

5. Strew mounts of macerates were prepared by placing several drops of glycerine on a clean slide and using a disposable clean Pasteur pipette to transfer some of the macerate (after shaking the bottle to make sure of obtaining a representative sample). A clean cover-slip was placed over the macerate and the slide placed upside down and gently pressed to disperse the organic matter. A coating of nail varnish was applied to the edges of the cover-slip to prevent dehydration.

3.10 Scanning electron microscopy, electron probe analyses and X-ray mapping

Use of the scanning electron microscope was limited to the examination of macerates and some rock specimens to gain some idea of their physical structure at high magnifications and to undertake electron probe analyses and X-ray mapping to check the composition of organic and mineral matter in selected specimens.

In scanning electron microscopes, an extremely finely focussed electron beam is scanned across a specimen and a signal produced by the incident primary beam is picked up by a detector and displayed as a brightness variation on a synchronously scanned cathode-ray tube (CRT) to form an image. 
The interaction of the primary beam with the specimen generates secondary electrons, back-scattered electrons, $X$ rays and other effects as shown in Figure 3-3.

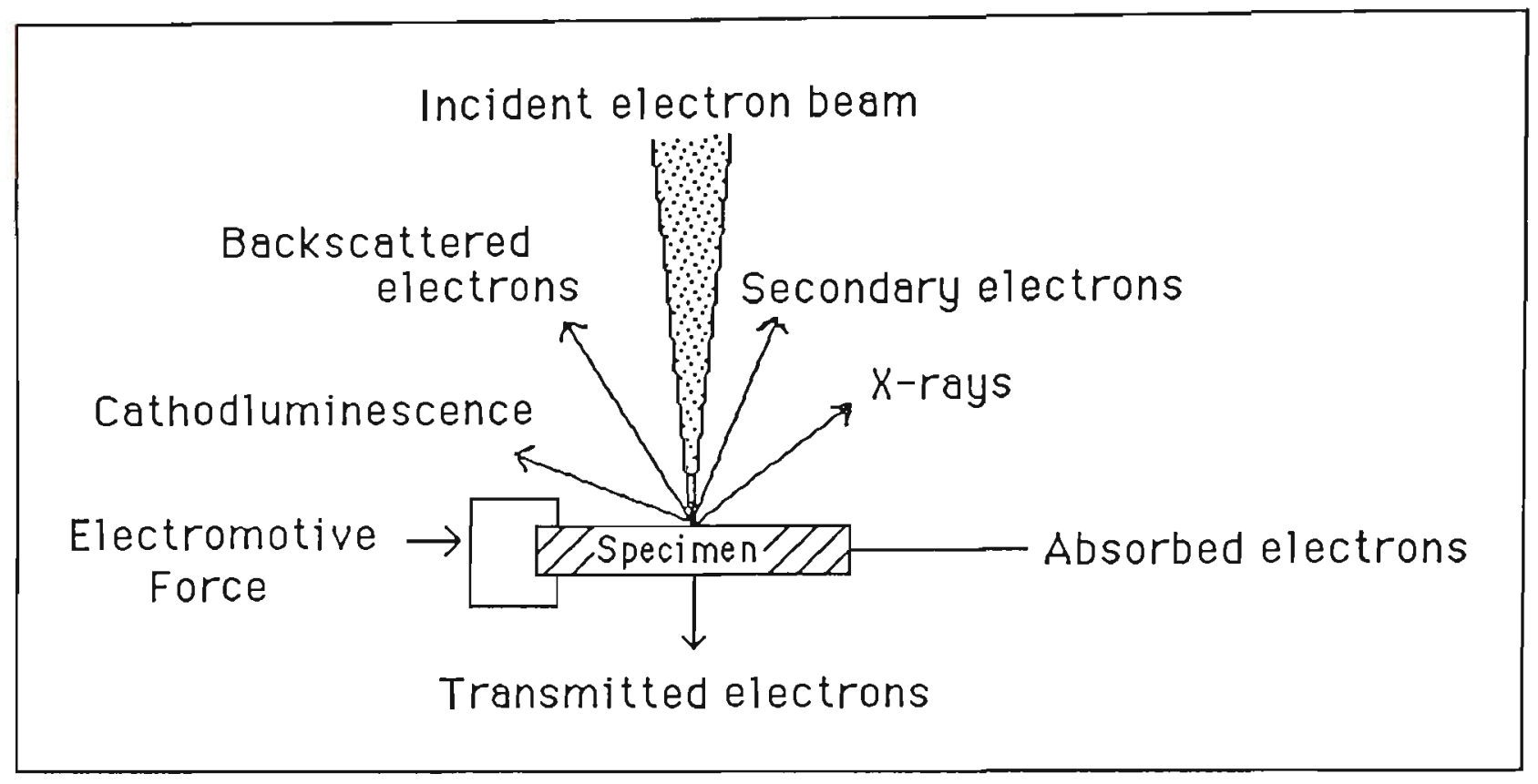

Figure 3-3. Signals emitted by a specimen by interaction with incident electron beam in a scanning electron microscope (modified from Jeol Ltd. JSM-35 Scanning Microscope Instructions).

Image magnifications are simply given by the ratio of the scanned length on the CRT to that on the specimen, and can be varied from about 10 times to 100 - 200 thousand times. Using secondary electron images has the twin advantages of high resolution and great depth of field. In practice it was found that the particular scanning electron microscope used in this study, a Jeol, model JSM-35, which is one of the earlier models, had poor resolution above about 10 thousand times despite much effort to "fine-tune" it.

Secondary electron images show mostly variations in surface topography and some compositional variations whereas 
backscattered electrons produce images more related to marked compositional contrast than to topographical variations. Minerals composed of light elements appear darker than those composed of heavier elements in images produced by backscattered electrons (Robinson and Nickel, 1979; Robinson, 1980; Hall and Lloyd, 1981).

$\mathrm{X}$-ray emmision is measured using an $\mathrm{X}$-ray Energy Spectrometer, in this case a Kevex, model 5100, and displayed on a CRT as an X-ray energy spectrum. The elements that are present are identified by the location of their energy peaks along the horizontal axis, in this case using a program associated with the instrument that superimposed the major spectral lines for selected elements over the spectral display. The accuracy of the identification system was occasionally checked by examining the spectral lines of pyrite, which was commonly present in the specimens examined. In the period that I used the instrument the identification program was always well calibrated and did not require adjustment. X-ray mapping of selected elements was achieved by selecting the area under their major energy peaks on the CRT.

The macerates used in this part of the study were tranferred from their containers using clean Pasteur pipettes onto aluminium stubs and allowed to dry within a vacuum evaporator before coating with gold. Better electrical and thermal conductive properties are achieved with gold than carbon thereby giving sharper secondary electron images although carbon coatings are preferable for $\mathrm{X}$-ray analyses (Goldstein et al., 1981). Carbon coatings were used on the polished blocks selected for X-ray analyses. The aluminium 
stubs and polished blocks were carefully glued to a brass holder using colloidal graphite which gives good conductivity and allows any electrical charge built up on the specimen to dissipate.

Some of the polished blocks had to be trimmed with a diamond saw to fit into the SEM and care had to be taken with specimens previously examined using oil-immersion objectives, that any immersion oil had been removed by cleaning with light petroleum. Immersion oil can contaminate the SEM vacuum chamber, and can give spurious results during $\mathrm{X}$-ray analysis. On one occasion, immersion oil seeped from a microfracture in a polished block and gave an initially quite puzzling, strong chlorine peak.

\subsection{Extracts}

Samples were selected following initial screening for organic carbon content and maturity by Rock-Eval and TOC analyses. The samples were crushed, and organic matter extracted and fractionated by liquid chromatography into saturated, aromatic and ONS compounds using standard procedures (Powell, 1982) by the Organic Geochemistry Laboratory of the BMR. Some aromatic fractions were subdivided into monoaromatic, diaromatic and triaromatic fractions by HPLC techniques (Boreham and Powell, 1987) and the triaromatic fraction was analysed by capillary gas chromatography (Boreham and Powell, 1987) to determine Methyl Phenanthrene Indices (Radke and Welte, 1983). 


\subsection{Elemental analysis}

Kerogen was obtained from selected samples by acid digestion of extracted rock samples using standard procedures (Durand and Nicaise, 1980), and the analyses were made by AMDEL in Adelaide.

\subsection{Photographic film and processing}

Ektachrome ASA400 colour slide film was used for all photomicrographs. Processing of the film and producing colour positive prints was done by Canlab, Canberra, who, during the course of preparing this thesis, changed the size of their colour prints which resulted in some plates having odd-sized individual photomicrographs. The colour plates were produced from colour negatives by Bica. The black and white plates were photographed and processed by Photopol. All SEM photographs were made using Polaroid film. 


\section{CHAPTER 4}

\section{CLASSIFICATION AND NOMENCLATURE OF ORGANIC MATTER IN GEOLOGICAL FORMATIONS}

\subsection{Introduction}

The nomenclature adopted for describing organic matter in the McArthur Basin need not be related to any existing nomenclature system. This extremely ancient organic matter may be so completely different that a entirely new nomenclature system may have to be erected. However, it may have identical or similar characteristics to some forms of organic matter found in Phanerozoic rocks and therefore some existing terms could justifiably be used.

A large number of terms, currently used to describe naturally occurring organic substances, have originated from well in the past. Asphalt, for example, is a term originating from the Sumerians who lived in the Euphrates Valley in Iraq about 3800 to $2500 \mathrm{BC}$ and the expression "bitumen" is apparently derived from the Sanskrit language (Forbes, 1936, in Abraham, 1963). A large number of currently used terms (e.g. ozokerite (modern spelling now - ozoçerite) grahamite, gilsonite, wurtzilite) originated from Europe and the United States during the nineteenth century with the various substances being described usually in terms of appearance, hardness and for some, odour (summarised in Abraham, 1963). 


\section{2 "Global" Classification Schemes}

One of the earlier well-known schemes, was developed by Herbert Abraham who collated all reports on naturally occurring organic substances from around the world and produced a classification scheme wherein all such substances were either "bitumens" or "pyrobitumens" (Abraham, 1963) (Table 4-1). He defines "bitumen" as "a generic term applied to native substances of variable colour, hardness and volatility; composed principally of hydrocarbons, substantially free from oxygenated bodies; sometimes associated with mineral matter, the nonmineral constituents being fusible and largely soluble in carbon disulphide, yielding water-insoluble sulfonation products". He includes in this definition petroleums, defined as basically being a liquid, and native mineral waxes and asphaltites (gilsonite, glance pitch and grahamite). Petroleum is not fusible and therefore conflicts with his definition of bitumen. Pyrobitumen is "a generic term, applied to native substances of dark color; comparatively hard and non-volatile; composed of hydrocarbons, which may or may not contain oxygenated bodies; sometimes associated with mineral matter, the non-mineral constituents being infusible and relatively insoluble in carbon disulphide". He states that "this definition includes the asphaltic pyrobitumens (elaterite, wurtzilite, albertite and impsonite) also the non-asphaltic pyrobitumens (peat, lignite, bituminous coal and anthracite coal) and their respective shales". The inclusion in the term 


\begin{tabular}{|c|c|}
\hline \multicolumn{2}{|c|}{$\begin{array}{l}\text { A. BITUMEN - FUSIBLE AND LARGELY SOLUBLE IN CARBON } \\
\text { DISULPHIDE }\end{array}$} \\
\hline GROUP & MEMBERS \\
\hline $\begin{array}{l}\text { Petroleums } \\
\text { (liquid) }\end{array}$ & $\begin{array}{l}\text { Non-asphaltic petroleum } \\
\text { Semi-asphaltic petroleum } \\
\text { Asphaltic petroleum }\end{array}$ \\
\hline $\begin{array}{l}\text { Native } \\
\text { Asphalts }\end{array}$ & $\begin{array}{l}\text { 1. Pure or fairly pure } \\
\text { 2. Associated with mineral } \\
\text { matter, e.g. "rock asphalt" }\end{array}$ \\
\hline $\begin{array}{l}\text { Native mineral } \\
\text { waxes }\end{array}$ & $\begin{array}{l}\text { Ozokerite } \\
\text { Montan wax }\end{array}$ \\
\hline Asphaltites & $\begin{array}{l}\text { Gilsonite } \\
\text { Glance Pitch } \\
\text { Grahamite }\end{array}$ \\
\hline \multicolumn{2}{|c|}{$\begin{array}{l}\text { B. PYROBITUMEN - INFUSIBLE AND RELATIVELY INSOLUBLE } \\
\text { IN CARBON DISULPHIDE }\end{array}$} \\
\hline GROUP & MEMBERS \\
\hline $\begin{array}{l}\text { Asphaltic } \\
\text { Pyrobitumens }\end{array}$ & $\begin{array}{l}\text { Elaterite } \\
\text { Wurtzilite } \\
\text { Albertite } \\
\text { Impsonite } \\
\text { Asphaltic pyrobituminous } \\
\quad \text { shales }\end{array}$ \\
\hline $\begin{array}{l}\text { Non-asphaltic } \\
\text { Pyrobitumens }\end{array}$ & $\begin{array}{l}\text { Peat } \\
\text { Lignite } \\
\text { Bituminous Coal } \\
\text { Anthracite Coal } \\
\text { Coaly Shales }\end{array}$ \\
\hline
\end{tabular}

Table 4-1 Classification of naturally occurring organic matter, after Abraham (1963). 


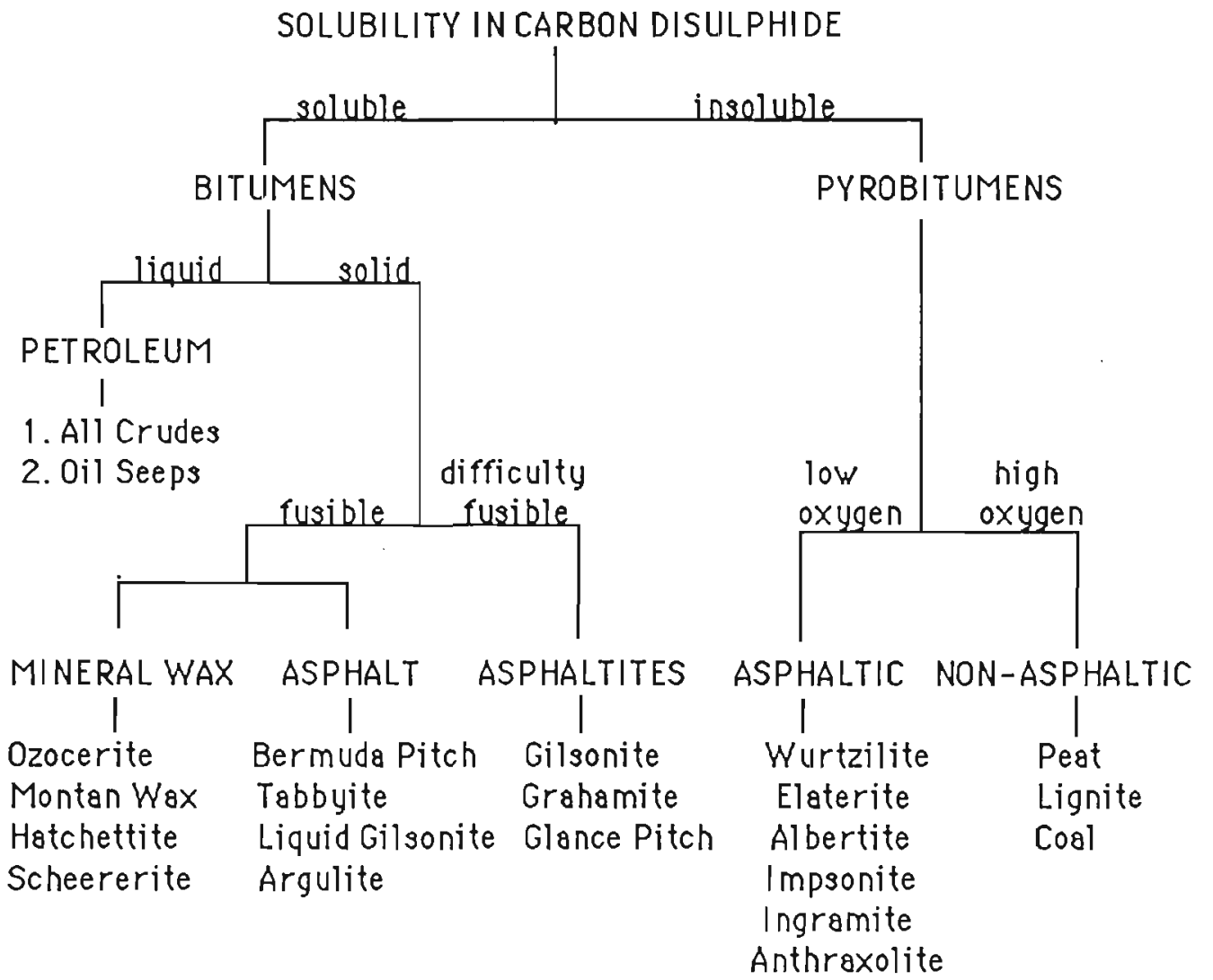

Table 4-2. Terminology and clasification of naturally occurring bituminous substances, after Hunt et al. (1954).

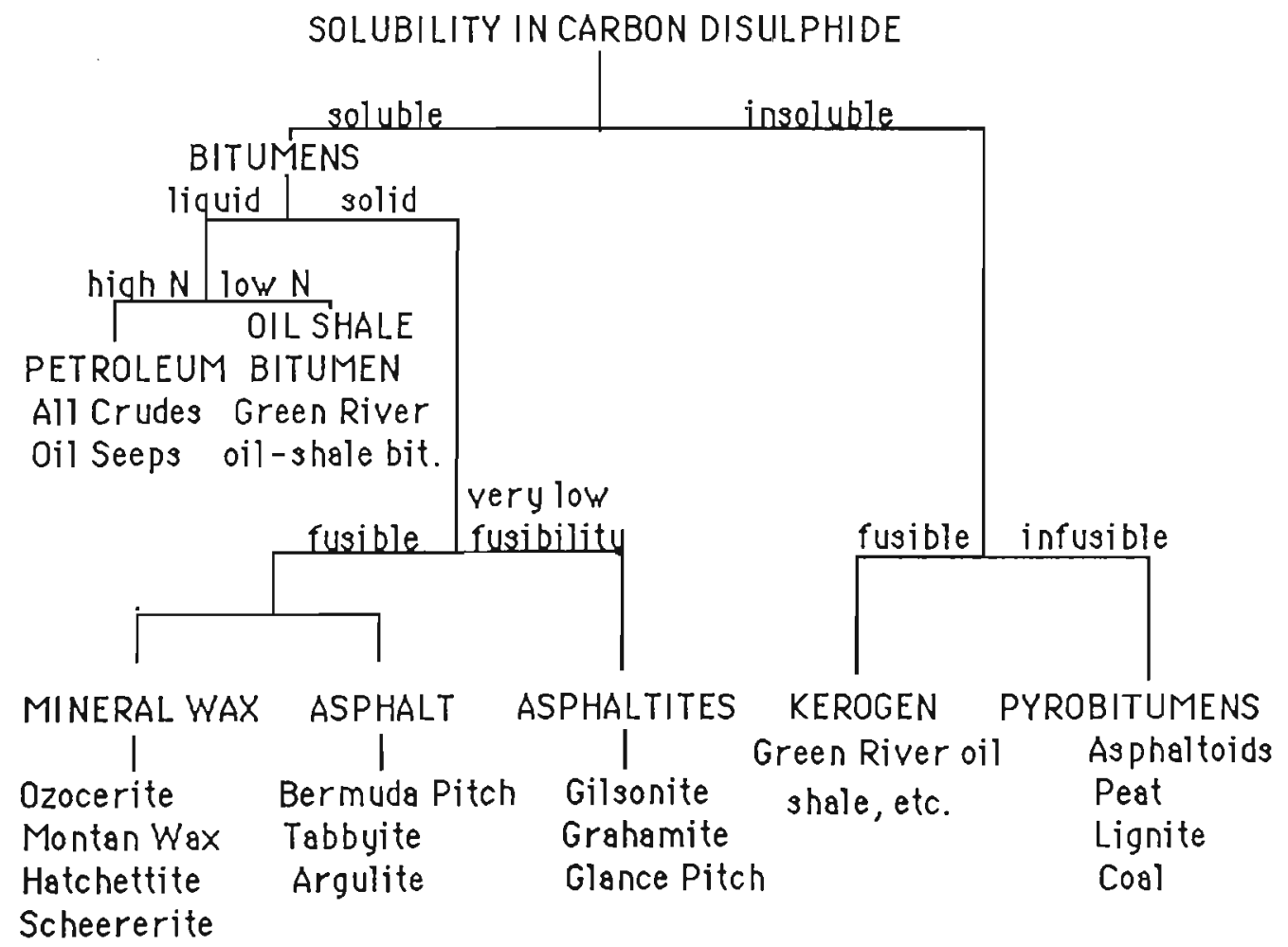

Table 4-3. Terminology and classification of naturally occurring bitumens and related substances, after Wen et al. (1978). (Author's note: oil-shales having high vitrinite or bituminite have high $N$, cf. Hutton et al., 1980) 
"bitumen" of coals and related types of organic matter is clearly at variance with accepted common usage.

Hunt et al. (1954) modified Abraham's classification scheme so that the distinction between bitumen and pyrobitumen is based solely on solubility in carbon disulphide thus eliminating the problem concerning the classification of petroleum (Table 4-2). Wen et al. (1978) prefer a classification scheme based on Abraham's but split the classification of petroleum into two groups based on how much nitrogen they contain and add another group called "kerogen" (Table 4-3).

A committee, formed following a resolution passed at the Third World Petroleum Congress to propose definitions and simple methods of analyses of the various kinds of organic matter occurring in geological formations, presented a classification scheme which has three major categories, to the Fifth World Petroleum Congress (Louis et al., 1959) (Table 4-4). The committee comments that the criteria used "are of a physico-chemical nature" and that "because of this, products of geologically different development may be classified in one group and vice versa."

King et al. (1963) proposed a genetically based classification scheme for all organic matter contained in geological formations with the major division being made on whether the organic matter was syngenetic or epigenetic (Table 4-5). Under this classification scheme all the bitumens and the asphaltic pyrobitumens of Abraham's are considered to be epigenetic. A number of researchers follow this classification 


\begin{tabular}{|c|l|}
\hline GROUP & MEMBERS \\
\hline \multirow{3}{*}{$\begin{array}{c}\text { NAPTHABITUMEN } \\
\text { (Substantially soluble in } \\
\text { carbon disulphide) }\end{array}$} & $\begin{array}{l}\text { Natural gas of petroleum } \\
\text { Crude Oil } \\
\text { Natural Asphalt } \\
\text { Ozokerite } \\
\text { Asphaltite }\end{array}$ \\
\hline NO CATEGORY & Asphaltoid - a black or \\
& dark brown structureless \\
& substance, insoluble in \\
& carbon disulphide \\
& probably had migrated in \\
& the past. \\
& Organic matter of muds \\
& Organic matter of source \\
& beds \\
KERABITUMEN & Organic matter of oil \\
shales (Kerogen) & \\
\hline COAL & Sapropelic coal \\
& Humic coal \\
\hline (substantially insoluble) & \\
\hline
\end{tabular}

Table 4-4. A classification scheme of sedimented organic matter and derived products, after Louis et al. (1959).

scheme referring to the epigenetic group as "bitumen" and commonly only referring to the solid bitumens within this group (e.g., Jacob, 1976, 1981; Curiale, 1985). Hunt (1979), in a modification of his earlier classification scheme (Hunt 1954), also subdivides coals and natural bitumens into two major groups depending on whether they are allochthonous or autochthonous (Table 4-6). 


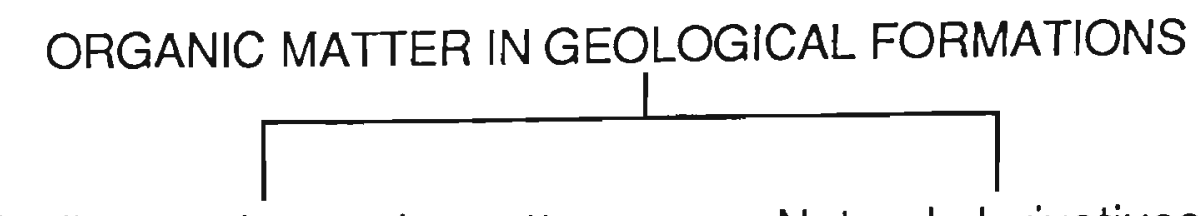

Sedimented organic matter

(Syngenetic Origin)

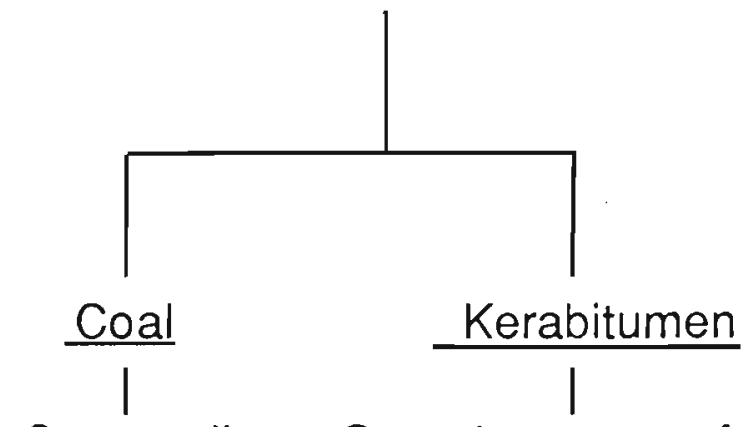

Sapropelic Organic matter of muds

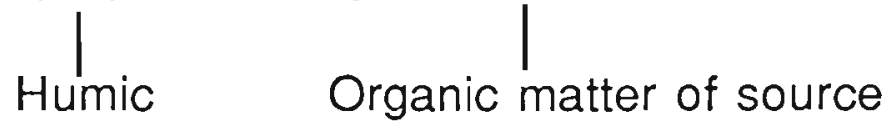
beds

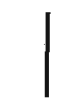

Organic matter of oil shales (kerogen)
Natural derivatives of sedimented organic matter (Epigenetic Origin)

(Division based on inherent physical and chemical properties)

Natural Gas
Petroleum
Ozokerite
Natural Asphalt
Wurtzilite
Elaterite
Gilsonite
Glance Pitch
Grahamite
Albertite
Impsonite
Thucholite
Anthraxolite
Secondary Graphite

Table 4-5. Classification scheme for organic matter in geological formations (after King et al. 1963).

However, petroleum-like substances have been observed in coals by $M$. Teichmuller (1974) who used the term "exsudatinite" to describe the organic matter that showed in fissures and pores of sub-bituminous and high-volatile bituminous coals which fluoresced when irradiated with short wavelength light. 


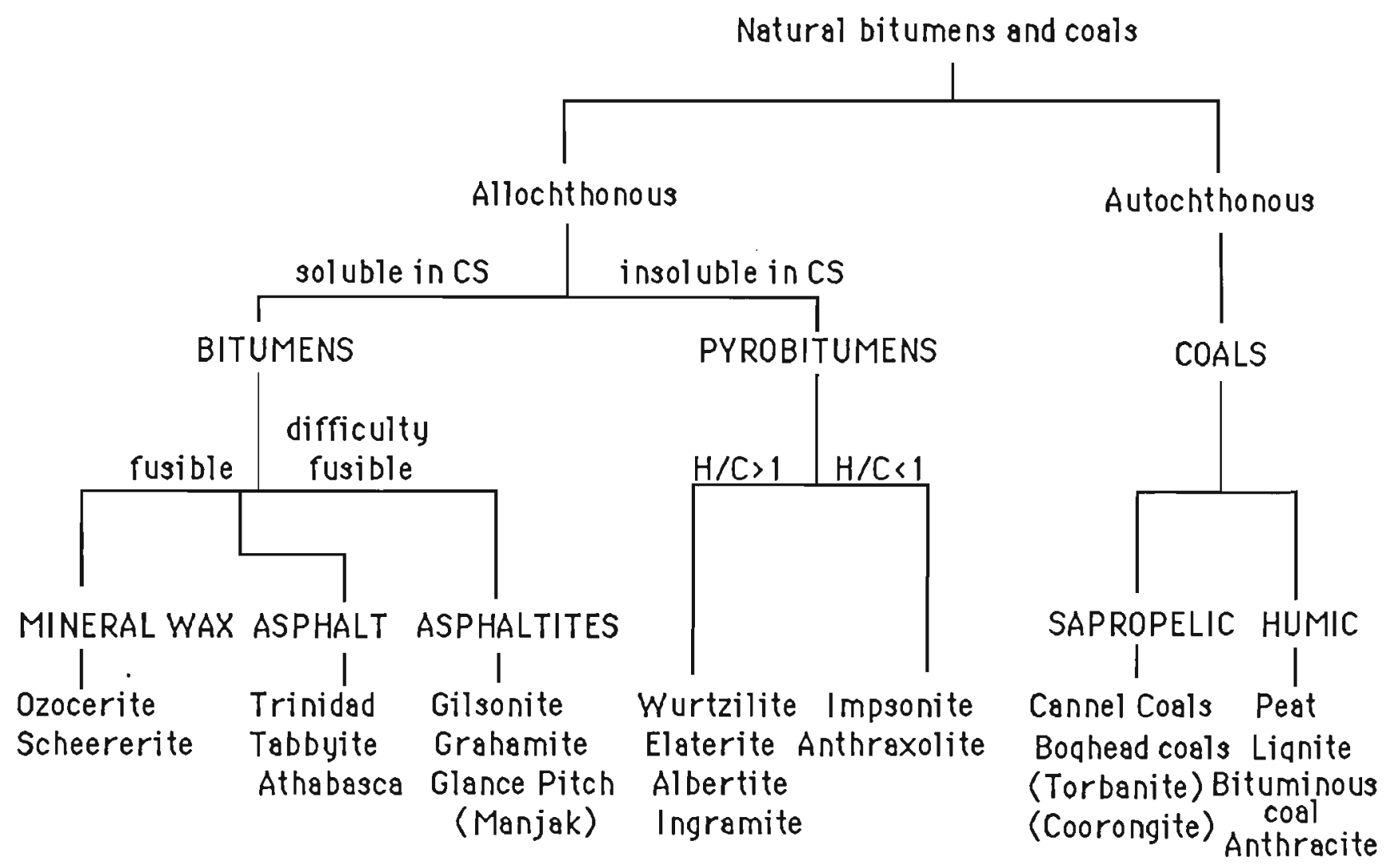

Table 4-6. Classification of natural bitumens and coals (after Hunt, 1979).

Exsudatinite generally occurs in veins, wedge-shaped cracks, infilling bedding-plane joints or infilling empty cell lumens or is found interstitially in pyrite concretions (Cook and Kantsler, 1982). Stach et al. (1982) also call exudates "bitumen" and comment that it begins to form during the sub-bituminous coal stage. On further coalification the newly formed bitumen is cracked into hydrocarbons of smaller molecular size on the one hand, and into strongly reflecting, polycondensed, residual products on the other. Exsudatinite has only been observed in humic coals and not in rocks containing organic matter derived from algae (Robert, 1980).

Some researchers (e.g. Tissot and Welte, 1978) follow strictly chemical criteria for classification of organic matter and define bitumen as being soluble in normally used organic 
solvents which since the 1970's or thereabouts does not include carbon disulphide. Huizinga et al. (1987) define bitumen for the purposes of their study "as the organic material that is generated from the thermal maturation of kerogen and soluble in a 9:1 dichloromethane/methanol mixture". They recognize two categories of bitumen, "bitumen-1" and "bitumen-2". "Bitumen1 " they define as "organic products that are readily extractable from the kerogen or kerogen plus mineral matrix" while "bitumen-2" refers to "organic products that are strongly adsorbed on the mineral matrix" and therefore "requires the destruction of the constituent minerals for the organic material to be solubilized". The term "bitumen" in this context means any extractable organic matter and therefore substances commonly referred to as bitumens which are insoluble, such as impsonite, wurtzilite and albertite, are excluded.

Jacob $(1976,1981)$ considers that the most important characteristic for distinguishing solid bitumens from coal under the microscope is "in general their passive behaviour with respect to their form" i.e. the variety of morphological form. Jacob (1976) gives examples of the variety of shapes bitumen may form, such as an evenly flat body with its edges defined by the crystal faces of quartz or carbonate or as "microplates" infilling cavities or fissures, infilling cavities in microfossils such as foraminifera or commonly forming very diffuse masses or rare, but typically globular bodies, in silty, marly or clayey rocks. 


\subsection{Bitumen associated with radioactive elements}

Many terms that have been proposed to describe solid bitumens associated with radioactive elements are not included in most of the global classification schemes reviewed in the previous section. In particular, a commonly used term "thucholite" is conspicuous by its absence in all classification schemes except that of King et al. (1963). Ellsworth (1928) coined the term to describe radioactive, carbonaceous, irregularly rounded nodules or more or less roughly globular masses from $1 \mathrm{~mm}$ to 1 inch (sic) in diameter within a pegmatite dyke in Ontario, Canada. Thucholite, as defined by Gary et al. (1974), is a "brittle jet-black mixture or complex of organic matter (hydrocarbons) and uraninite, with some sulphides, occurring especially in gold conglomerates (as in those of the Witswatersrand of South Africa) or in pegmatites (as in Canada); it may contain up to $48 \%$ thorium". Thucholite, occuring mainly in conglomeratic beds of the Witswatersrand system and commonly containing inclusions of uraninite, consists of small granules (up to $1.4 \mathrm{~mm}$ in diameter) or columnar and massive thucholite up to several millimeters in size (Liebenberg, 1955).

Other terms used to describe organic matter intimately associated specifically with uranium include "asphaltite" (Hawley et al., 1965), "urano-organic" (Haji-Vassiliou and Kerr, 1972,1973; Curiale, 1983), "organo-uranium" (Haji-Vassiliou and Kerr, 1980), and "uraniferous hydrocarbons" (Parnell and Eakin, 1987).

The spatial or genetic relationships between uranium mineralization and migrated hydrocarbons have frequently been 
noted. In one example, organic matter is the host of most of the uranium in the unoxidized or primary deposits of the Temple Mountain District, Utah (Hawley et al.,1965). They describe the organic matter as a "black, semi-lustrous to lustrous, rather hard uraniferous substance having a semiconchoidal fracture" which is found as nodules of various sizes, as interstitial fillings, and as massive replacements along bedding planes and the contacts of ore rolls. Urano-organic matter is associated with sulphide mineralisation at La Bajada, New Mexico, and occurs as spherical inclusions or filling cavities and fractures (Haji-Vassiliou and Kerr, 1972). It is a black, lustrous and breaks with a subchoncoidal to conchoidal fracture in hand specimen and is only slightly soluble in carbon disulphide (HajiVassiliou and Kerr, 1972). Dispersed urano-organic nodules which have uranium distributed fairly uniformly in them and occur in siltstones are described by Curiale et al. (1983). Hawley et al. (1965) describe the uraniferous asphaltite as commonly opaque but may in part be translucent (reddish-brown) and in polished section under cross-polars display distinctive mottling which is most intense around blebs of uraninite. Thucholite from the Witswatersrand system displays a marked increase in anisotropism, mottling and reflection pleochroism adjacent to uraninite grains (Liebenberg, 1955). Thucholite, described from the Isle of Man by Davidson and Bowie (1951), also displays similar petrographic characteristics. Thucholites which generally show an increase in reflectance and, more rarely, a decrease of fluorescence towards their centers, are present in sedimentary rocks of Precambrian to Mesozoic age and are more 
generally recognised by the accreted nature of the organic matter around their mineral core (Cook and Kantsler, 1982).

\subsection{Kerogen}

The term "kerogen" was first introduced by Crum-Brown in 1912 to denote specifically the organic matter in oil shale which, on heating and decomposition, gives rise to shale oil (Cane, 1976). It is now usually defined as being any organic material found in carbonaceous (non-coal) rocks which is insoluble in common organic solvents (Tissot and Welte, 1978). Most global classification schemes do not include this term except for Wen et al. (1978) who consider, erroneously, that kerogens are fusible.

Kerogen can be characterised geochemically by plotting its atomic ratio $\mathrm{H} / \mathrm{C}$ against its atomic ratio $\mathrm{O} / \mathrm{C}$ on what has been called a "van Krevelen diagram" by Tissot and Welte (1978) after van Krevelen (1961) who first used it to characterise coals and their coalification paths. Tissot et al. (1974) found that kerogen from shales from different localities and ages in the Phanerozoic formed three major evolution paths on a van Krevelen diagram which they called paths I, II and III, in a manner similar to the coalification paths of the major coal maceral groups as observed by van Krevelen (1961). Tissot and Welte (1978) refer to kerogen that plot on paths I, II and III as Type I, II or III, respectively. They describe Type I kerogen as having a high initial $\mathrm{H} / \mathrm{C}$ atomic ratio (ca. 1.5 or more) and a low initial $\mathrm{O} / \mathrm{C}$ atomic ratio (generally smaller than 0.1 ), Type II kerogen as having a relatively high $\mathrm{H} / \mathrm{C}$ and low $\mathrm{O} / \mathrm{C}$ ratio, and Type III kerogen as having a relatively low initial $\mathrm{H} / \mathrm{C}$ and a 
high $\mathrm{O} / \mathrm{C}$ atomic ratio (as high as 0.2 or 0.3 ). In addition to these three types, Tissot and Welte (1984) include a residual type which is characterised by abnormally low $\mathrm{H} / \mathrm{C}$ ratios associated with high $\mathrm{O} / \mathrm{C}$ ratios.

Cooles et al. (1986) divide kerogen into three parts based on its initial breakdown products: (1) labile kerogen which breaks down to form oil, (2) refractory kerogen which forms gas and (3) inert kerogen which "yields neither oil nor gas but eliminates hydrogen, oxygen, sulphur and nitrogen so as to achieve the most stable form of carbon - graphite". They also refer to labile kerogen and refractory kerogen collectively as reactive kerogen.

\subsection{Coal and Oil Shales}

Coal and oil shales are obviously of considerable economic importance and the organic matter in them has received a large amount of attention. Particularly relavent to this study is the nomenclature that has been developed which is based on petrographic criteria. The microscopic study of thin sections of coals commenced in the latter half of the nineteenth century but the practice of examining polished surfaces with oil-immersion objectives using reflected light, a method which gave less glare, did not become common until the 1930's (Stach et al, 1982). The use of fluorescence microscope techniques became common practice following its introduction for source rock studies by Jacob (1961) although the observation that irradiation with short-wavelength light causes fluorescence of some of liptinites had been known for some time (Teichmuller, 
1986). Its use has particularly facilitated the optical resolution of organic components in oil shales (Sherwood and Cook, 1984).

Coal contains a variety of microscopically discernable organic entities called macerals, a term introduced by Stopes (1935), whose definitions have been formalized by the International Committee for Coal Petrology (ICCP) and published in a handbook which is updated from time to time with supplements (International Handbook for Coal Petrography published by the ICCP; 1963, 1971, 1975). According to the definition in the handbook "a maceral is a microscopically recognizable individual constituent which does not contain any mineral substances resolvable with the microscope". Since the last edition of the handbook (1963) and supplements $(1971,1975)$ some new maceral terms have been proposed which are relevant to this study. Hutton et al. (1980), Cook et al. (1981), and Hutton (1982) undertook systematic studies of Phanerozoic oil shales, and defined two submacerals of alginite originally called alginite A and alginite B by Hutton et al. (1980) but renamed telalginite and lamalginite by Cook et al. (1982). Hutton (1987) states that the ICCP nomenclature system is suitable for describing organic matter in oil shales provided the terminology of organic matter derived from algal precursors is divided into these two submacerals.

\subsection{Classification of Precambrian Organic Matter}

Although major coal deposits did not form until after the first land plants had evolved during the Devonian, 370 m.y. ago (Stach et al., 1982), rocks containing significant amounts of carbonaceous matter are known from the Archaean 
(McKirdy, 1974) and some apparently contain sufficient organic matter in them to be classified as coal. The oldest known coal (anthracitic in rank) occurs in the Middle Huronian (ca. 2300 m.y.) in Michigan and contains probable algal structures (Stach et al., 1982). Anthracitic layers also occur in upper Huronian sediments in Michigan as lenticular bodies concordantly bedded in black pyritic shales and are considered by Tyler et al. (1957) to be derived from algal remains. Other coals (meta-coal, anthracite, shungite) which have been reported from the Proterozoic include those from the Soviet Karelia which are about 1800 to 1900 m.y. old (Cloud, 1972) and from the Koolpin Formation (1880 Ma, Page et al., 1984) in the Pine Creek Geosyncline of northern Australia (Crick et al., 1980).

Only a few petrographic observations of Precambrian organic matter have been published and these observations come from the Australian Precambrian. In the Amadeus Basin, some of the particulate organic matter in rocks from the Late Proterozoic have been described as "vitrinite-like" commonly having a micro-coke texture as a result of fusinitization and a variable reflectivity ranging from a mean $R_{0} \max$. of $1.40 \%$ to $3.20 \%$ suggesting a rank equivalent to semi-anthracite (A. Kantsler, pers. comm. in McKirdy, 1977). Thucholites having mean $R_{0}$ max values of between $1.7-1.8 \%$ and low reflectivity "algal balls" were also observed in one specimen (Kantsler, op. cit.).

Alginite, forming stringers up to 100 microns long but more commonly 20-30 microns long, which locally coalesce to form structureless complex agglomerations (mean $\mathrm{R}_{0} \max \sim 0.15 \%$ ) and thucholite, forming spheres about 10-50 microns in diameter, 
have been reported from Middle Proterozoic shales of the McMinn Formation in the Roper Group of the McArthur Basin (A. Kantsler, pers. comm. in McKirdy, 1977, and pers. comm. in Peat et al., 1978). A photomicrograph of this alginite is shown by Hutton et al. (1980) who call it "alginite B". The degree of coalification of the kerogen in the McMinn Formation increases towards a dolerite sill from a rank equivalent to low volatile bituminous coal to that of anthracite (McKirdy, 1977). McKirdy et al. (1984) calls this organic matter "vitrinite-like material" and notes that its reflectance reaches a maximum of $2.7 \%$ near the dolerite sill.

\subsection{Conclusions}

A large number of terms, used to describe organic matter in Phanerozoic rocks, are clearly unsuited for this study as they contain no petrographic criteria in their definitions. The term "bitumen", for example, cannot be used if its definition is based solely on the chemical criteria given by some authors. However it could justifiably be used if its definition is based on the petrographic criteria given by Jacob $(1976,1981)$.

The approach adopted in this study is not to ignore terms used to petrographically describe Phanerozoic organic matter, but to apply them if warranted. 


\section{CHAPTER 5}

\section{NOMENCLATURE AND PETROGRAPHIC DESCRIPTIONS OF THE ORGANIC MATTER IN PROTEROZOIC SEDIMENTARY ROCKS OF THE MCARTHUR BASIN}

\subsection{Introduction}

Organic matter in Proterozoic sedimentary rocks of the McArthur Basin can mostly be petrographically characterised by using existing descriptions, derived from Phanerozoic studies, as "lamalginite", "bitumen" and "thucholite". However, a new organic matter type, "oncalginite", is informally defined here from the McMinn Formation of the Roper Group. The origins of these organic matter types are discussed in Chapter 10.

\subsection{Nomenclature and Definitions}

\subsubsection{Lamalginite}

Lamalginite in Phanerozoic sediments is defined by Hutton et al. (1980) as finely-banded lamellar alginite intimately interbedded with mineral matter and composed of single isolated films, or aggregations of films that form thicker strands. It has a weak to strong fluorescence with fluorescence colours varying from green through yellow and orange to brown. It commonly "binds" mineral matter where it resembles an algal mat and the individual films or lamellae are typically around $0.001 \mathrm{~mm}$ to $0.002 \mathrm{~mm}$ but generally less than $0.005 \mathrm{~mm}$ thick and $0.05 \mathrm{~mm}$ to $1.5 \mathrm{~mm}$ in length (Cook and Kantsler, 1982). 
In this study the term lamalginite extends to organic matter that is nonfluorescing, and has a similar morphological appearance to fluorescing lamalginite. The informal term "nonfluorescent lamalginite" is applied to this organic matter. Individual lamellae within larger strands of nonfluorescent lamalginite are not recognizable.

\subsubsection{Oncalginite (new name)}

Organic matter that forms thin, commonly concentric bands, in oncolites is here called oncalginite. It differs from lamalginite in that the orientation of the organic matter is not along the bedding plane but is controlled by the morphology of the oncolite. An oncolite is defined by Gary et al. (1974) as " a small variously shaped (often spheroidal), concentrically laminated, calcareous sedimentary structure, resembling an oolith, and formed by the accretion of successive layered masses of gelatinous sheaths of blue-green algae. It is smaller than a stromatolite and generally does not exceed $10 \mathrm{~cm}$ in diameter." Monty (1976) simply refers to oncolites as "unattached subspherical, ovoid, lobate or flattened structures otherwise similar to stromatolites" and Walter (1976) defines an oncolite as a "unattached stromatolite with encapsulating laminae".

A more precise definition for oncalginite is not possible here as only one polished block containing a $5 \mathrm{~cm}$ thick bed of oncolites from the McMinn Formation in the Roper Group, (DDH Urapunga 4, $32.3 \mathrm{~m}$ ) was examined. The oncolites in this bed are spherical, elliptical or irregularly shaped bodies up to $3 \mathrm{~mm}$ in diameter, commonly having nucleii made of a grain or several 
grains of minerals, mostly quartz, and surrounded by concentric layers of lighter mineral and darker organic matter (Plate 32). The oncalginite is generally uniformly thin (less than 5 microns thick), but can reach up to about 15 microns in thickness (Plate 33). It is nonfluorescent, has a silvery appearance under reflected white light and forms single or multiple concentric bands within the oncolites.

Oncalginite clearly formed under different circumstances to the other types of organic matter described here from the McArthur Basin and has not been described elsewhere from Phanerozoic or other Precambrian sedimentary rocks.

\subsubsection{Bitumen}

The term "bitumen" is used here according to the definition of Jacob $(1976,1981)$ who considers that the most important characteristic for distinguishing solid bitumens from coal under the microscope is "in general their passive behaviour with respect to their form" i.e. the variety of morphological form.

The types of bitumen present in the McArthur Basin have here been mostly informally classified as: (1) Patchy dispersed bitumen, (Plates 6e,f; 25a; 26e,f; 27c,f; 28g,h) comprising loose aggregates of irregularly shaped grains whose margins are commonly defined by crystal faces of the mineral matrix and are generally less than 10 microns in size, as distinct from (2) disseminated bitumen (Plates 7b,c,d; 9a-f; 25a; 26e-h; 27c,f; $36 \mathrm{C}, \mathrm{D}, \mathrm{F}, \mathrm{G})$ made up of generally similarly sized and shaped bitumen grains but occurring as isolated grains and not in patches; (3) bitumen microspheres (Plate 26e,f) which are 
spherical bitumen structures less than 10 microns in diameter; (4) cauliflower bitumen (a term first used by McKirdy and Kantsler, 1980) which forms isolated cauliflower shapes up to 70 microns across (Plate 30a,b,c,f); (5) matrix bitumen (Plates 9e,f; $25 e, f, 28 i)$ which forms generally larger irregularly shaped masses, completely enveloping mineral grains; (6) vein bitumen (Plates 7a,e,g,h; 24d-i; 25h,i; 28d,e; 29; 31a,b) which runs parallel with or across bedding and in places form anastomosing veins and (7) vug bitumen (Plates 25g; 40E,F) which appears to occupy preformed spaces within the rock fabric.

\subsubsection{Thucholite}

Grains of organic matter formed around presumed or identified radioactive minerals, generally having a rounded shape and showing increased reflectivity towards the centre, have been classified as "thucholite" (Plates 8 and 38 ).

\subsection{Organic matter in sedimentary rocks of the McArthur Basin}

The amount of organic matter present in the lutaceous formations in the McArthur Basin varies from less than $1 \%$ to over $5 \%$ total organic carbon whereas, as would be expected, the mainly arenaceous units contained less than $1 \%$ total organic carbon (Figures 5-1,2). Lamalginite and bitumen are the most common types of organic matter whereas thucholite is less common and oncalginite has been observed in only one drill-core specimen (Table 5-1). 

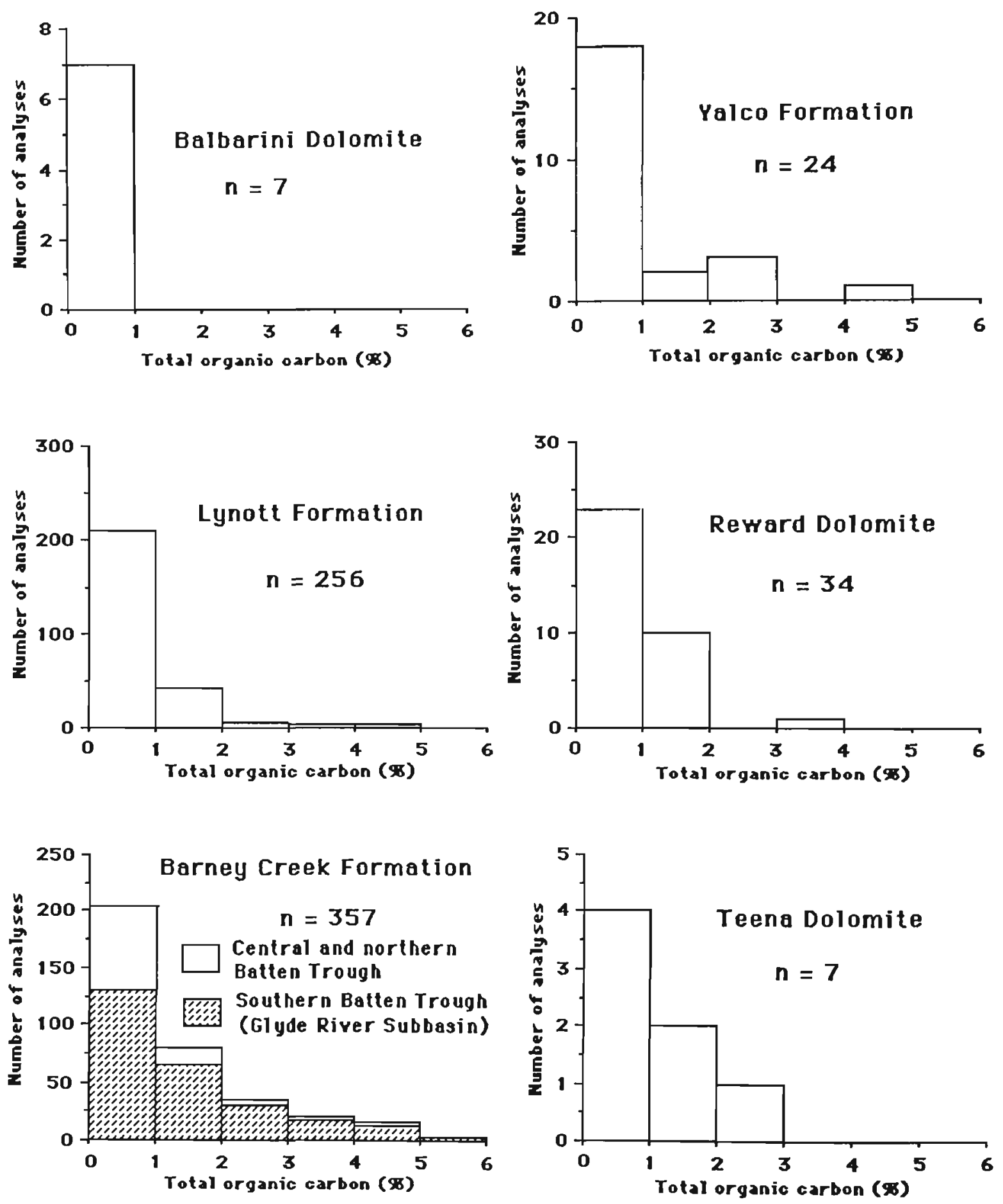

Figure 5-1. Histograms showing total organic carbon contents for some formations in the Nathan and McArthur Groups. 

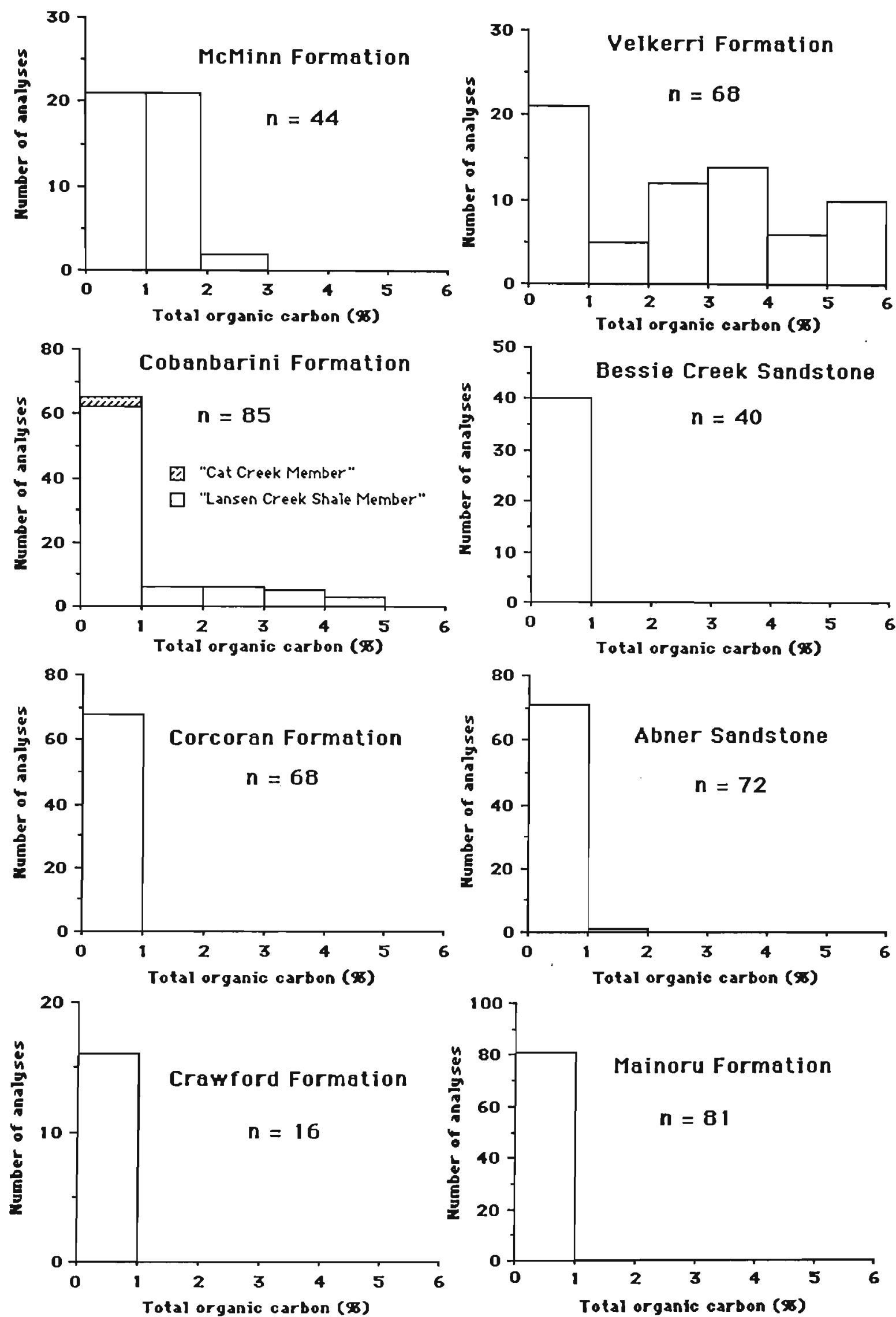

Figure 5-2. Histograms showing total organic carbon contents for formations of the Roper Group. 


\begin{tabular}{|c|c|c|c|c|c|c|c|c|c|c|c|}
\hline \multirow[b]{2}{*}{ EOBMATION/DDH } & \multicolumn{2}{|c|}{ Lamalginite } & \multicolumn{7}{|c|}{ Bitumen } & \multirow[t]{2}{*}{ Ih } & \multirow[t]{2}{*}{ Ono } \\
\hline & EL & $N L$ & $\mathrm{PDB}$ & $\mathrm{DB}$ & $\mathrm{MB}$ & $V B$ & $V G$ & $B M$ & $\mathrm{CB}$ & & \\
\hline ROPER GROUP & & & & & & & & & & & \\
\hline McMinn Formation & $x$ & $x$ & $x$ & & $x$ & & & & & $x$ & $x$ \\
\hline Velkerri Formation & $x$ & $x$ & $x$ & $x$ & $x$ & $x$ & & $x$ & $x$ & $x$ & \\
\hline $\begin{array}{l}\text { Cobanbirini Formation } \\
\text { "Cat Creek Member" }\end{array}$ & $x$ & $x$ & & & & & & & & $x$ & \\
\hline "Lansen Creek Shale" & $x$ & $x$ & $x$ & $x$ & & $x$ & & $x$ & & $x$ & \\
\hline Bessie Creek Sandstone & & $x$ & $x$ & & & & & & & & \\
\hline Corcoran Formation & & $x$ & $x$ & $x$ & & & & & & & \\
\hline Abner Sandstone & & $x$ & & $x$ & & $x$ & & & & & \\
\hline Crawford Formation & & $x$ & & & & & & & & $x$ & \\
\hline Mainoru Formation & & $x$ & $x$ & $x$ & $x$ & $x$ & & & & $x$ & \\
\hline "Mantungula Formation" & & $x$ & & & & & & & & & \\
\hline $\begin{array}{l}\text { NATHAN GROUP } \\
\text { Balbarini Dolomite }\end{array}$ & & $x$ & $x$ & $x$ & & & & & & & \\
\hline $\begin{array}{l}\text { MCARTHUR GROUP } \\
\text { Looking Glass Fmt. }\end{array}$ & & & & & & $x$ & $x$ & & & & \\
\hline Yalce Formation & $x$ & $x$ & & & $x$ & $x$ & & & & $x$ & \\
\hline Lynott Formation & $x$ & $x$ & $x$ & $x$ & $x$ & & & & & $x$ & \\
\hline Beward Dolomite & & & $x$ & $x$ & & $x$ & $x$ & & & $x$ & \\
\hline Barney Creek Fmt. & $x$ & $x$ & $x$ & $x$ & $x$ & $x$ & & & & $x$ & \\
\hline Ieena Dolomite & & $x$ & $x$ & & & $x$ & & & & $x$ & \\
\hline Emmerugga Dolomite & & & & $x$ & & $x$ & $x$ & & & & \\
\hline
\end{tabular}

Table 5-1. Organic matter types identified in some formations within the McArthur Basin. $(F L=$ fluorescent lamalginite,$N L=$ nonfluorescent lamalginite, $\mathrm{PDB}=$ patchy dispersed bitumen, $\mathrm{DB}=$ disseminated bitumen, $\mathrm{MB}=$ matrix bitumen, $\mathrm{VB}=$ vein bitumen, $\mathrm{BM}=$ bitumen microspheres, $V G=$ vug bitumen, $C B=$ cauliflower bitumen, $T h=$ thucholite, Onc $=$ oncalginite) 


\subsubsection{McArthur Group}

\section{Emmerugga Dolomite}

Crosscutting and anastomosing bitumen veins, in places containing fine disseminated pyrite are present in the two samples examined from this formation. The bitumen also appears in places to have replaced carbonate rhombs or filled voids formerly occupied by them (Plate 25h).

\section{Teena Dolomite}

The organic matter types identified from the three samples examined from this formation are nonfluorescent lamalginite, vein bitumen (Plate 25i), patchy dispersed bitumen and thucholite. The vein bitumen in places contains pyrite and sphalerite.

\section{Barney Creek Formation}

A. Southern Batten Trough (Glyde River Subbasin )

The organic matter types identified in the Barney Creek Formation from this subbasin are:

(1) Lamalginite (Plates 3-6, 17)

Fluorescent lamalginite is generally abundant within lutaceous sediments in this subbasin. It consists, in sections perpendicular to bedding, of filamentous-looking organic matter with the filaments elongate parallel to bedding, varying in size from several microns to hundreds of microns long by less than 2 microns wide. The individual filaments (lamellae) are commonly grouped together to form thicker strands or thin 
lenticular bodies or mats that are generally less than $0.5 \mathrm{~mm}$ long by $0.05 \mathrm{~mm}$ thick but, more rarely, up to lengths of several millimetres by $1 \mathrm{~mm}$ thick. In one case, they form apparently continuous mats (Plate 17). In one example, fluorescent lamalginite has been deformed by soft-sediment compaction around a large grain (Plate $4 e$ ).

Sections of fluorescent lamalginite parallel to bedding show an irregular but commonly roughly circular shape (Plate $4 d, h)$. SEM examination of macerates showed the mats are made up of a number of thin flat layers which are the individual lamellae (Plate 10e,f).

Detrital or diagenetic mineral matter, commonly euhedral to subhedral carbonate, commonly occurs within the mats and in places the lamellae are deformed around them. In one example, a large mat appears to have relatively more carbonate in it than the surrounding sediments (Plate 16d). Lamalginite itself does not contain appreciable amounts of elements with atomic weights heavier than carbon (Plates 15,16). In one exceptional sample, a nodule and lenses of calcium phosphate occur within a large mass of lamalginite (Plates 17-20). The phosphate has clearly formed soon after deposition of the organic matter as the lenses have in one place been scoured (Plate 17,1). Individual lamalginite lamellae, containing inclusions of quartz, pyrite and probably clay minerals (Plate 20i-I), have apparently been detached by the formation of the phosphate in one of the lenses. Disseminated fine-grained euhedral pyrite is common throughout most of the Barney Creek Formation in the subbasin. No pyrite framboids were observed although in one rare example, an 
aggregation of fine-grained pyrite is possibly pseudomorphous after a discoidal gypsum crystal (Plate 4f).

The fluorescence of the lamalginite varies from bright yellow to a dull brownish orange. There is an obvious decrease in fluorescence intensity and increase in its reddishness with depth. Figure 5-3 shows the intensity of fluorescence (I), as measured at $546 \mathrm{~nm}$, decreases with depth in DDH GR10 and the red/green quotient (Q) shows a slight increase with depth indicating a shift towards the red end of the spectrum of the fluorescence. At depths greater than about $600 \mathrm{~m}$, the lamalginite is not fluorescent.

The intensity of fluorescence of lamalginite generally changes when exposed to ultraviolet light irradiation for a period of time (Plate 9i). Figure 5-4 shows that after 30 minutes
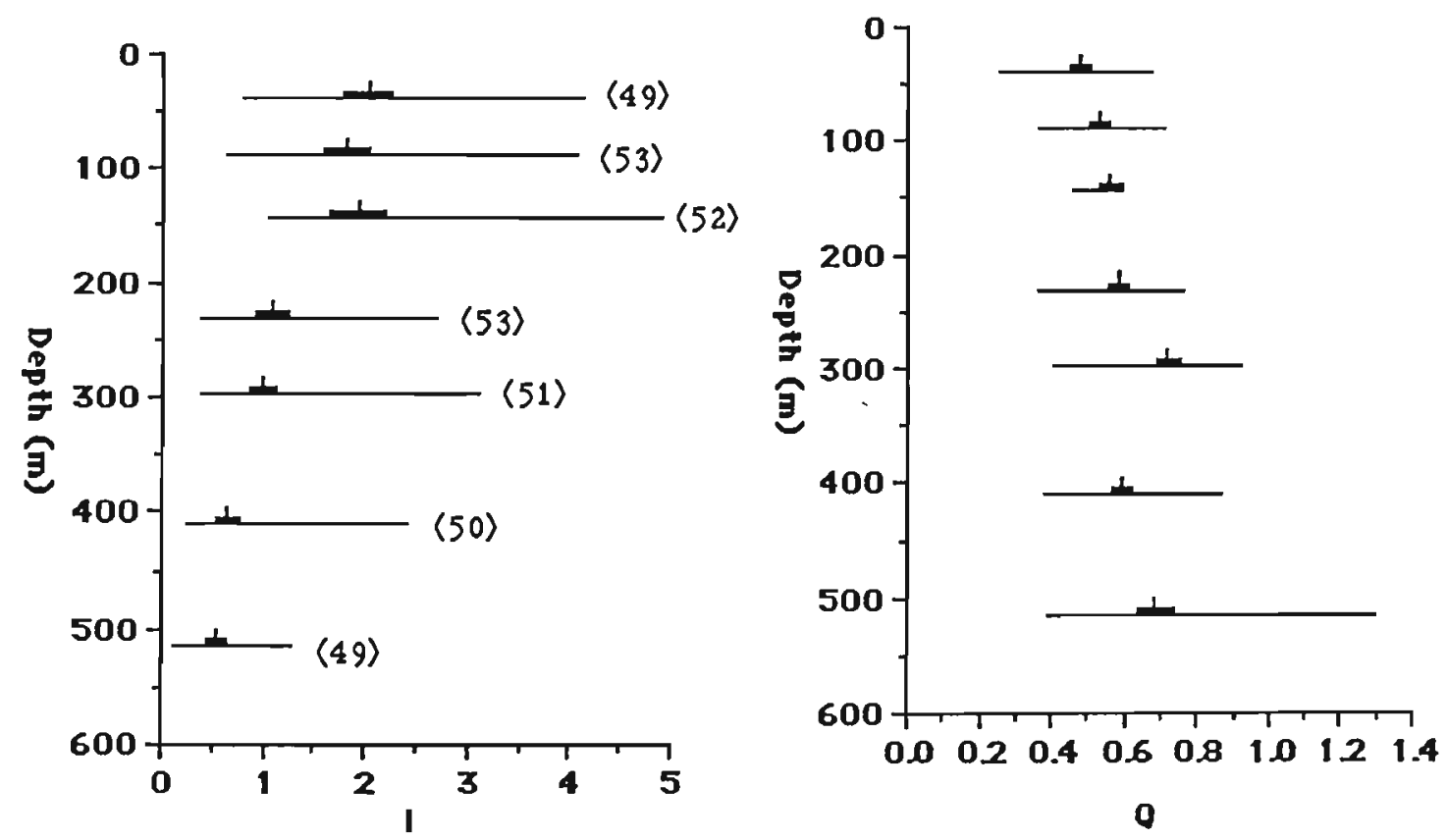

Figure 5-3. Measurements of fluorescence intensity (I) at $546 \mathrm{~nm}$ and the red/green quotient "Q" (650/500 $\mathrm{nm})$, plotted against depth, for lamalginite in the Barney Creek Formation, DDH GR10, Glyde River Subbasin. Mean value is the vertical line, 95\% confidence limits of the mean is the solid bar, range of readings is the horizontal line and number of readings is represented by the numerals in brackets. 


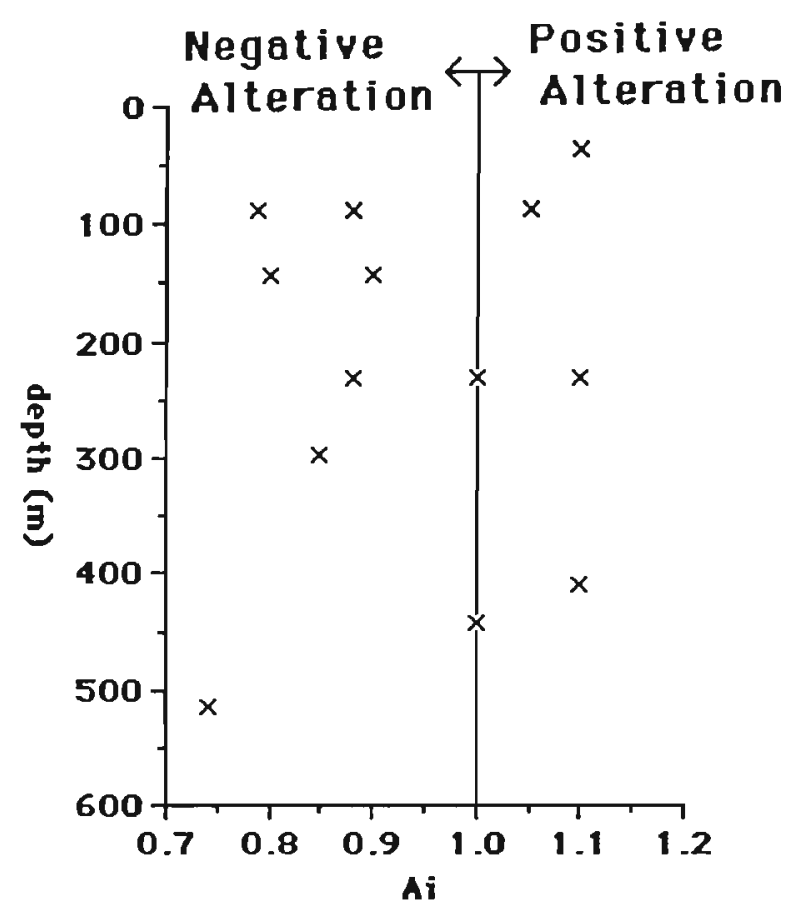

Figure 5-4. Alteration of fluorescence intensity at $546 \mathrm{~nm}$ of lamalginite (Ai) from DDH GR10, Barney Creek Formation, after 30 minutes of irradiation.

of irradiation, lamalginite from the Barney Creek in DDH GR10 altered, with the exception of two examples, either positively (Plate 9i) or negatively. It is likely that all alteration is positive and that negative alteration is due to experimental error.

Nonfluorescent lamalginite occurs at depths greater than about $200 \mathrm{~m}$ in the subbasin. It commonly appears more deformed and disjointed in morphology than fluorescent lamalginite.

(2) Bitumen.

Patchy dispersed bitumen and disseminated bitumen occur at depths greater than about $200 \mathrm{~m}$ in the subbasin and are commonly associated with low fluorescing or nonfluorescing lamalginite (Plates 6,7). Vein bitumen is also present from depths greater than about $300 \mathrm{~m}$ (Plate 7). 
Titaniferous bitumen nodules ranging in size from about 50 to 200 microns across, occur in drill-core from DDH GR10 at $37.4 \mathrm{~m}$ (Plates 11, 13 and 14). within a $2 \mathrm{~cm}$ band of greenishgrey claystone. Electron probe analyses of the nodules revealed the presence of the titanium as well as pyrite. The pyrite in one nodule has possibly replaced a piece of filamentous and branching algae trapped within the nodule (Plate 11). Larger nodules are probably composed of coalesced smaller nodules as $X$-ray mapping of one of the larger nodules for sulphur and iron shows these two elements surrounding what appears to be smaller nodules (Plate 14). A pyrite nodule having a spongy appearance and containing bright-yellow fluorescing inclusions of oil also occurs within this tuffaceous band (Plate 12). Titaniferous bitumen nodules and spongy pyrite nodules containing oil inclusions have not been observed elsewhere in the McArthur Basin.

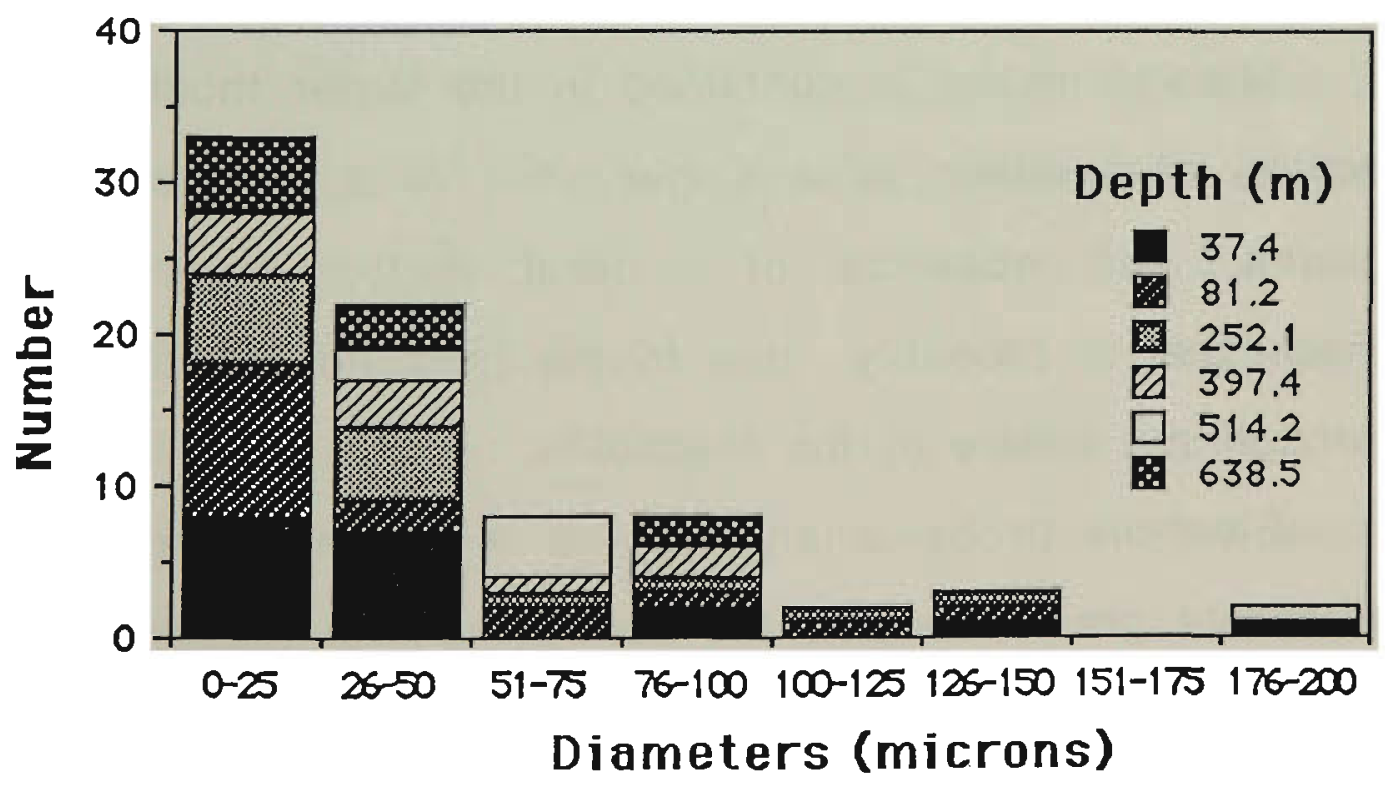

Figure 5-5. Histogram of diameters of thucholite grains from DDH GR10, Barney Creek Formation. 
(3) Thucholite

In hand-specimens, thucholite appears as black, commonly round, grains up to about $0.5 \mathrm{~mm}$ in diameter. Most thucholite grains in DDH GR10 have a maximum diameter of less than 50 microns (Figure 5-5). In polished blocks, thucholite grains have a silvery surface, like bitumen, and commonly have a noticeably higher reflecting central area and, in some cases, a reddish-brown to orange fluorescent halo.

The thucholitic bitumen is unaffected by the organic solvents toluene and chloroform. A polished block from $238.8 \mathrm{~m}$ in $\mathrm{DDH}$ GR10, which contained a number of thucholite grains, was immersed in toluene at room temperature for a total of 18 hours and in chloroform for a further 6 hours. Microscopic examination of the block and comparisons of photomicrographs taken before and after each session of immersion showed no apparent change to the polished surfaces or dimensions of the thucholites.

Mineral matter is contained in the larger thucholites in their central area either as a single grain or a number of scattered grains. The absence of mineral matter from the smaller thucholites is probably due to the polished section not passing through the centre of the thucholite.

Electron probe analyses and X-ray mapping of selected thucholite grains showed the central mineral matter is composed of thorium and silica and is therefore probably thorite ( $\mathrm{ThSiO}_{4}$ ) and that the thucholitic bitumen contains appreciable sulphur (Appendix E and Plates 21, 22). 
(4) Oil inclusions and matrix oil

Oil inclusions commonly occur within carbonate grains as small (generally less than 3 microns), brightly fluorescing objects, and in many cases contain a gas bubble which is constantly moving (Brownian movement) (Plate $9 \mathrm{~g}$ ). In some cases the oil inclusions do not appear to have a gas bubble, are rhombic in shape, and appear to occupy spaces caused by lattice defects within some carbonate grains. Larger oil inclusions occur in one specimen in which the oil may be filling a vug (Plate7i).

Mineral fluorescence is ubiquitous and varies from bright yellow-green to dull orange. Fluorescence intensities and colour can show great variation within one sample and even within one mineral grain. Some carbonate rhombs show a distinct fluorescence zonation. Overall, there is a lessening of fluorescence intensities with depth and a shift in colour towards the red end of the spectrum .

Much of the mineral fluorescence seen in specimens from this subbasin is probably due to the adsorption of liquid hydrocarbons or their inclusion into carbonates formed in the presence of liquid hydrocarbons. As a check, a drop of oil, extracted from the Velkerri Formation in the Roper Group, was placed on a block of non-fluorescing greywacke from eastern Australia (Lachlan Fold Belt) and irradiated with ultraviolet light. The greywacke fluoresced in a very similar manner to the mineral fluorescence commonly observed in the Glyde River Subbasin (Plate 35G). 
B. Central and northern Batten Trough

Organic matter in the Barney Creek Formation from this region is composed of nonfluorescent lamalginite, patchy dispersed bitumen, disseminated bitumen, matrix bitumen, vein bitumen and thucholite (Plate 25). No fluorescent lamalginite was observed and mineral fluorescence is weak to absent.

\section{Reward Dolomite}

Organic matter types identified in this formation are patchy dispersed bitumen, dispersed bitumen, vein bitumen and thucholite. Mineral fluorecence is weak to absent.

\section{Lynott Formation}

The Lynott Formation contains fluorescent and nonfluorescent lamalginite, patchy dispersed bitumen, disseminated bitumen, vein bitumen and thucholite. Fluorescent lamalginite occurred in one specimen (DDH 82/6, 290.3m) as thin, low fluorescing, strands up to 100 microns long by 1 to 3 microns in width. Mineral fluorescence is weak to absent.

\section{Yalco Formation}

Fluorescent and nonfluorescent lamalginite, matrix bitumen, vein bitumen and thucholite are present in this formation. The fluorescent lamalginite consists of thin (less than 3 microns wide) wavy strands, commonly in excess of 200 microns long, and in places have been disrupted by sandstone dykes (Plate 24a) or are in low-angle cross-beds (Plate 24b). 
Looking Glass Formation

Abundant vein and vug bitumen was present in the one specimen examined from this formation.

\subsubsection{Nathan Group}

\section{Balbarini Dolomite}

Nonfluorescent lamalginite, patchy dispersed and disseminated bitumen occur in the two specimens examined from this formation.

\subsubsection{Roper Group}

\section{Mainoru Formation}

Nonfluorescent lamalginite up to 600 microns long by less than 5 microns wide, but commonly less than 100 microns long by 5 microns wide, are present as discrete bodies. In one example the lamalginite is composed of two parallel thin strands (Plate $39 \mathrm{H}$ ). Patchy dispersed, disseminated, matrix and vein bitumen, and thucholite, are also present within the lutites of this formation (Plates 27g-i; 39G-I and 40A,E-H).

\section{Crawford Formation}

Nonfluorescent lamalginite, forming discrete bodies up to 200 microns long by 5 microns wide, occurs in the one example examined from this formation. 


\section{Abner Sandstone}

Discrete bodies of nonfluorescent lamalginite up to 200 microns by 5 microns are contained within the pelitic units of this formation (Jalboi and Arnold Members) (Plates 39F, 40B-D). Vein and disseminated bitumen are also present

\section{Corcoran Formation}

Nonfluorescent lamalginite forming thin discrete strands up to $5 \mathrm{~mm}$ long, in places showing soft-sediment deformation, together with patchy dispersed bitumen and disseminated bitumen occur in silty beds within this organically-poor unit (Plates 27e and 36E-G).

\section{Bessie Creek Sandstone}

Nonfluorescent lamalginite up to 50 microns long, patchy dispersed bitumen and disseminated bitumen occur in the one specimen observed from this formation (Plate 27a-d).

\section{Cobanbirini Formation}

Cat Creek Member

Discrete strands of fluorescent and nonfluorescent lamalginite up to 200 microns long by 10 microns wide, and thucholite were present in the one specimen examined. Fluoresence of the lamalginite varies from a dull orange to faint brownish-orange. 
Lansen Creek Shale Member

Fluorescent and nonfluorescent strands of lamalginite up to 500 microns long, patchy dispersed and disseminated bitumen, vein bitumen and thucholite occur in this formation (Plate 26). Fluorescence of the lamalginite varies from dull yellow to faint brownish-orange. In rare examples, the fluorescence of a single strand of lamalginite varies from dull yellow to being absent altogether (Plate 26b). In one sample, bitumen microspheres, less than 10 microns diameter, are associated with similarly-sized microspheres of calcium phosphate (Plates 26e and f; 42G-I).

\section{Velkerri Formation}

Fluorescent and nonfluorescent lamalginite, patchy dispersed bitumen, disseminated bitumen, matrix bitumen, bitumen balls, cauliflower bitumen, vein bitumen and thucholite are present in this formation. Fluorescent lamalginite forms strands up to 300 microns long and its fluorescence varies from yellow to a faint orange-brown (Plates 28b,c; 34A-F). Nonfluorescent lamalginite is, in places, deformed and poorly orientated by soft-sediment slumping (Plates $31 \mathrm{c}-\mathrm{g}, 35 \mathrm{~A}$ ). Bitumen microspheres, less than 10 microns in diameter, associated with similarly-sized calcium phosphate microspheres, which, in some cases, are within strands of nonfluorescent lamalginite, are present in places (Plates $30 \mathrm{~d}$; 34G; 42A-F). The phosphate microspheres display, in some cases, a fluorescent outer shell (Plate $34 \mathrm{H}$ ). 
Liquid hydrocarbons, which bubbled from core from DDH Urapunga 4 between 345.4 and $345.55 \mathrm{~m}$ (Jackson et al, 1986) is also present within vugs and fissures at $342.7 \mathrm{~m}$ (Plate 35E,F,H).

\section{McMinn Formation}

Fluorescent lamalginite, nonfluorescent lamalginite, oncalginite, patchy disseminated bitumen, matrix bitumen, vein bitumen and thucholite are present in this formation. Fluorescence of the lamalginite ranges from strong yellow to weak orange-brown. The fluorescent lamalginite varies in size from thin filamentous-like structures less than 10 microns long by 1 micron wide to long, wavy strands exceeding $2 \mathrm{~mm}$ in length by up to 50 microns thick (Plate 37 ). 


\section{CHAPTER 6}

\section{REFLECTANCES OF THE ORGANIC MATTER TYPES}

\subsection{Introduction}

Reflectance measurements were made on lamalginite and bitumen in the McArthur and Nathan Groups (Appendix F) and Roper Group (Appendix G). Thucholite reflectances were measured in samples from the Barney Creek Formation in the Glyde River subbasin where there are sufficient numbers of thucholite occurrences to allow such a study to be made (Appendix F)

\subsection{Reflectances of Lamalginite and Bitumen}

\subsubsection{Lamalginite}

The least mature specimens of fluorescent lamalginite display translucent pale reddish-brown reflective surfaces and low reflectances of less than $0.20 \%$. At higher reflectances these surfaces have a grey colour. Nonfluorescent lamalginite has a silvery surface and is noticeably anisotropic.

The presence of a radioactive mineral adjacent to fluorescent lamalginite produces a noticeable halo of increased reflectance and decreased fluorescence (Plate $8 e, f$ ). Care had to be exercised in measuring the reflectance of the lamalginite, particularly nonfluorescent lamalginite, to ensure that measurements were not made of surfaces affected by radioactivity.

Nonfluorescent lamalginite occurs with fluorescent lamalginite in some specimens (Plates 26a,b; 28b,c; 34E,F). In these 
cases, the fluorescent lamalginite have mean maximum reflectances in excess of $0.20 \%$ and the nonfluorescent lamalginite have reflectances of about twice that of the fluorescent lamalginite (Figure 6-1; Appendix H). There is, in some cases, an overlap in the range of reflectances of both types which may be attributed, at least in part, to the difficulty in deciding whether a piece of lamalginite is fluorescing or not. At very low levels of fluorescence, the decision is largely influenced by the operator's own acuity of eye and the intensity and wavelengths of the incident light.

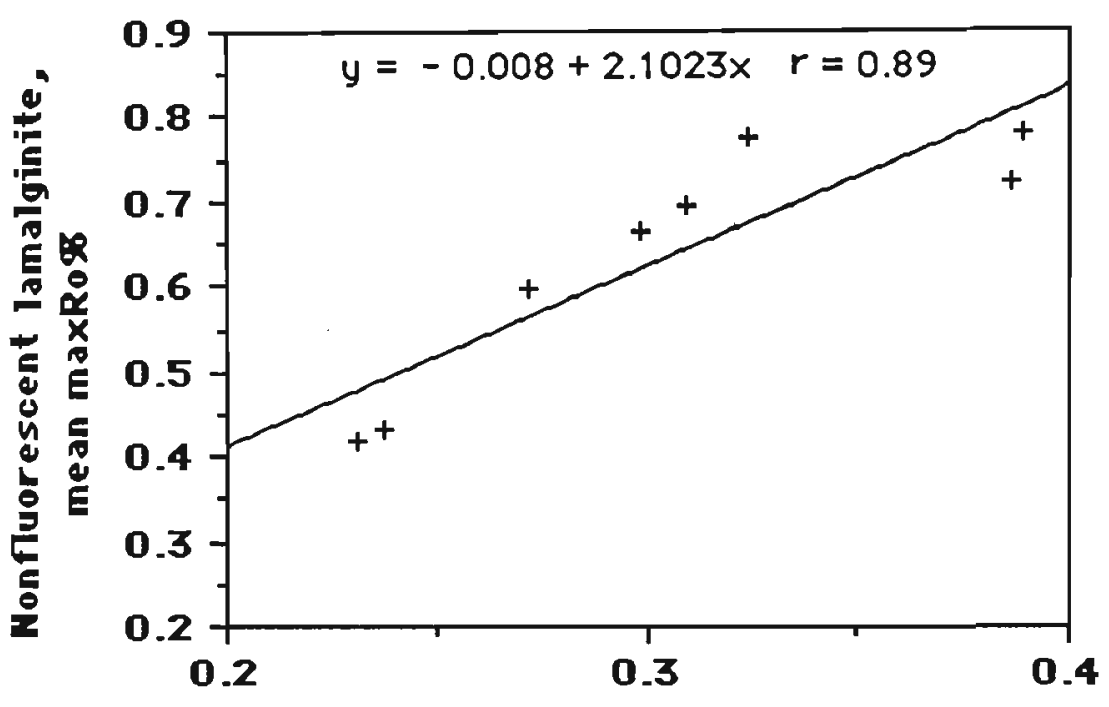

Fluorescent lamalginite, mean maxRos

Figure 6-1. Mean maximum reflectances (mean maxRo\%) for fluorescent and nonfluorescent lamalginite from the same specimens, Roper and McArthur Groups

\subsubsection{Bitumen}

Bitumen, under plane-polarised reflected light, has a silvery appearance and is commonly optically non-homogeneous but contains zones or areas of homogenous material (e.g. Plates 24d,e, and 29). Care had to taken in measuring its reflectance to ensure that the measuring field was kept placed over an homogenous area. 


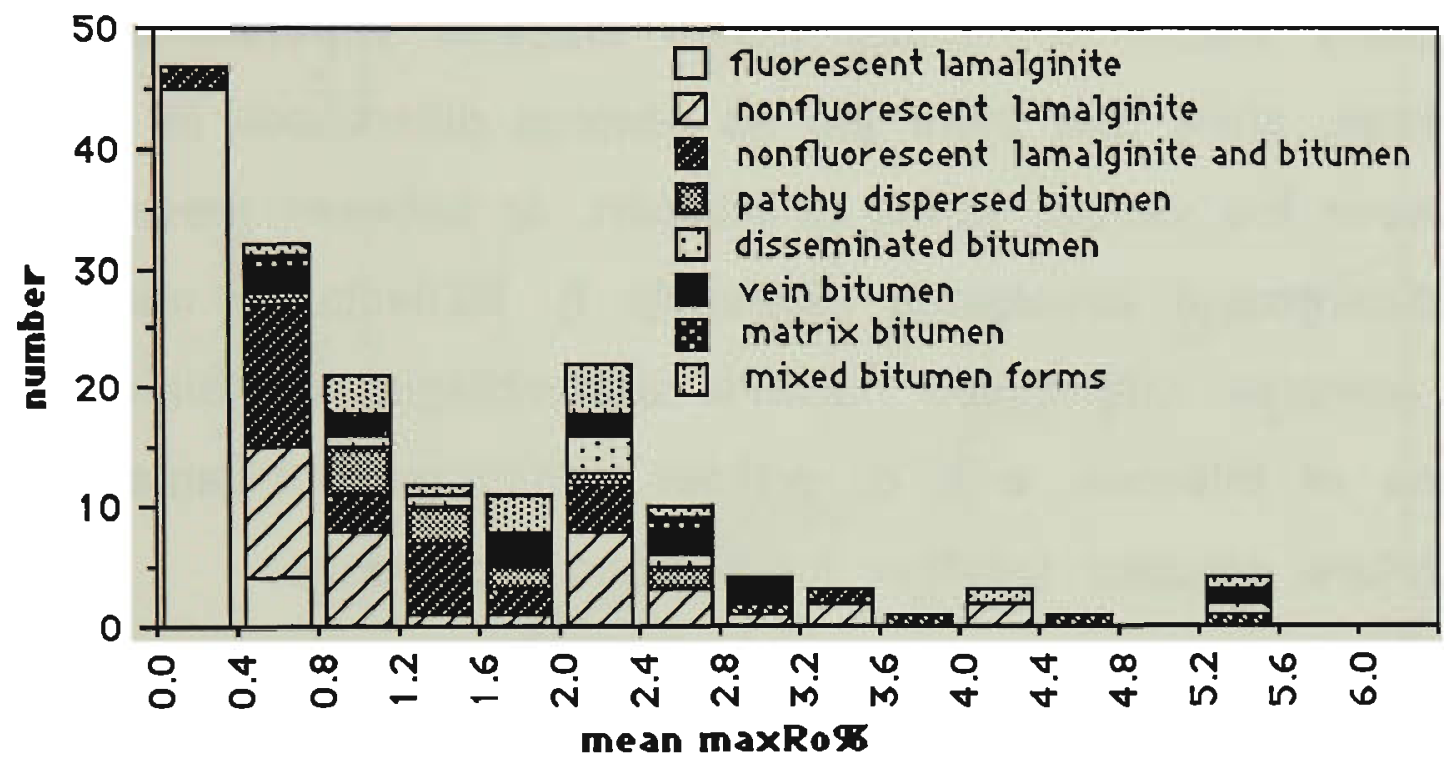

Figure 6-2. Histogram of mean maximum reflectances for the various organic matter types (excluding thucholite) in the McArthur Basin.

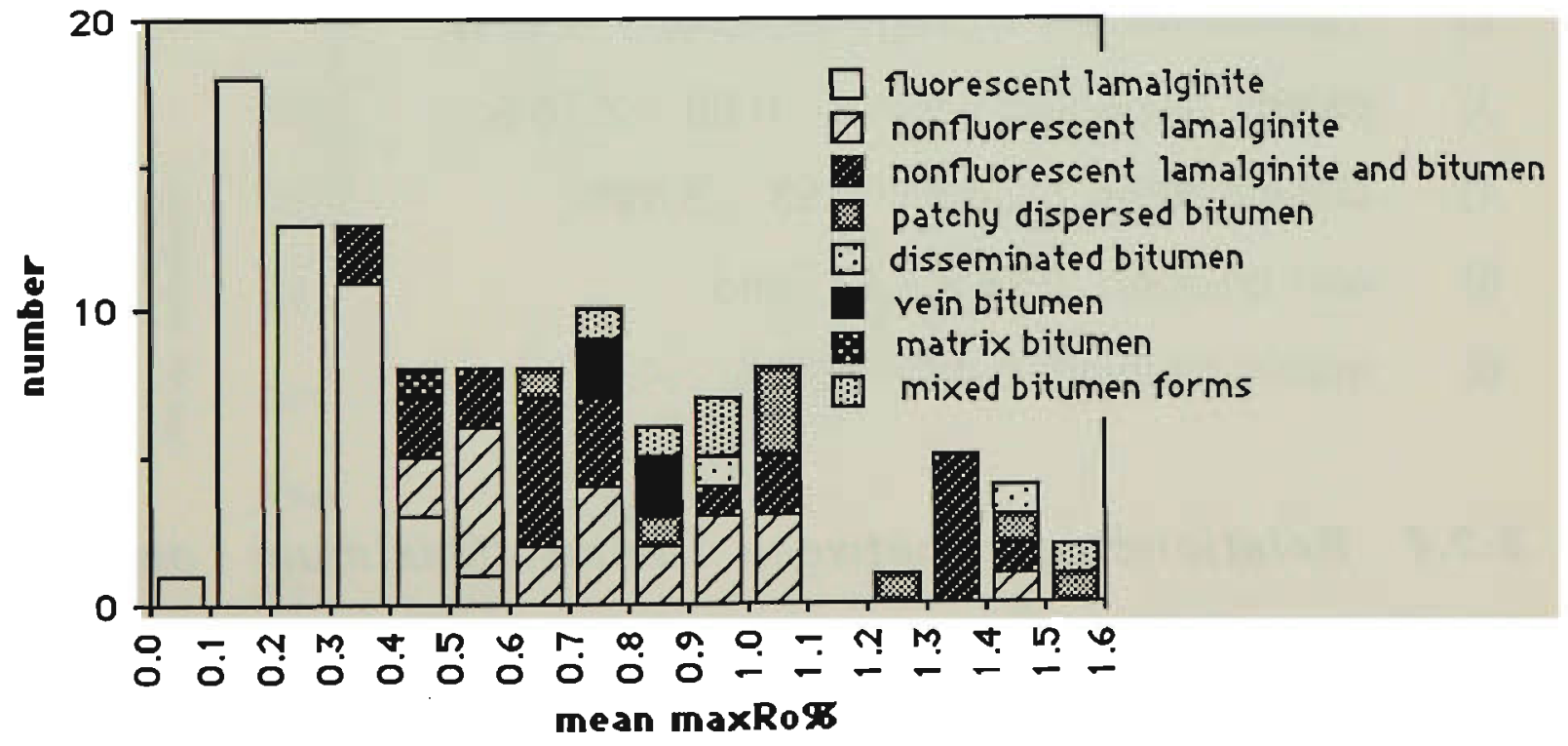

Figure 6-3. Histogram of mean maximum reflectances in the range $0.0-1.59 \%$ for various organic matter types (excluding thucholite) in the McArthur Basin. 
Reflectance measurements on organic matter in polished blocks containing mixed maceral populations, including bitumen, show that there are no obvious differences in reflectances between the various forms of bitumen, or between these forms and nonfluorescent lamalginite (Appendix I). Reflectance measurements on samples with mixed maceral assemblages containing different forms of bitumen, with or without nonfluorescent lamalginite, are therefore grouped together for statistical purposes.

\subsubsection{Ranges of Mean Maximum Reflectances}

The range of mean maximum reflectances for the various organic matter types, excluding thucholites, are shown in Figures 62, 3. In detail, the ranges observed are:

1) fluorescent lamalginite, $0.05-0.53 \%$;

2) nonfluorescent lamalginite, $0.42-4.27 \%$;

3) patchy dispersed bitumen, $0.68-2.76 \%$;

4) disseminated bitumen, 0.93 - 5.39\%;

5) vein bitumen, $0.79-5.34$, and

6) matrix bitumen, $0.44-2.77 \%$.

\subsubsection{Relationships between Mean Maximum and Mean} Minimum Reflectances

There is a clear relationship between mean maximum and mean minimum reflectances for these organic matter types. The relationship is best expressed as a logarithmic equation overall (Figure 6-4) but for mean maximum reflectances below $1.6 \%$, it is best expressed as a simple linear equation (Figure 6-5). 


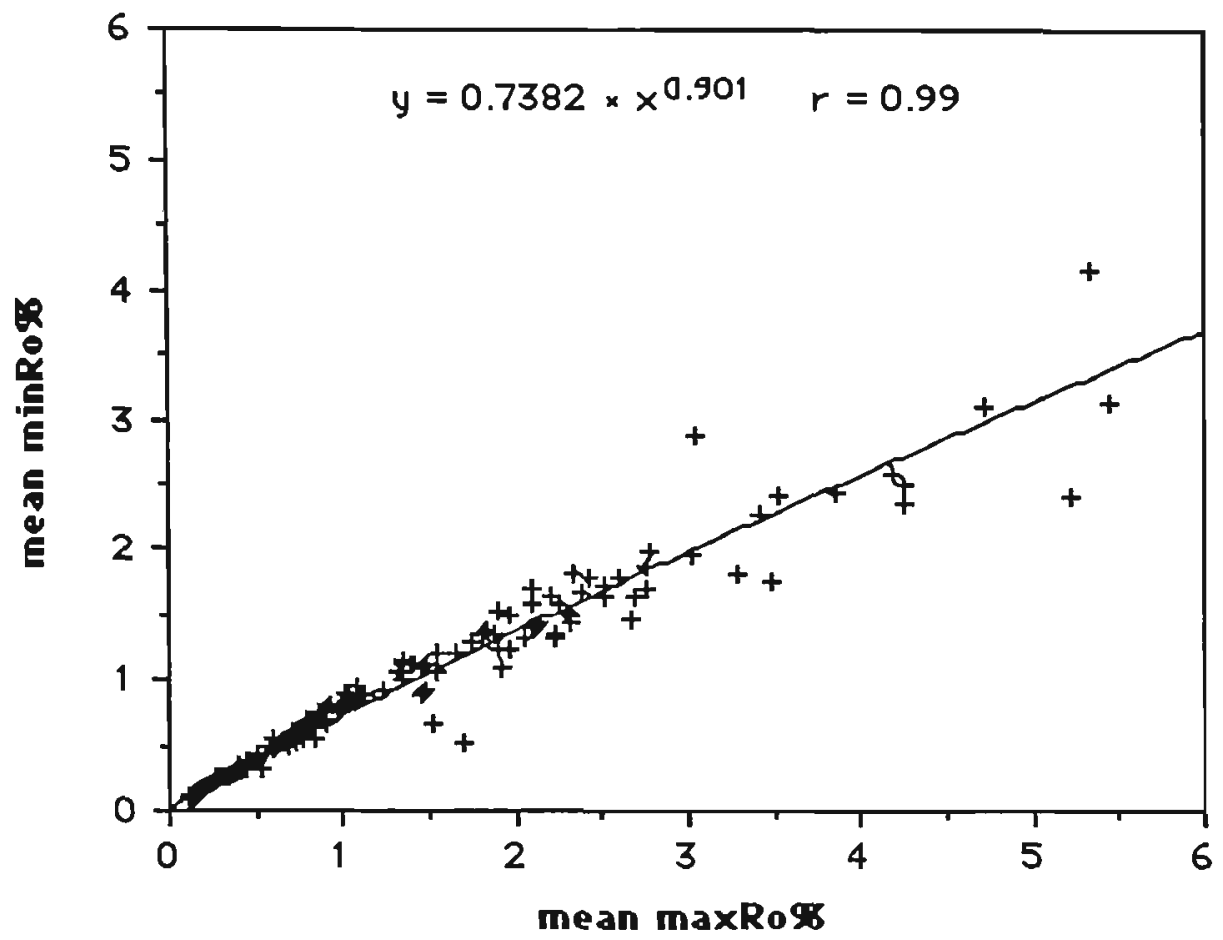

Figure 6-4. Relationship between maximum and minimum mean reflectances for all organic matter types, excluding thucholites, but including means of mixed maceral populations.

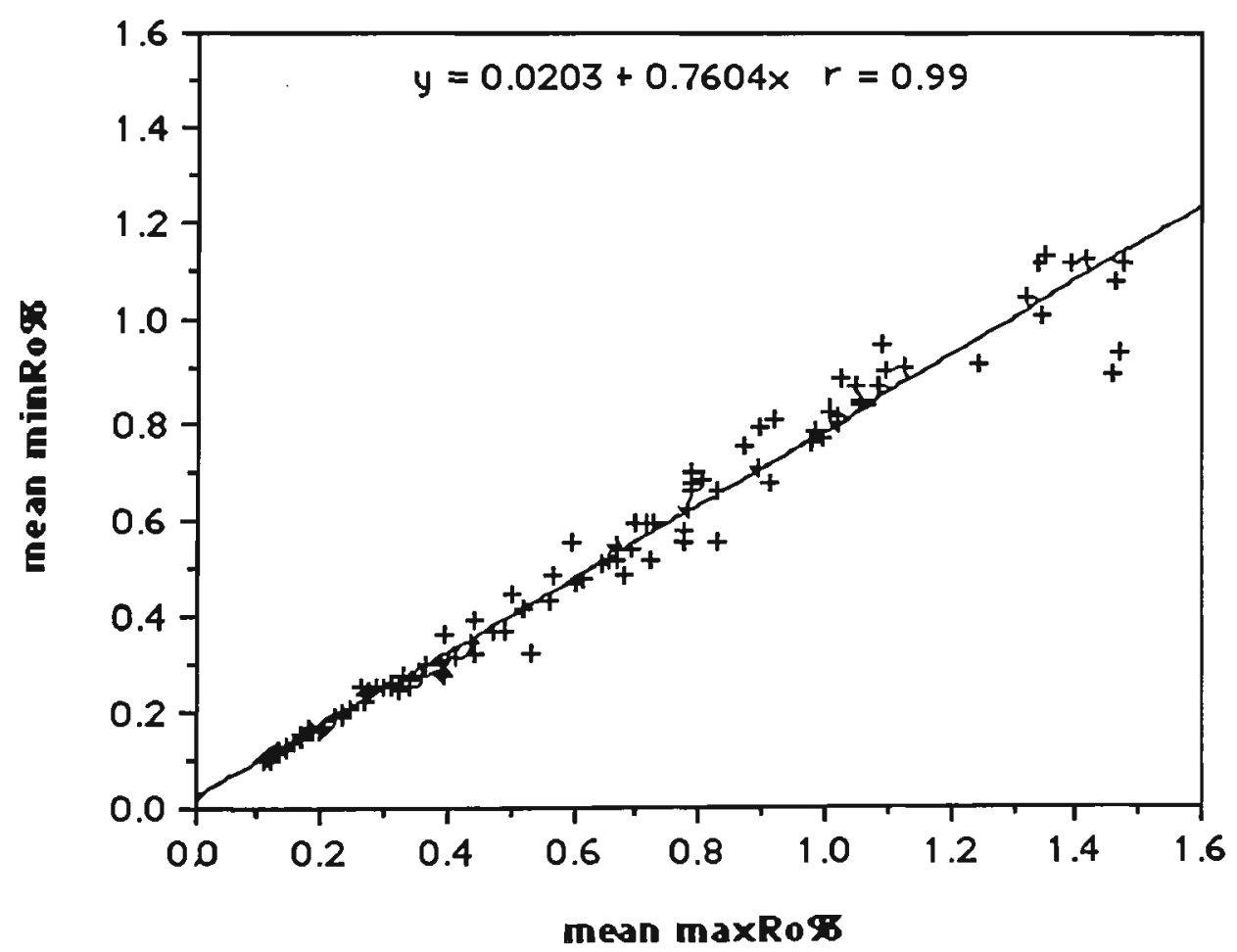

Figure 6-5. Relationship between maximum and minimum mean reflectances up to a maximum mean reflectivity of $1.5 \%$ for all organic matter types, excluding thucholites, but including means of mixed maceral populations. 


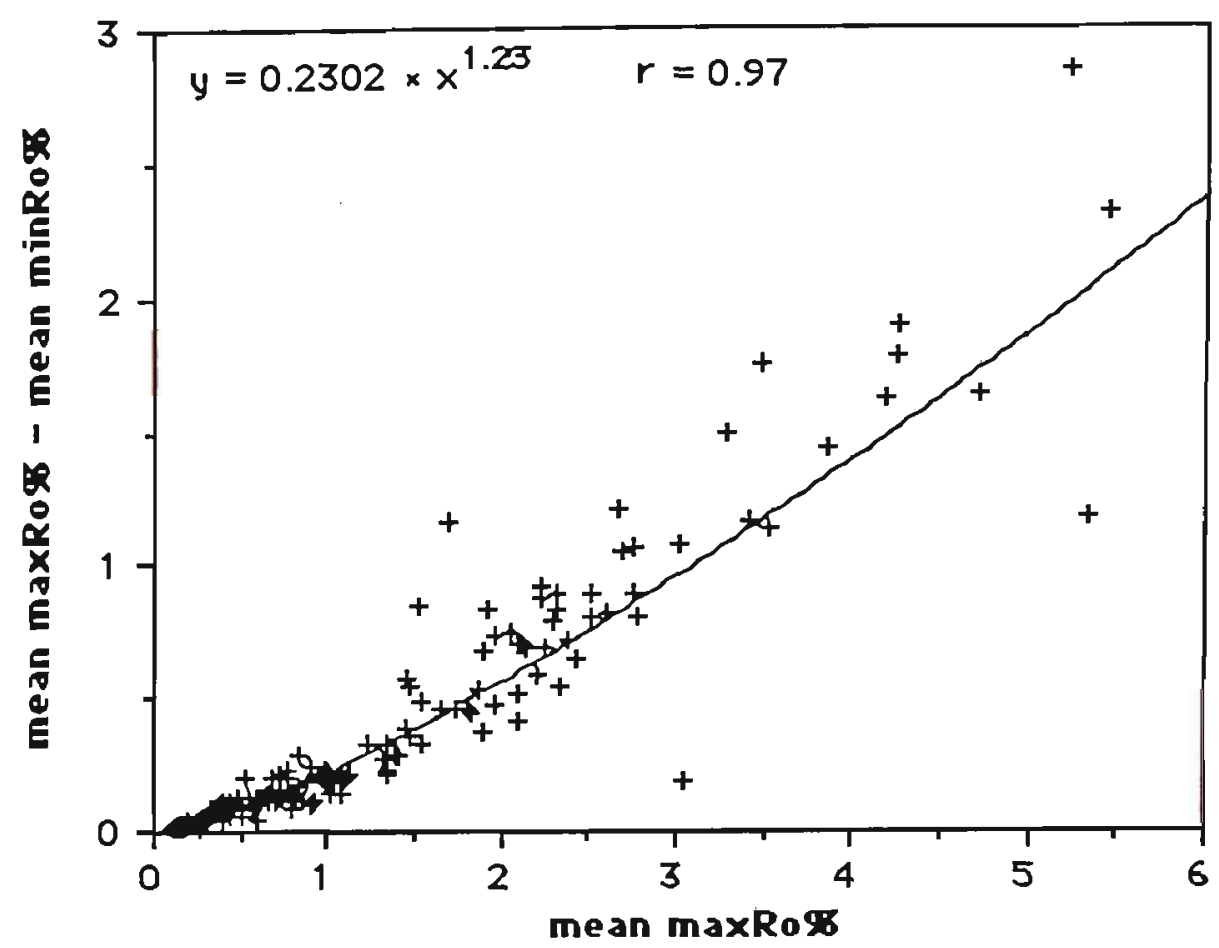

Figure 6-6. Relationship between maximum and maximum minus minimum mean reflectances for all organic matter types, excluding thucholites, but including means of mixed maceral populations.

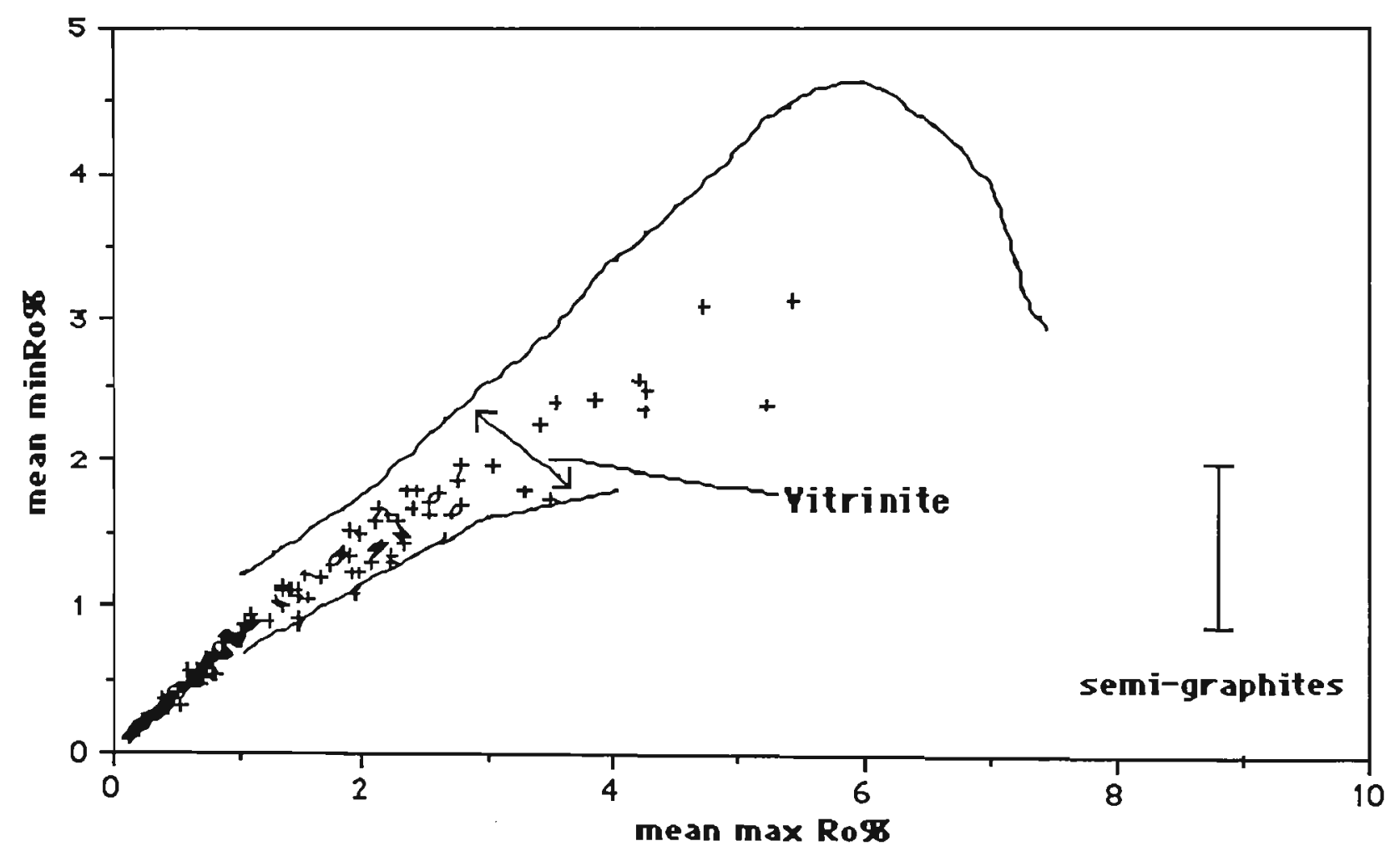

Figure 6-7. Relationship between maximum and minimum mean reflectances for all organic matter types, excluding thucholite, including means of mixed maceral populations, as for Figure 6-4, and showing vitrinite trend lines and semi-graphite range derived from Stach et al. (1982) and A. C. Cook (pers. comm.) 
All organic matter examined in the McArthur Basin is optically anisotropic which at low levels of reflectance is not marked but at higher reflectances is quite marked (Figure 6-6).

The relationship between maximum and minimum mean reflectances of the McArthur Basin organic matter above about $1.0 \%$ mean maximum reflectance is similar to that of vitrinite (Figure 67).

\subsection{Reflectances of Thucholite}

Large thucholites clearly show an increase in reflectance towards their center whereas in smaller thucholites the change in reflectance is commonly not obvious. Reflectance measurements made across large thucholites ( $>50$ microns) from DDH GR10 in the Barney Creek Formation commonly show an exponential increase in reflectance towards the center (Appendix J). The smaller thucholites (<50 microns) are more irregular in their reflectance patterns, but generally also show increasing reflectances towards their central areas.

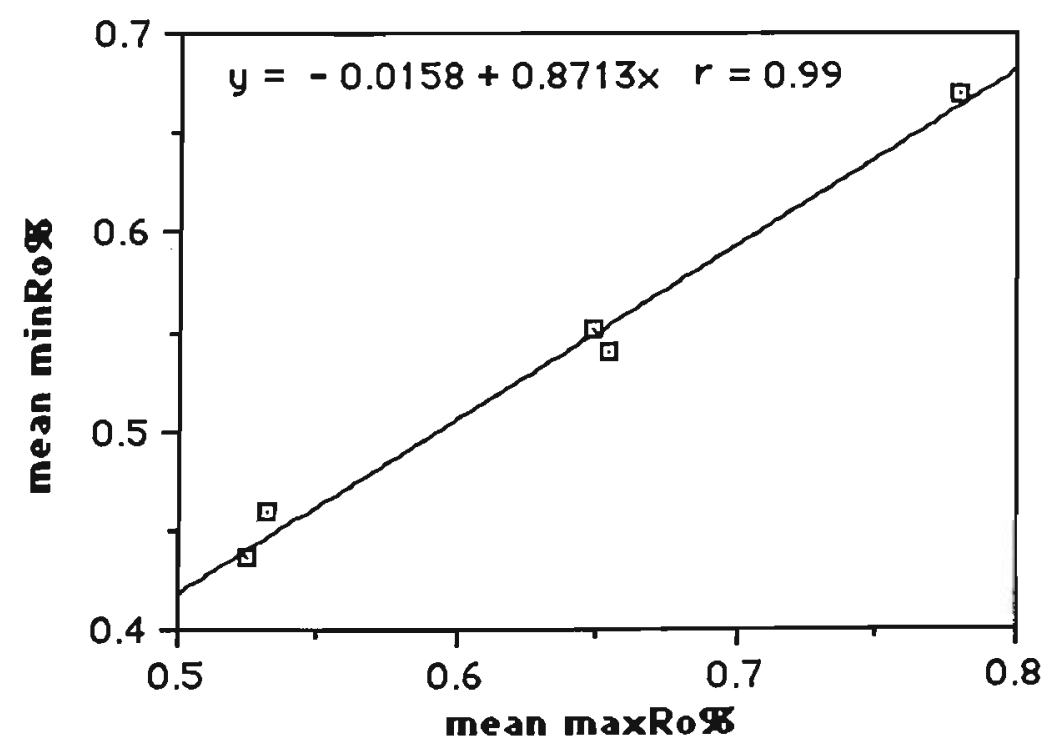

Figure 6-8. Relationship between maximum and minimum mean reflectances for thucholites from DDH GR10. Reflectance measurements made at 1 micron in from the edges. 


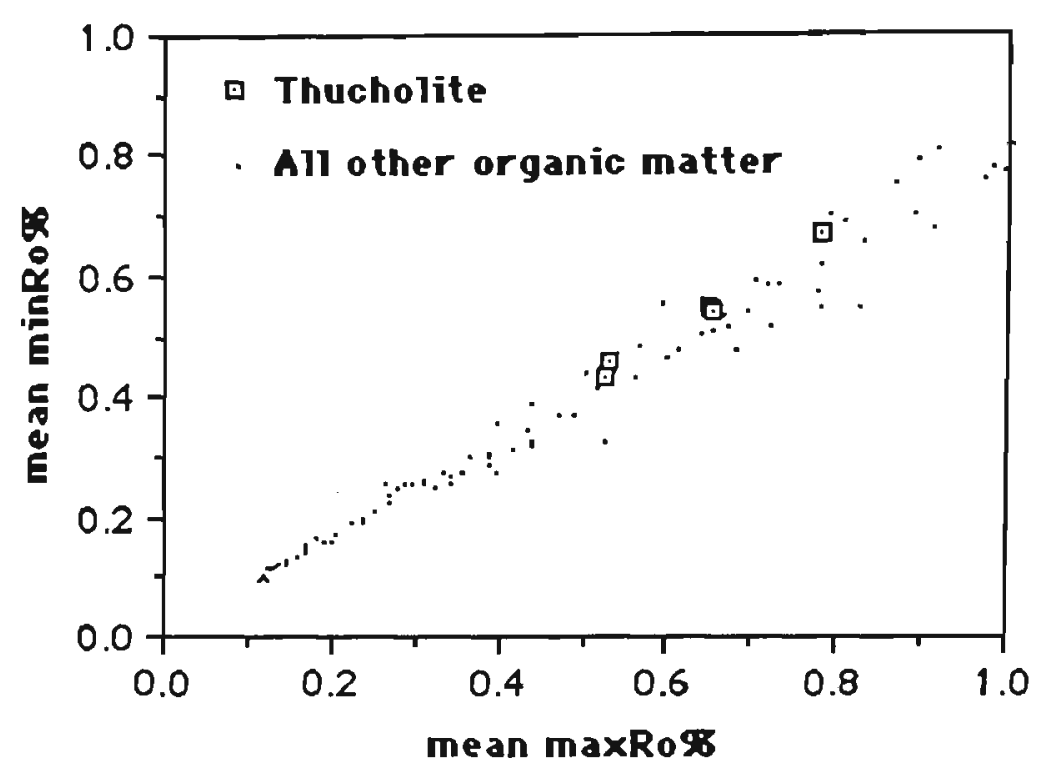

Figure 6-9. Relationship between maximum and minimum mean reflectances for all organic matter types, including thucholite, and also means of mixed maceral populations.

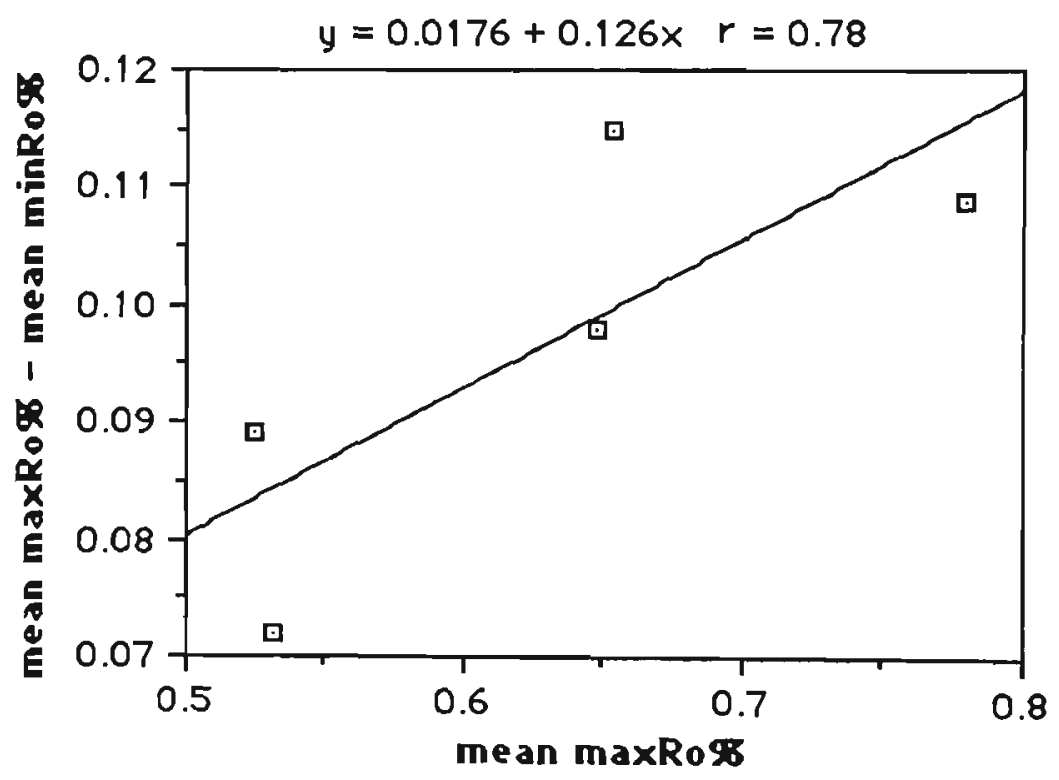

Figure 6-10. Relationship between maximum minus minimum mean reflectances versus mean maximum reflectances for thucholites from DDH GR10. Reflectance measurements made at 1 micron in from the edges.

Mean minumum reflectances of thucholitic bitumen are clearly less than the mean maximum reflectances (Figure 6-8) and are of the same order as for other types of organic matter in the McArthur 
Basin (Figure 6-9) Its optical anisotropy increases with increasing mean maximum reflectance (Figure 6-10).

\subsection{Changes to Reflectances with Increasing Depth}

With some exceptions, the reflectances of lamalginite and bitumen significantly increase with increasing depth in individual drill holes clearly demonstrating that the maturation processes resulting in the commonly observed increases in reflectances with depth of Phanerozoic organic matter are producing similar results in this Precambrian organic matter (discussed in more detail in Chapter 8).

Increases in reflectances with increasing depth for thucholites of all sizes or for thucholites having maximum diameters of less than 50 microns is less clear (Figure 6-11; Appendix $F$ ). The reflectance measurements were made on thucholites from DDH GR10 and taken one micron in from welldefined edges of the thucholites in an attempt to assess whether external maturation processes may have produced any changes. Such processes could conceivably superimpose over the effects produced by radiation with the greatest effect being produced closest to the edges. Thucholites of less than 50 microns in diameter are sections through much larger thucholites in many cases, and measurements taken one micron in from their edges are more likely to be closer to the edge than measurements made at the same distance in from the edge in larger thucholites.

Reflectances of thucholites of all sizes generally show a slight increase with increasing depth (Figure 6-11A). Surprisingly, the increase in reflectances of thucholites, less than 50 microns in 


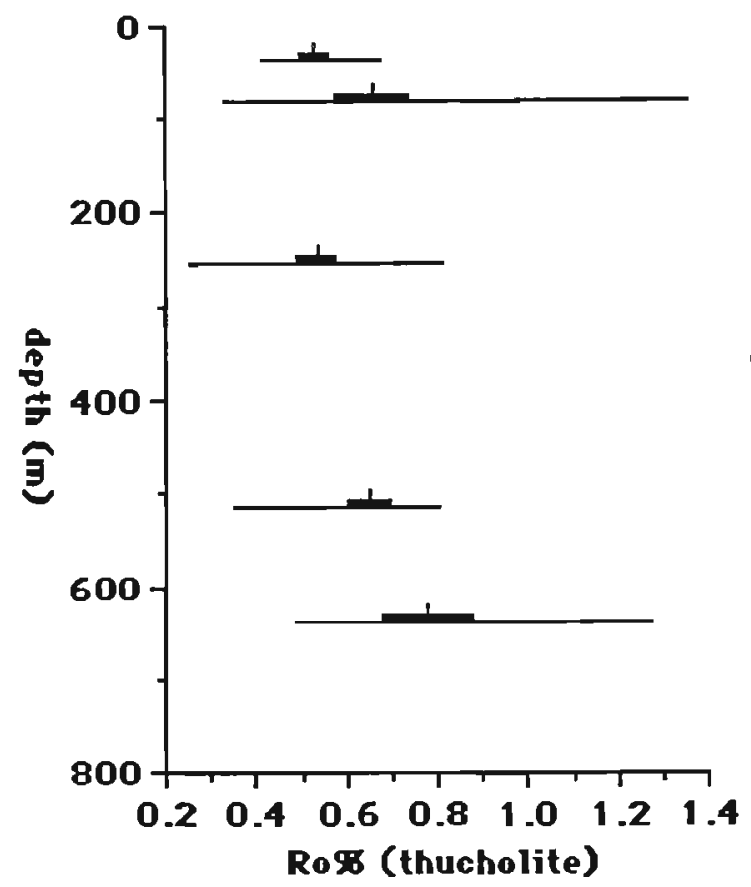

(A)

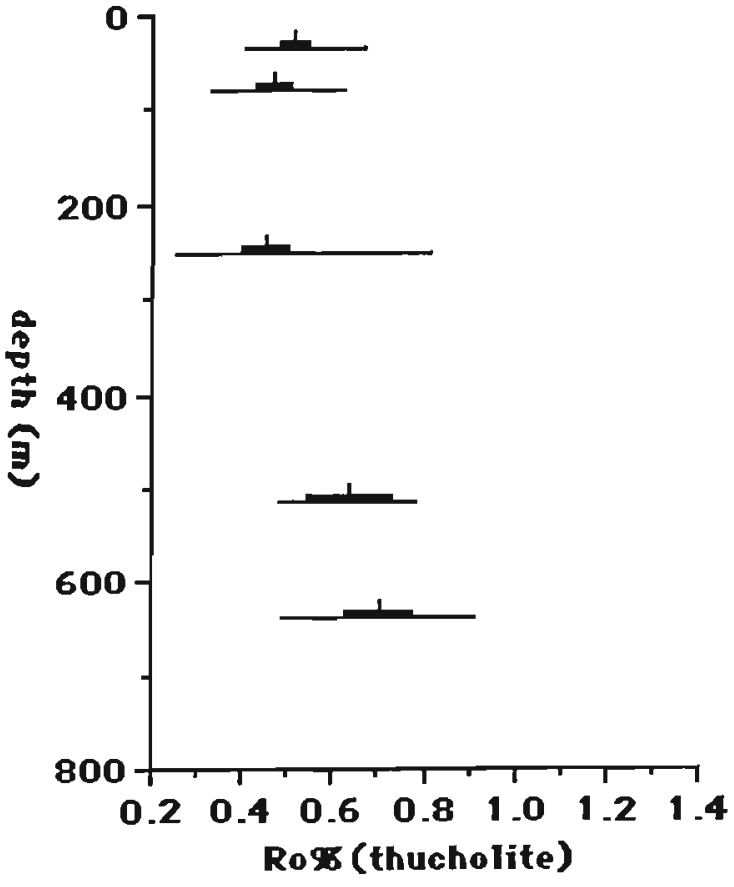

(B)

Figure 6-11. Mean maximum reflectance values (mean maxRo\%) showing the range (horizontal line), mean (vertical line) and 95\% confidence limits of the mean (black boxes), versus depth for thucholites of all sizes $(A)$ and for thucholites whose maximum sizes are less than $50 \mu(B)$ from DDH GR10 in the Barney Creek Formation, Glyde River Subbasin.

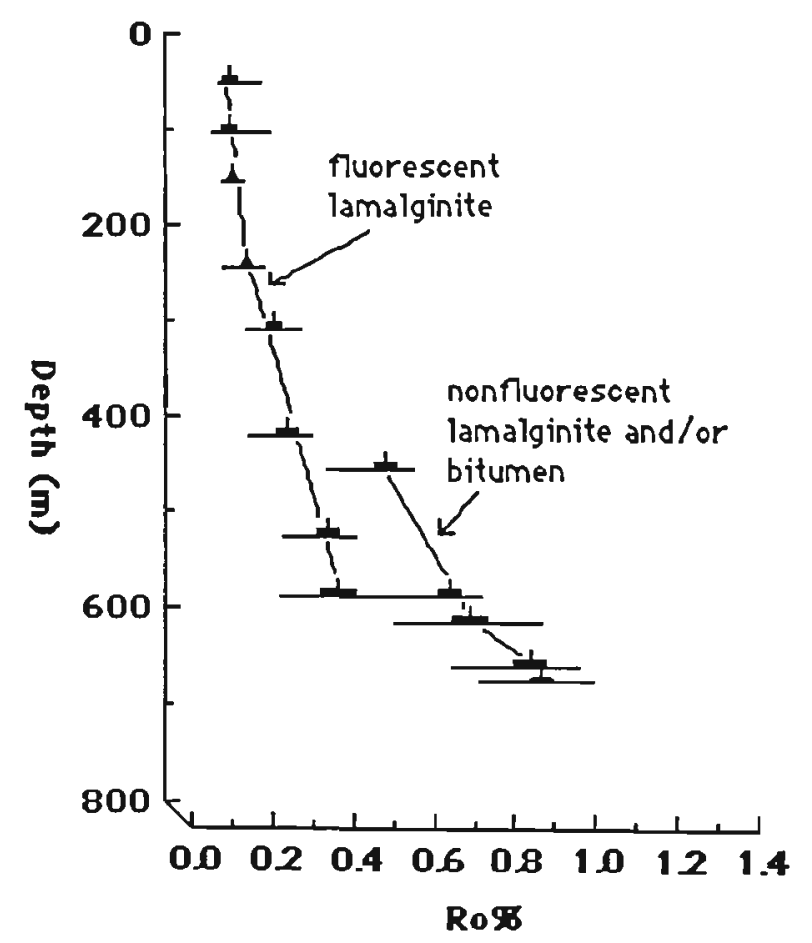

Figure 6-12. Maximum reflectances (maxRo\%) of lamalginite and bitumen showing the range (horizontal line), mean (vertical line) and $95 \%$ confidence limits of the mean (black boxes) versus depth for DDH GR10, Barney Creek Formation, McArthur Group. 
diameter, with increasing depth is less clear. Reflectances from these smaller thucholites are generally lower, as expected. However, absorption of incident light by the underlying mineral matrix in extremely thin sections of thucholites may have contributed to the lower reflectances and, to some extent, masked any increases in reflectances. Reflectances of fluorescent lamalginite, nonfluorescent lamalginite and/or bitumen show a more sharply defined increase with increasing depth in the same drill hole (Figure $6-12)$. 


\section{CHAPTER 7}

\section{ASSESSMENT OF MATURATION LEVELS}

\subsection{Introduction}

Indices which are used to determine maturation levels of organic matter in Phanerozoic sedimentary rocks may behave quite differently in these Precambrian rocks given the enormous amount of time between deposition and the present day, and the primitiveness of the source biota.

The approach adopted in this chapter is to compare three maturation indices (Tmax, reflectances, and calculated vitrinite reflectances derived from methylphenanthrene indices (MPI)) with published results from the Phanerozoic and with the "oilwindow" for McArthur Basin rocks. The use of MPI data provides an independent means for calibrating the various indices.

\subsection{Tmax}

The maturation index, Tmax, derived from Rock-Eval analyses, represents the temperature of maximum evolution of hydrocarbons during pyrolysis (Espitalie et al., 1977). Tmax is affected by the type of organic matter in the source-rock such that the range in variation of Tmax is narrower for Type I kerogen $\left(435-450^{\circ} \mathrm{C}\right)$ than for Type II (420-4600 C) or Type III kerogens $\left(400-600^{\circ} \mathrm{C}\right.$ ) (Espitalie et al.,1986) due to the differing bond energy spectrums of the different organic matter types (Tissot et al., 1987a). 


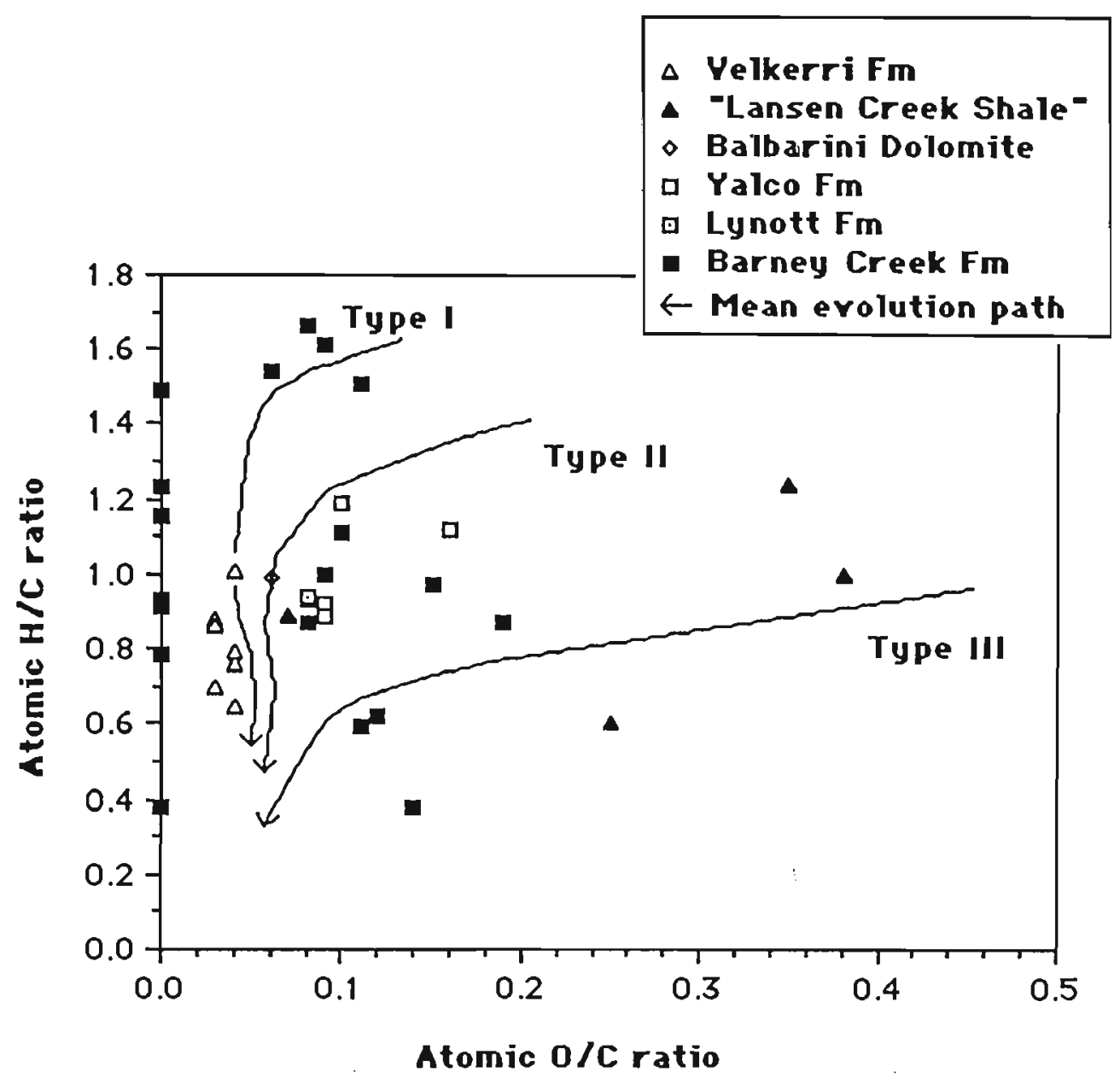

Figure 7-1. Van Krevelen diagram showing differences in the atomic $\mathrm{H} / \mathrm{C}$ and $\mathrm{O} / \mathrm{C}$ ratios of kerogen in selected samples.

A plot of $\mathrm{H} / \mathrm{C}$ versus $\mathrm{O} / \mathrm{C}$ ( a van Krevelen diagram (Tissot and Welte, 1978)) for elemental analyses of kerogen from the McArthur Basin (Figure7-1; Appendix Q) show that some of the kerogen samples from the Barney Creek Formation can be clearly classified as Type I kerogen whereas most of the kerogen is Type II, Type II/III or Type III. The clearest examples of Type I organic matter in Figure 7-1 come from within the top $300 \mathrm{~m}$ of $\mathrm{DDH}$ GR10 in the Glyde River Subbasin. 
Tmax measurements are unreliable in samples of low pyrolysis yields $(<0.2 \mathrm{~kg} /$ tonne) and samples containing migrated hydrocarbons; the latter results in a suppression of Tmax values commonly due to the poor separation of the $S 1$ and $S 2$ peaks during analysis (Clementz, 1979). The presence of migrated hydrocarbons is indicated from the Production Index (PI) which is the ratio of $S 1$ to $S 1+S 2$ where $S 1$ is the amount of free hydrocarbons released during pyrolysis (Espitalie et al., 1977) and can commonly be detected by the presence of positive anomalies in relation to the mean PI values (Espitalie et al., 1985). In the absence of any migrated hydrocarbon, production indices increase with increasing maturity as hydrocarbons are cracked from kerogen without going above about 0.5 for the oilproduction zone (Espitalie et al., 1985).

Tmax values were obtained on all samples collected from the McArthur Basin (Appendix N) but a considerable number of them are unreliable because of low pyrolysis yields $(<0.20 \mathrm{~kg} /$ tonne). PI values generally increase with depth as is the case for the Barney Creek in the Glyde River Subbasin (e.g. Figures 7-2, 4, and 6) and for the Velkerri Formation (Figures 7-8 and 7-10). Suppression of Tmax values related to relatively high $\mathrm{PI}$ values is clearly evident in the $90-140 \mathrm{~m}$ zone in Urapunga 3 (Figure 78).

The mineral matrix affect which can result in raising Tmax values (Espitalie et al., 1980) is more difficult to assess. There do not appear to be any anomalously high Tmax values (where S2 $\geq 0.2$ ) obviously due to this affect. 
Tmax values which are selected as representative for the McArthur Basin are those where $S 2$ is greater than $0.20 \mathrm{~kg} /$ tonne and there is no clear suppression of the Tmax values due to poor separation of the S1 and S2 peaks. These selected Tmax values generally show a systematic increase with depth, and range from 426 to $550^{\circ} \mathrm{C}$ for the McArthur Group and from 430 to $488^{\circ} \mathrm{C}$ for the Roper Group. Some Tmax values for the top of the Barney Creek Formation, McArthur Group, in the Glyde River Subbasin are less than $435^{\circ} \mathrm{C}$ which, if all the organic matter is Type 1 as is the case for the top of DDH GR10, suggests this organic matter is immature. The lowest Tmax value in the McArthur Group is $426^{\circ} \mathrm{C}$ and comes from the Yalco Formation. However, as the organic matter appears to be Type II then this value indicates that it is marginally mature. The majority of Tmax values in the McArthur Group are greater than $435^{\circ} \mathrm{C}$ indicating that the organic matter is mature to overmature. The Tmax values for the Roper Group suggest that the organic matter ranges from being mature to overmature if it is mostly Type II or Type III kerogen.

\subsection{Reflectance}

Reflectance values for organic matter in the McArthur Basin are given in Chapter 6. It is not possible to assess the maturation levels of lamalginite by comparison with Phanerozoic examples as no reflectance studies on Phanerozoic lamalginites have been published. However, if lamalginite has 

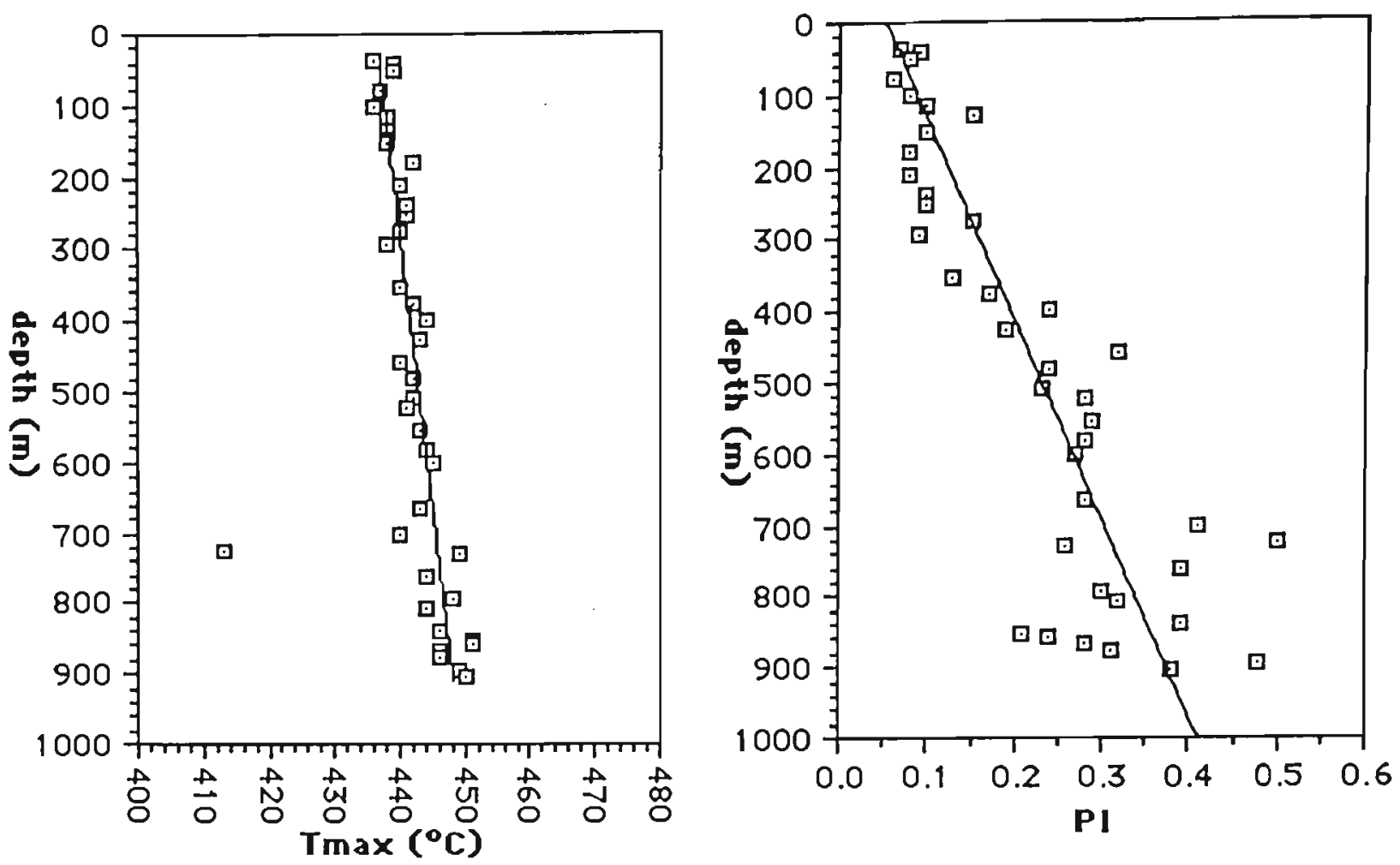

Figure 7-2. Tmax values and production indices (PI) versus depth for DDH GR7, Barney Creek Formation, McArthur Group.

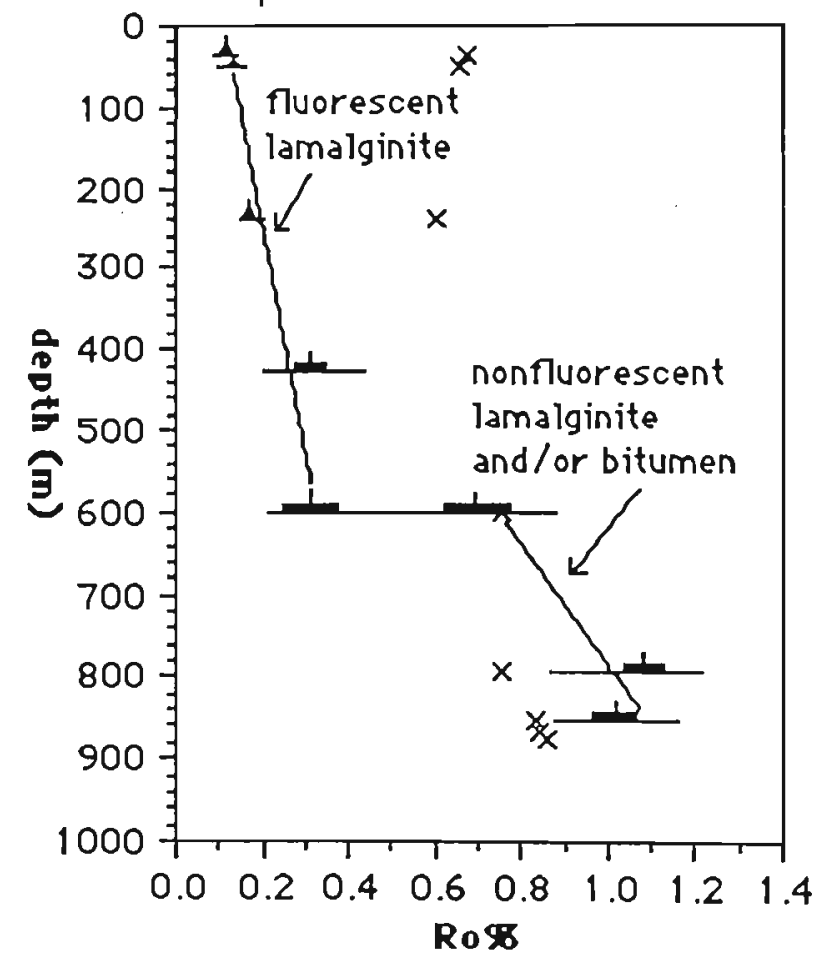

Figure 7-3. Maximum reflectances (maxRo\%) of lamalginite and bitumen showing the range (horizontal line), mean (vertical line) and $95 \%$ confidence limits of the mean (black boxes), and reflectances calculated from MPI-1 indices ( $x$ ) using equation 1 (Chapter 6 ), versus depth for DDH GR7, Barney Creek Formation, McArthur Group. 

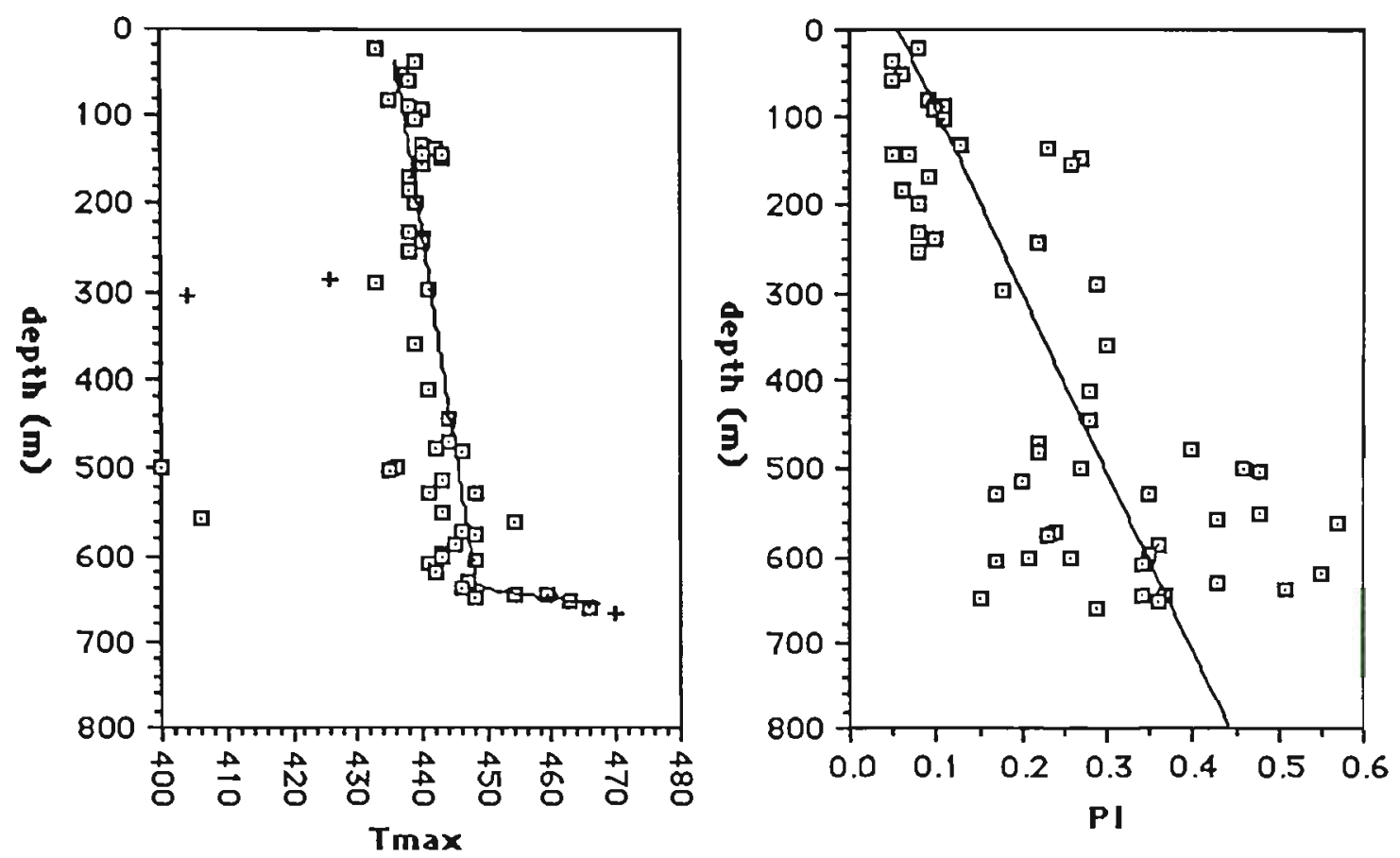

Figure 7-4. Tmax values and production indices (PI) versus depth for DDH GR10, Barney Creek Formation, McArthur Group. The symbols " + " are Tmax values where S2 is less than $0.2 \mathrm{~kg} /$ tonne.

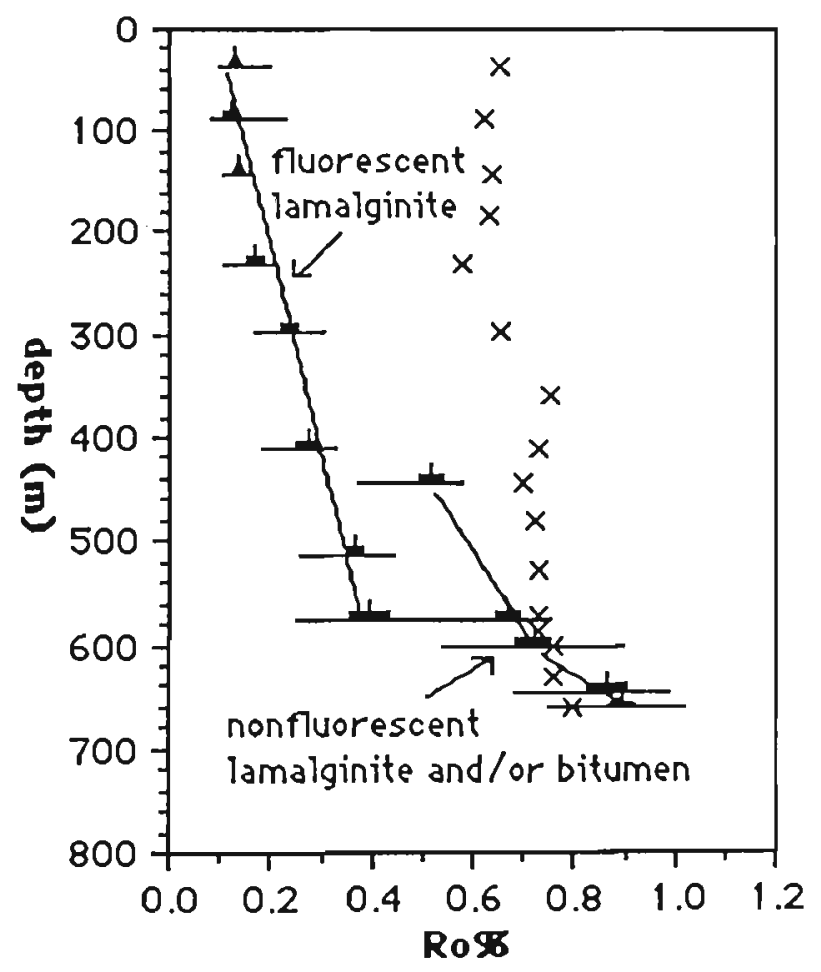

Figure 7-5. Maximum reflectances (maxRo\%) of lamalginite and bitumen showing the range (horizontal line), mean (vertical line) and $95 \%$ confidence limits of the mean (black boxes), and reflectances calculated from MPI-1 indices ( $x$ ) using equation 1 (Chapter 6 ), versus depth for DDH GR10, Barney Creek Formation, McArthur Group. 

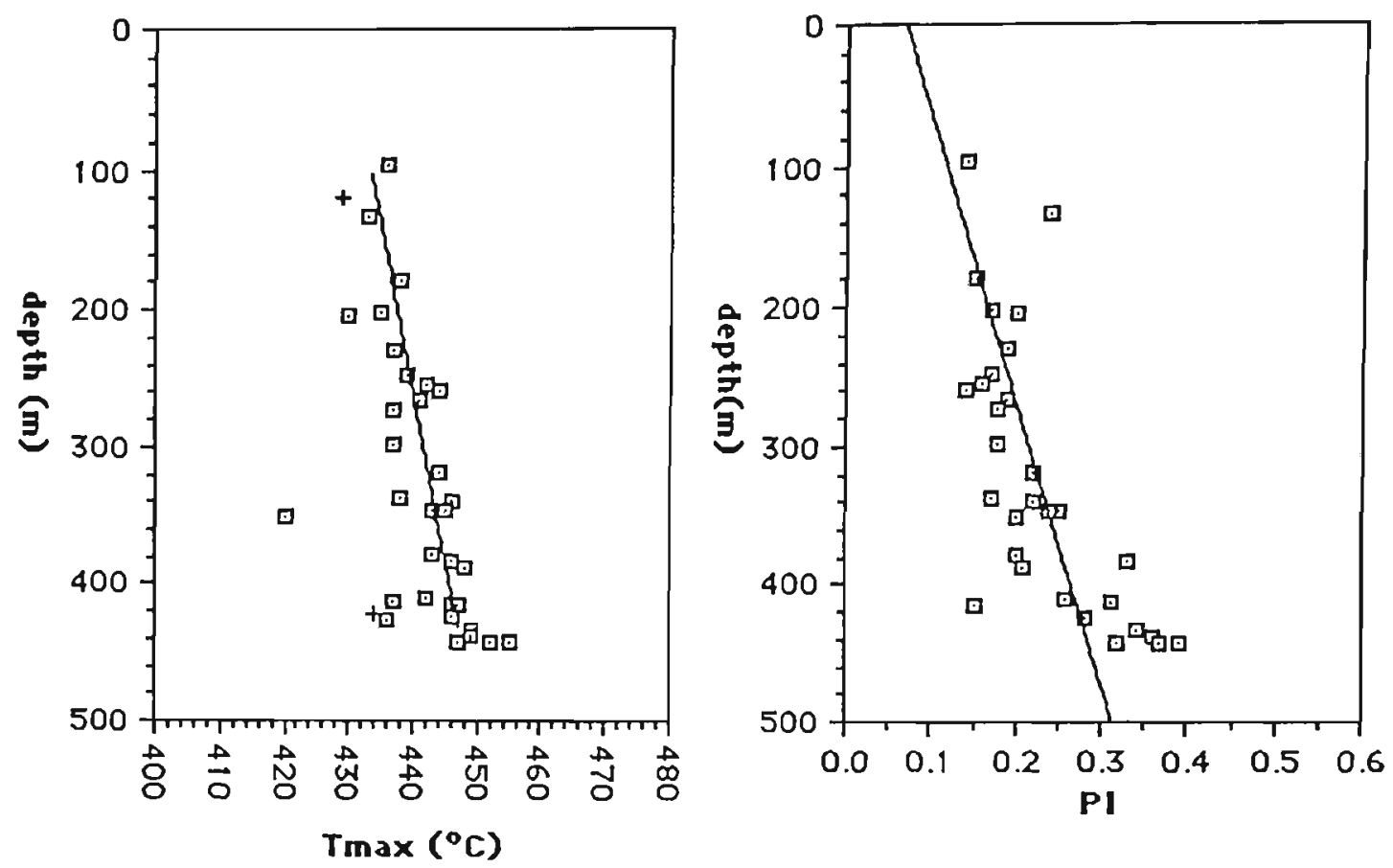

Figure 7-6. Tmax values and production indices (PI) versus depth for DDH GR11, Barney Creek Formation, McArthur Group. The symbols "+" are Tmax values where $S 2$ is less than $0.2 \mathrm{~kg} /$ tonne.

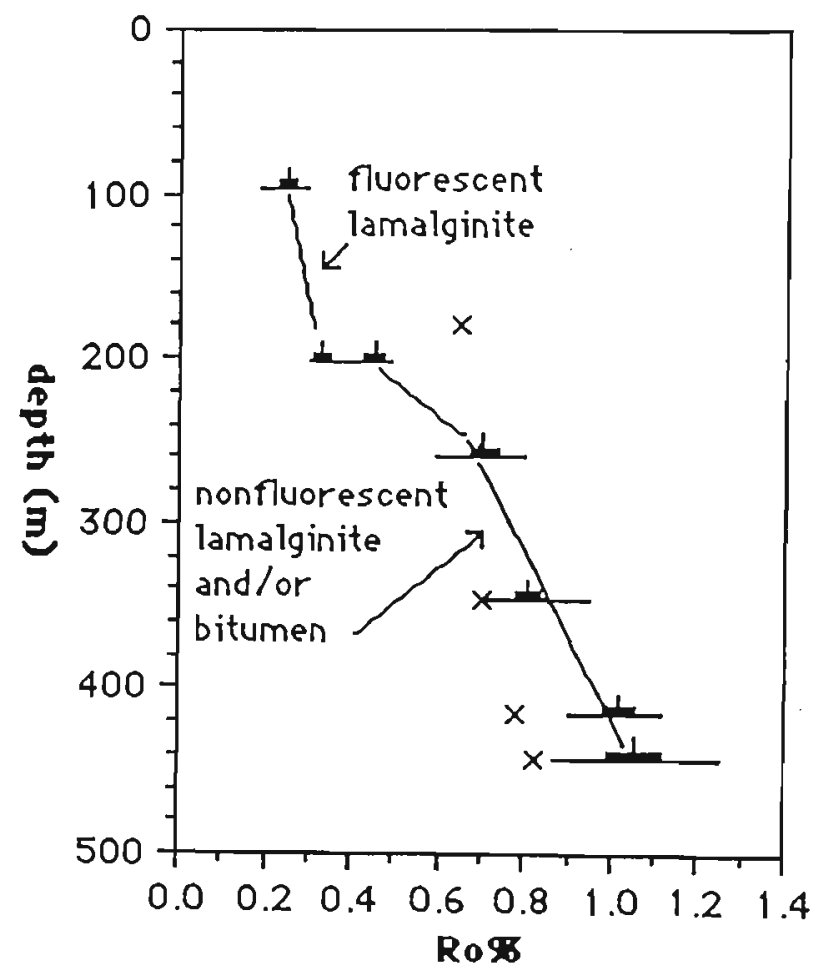

Figure 7-7. Maximum reflectances (maxRo\%) of lamalginite and bitumen showing the range (horizontal line), mean (vertical line) and $95 \%$ confidence limits of the mean (black boxes), and reflectances calculated from MPI-1 indices ( $x$ ) using equation 1 (Chapter 6), versus depth for DDH GR11, Barney Creek Formation, McArthur Group. 

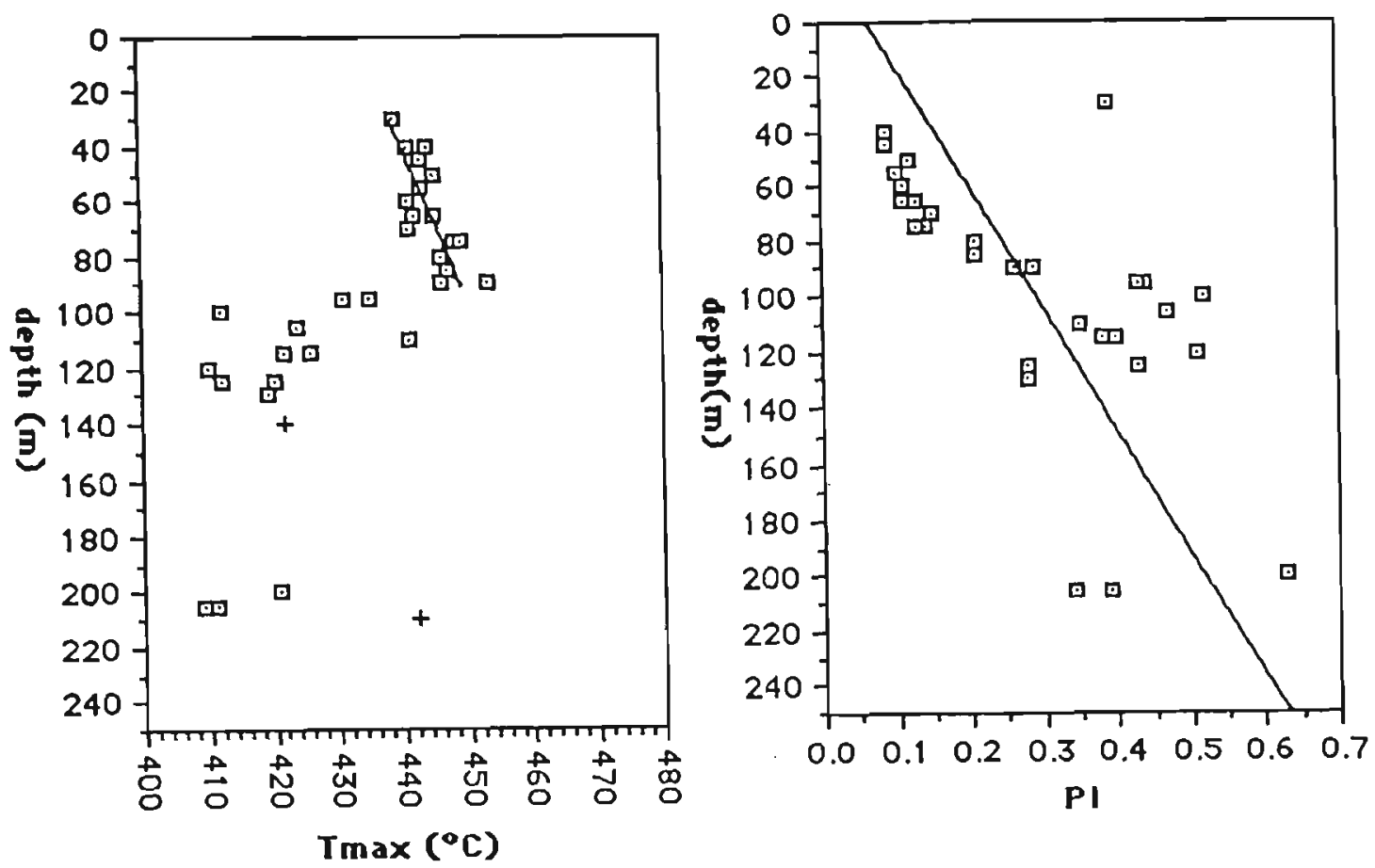

Figure 7-8. Tmax values and production indices $(\mathrm{PI})$ versus depth for DDH Urapunga 3, Velkerri Formation, Roper Group. The symbols "+" are Tmax values where $\mathrm{S} 2$ is less than $0.2 \mathrm{~kg} /$ tonne.

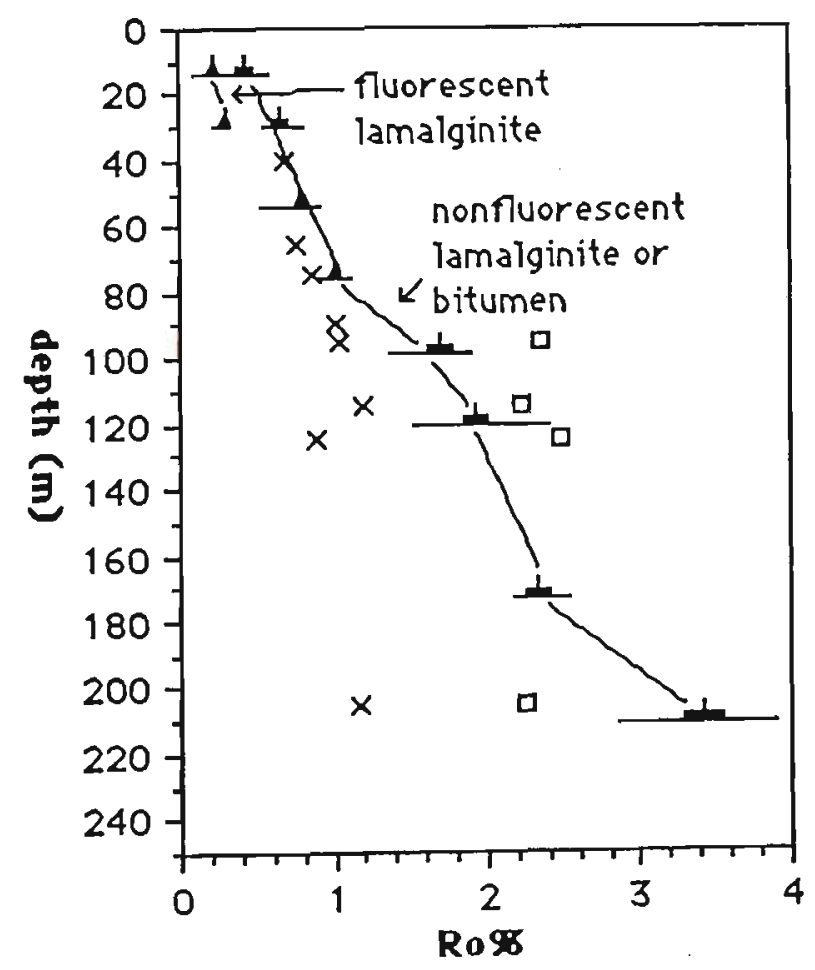

Figure 7-9. Maximum reflectances (maxRo\%) of lamalginite and bitumen showing the range (horizontal line), mean (vertical line) and $95 \%$ confidence limits of the mean (black boxes), and reflectances calculated from MPI-1 indices (x) using equation 1 (Chapter 6), versus depth for DDH Urapunga 3, Velkerri Formation, Roper Group. 

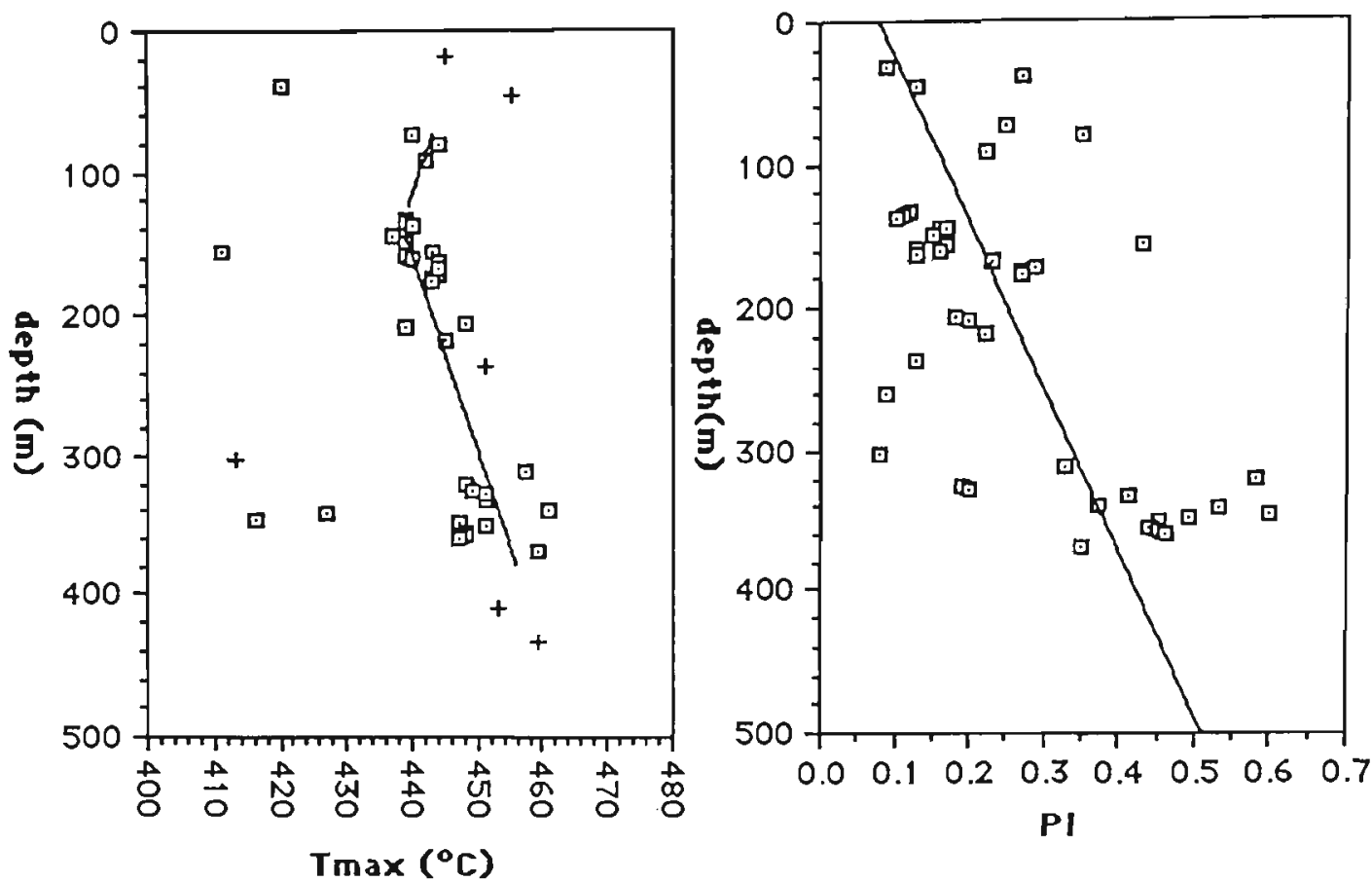

Figure 7-10. Tmax values and production indices (PI) versus depth for DDH Urapunga 4, McMinn Formation $(0-42 \mathrm{~m})$, Velkerri Formation $(42-372.5 \mathrm{~m})$ and Corcoran Formation (397.6-532m TD). The symbols " + " are Tmax values where $S 2$ is less than $0.2 \mathrm{~kg} /$ tonne.

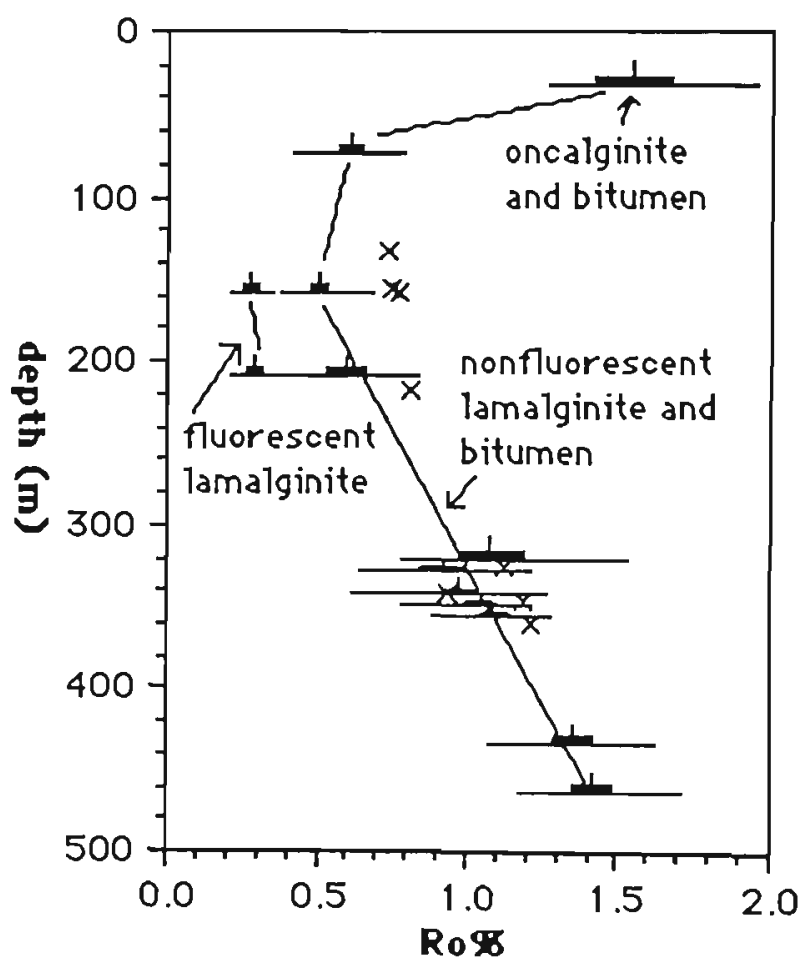

Figure 7-11. Maximum reflectances (maxRo\%) of lamalginite and bitumen showing the range (horizontal line), mean (vertical line) and $95 \%$ confidence limits of the mean (black boxes), and reflectances calculated from MPI-1 indices (x) using equation 1 (Chapter 6), versus depth for DDH Urapunga 4. 
similar reflectances for the same level of maturation as Phanerozoic sporinites then, using the data given in Smith and Cook (1980), lamalginite reflectances of between about 0.1 to $1.5 \%$ fall within the oil-window.

It is also not possible to reliably assess the maturation levels of bitumen in terms of its reflectances by comparison with the limited studies on Phanerozoic bitumens. Robert (1973) concentrated bitumen by a froth flotation technique from a number of sedimentary basins and measured random reflectances on the concentrates. His results mostly do not provide any clear indication of a relationship between bitumen reflectances and vitrinite reflectances due the problem of migrated bitumen but do indicate that for one group of non-migrated bitumen having a reflectance of about $2 \%$ that it is equivalent to a vitrinite reflectance also of $2 \%$. Ogunyami et al. (1980) measured random reflectances on asphaltic pyrobitumens separated from the rock by $\mathrm{HCl}$ and $\mathrm{HF}$ treatment from early Palaeozoic contintental margin deposits of the Quebec Appalachians and compared them to the level of illite crystallinity. No attempt was made to define bitumen reflectances in terms of vitrinite reflectances or other maturation indices other than to comment that bitumen having a reflectance of 1.0 to $1.5 \%$ may still be in the oil window.

\subsection{Methylphenanthrene Index}

The Methylphenanthrene Index (MPI-1), is one of a number molecular organic maturation indicators based on various ratios 
of aromatic hydrocarbons and one that has a strong correlation with vitrinite reflectance (Radke et al., 1982a, b; Radke and Welte, 1983; Radke et al., 1984). There are progressive changes with maturation of the distribution of phenanthrene and four of the methylphenanthrene isomers used to define MPI-1 such that there is a systematic increase in the relative abundance of 2and 3-methylphenanthrene over the 1- and 9- isomers. At higher temperatures, demethylation reactions lead to a lowering of the MPI-1 index. The MPI-1 index has been recalibrated against vitrinite reflectance using Australian Carboniferous, Permian, Jurassic and Tertiary sediments and coals (Boreham et al., 1988) where for vitrinite reflectance levels between $0.3 \%$ and about $1.7 \%$ the relationship is:

1) calculated vitrinite reflectance percentage $(R c \%)=0.7( \pm 0.05)(\mathrm{MPI}-1)+0.22$;

where the standard error is expressed as $( \pm 0.05)$. At vitrinite reflectances greater than about $1.7 \%$ the relationship is:

2) calculated vitrinite reflectance percentage $(\mathrm{Rc} \%)=-0.55(\mathrm{MPI}-1)+3.0$.

At vitrinite reflectances between $0.3-1.7 \%$ the relationship has a significant correlation ( $r=0.84,91$ samples) whereas at the higher vitrinite reflectance levels the relationship is less welldefined as it is based on only four samples due to the low yields of extractable hydrocarbons in the overmature zone (Boreham et al., 1988).

In the McArthur Basin, the MPI indices for selected samples is given in Appendix P. There is no apparent reversal of the MPI1 indices in samples from which organic matter reflectances were obtained (Figure 7-12). Therefore, for calculating the 
equivalent vitrinite reflectances for these samples equation 1 was used (Figure 7-13). However, a reversal of the MPI indices is noticeable in DDH Urapunga 3 at reflectances above about $2.0 \%$. Equation 2 provides a better correlation to these reflectances (Figure 7-9) which were obtained on different samples to those used for the MPl-1 analyses and therefore have not been included in Figures 7-12 and 7-13.

As can be seen from Figure 7-13, the values for fluorescent lamalginite mostly fall within the limits of measured reflectances for Phanerozoic liptinite between the trend-lines for telalginite and lamalginite, whereas most of the other organic types are within the limits of measured reflectances for Phanerozoic vitrinites. The reflectance of fluorescent lamalginite is depressed by about 0.4 to $0.5 \%$ with respect to the calculated values for vitrinite, a displacemant that is similar to that which would be predicted from the diagrams in Smith and Cook (1980) for plots of co-existing sporinite and vitrinites.

\subsection{Tmax versus extractable hydrocarbon yields.}

Selected core samples were analysed for extractable hydrocarbons (Appendix $O$ ) and the yield obtained is given as a percentage of the total organic carbon content (TOC). Most hydrocarbon yield values fall below $200 \mathrm{mg} / \mathrm{g}$ and between Tmax values of 425 to about $470^{\circ} \mathrm{C}$ (Figure 7-14). The Tmax values of some samples which are below $420^{\circ} \mathrm{C}$ are clearly suppressed due to migrated hydrocarbons and the two highest yields observed 


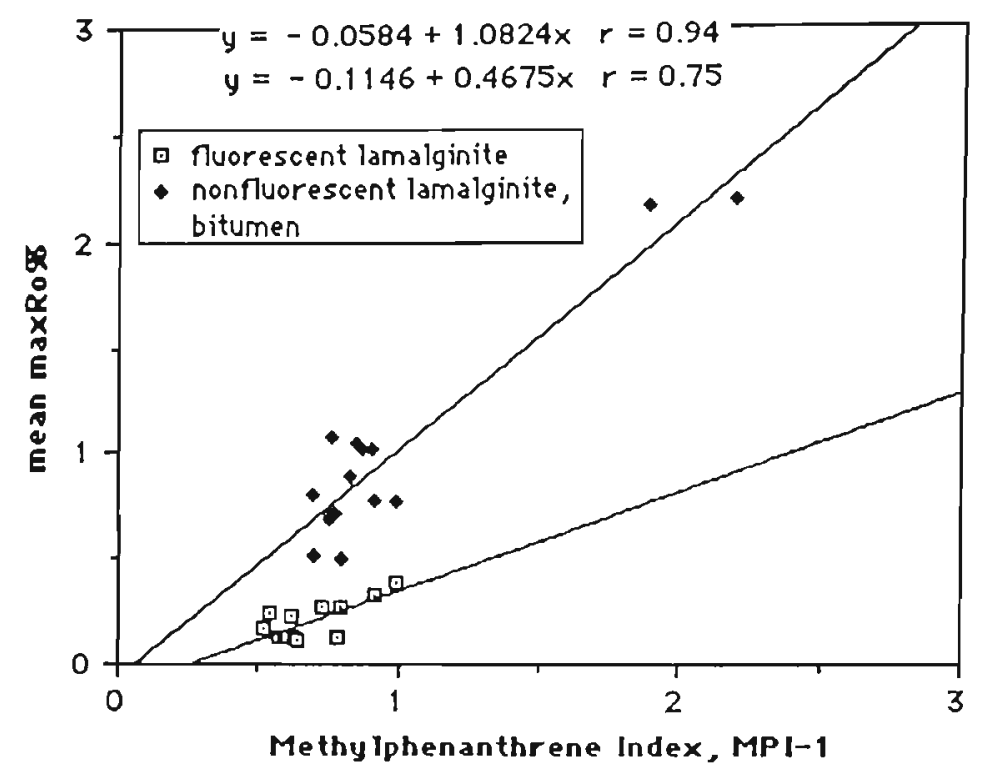

Figure 7-12. Methylphenanthrene indices (MPI-1) versus the measured mean maximum reflectances (mean maxRo\%) of organic matter from the same samples in the McArthur Basin.

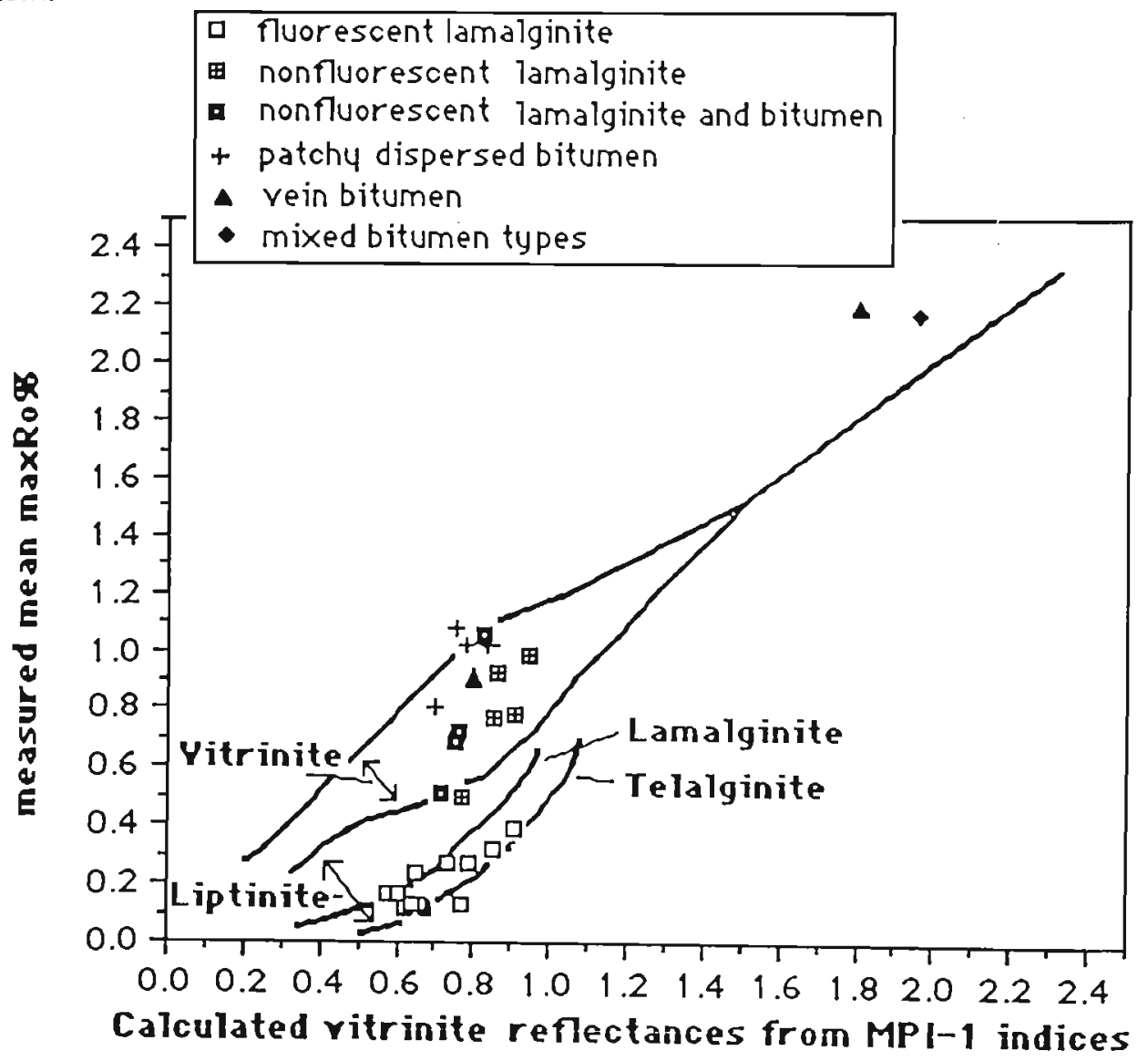

Figure 7-13. Measured mean maximum reflectances for lamalginite and bitumen plotted against their calculated vitrinite reflectances from methylphenanthrene indices (MPI-1). Superimposed are the limits of measured reflectances for vitrinite and liptinite (after Murchison et al., 1985) and trend lines for telalginite and lamalginite (A.C. Cook, unpublished data), from the Phanerozoic. 


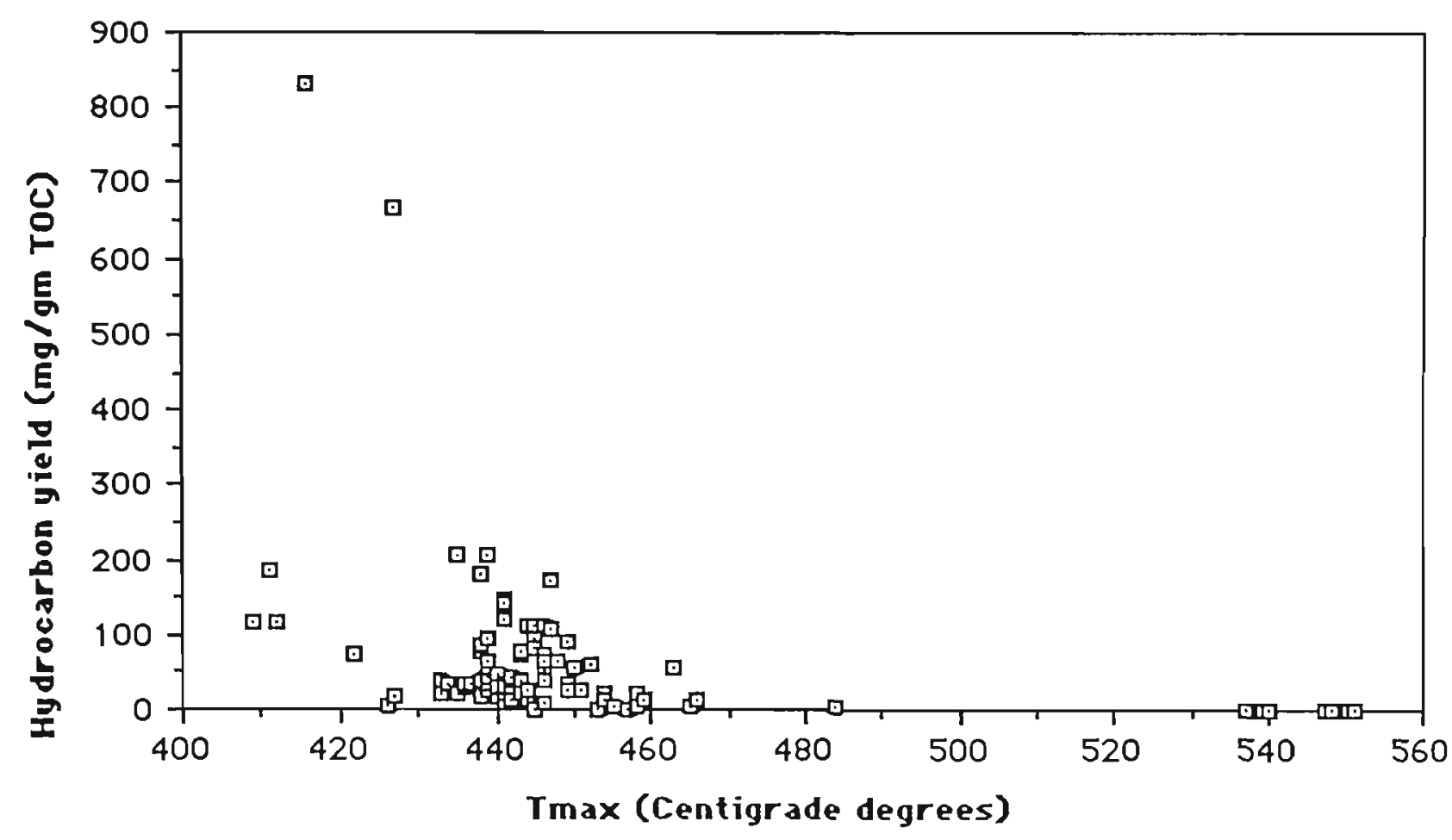

Figure 7-14. Hydrocarbon yield plotted against Tmax values where $S 2 \geq 0.20 \mathrm{~kg} /$ tonne.

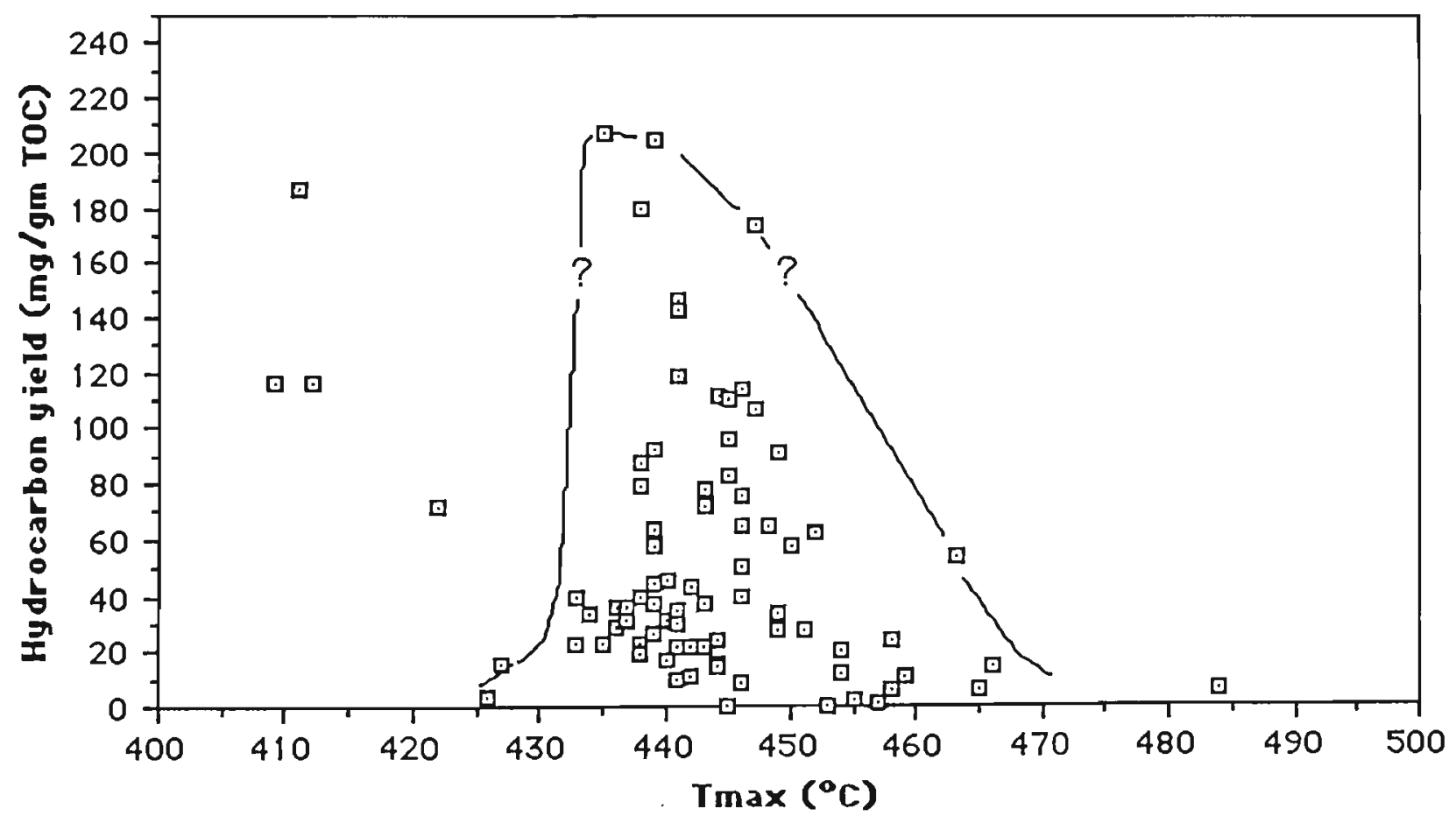

Figure 7-15. Hydrocarbon yield to $250 \mathrm{mg} / \mathrm{g}$ TOC plotted against Tmax values where S2 $\geq 0.20 \mathrm{~kg} /$ tonne, in the range $400-500^{\circ} \mathrm{C}$. The line encloses the oil window. 


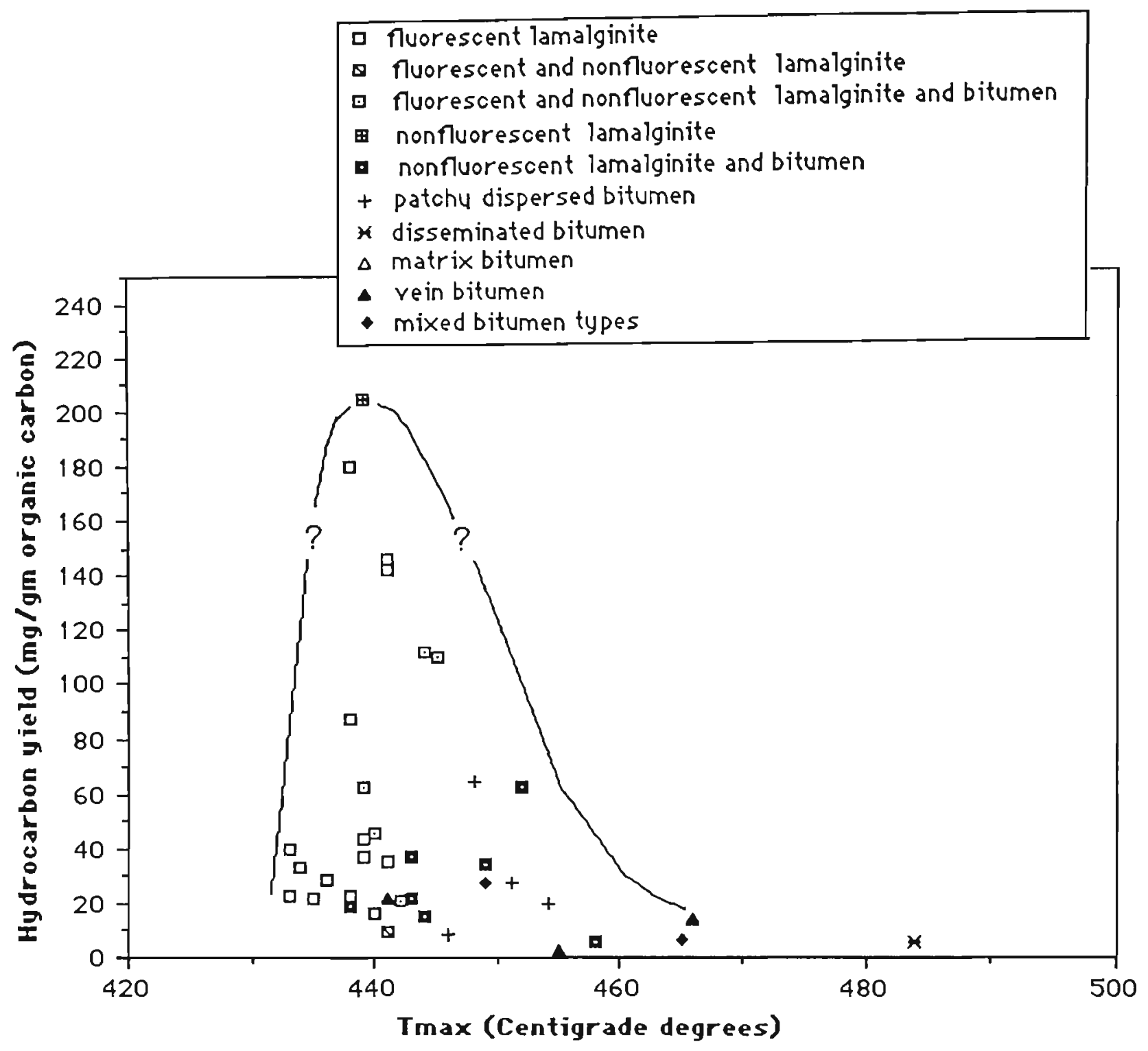

Figure 7-16. Hydrocarbon yield plotted against Tmax values where $S 2 \geq 0.20 \mathrm{~kg} /$ tonne, for the various organic matter types within the Tmax range $400-500^{\circ} \mathrm{C}$ and yield range $0-250 \mathrm{mg} / \mathrm{g}$ TOC. The line encloses the oil window.

are from the zone where free oil was found by Jackson et al. (1986) and clearly contain migrated hydrocarbons.

The oil-window (Figure 7-15) appears to lie between Tmax values of 425 and about $470^{\circ} \mathrm{C}$ and the zone of maximum oil-generation is at about $440^{\circ} \mathrm{C}$. Maximum yields of about 200 $\mathrm{mg} / \mathrm{g}$ for McArthur Basin organic matter are shown in Figure 7- 
15 whereas maximum yields of $150 \mathrm{mg} / \mathrm{g}$ are reported from Phanerozoic sediments containing Type I kerogen (Tissot and Welte, 1984) suggesting that some migrated hydrocarbons may have contributed to these yields. Lower maximum yields are reported from sediments containing Type $\|$ (100 mg/g TOC) and Type III kerogens (70 mg/g TOC) (Tissot and Welte,1984).

Fluorescent lamalginite is the main organic matter type for Tmax values below $440^{\circ} \mathrm{C}$ whereas nonfluorescent lamalginite and bitumen dominate in samples having Tmax's greater than $440^{\circ} \mathrm{C}$ (Figure 7-16). The loss of fluorescence in lamalginite therefore appears to occur near the middle of the oil-window and is clearly associated with hydrocarbon generation.

7.6 Reflectances versus extractable hydrocarbon yields.

The beginning of the oil window appears to start abruptly at a mean maximum reflectance of about $0.15 \%$ (fluorescent lamalginite) and finishes at about $1.4 \%$ (nonfluorescent lamalginite and/or bitumen) (Figure 7-17).

7.7 Calculated vitrinite reflectances derived from MPI1 indices versus extractable hydrocarbon yield.

The calculated vitrinite reflectance value for the onset of hydrocarbon generation is about $0.6 \%$. The end of the oil-window is not clear from the data but is somewhere between 1.30 to $1.60 \%$ (Figure $7-18$ ). 


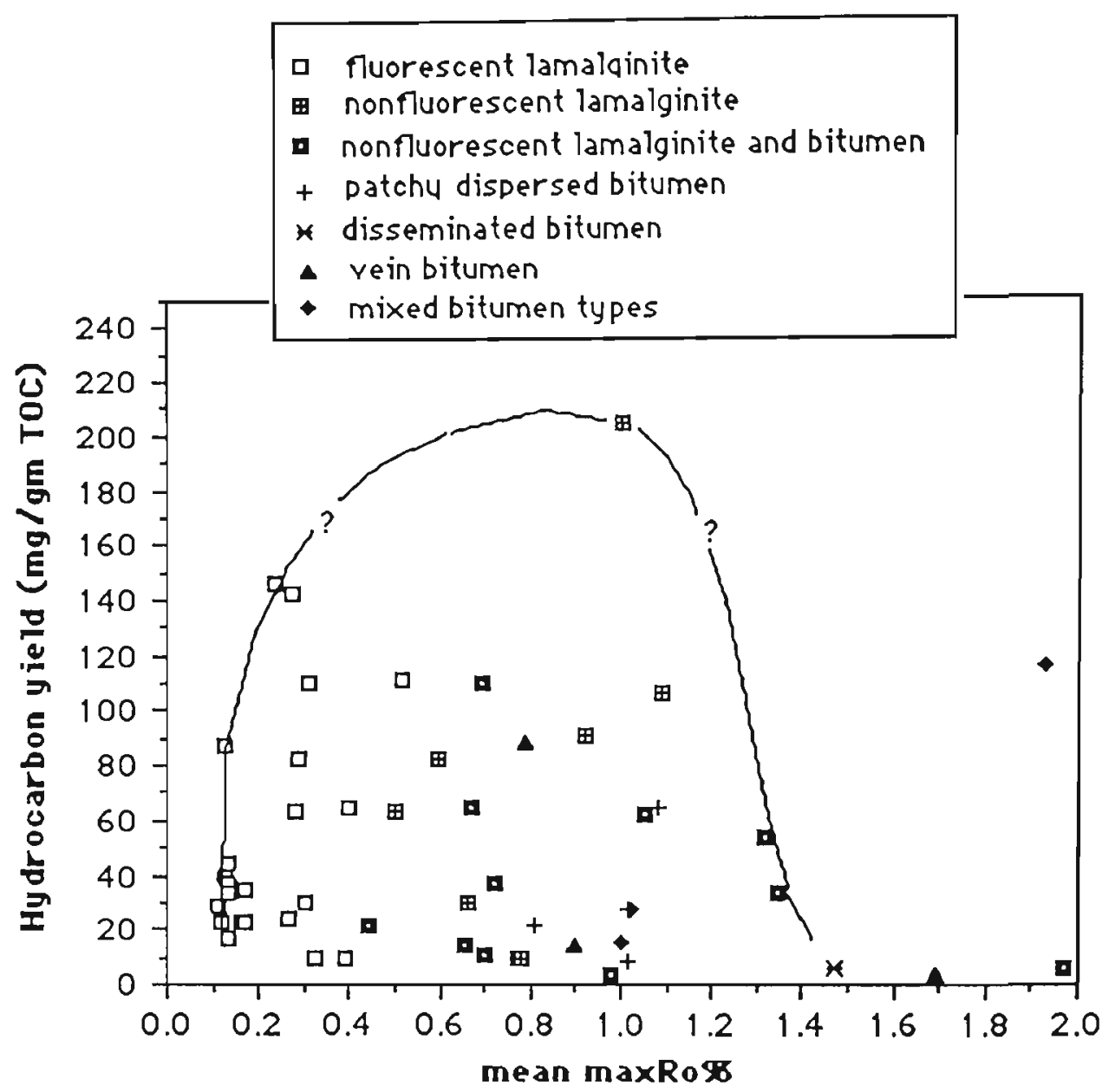

Figure 7-17. Yield of extractable hydrocarbons versus mean maximum reflectances (mean maxRo\%) in the range $0-2 \%$. The line encloses the oil-window.

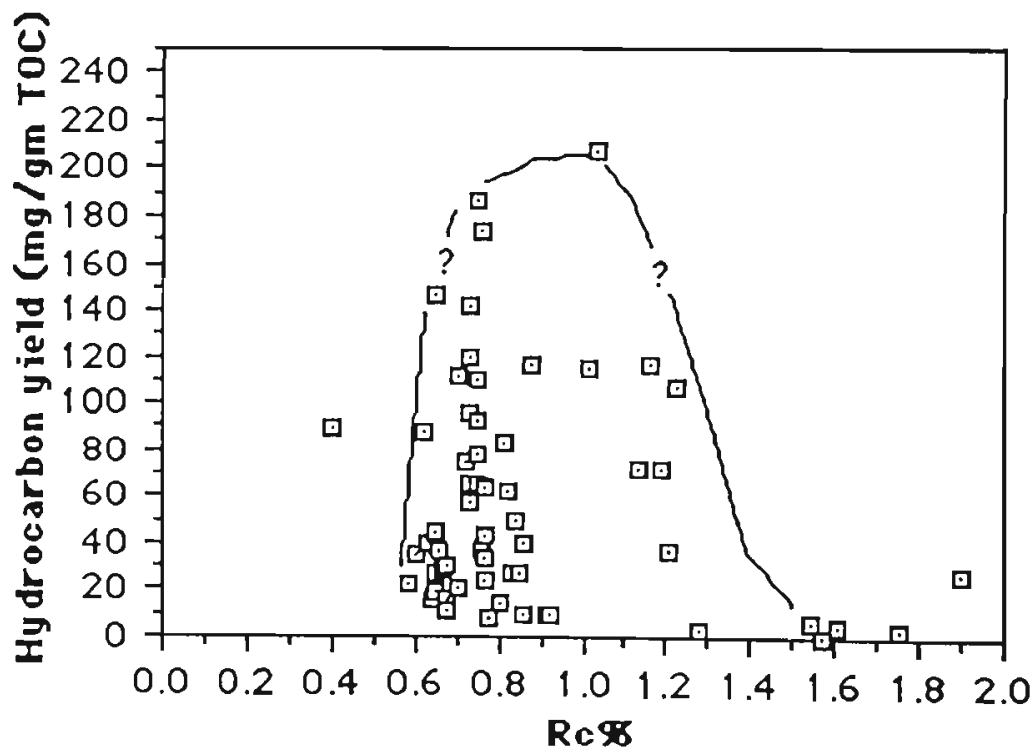

Figure 7-18. Calculated vitrinite reflectances from MPI-1 indices (Rc\%) plotted against hydrocarbon yields. 


\section{CHAPTER 8}

\section{LEVELS OF MATURATION WITHIN THE MCARTHUR BASIN}

\subsection{Introduction}

In the previous chapter the range of values for some maturation indices with respect to hydrocarbon generation was established. Maturation levels for organic matter in the McArthur Basin vary considerably and range from being at least marginally mature to overmature for hydrocarbon generation (Figure 8-1, Table 8-1). In this chapter, the youngest of the groups in the McArthur Basin, the Roper Group, is examined first as interpretation of maturation levels within this group is less complex and the results assist in the interpretation of maturation levels in the older groups.

\subsection{Maturation levels in the Roper Group}

Dolerite sills are common within the Roper Group and contact metamorphism related to these sills has produced localised and probably elongate zones of overmature organic matter. Reflectances of nonfluorescent lamalginite and/or bitumen near a dolerite sill, $174 \mathrm{~m}$ thick, within the Corcoran Formation in the Broadmere 1 well, have clearly been affected by contact metamorphism (Figure 8-2). No reliable Tmax values are available for comparison from near this dolerite sill. Reflectances of nonfluorescent lamalginite near a dolerite sill, $73 \mathrm{~m}$ thick, in DDH Urapunga 5 have also been similarly affected. 


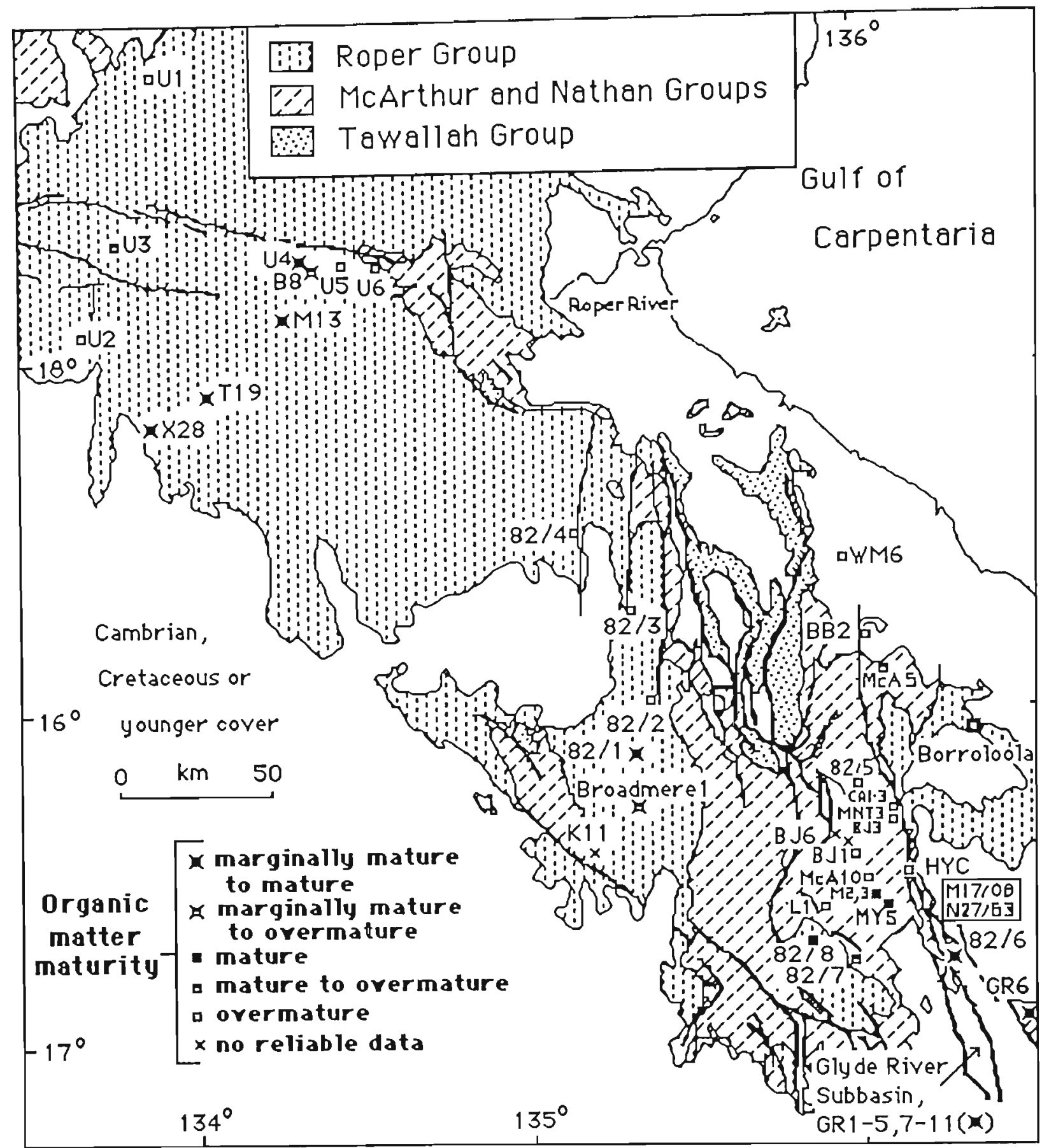

Figure 8-1. Maturation levels for organic matter in core from DDH's examined within the McArthur Basin. (U1-6 = DDH's Urapunga 1-6; MNT3 = DDH MANT79-3). 


\begin{tabular}{|c|c|c|c|}
\hline Group/Formation & $\begin{array}{c}\text { Tmax range } \\
\left(C^{\circ}\right)\end{array}$ & $\begin{array}{c}\text { moan maxho\% } \\
\text { range }\end{array}$ & $\begin{array}{l}\text { Rc\% } \\
\text { range }\end{array}$ \\
\hline \multicolumn{4}{|l|}{ Roper Group } \\
\hline McMinn Fm. & $430-488$ & $0.16(f l)-3.49(n f)$ & n.d. \\
\hline Velkerri Fm. & $437 \cdot 459$ & $0.23(f l)-3.42(n f)$ & $0.68-2.48$ \\
\hline Cobanbarini $\mathrm{Fm}$. & & & \\
\hline "Cat Creek Member" & n.r.d. & $0.39(\mathrm{fl})$ & n.d. \\
\hline "Lansen Creek Shale Mbr. & $436-468$ & $0.27(f \mid)-1.74(n f+b i t)$ & 0.86 \\
\hline Bessie Creek Sst. & n.r.d. & $1.46 \quad(n f+b i t)$ & n.d. \\
\hline Corcoran Fm. & n.r.d. & $1.35(n f+b i t)-5.24(n f+b i t)$ & n.d. \\
\hline Abner Sst. & n.r.d. & $2.39(n f+b i t)-5.34(v b)$ & n.d. \\
\hline Crawford Fm. & n.r.d. & $1.80(n f)$ & n.d. \\
\hline Mainoru Fm. & n.r.d. & $1.48(n f)-3.86(n f+b i t)$ & n.d. \\
\hline "Mantungula Fm." & n.r.d. & $2.78(n f)$ & n.d. \\
\hline \multicolumn{4}{|l|}{ Nathan Group } \\
\hline Balbarini Dolomite & 437 & $0.79(v b), 4.19(v b+p d b)$ & 0.40 \\
\hline \multicolumn{4}{|l|}{ McArthur Group } \\
\hline Stretton Sst. & n.r.d. & n.d. & n.d. \\
\hline Yalco Fm. & $426-458$ & $0.14(f l)-0.789(n f)$ & $0.68-0.91$ \\
\hline Lynott Fm. & $440-551$ & $1.34(n f+b i t)-2.76(p d b)$ & 0.77 \\
\hline $\begin{array}{l}\text { Reward Dolomite } \\
\text { Barney Creek Fm. }\end{array}$ & $441-475$ & $1.12(v b)-2.60(v b)$ & n.d. \\
\hline $\begin{array}{l}\text { Glyde River Subbasin } \\
\text { Central and northern }\end{array}$ & $429-466$ & $0.05(f l)-1.05(n f+b i t)$ & $0.58-0.86$ \\
\hline Batten Trough & $437-551$ & $1.24(p d b)-5.39(d b)$ & $0.65-2.48$ \\
\hline Teena Dolomite & 454 & $1.83(v b)-2.81(v b+d b)$ & n.d. \\
\hline Emmerugga Dolomite & n.d. & $2.43(v b), 3.05(v b)$ & n.d. \\
\hline
\end{tabular}

Table 8-1. Ranges of Tmax, reflectances and calculated vitrinite reflectances derived from the MPI-1 indices (Rc\%) for each formation examined in the McArthur Basin. The abbreviations enclosed in brackets after the reflectance values represent the type of organic matter measured to obtain the individual reflectance values where " $f$ " = fluorescent lamalginite, "nf" = nonfluorescent lamalginite, "bit" = bitumen, "pdb" = patchy dispersed bitumen, " $\mathrm{db}$ " = disseminated bitumen, and "vb" = vein bitumen. The Tmax values given are those where where $S 2 \geq 0.2 \mathrm{mg} / \mathrm{g}$ and where there is no suppression of the Tmax value due to migrated oil. ("n.r.d." = no reliable data, and "n.d." = no data). 

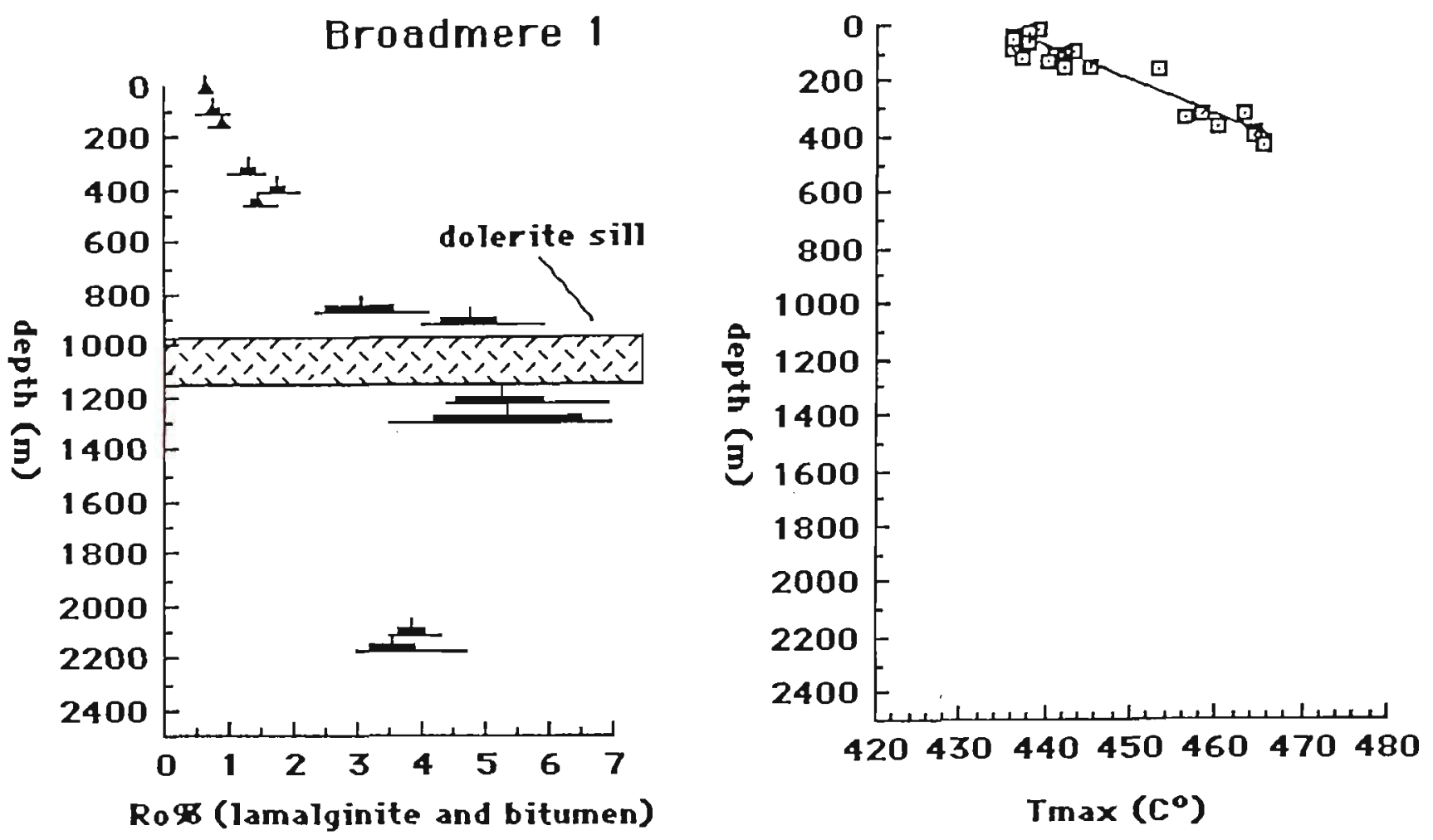

Figure 8-2. Reflectances (Ro\%) of nonfluorescent lamalginite and/or bitumen, and Tmax, versus depth for the wild-cat oil well, Broadmere 1, Roper Group. The range of reflectances is represented by the horizontal line, the mean by the vertical line and the $95 \%$ confidence limits of the mean by the boxes. Tmax values are those where $\mathrm{S} 2 \geq 0.20$ and there is no suppression of values due to migrated oil.

Maturation levels of organic matter in the top sections of DDH's Urapunga 4 and $82 / 3$, and in the lower sections of DDH's Urapunga 3 and B8 (Figure 8-3) have probably also been affected by contact metamorphism. Outcrop of a dolerite sill occurs close to, and stratigraphically above, DDH Urapunga 4 (J. Jackson, pers. comm.) and dolerite sills occur just below the bases of DDH's Urapunga 3 and B8, and stratigraphically above DDH 82/3, based on interpretation of geological maps of the region.

Organic matter in the McMinn, Velkerri and Cobanbarini Formations is marginally mature to mature where it has not been affected by contact metamorphism. Organic matter in the 
Bessie Creek Sandstone and older formations is at least marginally overmature (Table 8-1).

Maturation levels as defined by reflectance values, generally increase with the age of the formations in the Roper Group (excluding the organic matter affected by contact metamorphism) (Figure 8-4). Tmax values for the McMinn Formation are mostly less than Tmax values for the older Velkerri or Cobanbarini Formations unless affected by contact metamorphism (Figure 8-5). Tmax values are unreliable in

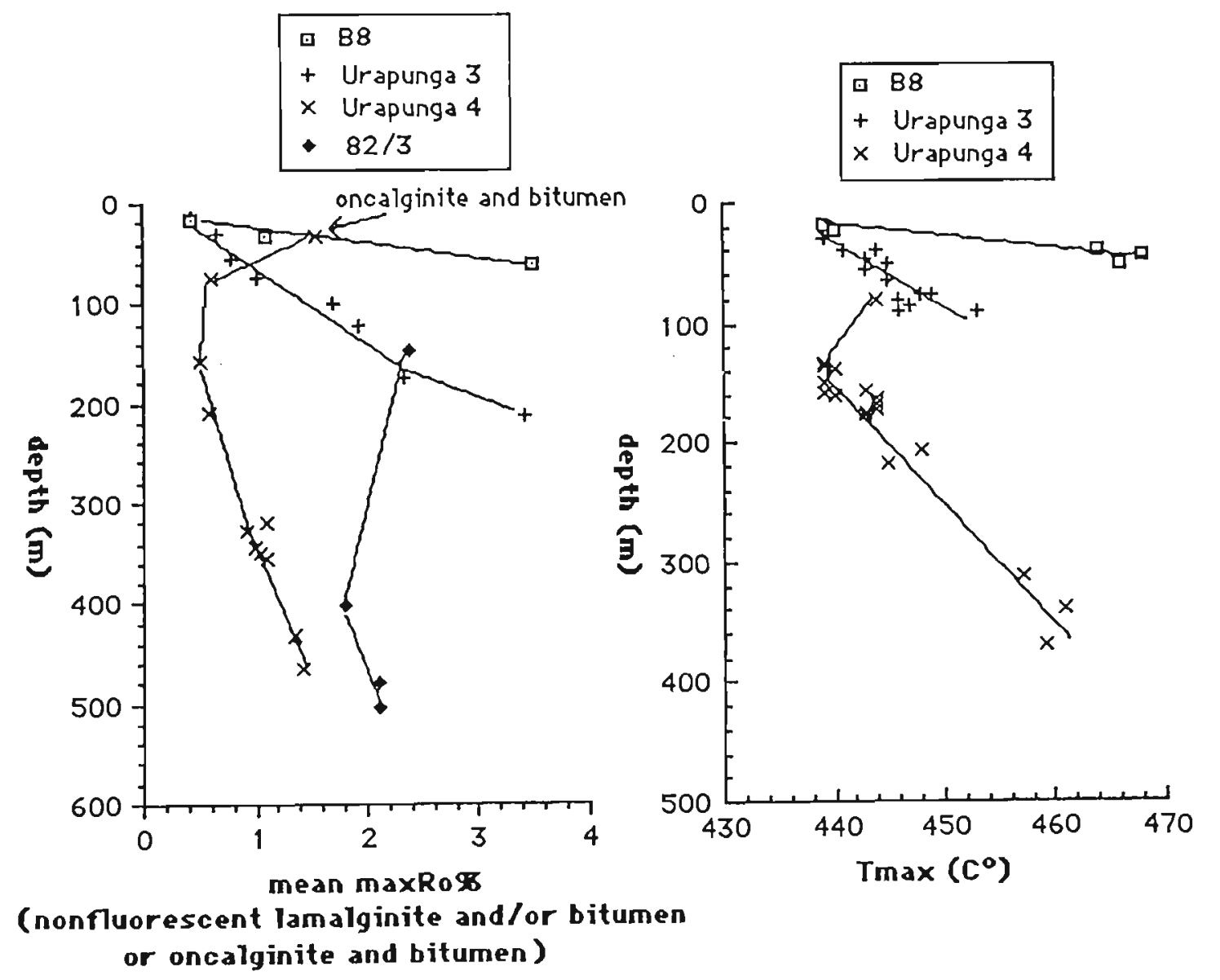

Figure 8-3. Mean maximum reflectances (mean maxRo\%) of nonfluorescent lamalginite and/or bitumen except where indicated, and Tmax, versus depth for DDH's B8, Urapunga 3 and 4, and 82/3, Roper Group. Tmax values are those where S2 $\geq 0.20$ and there is no suppression of values due to migrated oil. 
a McMinn Fm., fluorescent lamalginite

- McMinn Fm., nonfluorescent lamalginite or oncalginite and bitumen

- Yelkerri Fm., fluorescent lamalginite

- Yelkerri Fm., nonfluorescent lamalginite and/or bitumen

D Cobanbarini $\mathbf{F m}$., fluorescent lamalginite

- Cobanbarini Fm., nonfluorescent lamalginite or nonfluorescent lamalginite and bitumen

- Bessie Creek Sst., nonfluorescent lamalginite and/or bitumen

a Corcoran $\mathbf{F m}$., nonfluorescent lamalginite and/or bitumen

+ Abner Sst., nonfluorescent lamalginite and/or bitumen

$\times$ Cravford Fm. . nonfluorescent lamalginite

* Mainoru Fm., nonfluorescent lamalginite and/or bitumen

- Mantungula Fm.-, nonfluorescent lamalginite

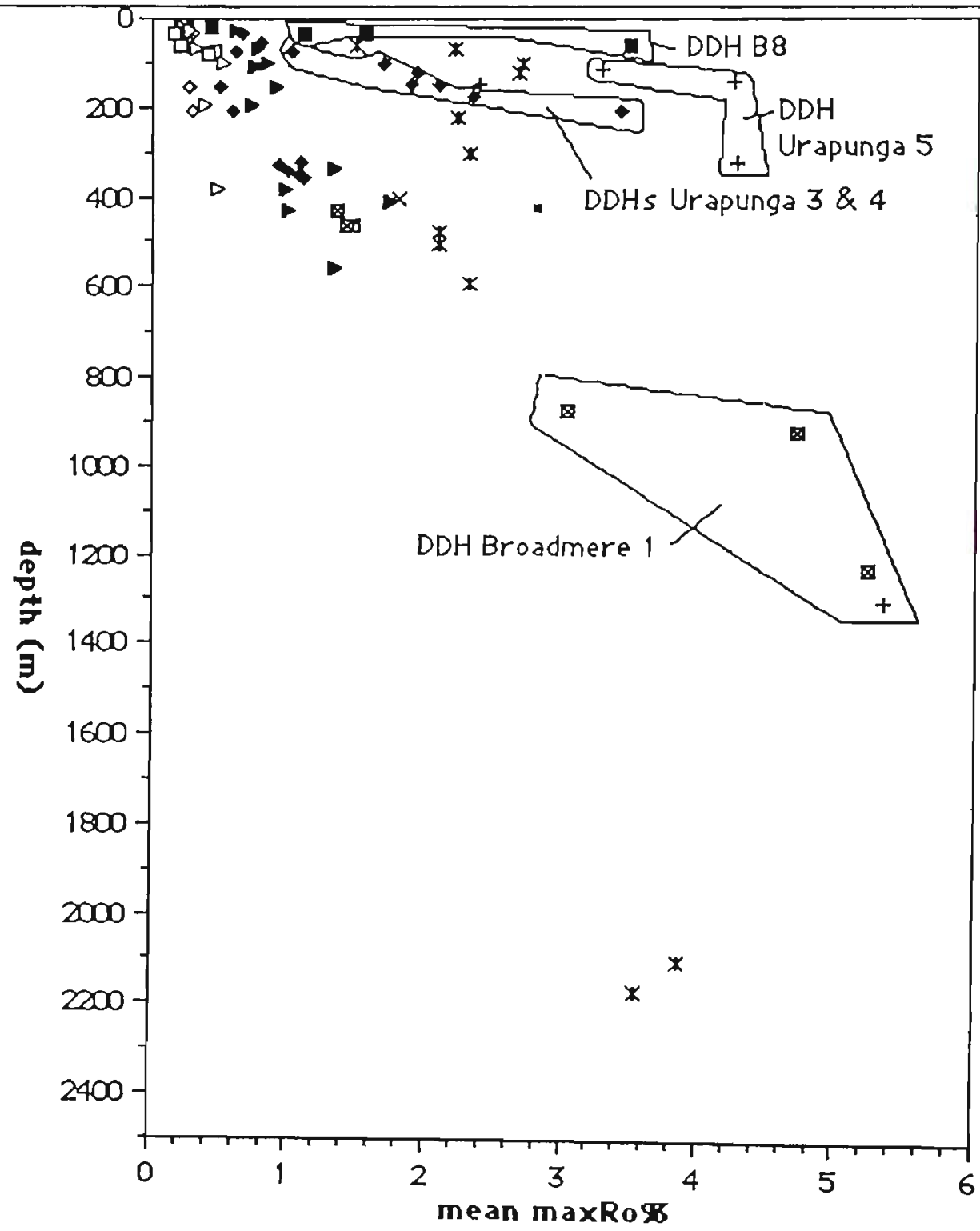

Figure 8-4. Mean maximum reflectances for fluorescent lamalginite or nonfluorescent lamalginite and/or bitumen (mean maxRo\%) plotted against depth, for formations in the Roper Group. The outlined reflectance values have been affected by contact metamorphism. 


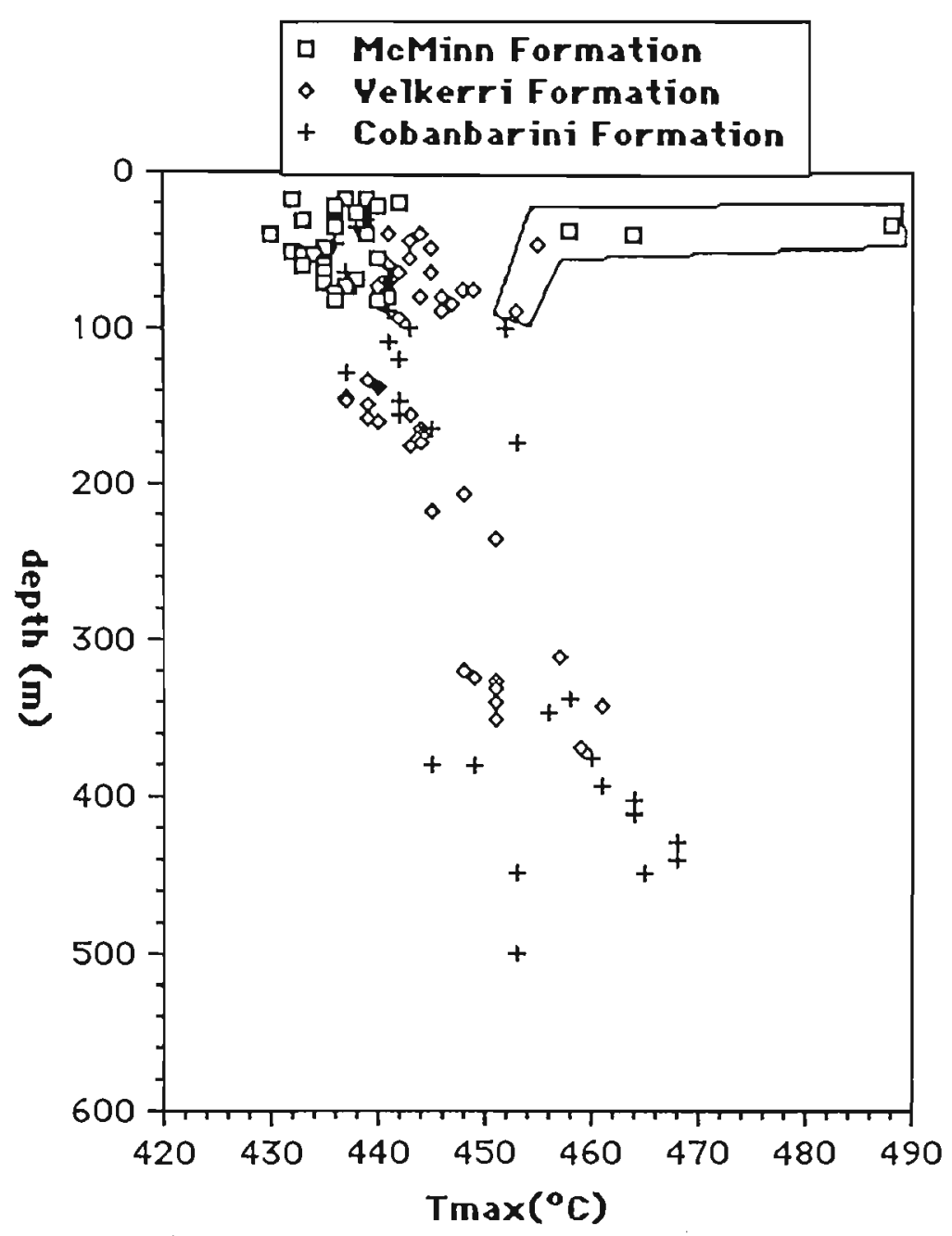

Figure 8-5. Tmax values plotted against depth for formations of the Roper Group. Tmax values are those where $\mathrm{S} 2$ is greater than $0.2 \mathrm{mg} / \mathrm{g}$, and the values show no suppression due to migrated oil. The outlined Tmax values have been affected by contact metamorphism.

formations older than the Cobanbarini or Velkerri Formations as the, older formations are organically lean and overmature.

The levels of maturation are fairly similar for the same formations over a wide areal extent. Such a pattern of coalification is consistent with the concept that the Roper Group formed during the sag phase of the basin's development and that the sedimentary rocks in the group have subsequently had a relatively uniform geological history. The main stage of 
coalification must have been associated with a phase or phases of relatively uniform subsidence. The localized zones of contact metamorphism were probably superimposed upon the regional pattern but it is possible that at least in part, the contact alteration predates much of the regional rank change, the evidence being, however, equivocal.

\subsection{Maturation levels in the McArthur and Nathan Groups}

Maturation levels in these groups range from being at least marginally immature to overmature. Maturation of organic matter in these groups has probably not been affected by contact metamorphism due, as in the case of the Roper Group, to the intrusion of dolerite sills. No igneous intrusions of any kind have been observed in this group (Jackson et al, 1987a). Anomalously high maturation indices do occur, however, in the McArthur Group in the Batten Trough.

Organic matter in core from two drill holes (M17/08, N27/63) in the Barney Creek Formation which passed through base metal mineralisation in the H.Y.C. deposit, have anomalously high reflectance and Tmax values at depths between about 250 to $350 \mathrm{~m}$ (Figures 8-6,7). This organic matter occurs within thin $(<3 \mathrm{~mm}$ thick), lutite beds within conformable, centimetre-thick, sulphide-rich bands containing pyrite, sphalerite, galena and chalcopyrite (in descending order of abundance). It consists mainly of disseminated, or in places, patches, of irregularly shaped bitumen pieces generally less 

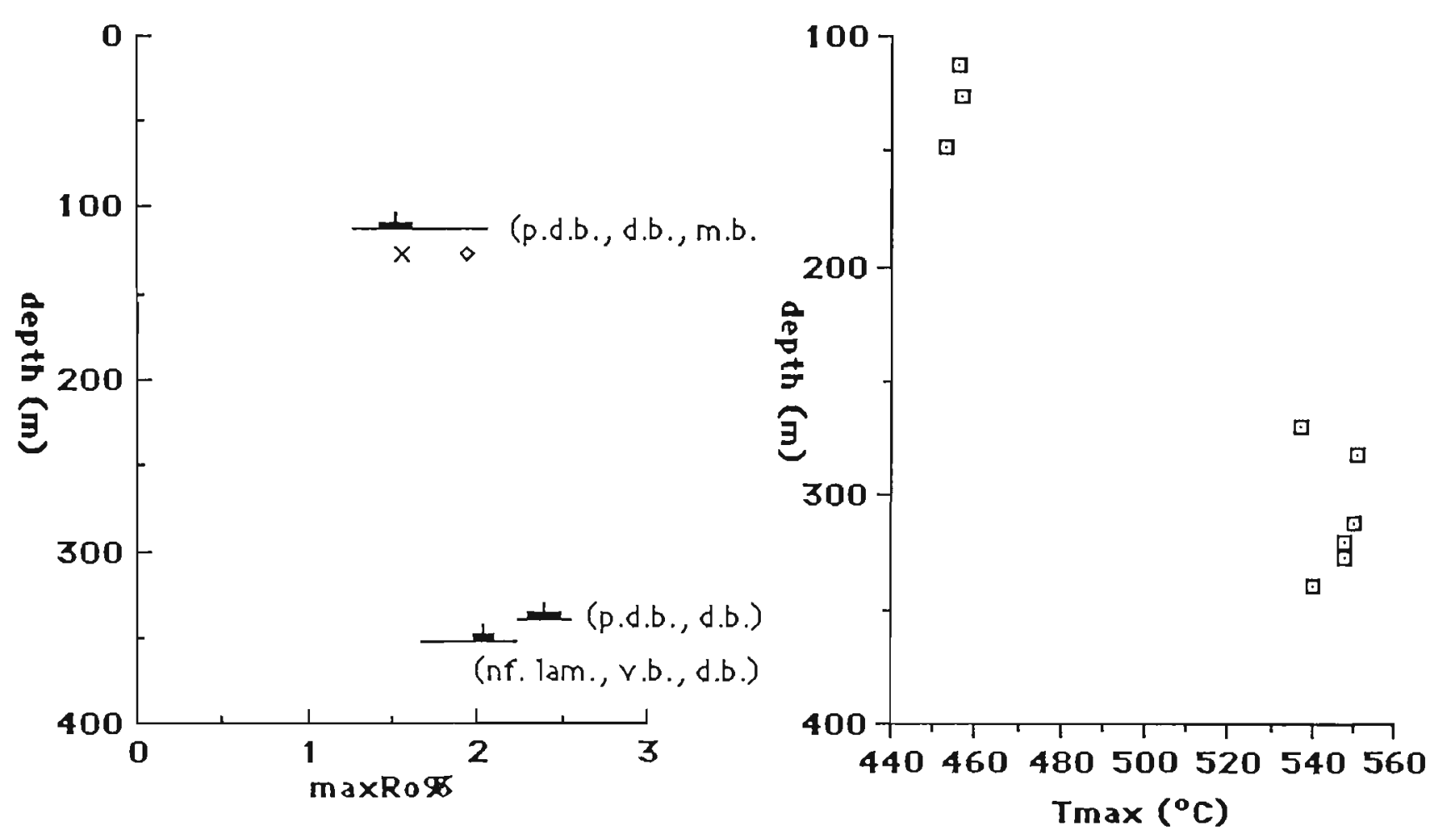

Figure 8-6 Measured reflectances (horizontal line $=$ range, vertical line $=$ mean, and rectangular boxes $=95 \%$ confidence limits of the mean), calculated reflectances from MPI-1 indices using equation $1(x)$ or equation 2 (open diamond shape), and Tmax values versus depth for DDH M17/08, H.Y.C. lead-zinc deposit, Barney Creek Formation. The Tmax values given are those where where $S 2 \geq 0.2 \mathrm{mg} / \mathrm{g}$ and where there is no suppression of the Tmax value due to migrated oil. The abbreviations "nf. lam." = nonfluorescent lamalginite, "v.b." = vein bitumen, "m.b." = matrix bitumen, "p.d.b." = patchy dispersed bitumen, and "d.b." = disseminated bitumen.

than 10 microns in size. In one sample (DDH N27/63, $313.0 \mathrm{~m}$ ), the organic matter appears as discrete, elongate bodies of nonfluorescent lamalginite, up to 30 microns long by generally less than 5 microns wide.

The H.Y.C. deposit occurs in the central region of the Batten trough (Figure 8-1) and is by far the largest of a number of base-metal deposits in the McArthur Group (Lambert and Scott, 1973). It contains an estimated 227 million tonnes of ore with an average grade of $9.2 \% \mathrm{Zn}, 4.1 \% \mathrm{~Pb}$, and $41 \mathrm{~g} / \mathrm{t} \mathrm{Ag}$ 

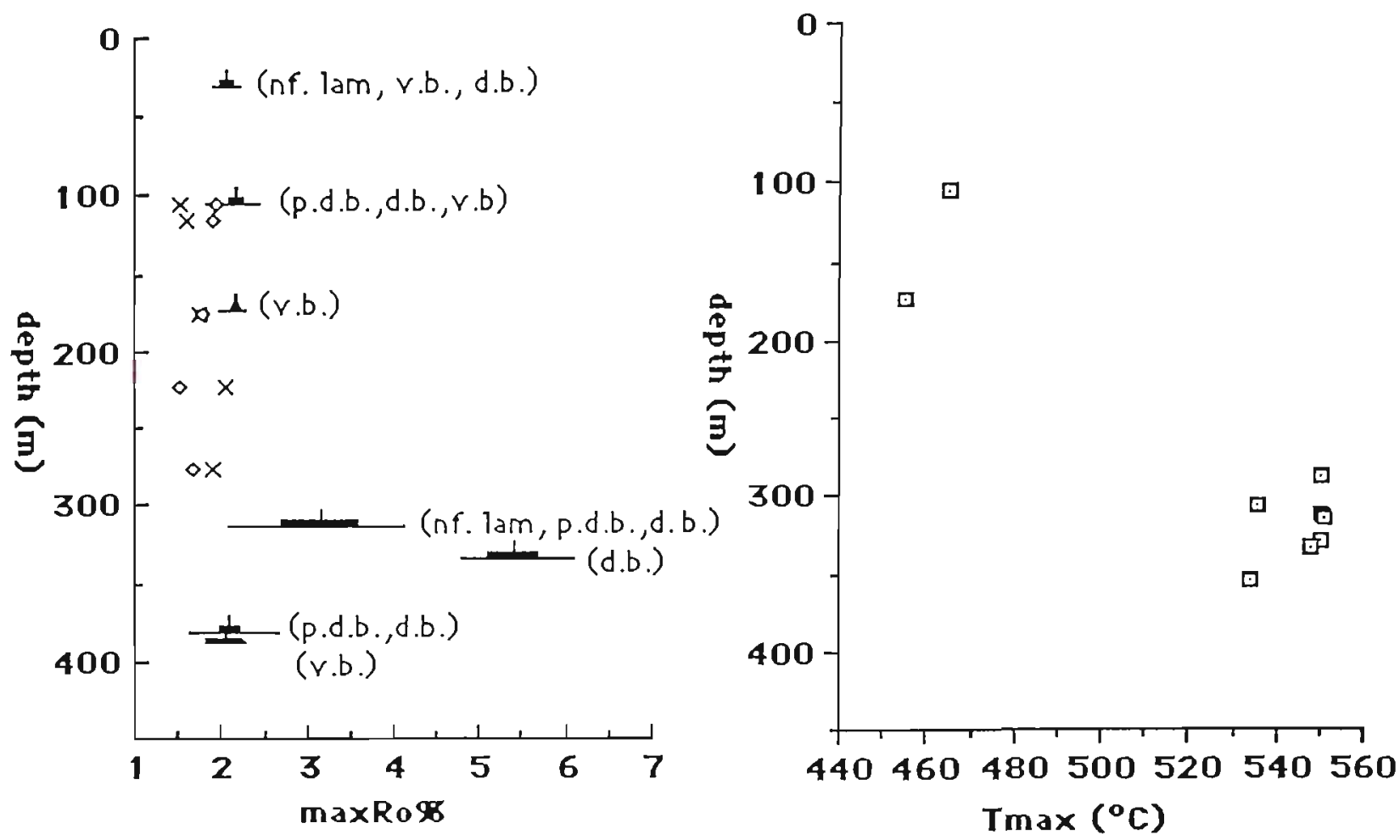

Figure 8-7 Measured reflectances (horizontal line $=$ range, vertical line $=$ mean, and rectangular boxes $=95 \%$ confidence limits of the mean), calculated reflectances from MPI-1 indices using equation $1(x)$ or equation 2 (open diamond shape), and Tmax values versus depth for DDH N27/63, H.Y.C. lead-zinc deposit, Barney Creek Formation. The Tmax values given are those where where $\mathrm{s} 2 \geq 0.2 \mathrm{mg} / \mathrm{g}$ and where there is no suppression of the Tmax value due to migrated oil. The abbreviations "nf. lam." = nonfluorescent lamalginite, "v.b." = vein bitumen, "p.d.b." = patchy dispersed bitumen, and "d.b." = disseminated bitumen.

(Buchanan, 1984). It extends over an area of approximately 1.5 $\mathrm{km}^{2}$ and consists of thin, closely-spaced, conformable sulphide bands in shales having a total thickness of generally about $55 \mathrm{~m}$ but reaching up to $130 \mathrm{~m}$ (Lambert and Scott, 1973). It probably formed from either syngenetic (Smith and Croxford, 1973, Lambert and Scott, 1973; Murray, 1975; Lambert, 1976) or epigenetic (Williams, 1978b) hydrothermal metalliferous solutions. The evidence as to whether the deposit formed syngenetically or epigenetically is equivocal (Williams, 1978b). 
The mineralising solutions had a temperature ranging from about $100^{\circ}$ to $260^{\circ} \mathrm{C}$ based on the sulphur isotope fractionations between galena and sphalerite (Smith and Croxford, 1973; Williams and Rye, 1974).

Epigenetic, discordant, $\mathrm{Pb}-\mathrm{Zn}-\mathrm{Cu}$ mineralisation occurs at a number of deposits near the H.Y.C. and closer to the Emu Fault, in the Emmerugga Dolomite and Cooley Dolomite Member (Williams 1978a). Textural and mineralogic characteristics of the mineralisation indicate that early stage, low-temperature $\left(<200^{\circ} \mathrm{C}\right)$, copper bearing solutions and later stage, $\mathrm{Pb}-\mathrm{Zn}$ bearing solutions, were responsible for the mineralisation (Williams, 1978a). The contours of $\mathrm{Cu} /(\mathrm{Pb}+\mathrm{Zn}$ ) ratios suggest that the mineralising fluids emanated from the Emu Fault and spread westwards towards the H.Y.C. (Williams, 1978a).

An increase in heat flow, emanating from relatively hot mineralising solutions as the H.Y.C. deposit formed, and the resulting higher temperatures in adjacent sediments, produced a more rapid maturation of the adjacent organic matter. The anomalously higher maturation indices in the zone of basemetal mineralisation in the H.Y.C. deposit therefore signal the effects of a form of contact metamorphism, in this case, produced by hot mineralised solutions.

Anomalously high maturation reflectances of patchy dispersed, disseminated or vein bitumen are evident elsewhere from the central region of the Batten Trough in the Barney Creek Formation, Reward and Emmerrugga Dolomites (DDHs BJ1, $30.6 \mathrm{~m}$; Mant 79-3, $279.8 \mathrm{~m} ;$ McA10, $139.3 \mathrm{~m}$ and $160.7 \mathrm{~m})$. 


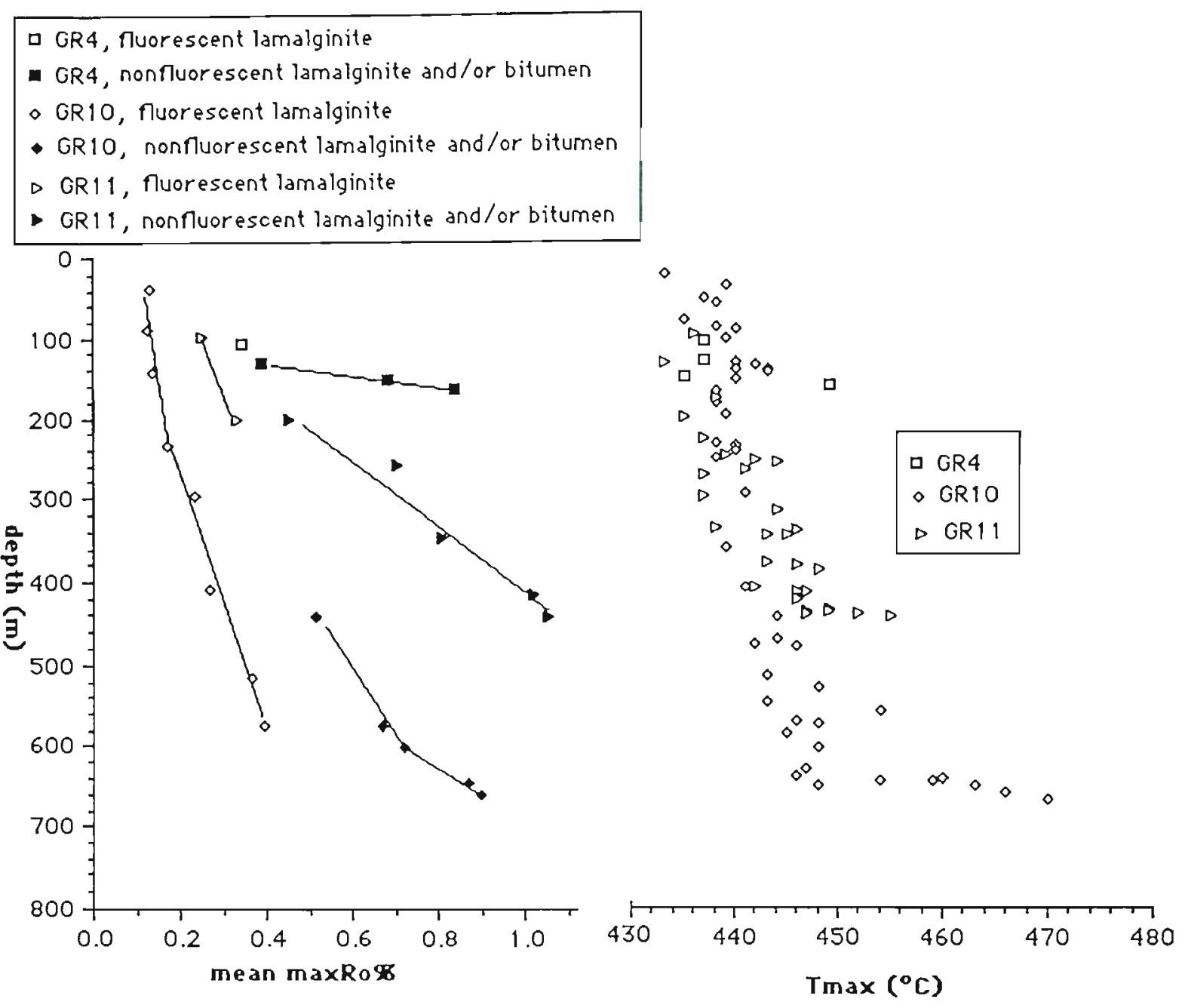

Figure 8-8. Mean maximum reflectances (maxRo\%) of fluorescent lamalginite, nonfluorescent lamalginite and/or bitumen, and Tmax versus depth for three drill holes (GR4, 10 and 11) in the Barney Creek Formation, Glyde River Subbasin.

Veins of sphalerite+pyrite and sphalerite+carbonate occur in DDH McA10 $(139.3 \mathrm{~m})$ clearly indicating that thermal activity from the passage of mineralised solutions may have produced the anomalously high reflectances in this sample. However, no base-metal mineralisation was observed in the other cases. Nevertheless, hydrothermal fluids need not necessarily contain metals in solution, and yet could produce localised zones of increased temperatures. 
Tmax values from near the bottom of DDH GR10 in the Barney Creek Formation of the Glyde River Subbasin, some 50 $\mathrm{km}$ to the south of the H.Y.C. deposit, show a sharp increase with increasing depth (Figure 7-4). Bitumen vein reflectances from this zone are slightly anomalously higher but not the calculated vitrinite reflectance values (Figure 7-5). Bitumen reflectances and Tmax values for DDH GR4 show a relatively sharp increase with depth near the bottom of the drill hole (Figure 8-8). Tmax values near the base of DDH GR11 also appear to increase sharply (Figure 7-6) although bitumen and nonfluorescent lamalginite reflectances, and calculated vitrinite reflectances from $\mathrm{MPl}-1$ indices, show no such sharp increases (Figure 7-7). It is possible in the cases of DDH's GR10 and 11, that the Tmax values near the base of these wells are portraying a rapid change in maturation levels that neither the measured reflectances nor the methylphenanthrene indices have recorded, although the reason for this is not clear and requires further work.

Organic matter in the Barney Creek Formation to the north of the Glyde River Subbasin in the central and northern regions of the Batten Trough, have mostly higher maturation indices than in the Glyde River Subbasin (Figure 8-9). Maturation indices for formations in the McArthur Group from the central and northern areas of the Batten Trough generally show a considerable overlap in values even when those values which are considered anomalous are taken into account (Figure 


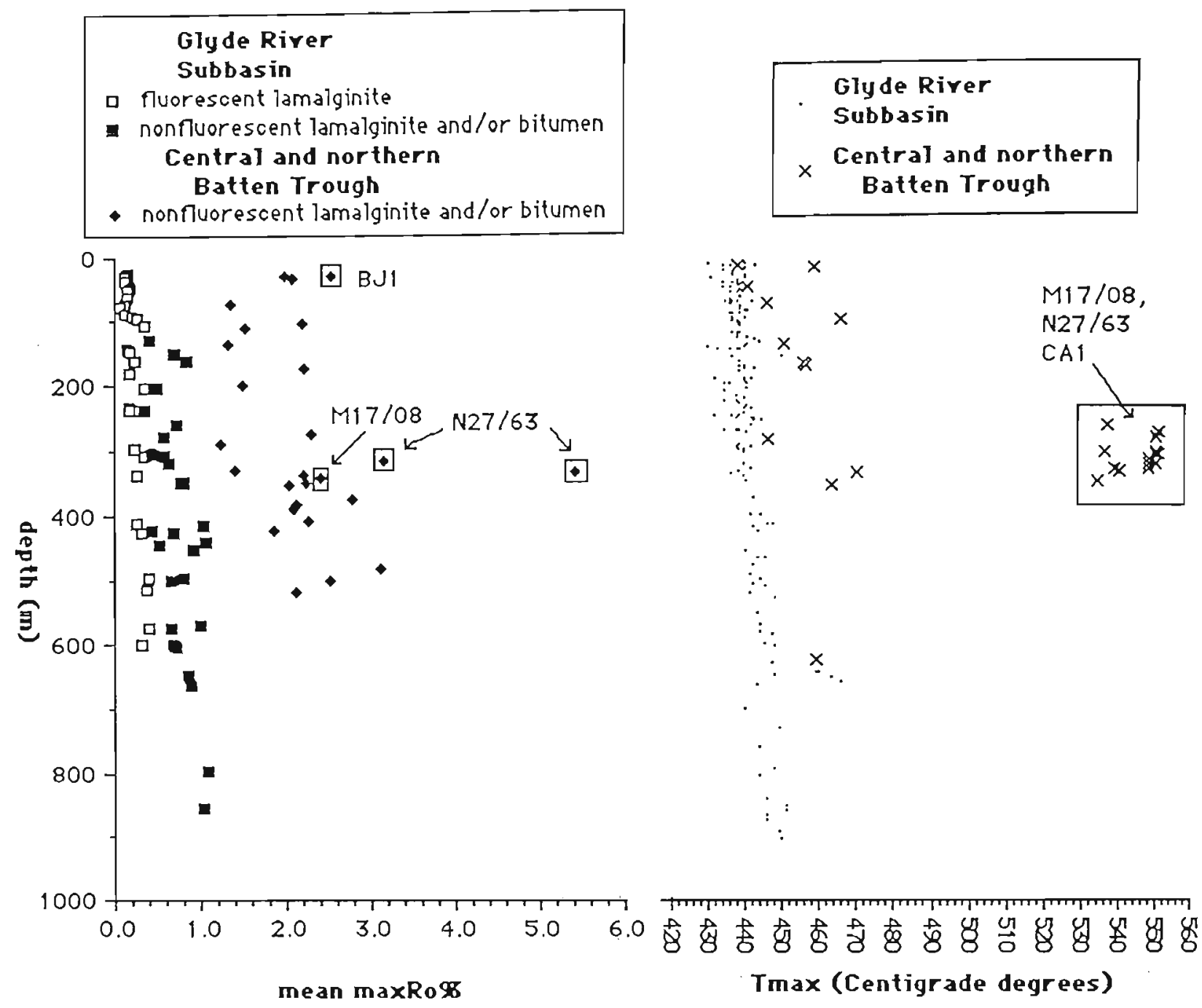

Figure 8-9. Mean maximum reflectances (mean maxRo\%) for fluorescent lamalginite, nonfluorescent lamalginite and/or bitumen, and Tmax values versus depth for the Barney Creek Formation. The Tmax values given are those where where $S 2 \geq 0.2$ $\mathrm{mg} / \mathrm{g}$ and where there is no suppression of the Tmax value due to migrated oil. The boxed points are anomalous values which may have been produced by hydrothermal activity. 


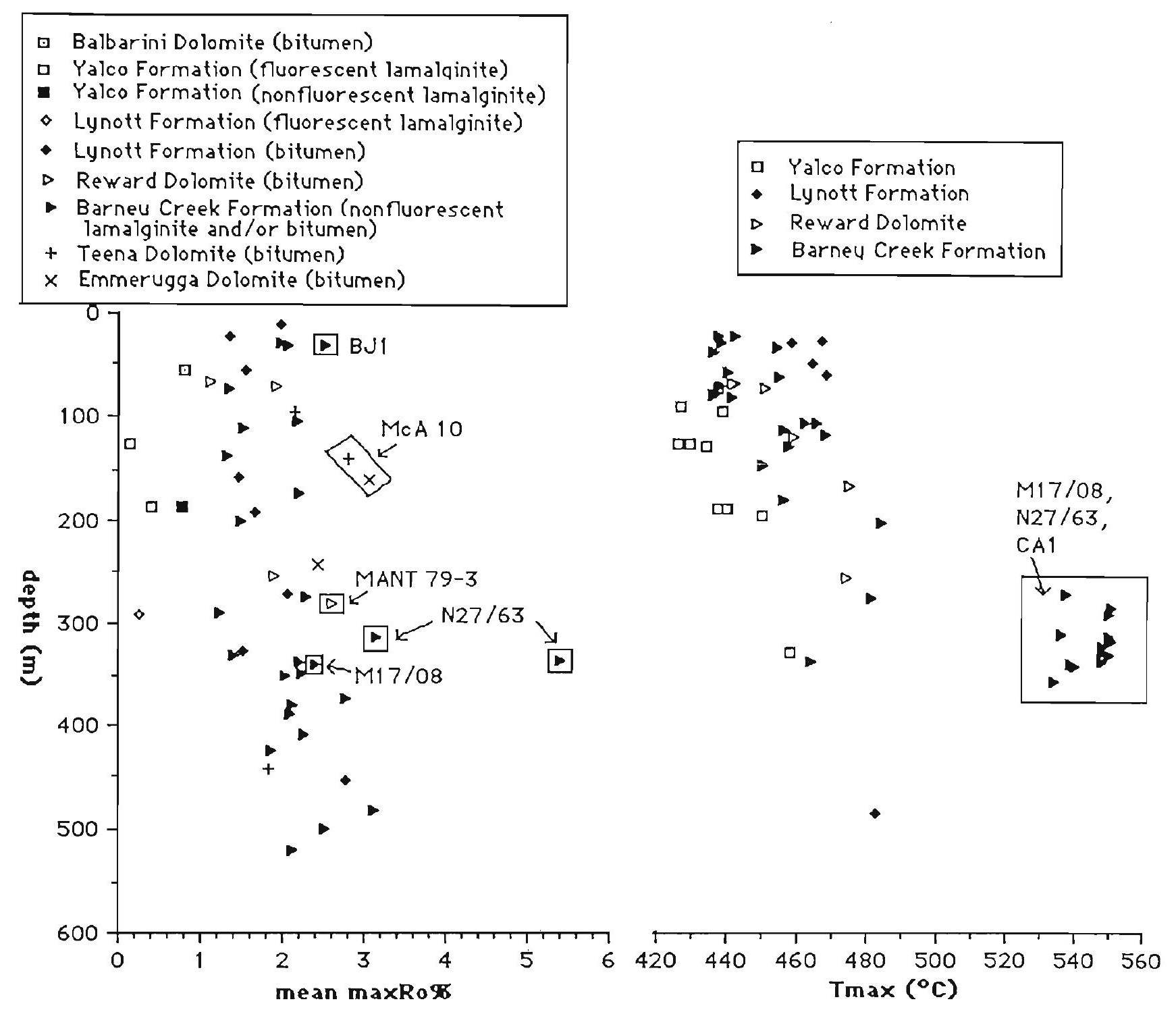

Figure 8-10. Mean maximum reflectances (mean maxRo\%) for fluorescent lamalginite, nonfluorescent lamalginite and/or bitumen, and Tmax values versus depth for formations in the McArthur Group and the Balbarini Dolomite in the Nathan Group in the central and northern areas of the Batten Trough. The Tmax values given are those where where $S 2 \geq 0.2 \mathrm{mg} / \mathrm{g}$ and where there is no suppression of the Tmax value due to migrated oil. The boxed points are anomalous values which may have been produced by hydrothermal activity.

8-10). They indicate a more complicated geological history for the McArthur Group than that of the Roper Group. Hydrothermal activity probably played a considerable role in the maturation process but it is unlikely that it affected all the organic matter in this region. The Batten Trough, up until near the end of 
deposition of the Balbarini Dolomite, was an active tectonic environment (Jackson et al, 1987a) in which there were differing rates of subsidence in various parts of the trough (Plumb et al., 1980). Deposition of the sediments took place in a series of northerly trending half-grabens with greatest subsidence occurring in the western areas of the half-grabens (Muir, 1983a). This activity was probably the final phase of extension prior to the sag phase during which sediments of the Roper Group were deposited. The thickness of the continental lithosphere over the hot asthenosphere in the Batten Trough may, therefore, have been variable and resulted in significant lateral variations in geothermal gradients throughout the trough. By the time the Roper Group was deposited, geothermal gradients throughout the region were relatively uniform and there is no evidence to suggest that there were significant variations in rates of subsidence or uplift within the Batten Trough after deposition of the Nathan Group. Lateral variations in subsidence rates and in geothermal gradients within the half-graben structures of the Batten Trough during deposition of the McArthur Group and the Balbarini Dolomite are the most likely causes for much of the overlap of maturation levels between individual formations of the McArthur Group observed here. Hydrothermal activity associated with active faults during this time also contributed significantly to the maturation process in places. 


\section{CHAPTER 9}

\section{GEOLOGICAL MODELLING AND TIMING OF OIL GENERATION}

\subsection{Introduction}

An attempt can now be made to construct geological models for specific wells and regions to assess past basinal thicknesses and the timing of oil generation in the Barney Creek Formation (McArthur Group) and the Velkerri Formation (Roper Group). Both formations are clearly the most organic-rich in the McArthur Basin (Figs. 5-1,2). Vitrinite reflectances are determined from these models and are compared to measured reflectances recalculated to vitrinite reflectances and to calculated vitrinite reflectances derived from the methylphenanthrene indices.

The widespread use of vitrinite reflectance for modelling in Phanerozoic basins is due to its advantages over a number of other maturation indices such as clay mineralogy, zeolites, fluid inclusions, apatite and zircon fission track annealing and stable isotopes in that it covers a wide temperature range of about $25^{\circ} \mathrm{C}$ to at least $4000^{\circ} \mathrm{C}$ and is not "metamorphic regressive" (Price and Barker, 1985). Data can be obtained for a wide range of samples and restrictions on sample type are less demanding than many other methods (Cook, 1988). It is assumed that reflectances measured from organic matter in the McArthur Basin are also not "metamorphic regressive".

The level of vitrinite reflectance is considered by many to be a function of time and temperature (e.g. Karweil, 1956; Lopatin, 1971; Hood and Castano, 1974, Connan, 1974; Buntebath, 1978 ) whereas Price (1983) considers that it is purely a function of the maximum temperature encountered by the organic matter and that 
geological time plays no role. Price (1983) examined the literature supporting the contention that geological age is a factor in organic metamorphism and concluded that in those studies where "hard scientific documentation" was available (Karweil, 1956; Lopatin, 1971; and Connan, 1974) the levels of organic metamorphism are better explained by high palaeogeothermal gradients resulting from major geological activity rather than by invoking geological time as a factor. He plotted vitrinite reflectance data from a number of basins ranging from 2 to $240 \mathrm{~m} . \mathrm{y}$. old which he considered are currently at or near maximum geothermal gradients and showed that the Ro data show a strong correlation with temperature but not with time.

Lopatin (1971) developed a "time-temperature index" (TTI) to quantify the effects of both time and temperature on the maturation of organic matter in sediments based on data from Huck and Karweil (1955). Lopatin proposed that definite TTI values correspond to the different stages of oil generation, however Waples (1980) considered they were incorrect because of errors in his original geological reconstruction. Waples (1980) developed a new scale of TTI versus vitrinite reflectance based on unpublished Chevron data. It was assumed by Lopatin (1971) and others before and after him (e.g. Karweil, 1956; Hood and Castano, 1974; Hood et al. 1975) that the overall complex processes in oil generation and coalification can be generalised as a simple, first-order chemical reaction where the reaction rate $(k)$ is a function of absolute temperature $(T)$ and activation energy (E) as expressed by the Arrhenius equation, $k=A e^{-E / R T}$. Tissot et al. (1987) comment that the values of maturation indices such as vitrinite 
reflectances, result from complex, poorly known, kinetics and that the $\mathrm{TTI}$ index does not take into account the differing rates of reactions of different organic matter types, but this argument is separate from that concerning the significance of time.

Given that the geological history of the McArthur Basin can only be very roughly reconstructed, use of simple "first-order" empirical methods is warranted rather than more sophisticated approaches. Two methods are used: (1) the Lopatin (1971) method as modified by Waples (1980), and (2) Price's (1983) method.

\subsection{Thermal history of the McArthur Basin}

Use of either Lopatin-Waples' or Price's methods requires, at the very least, a knowledge of the current geothermal gradients and preferably, knowledge of past geothermal gradients. Changes in heat flow in the McArthur Basin over its geological history must have occurred, particularly during the extensional tectonic phase of its development. By the time sediments of the Roper Group started to be deposited, during the sag phase, geothermal gradients had become relatively stable.

An inferred cooling history of Proterozoic rocks of the Pine Creek Geosyncline in the East Alligator River region, which had been overlain by sediments of the McArthur Basin, and which is adjacent to the present north-east margin of the McArthur Basin, has been derived from fission-track annealing temperatures of a number of minerals (Koul et al., 1988). Their results indicate that from $1428 \mathrm{Ma}$, at about the end of deposition of the Roper Group, to well into the Phanerozoic, a smooth cooling history resulted from declining radiogenic heat production and gradual stripping of the insulating sedimentary cover. Koul et al. (1988) 


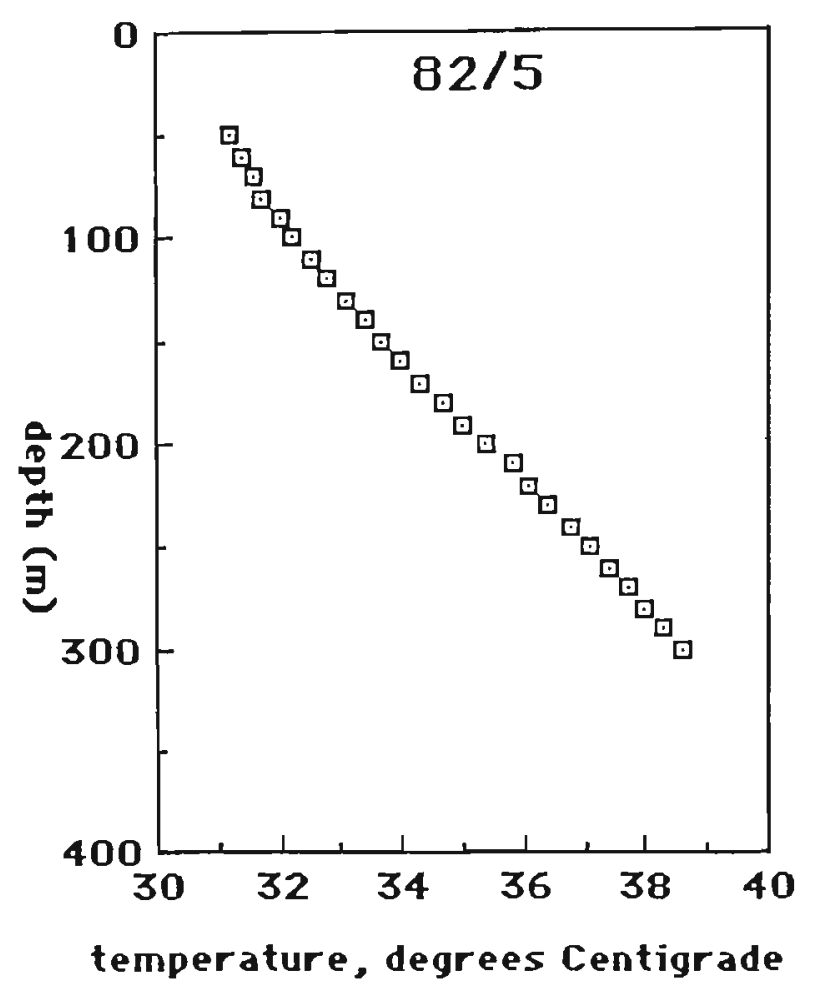

(a)

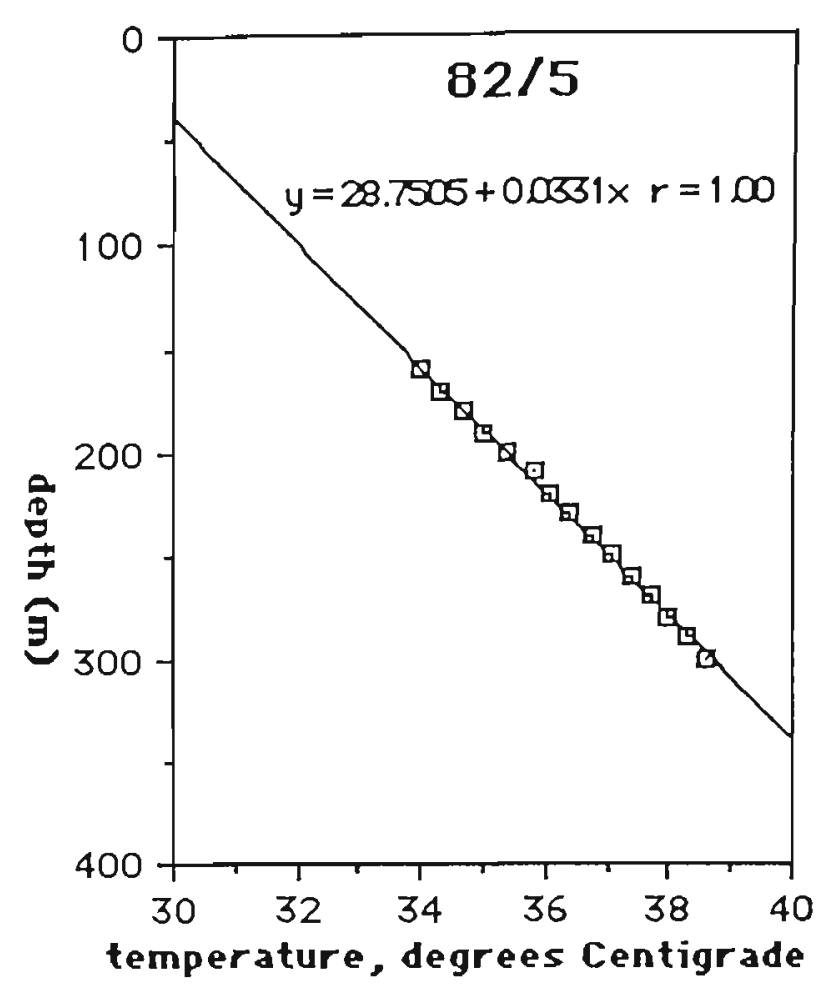

(b)

Figure 9-1. Temperature versus depth for DDH $82 / 5$ showing all data (a) and data from about $150 \mathrm{~m}$ depth downwards (b) where temperatures are unaffected by near-surface perturbations.
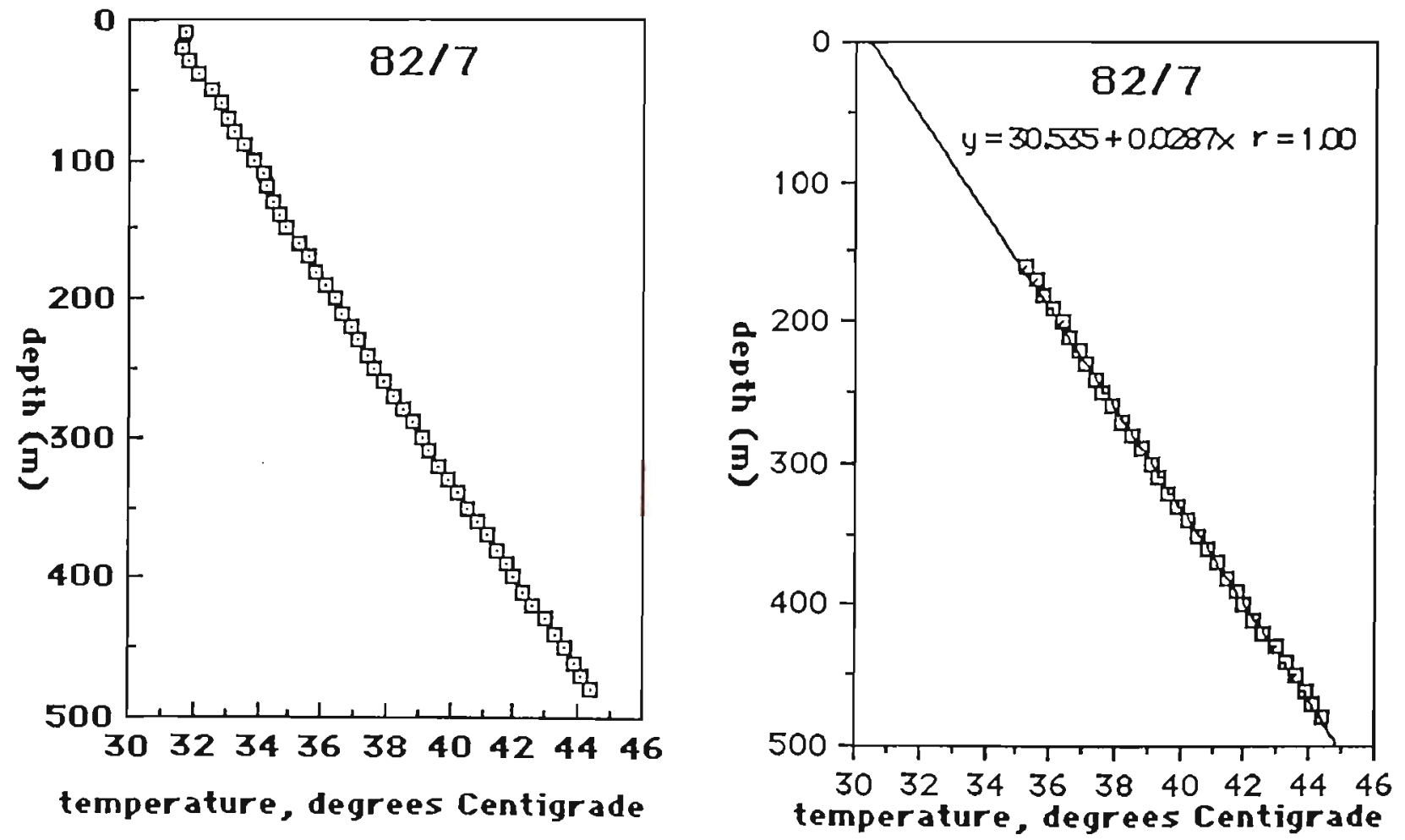

Figure 9-2. Temperature versus depth for DDH $82 / 7$ showing all data (a) and data from about $150 \mathrm{~m}$ depth downwards (b) where temperatures are unaffected by near-surface perturbations. 
comment that the cooling curve may have been influenced by several relatively short-term low-magnitude events such as the intrusion of dolerite dykes but they consider it "intuitively unreasonable that such small additions of magma could raise the temperature of the host rocks anything but locally and for a relatively short time".

\subsection{Present geothermal gradients}

Temperatures of the two measured Amoco stratigraphic drill holes show a regular increase in temperatures with depth from about 150 meters (Figures 9-1,2). The geothermal gradient at $\mathrm{DDH} 82 / 5$ is $33.1 \mathrm{C} / \mathrm{km}$ (zero intercept of $28.8^{\circ} \mathrm{C}$ ) and 28.7 $\mathrm{C}^{\circ} / \mathrm{km}$ at $82 / 7$ (zero intercept of $30.5^{\circ} \mathrm{C}$ ), which are both slightly above the average geothermal gradient in the upper crust of 25 Co/km (Melton and Giardini, 1984).

Temperature perturbations near the surface are probably due to ground-water movement and heating of the rock by insolation and were deleted when determining the geothermal gradients. The ambient air temperature at $\mathrm{DDH} 82 / 5$ was $31.1^{\circ} \mathrm{C}$ and $32.2^{\circ} \mathrm{C}$ at $\mathrm{DDH} 82 / 7$.

\subsection{Geological models}

\subsubsection{Glyde River Subbasin}

A number of geological models can be developed for the geological history of the Glyde River Subbasin. Information regarding possible thicknesses that may have developed over the Barney Creek Formation (Table 9-1) has been derived from regional studies of the southern McArthur Basin. 
Maximum and minimum thicknesses for the McArthur and Nathan Groups in the southern McArthur Basin (Jackson et al., 1987a) were used together with an extrapolated thickness of the Roper Group over the Glyde River subbasin of $600 \mathrm{~m}$ (Jackson et al., 1987b). Maximum thicknesses of nearby Cambrian Georgina Basin sediments (Bukalara Sandstone and Top Springs Limestone) and Cretaceous sediments (Mullaman Beds) were obtained from Plumb and Rhodes (1964). Based on field evidence, the amount of erosion that occurred after deposition of the Nathan Group and prior to the deposition of the Roper Group in the southern McArthur Basin, varies between 240 and 1805 m (Jackson et al., 1987a). No information regarding the amount of erosion that occurred between the Umbalooga and Batten Subgroups and the McArthur and Nathan Groups is available. Rates of sedimentation and erosion can only be guessed at.

Given the paucity of data, only very generalised models are attempted. The first set of models ( $1 \mathrm{a}$ to $8 \mathrm{a}$ ) is for the top of the Barney Creek Formation in the subbasin whereas the second set ( $1 b$ to $8 b)$ is for near the bottom of the formation in DDH GR7. The Barney Creek Formation attains a maximum thickness in the Glyde River Subbasin in this well and organic matter at that depth has not been affected by hydrothermal metamorphism. The range of lamalginite reflectances for drill core within the top 50 meters in the Glyde River Subbasin is $0.05-0.16 \%$ giving an equivalent vitrinite reflectance range of about $0.5-0.7 \%$. Patchy dispersed bitumen reflectances for DDH GR7 at a depth of $854 \mathrm{~m}$, near the base of the Barney Creek Formation $(820 \mathrm{~m}$ below the Bukalara Sandstone unconformity), have a mean value of $1.0 \%$ and the same equivalent vitrinite reflectance. 
The major variables in modelling the Glyde River Subbasin are the thickness of the McArthur and Nathan Groups that may have overlain the Barney Creek Formation, their depositional time (Table 9-2) and the amount eroded prior to deposition of the Roper Group.

\begin{tabular}{|c|c|c|}
\hline age/unit & thicknesses (m) & radiometric age (Ma) \\
\hline 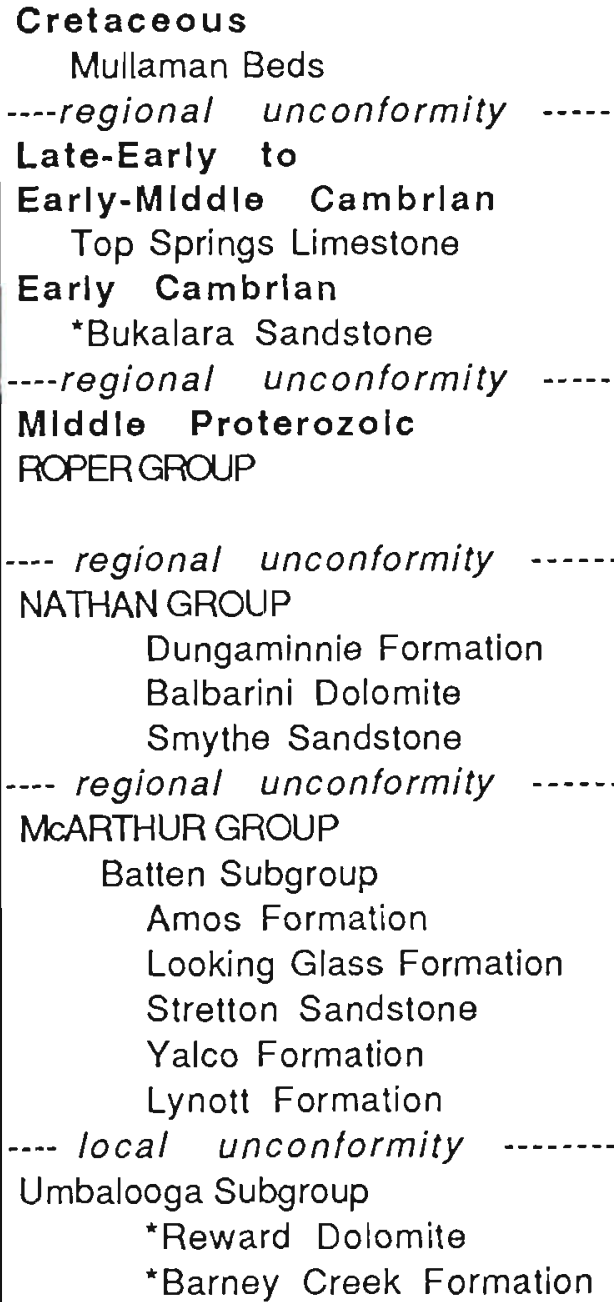 & $\begin{array}{c}240+ \\
1500 \\
0-65 \\
\\
50-80 \\
65+ \\
30-270 \\
\text { up to } 250 \\
50-600 \\
\\
10-350\end{array}$ & $\begin{array}{c}1429 \pm 31 \\
\text { (McMinn Formation) }\end{array}$ \\
\hline
\end{tabular}

Table 9-1. Thicknesses and ages of sedimentary units that probably overlaid the Barney Creek Formation in the Glyde River Subbasin. * = formations present in the subbasin.

Time-temperature indexes (TTI) were calculated arithmetically from these models and converted to equivalent vitrinite reflectances using Waples (1981) data, assuming that the present day geothermal gradient of about $30 . \mathrm{C} / \mathrm{km}$. has 
remained constant. A zero intercept of $20^{\circ} \mathrm{C}$ is also assumed, a figure lower than the present zero intercept of $30^{\circ} \mathrm{C}$, but is probably a reasonable average figure given the wide range of climatic conditions experienced by the McArthur Basin during the Proterozoic, ranging from arctic to tropical (Idnurm and Giddings, 1988). A constant geothermal gradient of $30 \mathrm{C} / \mathrm{km}$ with a zero intercept of $20^{\circ} \mathrm{C}$ was also used in calculating the maximum temperatures reached and converting them into vitrinite reflectances according to Price (1983). Reflectance values derived from both methods for all the models are shown in Tables 9-3 and 9-4 and the complete calculations are given in Appendix M.

\begin{tabular}{|l|c|c|}
\hline \multicolumn{1}{|c|}{ Unit } & $\begin{array}{c}\text { thickness(es) } \\
(\mathrm{m})\end{array}$ & $\begin{array}{c}\text { Time interval } \\
\text { (Ma.) }\end{array}$ \\
\hline McArthur and Nathan & $2,000-3420$ & $\begin{array}{c}1690-1670 \\
1690-1459\end{array}$ \\
Groups (above Barney & & \\
Creek Fm.) & 600 & $1449-1429$ \\
\hline Roper Group & 300 & $570-560$ \\
\hline Bukalara Sst. & 100 & $510-500$ \\
Top Springs Lst. & 200 & $100-90$ \\
\hline Mullaman Beds & & \\
\hline
\end{tabular}

Table 9-2. Thicknesses and depositional times used in models for the Glyde River subbasin.

The results of the Lopatin-Waples modelling show major differences associated with the varying assumptions. The results, using Price's method, have a small range showing that this method 


\begin{tabular}{|c|c|c|c|}
\hline Depositional-erosional models & $\begin{array}{l}\text { metho } \\
\text { Lopatin's, } \\
\text { Rv\% }\end{array}$ & $\begin{array}{l}\text { sed } \\
\text { Price's, } \\
\text { Rv\% }\end{array}$ & $\begin{array}{c}\text { Observed } \\
\text { equivalent } \\
\text { Rv\% }\end{array}$ \\
\hline $\begin{array}{l}\text { 1a. Maximum deposition of } 3420 \mathrm{~m} \text { of McArthur } \\
\text { and Nathan Groups above Barney Creek Fm. } \\
\text { from } 1690 \text { to } 1670 \mathrm{Ma} \text { followed by erosion of } \\
1805 \mathrm{~m} \text { to top of Amos Fm. from } 1670 \text { to } \\
1449 \mathrm{Ma} \text {. Deposition of } 600 \mathrm{~m} \text { of Roper Group } \\
\text { from } 1449 \text { to } 1429 \mathrm{Ma} \text { followed by erosion to } \\
\text { top of Barney Creek Fm from } 1429 \text { to } 570 \mathrm{Ma} \text {. } \\
\text { Deposition and erosion of Cambrian and } \\
\text { Cretaceous units. } \\
\text { 1b. As for above but including } 820 \mathrm{~m} \text { of Barney Creek } \\
\text { Creek Fm. deposited from } 1692 \text { to } 1690 \mathrm{Ma} \text {. }\end{array}$ & $\begin{array}{l}1.5 \\
2.2\end{array}$ & $\begin{array}{l}0.6 \\
0.7\end{array}$ & $\begin{array}{c}0.5-0.7 \\
1.0\end{array}$ \\
\hline $\begin{array}{l}\text { 2a. Maximum deposition of } 3420 \mathrm{~m} \text { of McArthur } \\
\text { and Nathan Groups above Barney Creek Fm. } \\
\text { from } 1690 \text { to } 1670 \mathrm{Ma} \text { followed by erosion of } \\
240 \mathrm{~m} \text { to top of Balbarini Dol. from } 1670 \text { to } \\
1449 \mathrm{Ma} \text {. Deposition and erosion of Roper Group } \\
\text { and Phanerozoic units as for model } 1 \text {. } \\
\text { 2b. As for above but including } 820 \mathrm{~m} \text { of Barney } \\
\text { Creek Fm. deposited from } 1692 \text { to } 1690 \mathrm{Ma} \text {. }\end{array}$ & $\begin{array}{l}2.2 \\
3.0\end{array}$ & $\begin{array}{l}0.7 \\
0.8\end{array}$ & $\begin{array}{c}0.5-0.7 \\
1.0\end{array}$ \\
\hline $\begin{array}{l}\text { 3a. Maximum deposition of } 3420 \mathrm{~m} \text { of McArthur } \\
\text { and Nathan Groups above Barney Creek Fm. } \\
\text { from } 1690 \text { to } 1459 \mathrm{Ma} \text { followed by erosion of } \\
1805 \mathrm{~m} \text { to top of Amos Fm. from } 1459 \text { to } \\
1449 \mathrm{Ma} \text {. Deposition and erosion of Roper Group } \\
\text { and Phanerozoic units as for model } 1 \text {. } \\
\text { 3b. As for above but including } 820 \mathrm{~m} \text { of Barney } \\
\text { Creek Fm. deposited from } 1692 \text { to } 1690 \mathrm{Ma} \text {. }\end{array}$ & $\begin{array}{l}1.4 \\
2.0\end{array}$ & $\begin{array}{l}0.6 \\
0.7\end{array}$ & $\begin{array}{c}0.5-0.7 \\
1.0\end{array}$ \\
\hline $\begin{array}{l}\text { 4a. Maximum deposition of } 3420 \mathrm{~m} \text { of McArthur } \\
\text { and Nathan Groups above Barney Creek Fm. } \\
\text { from } 1690 \text { to } 1459 \mathrm{Ma} \text { followed by erosion of } \\
240 \mathrm{~m} \text { to top of Balbarini Dol. from } 1459 \text { to } \\
1449 \mathrm{Ma} \text {. Deposition and erosion of Roper Group } \\
\text { and Phanerozoic units as for model } 1 . \\
\text { 4b. As for above but including } 820 \mathrm{~m} \text { of Barney } \\
\text { Creek Fm. }\end{array}$ & $\begin{array}{l}2.0 \\
2.6\end{array}$ & $\begin{array}{l}0.7 \\
0.8\end{array}$ & $\begin{array}{c}0.5 \cdot 0.7 \\
1.0\end{array}$ \\
\hline
\end{tabular}

Table 9-3. Depositional-erosional models for the Glyde River Subbasin, assuming maximum thicknesses of the McArthur and Nathan Groups above the Barney Creek Formation in the Glyde River subbasin, together with calculated vitrinite reflectance percentages (Rv\%) derived from Lopatin-Waples' and Price's (1983) methods assuming a constant geothermal gradient of $30 \mathrm{C} / \mathrm{km}$ with a zero intercept of $20^{\circ} \mathrm{C}$; and the observed equivalent vitrinite reflectances. Tables showing complete calculations are given in Appendix M. 


\begin{tabular}{|c|c|c|c|}
\hline Depositional-erosional models & $\begin{array}{l}\text { metho } \\
\text { Lopatin's, } \\
\text { Rv\% }\end{array}$ & $\begin{array}{l}\text { used } \\
\text { Price's, } \\
\text { Rv\% }\end{array}$ & $\begin{array}{l}\text { Observed } \\
\text { equivalent } \\
\text { Rv\% }\end{array}$ \\
\hline $\begin{array}{l}\text { 5a. Minimum deposition of } 2000 \mathrm{~m} \text { of McArthur } \\
\text { and Nathan Groups above Barney Creek Fm. } \\
\text { from } 1690 \text { to } 1670 \mathrm{Ma} \text { followed by erosion of } \\
1805 \mathrm{~m} \text { to top of Amos Fm. from } 1670 \text { to } \\
1449 \mathrm{Ma} \text {. Deposition and erosion of Roper Group } \\
\text { and Phanerozoic units as for model } 1 . \\
\text { 5b. As for above but including } 820 \mathrm{~m} \text { of Barney } \\
\text { Creek Fm. deposited from } 1692 \text { to } 1690 \mathrm{Ma} \text {. }\end{array}$ & $\begin{array}{l}0.7 \\
1.2\end{array}$ & $\begin{array}{l}0.4 \\
0.5\end{array}$ & $\begin{array}{c}0.5-0.7 \\
1.0\end{array}$ \\
\hline $\begin{array}{l}\text { 6a. Minimum deposition of } 2000 \mathrm{~m} \text { of McArthur } \\
\text { and Nathan Groups above Barney Creek Fm. } \\
\text { from } 1690 \text { to } 1670 \mathrm{Ma} \text { followed by erosion of } \\
240 \mathrm{~m} \text { to top of Balbarini Dol. from } 1670 \text { to } \\
1449 \mathrm{Ma} \text {. Deposition and erosion of Roper Group } \\
\text { and Phanerozoic units as for model } 1 . \\
\text { 6b. As for above but including } 820 \mathrm{~m} \text { of Barney } \\
\text { Creek Fm. deposited from } 1692 \text { to } 1690 \mathrm{Ma} \text {. }\end{array}$ & $\begin{array}{l}1.1 \\
1.8\end{array}$ & $\begin{array}{l}0.5 \\
0.6\end{array}$ & $\begin{array}{c}0.5-0.7 \\
1.0\end{array}$ \\
\hline $\begin{array}{l}\text { 7a. Minimum deposition of } 2000 \mathrm{~m} \text { of McArthur } \\
\text { and Nathan Groups above Barney Creek Fm. } \\
\text { from } 1690 \text { to } 1459 \mathrm{Ma} \text { followed by erosion of } \\
1805 \mathrm{~m} \text { to top of Amos Fm. from } 1459 \text { to } \\
1449 \mathrm{Ma} \text {. Deposition and erosion of Roper Group } \\
\text { and Phanerozoic units as for model } 1 . \\
\text { 7b. As for above but including } 820 \mathrm{~m} \text { of Barney } \\
\text { Creek Fm. deposited from } 1692 \text { to } 1690 \mathrm{Ma} \text {. }\end{array}$ & $\begin{array}{l}0.7 \\
1.2\end{array}$ & $\begin{array}{l}0.4 \\
0.5\end{array}$ & $\begin{array}{c}0.5-0.7 \\
1.0\end{array}$ \\
\hline $\begin{array}{l}\text { 8a. Minimum deposition of } 2000 \mathrm{~m} \text { of McArthur } \\
\text { and Nathan Groups above Barney Creek Fm. } \\
\text { from } 1690 \text { to } 1459 \mathrm{Ma} \text { followed by erosion of } \\
240 \mathrm{~m} \text { to top of Balbarini Dol. from } 1459 \text { to } \\
1449 \mathrm{Ma} \text {. Deposition and erosion of Roper Group } \\
\text { and Phanerozoic units as for model } 1 . \\
8 \mathrm{~b} \text {. As for above but including } 820 \mathrm{~m} \text { of Barney } \\
\text { Creek Fm. deposited from } 1692 \text { to } 1690 \mathrm{Ma} \text {. }\end{array}$ & $\begin{array}{l}1.0 \\
1.7\end{array}$ & $\begin{array}{l}0.5 \\
0.6\end{array}$ & $\begin{array}{c}0.5-0.7 \\
1.0\end{array}$ \\
\hline
\end{tabular}

Table 9-4. Depositional-erosional models for the Glyde River Subbasin, assuming minimum thicknesses of the McArthur and Nathan Groups above the Barney Creek Formation in the Glyde River Subbasin, logether with calculated vitrinite reflectance percentages (Rv\%) derived from Lopatin-Waples' and Price's (1983) methods assuming a constant geothermal gradient of $30 \mathrm{C} / \mathrm{km}$ with a zero intercept of $20^{\circ} \mathrm{C}$; and the observed equivalent vitrinite reflectances. Tables showing complete calculations are given in Appendix $M$. 
time (Ma) Bukalara Sst. and Top Springs Lmst.

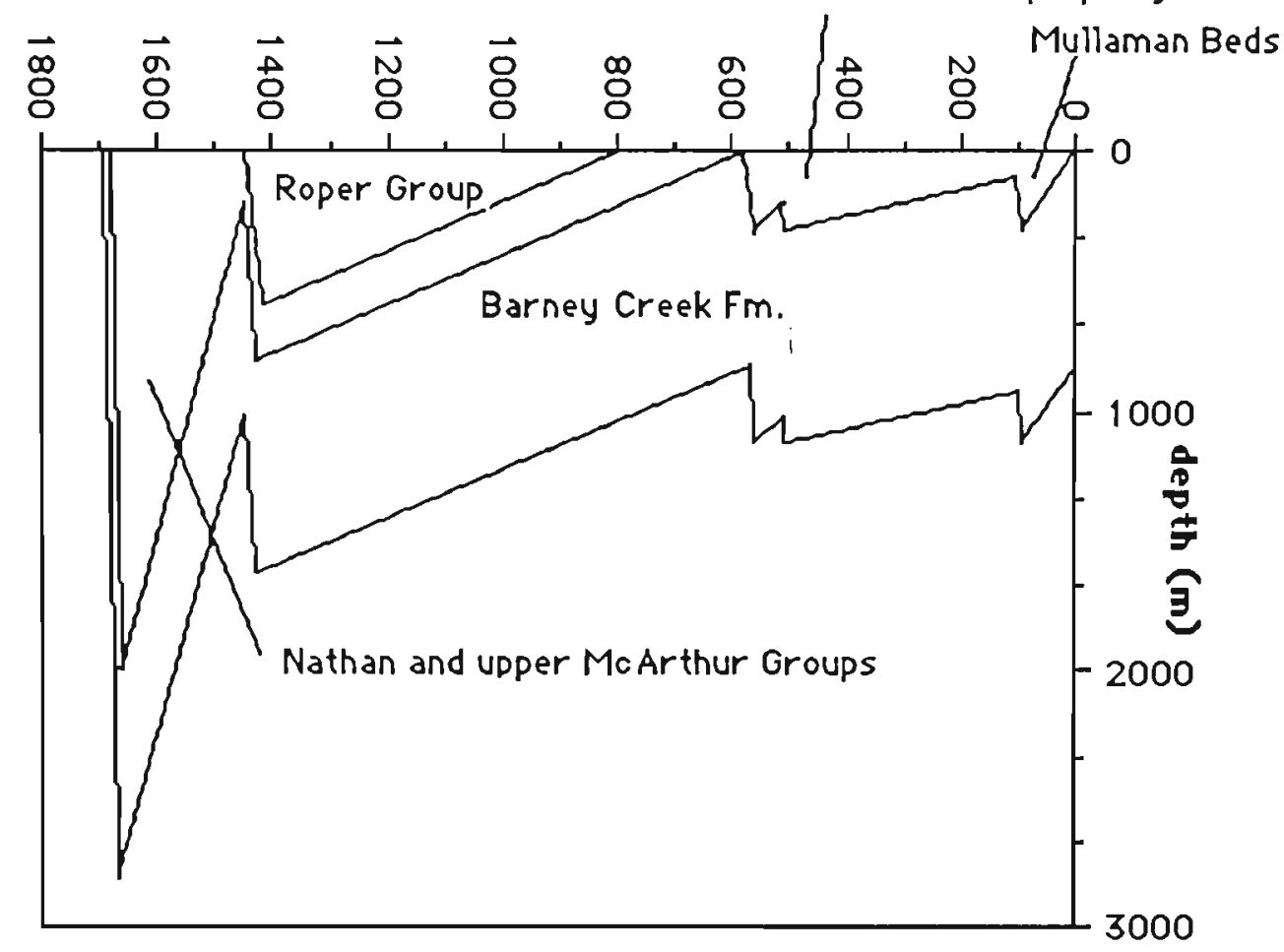

Figure 9-3. Burial history for the Barney Creek Formation, DDH GR7, Glyde River Subbasin, from the depositonal-erosional model 5 (Table 9-4)

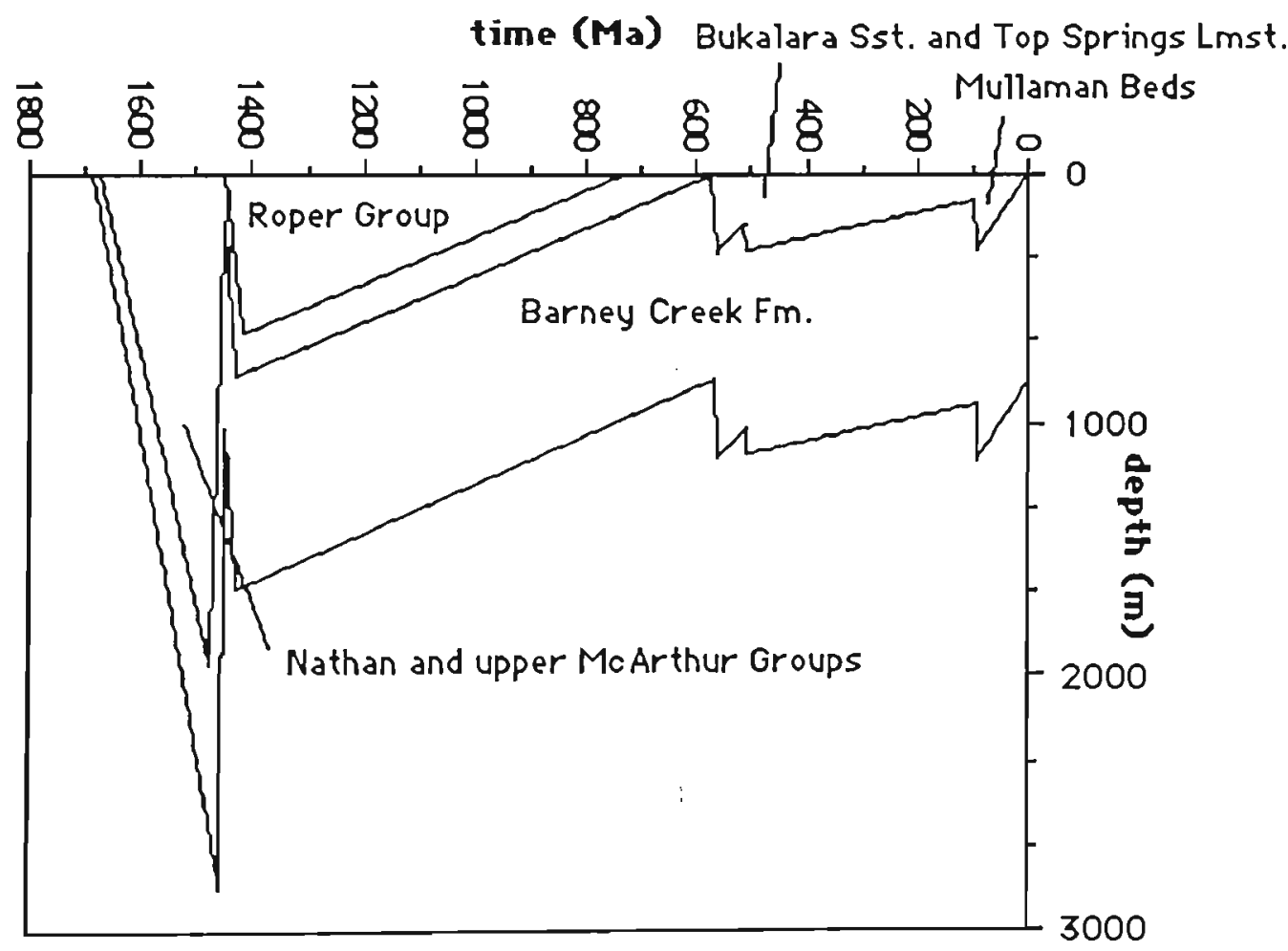

Figure 9-4. Burial history for the Barney Creek Formation, DDH GR7, Glyde River Subbasin, from the depositonal-erosional model 7 (Table 9-4). 
is insensitive to major changes of assumptions about stratigraphic thickness.

None of the models gives a perfect fit when vitrinite reflectances derived from using either the Lopatin-Waples or Prices methods are compared to the observed equivalent vitrinite refectances. Models which best fit using the Lopatin-Waples method, are those which have a minimum thickness of $2000 \mathrm{~m}$ for the McArthur and Nathan Group sediments overlying the Barney Creek Formation combined with maximum erosion of $1805 \mathrm{~m}$ prior to deposition of the Roper Group (Table 9-4, models 5 and 7; Figures 9-3 and 9-4). A better fit could be achieved if it is assumed that the minimum thickness of the overlying McArthur and Nathan Group sediments was several hundred meters less than given and that most of it was eroded away prior to deposition of the Roper Group sediments.

Almost all vitrinite reflectances derived by using Price's method, with the exception of models 5 and 7 , fit the observed values for the top of the Barney Creek Formation but are all lower than observed for the base of the formation.

\subsubsection{Central and Northern Batten Trough}

Maturation levels for the Barney Creek Formation are mostly higher than in the Glyde River Subbasin (Chapter 8). Hydrothermal metamorphism, higher geothermal gradients and greater depths of burial are the most probable causes.

\subsubsection{Roper Group}

For modelling the maturation levels of the Roper Group, Amoco's well, Broadmere 1, is used as it is the deepest well in the McArthur Basin, reaching a total depth of $2.174 \mathrm{~m}$ (Figure 9-4). It 
passes through most of the lower Roper Group and through $452 \mathrm{~m}$ of the Cobanbarini Formation at the base of the upper Roper Group, the Maiwok Subgroup. Unfortunately, the well-completion reports do not contain sufficient information in order to determine the geothermal gradient at Broadmere 1 , so the average geothermal gradient of $30 \mathrm{C} / \mathrm{km}$ with a zero intercept of $20^{\circ} \mathrm{C}$ is used in this modelling.

The Maiwok Subgroup reaches a maximum observed thickness of about $2000 \mathrm{~m}$ (Jackson et al., 1987b) and this figure is used together with the maximum observed thicknesses of Cambrian units (Bukalara Sandstone, $300 \mathrm{~m}$; Top Springs Limestone, $100 \mathrm{~m}$ ) and the Cretaceous Mullaman Beds (200 m) (Smith, 1964)

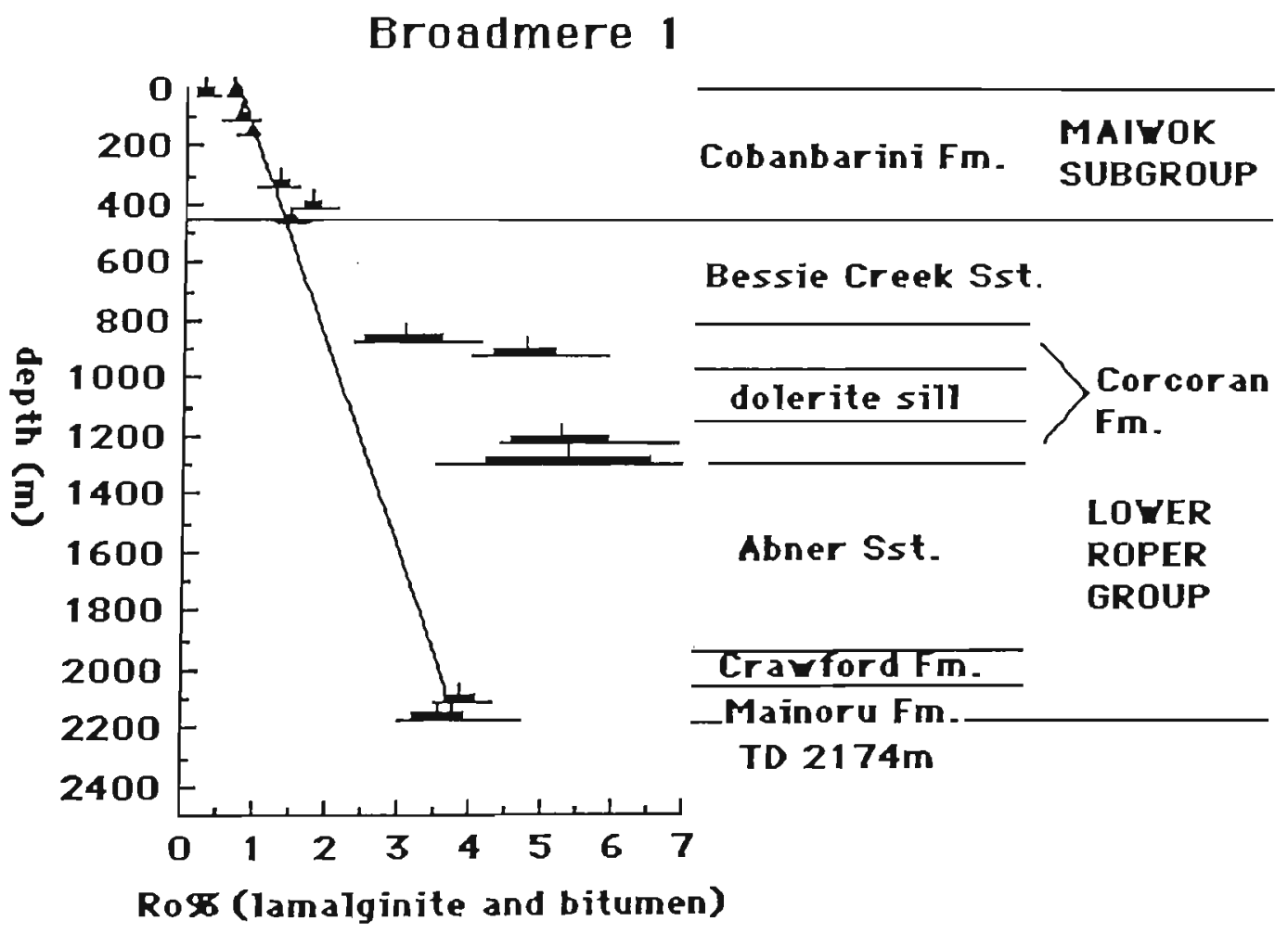

Figure 9-4. Depth versus reflectance (Ro\%) for lamalginite and/or bitumen and stratigraphy of Broadmere 1. The trend line indicates the change in reflectances with depth assuming the absence of contact metamorphism from intrusion of a dolerite sill at about $1000 \mathrm{~m}$. 
for Broadmere 1. The top of Broadmere 1 is stratigraphically about $30 \mathrm{~m}$ below the nearest Cretaceous unconformity surface, $15 \mathrm{~km}$ to the south-east of the well. Dolerite sills were formed within the Roper Group at about 1280 Ma (McDougall et al., 1965) and have an aggregate thickness of about $300 \mathrm{~m}$ (Dunn, 1963). A dolerite sill, $174 \mathrm{~m}$ thick, occurs in Broadmere 1 within the lower Roper Group (Amoco Australia Petroleum Company, Well Completion Report, 1985).

As in the case of the Glyde River Subbasin, many variables are unknown. For example, total thicknesses of the sediments that overlie this well, rates of sedimentation and erosion, past geothermal gradients, and the age of start of deposition of the Roper Group are all poorly known. Cessation of deposition of the Roper Group occurred at $1429 \pm 31 \mathrm{Ma}$ (Kralik, 1982) although Page et al. (1984) regard this as a minimum age. For the purposes of this exercise the $1429 \mathrm{Ma}$ age is used as the end of deposition of the Roper Group. Two times are used for the start of deposition at the base of Broadmere 1, one at $1529 \mathrm{Ma}$ and the other at $1449 \mathrm{Ma}$, to gauge the affect depositional time has upon the Lopatin-Waples modelling. In the absence of any contrary data it is assumed, for the sake of simplicity, that rates of sedimentation and erosion are uniform.

The time taken for deposition of the Roper Group, be it 100 million years (Table 9-5, model 1) or 20 million years (Table 9-5, model 2) makes little difference to the overall result $(<0.1 \%)$ using the Lopatin-Waples approach. Both results $(R v \%=2.4)$, however, are significantly lower than the observed reflectance of $3.5 \%$ (for nonfluorescent lamalginite and bitumen) for the base of 


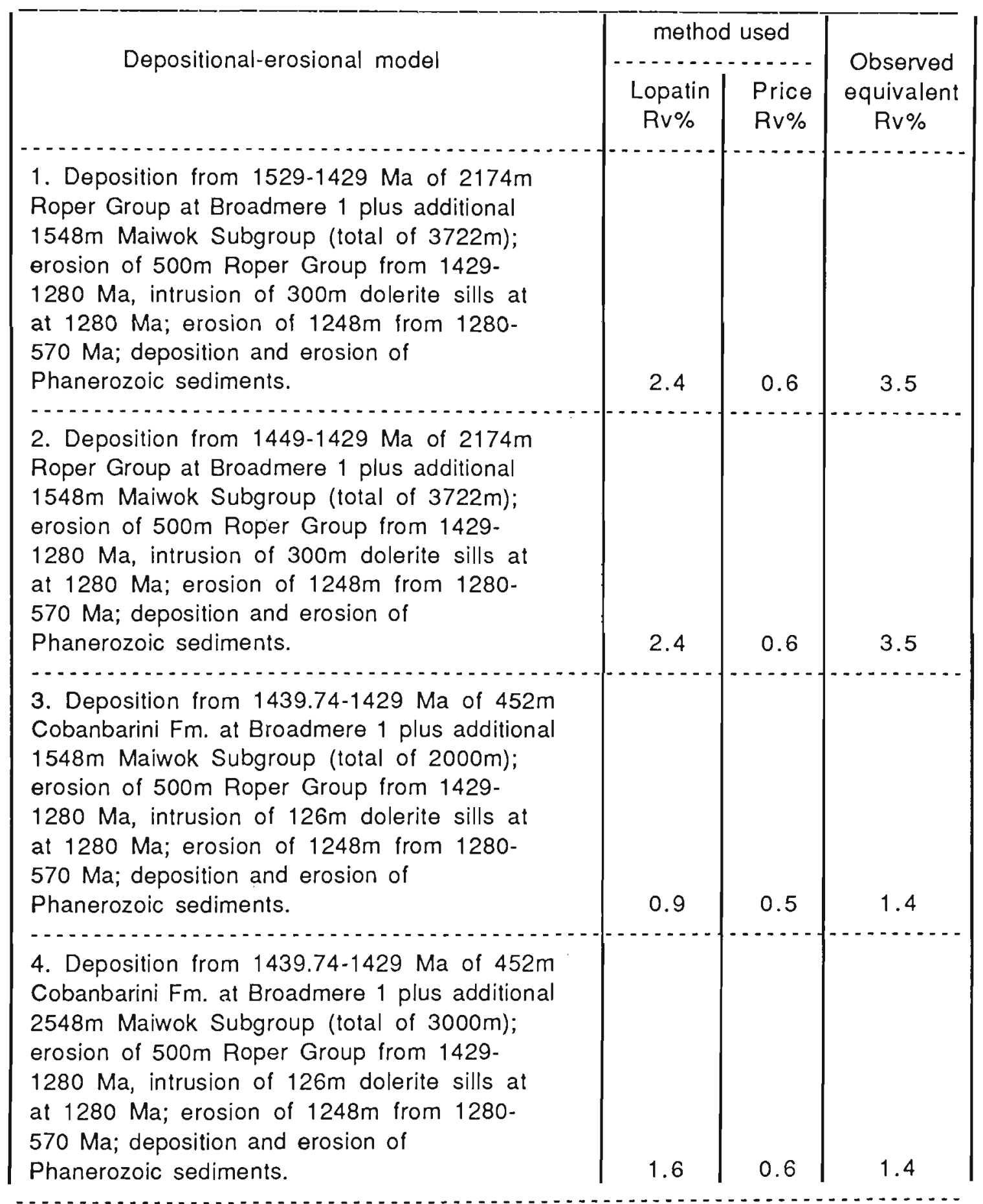

Table 9-5. Depositional-erosional models at Broadmere 1, Roper Group, logether with calculated vitrinite reflectance percentages (Rv\%) derived from Lopatin-Waples' and Price's (1983) methods assuming a constant geothermal gradient of $30 \mathrm{C} / \mathrm{km}$ with a zero intercept of $20^{\circ} \mathrm{C}$, and the observed equivalent vitrinite reflectances. Complete calculations are given in Appendix M. 
the well. Varying the time of deposition of the Roper Group obviously makes no difference to reflectances using Price's method which are considerably lower than the observed reflectance. Reflectance values for the base of the Cobanbarini Formation at Broadmere 1 are also too low, regardless of method (Table 9-5, model 3).

A number of reasons can be given to explain the lower than observed reflectances including:

1) the sedimentary thickness of the Maiwok Subgroup of the Roper Group may have been considerably thicker than observed today and included sediments which have been totally eroded away;

2) the aggregate thickness of dolerite sills at Broadmere 1 may have been greater;

3) sedimentary thicknesses of the Phanerozoic units may have been considerably greater, or

4) geothermal gradients may have been higher than the present.

It would seem impossible to determine which of these factors or which combination of them is the most likely cause. However, the evidence of Koul et al. (1986) does suggest that past geothermal gradients were much the same as today. It is probable that sedimentary thicknesses of the Cambrian units never greatly exceeded those used in this model as it is likely that this region was a topographic high at the time of deposition of the Georgina Basin (Shergold and Druce, 1980) and remained so for all of the Phanerozoic. The major factors remaining, which could be reasonably varied, are the maximum thickness of the Maiwok Subgroup and the aggregate thickness of dolerite sills in the Maiwok Subgroup. The top of the Maiwok Subgroup is not preserved (Jackson et al, 1987b) and its original thickness could therefore 
have been greater than $2000 \mathrm{~m}$. It would seem unlikely that significantly thick dolerite sills intruded the sedimentary pile near the top of the Maiwok Subgroup; most were probably emplaced at lower levels. Increasing the thickness of the Maiwok Subgroup by $1000 \mathrm{~m}$, assuming that the aggregate thickness of dolerite sills in the Subgroup remained at $300 \mathrm{~m}$, would give greater agreement, using the Lopatin-Waples method (Table 9-5, model 4, Fig. 9-5). Using Price's method, however, the calculated value of $0.6 \% \mathrm{Rv}$ versus an observed Ro\% of 1.4 for the base of the Maiwok Subgroup, is clearly still too low.

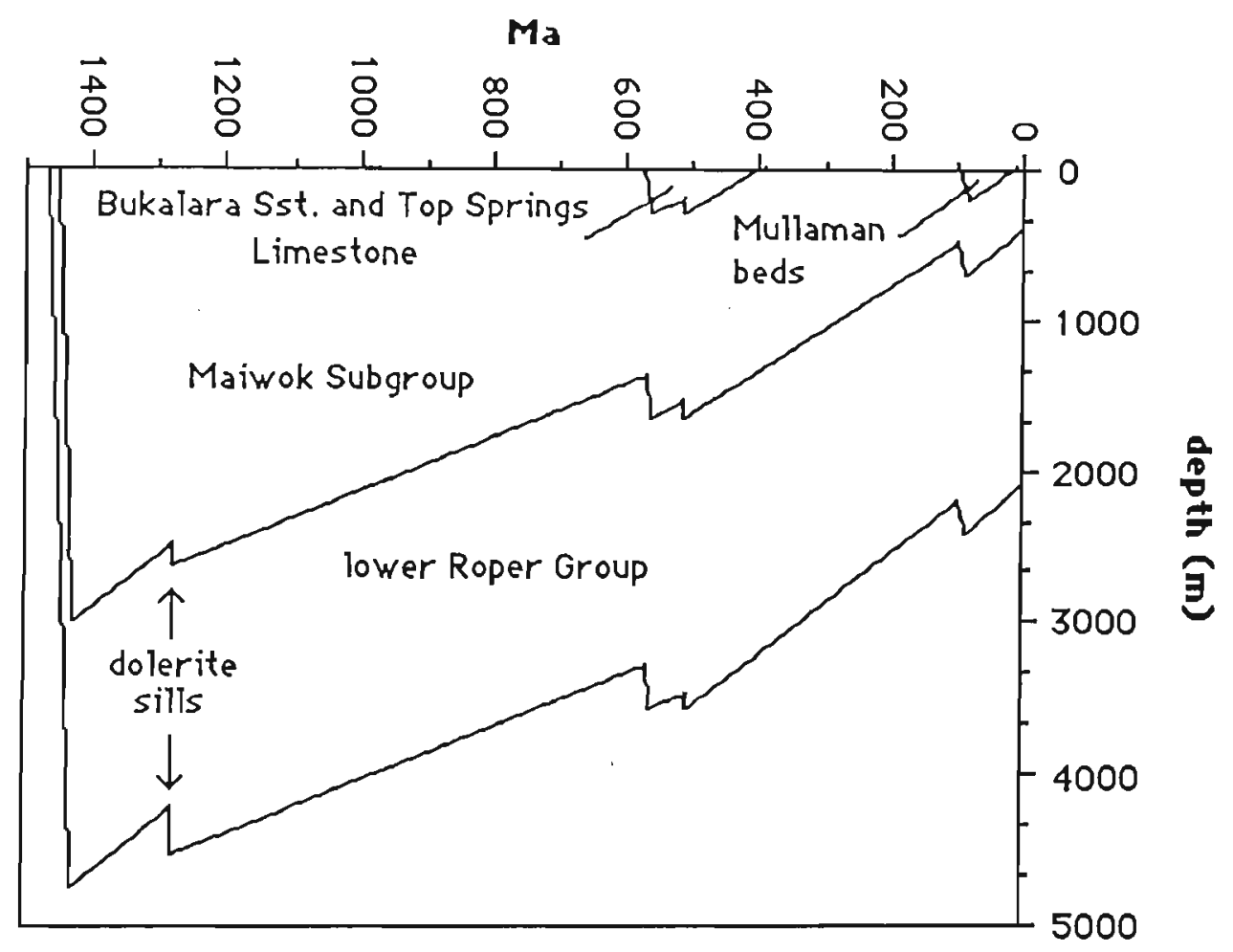

Figure 9-5. Burial history for Broadmere 1 well, assuming that $3000 \mathrm{~m}$ of Maiwok Subgroup sediments were deposited (model 4, Table 9-5).

Unless geothermal gradients were higher than observed today, and there is some evidence to suggest they were not (Koul et al., 1986) then Price's method for calculating rellectances is invalid, and time has been an important element in the 
maturation of organic matter in the Roper Group. It seems likely, given the results of this modelling using the Lopatin-Waples method, that the Maiwok Subgroup was significantly thicker than observed today.

\subsection{Timing of the generation of oil}

Oil generation in Phanerozoic sediments commences, according to the Lopatin-Waples model (Waples, 1980), at a TTI of $15(\mathrm{Rv} \%=0.65)$, reaches peak oil generation at a $\mathrm{TTI}$ of 75 $(R v \%=1.00)$ and ceases at a TTI of $160(R v \%=1.30 \%)$. For the McArthur Basin, oil generation commences at about a reflectance of $0.15 \%$ for fluorescent lamalginite which is equivalent to a vitrinite reflectance of between 0.55 to $0.65 \%$ and ceases at about $1.4 \%$ (Chapter 7 ). Oil generation probably reaches a peak between about 0.3 to $0.4 \%$ reflectance for fluorescent lamalginite which is equivalent to a vitrinite reflectance of between 0.7 to $0.9 \%$. In terms of $T_{T T}$ values, oil generation starts at between 8 and 15, reaches a peak between about 34 and 50 and ceases at a value of 217 . These values are therefore used in calculating the timing of oil generation.

Oil generation characteristics will vary due to differences in the original organic matter composition within a formation or between formations but such variations are probably within the ranges of the above TTI values. In addition, the unavoidably imprecise geological models used here to determine the timing of oil generation in the McArthur Basin means that such variations are probably insignificant.

Oil generation near the base of the Barney Creek Formation in the Glyde River Subbasin, commenced and reached a peak prior to 
deposition of the Roper Group according to the best-fit models (models 5 and 7, Table 9-4). As the calculated $R v \%$ value is slightly higher than the observed value (1.2 versus 1.0$)$ then peak oil-production may have occurred soon after deposition of the Roper Group. The onset and peak oil production for the base of the Maiwok Subgroup (base of the Velkerri Formation and its equivalent, the "Lansen Creek Shale") occurred within one hundred million years after deposition of the Roper Group for the model which assumes that the Maiwok Subgroup was $1000 \mathrm{~m}$ thicker than observed today (model 4, Table 9-5). Oil generation probably also occurred, in places, adjacent to dolerite sills during and, for a limited time, after their intrusion.

Tissot and Welte (1984) comment that at peak oil generation the reaction rates do not double every $10^{\circ} \mathrm{C}$, as assumed by the Lopatin-Waples method, but are multiplied by about 5 , whereas the activation energies required to break chemical bonds within the organic matter are relatively weak at the onset of oil and gas generation and at this stage the reaction rates double for every $10^{\circ} \mathrm{C}$ rise. Therefore peak oil generation probably commenced at an earlier time than that given using the Lopatin-Waples method.

Onset and peak oil generation for organic matter above the base of both formations obviously occurred at some later time than at their base. Organic matter in the uppermost part of the Barney Creek Formation in the Glyde River Subbasin has yet to reach the peak oil generation stage.

The Barney Creek Formation in the Glyde River Subbasin and the Velkerri Formation (except where affected by contact metamorphism) are still within the oil-window and are potentially capable of producing more oil given the right 
geological conditions. At some stage in the past, oil generation ceased in these formations as temperatures fell below a certain level. This level cannot be calculated from activation energies derived from high-temperature pyrolysis experiments and extrapolated to low-temperature geological systems via the Arrhenius equation as such calculations will result in a too high a temperature (Snowdon, 1979). Quantum mechanical tunnelling may be a significant factor at low-temperatures and the probability of tunnelling increases with a decrease in temperature and will result in the production of hydrocarbons at temperatures lower than those calculated from pyrolysis experiments (Snowdon, 1979). Gretener and Curtis (1982), using a modified Lopatin approach, consider that hydrocarbon generation in Phanerozoic sediments is almost at a standstill at temperatures below 50 to $70^{\circ} \mathrm{C}$. The Barney Creek and Velkerri Formations are considerably older than Phanerozoic source rocks and hydrocarbons may have been generated, albeit at very slow rates, at low temperatures over a considerable period of time (Figure 9-6). However, preliminary data from fission track analyses of apatite suggest that the Roper Group sediments emerged from the oil window during the middle Palaeozoic (A. Gleadow, personal communication). There is a possibility, though, that bush fires have affected the results as the samples came from outcrop. Additional samples from drill core are currently being analysed. 


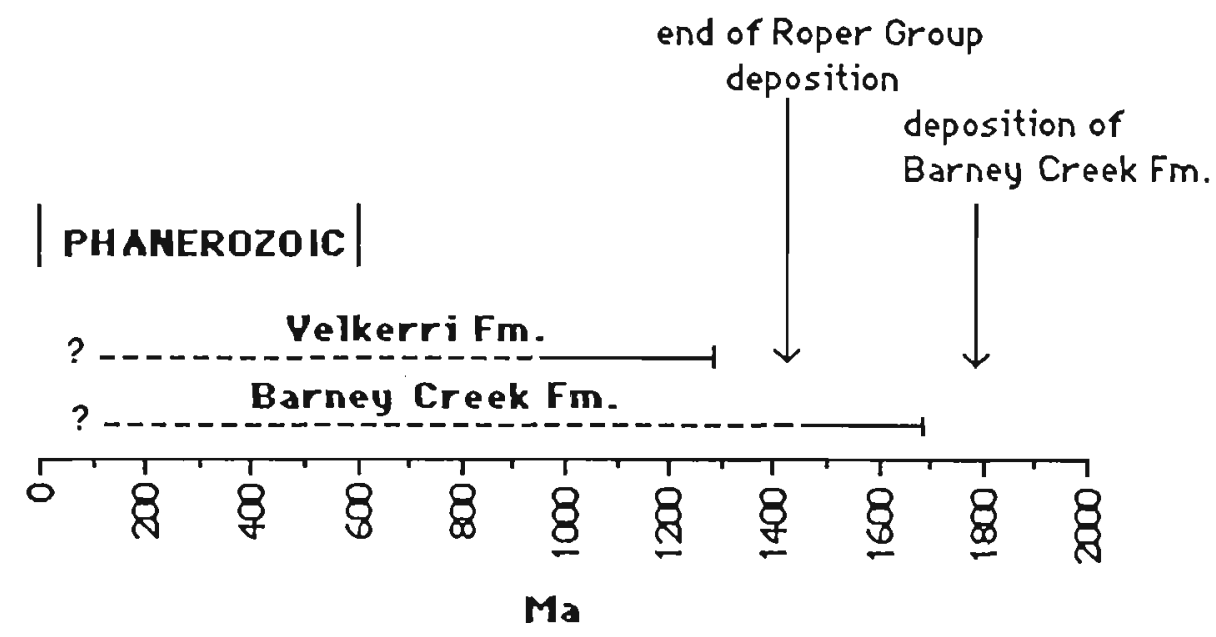

Figure 9-6. Diagram showing main oil generation periods (solid line) and possible lowtemperature (less than $70^{\circ} \mathrm{C}$ ) oil generation periods (dashed line) for the base of the Velkerri Formation, and the base of the Barney Creek Formation at DDH GR7 in the Glyde River Subbasin. 


\section{CHAPTER 10}

\section{ORIGIN OF THE ORGANIC MATTER}

\subsection{Introduction}

There is now well-documented evidence of organisms having existed on Earth since the Archaean which through most of the Proterozoic, were microscopic unicellular, colonial, or filamentous species existing as pelagic or benthic forms in the hydrosphere (Schopf, 1983). It was not until very late in the Precambrian that there is clear evidence for the existence of multicellular organisms (Glaessner and Wade, 1966). Palaeontological studies on the McArthur Basin have greatly contributed to this body of knowledge.

Since the first unpublished report of microfossils in the McArthur Basin in the McMinn Formation of the Roper Group by Norvick (1970), subsequent micropalaeontological studies have revealed an extensive microbiota preserved in a number of lithologies and formations (Croxford et al., 1973; Muir, 1974, 1976, 1982, 1983b; Hamilton and Muir, 1974; J. H. Oehler et al., 1976; J. H. Oehler, 1977; J. H. Oehler and Logan, 1977; D. Z. Oehler, 1978; Peat et al., 1978; Peat, 1979). A variety of singlecell, colonial, multicellular and filamentous micro-organisms have been described from all stratigraphic groups in the McArthur Basin. Stromatolites are present in the Tawallah and Nathan Groups and especially in the McArthur Group (Walter, 1972; Walter et al., 1988) but not in the Roper Group (Jackson et al.,1987a, b). 
A varied microfossil assemblage occurs in the Wollogorang Formation, Tawallah Group, but none appears to be unique to this formation, as they also occur within the younger McArthur Group (Muir 1982).

Croxford et al. (1973), Muir $(1974,1976)$ and Oehler et al., (1976) have all reported the presence of microfossils in the Amelia Dolomite, McArthur Group, which are interpreted by Hofmann and Schopf (1983) as being colonial and unicellullar spheroidal bacteria and/or cyanobacteria or cellular, filamentous bacteria and/or cyanobacteria. Hofman and Schopf (1983) describe additional microfossil taxa which include the genus Tetraphycus originally erected for tetrad clusters in the Balbarini Dolomite, Nathan Group, by Oehler (1978). Eoentophysalis belcherensis is also present in the Amelia Dolomite and as a taxon includes palmelloid and globular colonies of coccoids 2.5 - 9 micron across, with individual and common envelopes.

Hamilton and Muir (1974) examined kerogen extracted from shale associated with the H.Y.C. deposit in the Barney Creek Formation by acid digestion, and observed it commonly contained small cell outlines, averaging 2.6 microns long, some of which having been deformed by subsequent crystallisation of sulphides. J. H. Oehler (1977) examined numerous petrographic thin sections from chert blebs and layers within this shale and described a diverse assemblage of microfossils. Filamentous microfossils less than 1.5 microns thick and up to and exceeding 150 microns long, and encrusted with very fine-grained pyrite are commonly preserved as isolated structures whereas unicellular algal fossils which have cell diameters ranging from 
0.7 to 21.7 microns, are preserved within clumps of amorphous orgaric matter up to several hundred microns in size. Oehler (1977) considers that the unicellular forms probably represent a 'planktonic rain' while the filamentous forms were probably washed into deeper environments from near-shore environments. Muir (1983b) suggests that the abundant small cells described by Hamilton and Muir (1974) were probably the result of algal blooms occurring in small shallow lakes and that the other micro-organisms had perhaps washed in from supralittoral and littoral flats during periods of flooding.

Micro-organisms from the Balbarini Dolomite, Nathan Group, contain a diverse assemblage of organic microfossils in stromatolitic cherts dominated by coccoid forms which have cell diameters ranging from 0.8 to 20.7 microns (D. Z. Oehler, 1978). One of the most abundant organisms in the assemblage is Eoentophysalis belcherensis Hofmann which have cell diameters ranging from 3.0 to 9.7 microns, averaging 4.1 microns. They occur almost exclusively in chert and in cherty patches within dolomite and appear to have formed the basically flat laminae of stomatolites which grew in an arid, intertidal to supratidal environment (D. Z. Oehler, 1978). Preservation of these microfossils within the laminae varies from being wellpreserved to totally degraded with the laminae devoid of internal structure but still retaining the shape of the upper periphery of the Eoentophysalis belcherensis colonies.

The McMinn Formation of the Roper Group, besides containing a similar assemblage of micro-organisms to the older Groups, also contains large acritarchs up to 600 microns in diameter and short fragments of giant filaments up to 120 
microns wide (Peat et al., 1978; Peat, 1979). Comparable fossils are known to occur throughout the whole of the Roper Group (Knoll, Walter and Summons, unpubl. in Summons et al., 1988).

Peat et al. (1978) considered that some of the larger acritarchs in the Roper Group were probably eucaryotes. Eukaryotes also contributed to organic matter in sediments as old as the Barney Creek (1690 Ma) although most of the McArthur Basin organic matter was probably derived from prokaryotes (Summons et al., 1988). The presence of steranes at all stratigraphic levels in extractable hydrocarbons, derived from the same sample set used in this study, is strong evidence for the existence of eukaryotic organisms whereas the high abundances of branched alkanes indicates that most of the organic matter was probably derived from prokaryotes (Summons et al., 1988).

Most of the microfossils described from the Tawallah and McArthur Groups occurred mainly in cherts, and to a lesser extent in stromatolitic carbonates and rarely from carbonaceous clastic sediments. However, in the Roper Group, the microfossil assemblages were found in fine-grained clastic sediments of the McMinn Formation (Peat, 1979).

The Wollogorang Formation in the Tawallah Group shows evidence of both hydrothermal and bacterial sulphate reduction (Donnelly and Jackson, 1988) as does pyrite sulphur associated with mineralisation in the McArthur Group (Smith and Croxford, 1973; Croxford et al., 1978; Williams, 1978a,b; Walker et al., 1983; Muir et al., 1985). Disseminated pyrite sulphur in the Barney Creek Formation from DDH GR10 at $137.3 \mathrm{~m}$ from the Glyde River Subbasin has a $\partial^{34} \mathrm{~S}$ value of $+22.9 \%$ indicating 
that it formed by the action of sulphate-reducers in a restricted sulphate environment (Dr. I. B. Lambert, pers. comm.). Bacterial sulphate reduction also occurred in the Velkerri Formation of the Roper Group (Donnelly and Crick, 1988). Sulphate reducing bacteria therefore played a role in the degradation of the McArthur Basin's organic matter and no doubt form part of the source microbiota.

In Phanerozoic sediments, small, unicellular or thin-walled colonial planktonic or benthonic algae are the source microbiota for lamalginite (Hutton, 1987). Lamalginite in the Eocene oilshale deposits of Queenland contain, in some cases, identifiable (to the genus level) stellate lacustrine colonial algae, Pediastrum; freshwater dinoflagellates, Septodinium; and freshwater acritarchs, Cleistosphaeridium (Hutton, 1982, $1986,1987)$. The presence of these freshwater planktonic algae confirms what has previously been inferred from sedimentological studies that the lamalginites were deposited in a lacustrine environment (Hutton, 1986). The Eocene Green River Formation oil shale in the United States of America, also formed in a lacustrine environment and contains lamalginite (Ingram et al., 1983, Sherwood and Cook, 1984). Bradley (1964) identified Pediastrum in some samples of the Green River Formation oil shale and dinoflagellates (Hutton, 1982) or cyanobacteria (Hutton, 1986) have been suggested as possibly contributing to its original biomass. The retort oils from the Mahogany Zone, Green River Formation (Piceance Creek Basin) and the Kerosene Creek seam, Rundle Formation in Queensland, were both highly aliphatic $(H / C=1.7)$ suggesting $a$ predominantly algal origin (Ingram et al., 1983). Chain length 
distributions of the n-alkanes, 1-alkenes and nitriles indicate that algae were a major contributor but higher plants also contributed in a minor way to the shale-oil kerogens (Ingram et al., 1983).

Lamalginite in Cenozoic oil shales of Thailand originates from planktonic (e.g. Pediastrum) and possibly benthonic algal precursors within lakes having poor circulation and variable water levels so that transitions between swamps and lakes occur through time (Sherwood and Cook, 1984).

Lamalginite in the Cretaceous oil shales of the Toolebuc Formation in Australia is mostly derived from cysts of dinoflagellates and acritarchs with small contributions from indeterminate algal forms deposited under low energy, distal, offshore, marine conditions in an anaerobic environment (Sherwood and Cook, 1984).

\subsection{Microfossils observed in this study}

Only one probable microfossil, a tetrad of cells with a total diameter of 5 microns, was observed in ultra-violet light mode within fluorescing lamalginite of the Barney Creek Formation from the Glyde River Subbasin (Plate 2d). Given the simple structure of the tetrad it is not possible to positively identify it other than to suggest it was probably a small colonial micro-organism. Similarly sized cells, commonly forming tetrads, and composed of calcium phosphate, occur within a small nodule ( $1 \mathrm{~mm}$ in diameter) in another specimen from the Barney Creek Formation in the Glyde River Subbasin (Plate 18a-e). The nodule is one of a number of phosphate bodies which together with abundant lamalginite form a $2 \mathrm{~mm}$ thick 
bed that has been scoured in one place prior to deposition of the overlying sediments (Plate 17). The other phosphatic bodies are thin (less than $0.5 \mathrm{~mm}$ ) elongate forms up to several millimetres long that are made up of hexagonal crystals of phosphate (Plate 18d). It is not certain that the cellullarlooking phosphate grains are fossil micro-organisms as this phosphate is made up of radiating crystals emanating from almost a point source (Plate 18e). The phosphate may have developed around tiny nucleii and the shapes it produced are a preferential form of inorganic growth.

Macerates of fluorescent lamalginite of the Barney Creek Formation from the Glyde River Subbasin are made up of irregularly shaped bodies up to several millimetres in diameter. The macerates commonly display an irregular cellular structure ranging from several to over 20 microns in diameter (Plate 10a-d). Many of the "cells" display straight-edges, commonly hexagonal or rhombic, indicating the former presence of mineral crystals such as carbonates, or have irregular boundaries. The variety of shapes and sizes of these "cells" suggests that they are probably inorganic in their origin having formed during diagenesis by the growth of minerals within the organic matter or by the organic matter being moulded around mineral grains during compaction.

The Barney Creek Formation also contains rare spherical structures lined with pyrite which may be single-cell microfossils (Plate $2 b$ ) or could equally be pyritic-rimmed organic matter of indeterminate origin. In one specimen, pyrite appears to rim fragments of clumps of cells (Plate $2 \mathrm{c}$ ) but again this interpretation is speculative. Roughly rectangularly shaped 
pyrite grains, several microns long by about one micron wide, form two chains up to about 30 microns long, one of which has a small side branch, within a titaniferous bitumen nodule in the Barney Creek Formation (Plate 11a). The size and appearance of them suggests that they could be fossil filamentous bacteria.

Some isolated pieces of nonfluorescent lamalginite in the Roper Group, up to several hundreds of microns long by a few microns thick, are made up of two, commonly parallel, strands of organic matter (Plate 2a) suggesting that they are probably compressed large single cells or acritarchs as described by Peat et al. (1978) and Peat (1979).

Microspheres of calcium phosphate, commonly exhibiting fluorescent rims, occur in some specimens from the Velkerri Formation and the "Lansen Creek Shale" (Plates 26e,f; 34G,H and 42). The microspheres range in size from about 2 to 7 microns in diameter but are generally less than 5 microns in diameter. They are commonly closely associated with, or imbedded in, lamalginite or bitumen. SEM images of the microspheres commonly show a bright rim of phosphate around a darker nucleus (Plate $42 D, G$ ) with the phosphate forming radially around the nucleus (Plate 42A). SEM X-ray probing of the nucleii of several microspheres found no evidence of mineral matter apart from calcium phosphate.

Hollow phosphate microspheres 10 to 25 microns in diameter have been observed by Soudry and Southgate (1989) in mudstone phosphorites from the Cambrian Duchess phosphate deposit in the Georgina Basin. They interpret these microspheres as the phosphatized remnants of solitary and colonial unicells because some of them contained two concentric encapsulated 
envelopes, or cell-like units of 5 microns in diameter separated by rims of phosphate much thinner than the outer envelope of the sphere. No similar internal structures are present in the microspheres from the Roper Group but it is possible that they represent the fossilized remains of small unicells similar to those observed by Peat et al. (1978) from the McMinn Formation.

\subsection{Origin of the Organic Matter Types in the McArthur Basin}

\subsubsection{Lamalginite}

Palaeontological studies, outlined in the Introduction, show that a variety of micro-organisms inhabited the McArthur Basin. The contribution these micro-organisms made to the formation of lamalginite was no doubt significant and probably included small colonial forms in the case of lamalginite in the Barney Creek Formation, and small to large unicell forms in lamalginite from the Roper Group. However the absence of obvious microfossils within most of the lamalginite makes it difficult to assess the contribution made by the various microorganisms. The remains of most micro-organisms have been rendered unrecognisable by the effects of bacterial degradation (particularly by sulphate reducers), compaction and diagenesis.

Compaction of the lamalginite may have been substantial. Oil shales of the Posidonia Shale in Germany are one fortieth of their original vertical dimension compared to a compaction of one quarter of interbedded limestones (Bandel and Knitter, 


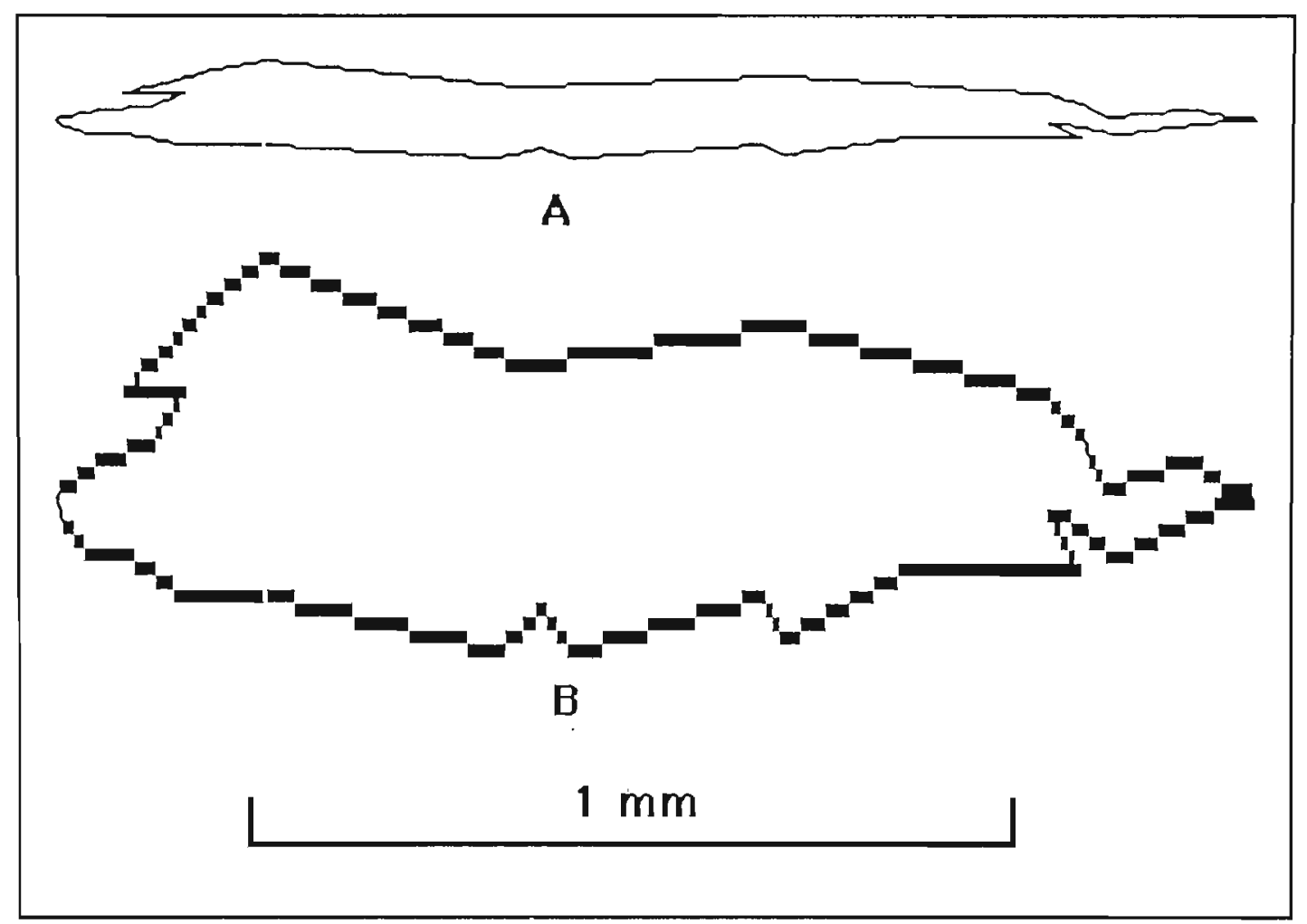

Figure 10-1. Outline drawings, perpendicular to bedding, of a large body of lamalginite from GR10, $37.4 \mathrm{~m}$, (Plate 4b) showing normal dimensions (A) and decompacted shape given a 4 times decompaction (B).

1986). A visual representation of the shape of a decompacted body of organic matter can be made by tracing its outline from a photomicrograph and stretching it vertically by using a computer graphics program, (Mac SuperPaint). Decompacting a large lenticular piece of lamalginite from the Barney Creek Formation (Plate 4b), assuming that the lateral dimensions remained much the same during decompaction, by a factor of 4 produces a more lenticular shape (Figure 10-1) whereas decompaction by a factor of about 15 or more produces a body whose height is greater than its width (Figure 10-2). Any detrital or pelagic organic matter would normally settle on the bottom with its maximum dimension orientated horizontally. 


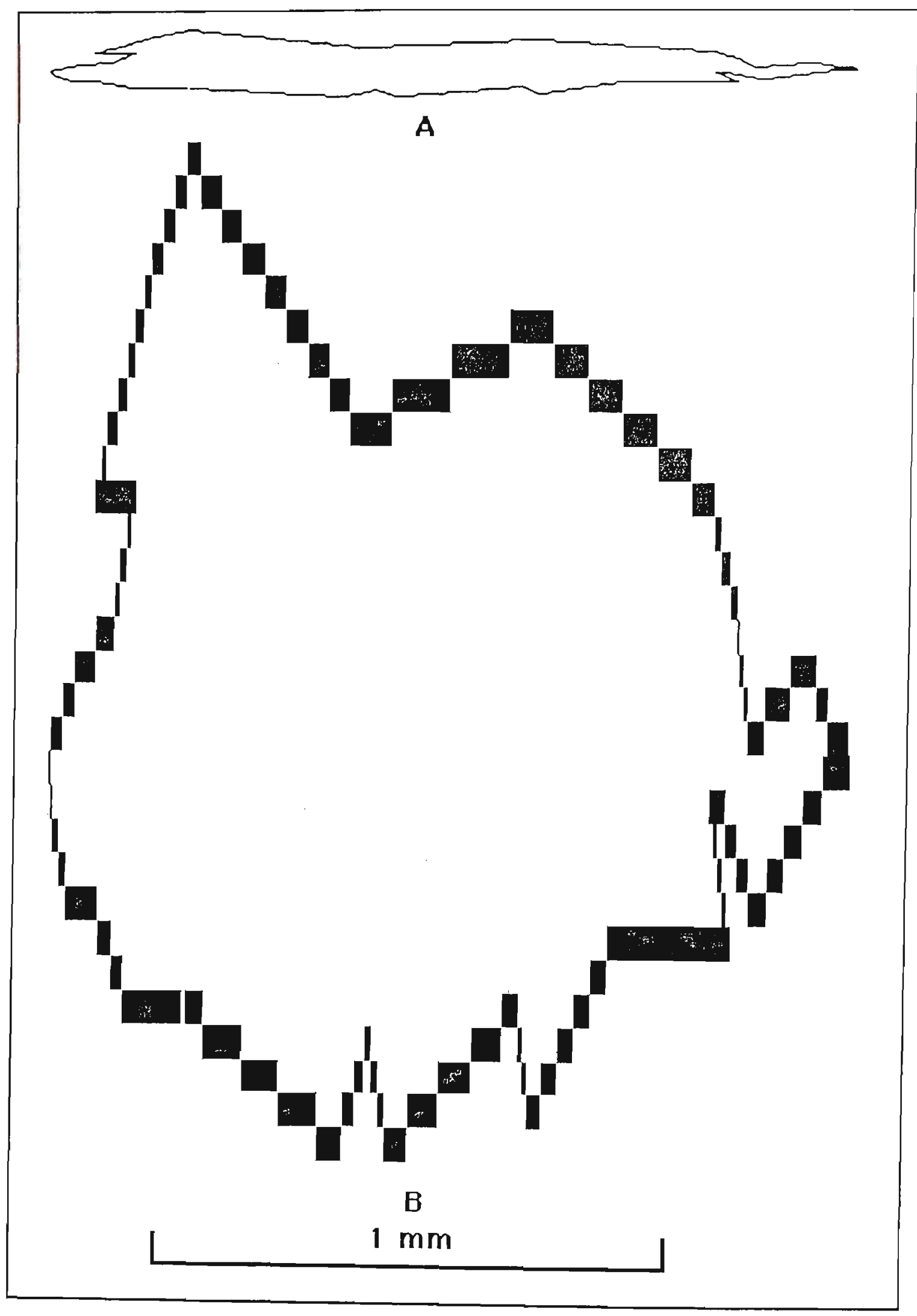

Figure 10-2. Outline drawings, perpendicular to bedding, of a large body of lamalginite from GR10, $37.4 \mathrm{~m}$, (Plate 4b) showing normal dimensions (A) and decompacted shape given a 15 times decompaction $(B)$. 
Organic matter which has its maximum dimensions orientated vertically are likely to have formed in situ. The degree of compaction in these sediments is not known and so it is not possible to clearly indicate the original form, prior to compaction, of the lamalginite. However, while some of the isolated lamalginite bodies in the Roper Group have formed from large, probably pelagic, acritarchs, the possibility clearly exists that at least some of the lamalginite formed as benthic microbial mats. It is possible also that some of the lamalginite formed from ripped up and redeposited microbial mats which originally grew in shallower parts of the basin. Microbial mats growing in the intertidal zone in parts of Shark Bay in Western Australia can be ripped up by wave action and form strand line deposits of irregularly shaped pieces (J. Bauld, pers. comm.).

\subsubsection{Oncalginite}

No microfossils were observed in, or associated with, oncalginite in oncolites from the one specimen examined from the McMinn Formation in the Roper Group. Early Proterozoic oncolites from the Nabberu Basin in Western Australia contain abundant filamentous cyanobacteria up to hundreds of microns long by 1 to 2 microns wide identified as Gunflintia minuta Barghoorn (Walter et al, 1976). Awramik (1984) considers that all oncolites were probably built by cyanobacteria which coated fragments that served as nucleii. Cyanobacteria therefore probably formed the oncalginite observed here. 


\subsubsection{Nonfluorescent Lamalginite and Bitumen}

The diminution of fluorescence intensity in lamalginite with increasing depth is due to hydrocarbon generation and expulsion of hydrocarbons and gradual carbonisation or coalification of the remaining material. Lamalginite exhibiting low levels of fluorescence or no fluorescence at all commonly appears more deformed and disrupted than lamalginite exhibiting strong fluorescence (e.g. Plate 9a-e). This is particularly apparent in lamalginite from the Barney Creek Formation in the Glyde River Subbasin where it is possible to observe, in core from one drill hole, brightly fluorescent lamalginite from near the surface to nonfluorescent lamalginite near the bottom and a gradation in between. Disruption of lamalginite may become so great that its original morphology is destroyed and all that remains are a collection of small pieces which would appear as patchy dispersed bitumen, disseminated bitumen or matrix bitumen under the microscope (e.g. Plates $6 e, f ; 9 a-f)$. In Phanerozoic sediments, Botryococcus alginite remains volatilize during bituminization at the same stage as sporinite reflectance begins to disappear $(1.3 \% \mathrm{Rm})(\mathrm{M}$. Teichmuller, 1980) and Tasmanales alginite leaves no residue or only fine shreds of inertinite when the reflectance of accompanying vitrinite exceeds $1.3 \%$ (Stach et al., 1982).

The commonly more deformed and disrupted morphology of lamalginite showing low to no fluorescence suggests that it becomes plastic after most oil has been expelled from it. Vitrinites in the medium- to low-volatile bituminous coal range also appear to undergo a degree of fluidization at appropriate temperatures (Murchison et al., 1985). In beds containing 
abundant lamalginite that have at least reached this stage, the lamalginite may flow and coalesce to form matrix bitumen or even veins of bitumen. Matrix bitumen may also be formed from vein bitumen. A bitumen vein in DDH Urapunga 3 in the Velkerri Formation appears to have flowed initially conformably and then across bedding and dispersed into a layer containing abundant matrix bitumen (Plate 29). The presence of oil inclusions in carbonates adjacent to this vein (Plate 29h,i) and strong mineral fluorescence adjacent to some bitumen veins elsewhere (Plate $7 \mathrm{~g}, \mathrm{~h}$ ) suggest that liquid hydrocarbons flowed through the veins prior to the bitumen or that an early phase asphaltenerich oil released liquid hydrocarbons, perhaps by the "deasphalting process" (Evans et al., 1971). Deasphalting takes place when normal maturation processes of liquid hydrocarbons produce light paraffins and asphaltenes which cannot coexist in a single liquid phase and results in the separation of the asphaltic components (Silverman, 1971). However, the vein could conceivably have formed from coalesced nonfluorescent lamalginite which initially generated some liquid hydrocarbons.

The origin of the bitumen microspheres is obviously related to the presence of the phosphate microspheres. Both occur only in the Velkerri and Cobanbarini Formations, have the same dimensions (generally less than 10 microns in diameter) and are commonly in close proximity to each other (e.g. Plate 26f). Phosphate microspheres are, in places, imbedded in bitumen (e.g. Plate 34G,H). Bitumen microspheres probably formed, therefore, by the bitumen filling voids previously occupied by phosphate microspheres. 
Titaniferous bitumen nodules, less than 200 microns in diameter and found only in one sample from the Barney Creek Formation in the Glyde River Subbasin (Plates 11, 13, and 14), may have formed from oil or bitumen seeping towards the surface. The nodules are within a thin greenish-grey claystone bed approximately $2 \mathrm{~cm}$ thick which occurs between grey calcareous siltstones. The claystone formed probably from the devitrification and alteration of a tuff bed. Devitrification and alteration of volcanic particles in this bed probably released titanium from minerals, such as ilmenite, which was then preferentially incorporated by the bitumen. The nodules are rimmed by pyrite and some larger nodules appear to have formed by coalescence of a number of individual nodules rimmed with pyrite. (e.g. Plate 14). The nodules may have formed from oil or bitumen which seeped out subaqueously from the sediments and floated to the surface as small globules. Ash from a volcanic eruption then blanketed the globules and forced them to the bottom. Any ash adhering to the surface of the globules may have included fine-grained pyrite but most of the pyrite associated with the nodules was probably formed as a result of the action of sulphate-reducing bacteria. In some cases, the bitumen or oil globules were almost entirely replaced by pyrite and formed pyritic nodules which, in places, contain oil inclusions (Plate 12).

\subsubsection{Thucholite}

Schidlowski (1969) proposes that thucholite from the Precambrian Witswatersrand system were formed from migrating hydrocarbons condensing and polymerizing around 
detrital uraninite through the effects of radiation from the uraninite. Smit (1984) proposes a different origin for thucholite from the Witswatersrand System, suggesting that it formed by growth of microbial organisms around and into uraninite grains resulting in the observed fragmented nature of the uraninite grains. However, polymerization of liquid hydrocarbons seeping into fractures or along cleavage planes of the mineral, could also account for the fragmented nature of the mineral grains.

There is no compelling evidence to suggest that the thucholite in the McArthur Basin formed from growth of microbial organisms around mineral grains as there are no morphological signs that these organisms existed. Further, the observed relatively random occurrence of the thucholite in both fine-grained organic-rich rocks containing lamalginite and in coarser grained units containing virtually no other organic matter, suggests a different origin. The presence of the radioactive mineral, thorite, in the central areas of some large thucholites in the Barney Creek Formation, clearly indicates that the McArthur Basin thucholites formed by accretion of mobile hydrocarbons around radioactive minerals in the manner proposed by Schidlowski (1969).

The presence of noticeable amounts of sulphur in the thucholitic bitumen (Plates $22 \mathrm{c}$ and $23 \mathrm{c}$ ) is not surprising given that sulphur is the third most abundant atomic constituent of crude oils, following hydrogen and carbon (Tissot and Welte, 1978). 
CHAPTER 11

\section{SUMMATION AND SIGNIFICANCE TO PETROLEUM AND MINERAL EXPLORATION IN THE PRECAMBRIAN}

\subsection{Introduction}

Organic matter in the middle Proterozoic sequences of the McArthur Basin is contained predominately within fine grained clastic sediments. A number of stratigraphic units contain intervals with TOC greater than $1.0 \%$ and two units, the Velkerri and Barney Creek Formations, contain intervals where TOC is up to $7 \%$.

\subsection{Organic matter types}

The organic matter is made up of a number of petrographically discernable entities:

(1) Fluorescent filamentous-looking organic matter with the filaments generally elongate parallel to bedding, varying in size from several microns to hundreds of microns long by less than 2 microns wide. In many cases, the individual filaments appear to group together to form thicker bodies or strands, which, in places, occur as thin lenticular shapes that are generally less than $0.5 \mathrm{~mm}$ long by $0.05 \mathrm{~mm}$ thick but, more rarely, are up to several millimetres in length by $1 \mathrm{~mm}$ in thickness. In one case, they form apparently continuous mats. In sections cut parallel to bedding, the thin lenticular bodies show an irregular but commonly roughly circular shape. Fluorescence varies from a bright yellow to a dull brownish orange. This type of organic matter occurs in the McMinn, Velkerri and Cobanbarini 
Formations of the Roper Group and in the Yalco, Lynott and Barney Creek Formations of the McArthur Group.

This fluorescent organic matter is petrographically identical to a type described from a number of Phanerozoic oil shales by Hutton et al., (1980), Cook et al. (1981), Hutton (1982), Cook and Kantsler (1982), Sherwood and Cook (1984) which initially was called "alginite B" by Hutton et al. (1980) but renamed "lamalginite" by Cook et al. (1982). It can, therefore, with some confidence, be called lamalginite and has been informally referred to here as "fluorescent lamalginite".

(2) Nonfluorescent bands of organic matter which are generally parallel to bedding and vary in size from several microns long by less than two microns wide up to several hundreds of microns long by less than 20 microns wide. In places, they occur with fluorescent bands having a similar morphology or, more rarely, one band may show a gradation along its length from no fluorescence to a dull orange fluorescence.

The nonfluorescent forms are commonly more irregular in thickness than the fluorescent forms. In places, they have a disjointed and partly broken up appearence and, more rarely, form groups, up to several hundreds of microns long, of smaller irregular shapes, less than a few microns in size, which are dispersed along a bedding plane. More rarely again, the nonfluorescent forms are made up of two distinct bands less than 5 microns thick, up to several hundreds of microns long. The nonfluorescent forms, however, do not display the fine laminations observed in the larger bodies of the fluorescent forms. They are, in places, surrounded by a dark nonfluorescent bitumen-impregnated mineral zone. These forms are found in 
most of the formations examined with the exception of the Looking Glass Formation, Reward and Emmerugga Dolomites, in the McArthur Group.

These forms are morphologically similar to the fluorescent form and have obviously been derived from it. It has therefore been informally called "nonfluorescent lamalginite".

(3) Uniformly thin, generally less than 5 microns thick, silvery nonfluorescent organic matter which occurs as single or concentric bands within oncolites; observed in one specimen from the McMinn Formation of the Roper Group. It differs from lamalginite in that the orientation of the organic matter is not along the bedding plane but follows the morphology of the oncolite. It is therefore referred to informally as "oncalginite".

(4) Small irregularly shaped bodies of nonfluorescent organic matter, generally less than 10 microns in size, which occur in patches containing several to less than about 50 individual pieces or as discrete individual pieces. In one polished block, isolated bodies of organic matter formed comparatively large cauliflower shapes up to 70 microns across. The boundaries of the patches are generally irregular in shape but, in places, appear as lenticular bodies up to about 50 microns by 30 microns in overall size. With the exception of the large cauliflower forms which occur only in the Velkerri Formation, the other forms are found in the majority of the formations in the McArthur Basin.

The larger pieces are commonly optically non-homogenous under plane-polarised reflected light, particularly the cauliflower shaped forms, and contain zones of lighter or darker reflecting organic matter which, on rotation of the stage, varied in brightness. 
These small irregularly shaped bodies of organic matter which occur in patches or as isolated small discrete pieces are similar, apart from the larger cauliflower forms, to particulate pieces of vitrinite or inertinite. However, as no land plants had evolved by the time the McArthur Basin was formed, it is clearly unsuitable to refer to them as vitrinite or inertinite. Their irregular morphology is consistent with descriptions given of bitumen in Phanerozoic sediments by Jacob $((1976,1981)$ who considers bitumen's most important characteristic is the variety of its morphological form. This organic matter is therefore called bitumen. Patches of bitumen are informally referred to as "patchy dispersed bitumen", the small isolated and discrete grains of bitumen as "disseminated bitumen" and the larger cauliflower forms as "cauliflower bitumen".

(5) More massive organic matter than (4) which is generally optically homogenous and surrounds mineral grains forming an organic matrix. This type of organic matter forms an organic mass containing "imbedded" mineral grains, and has irregular dimensions which are generally less than 100 microns in size but, in places, can be much larger. It is generally nonfluorescent but does display in rare cases, a dull orange fluorescence. It occurs in the McMinn, Velkerri and Mainoru Formations of the Roper Group, in the Balbarini Dolomite of the Nathan Group and in the Reward Dolomite, Lynott and Barney Creek Formations of the McArthur Group.

The variety of its morphological form clearly identifies it as bitumen and as it forms a matrix to mineral matter it is called "matrix bitumen". 
(6) Bitumen veins which crosscut or are conformable to beding. The width of the veins vary from a few microns to up to several hundreds of microns. They occur in the majority of formations in the McArthur Basin. The veins are, in places, optically non-homogeneous, either displaying variably shaped optically homogenous zones of varying brightness, or alternating dark and brightly reflecting laminae.

(7) Vug bitumen that appears to fill pre-existing spaces, or vugs, in the rock fabric. They vary in size from less than 20 microns to in excess of 50 microns. They occur in carbonates of the McArthur Group within the Looking Glass Formation and the Reward and Emmerugga Dolomites. Very few examples of this type of organic matter were observed and no reflectance measurements were made.

(8) Round grains of organic matter up to $0.5 \mathrm{~mm}$ in diameter, which in handspecimens appear black but under the microscope have a silvery surface, and commonly have noticeably higher reflecting central areas. In some cases the peripheral organic matter displays a weak orange fluorescence. Some grains have mineral cores which, in some cases, is the mineral thorite. Reflectances generally increase exponentially towards the center of these grains and they are optically markedly anisotropic. This organic matter is called "thucholite" as it is identical to thucholites described by Cook and Kantsler (1982) from Australian sedimentary rocks ranging in age from the Precambrian to the Mesozoic.

(9) Microspheres of nonfluorescent organic matter, less than 10 microns in diameter, which show no obvious increase in reflectance towards their centers and are associated with 
phosphate microspheres having the same dimensions, in the Velkerri and Cobanbarini Formations of the Roper Group. This organic matter has probably occupied spaces formerly occupied by the phosphate microspheres, and could therefore be termed vug bitumen. However because it has a clearly defined morphology, although an assumed morphology, it is called bitumen microspheres.

\subsection{Origin of the Organic Matter}

Previous micropalaeontological studies have revealed an extensive microbiota consisting of unicellullar, colonial and filamentous forms preserved in cherts, carbonates, and fine grained clastic sediments in the McArthur Basin. The contribution these micro-organisms made to the formation of lamalginite was probably significant and included small colonial forms in the case of lamalginite in the Barney Creek Formation, and small to large unicell forms in lamalginite from the Roper Group. Microbial organisms, possibly cyanobacteria, also formed the source biota for oncalginite. The remains of most microorganisms have been rendered unrecognisable by the effects of bacterial degradation (particularly by sulphate reducers, who are also probably included in the preserved biomass), compaction and diagenesis.

With increasing maturation, fluorescence in lamalginite diminishes and eventually ceases. Nonfluorescent lamalginite commonly exhibits a more deformed and disrupted morphology than fluorescent lamalginite. Fine lamellae, observed in the larger bodies of fluorescent lamalginite, are absent. Disaggregation of nonfluorescent lamalginite, possibly related to 
hydrocarbon generation, may have led to the formation of patchy dispersed bitumen or disseminated bitumen. If sufficient nonfluorescent lamalginite was present it may have coalesced to produce matrix or vein bitumen.

\subsection{Reflectances of the Organic Matter Types}

Reflectances of fluorescent lamalginite are generally lower than the other types of organic matter. Mean maximum reflectances range from 0.05 to $0.53 \%$. It is optically slightly anisotropic but shows a systematic increase in anisotropy with increasing reflectance. Where fluorescent lamalginite, nonfluorescent lamalginite and/or bitumen are present in the same polished block, the reflectance of fluorescent lamalginite is about half that of the other types.

Mean maximum reflectances of nonfluorescent lamalginite range from 0.42 to $4.27 \%$ and for bitumen they range from 0.44 to $5.39 \%$. Nonfluorescent lamalginite and bitumen are optically anisotropic which at low levels of reflectance is not marked but at high reflectances is quite marked.

\subsection{Assessment of Maturation Levels}

The advantage of using reflectance and Tmax indices over other maturation indices is that they are relatively quick and easy to obtain. Assessing maturation levels by the colour of organic matter in strew mounts or thin sections requires more preparation and the results are qualitative. Molecular maturation indices, such as the MPI-1, require the most effort and are difficult to obtain in the overmature zone due to low yields of extractable hydrocarbons. An additional problem, in the case of 
the MPI-1 index, is that, at high temperatures, demethylation reactions lead to a lowering of the index. Tmax indices are also similarly difficult to obtain from overmature organic matter as most hydrocarbon has already been cracked from the kerogen. Tmax results are also unreliable in samples containing low amounts of organic matter. Both Tmax and molecular maturation indices are affected by migrated oil. Reflectances, on the other hand, can be obtained from samples containing low amounts or overmature organic matter and also from partly weathered samples unsuitable for geochemical anylyses. Rock-Eval analyses are comparatively quick and easy to do whereas obtaining reflectance measurements requires a larger sample, more sample preparation, and a degree of cognitive and manipulative skill. Both indices, however, required calibration with respect to the oil generative window in the Precambrian to be of any use.

In the McArthur Basin, Tmax values between 425 and $470^{\circ} \mathrm{C}$ and maximum reflectances between $0.15 \%$ for fluorescent lamalginite and $1.4 \%$ for nonfluorescent lamalginite and/or bitumen, are within the oil window. Reflectances of fluorescent lamalginite are depressed by about 0.4 to $0.5 \%$ with respect to vitrinite reflectances calculated from methylphenanthrene indices. Maximum reflectances of nonfluorescent lamalginite and/or bitumen are similar to vitrinite reflectances calculated from methylphenanthrene indices.

Fluorescent lamalginite is present only from the start to the middle zone of the oil window whereas nonfluorescent lamalginite and/or bitumen occurs only from the middle zone to the base of the oil window. The reduction and eventual loss of fluorescence in lamalginite is clearly associated with 
hydrocarbon generation. Maturation levels of specimens containing both fluorescent and nonfluorescent lamalginite are variable and range across the middle zone of the oil window. The differing fluorescing characteristics at the same maturation levels may be attributable to variations in the chemical composition and source biota of the lamalginite.

Levels of maturation as measured by reflectance and Tmax generally show a systematic increase with increasing depth in individual drill holes showing that maturation processes that produce such changes in the Phanerozoic produce similar changes in the Precambrian. Reflectances were obtained on a number of samples which produced unreliable results from RockEval pyrolyses due to low TOC, migrated hydrocarbons or overmature organic matter. They therefore proved to be a far more useful measure of maturation levels in the basin.

\subsection{Maturation Patterns and History of the McArthur} Basin.

Organic matter in the Maiwok Subgroup of the Roper Group is marginally mature to mature but in places is overmature as a result of contact metamorphism adjacent to dolerite sills. Maturation levels in the lower Roper Group are at least marginally overmature. Maturation levels that have not been affected by contact metamorphism increase with the age of formations in the Roper Group and are fairly similar for the same formation over a wide areal extent. Such a pattern is consistent with the concept that the Roper Group formed during the sag phase of the basin's development and that there has been subsequently a relatively uniform geological history. The 
localized zones of contact metamorphism were probably superimposed upon the regional pattern but it is possible that at least in part, the contact alteration predates much of the regional rank change, the evidence being, however, equivocal.

Maturation levels in the Nathan and McArthur Groups range from being at least marginally immature to overmature. Hydrothermal activity, producing localised zones of increased temperatures, and, in places associated with base-metal mineralisation, have affected some maturation levels in a manner similar to contact metamorphism. Maturation levels, unaffected by hydrothermal activity, show considerable overlap between formations. Such a pattern probably resulted from variable subsidence rates and geothermal gradients during the final phase of extension in the basin which preceded the sag phase.

Modelled maturation levels based on reconstructions of the geological history of the basin and using two methods, the Lopatin (1971) method as modified by Waples (1980) and Price's (1983) method, are compared with observed reflectances recalculated to vitrinite reflectances. The Lopatin-Waples method assumes that time and temperature are factors in the maturation process, provides the best fit between modelled and observed recalculated reflectances in the Roper Group. By contrast, Price's (1983) method assumes that the maximum temperature experienced by organic matter is the only factor.

Time is therefore an important factor in the maturation of organic matter unaffected by contact metamorphism in the Roper Group and by extension, for all organic matter in the basin which has not experienced high temperatures. The modelling results for 
the Roper Group, using the Lopatin-Waples method, suggest that it was up to about $1000 \mathrm{~m}$ thicker than its observed maximum thickness. The modelling results for the Barney Creek Formation in the Glyde River Subbasin, using the Lopatin-Waples method, indicate that the sedimentary cover overlying this subbasin was never greater than about $2000 \mathrm{~m}$.

\subsection{Timing of oil generation}

The timing of oil generation within the two formations containing the most organic matter in the basin (Barney Creek and Velkerri Formations), based on the Lopatin-Waples method, indicates that the onset and peak oil generation, from the base of these formations occurred before about $1400 \mathrm{Ma}$ for the Barney Creek Formation and before about $1000 \mathrm{Ma}$ for the Velkerri Formation. However, the start and peaking of oil production for sections above the base of these formations occurred later and in the case of the uppermost section of the Barney Creek Formation in the Glyde River Basin, it has never reached peak oil production. If geothermal gradients in the past were much the same as observed today $(30 \mathrm{c} / \mathrm{km})$, and there is some evidence to suggest this is the case since deposition of the Roper Group, then temperatures at the base of both formations have been less than $70^{\circ} \mathrm{C}$ since about $1000 \mathrm{Ma}$ in the case of the Velkerri Formation

and since about $1400 \mathrm{Ma}$ for the Barney Creek Formation. Oil generation virtually ceases at temperatures below about 50 $70^{\circ} \mathrm{C}$ (Gretener and Curtis, 1982) but may proceed at very slow rates due to the quantum mechanical tunnelling effect (Snowdon, 1979). Hydrocarbons may therefore have been generated, albeit at 
very slow rates, for a considerable period extending well into the Phanerozoic.

\subsection{Significance for petroleum and mineral exploration} Exploration for petroleum in Precambrian basins is considered a high risk venture and fraught with problems. One of the major problems is that organic matter in such basins is commonly overmature or thought to be overmature due to the antiquity of the basins. The commonly used maturation indices, reflectance and Tmax, developed from studies in Phanerozoic basins, may be misleading and no research had previously been undertaken in an attempt to establish their reliability or ranges with respect to the oil window in Precambrian basins. This study has established that both reflectance and Tmax indices can be used successfully and has defined their ranges with respect to the oil-window in the McArthur Basin. It is probable that the oilwindow for organic matter in other Precambrian basins will be broadly the same with respect to these indices given the relative lack of diversity in Precambrian biota with respect to Phanerozoic biota.

This study has also demonstrated that oil and gas, which were generated from a number of organic rich units in the McArthur Basin, would not have become thermally degraded in certain areas. Economic accumulations of hydrocarbons could occur in the upper part of the Roper Group which is present over broad areas of the basin, and within smaller areas containing McArthur and Nathan Group sediments where the organic matter in them is not significantly overmature. 
The observation that anomalously high maturation levels of organic matter in the McArthur Group are probably caused by hydrothermal activity, which, in places, is associated with base metal mineralisation such as the large H.Y.C. deposit, could help in the search for similar ore-bodies in the McArthur Basin and in other Precambrian basins. An anomalously high maturation level in a barren mineral exploration drill hole, may indicate a nearby ore body. 


\section{REFERENCES}

ABRAHAM, H., 1963. Asphalts and Allied Substances. Volume 5, 6th. edition, D. van Nostrand Co. Inc., Princeton, New Jersey, 325 p.

AL-MARJEBY, A. and NASH, D., 1986. A summary of the geology and oil habitat of the eastern flank hydrocarbon province of South Oman. Marine and Petroleum Geology, 3, 306-315.

AWRAMIK, S.M., 1984. Ancient Stromatolites and Microbial Mats.

In: Cohen, Y., Castenholz, R.W. and Halvorson, H.O. (eds.) Microbial Mats: Stromatolites, Alan R. Liss Inc., New York; pp.1-22.

BANDEL, K. and KNITTER, H., 1986. On the origin and diagenesis of the bituminous Posidonia Shale (Toarcian) of southern Germany. In: Degens, E.T., Meyers, P.A., \& Brassell, S.C. (eds.): Biogeochemistry of Black Shales, SCOPE/UNEP Sonderband, Hamburg, 1986, pp. 151-177.

BOREHAM, C.J. and POWELL, T.G., 1987. Sources and preservation of organic matter in the Toolebuc Formation, eastern Australia. Organic Geochemistry, 11, 433-449.

BOREHAM, C.J., CRICK, I.H. and POWELL, T.G., 1988. Alternative calibration of the methylphenanthrene index against vitrinite reflectance: Application to maturity measurements on oils and sediments. Organic Geochemistry, 12, 289-294. 
BRADLEY, W.H., 1964. Geology of the Green River Formation and associated Eocene rocks in the southwestern Wyoming and adjacent parts of Colorado and Utah. United States Geological Survey Professional Paper 496A, 1-86.

BUCHANAN, D. T., 1984. The McArthur River project. Proceedings of the Australian Institute of Mining and Metallurgy Conference, Darwin, N.T., August, 1984, pp. 49-57.

BUNTEBATH, G., 1978. The degree of metamorphism of organic matter in sedimentary rocks as a paleo-geothermometer, applied to the Upper Rhine Graben. Pure and Applied Geophysics, 117, 83-91.

CANE, R. F., 1976. The origin and formation of oil-shale. In:

Yen, T.F. and Chililgarian, G.V. (eds.): Oil Shale. Elsevier, Amsterdam, pp. 27 - 60.

CLEMENTZ, D.M., 1979. Effect of oil and bitumen saturation on source rock pyrolysis. American Association of Petroleum Geologists Bulletin, 60, 608-626.

CLOUD, P., 1972. A working model of the primitive earth, American Journal of Science, 272, 537-548.

CONNAN, J., 1974. Time-temperature relation in oil genesis. American Association of Petroleum Geologists Bulletin, 58, $1516-1521$. 
COOK, A.C., 1988. Course on Organic Geochemistry and its Application to the Oil Industry. University of Wollongong Printery. pp. 73.

COOK, A.C. and KANTSLER, A.J., 1982. Description of the maceral groups and macerals found in coals, oil shales, and as dispersed organic matter in sediments. In: Cook, A.C. (ed.), The Origin and Petrology of Organic Matter in Coal, Oil-Shales and Petroleum Source-Rocks. University of Wollongong, Wollongong, Australia, pp. 106.

COOK, A.C., HUTTON, A.C. and SHERWOOD, N.R., 1981. Classification of oil shales. Bulletin des Centres Recherches ExplorationProduction Elf-Aquitaine, 5, 353-381.

COOK, A.C., HUTTON, A.C. and SHERWOOD, N.R., 1982. Letter to Commission II, International Commission on Coal Petrology.

COOLES, G.P, MACKENZIE, A.S. and QUIGLEY, T.M.,1986. Calculation of petroleum masses generated and expelled from source rocks. Organic Geochemistry, 10, 235-245.

CRICK, I.H., MUIR, M.D., NEEDHAM, R.S. and ROARTY, M.J. 1980. The geology and mineralisation of the South Alligator Valley Uranium Field. In: Ferguson, J. and Goleby, A.B. (eds.), Uranium in the Pine Creek Geosyncline. International Atomic Energy Agency, Vienna, pp. 273-285. 
CROXFORD, J.N.W., JANECEK, J., MUIR, M.D. and PLUMB, K.A., 1973. Micro-organisms of Carpentarian (Precambrian) age from the Amelia Dolomite, McArthur Group, Northern Territory, Australia. Nature, 245, 28-30.

CROXFORD, J.N.W., GULSON, B.L. and SMITH, J.W., 1978. The McArthur River Deposit: a review of the current situation. Mineralium Deposita, 10, 302-304.

CULL, J.P. and SPARKSMAN, G.F., 1977. Measurement of Surface Heat Flow. Bureau of Mineral Resources, Geology and Geophysics, Australia, Record 1977/39.

CURIALE, J.A., 1985. Origin of solid bitumens, with emphasis on biological marker results. Organic Geochemistry, 10, 559-580.

CURIALE, J.A., BLOCH, S., RAFALSKA-BLOCH, J. and HARRISON, W.E., 1983. Petroleum-related origin for uraniferous organic-rich nodules of Southwestern Oklahoma. American Association of Petroleum Geologists Bulletin, 67, 588-608.

DASHLOOTY, S.A. and DAVIDSON, G.J., 1986. Evolution of the Carpentarian Glyde River sub-basin, McArthur Basin, N.T. Eighth Australian Geological Convention, Adelaide. Geological Society of Australia Abstracts 15, pp. 54. 
DAVIDSON, C.F. and BOWIE, S.H.U., 1951. On thucholite and related hydrocarbon-uraninite complexes, with a note on the origin of the Witswatersrand gold ores. Geological Survey of Great Britain Bulletin, 3, 1-18.

DONNELLY, T.H. and CRICK, I.H., 1988. Depositional environment of the middle Proterozoic Velkerri Formation in northern Australia: geochemical evidence. Precambrian Research 42, 165-172.

DONNELLY, T.H. and JACKSON, M.J., 1988. Sedimentology and geochemistry of a mid-Proterozoic lacustrine unit from northern Australia. Sedimentary Geology, 58, 145 -169.

DUNN, P.R., 1963. Urapunga, Northern Territory - 1:250,000 Geological Series. Bureau of Mineral Resources, Australia, Explanatory Notes SD/5, pp. 3-10.

DURAND, B. and NICAISE, G., 1980. Procedures for kerogen isolation. In: Durand, B. (ed.), Kerogen - Insoluble Organic Matter from Sedimentary Rocks, Editions Technip, Paris, pp. 35-54.

ELLSWORTH, H.V., 1928. Thucholite, a remarkable primary carbon mineral from Parry Sound. American Mineralogist, 13, 419-439.

ESPITALIE, J., DEROO, G. and MARQUIS, F., 1985. Rock Eval pyrolysis and its applications. Institute Francais du Petrole, publication no. 27299, English Translation. 
ESPITALIE, J., LAPORTE, J.L., MADEC, M., MARQUIS, F., LEPLAT, P., PAULET, J. and BOUTEFEU, A., 1977. Methode rapide de caracterisation des roche meres, de leur potentiel petrolier et de leur degre d'evolution. Review Institute du Francais Petrole, 32, 23-42.

ESPITALIE, J., MADEC, M. and TISSOT, B., 1980. Role of mineral matrix in kerogen pyrolysis: influence on petroleum generation and migration. American Association of Petroleum Geologists Bulletin, 64, 59-66.

EVANS, C.E., ROGERS, M.A. and BAILEY, N.J.L., 1971. Evolution and alteration of petroleum in western Canada. Chemical Geology, $8,147-170$.

GALLAGHER, F.M. and MacKAY, P.A., 1981. 1981 Field report. McArthur River area - Northern Territory, CSA \& FE region. Amoco Australian Petroleum Company Report (unpublished).

GARY, M., McAFEE, R.Jr. and WOLF, C.L. (eds.), 1974. Glossary of geology. American Geological Institute, 805 p.

GLAESSNER, M.F. and WADE, M., 1966. The late Precambrian fossils from Ediacara, South Australia. Palaeontology, 9, 10-11.

GOLDSTEIN, J. I., NEWBURY, D. E., ACHLIN, P., JOY. D.C., FIORI, C. and LIFSHIN, E., 1981. Scanning electron microscopy and Xray microanalysis. Plenum Press. New York, 235 p. 
GORTER, J.D., BELLIS, C.J., DEE, C.N. and SCHRODER, R.J., 1982. Dingo No. 1 well completion report. Pancontinental Petroleum Limited, Report 27 (unpublished).

GRETENER, P.E. and C.D. CURTIS, 1982. Role of temperature and time in organic metamorphism. American Association of Petroleum Geologists Bulletin, 66, 1124-1149.

HAJI-VASSILOU, A. and KERR, P.F., 1972. Urano-organic matter association at La Bajada, New Mexico. Economic Geology, 67, 41-54.

HAJI-VASSILOU, A. and KERR, P.F., 1973. Analytic data on nature of urano-organic deposits. American Association of Petroleum Geologists Bulletin, 57, 1291-1296.

HAJI-VASSILOU, A. and KERR, P.F., 1980. The form and occurrence of uranium in deposits associated with organic matter. Economic Geology, 75, 609-617.

HALL, M.G. and LLOYD, G.E., 1981. The SEM examination of geological samples with a semi-conductor back-scattered electron detector. American Mineralogist, 66, 362-368.

HAMILTON, L.H. and MUIR, M.D., 1974. Precambrian microfossils from the McArthur Lead-Zinc Deposit North Territory, Australia. Mineralium Deposita, 9, 83-86. 
HATCH, J.R. and MOREY, G.B., 1985. Hydrocarbon source rock evaluation of Middle Proterozoic Solar Church Formation, North American mid-continent rift system, Rice County, Minnesota. American Association of Petroleum Geologists Bulletin, 69, 1208-1216.

HAWLEY, C.C., WYANT, D.G., and BROOKS, D.B., 1965. Geology and Uranium Deposits of the Temple Mountain District Emery County, Utah. United States Geological Survey Bulletin 1192, $154 \mathrm{p}$.

HOFMANN H.J. and SCHOPF, J.W., 1983. Early Proterozoic microfossils. In: Schopf, J.W. (ed.), Earth's Earliest Biosphere. Princeton University Press, Princeton, pp. 321-360.

HOOD, A. and CASTANO, J.R., 1974. Organic metamorphism, its relationship to petroleum generation and application to studies of authigenic minerals. United Nations Economic and Social Commission for Asia and the South Pacific, Committee for Co-ordination of Joint Prospecting for Mineral Resources Technical Bulletin, 8, 85-118.

HOOD, A., GUTJAHR, C.C.M., and HEACOCK, R.L., 1975. Organic metamorphism and the generation of petroleum. American Association of Petroleum Geologists Bulletin, 59, 986-996.

HUCK, G. and KARWEIL, J., 1955. Physikalisch-chemische Probleme der Inkohlung. Brennstoffe-Chemie, 36, 1-11. 
HUIZINGA, B.J., TANNENBAUN, E and KAPLAN, I.R., 1987. The role of minerals in the thermal alteration of organic matter - III. Generation of bitumen in laboratory experiments. Organic Geochemistry, 11, 591-604.

HUNT, J.M., 1979. Petroleum geochemistry and geology. W. H. Freeman and Company, San Francisco, 617 p.

HUNT, J.M., STEWART, F. and DICKEY, P.A., 1954. Origin of hydrocarbons of the Uinta Basin, Utah. American Association of Petroleum Geologists Bulletin, 38, 1671-1698.

HUTTON, A.C., 1982. Organic petrology of oil shales. Doctor of Philosophy thesis, University of Wollongong, Australia, $519 \mathrm{p}$.

HUTTON, A.C., 1986. Duaringa - a bipartite oil shale deposit. Australian Coal Geology, 6, 27-40.

HUTTON, A.C., 1987. Petrographic classification of oil shales. International Journal of Coal Geology, 8, 203-231.

HUTTON, A.C., KANTSLER, A.J., COOK, A.C. and McKIRDY, D.M., 1980. Organic matter in oil shales. Australian Petroleum Exploration Association Journal, 20, 44-67.

IDNURM, M. and GIDDINGS, J. W., 1988. Australian Precambrian polar wander: A Review. Precambrian Research, 40/41, 61-88. 
INGRAM, L.L., ELLIS, J., CRISP, P.T. and COOK, A.C., 1983. Comparitive study of oil shales and shale oil from the Mahogany Zone, Green River Formation (U.S.A) and the Kerosene Creek Seam, Rundle Formation (Australia). Chemical Geology, $38,185-212$.

International Commission for Coal Petrology, 1963. International handbook of coal petrology. Centre National de la Recherche Scientifique, Paris.

International Commission for Coal Petrology, 1971. International Handbook of Coal Petrology. Centre National de la Recherche Scientifique, Paris.

International Commission for Coal Petrology, 1975. International Handbook of Coal Petrology. Centre National de la Recherche Scientifique, Paris.

JACKSON, M.J., MUIR, M.D. and PLUMB, K.A., 1987a. Geology of the southern McArthur Basin, Northern Territory. Bureau of Mineral Resources, Australia, Bulletin 220, 173 p.

JACKSON, M.J., SWEET, I.P. and POWELL, T.G., 1987b. Geology and assessment of petroleum prospectivity. In: Petroleum Geology and Geochemistry, Middle Proterozoic McArthur Basin. Bureau of Mineral Resources, Australia, Record 1987/48, 11-98. 
JACKSON, M.J., POWELL, T.G., SUMMONS, R.E. and SWEET, I.P., 1986. Hydrocarbon shows and petroleum source rocks in sediments as old as $1.7 \times 10^{7}$ years. Nature, 322, 727-729.

JACOB, H., 1961. Uber bituminose Schiefer, humose Tone, Brandschiefer und ahnliche Gesteine. Ein Beitrag zur Frage der Erdolgenesis aus kohlen petrographischer Sicht. Erdol und Kohle, 14, 2-11.

JACOB, H., 1976. Petrologie, Nomenklatur und Genesis naturlicher, fester Erdolbitumina. Gemeinschaftstagung OGEW/DGMK, 4(6), 36-49.

JACOB, H., 1981. Mikroskopphotometrische Analyse disperser Ferstbitumina in Sedimenten. Erdol und Kohle-ErdgasPetrochemie vereinigt mit Brenstoff-Chemie, (EKEP-Synopse 8133), 34(11), p. 507.

KARWEIL, J., 1956. Die metamorphose der Kohlen von Stanpunkt der physikalischen Chemie. Zeitschrift der Deutschen geologischen Gesellschaft, 107, 132-139.

KING, L.H., GOODSPEED, F.E. and MONTGOMERY, D.S., 1963. Study of sedimented organic matter and its natural derivatives. Mines Branch Report R114, Department of Mines and Technical Surveys, Ottawa. 
KOUL, S.L., WILDE, A.R. and TICKOO, A.K., 1988. A thermal history of the Proterozoic East Alligator River Terrain, N.T., Australia: a fission track study. Tectonophysics, 145, 101-111.

KRALIK, M., 1982. Rb-Sr age determinations on Precambrian carbonate rocks of the Carpentarian McArthur Basin, Northern Territory, Australia. Precambrian Research, 18, 157-170.

LAMBERT, I.B., 1976. The McArthur zinc-lead-silver deposit: features, metallogenesis and comparisons with other stratiform ore. In: Wolf, K.H. (ed) Handbook of Stratiform Ore Deposits. Elsevier, Amsterdam, pp. 535 - 585.

LAMBERT, I.B. and SCOTT, K.M., 1973. Implications of geochemical investigations of sedimentary rocks within and around the McArthur zinc-lead-silver deposit, Northern Territory. Journal of Geochemical Exploration, 2, $307-330$.

LIEBENBERG, W.R., 1955. The occurrence and origin of gold and radioactive minerals in the Witswatersrand system, the Dominion reef, the Ventersdorp contact reef, and the Black reef (with discussion). Geological Society of South Africa Transactions, 58, 101-254. 
LOGAN, R.G. and WILLIAMS, N., 1984. Sedimentary controls on the hydrothermal system that formed the H.Y.C. deposit at McArthur River, Northern Territory. In: Geosciences in the Development of Natural Resources. Seventh Australian Geological Convention, Sydney. Geological Society of Australia, Abstracts, 12, p. 339.

LOPATIN, N.V., 1971. Temperature and geological time as factors in coalification. Akademiya Nauk SSSR Isvestiya, Seriya Geologicheskaya, 3, 95-106.

LOUIS, M., EISMA, E., HANSON, W.E., JACKSON, C.F. and SCHULTZE, G.R., 1959. Report by the committee dealing with Resolution 4 of the Third World Petroleum Congress. Fifth World Petroleum Congress, New York, 1955, Proceedings, Section 1, pp. 10371042.

McDOUGALL, I., DUNN, P.R., COMPSTON, W., WEBB, A.W., RICHARDS, J.R. and BOFINGER, V.M., 1965. Isotopic age determinations on Precambrian rocks of the Carpentaria region, Northern Territory, Australia. Journal of the Geological Society af Australia, 12, 67-90.

McEVOY, D., 1987. Esso downgrades Australia's crude oil discovery potential. News Release, Esso Australia Ltd., December 6, 1987. 
MCKENZIE, D.P., 1978. Some remarks on the development of sedimementary basins. Earth and Planetary Science Letters, $40, \quad 25-32$.

McKIRDY, D.M., 1974. Organic geochemistry in Precambrian research. Precambrian Research, 1, 75-137.

MCKIRDY, D.M., 1977. Diagenesis of microbial organic matter: a geochemical classification and its use in evaluating the hydrocarbon-generating potential of Proterozoic and Lower Palaeozoic sediments, Amadeus Basin, central Australia. Doctor of philosophy thesis, Australian National University.

McKIRDY, D.M. and KANTSLER, A.J., 1980. Oil geochemistry and potential source rocks of the Officer Basin, South Australia. Australian Petroleum Exploration Association Journal, 20, 6886.

McKIRDY, D.M., WATSON, B.L. and MOONEY, B.A., 1984. Optical and pyrolytic characterisation of pre-Devonian oil-prone kerogens. In: Geosciences in the Development of Natural Resources. Seventh Australian Geological Convention, Geological Society of Australia, Abstracts, 12, p. 375.

MELTON, C.E. and GIARDINI, A.A., 1984. Petroleum formation and the thermal history of the earth's surface. Journal of Petroleum Geology, 7, 303-312. 
MEYERHOFF, A.A., 1980. Geology and petroleum fields in Proterozoic and Lower Cambrian strata, Lena-Tunguska Petroleum Province, Eastern Siberia, USSR. In: Halbouty, M.T. (ed.), Giant Fields of the Decade. American Association of Petroleum Geologists Memoir, 30, 225-252.

MONTY, C.L.V., 1976. The origin and development of cryptalgal fabrics. In: Walter, M.R. (ed.): Stromatolites. Developments in Sedimentology, 20, Elsevier, Amsterdam, pp. 193 -249.

MUIR, M.D., 1974. Microfossils of the Middle Precambrian McArthur Group, Northern Territory, Australia. Origins of Life, 5, 105-118.

MUIR, M.D., 1976. Proterozoic microfossils from the Amelia Dolomite, McArthur Basin, Northern Territory. Alcheringa, 1, 143-158.

MUIR, M.D., 1979. A sabkha model for deposition of part of the Proterozoic McArthur Group of the Northern Territory, and implications for mineralization. Bureau of Mineral Resources, Australia, Journal of Australian Geology and Geophysics, 4, 149-162.

MUIR, M.D., 1980. Palaeontological evidence for the Early Cambrian age of the Bukalara Sandstone, McArthur Basin, Northern Territory. Bureau of Mineral Resources, Australia, Journal of Australian Geology and Geophysics, 5, 159-160. 
MUIR, M.D., 1982. A microfossil assemblage for the Wollogorang Formation, Tawallah Group, Middle Proterozoic, N.T., Australia. Bureau of Mineral Resources Australia Record $1982 / 4$.

MUIR, M.D., 1983a - Depositional environments of host rocks to northern Australian lead-zinc deposits, with special reference to McArthur River. Geological Association of Canada/Mineralogical Association of Canada Annual Meeting, Victoria, Canada, May 1983, Short Course Contribution, pp. 141-174.

MUIR, M.D., 1983b. Proterozoic microfossils from the Mara Dolomite Member, Emmerugga Dolomite, Mcarthur Group, from the Northern Territory, Australia. Botanical Journal of the Linnean Society, 86, 1-18.

MUIR, M.D., ARMSTRONG, K.J. and JACKSON, M.J., 1980. Precambrian hydrocarbons in the McArthur Basin, N.T. Bureau of Mineral Resources, Australia, Journal of Australian Geology and Geophysics, 5, 301-304.

MUIR, M.D., DONNELLY T.H., WILKINS R.W.T. and ARMSTRONG K.J., 1985. Stable isotope petrological, and fluid inclusion studies of minor mineral deposits from the McArthur Basin: Implications for the genisis of some sediment-hosted metal mineralization from the Northern Territory. Australian Journal of Earth Sciences, 32, 239-260. 
MURCHISON, D.G., COOK, A.C. and RAYMOND, A.C., 1985. Optical properties of organic matter in relation to thermal gradients and structural deformation. Philosophical Transactions of the Royal Society, London, A315, 157-186.

MURRAY, G.E., KACZOR, M.J. and McARTHUR, R.E., 1980. Indigenous Precambrian petroleum revisited. American Association of Petroleum Geologists Bulletin, 64 (10), 1681 - 1700.

MURRAY, W.J., 1975. McArthur River H.Y.C. lead-zinc and related deposits, Northern Territory. In: Knight, C.L. (ed.), Economic Geology of Australia and Papua New Guinea 1: Metals. Australasian Institute of Mining and Metallurgy, Melbourne, Monograph Series, 5, pp. 329-339.

NORVICK, M.S., 1970. Palynological report on late Precambrian samples from South Australia and Northern Territory. Bureau of Mineral Resources, Australia, Palynological File No. 240.

OEHLER, D.Z., 1978. Microflora of the Middle Proterozoic Balbarini Dolomite (McArthur Group) of Australia. Alcheringa, 2, 269-309.

OEHLER, J.H., 1977. Microflora of the H.Y.C. Pyritic Shale Member of the Barney Creek Formation (McArthur Group-, Middle Proterozoic of Northern Australia. Alcheringa, 1, 315-349. 
OEHLER, J.H., OEHLER, D.Z. and MUIR, M.D., 1976. On the significance of tetrahedral Tetrads of Precambrian Algal Cells. Origins of Life, 7, 259-267.

OGUNYOMI, O., HESSE, R. and HEROUX, Y., 1980. Preorogenic and synorogenic diagenesis and anchimetamorphism in lower Paleozoic continental margin sequences of the northern Appalachians in and around Quebec City, Canada. Bulletin of Canadian Petroleum Geology, 28, 559-577.

PAGE, R.W., 1981. Depositional ages of the stratiform base metal deposits at Mount Isa and McArthur River, Australia, based on $\mathrm{U}-\mathrm{Pb}$ zircon dating of concordant tuff horizons. Economic Geology, 76, 648-658.

PAGE, R.W., MCCULLOCH, M.T. and BLACK, L.P., 1984. Isotopic record of major Precambrian events in Australia. Proceedings 27th International Geological Congress, Moscow, 5, 25-72.

PARNELL, J. and EAKIN, P., 1987. The replacement of sandstones by uraniferous hydrocarbons: significance for petroleum migration. Mineralogical Magazine, 51, 505-515.

PEAT, C.J., 1979. A Proterozoic microbiota from the Roper Group, Australia. Doctor of philodophy thesis, University of London, 298 p. 
PEAT, C.J., MUIR, M.D., PLUMB, K.A., McKIRDY, D.M. and NORVICK, M.S., 1978. Proterozoic microfossils from the Roper Group, Northern Territory, Australia. Bureau of Mineral Resources, Australia, Journal of Australian Geology and Geophysics, 3, $1-17$.

PLUMB, K.A., 1987. Proterozoic extension and mineralisation in the McArthur Basin, Northern Territory, Australia. 16th Bureau of Mineral Resources, Geology and Geophysics, Australia, Research Symposium; Extended Abstracts, Applied Extension Tectonics. Bureau of Mineral Resources, Geology and Geophysics, Australia, Record 1987/51.

PLUMB, K.A. and DERRICK, G.M., 1975. Proterozoic of Kimberley (W.A.) to Mount Isa (Qld.) region - regional geology. In:

Knight, C.L. (ed.), Economic Geology of Australia and Papua New Guinea. 1. Metals. Australasian Institute of Mining and Metallurgy, Monograph Series, 5, pp. 217-252.

PLUMB, K.A. and RHODES, J.M., 1964. Wallhallow, Northern Territory, 1:250,000 Geological Series, Bureau of Mineral Resources, Australia, Explanatory Notes, SE/ 53-7, 21 p.

PLUMB, K.A. and WELLMAN, P., 1987. McArthur Basin, Northern Territory: mapping of deep troughs using gravity and magnetic anomalies. Bureau of Mineral Resources, Australia, Journal of Australian Geology and Geophysics, 10, 243-251. 
PLUMB, K.A., DERRICK, G.M., NEEDHAM, R.S. and SHAW, R.D. 1981. The Proterozoic of Northern Australia. In Hunter, D.R. (ed.), Precambrian of the Southern Hemisphere. Developments in Precambrian Geology 2, Elsevier, Amsterdam, pp. 205-307.

PLUMB, K.A., DERRICK, G.M. and WILSON, I.H., 1980. Precambrian geology of the McArthur River - Mount Isa region, northern Australia. In: Henderson, R.A. and Stephenson, P.J. (eds.), The Geology and Geophysics of Northeastern Australia. Geological Society of Australia, Queensland Division, 4, pp. 71-88.

POWELL, T.G., 1982. Petroleum geochemistry of the Verrill Canyon Formation: a source for Scotian Shelf hydrocarbons. Bulletin of Canadian Petroleum Geology, 30, 167-179.

PRICE, L.C., 1983. Geologic time as a parameter in organic metamorphism and vitrinite reflectance as an absolute paleogeothermometer. Journal of Petroleum Geology 6(1), 5-38.

PRICE, L.C. and BARKER, C.E., 1985. Suppression of vitrinite reflectance in amorphous rich kerogen - a major unrecognized problem. Journal of Petroleum Geology, 8, 59-84.

RADKE, M. and WELTE, D.H., 1983. The Methylphenanthrene Index (MPI): a maturity parameter based on aromatic hydrocarbons. In: Bjoroy, M. et al. (eds.), Advances in Organic Geochemistry 1981, Wiley, Chichester, pp. 504-512. 
RADKE, M., LEYTHAEUSER, D. and TEICHMULLER, M., 1984. Relationship between rank and composition of aromatic hydrocarbons for coals of different origins. In: Schenck, P.A., De Leeuw, J.A. and Lijmbach, G.W.M. (eds.), Advances in Orgaric Geochemistry 1983. Organic Geochemistry, 6, 423-430.

RADKE, M., WELTE, D.H. and WILLSCH, H., 1982a. Geochemical study on a well in the Western Canada Basin: relation of the aromatic distribution pattern to maturity of organic matter. Geochimica et Cosmochimica Acta, 46, 1 -10.

RADKE, M., WILLSCH, H., LEYTHAEUSER, D. and TEICHMULLER, M., 1982b. Aromatic components of coal: relation of distribution pattern to rank. Geochimica et Cosmochimica Acta, 46, 18311848.

RICHARDS, J.R., 1963. Isotopic composition of Australian leads, III, northwestern Queensland and the Northern Territory - A reconnaissance. Geochimica et Cosmochimica Acta, 27, 217240 .

ROBERT, P., 1973. Analyse microscopique des charbons et des bitumes disperses dans les roches et mesure de leur povoir reflecteur. Application a l'etude de la paleogeothermie des bassins sediment aires et de la genese des hydrocarbures. In: Tissot, B. and Bienner, F. (eds.), Advances in Organic Geochemistry 1972, Rueil-Malmaison, pp. 549-69. 
ROBERT, P., 1980. The optical evolution of kerogen and geothermal histories applied to oil and gas exploration.

In: Durand, B. (ed.), Kerogen. Editions Technip, Paris, pp. 386-412.

ROBINSON, B.W. and NICKEL, E.H., 1979. A useful new technique for mineralogy: the backscattered electron/low vacuum mode of SEM operation. American Mineralalogist, 64, 1322-1328.

ROBINSON, V.N.E., 1980. Imaging with backscattered electrons in a scanning electron microscope. Scanning, 3, 15-26.

SCHIDLOWSKI, M., 1969. Critical remarks on a postulated genetic relationship between Precambrian thucholite and boghead coal. In: Schenk, P.A. and Havenaar, I. (eds.), Advances in Organic Geochemistry 1968, Pergamon, Oxford, pp. 579-592.

SCHOPF, J.W. (ed.), 1983. Earth's earliest biosphere. Princeton University Press, Princeton, N.J., 543 p.

SHERGOLD, J.H. and DRUCE, E.C., 1980. Upper Proterozoic and lower Palaeozoic rocks of the Georgina Basin. In: Henderson, R.A. and Stephanson, P.J. (eds.): The Geology and Geophysics of North-Eastern Australia. Geological Society of Australia, Queensland Division, 4, pp.149-174. 
SHERWOOD, N.R. and COOK, A.C., 1984. Final Project Report to the Department of National Development and Energy on NERD \& D Program Project 79/9014. Low Rank Oil Shales: Part 1 Organic Petrology. Department of Geology, University of Wollongong, pp. 293.

SILLER, C.W., MURRAY, G. E., HOPKINS, R. M. and McNAUGHTON, D. A., 1963. Aussie strike attacts interest. Oil and Gas Journal $61,189-191$.

SILVERMAN, S.R., 1971. Influence of petroleum origin and transformation on its distribution and redistribution in sedimentary rocks. Eighth World Petroleum Congress Proceedings, 2, 47-54.

SMIT, G., 1984. Some aspects of the uranium minerals in the Witswatersrand sediments of the Early Proterozoic. Precambrian Research, 25, 37-59.

SMITH, G.C. and COOK, A.C., 1980. Coalification paths of exinite, vitrinite and inertinite. Fuel, 59, 641-646.

SMITH, J.W. 1964. Bauhinia Downs, Northern Territory 1:250,000 Geological Series, Bureau of Mineral Resources, Australia, Explanatory Notes, SE/ 53-3, 20 p.

SMITH, J.W. and CROXFORD, N.J.W., 1973. Sulphur isotope ratios in the McArthur lead-zinc-silver deposit. Nature, 245, 10-12. 
SNOWDON, L.R., 1979. Errors in extrapolation of experimental kinetic parameters to organic geochemical systems. American Association of Petroleum Geologists Bulletin, 63, 1128 1138.

SOUDRY, D. and SOUTHGATE, P.N., 1989. Ultrastructure of a Middle Cambrian nonpelletal phosphorite and its early transformation in phosphate vadoids: Georgina Basin, Australia. Journal of Sedimentary Petrology, 59, 53-64.

STACH, E., MACKOWSKY, M.-TH., TEICHMULLER, M., TAYLOR, G.H., CHANDRA, D. and TEICHMULLER, R., 1982. Stach's textbook of coal petrology. Third Edition, Gebruder Borntraeger, Berlin, $535 \mathrm{p}$.

STAPLIN, F.L., POCOCK, S.J., JANSONIUS, J. and OLIPHANT, E.M., 1960. Palynological techniques for sediments. Micropaleontology, 6, 329-331.

STOPES, M.C., 1935. On the petrology of banded bituminous coals. Fuel, 14, 4-13.

SUMMONS, R.E., POWELL, T.G. and BOREHAM, C.J., 1988. Petroleum geology and geochemistry of the middle Proterozoic McArthur Basin, northern Australia, III. Composition of extractable hydrocarbons. Geochimica et Cosmochimica Acta 52, 1747 1763. 
TEICHMULLER, M., 1974. Generation of petroleum-like substances in coal seams as seen under the microscope. In: Tissot, B. and Bienner, F. (eds.), Advances in Organic Geochemistry 1973, Editions Technip, Paris, pp. 321-348.

TEICHMULLER, M., 1980. Recherche sur la fluorescence en microscopie et diagenese des matieres organiques dans les charbons et les schistes bitumineux. In: Kubler, B. and Zweidler, D. (eds.): Geologie du Petrole. 3eme Cycle Romand des Sciences de le Terre, Neuchatel, pp. 1-19.

TEICHMULLER, M., 1986. Organic petrology of source rocks, history and state of the art. Organic Geochemistry, 10, 581- 599.

TISSOT, B.P. and WELTE, D.H., 1978. Petroleum Formation and Occurrence. 1st. edition, Springer-Verlag, Berlin, 527 p.

TISSOT, B.P. and WELTE, D.H., 1984. Petroleum Formation and Occurrence. 2nd. edition, Springer-Verlag, Berlin, 699 p.

TISSOT., B.P., DURAND, B., ESPITALIE, J. and COMBAZ, A., 1974. Influence of nature and diagenesis of organic matter in formation of petroleum. American Association of Petroleum Geologists Bulletin, 58, 499-506.

TISSOT, B.P., PELET, R. and UNGERER, PH., 1987a. Thermal history of sedimentary basins, maturation indices, and kinetics of oll and gas generation. American Association of Petroleum Geologists Bulletin, 71, 1445-1466. 
TISSOT, B.P., WELTE, D.H. and DURAND, B., 1987b. The role of geochemistry in exploration risk evaluation and decision making. Twelth World Petroleum Congress Proceedings, Part $3,1-14$.

TUCKER, D.H. and BOYD, D.M., in press. Dykes of Australia detected by airborne magnetic surveys. Geological Association of Canada, Special Paper on Mafic Dyke Swarms.

TYLER, S.A., BARGHORN, E.S. and BARRETT, L.P., 1957. Anthracitic coal from the Precambrian Upper Huronian shale of the Iron

River District, Northern Michigan. Bulletin of the Geological Society of America, 66, 1293-1304.

VAN KREVELEN, D.W., 1961. Coal; Typology, Chemistry, Physics and Constitution. Elsevier, Amsterdam, 514 p.

VASSOEVICH, N.B., 1971. The source of petroleum: A biogenic carboniferous substance. Priroda, 3, 58-69.

WADE, A., 1926. The search for oil in Australia. Journal of the Institute of Petroleum Technology, 12, 145-172.

WALKER, R.N., GULSON, B. and SMITH, J.W. 1983. The Coxco Deposit. A Proterozoic Missippi Valley-type deposit in the McArthur River district, Northern Territory, Australia. Economic Geology, 78, 214-249. 
WALTER, M.R., 1972. Stromatolites and the biostratigraphy of the Australian Precambrian and Cambrian. Special Papers in Palaeontology, The Palaeontological Association, London, 11, $190 \mathrm{p}$.

WALTER, M.R., GOODE, A.D.T. and HALL, W.D.M., 1976. Microfossils from a newly discovered Precambrian stromatolitic iron formation in Western Australia. Nature, 261, 221-223.

WALTER, M.R., KRYLOV, I.N. and MUIR, M.D., 1988. Stromatolites from the Middle and Late Proterozoic sequences in the McArthur and Georgina Basins and the Mount Isa Province, Australia. Alcheringa, 12, $79-106$.

WAPLES, D.W., 1980. Time and temperature in petroleum formation: Application of Lopatin's method to petroleum exploration. American Association of Petroleum Geologists Bulletin, 64, 916-929.

WAPLES, D.W., 1981. Organic Geochemistry for Exploration Geologists. Burgess Publishing Co., U.S.A, 151 p.

WEBB, A.W., McDOUGALL, I. and COOPER, J.A., 1963. Retention of radiogenic argon in glauconites from Proterozoic sediments, northern Australia. Nature, 199, 270-271. 
WEN, C.S., CHILINGARIAN, G.V. and YEN, T.F., 1978. Properties and structure of bitumens. In: Chilingarian, G.V. and Yen, T.F. (eds.), Bitumens, Asphalts and Tar sands. Developments in Petroleum Science, 7, Elsevier, Amsterdam, pp.155-190.

WILLIAMS, N., 1978a. Studies of base metal sulphide deposits at McArthur River, Northern Territory, Australia, I. The Cooley and Ridge Deposits. Economic Geology, 73, 1005-1035.

WILLIAMS, N., 1978b. Studies of base metal sulphide deposits at McArthur River, Northern Territory, Australia, II. The sulphide$S$ and organic-C relationships of the concordant deposits and their significance. Economic Geology, 73, 1036-1056.

WILLIAMS, N. and LOGAN, R.G., 1981. Depositional environments of the sediments hosting the McArthur River stratiform $\mathrm{Pb}-\mathrm{Zn}$ deposits. In: Groves, D.I. et al. (eds.), Sediments through the Ages. Fifth Australian Geological Convention, Perth. Geological Society of Australia, Abstracts, 3, p. 8.

WILLIAMS, N. and RYE, D.M., 1974. Alternative interpretation of sulphur isotope ratios in the McArthur lead-zinc-silver deposit. Nature, 247, 535-537.

WOMER, M.B., 1986. Hydrocarbon occurrences and diagenetic history within Proterozoic sediments, McArthur River area, Northern Territory, Australia. Australian Petroleum Exploration Association Journal 26, 363-374. 
Article below removed for copyright reasons, please refer to the citation:

Petroleum Geology and Geochemistry of Middle

Proterozoic McArthur Basin, northern Australia II

Assessment of Source Rock Potential, by I. H. Crick,

C. J. Boreham, A. C. Cook, and T. G. Powell. The

American Association of Petroleum Geologists

Bulletin, v. 72, no. 12 (December 1988),

pp. 1495 - 1514 . 


\section{VOLUME 2}

A thesis submitted in fulfilment of the requirements for the award of the degree of

DOCTOR OF PHILOSOPHY

from

THE UNIVERSITY OF WOLLONGONG

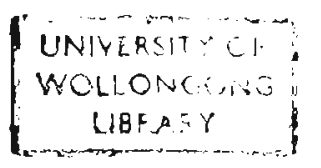

by

\section{IAN H. CRICK}

(B.Sc.(Hons), University of Melbourne, 1967)

Department of Geology 
CONTENTS

page

LIST OF PLATES

APPENDIX A LOCATION OF DRILLHOLES IN THENATHAN AND

1

MCARTHUR GROUPS

APPENDIX B LOCATION OF DRILLHOLES IN THE ROPER GROUP 5

APPENDIX C ROCKTYPES AND ORGANIC MATTER TYPES, NATHAN

AND MCARTHUR GROUPS

APPENDIX D ROCK AND ORGANIC MATTER TYPES, ROPER GROUP

APPENDIX E SCANNING ELECTRONMICROSCOPEDATA

APPENDIX F

REFLECTANCE MEASUREMENTS, NATHAN AND

APPENDIX G MCARTHUR GROUPS

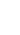

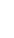

APPENDIX H

APPENDIX I

APPENDIX J

APPENDIX K

APPENDIX L

APPENDIX M

APPENDIX N

APPENDIX 0

APPENDIX P

APPENDIX Q

APPENDIX R
REFLECTANCE MEASUREMENTS, ROPER GROUP

REFLECTANCE HISTOGRAMS FOR SELECTED SAMPLES CONTAINING BOTH FLUORESCENT AND NONFLUORESCENT LAMALGINITE

REFLECTANCE HISTOGRAMS FOR SELECTED SAMPLES CONTAINING LAMALGINITE AND BITUMEN

REFLECTANCE TRAVERSES OF THUCHOUTES

INTHE MCARTHUR AND NATHAN GROUPS

REFLECTANCE VERSUS DEPTH GRAPHS FOR DRILLHOLES INTHE ROPER GROUP

52

CALCULATIONS USING WAPLES (1981)

AND PRICE (1983) METHODS

ROCK-EVAL AND ORGANIC CARBON ANALYSES

84

SOLUBLE EXTRACT AND HYDROCARBON YIELDS

119

AROMATIC MATURATION INDICES

129

ELEMENTAL ANALYSES OF ISOLATED KEROGENS

134

PHOTOMICROGRAPHS 


\section{LIST OF PLATES}

PLATE 1 Abner Range; measuring geothermal gradients;

microscope room.

PLATE 2 Probable microfossils, McArthur Basin.

PLATE 3 Fluorescent lamalginite from the Barney Creek Formation, Glyde River Subbasin, DDH's GR3, 5 \& 7; low magnification photomicrographs.

PLATE 4 Fluorescent lamalginite from the Barney Creek Formation, Glyde River Subbasin, DDH GR10, low magnification photomicrographs.

PLATE 5 Fluorescent lamalginite from the Barney Creek Formation, Glyde River Subbasin, DDH GR10, 88.4m - 442.9m.

PLATE 6 Low fluorescent lamalginite and bitumen from the Barney Creek Formation, Glyde River Subbasin, DDH GR 10, $575.3 \mathrm{~m}$.

PLATE 7 Bitumen in the Barney Creek Formation, Glyde River Subbasin, DDH GR10.

PLATE 8 Thucholite and radiation-affected lamalginite, Barney Creek Formation, Glyde River Subbasin, DDH GR10.

PLATE 9 Fluorescent lamalginite, matrix and disseminated bitumen, Barney Creek Formation, Glyde River Subbasin, DDH's GR3 \& 7.

PLATE 10 Kerogen (fluorescent lamalginite) in strew mounts and SEM photographs of fluorescent lamalginite, Barney Creek Formation, Glyde River Subbasin, DDH GR10.

PLATE 11 A titaniferous bitumen nodule, containing possible filamentous microfossils; Barney Creek Formation, Glyde River Subbasin, DDH GR10, $37.4 \mathrm{~m}$; perpendicular to bedding. 
PLATE 12 A pyritic nodule containing oil inclusions, Barney Creek Formation, Glyde River Subbasin, DDH GR10, 37.4 m.

PLATE 13 A titaniferous bitumen nodule, Barney Creek Formation, Glyde River Subbasin, DDH GR10, $37.4 \mathrm{~m}$.

PLATE 14 A titaniferous bitumen nodule, Barney Creek Formation, Glyde River Subbasin, DDH GR10, $37.4 \mathrm{~m}$.

PLATE 15 SEM $X$-ray maps of a fluorescent lamalginite body and surrounding mineral matrix, Barney Creek Formation, Glyde River Subbasin, DDH GR10, $92.6 \mathrm{~m}$.

PLATE 16 SEM X-ray maps of a large mat of fluorescent lamalginite, Barney Creek Formation, Glyde River Subbasin, DDH GR5, $72.5 \mathrm{~m}$.

PLATE 17 A scoured bed containing phosphate and fluorescent lamalginite, Barney Creek Formation, Glyde River Subbasin, DDH GR7, $180.0 \mathrm{~m}$.

PLATE 18 SEM images of the phosphate nodule shown in Plate 17a from the Barney Creek Formation, Glyde River Subbasin, DDH GR7, 180.0 m.

PLATE 19 Phosphate laminae and nodule from the Barney Creek Formation, Glyde River Subbasin, DDH GR7, $180.0 \mathrm{~m}$.

PLATE 20 Phosphate laminae and nodule from the Barney Creek Formation, Glyde River Subbasin, DDH GR7, $180.0 \mathrm{~m}$.

PLATE 21 SEM X-ray maps of a thucholite grain, Barney Creek Formation, Glyde River Subbasin, DDH GR10, $37.4 \mathrm{~m}$.

PLATE 22 SEM X-ray maps of a thucholite grain, Barney Creek Formation, Glyde River Subbasin, DDH GR10, $297.2 \mathrm{~m}$.

PLATE 23 SEM X-ray maps of a thucholite grain, Barney Creek Formation, Glyde River Subbasin, DDH GR10, $297.2 \mathrm{~m}$. 
PLATE 24 Organic matter from the Yalco and Lynott Formations, central Batten Trough, McArthur Group.

PLATE 25 Organic matter in the Barney Creek Formation and Emmerugga, Teena and Reward Dolomites from the central and northern parts of the Batten Trough.

PLATE 26 Organic matter in the Cobanbarini Formation, "Lansen Creek Shale Member", Roper Group, Broadmere 1 well.

PLATE 27 Organic matter in the lower Roper Group (Mainoru Formation to Bessie Creek Sandstone), Broadmere 1 well.

PLATE 28 Organic matter in the Velkerri Formation, Maiwok Subgroup, Roper Group, DDH Urapunga 3.

PLATE 29 Vein bitumen, Velkerri Formation, Maiwok Subgroup, Roper Group, DDH Urapunga 3, $98.3 \mathrm{~m}$.

PLATE 30 Carbonate and pyrite pseudomorphs after gypsum, and organic matter in the Velkerri Formation, Maiwok Subgroup, Roper Group, DDH Urapunga $3,120.0$ to $150.1 \mathrm{~m}$.

PLATE 31 Organic matter in the Velkerri Formation, Maiwok Subgroup, Roper Group, DDH Urapunga 3, 150.1 to $210.7 \mathrm{~m}$.

PLATE 32 Oncolites, McMinn Formation, Maiwok Subgroup, Roper Group; DDH Urapunga $4,32.3 \mathrm{~m}$.

PLATE 33 Oncalginite and bitumen, McMinn Formation, Maiwok Subgroup, Roper Group, DDH Urapunga 4, $32.3 \mathrm{~m}$.

PLATE 34 Organic matter in the Velkerri Formation, Maiwok Subgroup, Roper Group, DDH Urapunga $4 ; 157.3$ to $209.5 \mathrm{~m}$.

PLATE 35 Organic matter in the Velkerri Formation, Maiwok Subgroup, Roper Group, DDH Urapunga $4 ; 258.5$ to $348.2 \mathrm{~m}$. 
PLATE 36 Organic matter in the Velkerri and Corcoran Formations, Roper Group, DDH Urapunga $4 ; 354.7$ to $463.8 \mathrm{~m}$.

PLATE 37 Organic matter in the McMinn Formation, Maiwok Subgroup, Roper Group, DDH X28.

PLATE $38 \quad$ Thucholite grains in the Roper Group.

PLATE 39 Possible pseudomorphs after gypsum in the Velkerri Formation and organic matter in the Velkerri Formation, Abner Sandstone and Mainoru Formation in DDH's 82/1,2,3 \& 8.

PLATE 40 Organic matter in the Abner Sandstone and Mainoru Formation, Roper Group; DDH's Urapunga 1 \& 5.

PLATE 41 SEM X-ray maps of bitumen veins in the Velkerri Formation, DDH Urapunga $3,98.3 \mathrm{~m}$.

PLATE 42 SEM images and X-ray maps of phosphates in the Roper Group. 
$\mathrm{DDH} / \mathrm{Fm}$.

GR1 (Amoco)

Bukalara Sst.

Barney Creek Fm. 13.6 - 359.0 T.D.

GR2 (Amoco)

Bukalara Sst. $0-45.5$

Bauhinia Doowns $16^{\circ} 56^{\prime}, 136^{\circ} 17^{\prime}$ Glyde

Barney Creek Fm. 45.5 - 239.0 T.D.

GR3 (Amoco)

Bukalara Sst.

Bauhinia Downs

$16^{\circ} 52^{\prime}, \quad 136^{\circ} 14^{\prime}$ Glyde $0-14.2$

Barney Creek Fm. 14.2 - 458.0

Coxco Dolomite 458.0 - 509.0 T.D

GR4 (Amoco)

Bukalara Sst.

Bauhinia Downs $16^{\circ} 59^{\prime}, 136^{\circ} 18^{\prime}$ Glyde $0-89.0$

Barney Creek Fm. 89.0 - 208.0

Coxco Dolomite 208.0 - 275.0 T.D.

GR5 (Amoco/Kennecott) Bauhinia Downs 16 $53^{\prime}, 136^{\circ} 17^{\prime}$ Glyde Bukalara Sst. $\quad 0-23.0$

Reward Dolomite $23.0-41.5$

Barney Creek Fm. 41.5 - 512.7 T.D.

\section{GR6 (Amoco)}

Bauhinia Downs

McArthur or Tawallah

Group (uncertain) 0 - 194.0 T.D.

GR7 (Amoco/Kennecott) Bauhinia Downs 16 $54^{\prime}$, 136 $16^{\prime}$ Glyde Bukalara Sst. $\quad 0-34.2$

Barney Creek Fm. 34.2 - 917.0 T.D.

GR8 (Kennecott)

Bukalara Sst.

Bauhinia Doowns $16^{\circ} 59^{\prime}, 136^{\circ} 20^{\prime}$ Glyde

418206

Barney Creek Fm. 10.2 - 613.0 T.D.

GR9 (Kennecott)

Bukalara Sst.

Bauhinia Downs

$16^{\circ} 58^{\prime}, \quad 136^{\circ} 19^{\prime}$ Glyde

402238

Barney Creek Fm. 42.5 - 501.8

Coxco Dolomite 501.76 - 534.0 T.D.

GR10 (Shell)

Bukalara Sst. $0-12.0$

Bauhinia Downs

$16^{\circ} 56^{\prime}, \quad 136^{\circ} 18^{\prime}$ Glyde

392277

Barney Creek Fm. 12.0 - 699.1

Coxco Dolomite 699.1 - 704.0 T.D.

GR11 (Shell)

Bukalara Sst.

Wallhallow

Barney Creek Fm. 10.5 - 451.0

Coxco Dolomite 451.0 - 470.0 T.D.

366275

317333

385204

362319

385306

318579 
$\begin{array}{lccccc}\mathrm{DDH} / \mathrm{Fm} . & \text { depth(m) } \begin{array}{c}1: 250,000 \\ \text { she t t }\end{array} & \text { lat. } & \text { long. } & \begin{array}{c}1: 100,000 \\ \text { sheet }\end{array} & \text { grid ref. } \\ \text { Bauhinia Downs } & 16^{\circ} 25^{\prime}, 135^{\circ} 56^{\prime} & \text { Batten } & 001835\end{array}$

(A.O.(Aust.) Pty. Ltd./Shell)

Lynott Fm. $\quad 0-27.0$

?Reward Dolomite $27.0-28.0$

Barney Creek Fm. 28.0 - 53.0

Coxco Dolomite 53.0 - 101.0 T.D.

$\begin{array}{llllll}\text { B B 2 (Shell) } & \text { Mount Young } & 15^{\circ} 48^{\prime}, 135^{\circ} 58^{\prime} & \begin{array}{c}\text { Tawallah } \\ \text { Range }\end{array} & 042533 \\ \text { Lynott Fm. } & 0-35\end{array}$

Reward Dolomite $35-255$

Bamey Creek Fm. $255-420$

Teena Dolomite 420 - 443 T.D.

BB5 (Shell) Mount Young $15^{\circ} 47^{\prime}, 136^{\circ} 03^{\prime}$ Bing Bong 108539

Lynott Fm. $\quad 0-65$

Reward Dolomite $65-220$

Barney Creek Fm. 220 - 350

Teena Dolomite $350-370$ T.D.

BJ3 Bauhinia Downs $16^{\circ} 26^{\prime}, 135^{\circ} 26^{\prime}$ Batten 991842

(A.O.(Aust) Pty. Ltd./Shell)

Lynott Fm. $\quad 0-4.7$

?Reward Dolomite 54.7 - 57.7

Bamey Creek Fm. 57.7 - 135.0

Coxco Dolomite 135.0 - 151.5 T.D.

BJ6 Bauhinia Downs $16^{\circ} 24^{\prime}, 135^{\circ} 53^{\prime}$ Batten 933865

(A.O.(Aust) Pty. Ltd./Shell)

Lynott Fm. $\quad 0-204.0$ T.D.

CA 1

Bauhinia Downs $16^{\circ} 18^{\prime}, 136^{\circ} 05^{\prime}$ Borroloola 149977

(C.R.A.E., Amoco)

Lynott Fm. $\quad 0-200$

Reward Dolomite $200-300$

Barney Creek Fm. $300-610$ TD

CA 2

(C.R.A.E., Amoco)

Lynott Fm. $\quad 0-166$

Reward Dolomite $166-479$

Barney Creek Fm. 479 - 632

Coxco Dolomite $632-688$ TD

CA 3

(C.R.A.E., Amoco)

Lynott Fm. $\quad 0-189$

Reward Dolomite $189-405$

Barney Creek Fm. $405-567$

Cooley Dolomite $567-718$ TD

APPENDIX A ctd. Locations and stratigraphy of drill holes (BJ-1 - CA3) Nathan and McArthur Groups, central and northern Batten Trough 


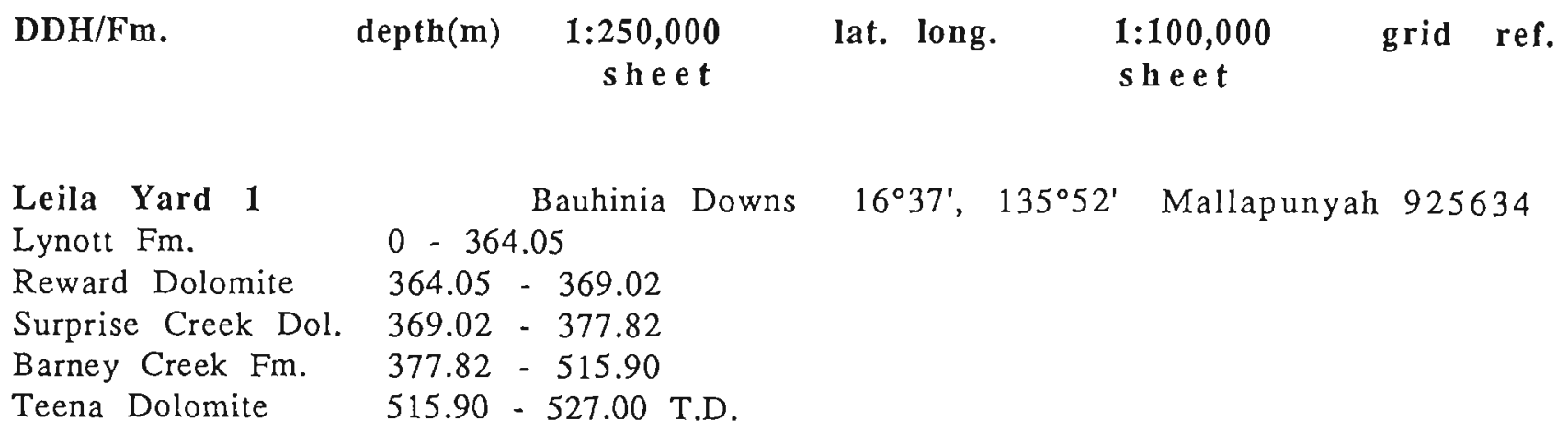


DDH/Fm. depth(m) $\begin{gathered}1: 250,000 \\ \text { sheet }\end{gathered} \quad$ lat. long. $\begin{gathered}1: 100,000 \\ \text { sheet }\end{gathered}$ grid ref.

$\begin{array}{llrl}\text { WM6 } & \text { Mount Young } 15^{\circ} 35^{\prime}, 135^{\circ} 55^{\prime} & \begin{array}{c}\text { Tawallah } \\ \text { (Shell, A.O.(Aust.)Pty. Ltd.) }\end{array} & 979775\end{array}$

Lynott Fm. $\quad 0-42.00$

Reward Dolomite $\quad 42.00-91.63$

Bamey Creek Fm. 91.63 - 543.00 T.D.

$82 / 4 \quad$ Mount Young $15^{\circ} 30^{\prime}, 135^{\circ} 07^{\prime}$ Towns 130867

Balbarini Dolomite $0-222$

unspec McA. Gp. $222-541$ TD

$82 / 5 \quad$ Bauhinia Downs 16 $26^{\circ}$, 135 $58^{\prime}$ Batten 037062

Donnegan Member $0-45$

Hot Spring Member $45-455 \mathrm{TD}$

(Lynott Fm.)

$82 / 6 \quad$ Bauhinia Downs 16²4, 136 $16^{\prime}$ Glyde 319527

Looking Glass Fm. $0-23$

Stretton Sandstone $23-42$

Yalco Formation $42-266$

Lynott Formation $266-300$ TD

$82 / 7$ Bauhinia Downs $16^{\circ} 46^{\prime}, 136^{\circ} 00^{\prime}$ Mallapunyah 6064445

Balbarini Dolomite $0-54.7$

Looking Glass Fm. 54.7 - 81.0

Stretton Sandstone $81.0-116$

Yalco Formation $116-269$

Lynott Formation $269-464$ TD

APPENDIX A ctd. Locations and stratigraphy of drill holes (WM6 - 82/7), Nathan and McArthur Groups, central and northern Batten Trough. 
DDH/Fm. depth(m) 1:250,000 lat. long. 1:100,000 grid ref.

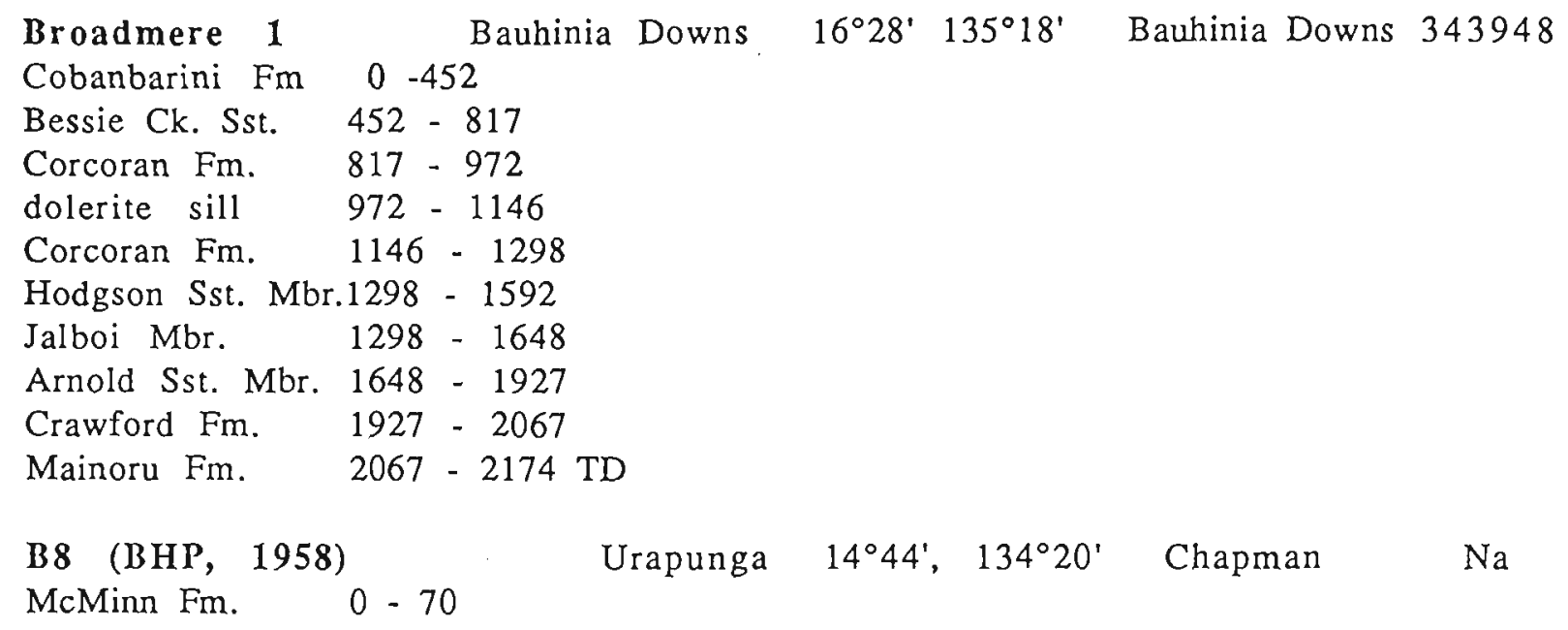

APPENDIX B. Location and stratigraphy of drill holes (Broadmere 1 - Urapunga 4) in the Roper Group 

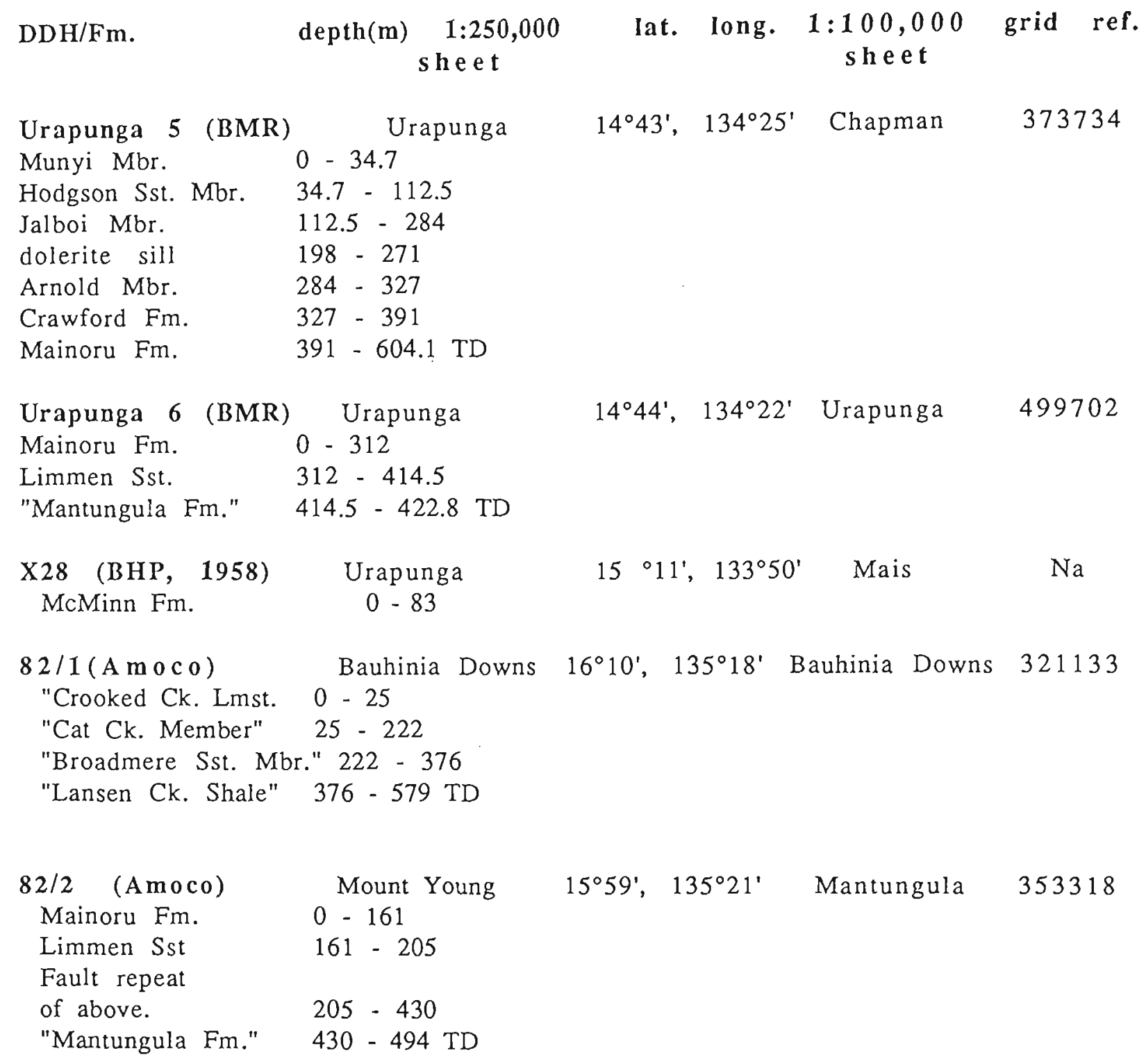
82/3 (Amoco) Hodgson Mbr. Jalboi Mbr. Mount Young $15^{\circ} 44^{\prime}, 135^{\circ} 16^{\prime} \quad$ Mantungula 285605 Arnold Mbr. Crawford Fm. Mainoru Fm. $0-144.9$ $144.9-243.3$ $243.3-287.1$ $287.1-459.0$ 459.0 - 592 TD

82/8 (Amoco) Velkerri Fm. Bauhinia Downs $0-103$ $16^{\circ} 41^{\prime}, 135^{\circ} 49^{\prime} \quad$ Mallapunyah 880553 Bessie Ck. Sst. $103-221 \mathrm{TD}$

APPENDIX B ctd. Location and stratigraphy of drill holes (Urapunga 5 - 82/8) in the Roper Group. 
DDH/Fm.

GR 1

Barney Ck. Fm.

26.5 dark grey calcilutite

lam., thuch.

92.2 dark grey calcilutite

lam., thuch.

279.5 light grey to dark grey banded calcilutite

320.2 dark grey calcilutite

lam., thuch.

\section{GR 2}

Barney Ck. Fm. 62.9 dark grey calcilutite

180.5 grey calcilutite grading into fine calcarenite

238.2 dark grey calcilutite

d.b., nf. lam., thuch.

\section{GR 3}

30.1 dark grey calcilutite

162.8 dark grey calcilutite

302.6 dark grey calcilutite

lam., thuch.

lam.,thuch.

lam.,nf. lam., p.d.b., thuch.

$\begin{array}{lll}\text { Barney Ck. Fm. } & 30.1 & \text { dark grey calcilutite } \\ & 162.8 & \text { dark grey calcilutite } \\ & 302.6 & \text { dark grey calcilutite }\end{array}$

lam., thuch. lam., thuch.

GR 4

Barney Ck. Fm. 107.7 laminated light and dark grey calcilutite

129.5 laminated light and dark grey calcilutite, carbonate veins

151.4 laminated light and dark grey calcilutite

162.6 laminated off-white and black calcilutite

GR 5

Barney Ck. Fm.

72.5 dark grey calcilutite grading

into fine calcarenite

150.0 dark grey calcilutite

306.3 dark grey calcilutite

426.0 laminated light and dark

grey calcilutite

494.8 dark grey calcilutite

GR7

38.7 dark grey calcilutite

50.3 dark grey calcilutite

180.0 dark grey calcilutite containing thin phosphate laminae

238.8 dark grey calcilutite

426.7 dark grey calcilutite

601.5 dark grey calcilutite grading into very fine calcarenite

794.6 dark grey calcilutite, minor thin carbonate veins

854.0 dark grey calcilutite

lam., thuch.

lam., nf. lam., p.d.b., thuch. p.d.b., nf. lam., lam.

$$
\text { p.d.b., d.b., v.b. }
$$

lam., thuch. lam., thuch.

lam.,nf. lam, p.d.b., d.b., thuch.

d.b., nf. lam., lam., p.d.b., thuch. lam., nf. lam., d.b., p.d.b., thuch.

$$
\begin{aligned}
& \text { lam., thuch. } \\
& \text { lam., thuch. } \\
& \text { lam., thuch. } \\
& \text { lam., thuch. } \\
& \text { lam., thuch. }
\end{aligned}
$$

lam., nf. lam., p.d.b., thuch.

p.d.b., thuch.

p.d.b., thuch.

\section{ABBREVIATIONS}

lam. = fluorescent lamalginite;

nf. lam. = nonfluorescent lamalginite;

p.d.b. = patchy dispersed bitumen; d.b.= disseminated bitumen;

v.b. = vein bitumen; m.b. = matrix bitumen; vg.b. = vug bitumen thuch = thucholite;

\section{APPENDIX C. Rock and organic matter types, Nathan and McArthur Groups, DDH's GR1 - 7.}


GDH 8

Barney CK. Fm.
49.2 dark grey calcilutite grading

into fine calcarenite

250.4 laminated light grey and dark grey calcilutite

349.3 dark grey calcilutite

451.0 dark grey calcilutite

570.8 dark grey calcilutite

GR 9

Barney Ck. Fm.

GR 10

Barney Ck. Fm. 23.2 dark grey caicilutite

37.4 laminated, grey calcilutite grading into fine calcarenite, with greenish-grey tuffaceous laminae

88.4 dark grey calcilutite

92.6 very fine carbonate pebble $(\leq 4 \mathrm{~mm})$ conglom., black lutite bed

133.8 dark grey calcilutite

137.3 dark grey calcilutite grading into fine calcarenite

141.9 dark grey calcilutite

143.3 dark grey calcilutite

146.4 dark grey calcilutite grading into fine calcarenite

155.2 dark grey calcilutite grading to very fine carbonate $(\leq 4 \mathrm{~mm})$ conglom.

170.3 very fine calcarenite

232.8 dark grey calcilutite

297.2 dark grey calcilutite

304.4 grey calcilutite grading into

light grey fine calcarenite

410.0 dark grey calcilutite grading into

fine calcarenite

443.0 grey calcilutite, trace glauconite

514.2 dark grey calcilutite

575.3 laminated, grey calcilutite grading into fine calcarenite

602.5 dark grey calcilutite

646.9 dark grey calcilutite

662.1 calcilutite grading into fine calcarenite
Organic matter types

lam., thuch.

lam., thuch.

lam., nf. lam., d.b., p.d.b., thuch. nf. lam., p.d.b., d.b., thuch. nf. lam., p.d.b., d.b., thuch.

lam., thuch.

lam., thuch.

lam., nf. lam., p.d.b., thuch. nf. lam., p.d.b., d.b., thuch.

lam., thuch lam., thuch., titaniferous bitumen lam., thuch.

lam, thuch

lam., thuch

lam.

lam., thuch.

lam., thuch.

lam., thuch

lam., thuch

lam., thuch.

lam., thuch.

lam., thuch.

lam., thuch

lam., thuch. lam., nf. lam.,v.b., p.d.b., d.b., thuch. lam., thuch. lam., nf. lam., d.b., p.d.b., thuch. nf. lam., p.d.b., thuch.

v.b.

v.b. 


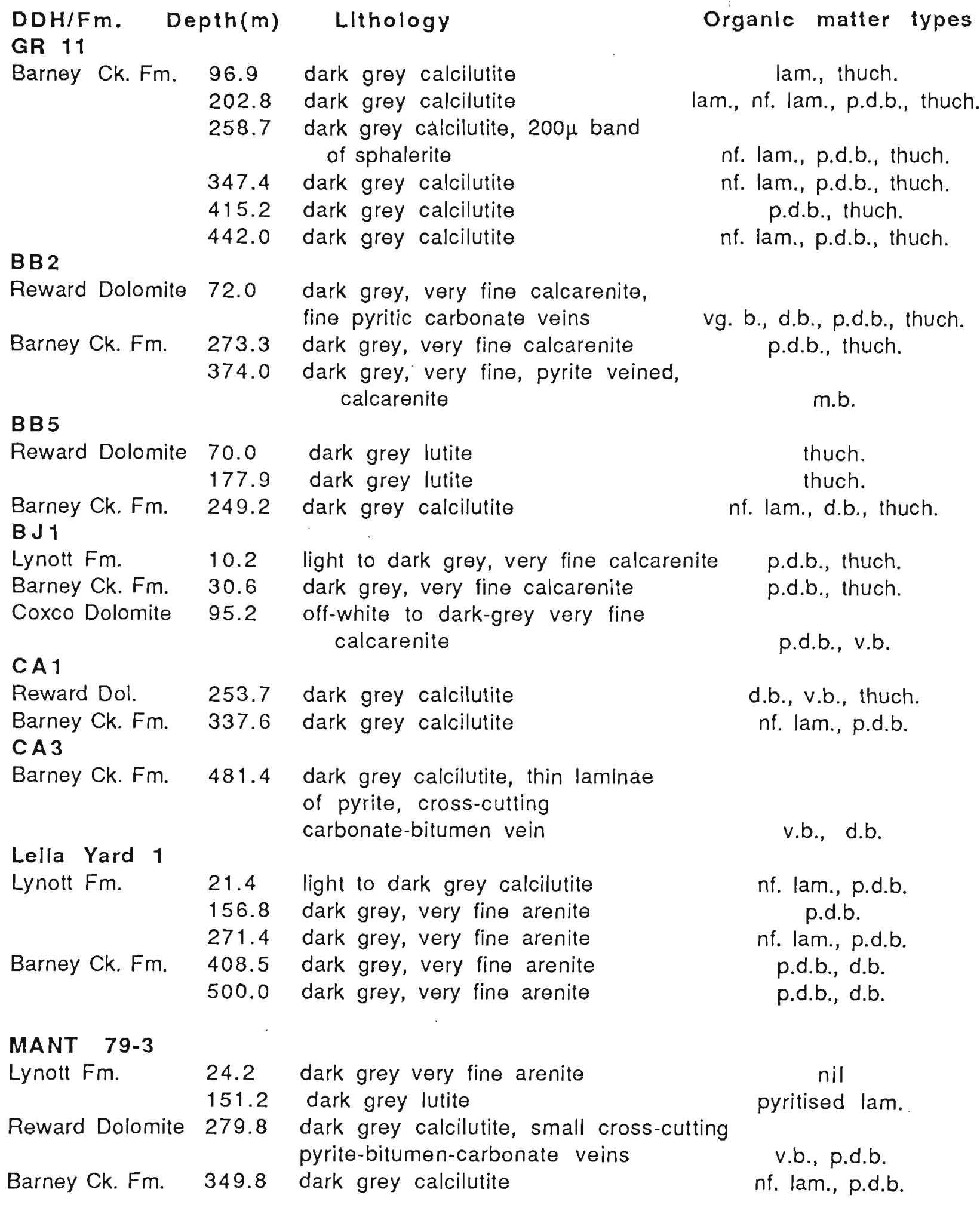

\footnotetext{
APPENDIX C ctd. Rock and organic matter types, Nathan and McArthur Groups, Glyde River Subbasin, DDH GR11, and central and northern Batten Trough (DDH's BB2 - MANT 79-3)
} 
McA 5

Barney Ck. Fm.

Teena Dolomite

McA. 10

Barney Ck. Fm.

Teena Dolomite

27.8 dark grey calcilutite

139.3 dark grey calcilutite, numerous

py-carbonate,py-sphal. veinlets

Emmerugga Dol.

\section{MY 5}

Reward Dol.

Barney Ck. Fm.

\section{M17/08}

Barney Ck. Fm.

\section{N27/63}

Barney Ck. Fm. oxidised fracture

74.0 dark grey, very fine calcarenite

138.2 light to dark grey, very fine calcarenite

265.0 dark grey calcilutite

306.4 dark grey, very fine calcarenite

357.4 dark grey, very fine calcarenite

441.4 light-grey calcilutite separated

from silicified banded carbonate

by a stylolite

carbonate-bitumen vein

243.1 light to dark grey calcilutite to

very fine calcarenite

67.2 silicified, veined, carbonate

288.0 dark grey, very fine calcarenite

330.7 dark grey calcilutite,

sphalerite microveins

112.0 dark grey calcilutite, with

pyrite-rich laminae

of carbonate-sphalerite-galena

351.4 dark grey lutite grading into

medium grained arenite
59.4 dark grey calcilutite, small

160.7 light to dark grey calcilutite, cross-cutting

v.b.

nf. lam., d.b., p.d.b., thuch.

nf. lam., p.d.b., thuch.

nf. lam., p.d.b., thuch.

nf. lam., d.b., thuch.

$$
\text { v.b., d.b., vg.b. }
$$

v.b., vg.b.

v.b.

p.d.b.

p.d.b., nf. lam., thuch.

nf. lam., p.d.b., d.b., m.b., v.b., thuch.

339.5 dark grey calcilutite, with pyrite-rich

laminae, and irregular veins and patches

p.d.b., d.b.

nf. lam., v.b., d.b.

31.7 dark grey lutite, small band of calcilutite nf. lam., p.d.b., d.b.

105.5 dark grey, very fine grained calcarenite, pyrite rich laminae

172.8 dark grey calcilutite, with pyrite or sphalerite rich laminae, grading into medium grained calcarenite

313.0 dark grey lutite with numerous sphalerite/galena or pyrite laminae

335.0 dark grey lutite with numerous sphalerite/galena or pyrite laminae

380.9 grey calcilutite with fine greenish-grey bands

388.9 irregularly banded carbonate, with p.d.b., d.b., v.b. network veins of pyrite, bitumen and sphalerite v.b.

nf. lam., p.d.b., d.b.

d.b.

d.b.,p.d.b.

v.b.

APPENDIX $\mathrm{C}$ ctd. Rock and organic matter types, Nathan and McArthur Groups, central and northern Batten Trough (DDH's McA5 N27/63) 
DDH/Fm. Depth(m) LIthology

Organlc matter types

WM 6

Barney Ck. Fm. 200.8 dark grey calcilutite

423.6 dark grey calcilutite

519.3 dark grey calcilutite

d.b., thuch.

nf. lam.,d.b., thuch.

d.b., thuch.

\section{$82 / 4$}

61.8 calcilutite breccia

84.2 laminated grey to dark grey calcilutite

unspec. McA. Gp. 468.7

dark grey calcilutite

d.b.

nf. lam., p.d.b.

\section{$82 / 5$}

Lynott Fm.

54.7 dark grey calcilutite

191.7 laminae of very fine grained light grey arenite and dark grey lutite

453.6 dark grey very fine grained arenite with

cross cutting carbonate veins

nf. lam., d.b., p.d.b.

p.d.b., d.b.

v.b., p.d.b.

p.d.b.

\section{$82 / 6$}

Yalco Fm.

125.7 laminae of very fine grained light grey

arenite and dark grey lutite,

patches of pyrite.

lam.

Lynott Fm.

290.3 light-grey lutite with dark-grey laminations, irregular lenses of very tine grained arenite.

lam., thuch.

\section{$82 / 7$}

Looking Glass Fm. 55.5

Yalco Fm.

186.3
327.5

very fine grained calcarenite with chalcedony patches

dark-grey lutite

carbonate breccia

v.b.,vg.b.

lam., nf. lam., v.b., m.b., thuch. v.b.

APPENDIX C ctd. Rock and organic matter types, Nathan and McArthur Groups, central and northern Batten Trough (DDH's WM6 82/7). 
DDH/Fm. Depth $(m)$ Lithology

Broadmere 1

Cobanbirini Fm.

$\begin{array}{ll}27.4 & \text { dark grey siltstone } \\ 109.7 & \text { dark grey siltstone } \\ 155.4 & \text { dark grey siltstone, } \\ 335.3 & \text { dark to light grey siltstone } \\ 411.5 & \text { dark to greenish-grey siltstone }\end{array}$

Bessie Ck. Sst. 466.3 dark to greenish-grey siltstone, some fine-grained sandstone

Corcoran Fm. $\quad 874.8$ grey siltstone, fine sandstone

920.5 grey siltstone, fine sandstone

974.8 to dolerite

1148.2 sill

1231.0 grey to light greenish grey siltstone

Hodgson Sst. Mbr. 1304.5 grey siltstone

Mainoru Fm. $\quad 2106.2$ fine glauconitic sandstone, grey siltstone

2170.2 fine glauconitic sandstone, grey siltstone

B 8

McMinn Fm.

17.4 dark grey mudstone

33.2 grey mudstone

59.4 grey mudstone with central $1 \mathrm{~cm}$. bed of fine sandstone lam., nf. lam.

lam.,nf. lam., p.d.b., b.m.

nf. lam., p.d.b.

nf. lam., p.d.b., d.b.,

nf. lam., p.d.b., d.b., v.b.

nf. lam., p.d.b.

nf. lam., d.b.

nf. lam., p.d.b.

nf. lam., p.d.b.

v.b., d.b.

nf. lam., v.b., d.b.

nf. lam., p.d.b., d.b., v.b.

lam., nf. lam., thuch.

nf. lam., p.d.b., thuch.

nf. lam.

Urapunga 1

Mainoru Fm.

102.9 very fine grained glauconitic quartz arenite

with light grey laminae of siltstone

nf. lam.

120.9 very fine grained quartz arenite, with light grey

laminae of siltstone, laminae distorted

and, in places, brecciated

nf. lam.

\section{ABBREVIATIONS}

lam. = fluorescent lamalginite; nf. lam. = nonfluorescent lamalginite;

p.d.b. = patchy dispersed bitumen; d.b. = disseminated bitumen;

v.b. = vein bitumen; c.b. = cauliflower bitumen; m.b. = matrix bitumen;

b. m. = bitumen microspheres; oncalg = oncalginite;

thuch. $=$ thucholite

APPENDIX D. Rock and organic matter types, Roper Group, DDH's Broadmere 1, B8, Urapunga 1. 
DDH/Fm. Depth $(m) \quad$ Lithology

Organic matter types

Urapunga 3

Velkerri Fm.

13.3 finely laminated dark grey to light grey

$$
\text { siltstone }
$$

30.3 light-grey siltstone with black laminae;

some sub - euhedral pyrite up to $1 \mathrm{~mm}$. lam., nf. lam.

54.4 dark grey siltstone, with cross-cutting carbonate-bitumen vein

75.2 dark grey siltstone

98.3 dark grey siltstone

120.0 dark-grey siltstone wih some off-white

laminae, phosphatic

137.4 dark-grey siltstone with lighter grey laminae

nf. lam., p.d.b., d.b.,b.m.,c.b.

v.b., nf. lam.

p.d.b., d.b.

v.b., m.b.

150.1 light-grey, easily fractured, siltstone

with random black flecks of organic matter

$\leq 1 \mathrm{~mm}$ long, and numerous thin

\section{Urapunga 4}

Sherwin Creek Ironstone Member, McMinn Fm.

Velkerri Fm.

74.4

157.3

209.5

320.0

327.5

342.7

348.2

354.7

Corcoran Fm. $\quad 433.4$

463.8 bitumen veins

172.6 light grey, easily fractured, siltstone with randomly orientated dispersed flecks of organic matter, $\leq 1 \mathrm{~mm}$ long

210.7 light grey siltstone with poorly orientated

strands of organic matter $\leq 10 \mathrm{~mm}$ long nf. lam., thuch.

fine to medium quartz arenite containing oncolites $\leq 3 \mathrm{~mm}$; patches of reddish clay

(?containing hydrated iron oxides)

interstitial to quartz grains. oncolam, v.b., m.b.

dark grey silty claystone, containing some

pyrite framboids $\leq 1 \mathrm{~mm}$ diam. lam., nf. lam., thuch.

dark grey mudstone, phosphatic lam., nf. lam., m.b., b.m., thuch.

dark grey mudstone, phosphatic,

grading into fine arenite,

containing diagenetic rounded grey to

green ?glauconite $\leq 1 \mathrm{~mm}$

dark grey mudstone

dark grey mudstone

dark grey mudstone to very fine

grained sandstone, containing

oil-stained vugs $\leq 0.5 \mathrm{~mm}$ long

nf. lam., v.b.

nf. lam.

lam., nf. lam., m.b., b.m.

nf. lam., p.d.b., d.b., thuch.

nf lam., d.b., p.d.b., thuch.

nf. lam., d.b., p.d.b.

dark grey mudstone to very

fine grained sandstone

dark grey mudstone

dark grey, faintly laminated, claystone,

containing black flecks $\leq 2 \mathrm{~mm}$.

nf. lam., p.d.b., thuch.

nf. lam., p.d.b., thuch.

nf. lam., p.d.b., d.b.

nf. lam., p.d.b., d.b.

\footnotetext{
APPENDIX D ctd. Rock and organic matter types, Roper Group, DDH's Urapunga 3 and 4.
} 
DDH/Fm.

$$
\operatorname{Depth}(m)
$$

Urapunga 5

Jalboi Member

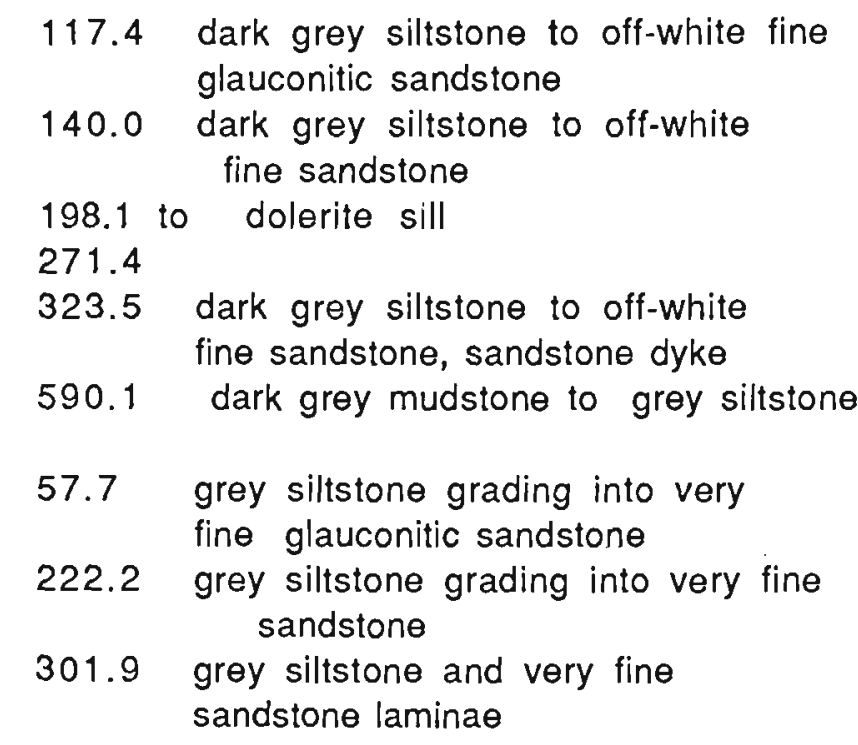

\section{$\times 28$}

McMinn Fm.
16.9

32.0

grey mudstone
grey mudstone
grey mudstone

61.0 grey mudstone

74.1 grey mudstone to very fine patchy reddish sandstone; sst. dykes.

82.9 grey very fine sandstone to pinkish fine sandstone nf. lam.

nf. lam.

nf. lam.

d.b., thuch.

nf. lam., thuch.

nf. lam., d.b.

nf. lam., d.b., m.b.

lam., thuch.

lam., thuch.

lam., thuch.

lam., nf. lam., thuch

lam., nf. lam., thuch.

APPENDIX D ctd. Rock and organic matter types, Roper Group, DDH's Urapunga 5 and 6, X28. 
$\mathrm{DDH} / \mathrm{Fm}$.

$\operatorname{Depth}(m)$

Lithology

Organlc matter types

$82 / 1$

Cobanbarini Fm.

"Cat Ck. Member" 193.3 grey mudstone to very fine off-white sandstone lam., nf. lam., thuch.

"Lansen Ck. Shale" 380.6 grey calcareous mudstone, dissem. quartz-pyrite pseuds. after gypsum.

lam., nf. lam., p.d.b., thuch.

427.8 dark grey mudstone, cross-cutting vein pyrite nf. lam., thuch.

560.7 grey mudstone to very fine off-white sandstone nf. lam., thuch.

$82 / 2$

Mainoru Fm. $\quad 66.8$ grey mudstone grading into very fine glauconitic sandstone

nf. lam.

"Mantungula Fm." 432.9 grey mudstone grading into

very fine sandstone nf. lam.

$82 / 3$

145.3 grey siltstone to off-white

very fine sandstone

nf. lam.

Crawford Fm. 400.7 grey mudstone to off-white glauconitic very fine sandstone nf. lam., thuch.

Mainoru Fm. $\quad 478.5$ dark grey mudstone

504.9 grey siltstone to off-white very fine sandstone nf. lam., thuch.

nf. lam., thuch.

$82 / 8$

Cobanbarini Fm.

"Lansen Creek

67.4 grey, black flecked, easily fractured, mudstone.

lam., nf. lam.

Shale Member" 100.5 grey siltstone to off-white very fine sandstone.

lam., nf. lam.

APPENDIX D ctd. Rock and organic matter types, Roper Group, DDH's $82 / 1,3$ and 8 . 
$\mathrm{DDH} / \mathrm{Fm}$. Depth $(\mathrm{m}) \quad$ Area analysed Elements (In order of abundance)

GR3

Barney Ck. Fm. $\quad 30.1$

large lamalginite mat

large grain in mat (1)

large grain in mat (2)

diffuse mineral in mat

\section{GR5}

Barney Ck. Fm.

72.5

general

large mat

GR7

Barney Ck. Fm. $180.0 \mathrm{~B}$

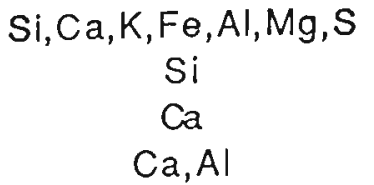

$\mathrm{Si}, \mathrm{Ca}, \mathrm{K}, \mathrm{S}, \mathrm{Al}, \mathrm{Fe}, \mathrm{Mg}$

$\mathrm{Si}, \mathrm{Ca}, \mathrm{K}, \mathrm{S}, \mathrm{Al}, \mathrm{Fe}, \mathrm{Mg}$

$$
\begin{gathered}
\mathrm{Si}, \mathrm{K}, \mathrm{Ca}, \mathrm{S}, \mathrm{Al}, \mathrm{Fe}, \mathrm{Mg}, \mathrm{P}, \mathrm{Ti} \\
\mathrm{Ca}, \mathrm{P} \\
\text { Si,Ca,P } \\
\mathrm{Ca}, \mathrm{P} \\
\mathrm{Si}, \mathrm{K}, \mathrm{Ca}, \mathrm{Al}, \mathrm{S}, \mathrm{Fe} \\
\text { Si, S, Fe,Al, K, Ca }
\end{gathered}
$$

$$
\begin{gathered}
\mathrm{Ca}, \mathrm{Si}, \mathrm{Mg}, \mathrm{K}, \mathrm{Al}, \mathrm{Fe} \\
\mathrm{Ca}, \mathrm{Si}, \mathrm{S}, \mathrm{Fe}
\end{gathered}
$$

"waxy" lutite band (2)

"non-waxy" lutite band (1)

"non-waxy" lutite band (2)

$\mathrm{Si}, \mathrm{Ca}, \mathrm{K}, \mathrm{Al}, \mathrm{Mg}, \mathrm{Fe}, \mathrm{S}, \mathrm{Ti}$

$\mathrm{Si}, \mathrm{Ca}, \mathrm{K}, \mathrm{Al}, \mathrm{Fe}=\mathrm{S}, \mathrm{Mg}, \mathrm{Ti}$
GR10

Barney Ck. Fm. 23.2

$$
\begin{gathered}
\text { general (1) } \\
\text { general (2) } \\
\text { large mat(1) } \\
\text { large mat(2) }
\end{gathered}
$$

37.4 A general area containing Ti nodules(1) general area containing $\mathrm{Ti}$ nodules(2) general area containing $\mathrm{Ti}$ nodules(3)

Ti-nodule with branching pyritic filament filament itself organic nodule organic nodule lobate-shaped organic nodule general area adjacent to above white mineral in above black mineral in above small organic nodule lobate organic nodule thucholite, whole grain thucholite, central area light grain in central area general area adjacent to thuch. nearby strand of lamalginite (1) nearby strand of lamalginite (2)

$37.4 \mathrm{~B}$ general
$\mathrm{Si}, \mathrm{Ca}, \mathrm{K}, \mathrm{Al}, \mathrm{Mg}, \mathrm{S}, \mathrm{Fe}$, trace $\mathrm{Ti}$, $\mathrm{Si}, \mathrm{Ca}, \mathrm{K}, \mathrm{Al}, \mathrm{Mg}, \mathrm{Fe}, \mathrm{S}$, trace $\mathrm{Ti}$, $\mathrm{Si}, \mathrm{Ca}, \mathrm{K}, \mathrm{Al}, \mathrm{Mg}, \mathrm{S}, \mathrm{Fe}$ $\mathrm{Si}, \mathrm{S}, \mathrm{Ca}, \mathrm{K}, \mathrm{Fe}, \mathrm{Al}$

$$
\begin{gathered}
\mathrm{Si}, \mathrm{K}, \mathrm{Al}, \mathrm{Ca}, \mathrm{Fe}, \mathrm{Mg}, \mathrm{S}, \mathrm{Ti} \\
\mathrm{K}=\mathrm{Si}, \mathrm{Al}, \mathrm{Ti}, \mathrm{Fe}, \mathrm{Mg}, \mathrm{S} \\
\mathrm{Si}, \mathrm{Al}, \mathrm{K}, \mathrm{S}, \mathrm{Fe}, \mathrm{Ti} \\
\mathrm{Ti}, \mathrm{S}, \mathrm{Si}, \mathrm{Fe}, \mathrm{K}, \mathrm{Ca} \\
\mathrm{S}, \mathrm{Fe}, \mathrm{Ti} \\
\mathrm{Ti}, \mathrm{S}=\mathrm{Si} \\
\mathrm{Ti}, \mathrm{S}, \mathrm{Si} \\
\mathrm{Ti}, \mathrm{S}, \mathrm{Si} \\
\mathrm{Si}, \mathrm{Ca}, \mathrm{K}, \mathrm{Al}, \mathrm{Mg}, \mathrm{Fe}, \mathrm{Ti} \\
\mathrm{Si}>\mathrm{Ca}, \mathrm{K}, \mathrm{Al} \\
\mathrm{Si}, \mathrm{K}, \mathrm{Ca}=\mathrm{Al} \\
\mathrm{Ti}=\mathrm{S}, \mathrm{Si} \\
\mathrm{Si}, \mathrm{S}=\mathrm{Ti} \\
\mathrm{S}>>\mathrm{Si}, \mathrm{Fe}, \mathrm{Al}, \mathrm{Th} \\
\mathrm{Si}, \mathrm{S}, \mathrm{Th} \\
\mathrm{Th}, \mathrm{Si}, \mathrm{S} \\
\mathrm{Ca}, \mathrm{Si}, \mathrm{Mg}, \mathrm{K}, \mathrm{Al}, \mathrm{Fe} \\
\mathrm{Si}, \mathrm{Mg}, \mathrm{K}, \mathrm{Ca} \\
\mathrm{Si}, \mathrm{Ca}, \mathrm{Mg}, \mathrm{K}, \mathrm{Fe}, \mathrm{Al} \\
\mathrm{Si}, \mathrm{Ca}, \mathrm{K}, \mathrm{Al}, \mathrm{Mg}, \mathrm{S}, \mathrm{Ti}, \mathrm{Fe}
\end{gathered}
$$

\footnotetext{
APPENDIX E. Scanning Electron Microscope X-Ray Probe Data, McArthur Group, DDH'S GR3,7 and 9.
} 
DDH/Fm.

GR10 ctd.

Barney Ck. Fm. 51.4

strew mount
general
organic matter (1)
organic matter (2)
general
spot grain analysis (1)
spot grain analysis (2)
spot grain analysis (3)
mat
thucholite grain 1
whole area
small rectangular grain near center
small square grain near center
rect. grain near center
thucholite grain 2
irregular small grain near center
ditto
ditto
ditto
thucholite 1, general
central triangular grain
amongst several in the area
small peripheral patch
thucholite 2
whole grain

one white grain amongst several near central area

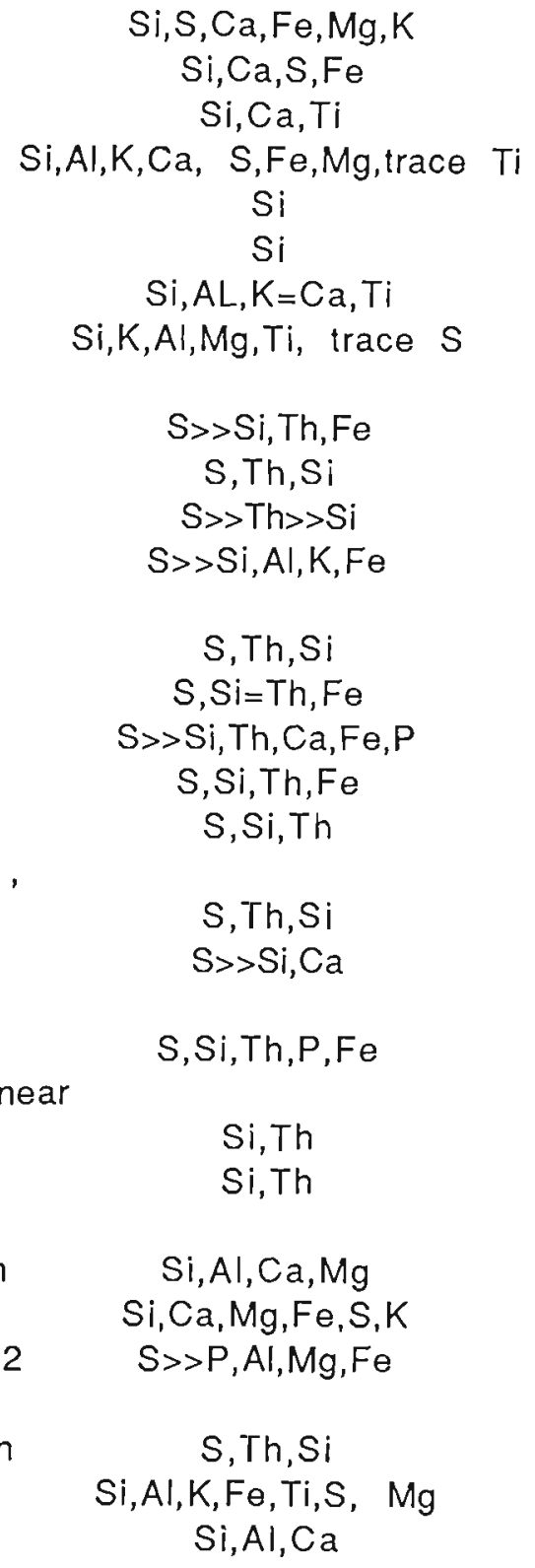

N27/63

Barney Ck. Fm.

10.5 .5

general discrete grain of ?bitumen composite grain of ?bitumen

172.8 cross-cutting bitumen vein white ring near edge thucholite 3 spot (probe) just outside grain probe on edge of thuch. 2 probe in central area of thuch. 2 thucholite grain rectangular white central grain mineral matrix (1) mineral matrix
$\mathrm{Si}, \mathrm{S}, \mathrm{Fe}, \mathrm{Ca}=\mathrm{K}, \mathrm{Al}, \mathrm{Mg}, \mathrm{Zn}, \mathrm{Ti}$
$\mathrm{Si}, \mathrm{S}, \mathrm{Fe}, \mathrm{Ca}=\mathrm{K}, \mathrm{Al}, \mathrm{Mg}, \mathrm{Zn}, \mathrm{Ti}$
$\mathrm{Zn}, \mathrm{Ti}, \mathrm{Si}, \mathrm{S}, \mathrm{K}, \mathrm{Ca}, \mathrm{Al}, \mathrm{Fe}$
$\mathrm{Ca}, \mathrm{Si}, \mathrm{K}, \mathrm{Fe}, \mathrm{Mg}, \mathrm{Al}, \mathrm{Cu}$ area 
$\mathrm{DDH} / \mathrm{Fm}$.

Broadmere 1

Velkerri Fm.

Urapunga 3

Velkerri Fm.

Urapunga 4

Velkerrie $\mathrm{Fm}$.
$\operatorname{Depth}(\mathrm{m})$

Area analysed

Elements (In order of abundance)

109.7

general

microsphere, $3 \mu$ diameter

$\mathrm{Si}, \mathrm{Al}, \mathrm{K}, \mathrm{Ca}, \mathrm{S}, \mathrm{Fe}, \mathrm{P}$

$\mathrm{Ca}, \mathrm{P}$

49.8

general
area containing microspheres
microsphere 1
microsphere 2
general
bitumen vein

32.3

157.3

342.7 oolitic ironstone central grain of oolite oolite rings general microsphere, $6 \mu$ diameter general

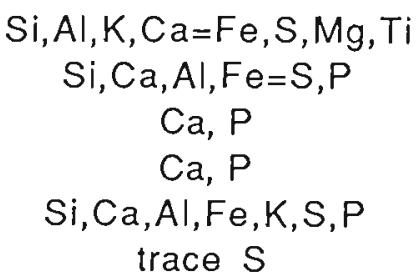

$\mathrm{Si}$

$\mathrm{Fe}, \mathrm{Si}=\mathrm{Al}, \mathrm{Ca}, \mathrm{Mg}, \mathrm{S}$

$\mathrm{Si}, \mathrm{Al}, \mathrm{K}, \mathrm{Fe}, \mathrm{Ca}, \mathrm{Ti}$

$\mathrm{Ca}, \mathrm{P}$

$\mathrm{Si}, \mathrm{Al}, \mathrm{K}, \mathrm{Mg}, \mathrm{Ti}$

APPENDIX E ctd. Scanning Electron Microscope X-Ray Probe Data, Roper Group, Broadmere 1, Urapunga 3 and 4. 


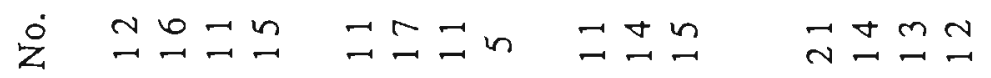

希

更

至

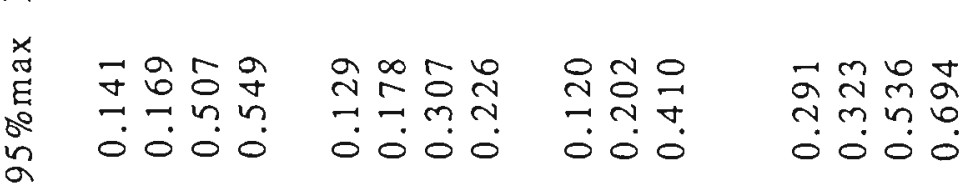

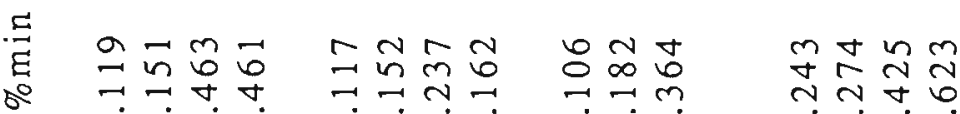

乞 $\dot{0} \dot{0} \dot{0} \dot{0} \dot{0} \dot{0} \dot{0} 0$ 잉

윰

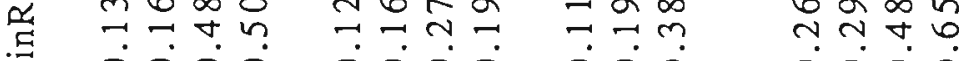

严 $0 \dot{00} 0000000000000$

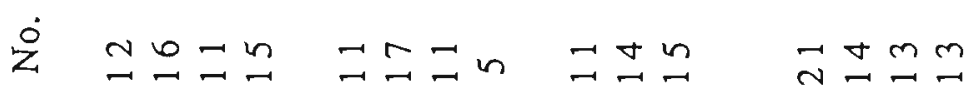

葛

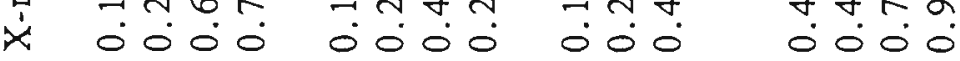

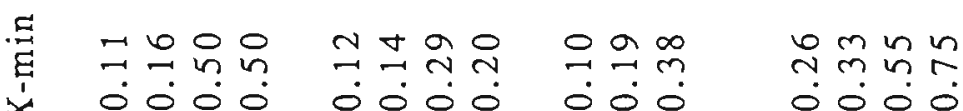

$x$ 000 0000000000

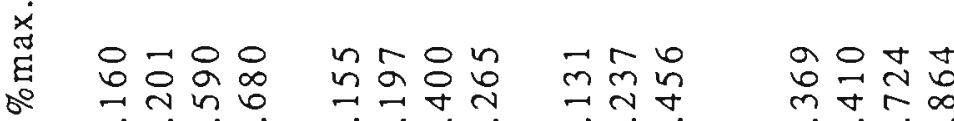

向 $\dot{0} 0 \dot{0}$ : $\dot{0} 0 \dot{0}$ :

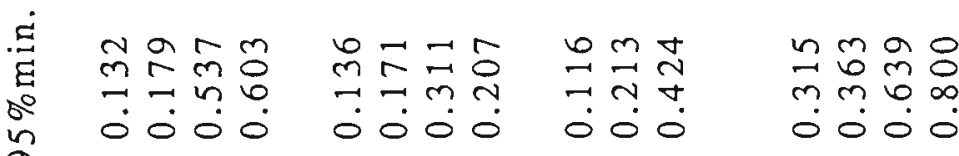

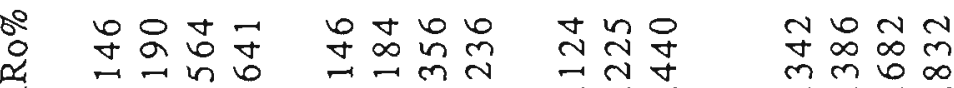
:ं்

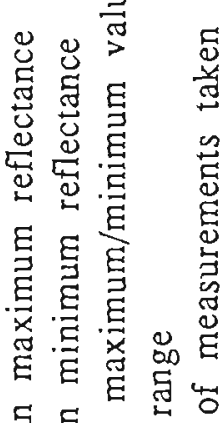

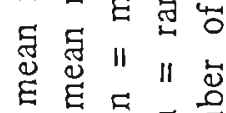

॥

옳

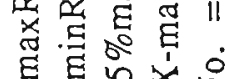

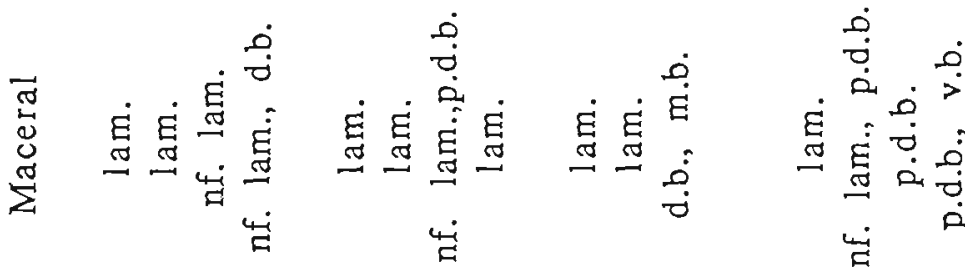

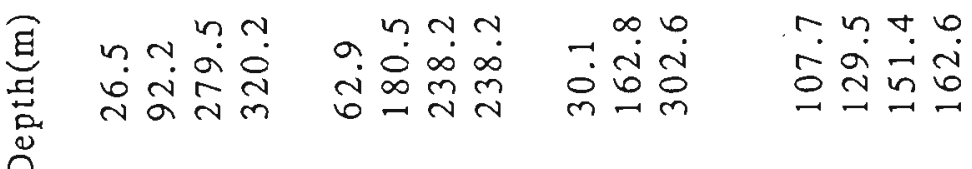
$\stackrel{\infty}{\circ}$

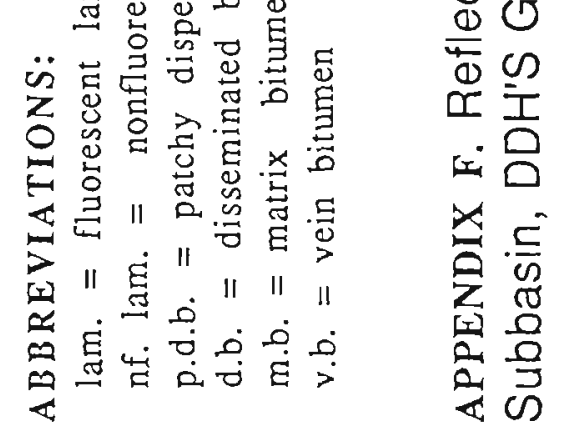

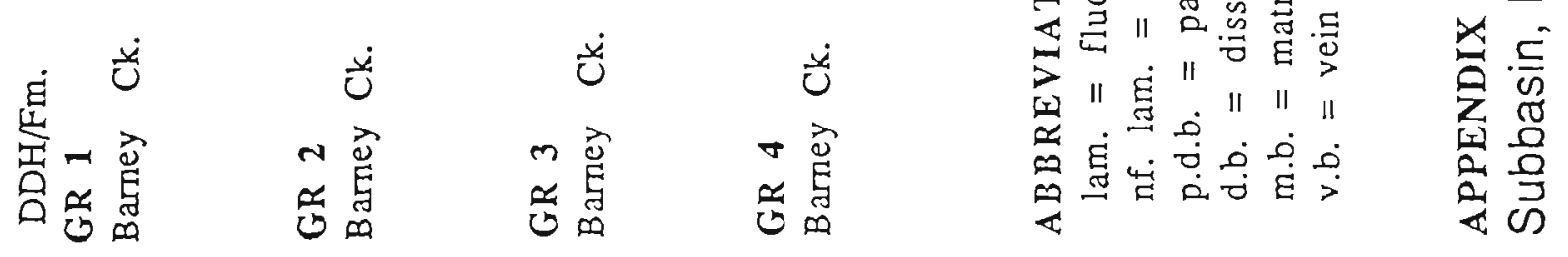




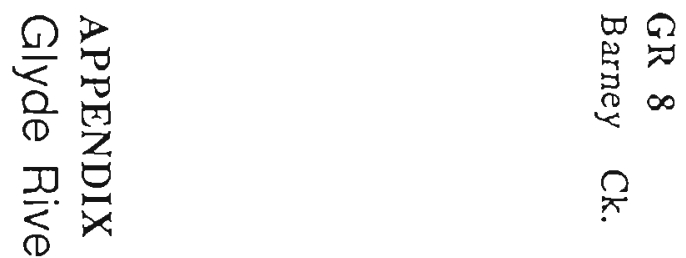

$\infty$ va $a+N$ un u $000 N \omega 0$

$\frac{1}{0}$

O

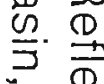
$\infty$ in

$\triangle A \Delta \omega \omega \curvearrowleft \sim$

$\forall \forall N O 0$ Un $\rightarrow+a$ a 0 in $\infty \infty_{0}$ in is

曷

$0 \stackrel{?}{0}$

ㄷํㅇ

CD

() 3

D $D$

○ $\stackrel{\varrho}{\leftrightarrows}$

$\infty$

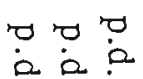

वं व

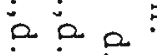

$\dot{\sigma} \dot{\sigma} \dot{\sigma}$

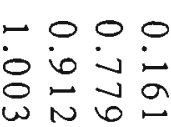

0000

io $\infty$ i

计 $₫ 0$

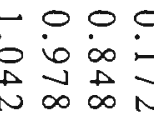

$\frac{0}{3}$
$\frac{0}{0}$
$\frac{0}{7}$
$\frac{0}{5}$
$\frac{5}{3}$
$\frac{10}{3}$

$\frac{2}{3}$

$\frac{0}{2}$

$\frac{3}{\Omega}$
$\frac{1}{3}$
$\vdots$
$\frac{5}{5}$

옹

0000

讨 N

N

$\stackrel{\sim}{\sim} \sim$

0000

$\infty$ a ur

$\vec{\infty} \vec{\omega} \overrightarrow{0} \omega$

0000

的 $\rightarrow$ in

$-\infty+\nu$

0000

$\infty$ i

UNNA

0000 on $\begin{aligned} & 0 \\ & \text { un }\end{aligned}$

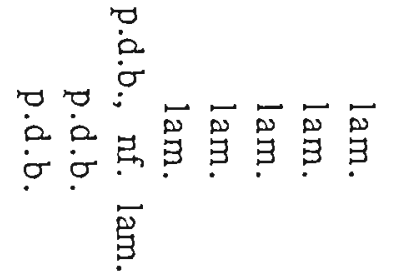

吊 只

ह

广

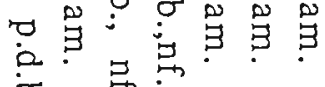

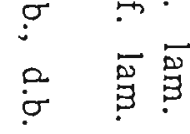

0.00000

is a in is i

$\infty \sim v a \wedge v N$

$\circ 0$ o ${ }^{\circ} \omega$ i

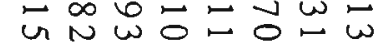

$0-000000$

io o in in i i i a $w N+v a N O$

0000000

- is a in in i

$a \infty \rightarrow 0$ b a 0

$\infty N$ un $\triangle \infty-\infty$

0000000

$\infty$ is i i i i

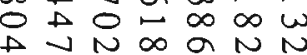

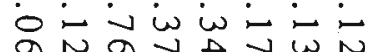

ด ำ

00000000

$\infty$ 少

0000000

$\checkmark n$ un $A$ in 0

0000000

$\infty$ in $-i$ in

$a$ i $\infty i$ is i

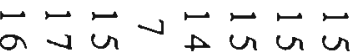

00000000

$\checkmark \infty$ in i i i i 0

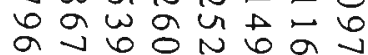

00000000

is is ini.

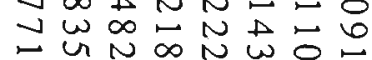

00000000

$\infty$ in is i i. i

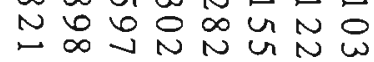

00000000

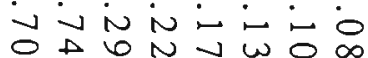

0.00000

in is i i i i 0

$\infty 0 a v \sim \omega \infty$

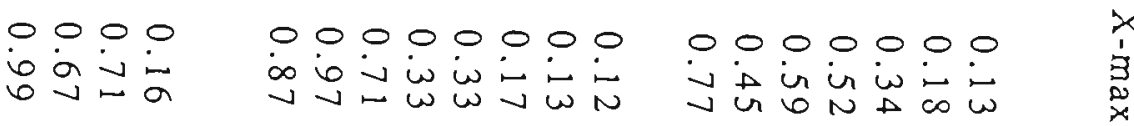

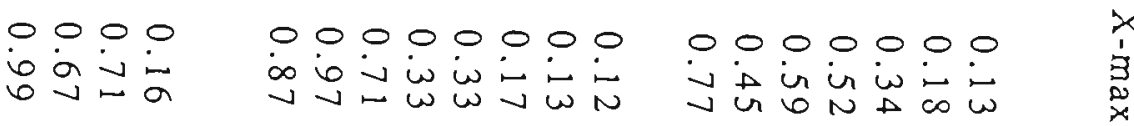

3
2
0
0
0
0

3
0
0
0
0
0
0

0
un
ô
3
3
3

0
4
3
0
0
0

$x$

3

齐

ZZ

0.00000

a $w$ in is i i

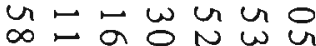

0000000 u

o is is i i i 0 ol

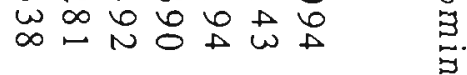

0000000 u

o $w$ in $\rightarrow$ i i i

w

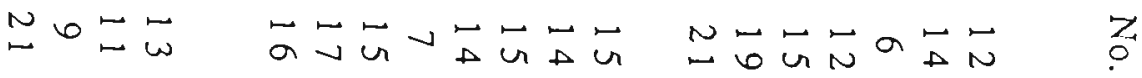




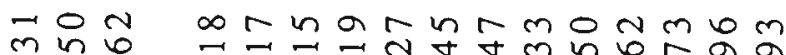

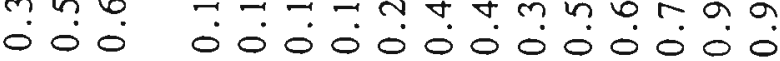

$\operatorname{nin} \pi \infty n$ nmm 000000.

글 000 $\dot{0} 00000000000$

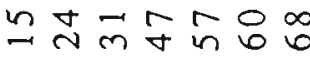
0ं0்

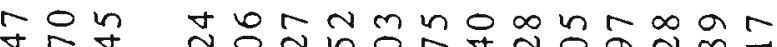

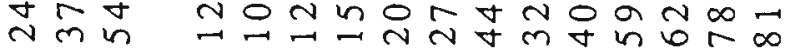
$\dot{0} \dot{0} \dot{0} \dot{0} \dot{0} \dot{0} 0 \dot{0} \dot{0} 0 \dot{0}$

ㅇํㅇㅊำ N ல000்

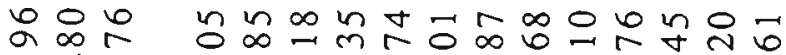
엑 어에 00 $\dot{0} 00000000000$

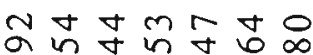
$\because$ ก m n m 0ं00ं0்

సี心 Nmn 000 0000000்0000

읟ํㅇำ N 000் 000

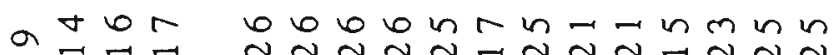
Nan

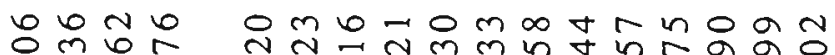
- $\dot{0} \dot{0} \dot{0} \dot{0} \dot{0} \dot{0} \dot{0} \dot{0} \dot{0} \dot{0} \dot{0} \dot{0} \dot{ }$

añ 0 n 2 n $\dot{0} \dot{0} \dot{0} \dot{0} \rightarrow \dot{-1}$

mon 0 n $0 \infty$ n 00ல் $\dot{0} \dot{0} 0 \dot{0} 0 \dot{0} 0 \dot{0} 0$

이의웅 ல் $\dot{0} \dot{0} \dot{0}$

n

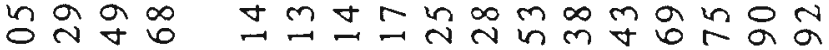
ம் $\dot{0} \dot{0} \dot{0} \dot{0} \dot{0} \dot{0} \dot{0} \dot{0} \dot{0} \dot{0} \dot{0} \dot{0}$

To a $\infty$ in

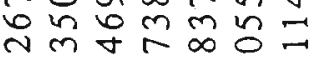
$\dot{0} \dot{0} \dot{0} \dot{0}-\dot{-}$

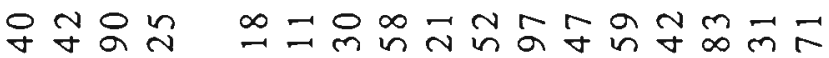

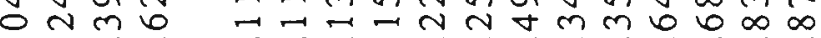

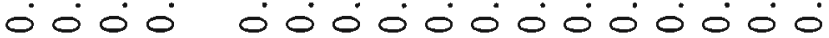

nI तथ $\dot{0} \dot{0} \dot{0} \dot{0} \dot{0} 0$

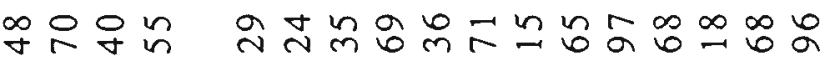

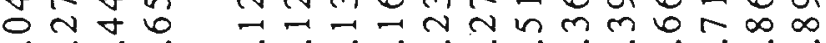
0000 0000000000000

ㅅำ ป m 00000 -

$$
\stackrel{0}{\rightarrow} \quad \dot{0}
$$

皇身 $\stackrel{\dot{0}}{\dot{0}} \quad \stackrel{\dot{0}}{\dot{0}}$

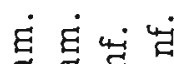

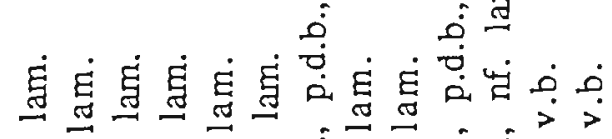
am

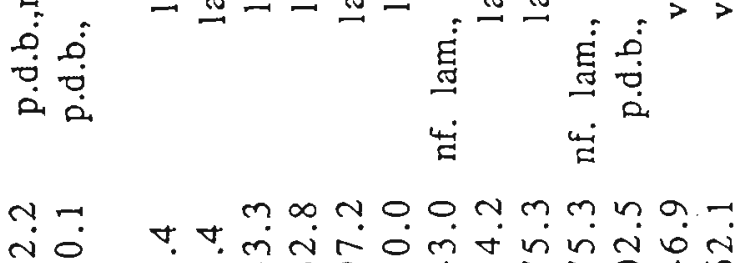

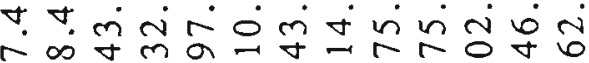

$a_{\infty}$ m m no 官 家 غ 坖焉

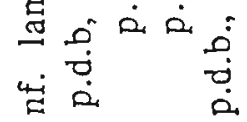

$\frac{5}{\frac{5}{\pi}}$

$\stackrel{\frac{5}{0}}{\frac{5}{5}}$

흠

$\frac{\stackrel{0}{.}}{\frac{\sigma}{\sigma}}$

$\overleftarrow{\circ}$

足 


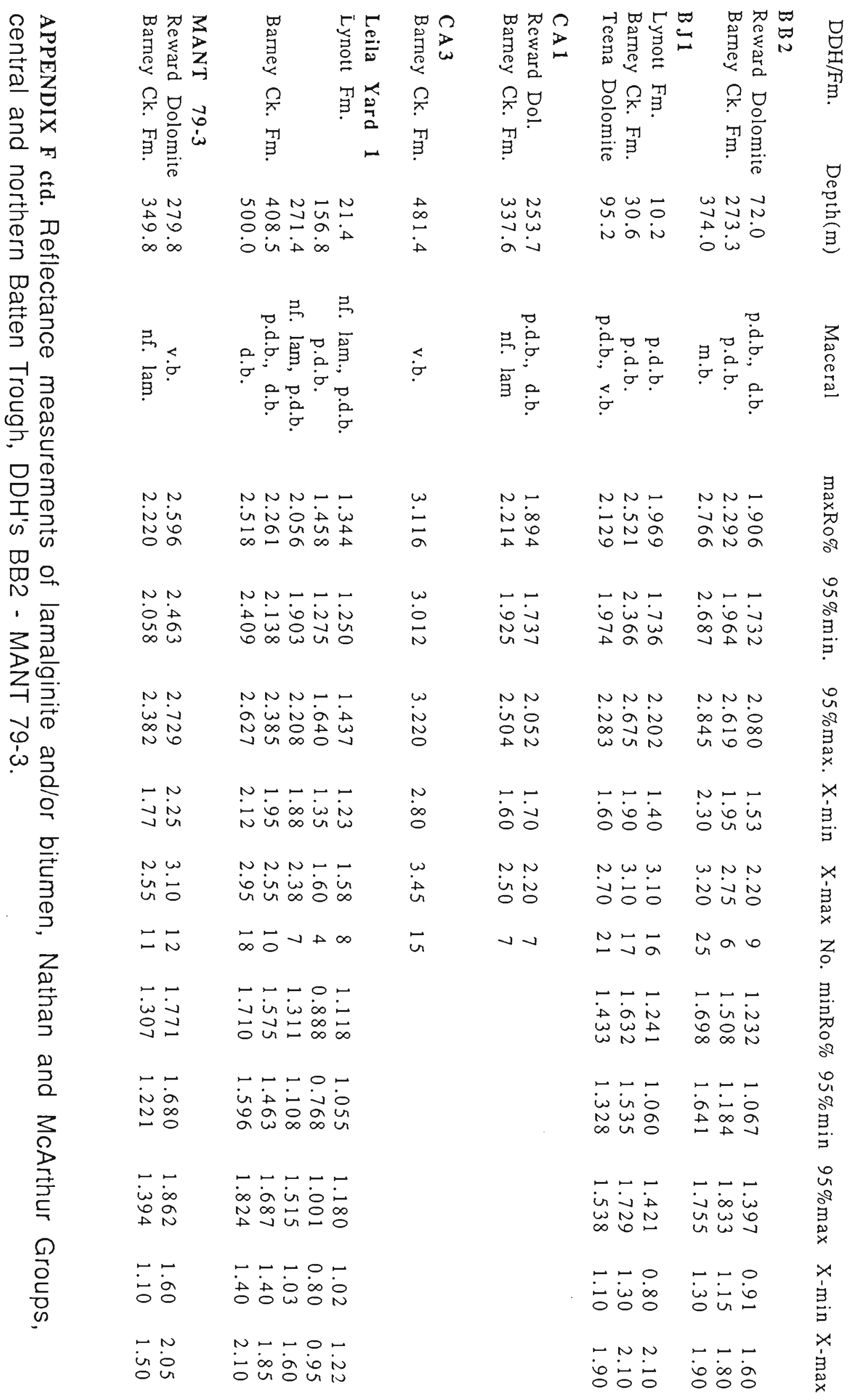

ேッ 


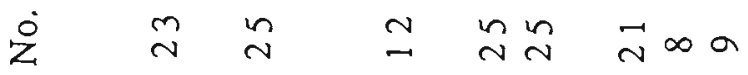

.

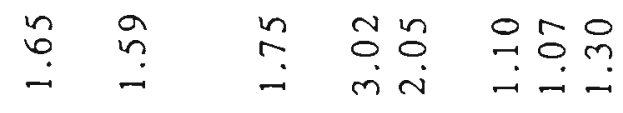

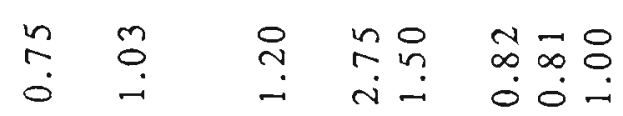

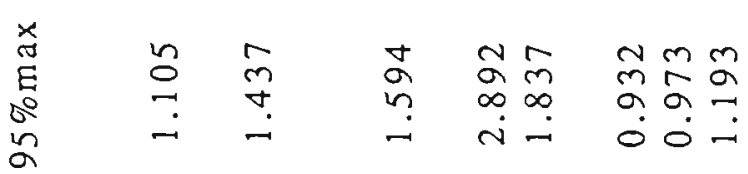

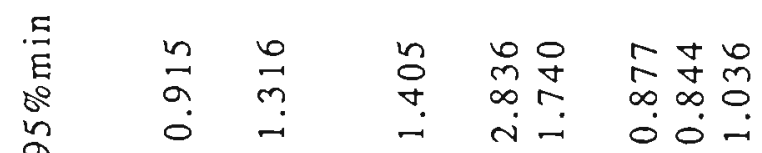

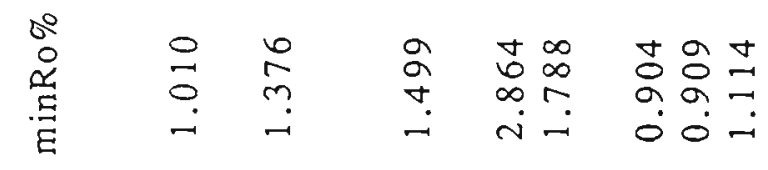

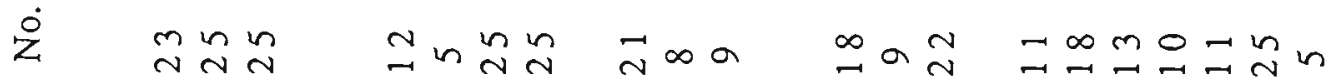

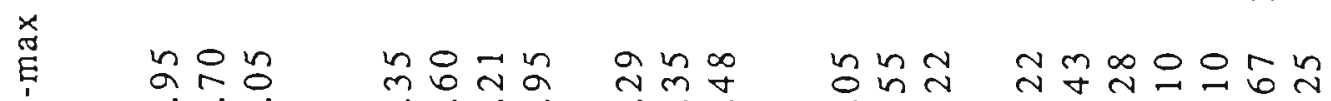

$\dot{x}$

$\cdot \frac{\Xi}{5}$

-in

i்

نं

4⿻inim

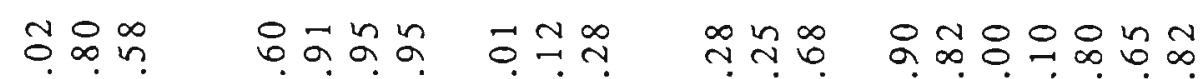

-0!

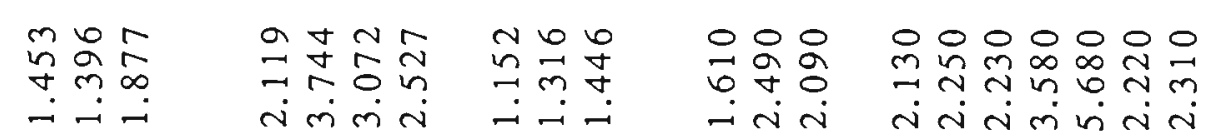

$\frac{8}{E}$

$\operatorname{mon}$

N $N$

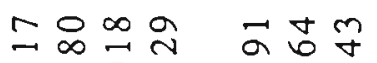

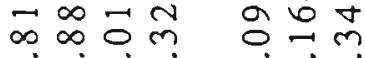

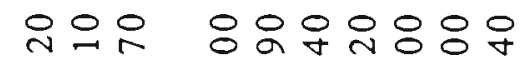

$\frac{2}{8}$

๓ $\stackrel{7}{m} \infty$ $-\rightarrow m r$

$\dot{-} \dot{-} \dot{\sim} \dot{-}$

4.

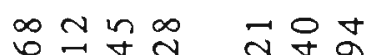
ด $\infty$ ๖

응ㅇㅇ

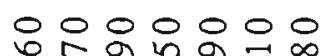
- $\dot{i} \dot{\sim} \dot{-} \dot{ }$ मतं

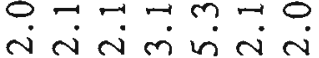

灾 忢

فُ

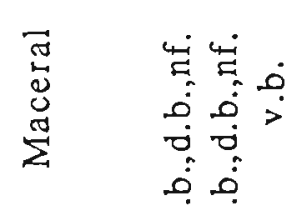

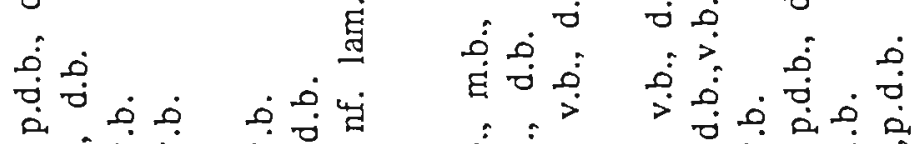

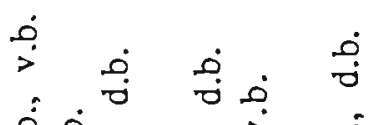
i

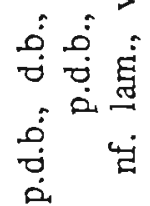
ف

ம

$m$ ก.

$\therefore$ m 0 \%

ง $\stackrel{0}{0}$

‥ ㄴ. 7

n $\infty$ o 0 a

음 $\because \dot{0} \approx m i \infty$ 4
0
0 N-IN $\rightarrow m \mathrm{~m}$ $m$ m들 $m$ m 


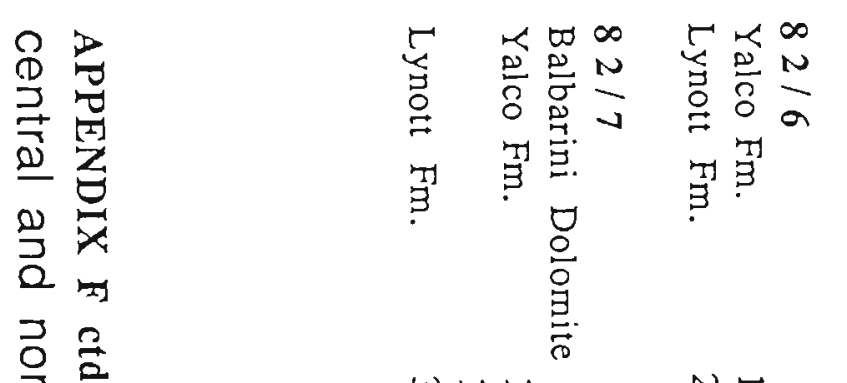

$\omega \rightleftharpoons$ va a in in $i \omega$ in

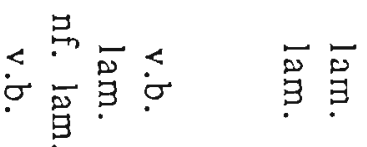

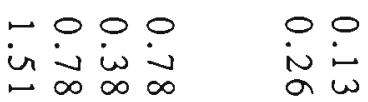

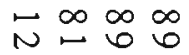

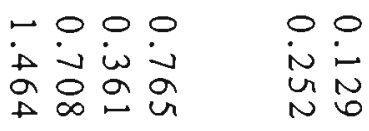

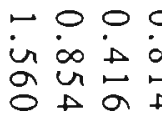

- 000

is in $\omega$ 虫

o 0

$\underset{n}{n}$

00 $\infty_{0}^{\infty} \stackrel{1}{\circ}$

$\frac{0}{3}$
$\frac{2}{0}$
$\frac{0}{5}$
$\frac{5}{3}$
$\frac{3}{3}$

$\frac{2}{3}$

อ

3
$\frac{2}{3}$
든

G)

응

00
is
0 ur

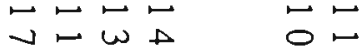

0000

00

aำ

00000

o in $n$ a $\quad$ in

记

is in $\begin{aligned} & 0 \\ & \text { i }\end{aligned}$

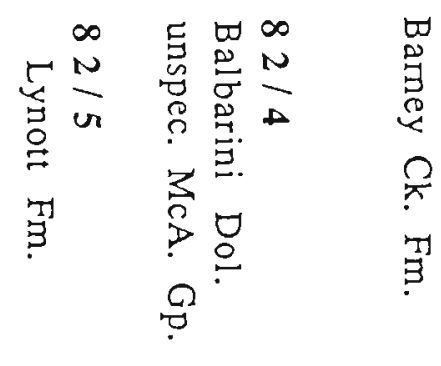

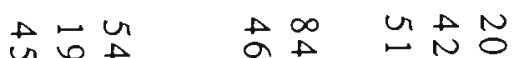

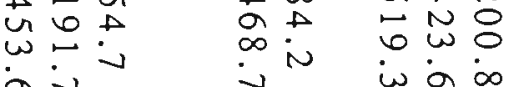

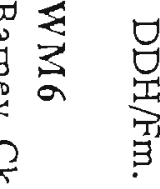

吕吕: $\dot{\sigma} \dot{\sigma} \dot{\sigma}$

$\dot{\sigma} \div$

名

प वें

वृ

3
2
0
0
0
0

N.:

aे 9 u u

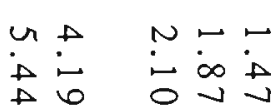

3
㟧
0
0
0
0

N.:

in in is

$\stackrel{\Delta}{\sim} \stackrel{\omega}{\sim}$

i॰

No uñ

N:

$i \infty a$

$n \perp N N-$

gi

$-\omega N$

un

in: •

$0+0$

$\omega$ -

No 0

$\because \perp N N \cdot$

\&

$\infty a v$

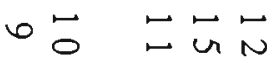

0
0
$0^{9}$
3
3

•ロ

$\infty$ i

WN

in in $\rightarrow \omega$ io

Nu

0
un
09
3
0
$x$

$x$

章.

离

•・

NN

is 늠

Ш $\omega$

$N ロ ・$

o i is

w U

in

wo

- 00

NN:O :

$\because \rightarrow$ i $i$

$a b \infty$

$000 \infty$

0000

ฟ $\omega$ w

00

$N \curvearrowleft$

Ni $i_{\infty}$

山N

io io is

7

量

39

un

o

寻.

in

$3^{9}$

㝵

U

$\infty a-$

๒ち ேピ

z 


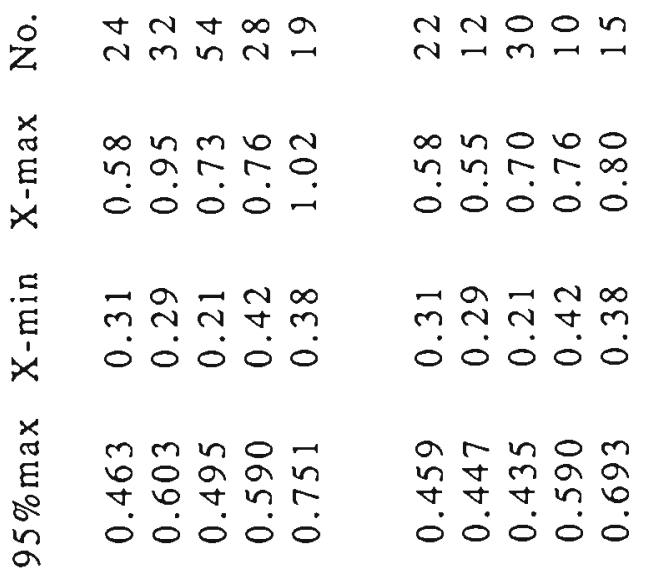

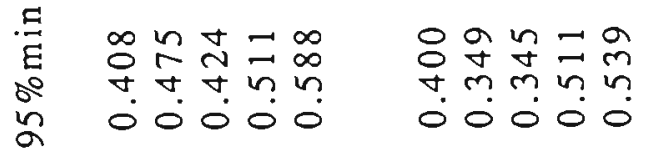

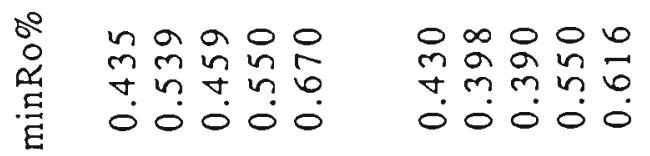

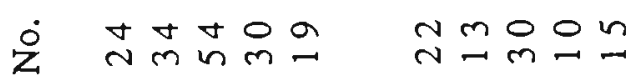

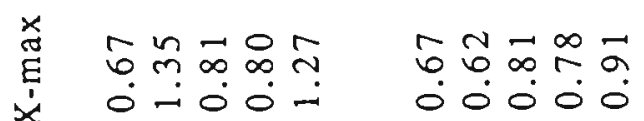

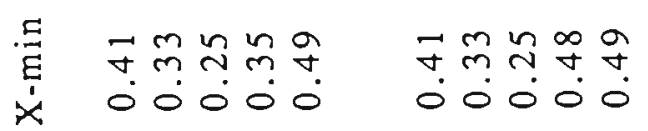

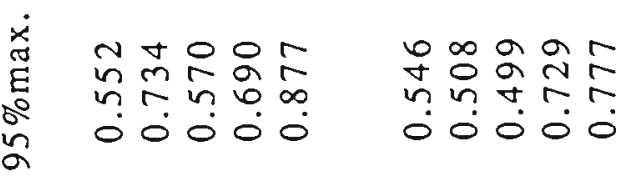

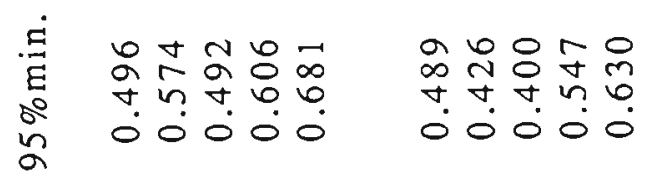

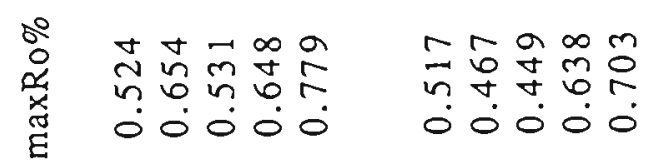

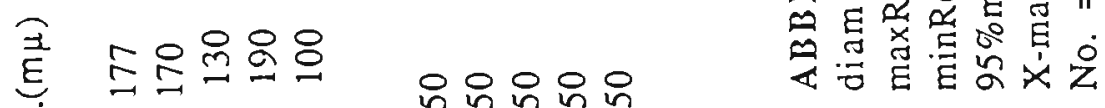




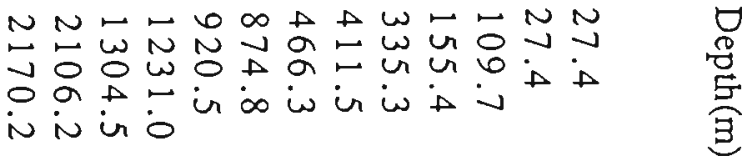
is is is

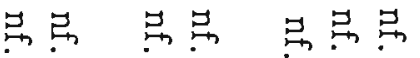

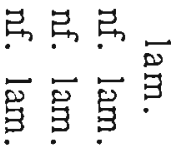

Zุ×
오

옴

$\infty$

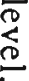

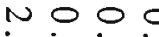

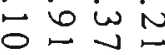

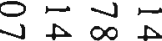

0000 biñ

noO 向㶽然

w.

눙 $\dot{8} \dot{\circ} \dot{0} \dot{0}$ $\rightarrow ? 00$

ルேே

. 0.0 $\vec{\Delta} \infty \underset{b}{\infty} \overrightarrow{0}$

- 000 $\omega \infty \omega \mapsto$

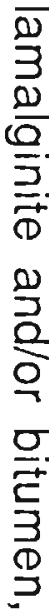

गु.

ญ

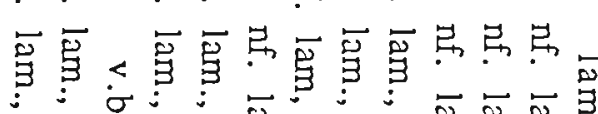

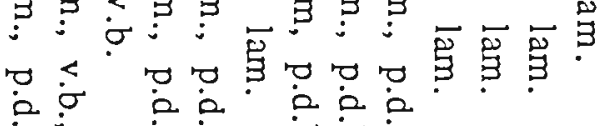
$\dot{\sigma} \sigma \dot{\sigma} \dot{\sigma} \sigma \dot{\sigma}$ 家 뭉

$\overleftarrow{\sigma}$

$\omega \omega u$ un

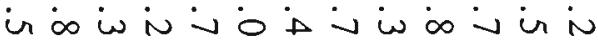
AOWwNWaw. OW

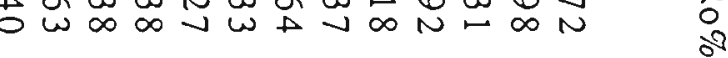
w. Wh

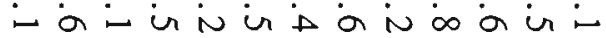

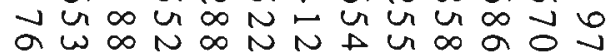

$\omega \rightarrow$ anuwr

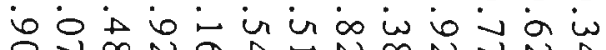
\&

$\omega \mapsto 00$

$\omega \omega \omega+A N-100000$

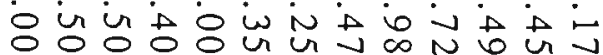
$\triangle A v a u n-N$ V ৩

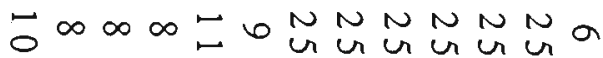
$N N A N \omega \sqcap \mapsto \curvearrowleft \mapsto 000$

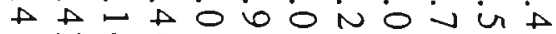
- wa 0 lo $a \infty_{\infty}+0 \infty$ a

- nNNNT-1.00000

io 0 in in ${ }^{\circ}$ is io in is $\infty$ N

NNUNWN-T-OO $\infty-i s$ in a in $i \omega$ i $i$ is is

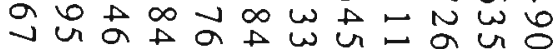

- NNNNROR bं $\omega^{2}$ i

$x$ w wan+N-W-000

a 0 응 in in in $\infty$ in $\infty a \infty+\infty N N N N N$
旁 


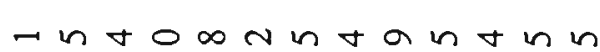

onn n m 010 n

$\sum \stackrel{2}{2}$

x

E $\quad$ !

$-\dot{-}$

E $\quad \circ n$

$\stackrel{7}{*} \sim$

$\infty \infty$

$n \infty$

? ?

$-1$

3
$\sigma^{\circ}$
2

m n

กุ?

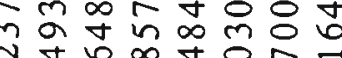
$\circ .0 \infty$ t.

กลลำำสำ Nin 0 an $-\infty m$ $00000-i n$

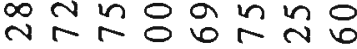
oo - in

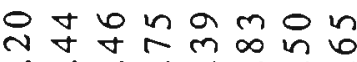
○ं0்0்-1

$\rightarrow-$

$\dot{0} \overline{0}$

J

- -

$\stackrel{\sim}{\rightarrow}$

$\approx 00 n n n m=b n$

ำm กิบ

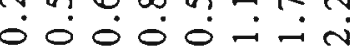

으유

ले

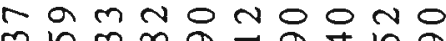
mo000-inam

ㅇำ

in

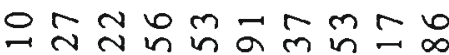

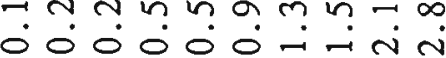

市

$\infty \infty$

$\dot{i}$

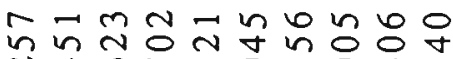
4.

$\infty 5$

n in

in

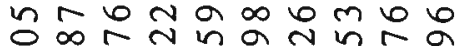

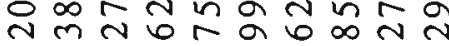
०0ं0்0-

$2 \sqrt{2}$

ลิ่

in

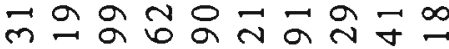
ก寸

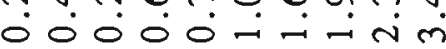

สํำ 密 崩岩

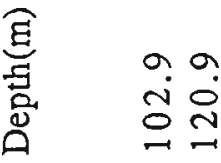

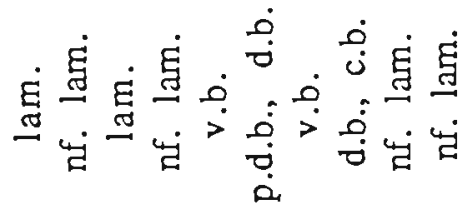

mmmmtnmo: mi்ㅁำ

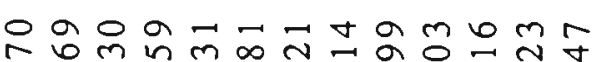

- $0 \dot{0} 0 \dot{0}-\dot{1} \dot{0}-\dot{-}$

NaG-antmb-nmo

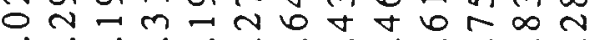
- $000000 \dot{0} 0 \dot{0} 0$

$\forall \infty \forall b \forall b a 0 m+4 b \omega$

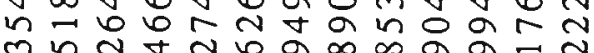
- $00000 \dot{0} 0 \dot{0} \dot{0} \dot{ }$

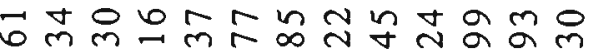
0 antythry - $\dot{0} 0 \dot{0} 00000-1$

กㄴ

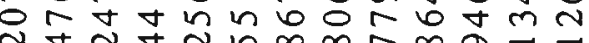
N.0000, n +ं

- $-m-N N N M N N$

$n \infty n \infty m m m N N-\infty N-$ armom

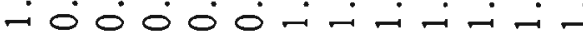

กงก

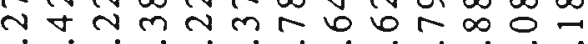
- $0 \dot{0} 0 \dot{0} 0 \dot{0} 0 \dot{0}-\dot{1}$

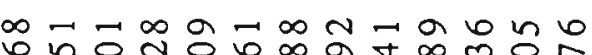
ob - $00000 \dot{0} \dot{0} \dot{-1}-\dot{-}$

$\infty m \infty n \pi-6$ a 0 nn -

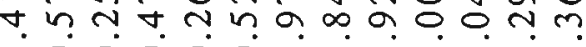
- $\dot{0} \dot{0} \dot{0} \dot{0} \dot{0} \dot{0} \dot{0} \dot{-1}-$

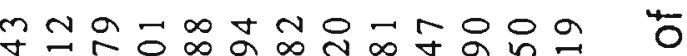
ที่ - $0 \dot{0} 0 \dot{0} 0 \dot{0} 0 \dot{0} \dot{-1}$

نं

$\stackrel{5}{\Phi}$

tmmnnonn n t m.

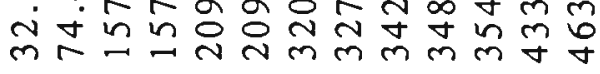




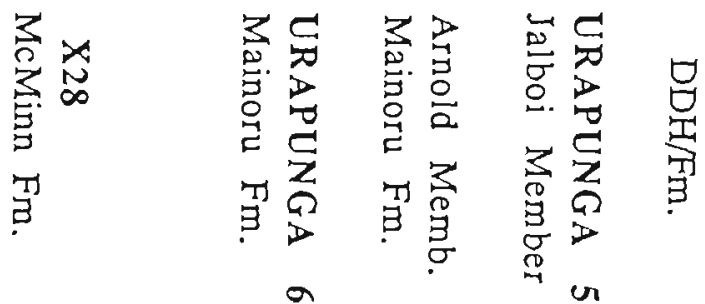

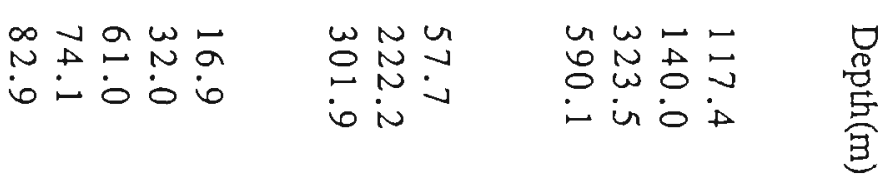

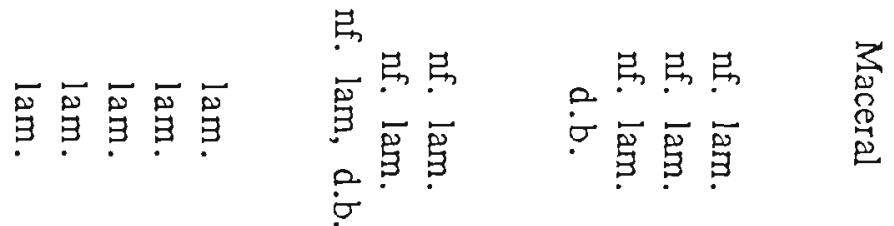

00000 NN!

is $\omega_{i} i \quad$ i $N$ is

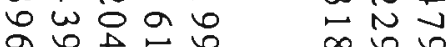

$N \rightarrow \omega$
$\omega i$

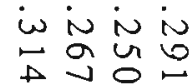

00000

$N N$

$N \triangleright \omega \omega$

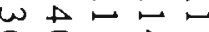

i。

计云

a u \&

3
0
0
0
0
09
0
$u$
0
$\vdots$
3
0

00000

$N N \cdot$

$A$ i $N$ i i is in

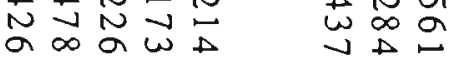

$N A D \omega$

$\rightarrow \perp$ in

$\stackrel{a}{\circ}$ u

Nw

00000

-N口

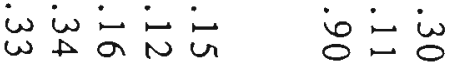

ᄋㅇㅇㅇ

0.000

$N N$

$\forall$ in a

$\omega \bowtie u \omega$

UUN

un

용ㅇㅇㅇ

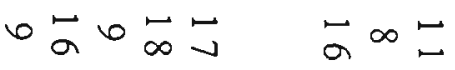

セヘッேே

00000

・・・

DNN

way

$\infty$ ur

59

0.0000

i

iv

- NN

is i i in

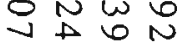

0
v
$0^{2}$
0

$x$

$\infty \infty \omega \tilde{\omega}$

$\infty w$ in

00000

in in

$-N N N$

in a ir:

$\omega \stackrel{\Delta}{\infty}$

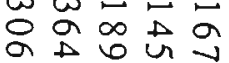

㐫

$\infty \infty \Delta v$

00000

少正二方

๙

•

○ம

00000

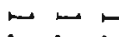

- $\omega \omega N$

$\omega_{A} i \overrightarrow{0} i$

응

ठ잉

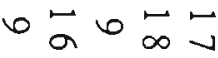

$\vec{a} \infty$

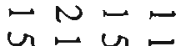

0
uे
3
3
0

5

$x$

题

Z

寻 


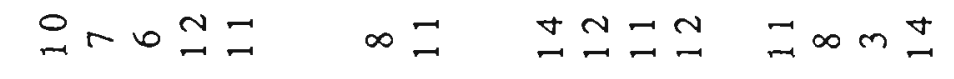

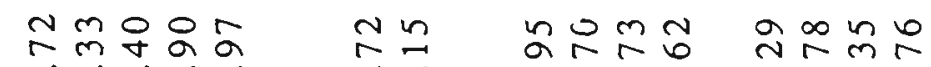
00000

mañ ப்000.

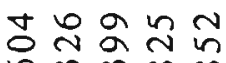
m $m \infty \infty$

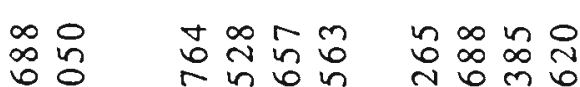
0ं0்

ก!

$\therefore \dot{n}-\dot{-} \dot{0} 0 \dot{0}$

ำ

Nin

$0 \dot{0} 0 \dot{0}$

n.

ก .

0000

茴

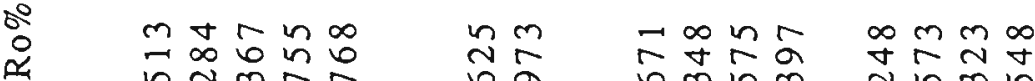
जீ?

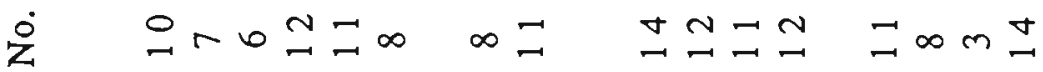

a

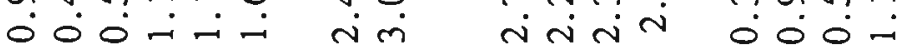

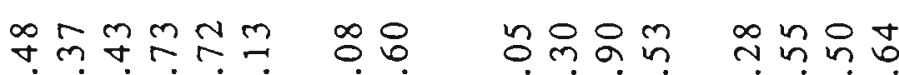
ப்

గீ丨 0 オ

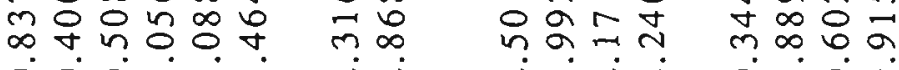
ம் $\dot{0}-$ तथ

$\sin 2 \pi$

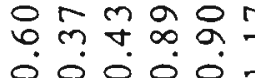

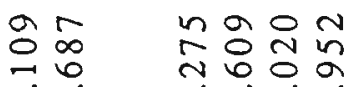

m क जि

Niণ

ขึำ in

तm

M $\quad \infty \quad \infty \circ$

ปัก $\dot{0} \dot{0} \dot{0} \dot{0}$

n. $m \infty 00$

? त- ति

홍

总

茨

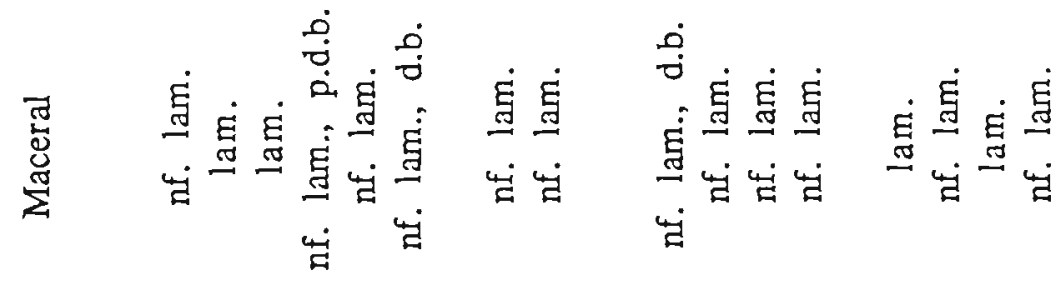

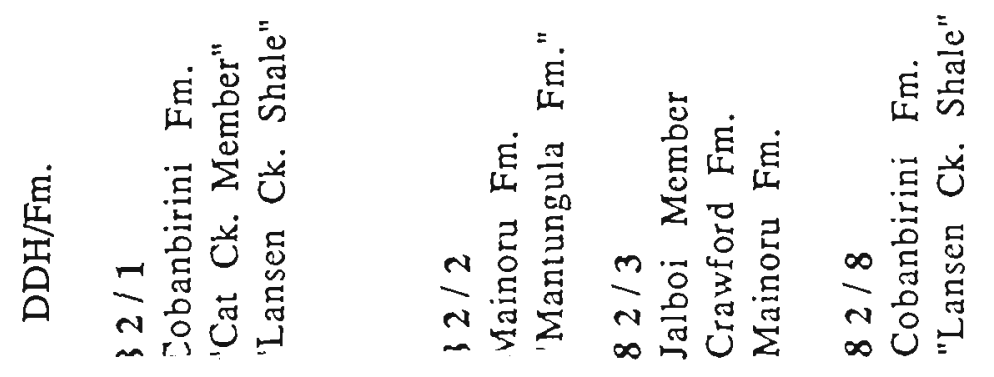



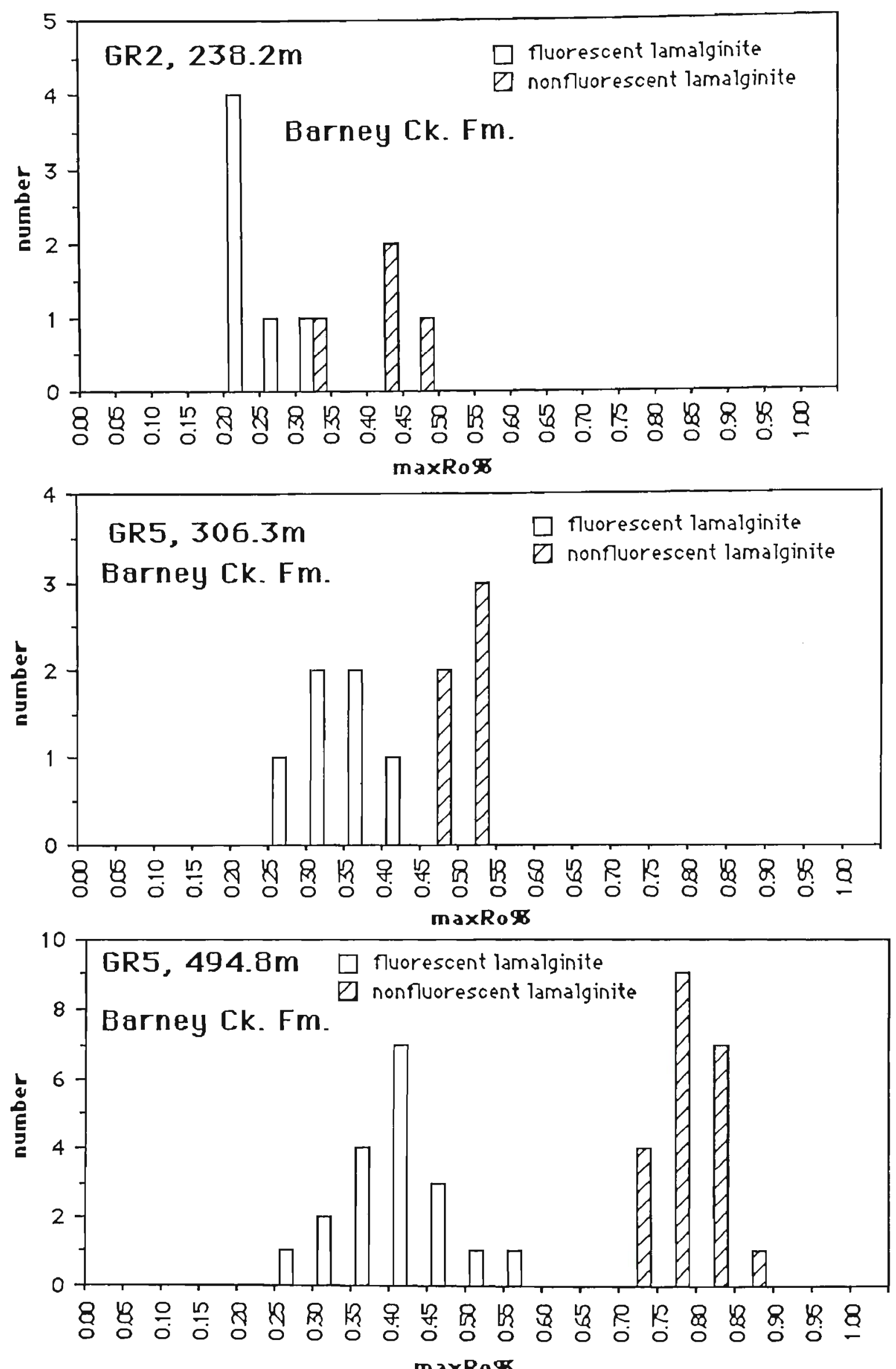

APPENDIX H. Mean maximum reflectance (maxRo\%) histograms for selected samples containing both fluorescent and nonfluorescent lamalginite; McArthur Group, Glyde River Subbasin. 

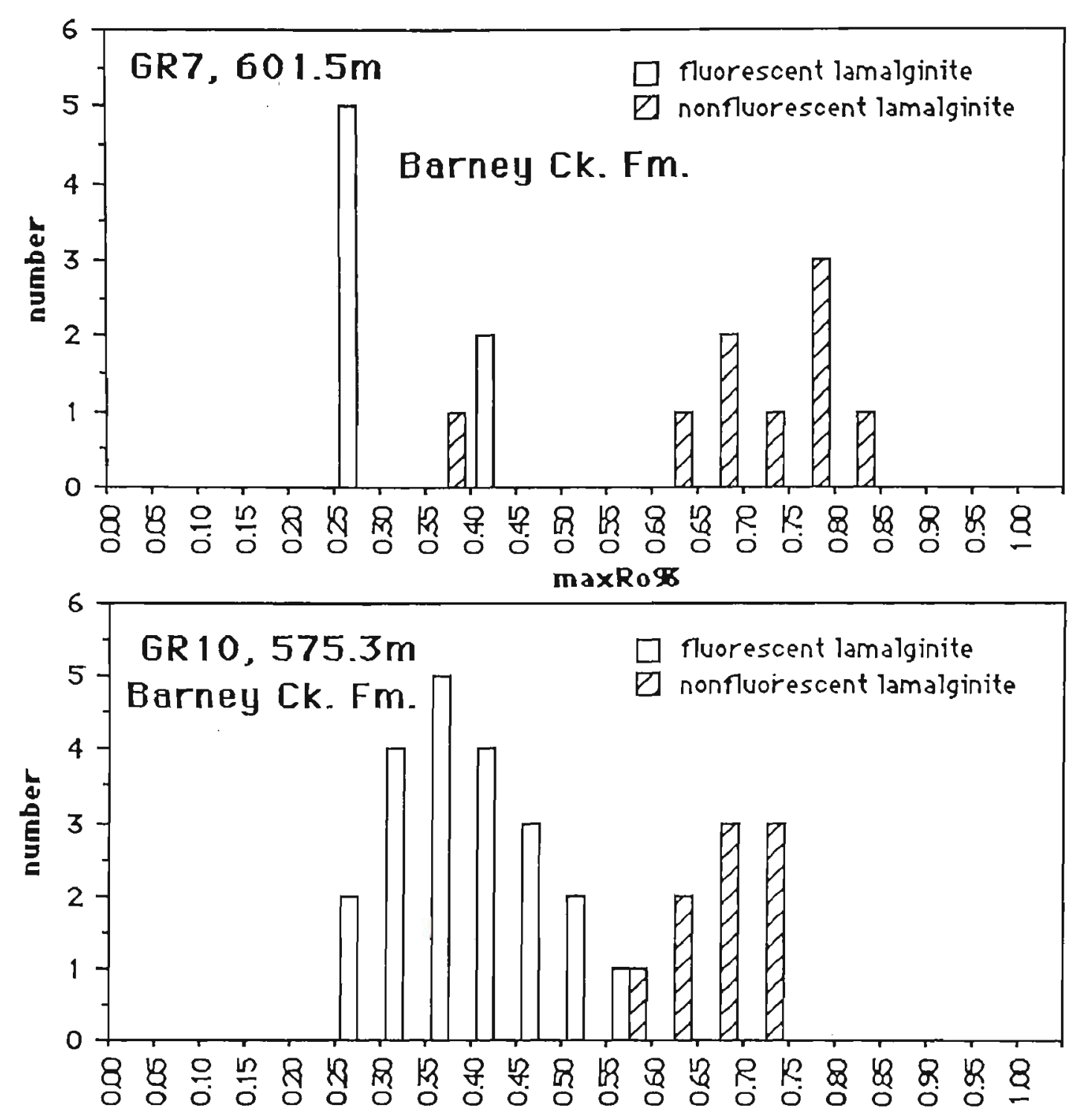

maxRos

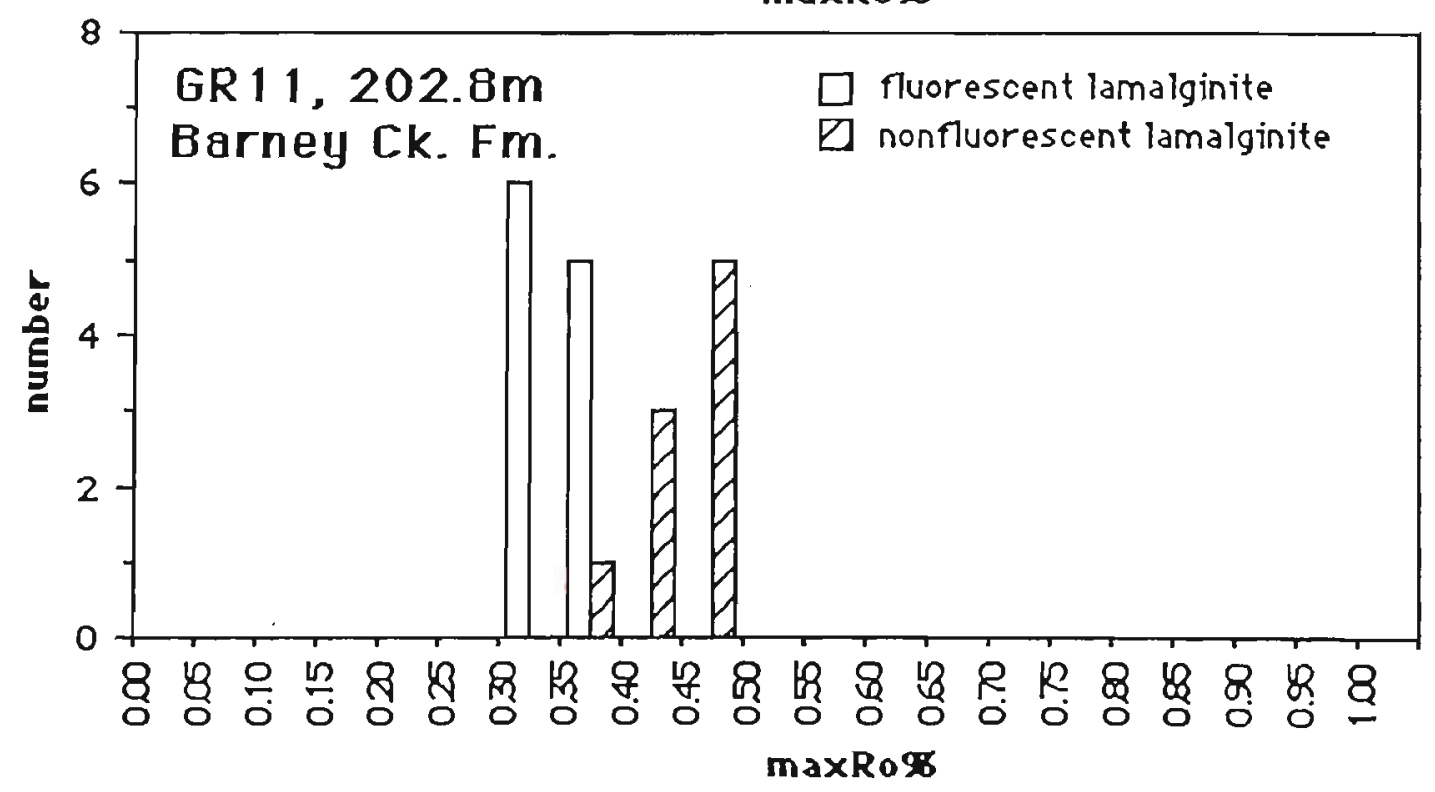

APPENDIX H ctd. Mean maximum reflectance (maxRo\%) histograms for selected samples containing both fluorescent and nonfluorescent lamalginite; McArthur Group, Glyde River Subbasin. 

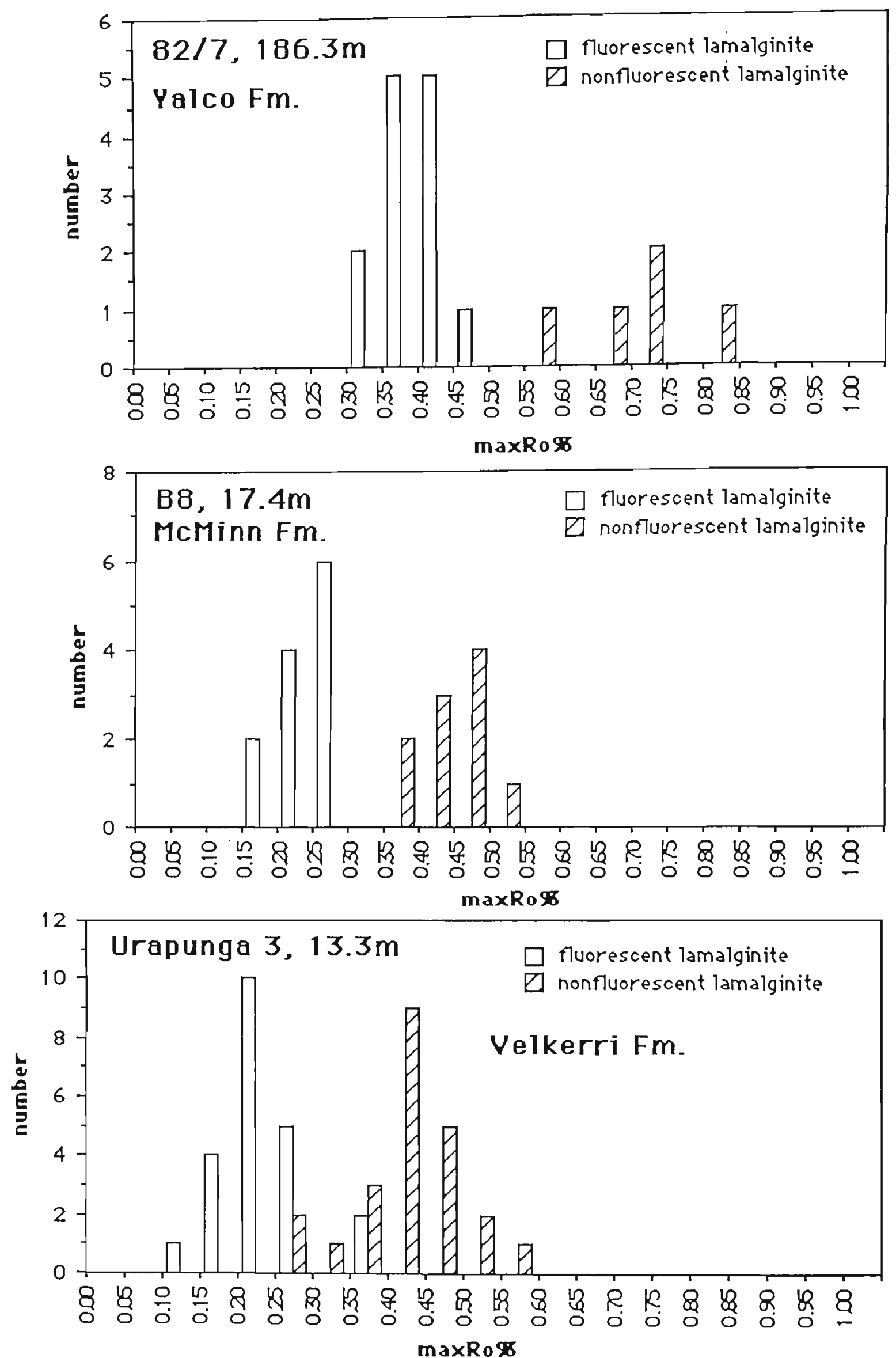

APPENDIX H ctd. Mean maximum reflectance (maxRo\%) histograms for selected samples containing both fluorescent and nonfluorescent lamalginite, McArthur Group from the central and northern Batten Trough; and Roper Group 


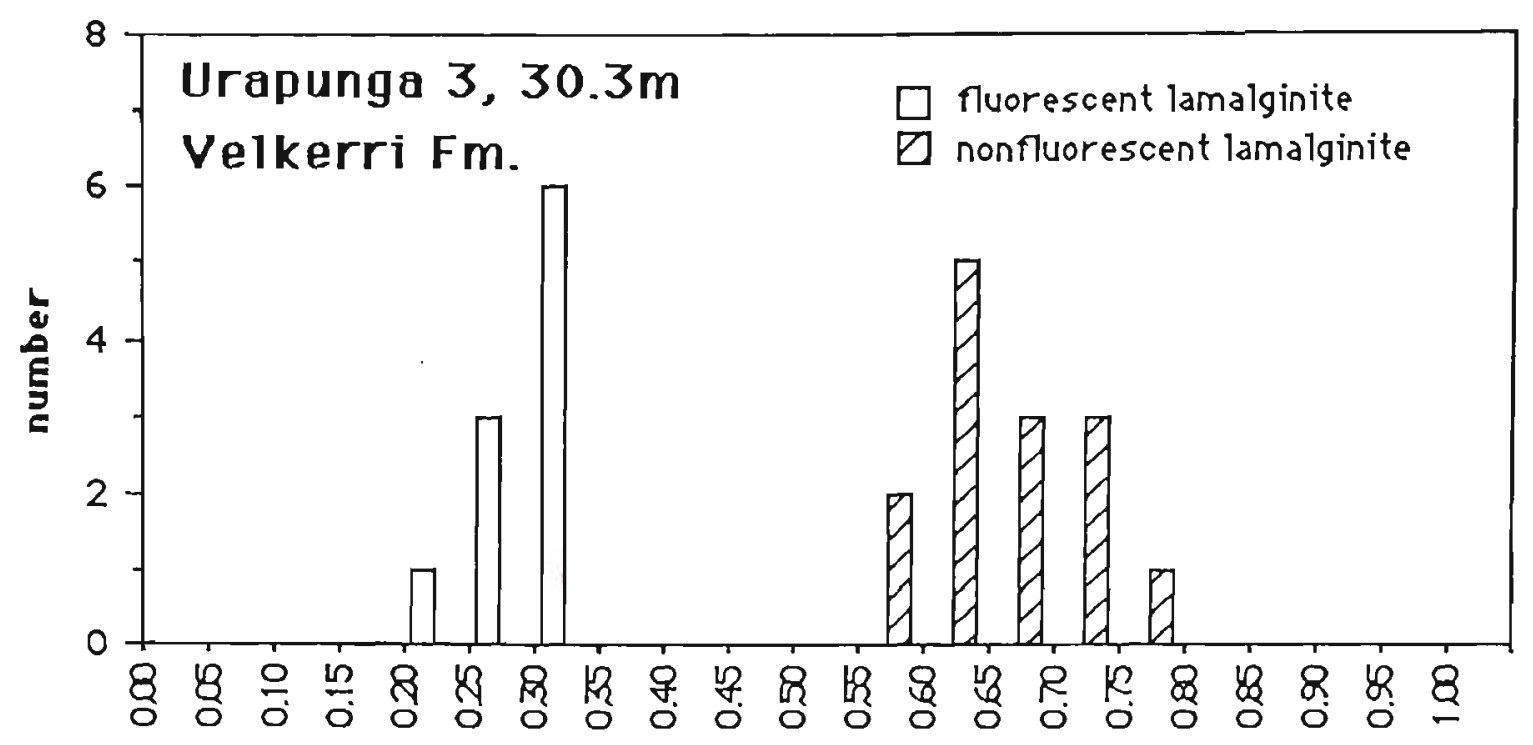

maxRos
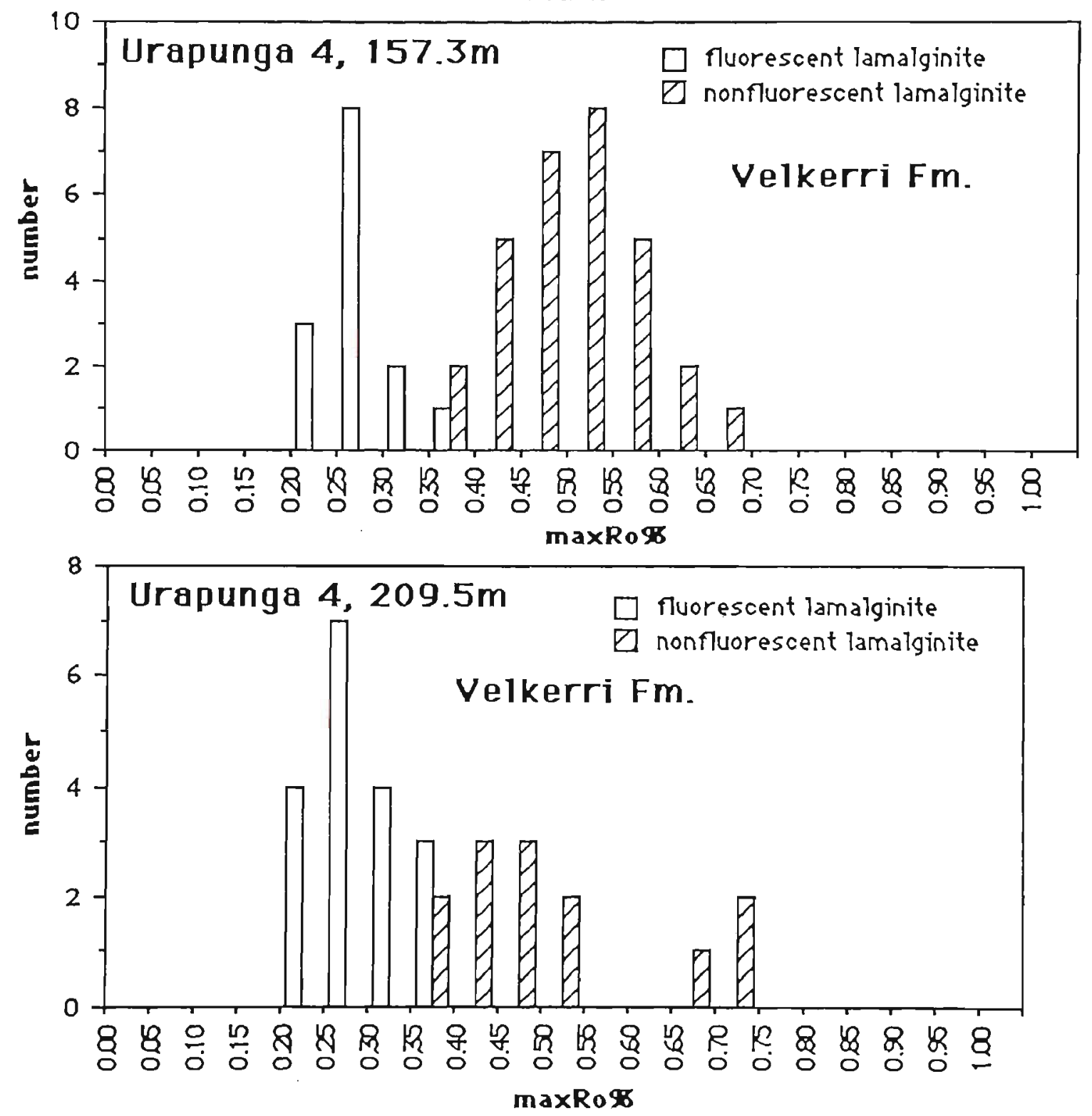

APPENDIX $\mathrm{H}$ ctd. Mean maximum reflectance (maxRo\%) histograms for selected samples containing both fluorescent and nonfluorescent lamalginite; Roper Group. 

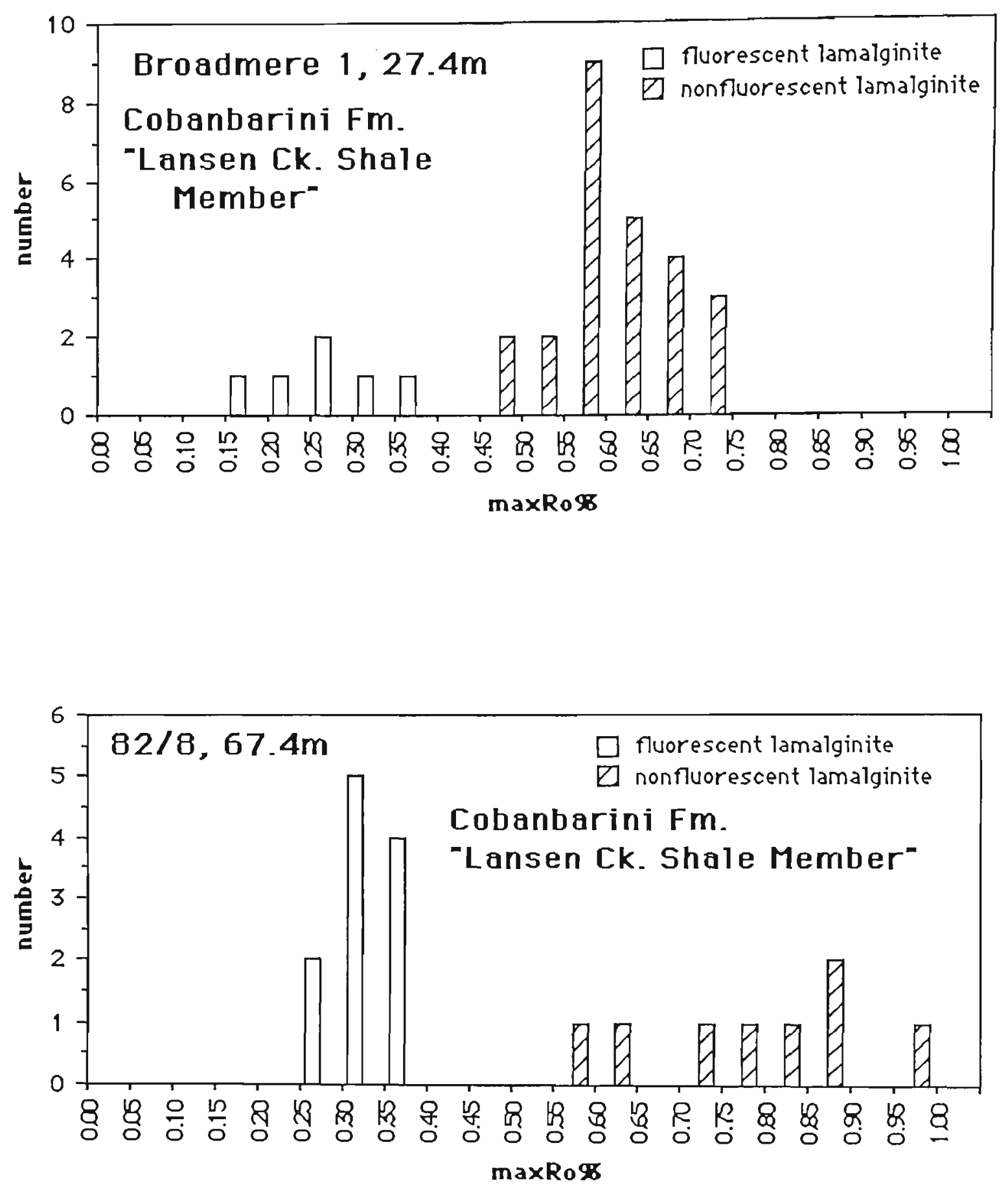

APPENDIX H ctd. Mean maximum reflectance (maxRo\%) histograms for selected samples containing both fluorescent and nonfluorescent lamalginite; Roper Group. 

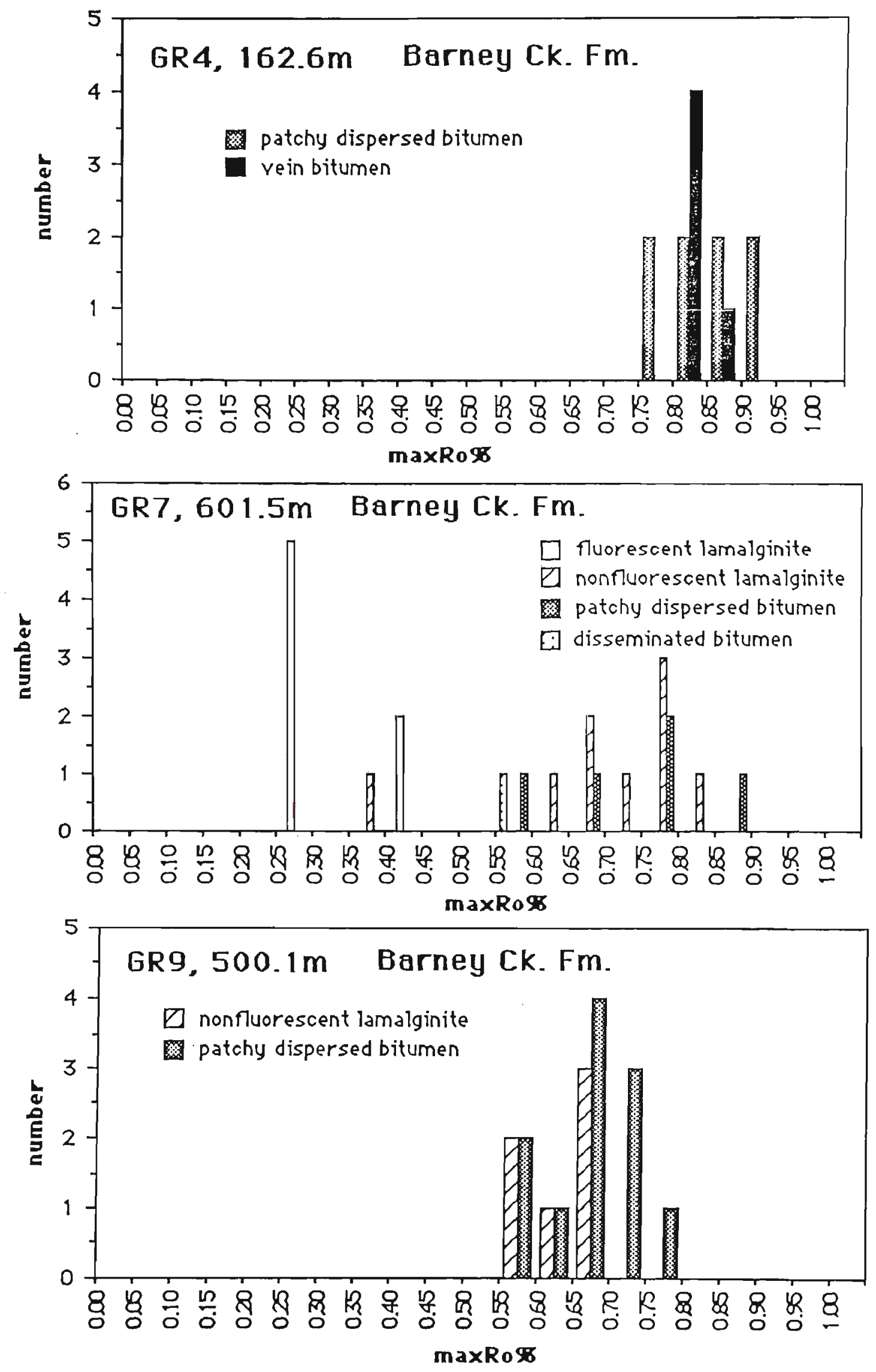

APPENDIX I. Mean maximum reflectance (maxRo\%) histograms for selected samples containing nonfluorescent lamalginite and/or bitumen; McArthur Group, Glyde River Subbasin. 

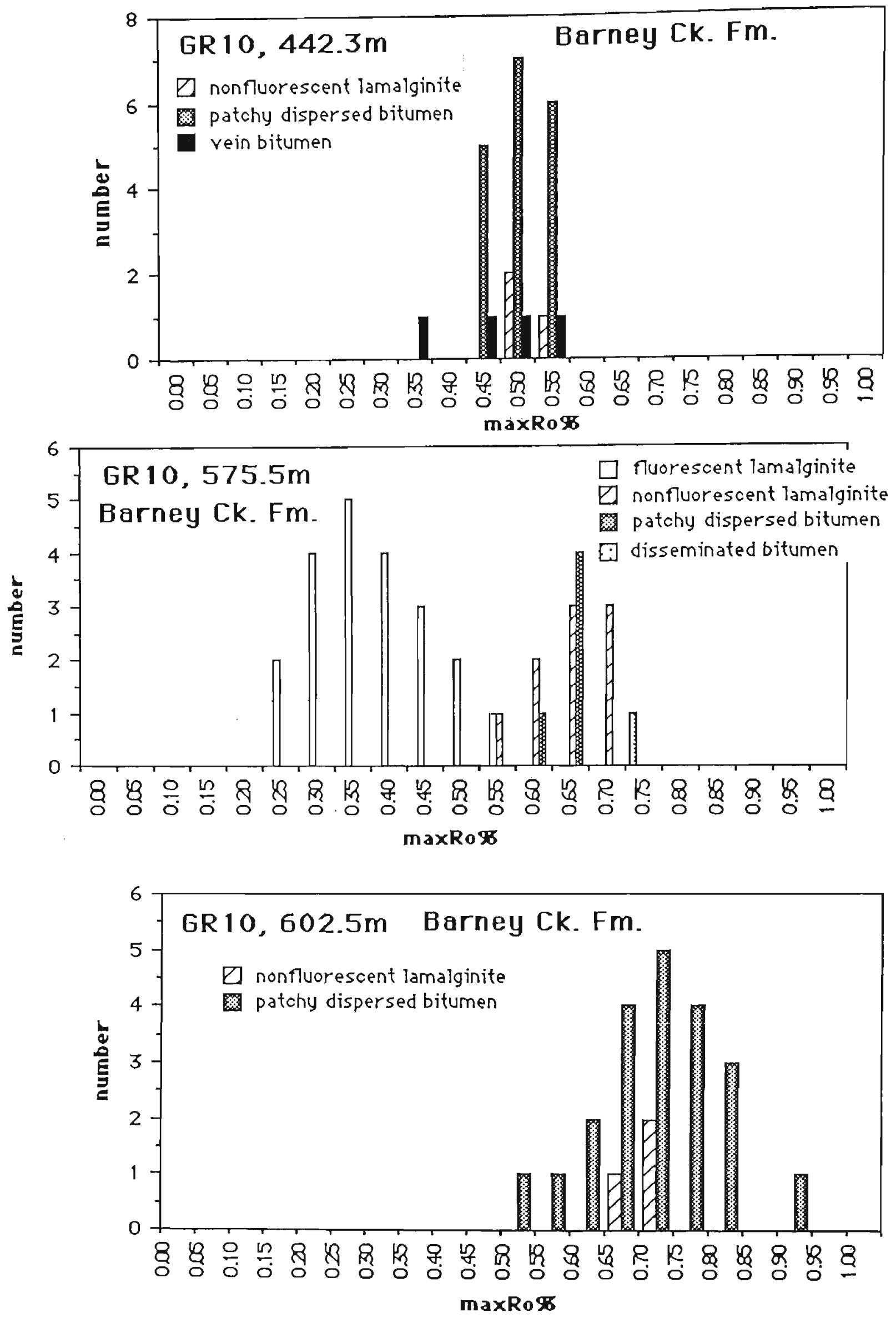

APPENDIX I ctd. Mean maximum reflectance (maxRo\%) histograms for selected samples containing lamalginite and/or bitumen; McArthur Group, Glyde River Subbasin. 

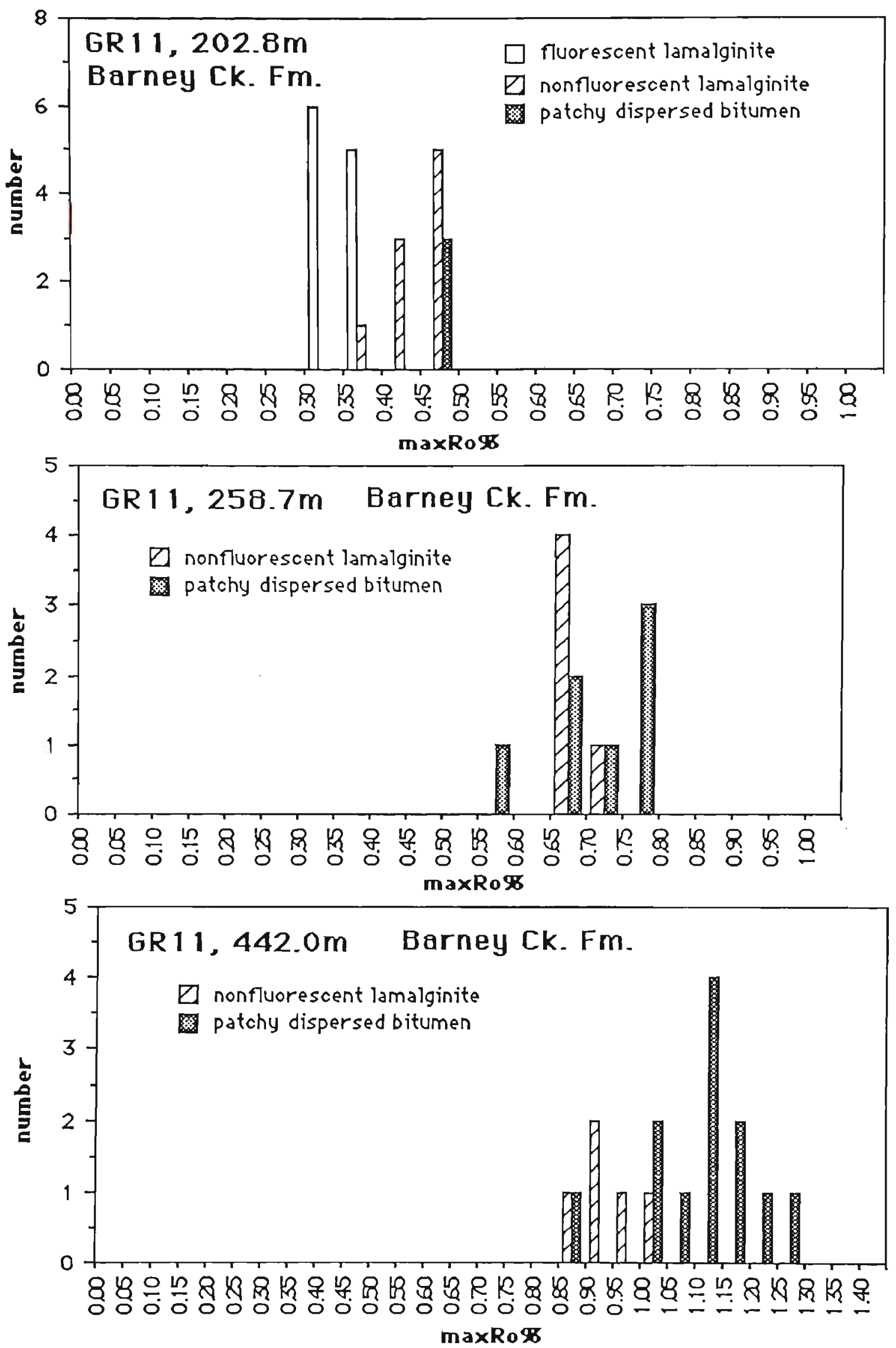

APPENDIX 1 ctd. Mean maximum reflectance (maxRo\%) histograms for selected samples containing lamalginite and/or bitumen; McArthur Group, Glyde River Subbasin. 

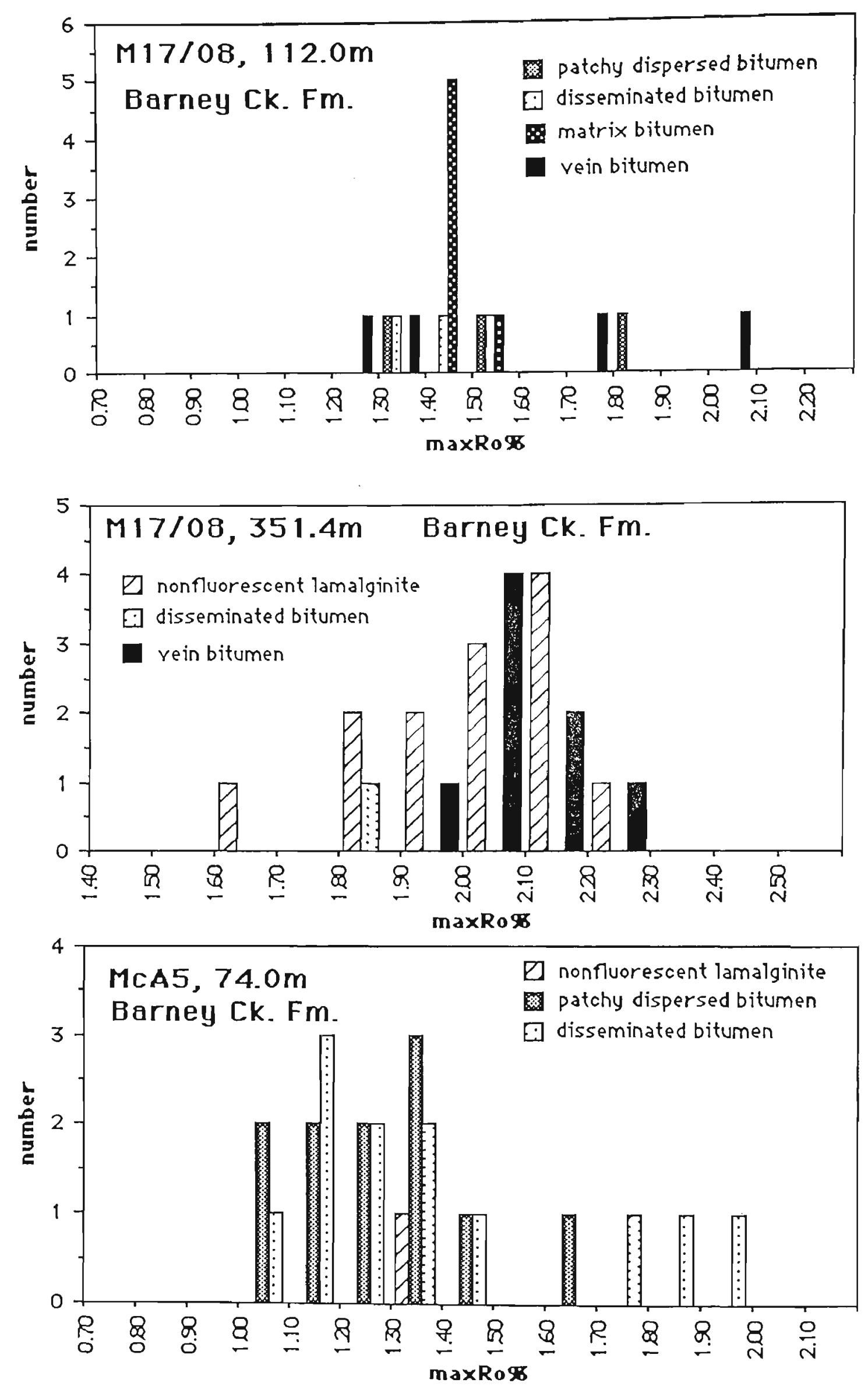

APPENDIX I ctd. Mean maximum reflectance (maxRo\%) histograms for selected samples containing lamalginite and/or bitumen; McArthur Group, central and northern Batten Trough. 

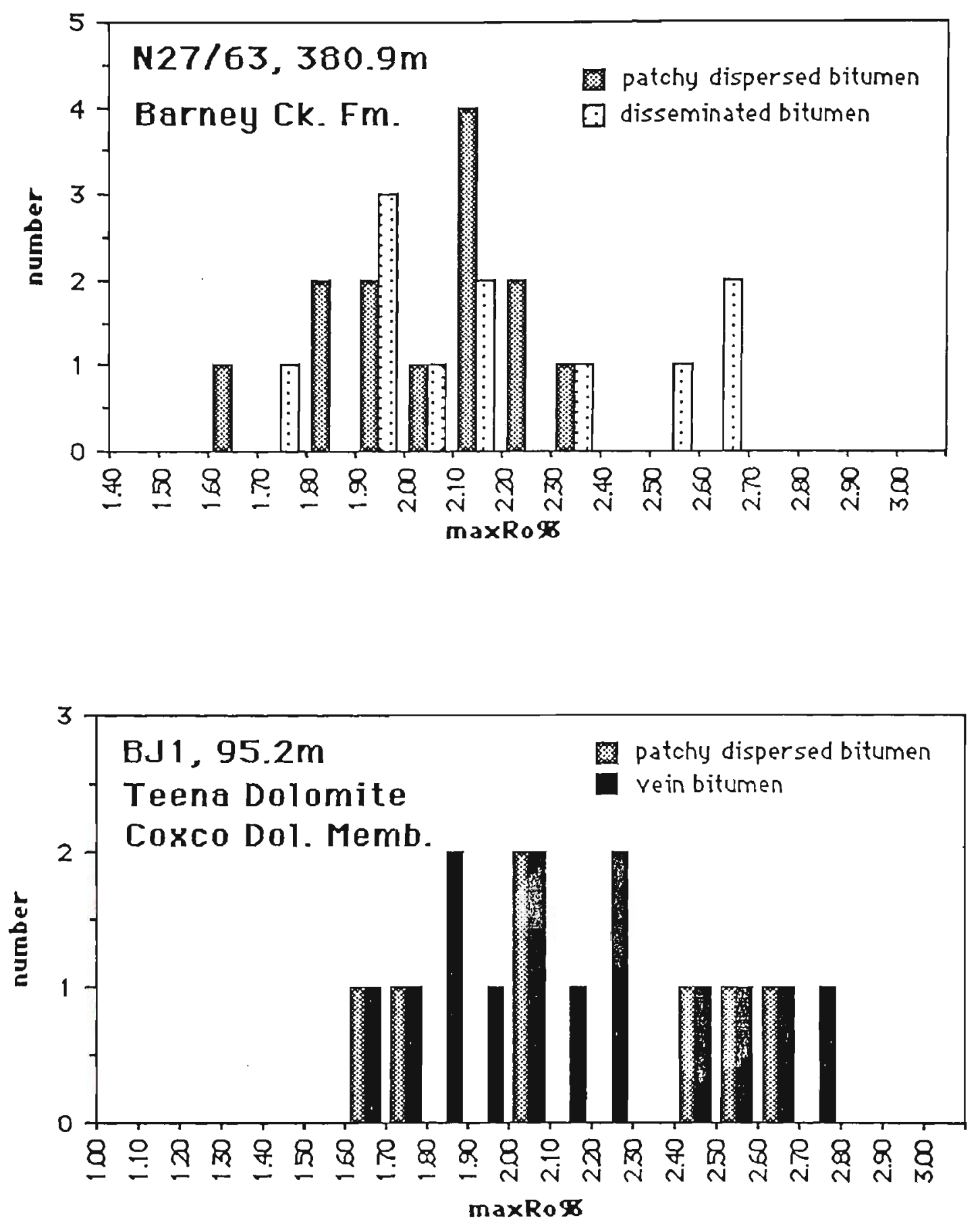

APPENDIX I ctd. Mean maximum reflectance (maxRo\%) histograms for selected samples containing lamalginite and/or bitumen; McArthur Group, central and northern Batten Trough. 

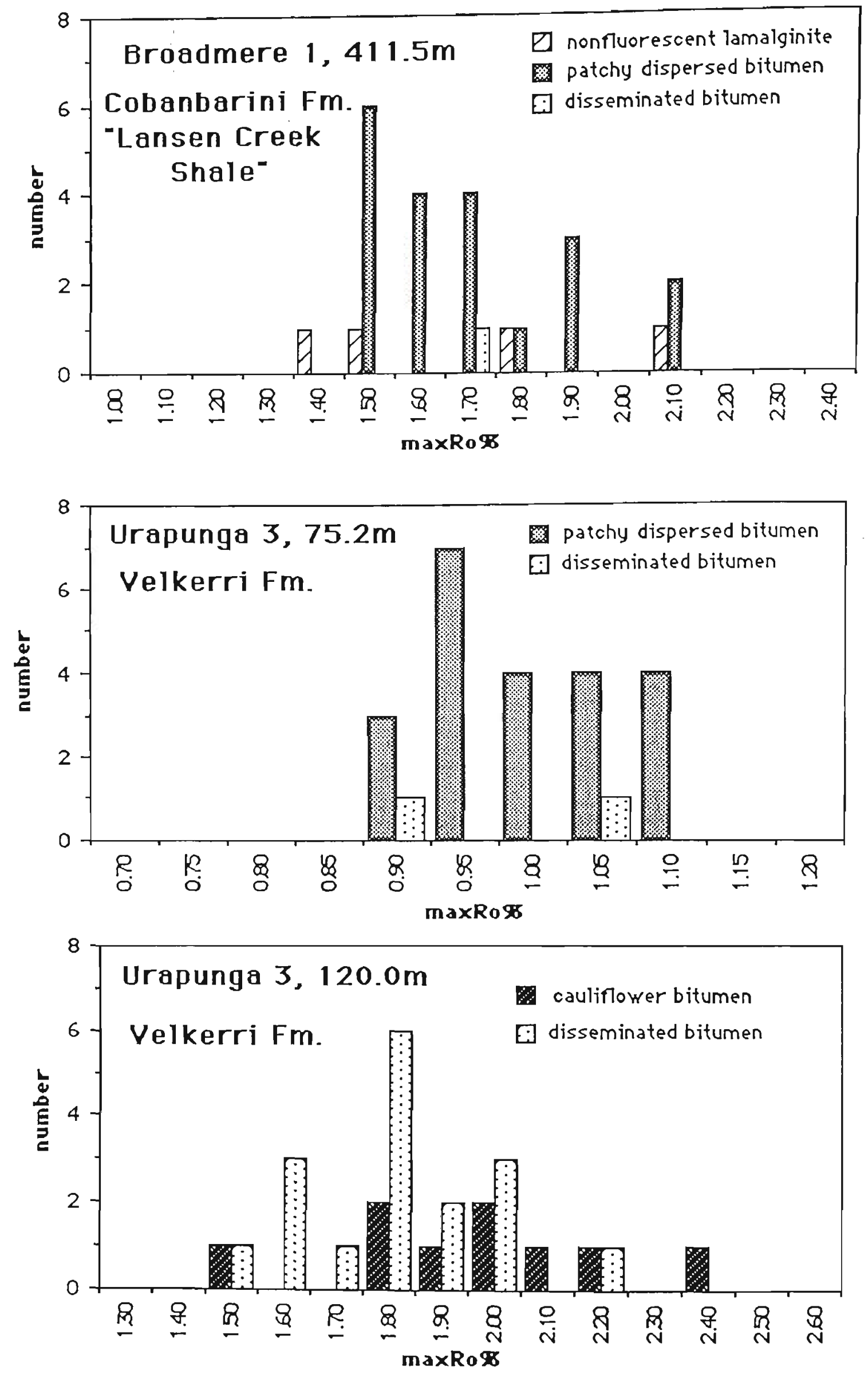

APPENDIX I ctd. Mean maximum reflectance (maxRo\%) histograms for selected samples containing lamalginite and/or bitumen; Roper Group. 

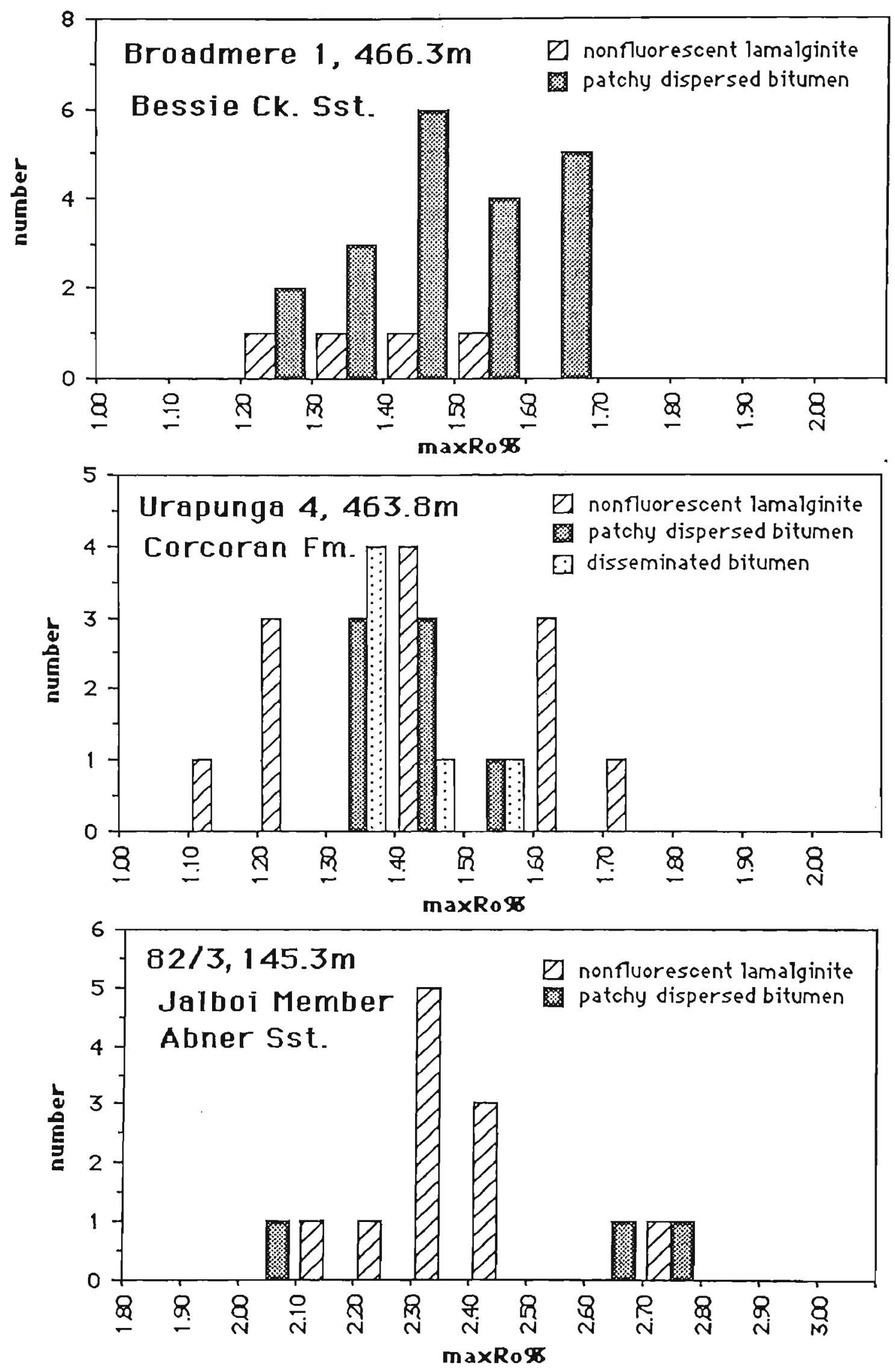

APPENDIX I ctd. Mean maximum reflectance (maxRo\%) histograms for selected samples containing lamalginite and/or bitumen; Roper Group. 
$y=0.6664-0.0056 x+6.362 e-4 x^{\wedge} 2-6.276 e-6 x^{\wedge} 3+1.606 e-8 x^{\wedge} 4 \quad R=0.98$
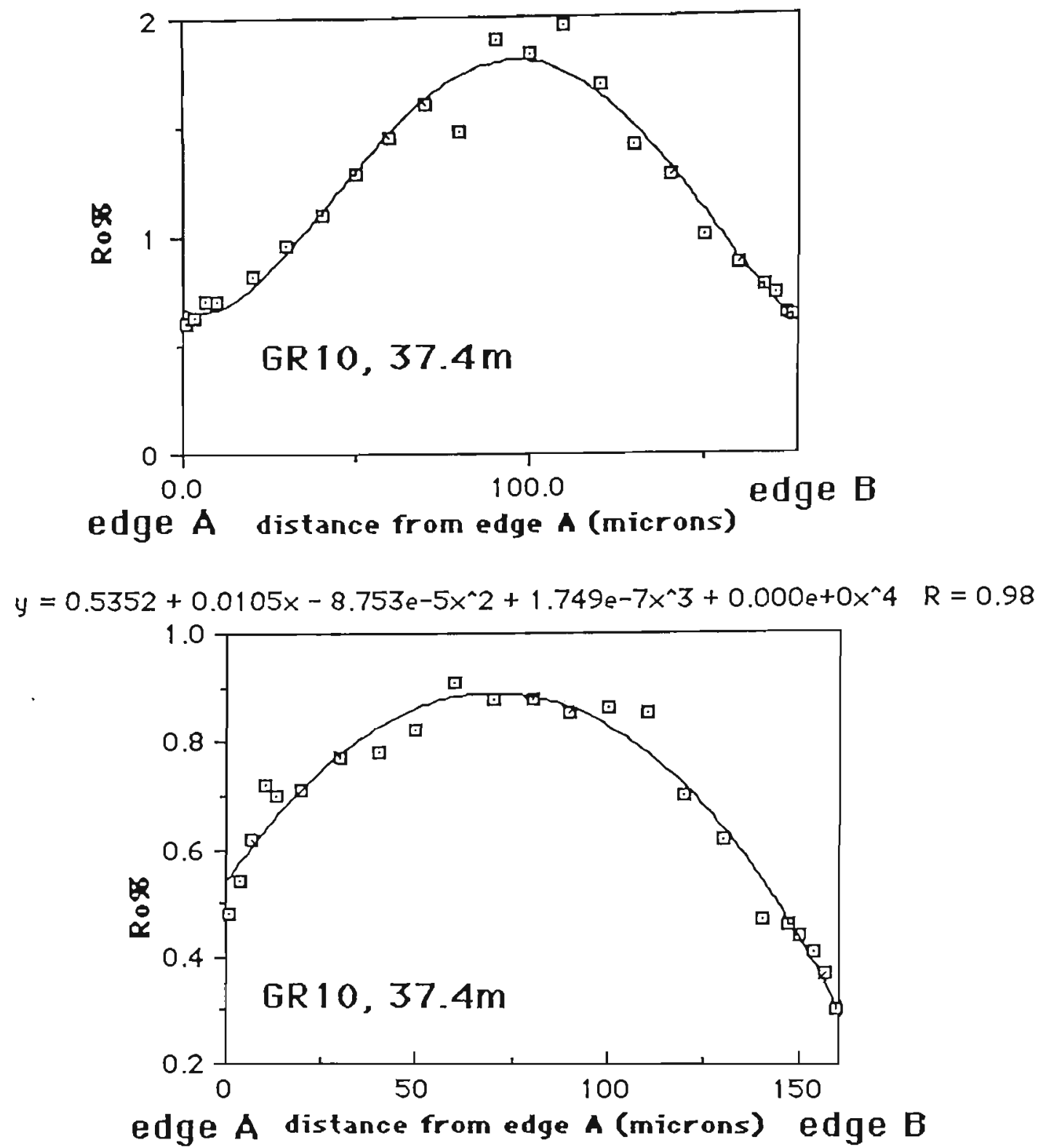

$y=0.7777-0.019 x+0.004 x^{\wedge} 2-9.630 e-5 x^{\wedge} 3+6.084 e-7 x^{\wedge} 4 \quad R=0.99$

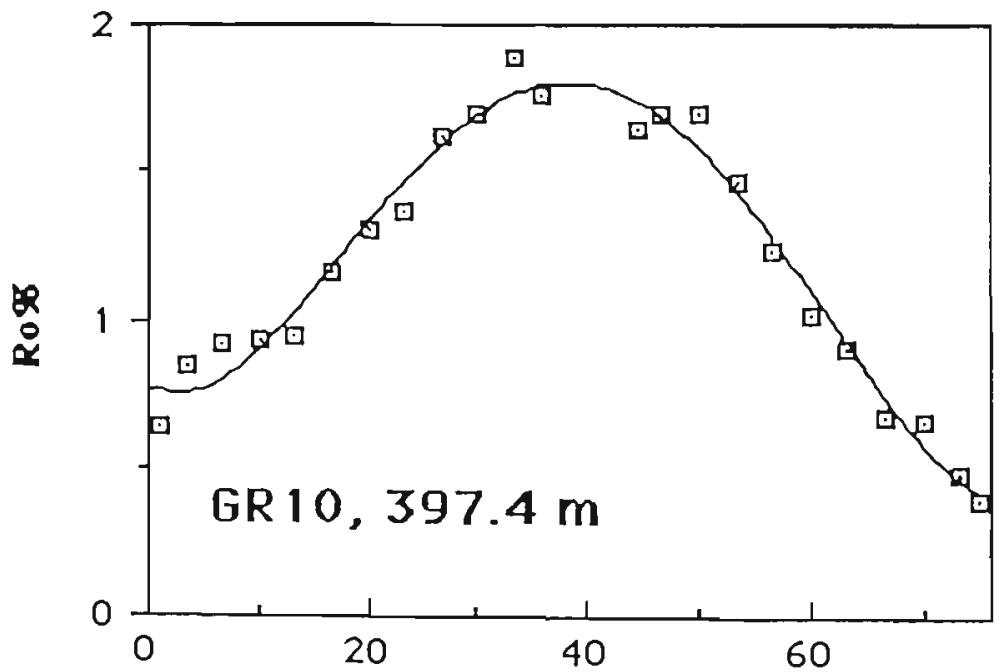

edge $A$ distance from edge A (microns) edge $B$

APPENDIX J. Random reflectances (Ro\%) across a section through a thucholite grain; DDH GR10, Barney Creek Formation, Glyde River Subbasin 
$y=0.7622+0.0357 x+0.0045 x^{\wedge} 2-1.240 e-4 x^{\wedge} 3+7.745 e-7 x^{\wedge} 4 \quad R=0.99$

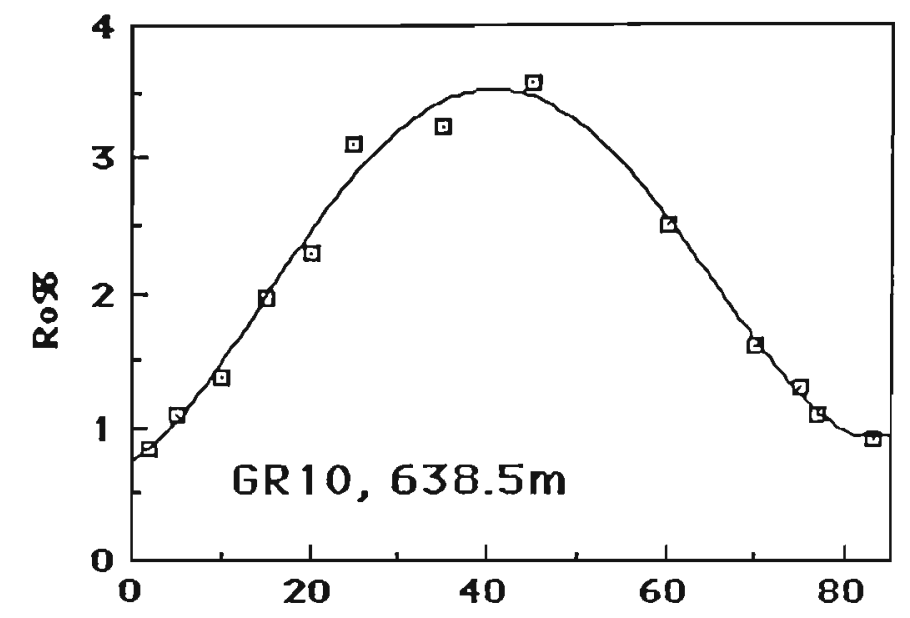

edge A distance from edge A (microns) edge B

$y=0.5562-0.0213 x+0.0065 x^{\wedge} 2-1.214 e-4 x^{\wedge} 3+5.896 e-7 x^{\wedge} 4 \quad R=0.99$

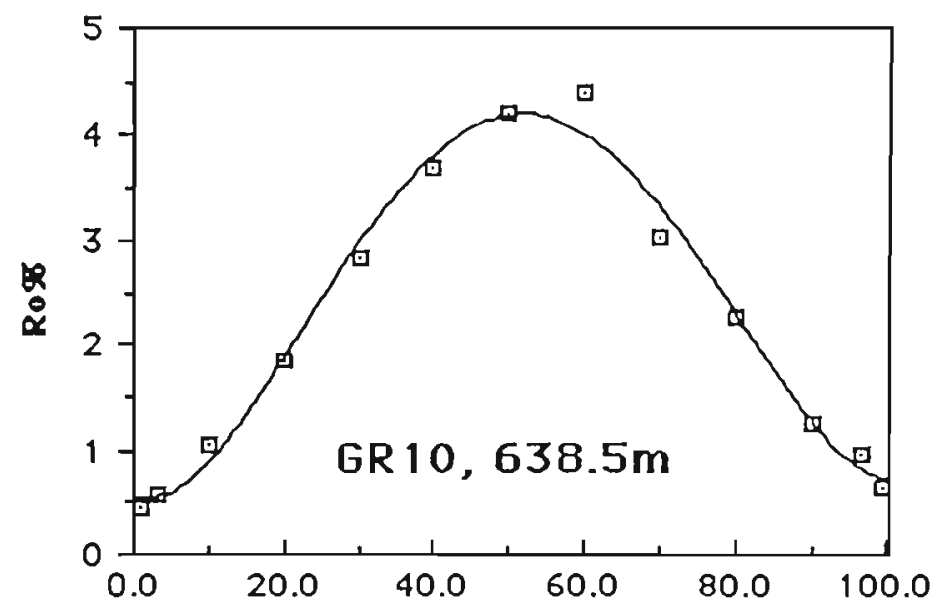

edge A distance from edge $A$ (microns) edge $B$

$y=0.2492+0.0634 x-0.0077 x^{\wedge} 2+3.686 e-4 x^{\wedge} 3-6.255 e-6 x^{\wedge} 4 \quad R=0.98$

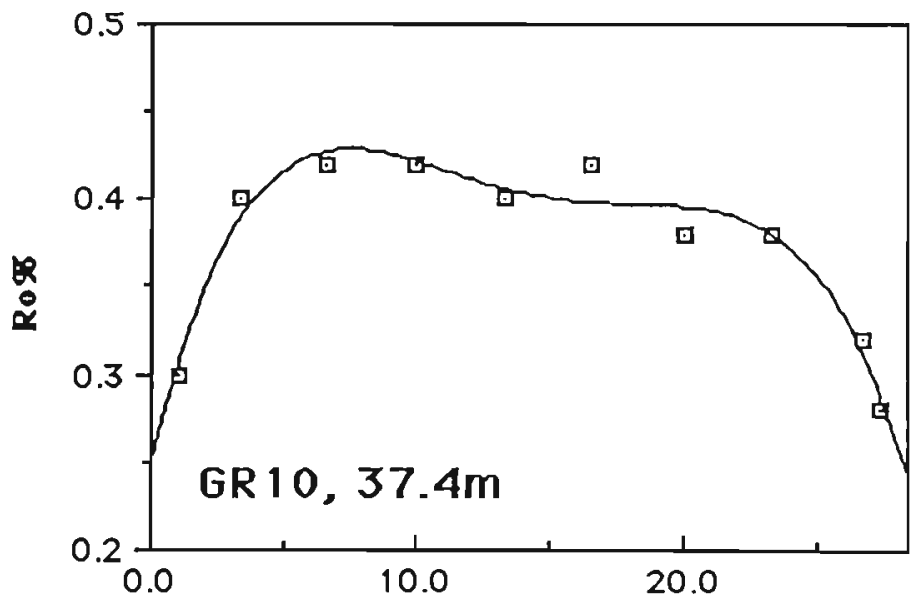

edge $A$ distance from edge $A$ (microns) edge $B$

APPENDIX J ctd. Random reflectances (Ro\%) across a section through a thucholite grain; DDH GR10, Barney Creek Formation, Glyde River Subbasin. 
$y=0.2338+0.0042 x+0.0032 x^{\wedge} 2-3.705 e-4 x^{\wedge} 3+8.632 e^{-6 x}-4 \quad R=0.99$

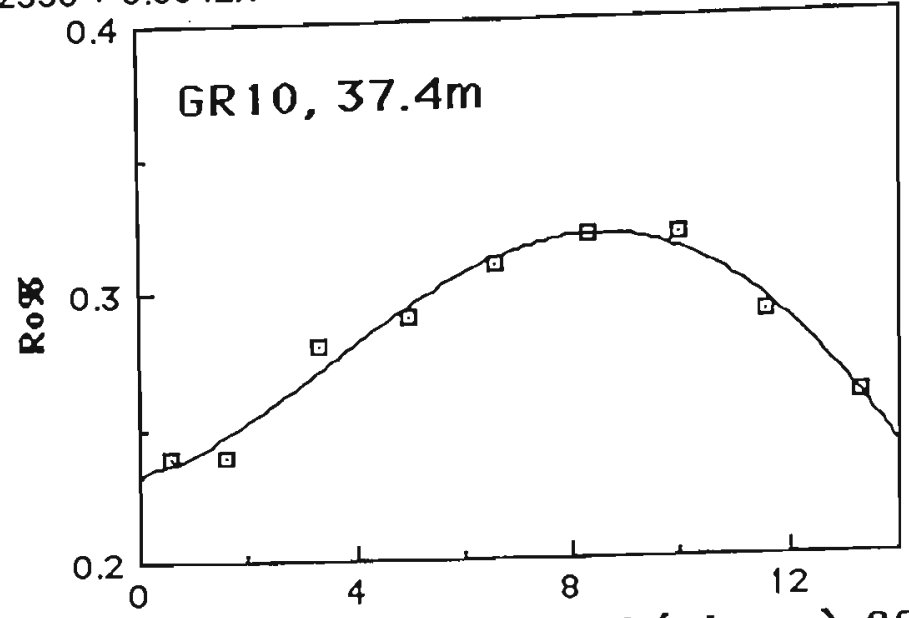

edge $A$ distance from edge A (microns) edge B $y=0.3495+0.0894 x-0.0162 x^{\wedge} 2+0.001 x^{\wedge} 3-2.196 e-5 x^{\wedge} 4 \quad R=0.87$

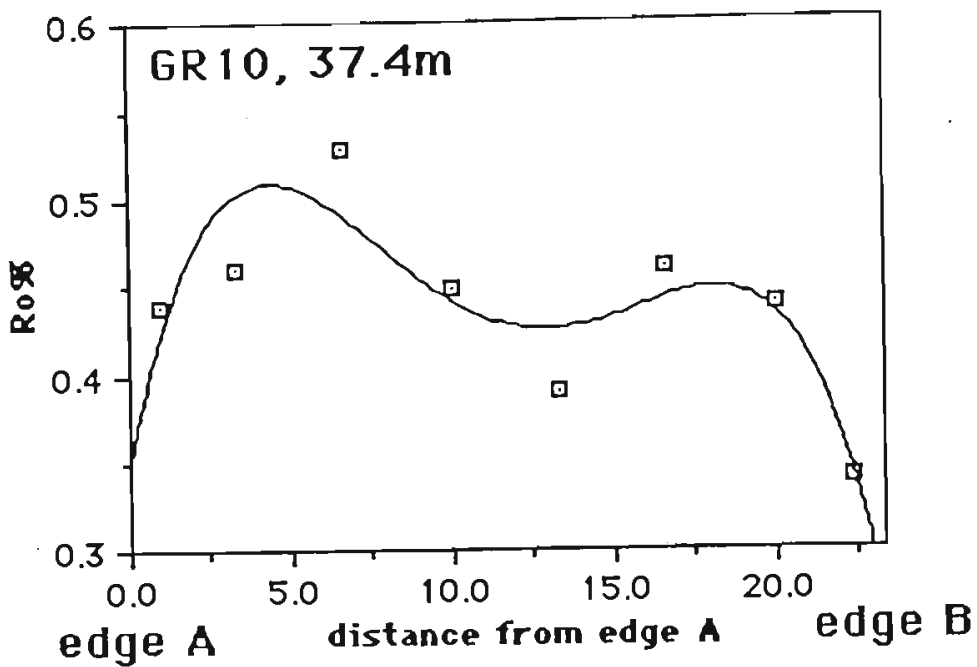

$y=0.1854+0.0297 x-8.899 e-4 x^{\wedge} 2+1.124 e^{-5 x^{\wedge} 3}-1.243 e-7 x^{\wedge} 4 \quad R=0.98$

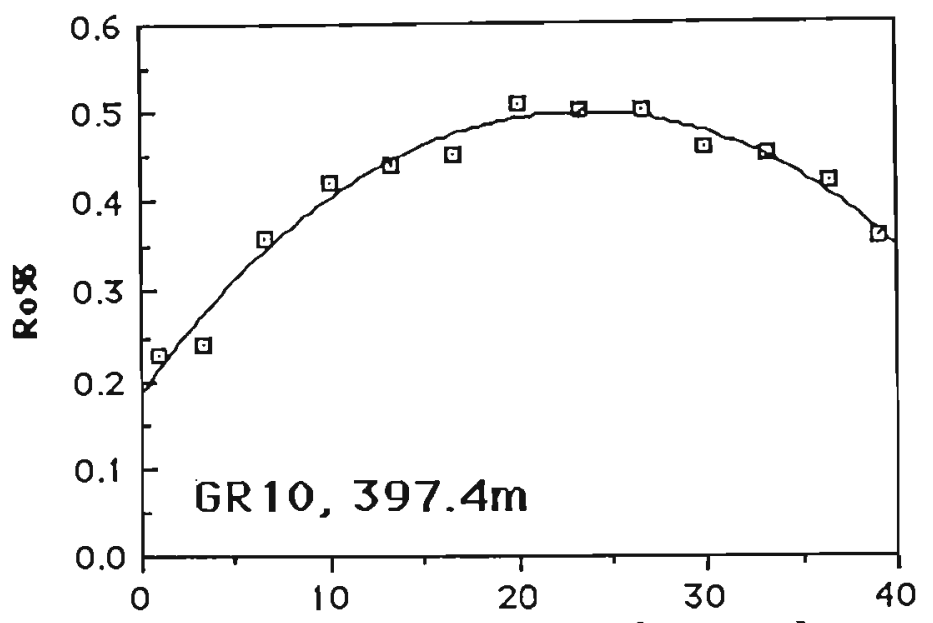

edge A distance from edge $A$ (microns) edge $B$

APPENDIX J. Random reflectances (Ro\%) across a section through a thucholite grain; DDH GR10, Barney Creek Formation, Glyde River Subbasin. 

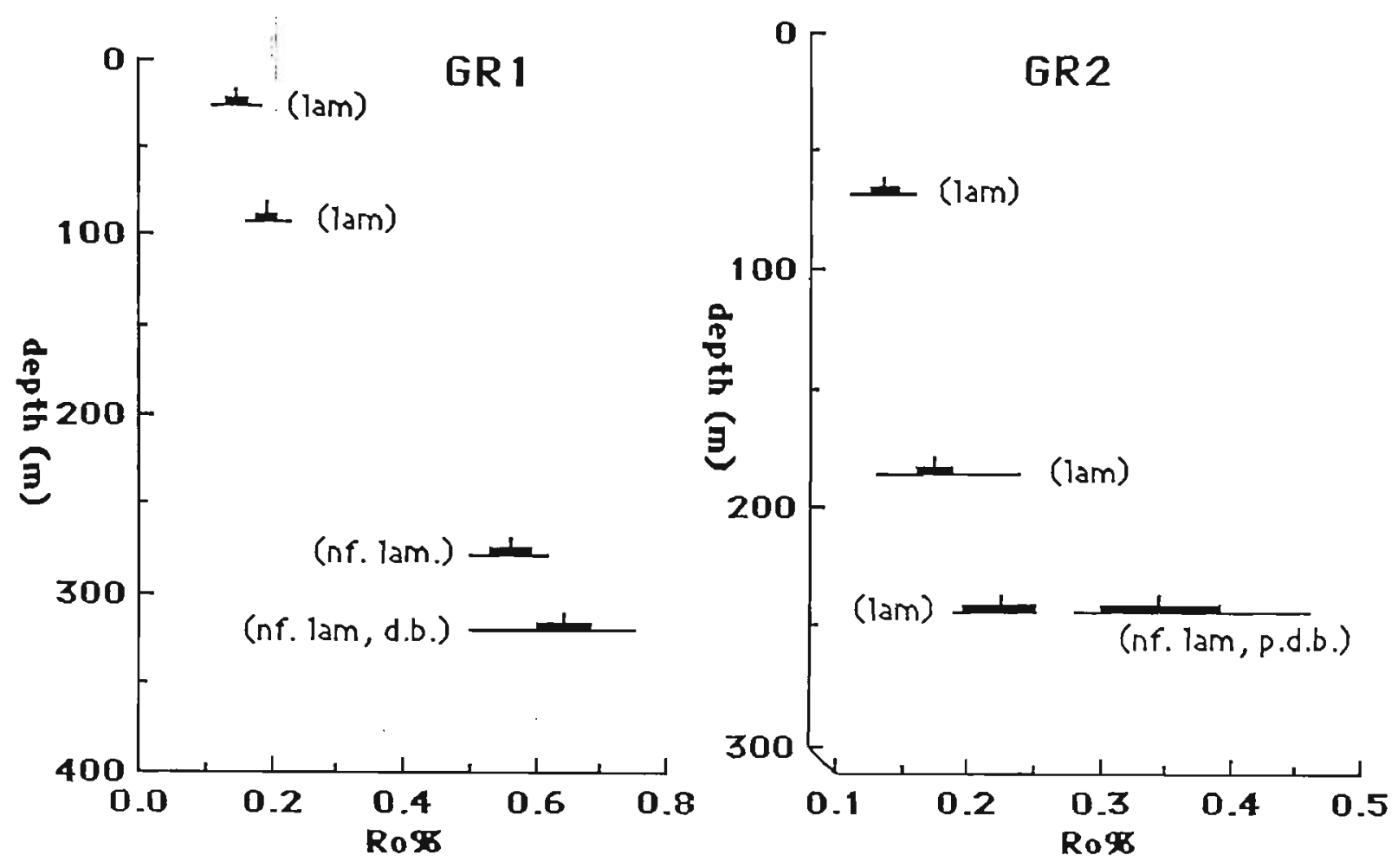

\section{ABBREVIATIONS:}

lam $=$ fluorescent lamalginite,

nf. lam = nonfluorescent lamalginite,

d.b. = dispersed bitumen,

m.b. = matrix bitumen,

p.d.b. = patchy dispersed bitumen,

v.b. = vein bitumen,

APPENDIX K. Reflectances (Ro\%) of lamalginite and/or bitumen versus depth; Barney Creek Formation, Glyde River Subbasin. Mean reflectance values are represented by the vertical lines, 95\% confidence limits of the mean by the black rectangles and the range by the horizontal line. 

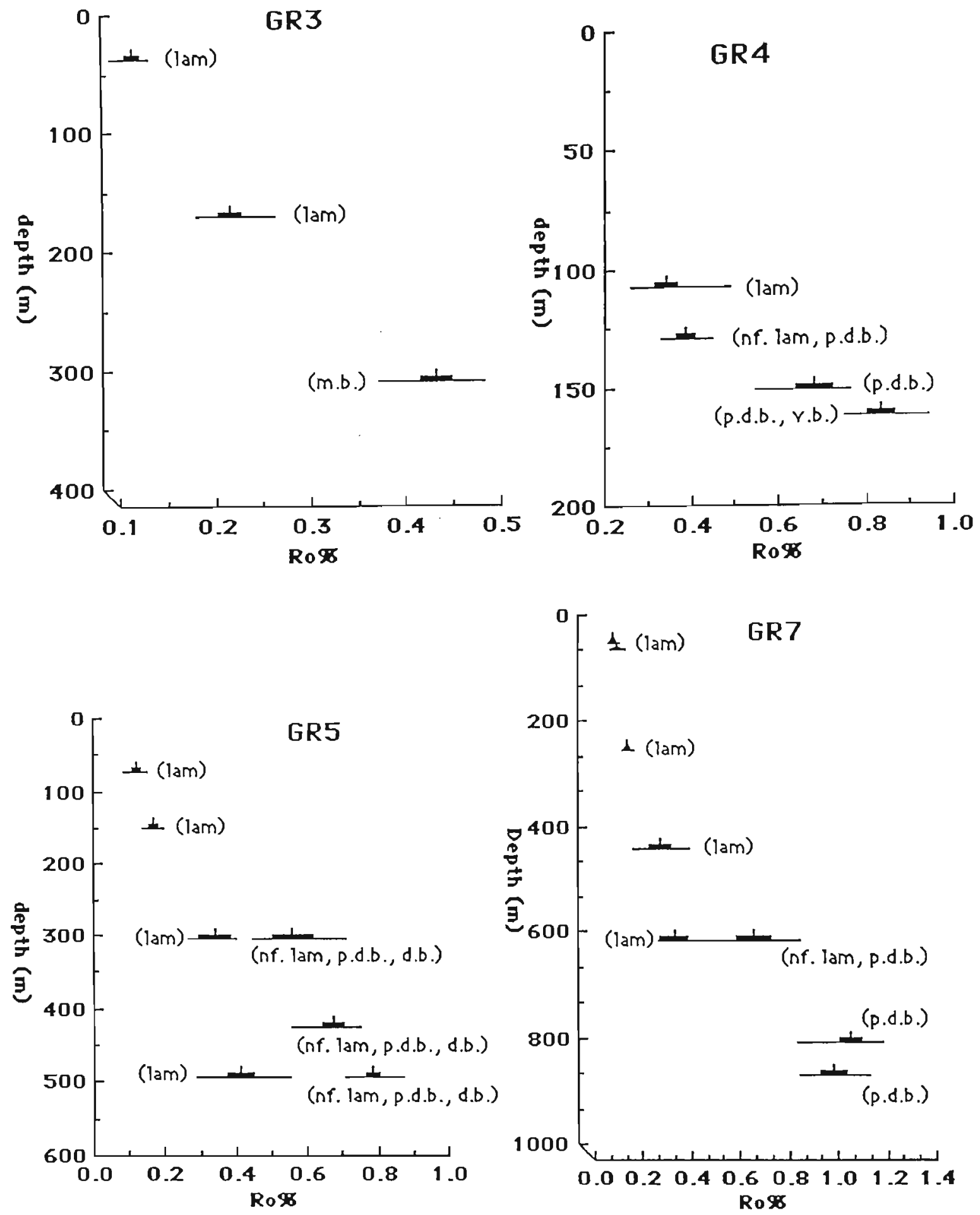

APPENDIX $\mathbf{K}$ ctd. Reflectances (Ro\%) of lamalginite and/or bitumen versus depth; Barney Creek Formation, Glyde River Subbasin. Mean reflectance values are represented by the vertical lines, $95 \%$ confidence limits of the mean by the black rectangles and the range by the horizontal line. 

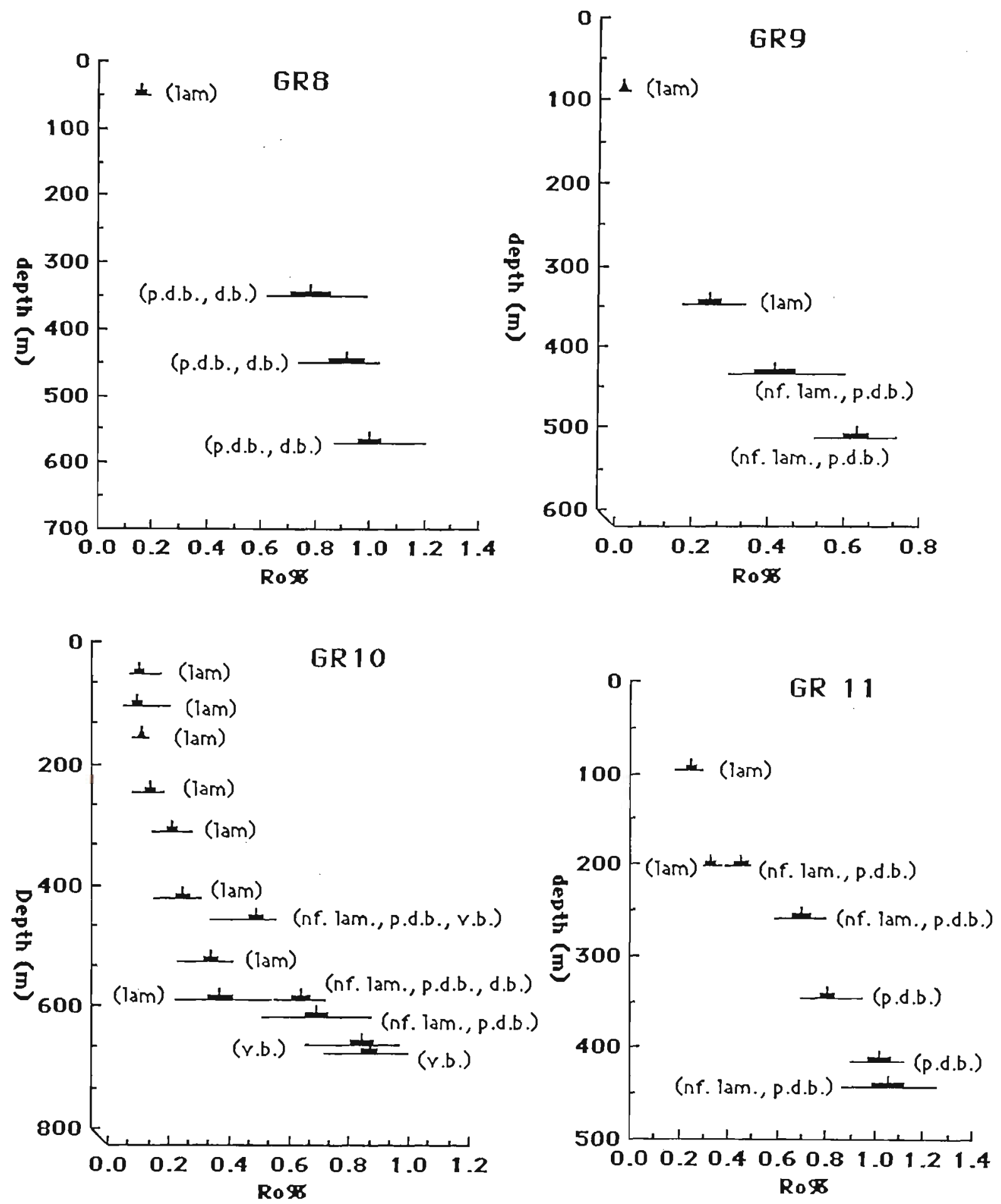

APPENDIX $\mathbf{K}$ ctd. Reflectances (Ro\%) of lamalginite and/or bitumen versus depth; Barney Creek Formation, Glyde River Subbasin. Mean reflectance values are represented by the vertical lines, 95\% confidence limits of the mean by the black rectangles and the range by the horizontal line. 

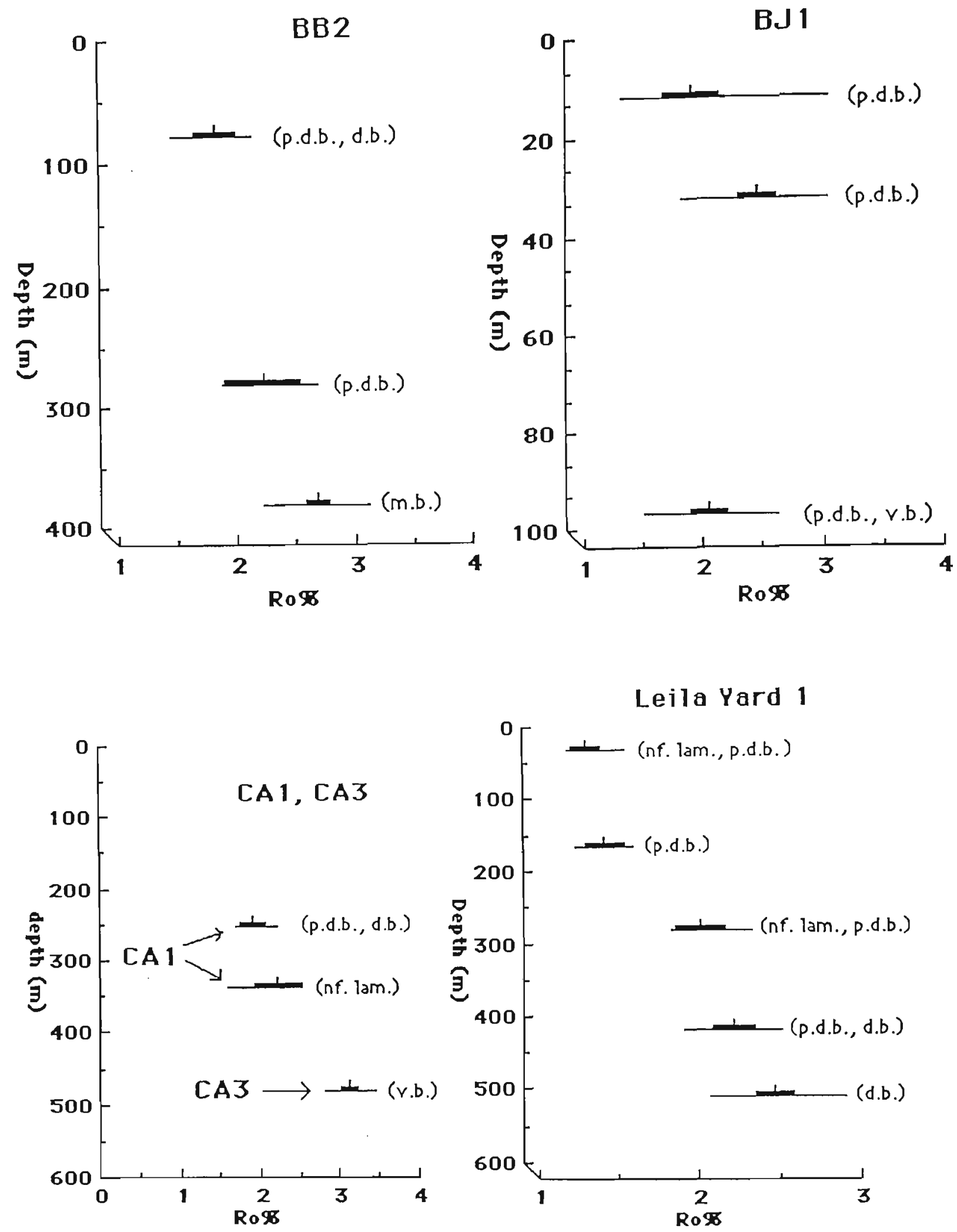

APPENDIX $K$ ctd. Reflectances (Ro\%) of lamalginite and/or bitumen versus depth; northern and central Batten Trough. Mean reflectance values are represented by the vertical lines, 95\% confidence limits of the mean by the black rectangles and the range by the horizontal line. 

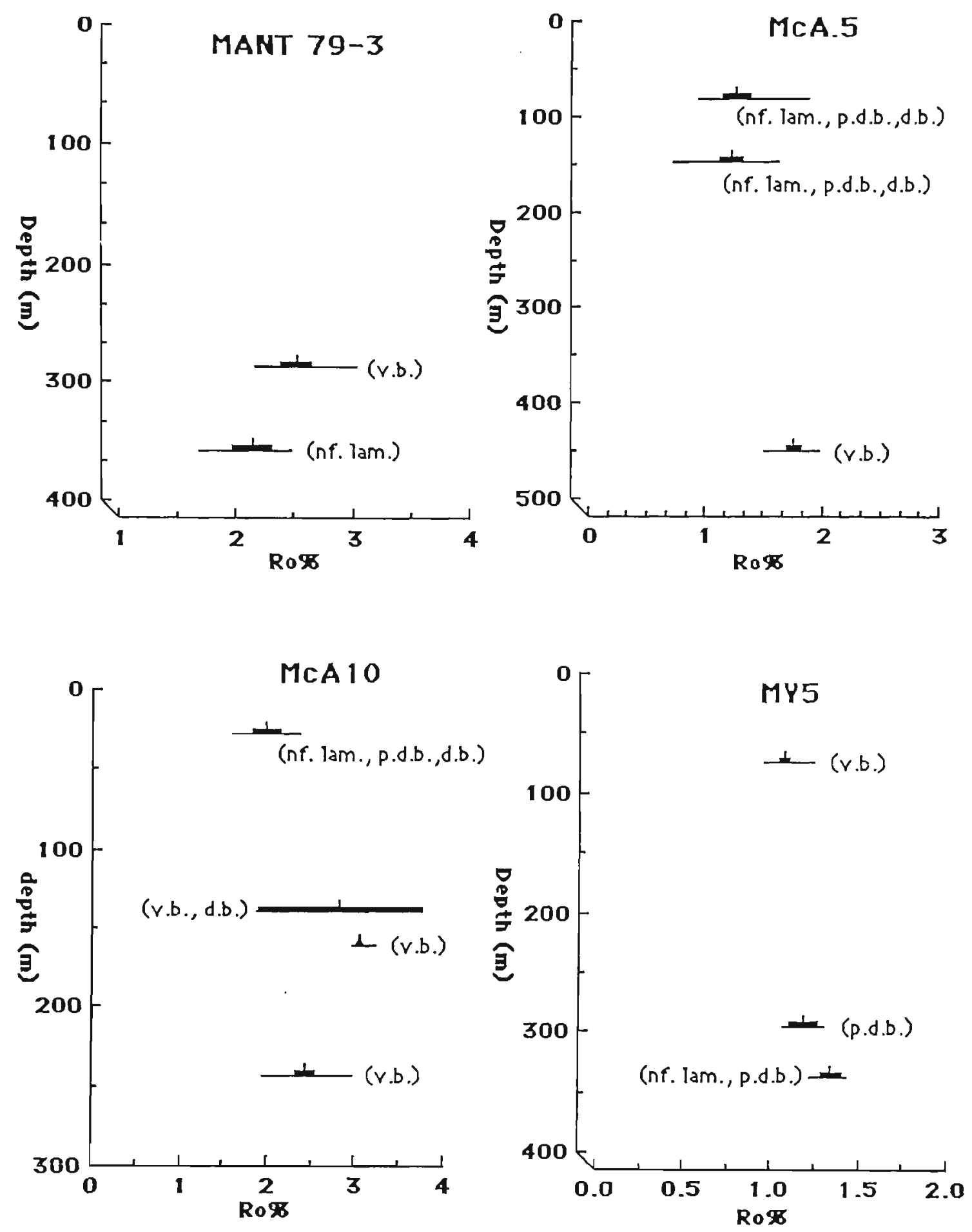

APPENDIX $\mathbf{K}$ ctd. Reflectances (Ro\%) of lamalginite and/or bitumen versus depth; northern and central Batten Trough. Mean reflectance values are represented by the vertical lines, 95\% confidence limits of the mean by the black rectangles and the range by the horizontal line. 

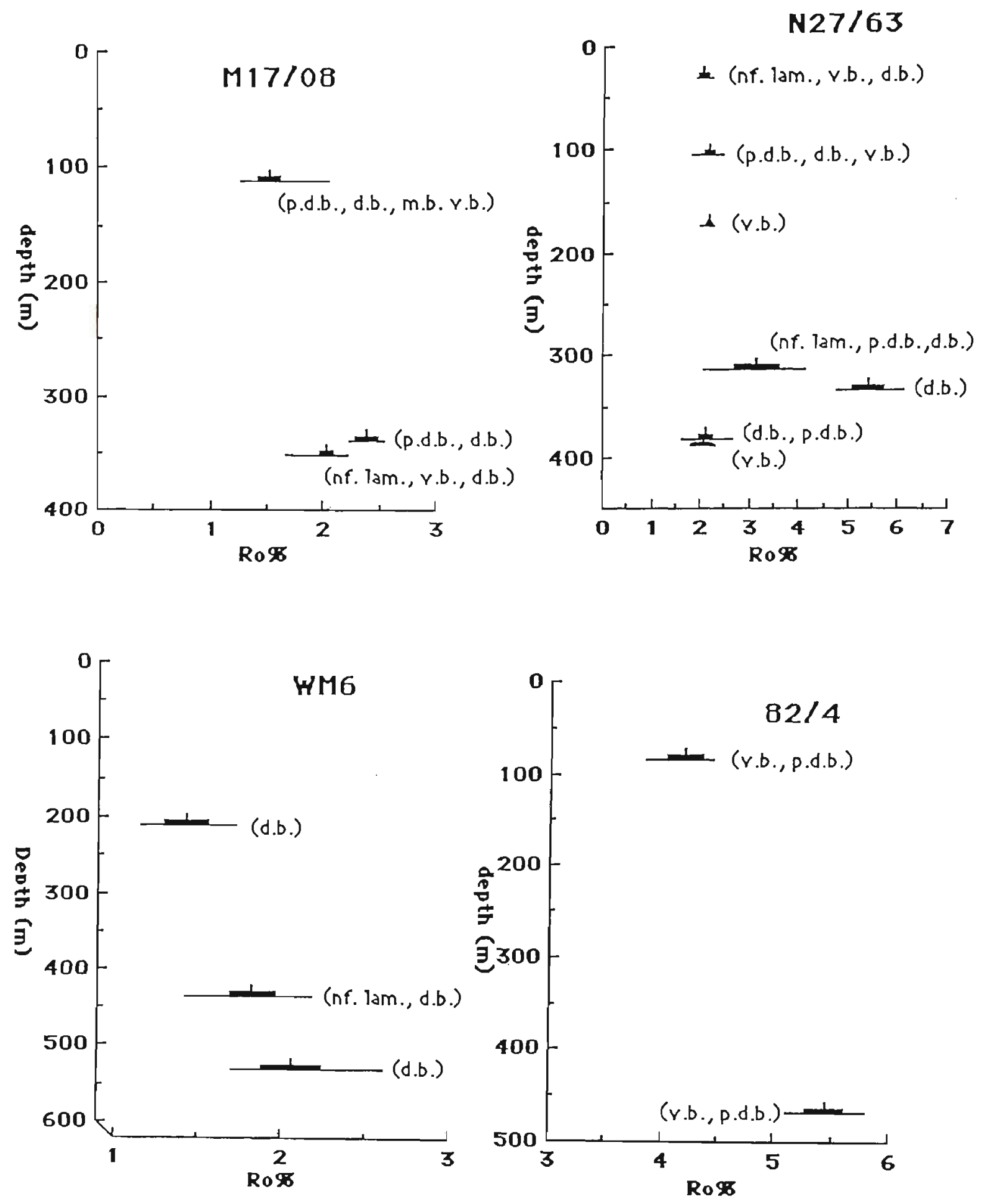

APPENDIX $K$ ctd. Reflectances (Ro\%) of lamalginite and/or bitumen versus depth; northern and central Batten Trough. Mean reflectance values are represented by the vertical lines, 95\% confidence limits of the mean by the black rectangles and the range by the horizontal line. 

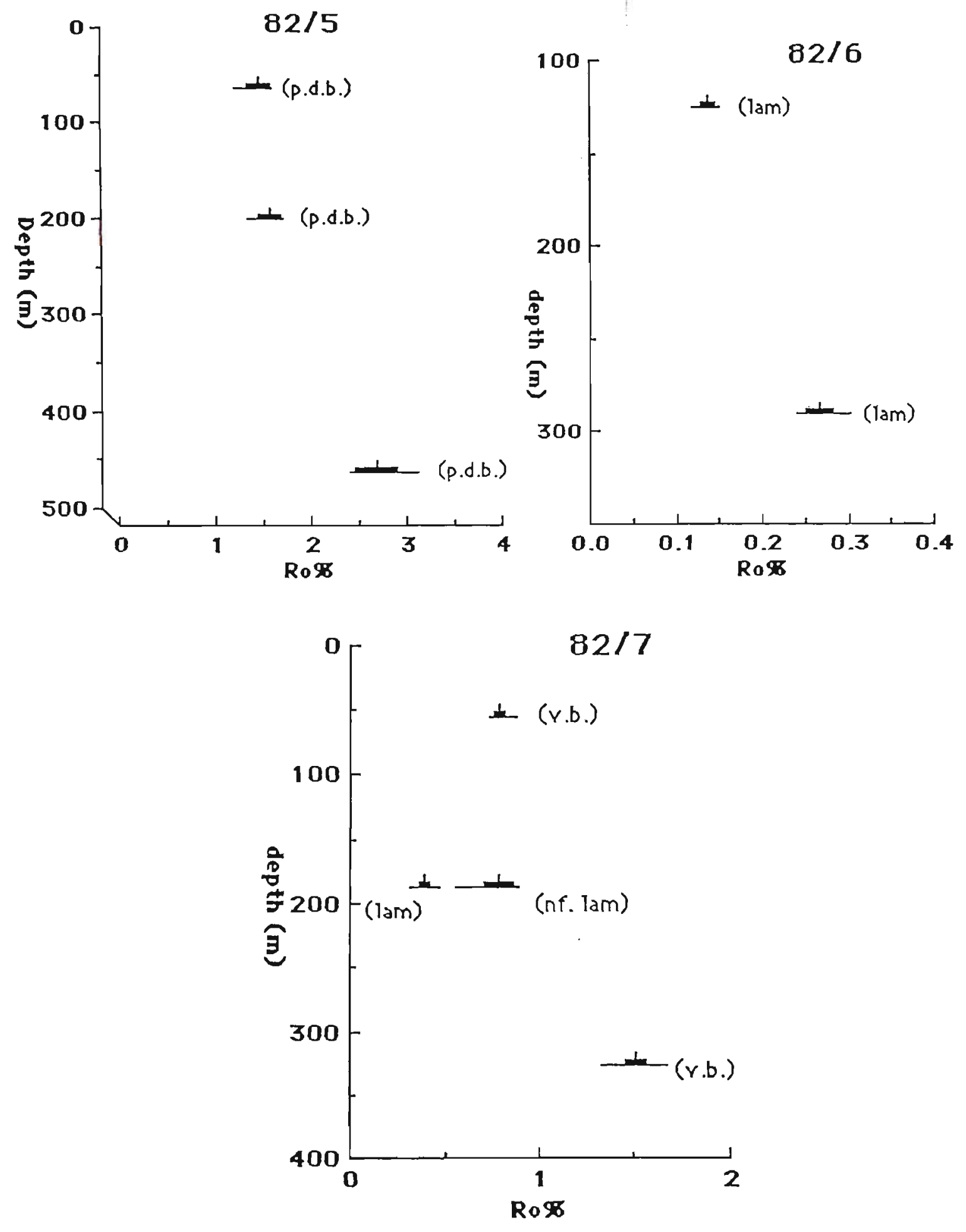

APPENDIX K ctd. Reflectances (Ro\%) of lamalginite and/or bitumen versus depth; northern and central Batten Trough. Mean reflectance values are represented by the vertical lines, 95\% confidence limits of the mean by the black rectangles and the range by the horizontal line. 

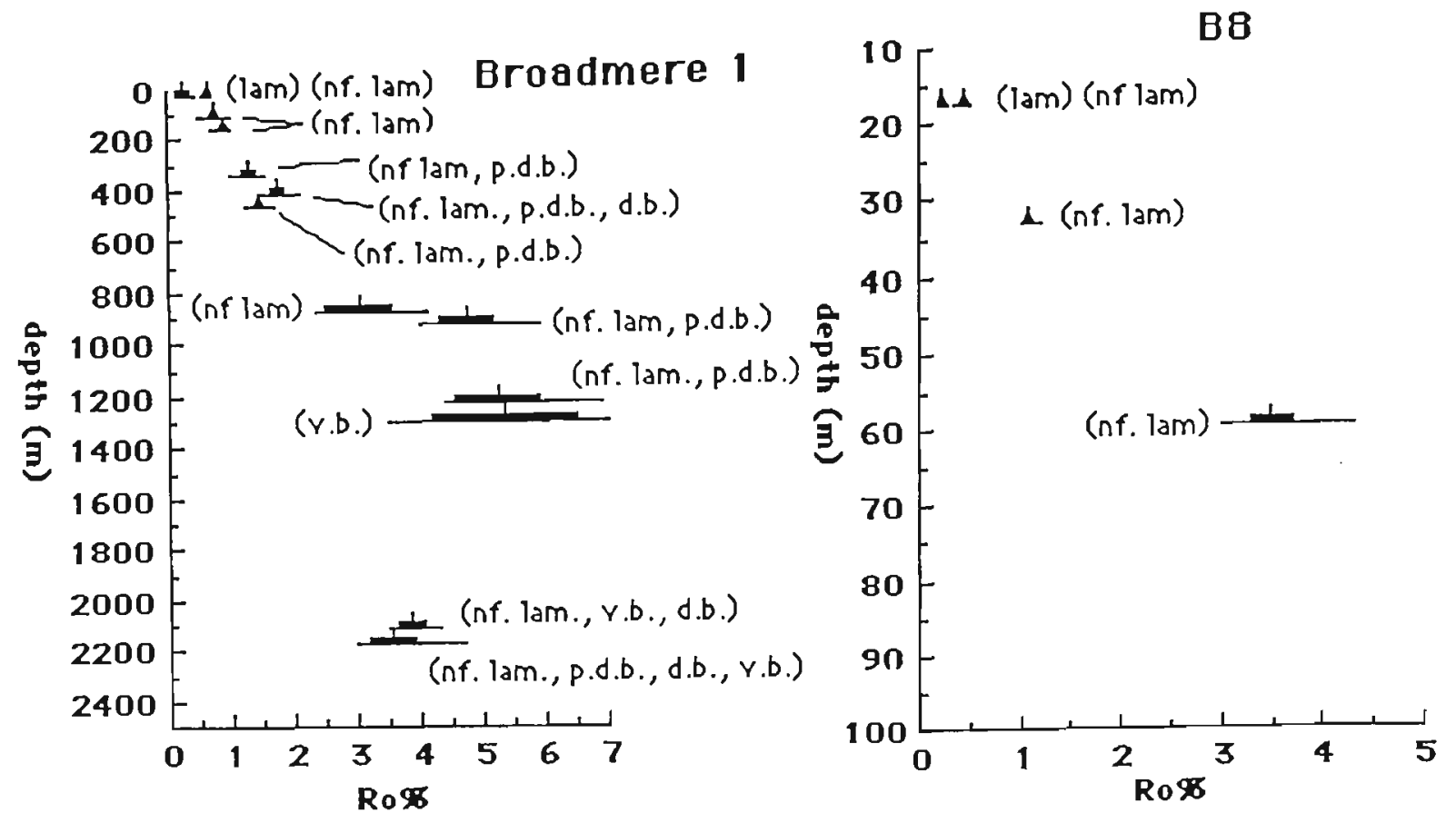

\section{ABBREVIATIONS:}

lam = fluorescent lamalginite,

nf. lam = nonfluorescent lamalginite,

oncalg. = oncalginite

d.b. = dispersed bitumen,

m.b. = matrix bitumen,

p.d.b. = patchy dispersed bitumen,

v.b. = vein bitumen,

c.b. = cauliflower bitumen

APPENDIX L. Reflectances (Ro\%) of lamalginite and/or bitumen versus depth; Roper Group. Mean reflectance values are represented by the vertical lines, $95 \%$ confidence limits of the mean by the black rectangles and the range by the horizontal line. 

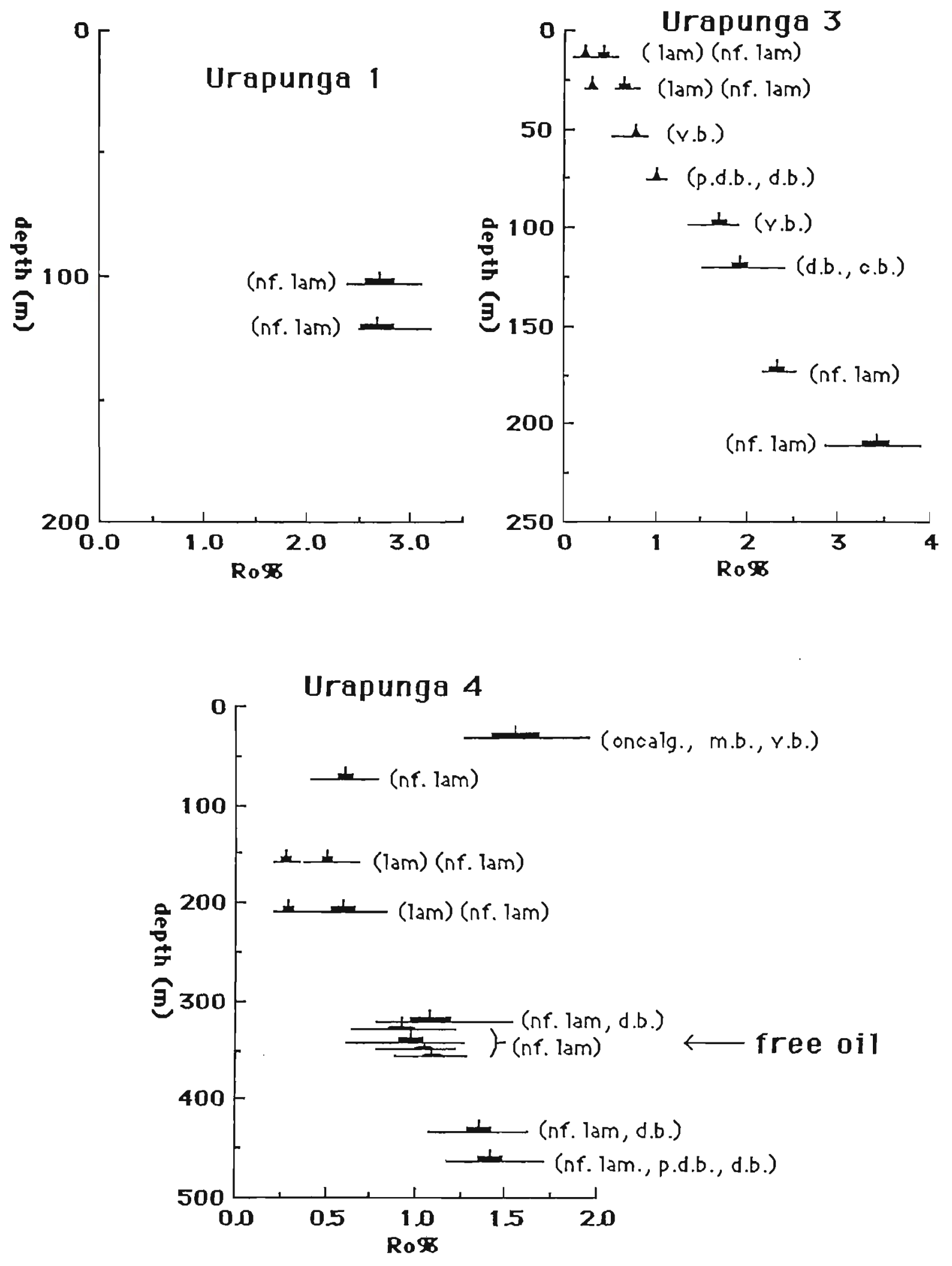

APPENDIX L ctd. Reflectances (Ro\%) of lamalginite and/or bitumen versus depth; Roper Group. Mean reflectance values are represented by the vertical lines, $95 \%$ confidence limits of the mean by the black rectangles and the range by the horizontal line. Oil bubbled out of a $0.1 \mathrm{~m}$ section of core (arrow) in Urapunga 4 (Jackson et al., 1986). 

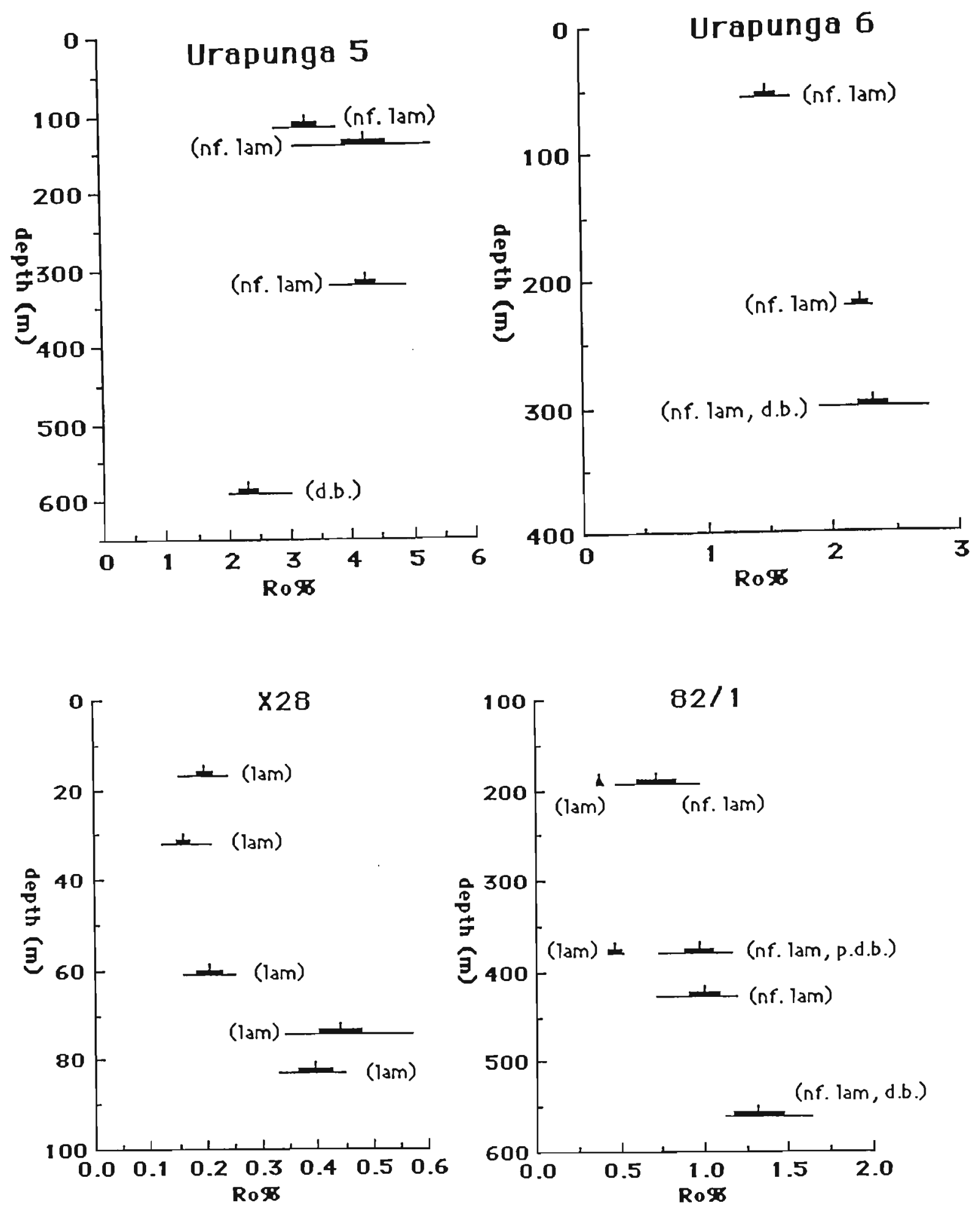

APPENDIX L ctd.. Reflectances (Ro\%) of lamalginite and/or bitumen versus depth; Roper Group. Mean reflectance values are represented by the vertical lines, $95 \%$ confidence limits of the mean by the black rectangles and the range by the horizontal line. 

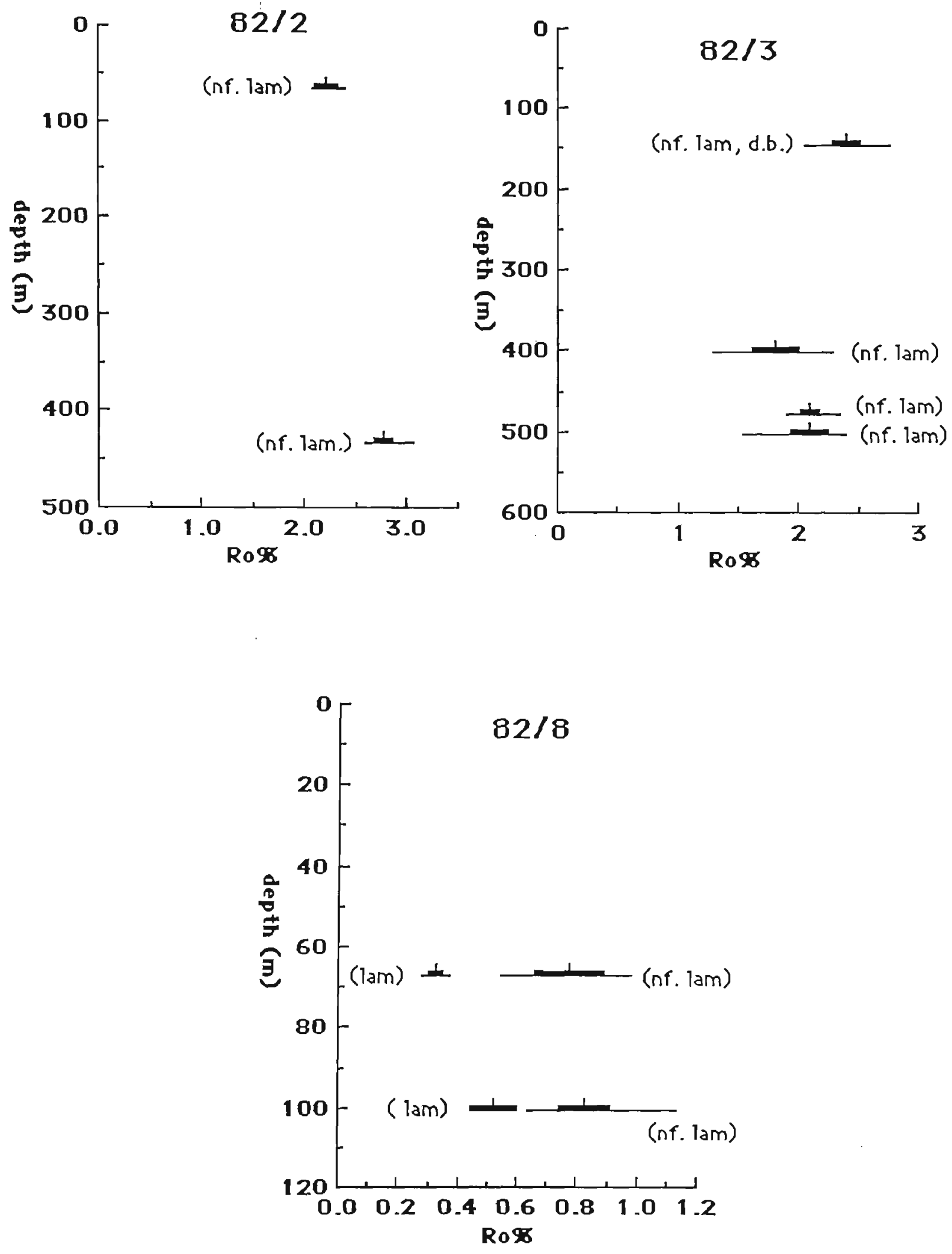

APPENDIX $L$ ctd. Reflectances (Ro\%) of lamalginite and/or bitumen versus depth; Roper Group. Mean reflectance values are represented by the vertical lines, $95 \%$ confidence limits of the mean by the black rectangles and the range by the horizontal line. 
Glyde River Subbasin, Temperature Time model 1a. range $\left({ }^{\circ} \mathrm{C}\right)$ (m.y.)

\begin{tabular}{|c|c|c|c|c|c|}
\hline Deposition of $3420 \mathrm{~m}$ & $20-30$ & 1.95 & 0.0039 & 0.01 & 0.01 \\
\hline above Barney Ck. & $30-40$ & 1.95 & 0.0078 & 0.02 & 0.03 \\
\hline Fm. from 1690 to & $40-50$ & 1.95 & 0.0156 & 0.03 & 0.06 \\
\hline \multirow[t]{8}{*}{$1670 \mathrm{Ma}$. } & $50-60$ & 1.95 & 0.0313 & 0.06 & 0.12 \\
\hline & $60-70$ & 1.95 & 0.0625 & 0.12 & 0.24 \\
\hline & $70-80$ & 1.95 & 0.125 & 0.24 & 0.48 \\
\hline & $80-90$ & 1.95 & 0.25 & 0.49 & 0.97 \\
\hline & $90-100$ & 1.95 & 0.5 & 0.98 & 0.94 \\
\hline & $100-110$ & 1.95 & 1 & 1.95 & 3.89 \\
\hline & $110-120$ & 1.95 & 2 & 3.90 & 7.79 \\
\hline & $120-130$ & 0.39 & 4 & 1.56 & 9.35 \\
\hline Erosion from & $120-130$ & 10.61 & 4 & 42.44 & 51.79 \\
\hline 1670 to $1449 \mathrm{Ma}$ & $110-120$ & 40.8 & 2 & 81.60 & 133.39 \\
\hline \multirow[t]{5}{*}{ of $1805 \mathrm{~m}$. } & $100-120$ & 40.8 & 1 & 40.80 & 174.19 \\
\hline & $90-100$ & 40.8 & 0.5 & 20.40 & 194.59 \\
\hline & $80-90$ & 40.8 & 0.25 & 10.20 & 204.79 \\
\hline & $70-80$ & 40.8 & 0.125 & 5.10 & 209.89 \\
\hline & $60-70$ & 6.31 & 0.0625 & 0.39 & 210.28 \\
\hline Deposition of $600 \mathrm{~m}$ & $60-70$ & 1.72 & 0.0625 & 0.11 & 210.28 \\
\hline Roper Group from & $70-80$ & 11.11 & 0.125 & 1.39 & 211.67 \\
\hline 1449 to $1429 \mathrm{Ma}$. & $80-90$ & 7.17 & 0.25 & 1.79 & 213.46 \\
\hline Erosion to top of & $80-90$ & 83.34 & 0.25 & 20.84 & 234.3 \\
\hline Barney Ck. Fm. from & $70-80$ & 129.19 & 0.125 & 16.15 & 250.45 \\
\hline \multirow[t]{5}{*}{1429 to $570 \mathrm{Ma}$. } & $60-70$ & 129.19 & 0.0625 & 8.07 & 258.52 \\
\hline & $50-60$ & 129.19 & 0.0313 & 4.04 & 262.56 \\
\hline & $40-50$ & 129.1 & 0.0156 & 2.01 & 264.57 \\
\hline & $30-40$ & 129.1 & 0.0078 & 1.01 & 265.58 \\
\hline & $20-30$ & 129.1 & 0.0039 & 0.50 & 266.08 \\
\hline Deposition and erosio & $20-30$ & 570 & 0.0039 & 2.22 & 268.3 \\
\hline
\end{tabular}

of Cambrian and

$\begin{array}{ccc}\text { Temperature } & \text { Interval } & \text { Total } \\ \text { factor } & \text { TTI } & \text { TTI }\end{array}$

Cretaceous sediments,

$570 \mathrm{Ma}$ to present.

$\mathrm{Rv} \%$ for a total TTI of 268 is 1.5 ;

Price's (1983) method:

maximum burial $=3420 \mathrm{~m}$, maximum temperature $=122.6^{\circ} \mathrm{C}, \mathrm{Rv} \%=0.6$

Observed equivalent Rv\% for the top of the Barney Creek Fm. in the Glyde River Subbasin is 0.5 to 0.7 .

Appendix M1. Calculations following Waples' (1981) method and Price's (1983) method, assuming a constant geothermal gradient of $30 \mathrm{C}^{\circ} / \mathrm{km}$ with a zero intercept of $20^{\circ} \mathrm{C}$. Near top of Barney Creek Formation, Glyde River Subbasin, depositional-erosional model 1a. 


\begin{tabular}{|c|c|c|c|c|c|}
\hline $\begin{array}{l}\text { Glyde River Subbasin, } \\
\text { model lb. }\end{array}$ & $\begin{array}{l}\text { Temperature } \\
\text { range }\left({ }^{\circ} \mathrm{C}\right)\end{array}$ & $\begin{array}{l}\text { Time } \\
\text { (m.y.) }\end{array}$ & $\begin{array}{l}\text { Temperature } \\
\text { factor }\end{array}$ & $\begin{array}{l}\text { Interval } \\
\text { TTI }\end{array}$ & $\begin{array}{r}\text { Total } \\
\text { TTI }\end{array}$ \\
\hline $\begin{array}{l}\text { Deposition of } 3420 \mathrm{~m} \\
\text { above Bamey Ck. Fm. } \\
\text { deposited over } 20 \mathrm{my} \\
\text { plus } 820 \mathrm{~m} \text { of } \\
\text { Barney CK. Fm. } \\
\text { deposited over } 2 \mathrm{my} \text {. } \\
\text { A total of } 4240 \mathrm{~m} \\
\text { deposited from } 1692 \\
\text { to } 1670 \mathrm{Ma} \text {. }\end{array}$ & $\begin{array}{l}20-30 \\
30-40 \\
40-50 \\
50-60 \\
60-70 \\
70-80 \\
80-90 \\
90-100 \\
100-110 \\
110-120 \\
120-130 \\
130-140 \\
140-150\end{array}$ & $\begin{array}{l}0.81 \\
0.81 \\
1.42 \\
1.95 \\
1.95 \\
1.95 \\
1.95 \\
1.95 \\
1.95 \\
1.95 \\
1.95 \\
1.95 \\
1.40\end{array}$ & $\begin{array}{l}0.0039 \\
0.0078 \\
0.0156 \\
0.0313 \\
0.0625 \\
0.125 \\
0.25 \\
0.5 \\
1 \\
2 \\
4 \\
8 \\
16\end{array}$ & $\begin{array}{r}0.00 \\
0.01 \\
0.02 \\
0.06 \\
0.12 \\
0.24 \\
0.49 \\
0.98 \\
1.95 \\
3.90 \\
7.80 \\
15.60 \\
22.45\end{array}$ & $\begin{array}{r}0 \\
0.01 \\
0.03 \\
0.09 \\
0.21 \\
0.45 \\
0.94 \\
1.91 \\
3.86 \\
7.76 \\
15.56 \\
31.16 \\
53.61\end{array}$ \\
\hline $\begin{array}{l}\text { Erosion from } \\
1670 \text { to } 1449 \mathrm{Ma} \\
\text { of } 1805 \mathrm{~m} .\end{array}$ & $\begin{array}{l}140-150 \\
130-140 \\
120-130 \\
110-120 \\
100-110 \\
90-100\end{array}$ & $\begin{array}{l}29.38 \\
40.80 \\
40.80 \\
40.80 \\
40.80 \\
28.35\end{array}$ & $\begin{array}{l}16 \\
8 \\
4 \\
2 \\
1 \\
0.5\end{array}$ & $\begin{array}{r}470.08 \\
326.40 \\
163.20 \\
81.60 \\
40.80 \\
14.18\end{array}$ & $\begin{array}{r}523.69 \\
850.09 \\
1013.29 \\
1094.89 \\
1135.69 \\
1149.87\end{array}$ \\
\hline $\begin{array}{l}\text { Deposition of } 600 \mathrm{~m} \\
\text { Roper Group from } \\
1449 \text { to } 1429 \mathrm{Ma} \text {. }\end{array}$ & $\begin{array}{l}90-100 \\
100-110 \\
110-120\end{array}$ & $\begin{array}{r}7.72 \\
11.11 \\
1.16\end{array}$ & $\begin{array}{l}0.5 \\
1 \\
2\end{array}$ & $\begin{array}{r}3.86 \\
11.11 \\
2.32\end{array}$ & $\begin{array}{l}1153.73 \\
1164.84 \\
1167.16\end{array}$ \\
\hline $\begin{array}{l}\text { Erosion to top of } \\
\text { Barney Ck. Fm. from } \\
1429 \text { to } 570 \mathrm{Ma} \text {. }\end{array}$ & $\begin{array}{l}110-120 \\
100-110 \\
90-100 \\
80-90 \\
70-80 \\
60-70 \\
50-60 \\
40-50\end{array}$ & $\begin{array}{r}13.56 \\
129.20 \\
129.20 \\
129.20 \\
129.20 \\
129.20 \\
129.20 \\
69.77\end{array}$ & $\begin{array}{l}2 \\
1 \\
0.5 \\
0.25 \\
0.125 \\
0.0625 \\
0.0313 \\
0.0156\end{array}$ & $\begin{array}{r}27.12 \\
129.20 \\
64.60 \\
32.30 \\
16.15 \\
8.08 \\
4.04 \\
1.09\end{array}$ & $\begin{array}{l}1194.28 \\
1323.48 \\
1388.08 \\
1420.38 \\
1436.53 \\
1444.60 \\
1448.64 \\
1449.73\end{array}$ \\
\hline $\begin{array}{l}\text { Deposition of } 300 \mathrm{~m} \text { of } \\
\text { Bukalara Sst. from } \\
570 \text { to } 560 \mathrm{Ma} \text {. }\end{array}$ & $\begin{array}{l}40-50 \\
50-60\end{array}$ & $\begin{array}{l}6.00 \\
4.00\end{array}$ & $\begin{array}{l}0.0156 \\
0.0313\end{array}$ & $\begin{array}{l}0.09 \\
0.13\end{array}$ & $\begin{array}{l}1449.82 \\
1449.95\end{array}$ \\
\hline $\begin{array}{l}\text { Erosion of } 100 \mathrm{~m} \text { of } \\
\text { Bukalara Sst. from } \\
560 \text { to } 510 \mathrm{Ma} \text {. }\end{array}$ & $50-60$ & 50.00 & 0.0313 & 1.57 & 1451.51 \\
\hline $\begin{array}{l}\text { Deposition of } 100 \mathrm{~m} \text { of } \\
\text { Top Springs Lmst. } \\
\text { from } 510 \text { to } 508 \mathrm{Ma} \text {. }\end{array}$ & $50-60$ & 2.00 & 0.0313 & 0.06 & 1451.57 \\
\hline
\end{tabular}




$\begin{array}{llllll}\text { Erosion of Top Springs } & 50-60 & 228.57 & 0.0313 & 7.15 & 1471.55 \\ \begin{array}{l}\text { Lmst. and Bukalara } \\ \text { Sst. (200m) to Cretaceous }\end{array} & 40-50 & 181.43 & 0.0156 & 2.83 & 1474.38 \\ \begin{array}{l}\text { unconformity from } \\ 508 \text { to } 100 \mathrm{Ma}\end{array} & & & & \\ & & & & & \\ \begin{array}{l}\text { Deposition of } 200 \mathrm{~m} \\ \text { of Cretaceous }\end{array} & 40-50 & 4.00 & 0.0156 & 0.06 & 1474.44 \\ \text { Mullaman Beds from } & 50-60 & 6.00 & 0.0313 & 0.19 & 1474.63 \\ 100 \text { to } 90 \mathrm{Ma} & & & & & \\ & & & & & \\ \text { Erosion from 90 Ma } & 50-60 & 9.64 & 0.0313 & 0.30 & 1474.93 \\ \text { to present } & 40-50 & 26.79 & 0.0156 & 0.42 & 1475.35 \\ & 30-40 & 26.79 & 0.0078 & 0.21 & 1475.56 \\ & 20-30 & 26.79 & 0.0039 & 0.10 & 1475.66\end{array}$

Rv\% for a total TTI of 1476 is 2.2 ;

Price's (1983) method:

maximum burial $=4240 \mathrm{~m}$, maximum temperature $=147^{\circ} \mathrm{C}, \mathrm{Rv} \%=0.7$

Observed equivalent Rv\% for near the base of the Barney Creek Fm. in the Glyde River Subbasin (DDH GR7 at $854 \mathrm{~m})=1.0$.

Appendix M2. Calculations following Waples' (1981) method and Price's (1983) method, assuming a constant geothermal gradient of $30 \mathrm{C} / \mathrm{km}$ with a zero intercept of $20^{\circ} \mathrm{C}$. Near base of DDH GR7, Barney Creek Formation, Glyde River Subbasin, depositionalerosional model $1 \mathrm{~b}$. 


\begin{tabular}{|c|c|c|c|c|c|}
\hline $\begin{array}{l}\text { Glyde River Subbasin, } \\
\text { model 2a. }\end{array}$ & $\begin{array}{l}\text { Temperature } \\
\text { range }\left({ }^{\circ} \mathrm{C}\right)\end{array}$ & $\begin{array}{l}\text { Time } \\
\text { (m.y.) }\end{array}$ & $\begin{array}{l}\text { Temperature } \\
\text { factor }\end{array}$ & $\begin{array}{c}\text { Interva } \\
\text { TTI }\end{array}$ & $\begin{array}{r}\text { Total } \\
\text { TTI }\end{array}$ \\
\hline $\begin{array}{l}\text { Deposition of } 3420 \mathrm{~m} \\
\text { above Barney } \mathrm{Ck} \text {. } \\
\text { Fm. from } 1690 \text { to } \\
1670 \mathrm{Ma} \text {. }\end{array}$ & $\begin{array}{l}20-30 \\
30-40 \\
40-50 \\
50-60 \\
60-70 \\
70-80 \\
80-90 \\
90-100 \\
100-110 \\
110-120 \\
120-130\end{array}$ & $\begin{array}{l}1.95 \\
1.95 \\
1.95 \\
1.95 \\
1.95 \\
1.95 \\
1.95 \\
1.95 \\
1.95 \\
1.95 \\
0.39\end{array}$ & $\begin{array}{l}0.0039 \\
0.0078 \\
0.0156 \\
0.0313 \\
0.0625 \\
0.125 \\
0.25 \\
0.5 \\
1 \\
2 \\
4\end{array}$ & $\begin{array}{l}0.01 \\
0.02 \\
0.03 \\
0.06 \\
0.12 \\
0.24 \\
0.49 \\
0.98 \\
1.95 \\
3.90 \\
1.56\end{array}$ & $\begin{array}{l}0.01 \\
0.03 \\
0.06 \\
0.12 \\
0.24 \\
0.48 \\
0.97 \\
1.94 \\
3.89 \\
6.79 \\
8.35\end{array}$ \\
\hline $\begin{array}{l}\text { Erosion from } \\
1670 \text { to } 1449 \mathrm{Ma} \\
\text { of } 240 \mathrm{~m} .\end{array}$ & $\begin{array}{l}120-130 \\
110-120\end{array}$ & $\begin{array}{l}79.84 \\
60.46\end{array}$ & $\begin{array}{l}4 \\
2\end{array}$ & $\begin{array}{l}319.36 \\
120.92\end{array}$ & $\begin{array}{l}327.71 \\
448.63\end{array}$ \\
\hline $\begin{array}{l}\text { Deposition of } 600 \mathrm{~m} \\
\text { Roper Group from } \\
1449 \text { to } 1429 \mathrm{Ma} \text {. }\end{array}$ & $\begin{array}{l}110-120 \\
120-130 \\
130-140\end{array}$ & $\begin{array}{r}5.11 \\
11.11 \\
3.78\end{array}$ & $\begin{array}{l}2 \\
4 \\
8\end{array}$ & $\begin{array}{l}10.22 \\
44.44 \\
30.24\end{array}$ & $\begin{array}{r}458.85 \\
503.296 \\
533.54\end{array}$ \\
\hline $\begin{array}{l}\text { Erosion to top of } \\
\text { Barney Ck. Fm. from } \\
1429 \text { to } 570 \mathrm{Ma} \text {. }\end{array}$ & $\begin{array}{l}130-140 \\
120-130 \\
110-120 \\
100-120 \\
90-100 \\
80-90 \\
70-80 \\
60-70 \\
50-60 \\
40-50 \\
30-40 \\
20-30\end{array}$ & $\begin{array}{l}25.77 \\
75.75 \\
75.75 \\
75.75 \\
75.75 \\
75.75 \\
75.75 \\
75.75 \\
75.75 \\
75.75 \\
75.75 \\
75.75\end{array}$ & $\begin{array}{l}8 \\
4 \\
2 \\
1 \\
0.5 \\
0.25 \\
0.125 \\
0.0625 \\
0.0313 \\
0.0156 \\
0.0078 \\
0.0039\end{array}$ & $\begin{array}{r}206.16 \\
303.00 \\
151.50 \\
75.75 \\
37.88 \\
18.94 \\
9.47 \\
4.73 \\
2.37 \\
1.18 \\
0.59 \\
0.30\end{array}$ & $\begin{array}{r}739.7 \\
1042.69 \\
1194.19 \\
1269.94 \\
1307.82 \\
1326.76 \\
1336.23 \\
1340.96 \\
1343.33 \\
1341.51 \\
1345.1 \\
1345.4\end{array}$ \\
\hline $\begin{array}{l}\text { Deposition and erosion } \\
\text { of Cambrian and } \\
\text { Cretaceous sediments. }\end{array}$ & $20-30$ & 570 & 0.0039 & 2.22 & 1347.62 \\
\hline
\end{tabular}

$\mathrm{Rv} \%$ for a total TTI of 1348 is 2.2 ;

Price's (1983) method:

maximum burial $=3780 \mathrm{~m}$, maximum temperature $=133.4^{\circ} \mathrm{C}, \mathrm{Rv} \%=0.7$

Observed equivalent Rv\% for the top of the Barney Creek Fm. in the Glyde River Subbasin is 0.5 to 0.7 .

Appendix M3. Calculations following Waples' (1981) method and Price's (1983) method, assuming a constant geothermal gradient of $30 \mathrm{C} / \mathrm{km}$ with a zero intercept of $20^{\circ} \mathrm{C}$. Near top of Barney Creek Formation, Glyde River Subbasin, depositional-erosional model 2a. 
Glyde River Subbasin, model $2 b$.

Deposition of $3420 \mathrm{~m}$ above Barney $\mathrm{Ck}$. Fm. deposited over 20 my plus $820 \mathrm{~m}$ of

Barney Ck. Fm.

deposited over 2 my. A total of $4240 \mathrm{~m}$ deposited from 1692 to $1670 \mathrm{Ma}$.

Erosion from

1670 to $1449 \mathrm{Ma}$

of $240 \mathrm{~m}$.

Deposition of $600 \mathrm{~m}$

Roper Group from

1449 to $1429 \mathrm{Ma}$

Erosion to top of

Barney Ck. Fm. from 1429 to $570 \mathrm{Ma}$.

Deposition of $300 \mathrm{~m}$ of

Bukalara Sst. from

570-560 Ma.

Erosion of $100 \mathrm{~m}$ of

Bukalara Sst. from

560-510 Ma.

Deposition of $100 \mathrm{~m}$ of $50-60$

Top Springs Lmst.

from 510-508 Ma.

\section{Temperature Time}

range $\left({ }^{\circ} \mathrm{C}\right)$ (m.y.)

$\begin{array}{lll}20-30 & 0.81 & 0.0039 \\ 30-40 & 0.81 & 0.0078 \\ 40-50 & 1.42 & 0.0156 \\ 50-60 & 1.95 & 0.0313 \\ 60-70 & 1.95 & 0.0625 \\ 70-80 & 1.95 & 0.125 \\ 80-90 & 1.95 & 0.25 \\ 90-100 & 1.95 & 0.5 \\ 100-110 & 1.95 & 1 \\ 110-120 & 1.95 & 2 \\ 120-130 & 1.95 & 4 \\ 130-140 & 1.95 & 8 \\ 140-150 & 1.40 & 16\end{array}$

$140-150 \quad 221.00$
$177.76 \quad 3767.22$

$71.92 \quad 3839.14$

$\begin{array}{rr}969.76 & 4808.90 \\ 606.08 & 5414.98 \\ 303.04 & 5718.02 \\ 151.52 & 5869.54 \\ 75.76 & 5945.30 \\ 37.88 & 5983.18 \\ 18.94 & 6002.12 \\ 9.47 & 6011.59 \\ 4.74 & 6016.33 \\ 2.37 & 6018.70 \\ 0.64 & 6019.34\end{array}$

$\begin{array}{lll}140-150 & 60.61 & 16 \\ 130-140 & 75.76 & 8 \\ 120-130 & 75.76 & 4 \\ 110-120 & 75.76 & 2 \\ 100-110 & 75.76 & 1 \\ 90-100 & 75.76 & 0.5 \\ 80-90 & 75.76 & 0.25 \\ 70-80 & 75.76 & 0.125 \\ 60-70 & 75.76 & 0.0625 \\ 50-60 & 75.76 & 0.0313 \\ 40-50 & 40.91 & 0.0156\end{array}$

$0.00 \quad 0.00$

$0.01 \quad 0.01$

$0.02 \quad 0.03$

$0.06 \quad 0.09$

$0.12 \quad 0.21$

$0.24 \quad 0.45$

$0.49 \quad 0.94$

$0.98 \quad 1.91$

$1.95 \quad 3.86$

$3.90 \quad 7.76$

$\begin{array}{ll}7.80 & 15.56\end{array}$

$15.60 \quad 31.16$

$22.45 \quad 53.61$

$3536.00 \quad 3589.62$

$\begin{array}{lllll}130-140 & 8.99 & 8 & 71.92 & 3839.14\end{array}$

$\begin{array}{lllll}40-50 & 6.00 & 0.0156 & 0.09 & 6019.43\end{array}$

$\begin{array}{lllll}50.60 & 4.00 & 0.0313 & 0.13 & 6019.56\end{array}$

$\begin{array}{lllll}50-60 & 50.00 & 0.0313 & 1.57 & 6021.12\end{array}$ 


$\begin{array}{lrrrrr}\text { Erosion of Top Springs } & 50-60 & 228.57 & 0.0313 & 7.15 & 6028.33 \\ \text { Lmst. and Bukalara } & 40-50 & 181.43 & 0.0156 & 2.83 & 6031.16 \\ \begin{array}{l}\text { Sst. (200m) to Cret. } \\ \text { unconformity from }\end{array} & & & & & \\ 508 \text { to } 100 \mathrm{Ma} \text {. } & & & & & \\ & & & & & \\ \begin{array}{l}\text { Deposition of } 200 \mathrm{~m} \\ \text { of Cretaceous }\end{array} & 40-50 & 4.00 & 0.0156 & 0.06 & 6031.22 \\ \text { Mullaman Beds from } & 50-60 & 6.00 & 0.0313 & 0.19 & 6031.41 \\ 100 \text { to 90 Ma. } & & & & & \\ & 50-60 & 9.64 & 0.0313 & 0.30 & 6031.71 \\ \text { Erosion from 90 Ma } & 40-50 & 26.79 & 0.0156 & 0.42 & 6032.13 \\ \text { to present. } & 30-40 & 26.79 & 0.0078 & 0.21 & 6032.34 \\ & 20-30 & 26.79 & 0.0039 & 0.10 & 6032.44\end{array}$

Rv\% for a total TTI of 6032 is 3.0 ;

Price's (1983) method:

maximum burial $=4600 \mathrm{~m}$, maximum temperature $=158^{\circ} \mathrm{C}, \mathrm{Rv} \%=0.8$

Observed equivalent Rv\% for near the base of the Barney Creek Fm. in the Glyde River Subbasin (DDH GR7 at $854 \mathrm{~m})=1.0$.

Appendix M4. Calculations following Waples' (1981) method and Price's (1983) method, assuming a constant geothermal gradient of $30 \mathrm{C}^{\circ} / \mathrm{km}$ with a zero intercept of $20^{\circ} \mathrm{C}$. Near base of DDH GR7, Barney Creek Formation, Glyde River Subbasin, depositionalerosional model $2 b$. 


\begin{tabular}{|c|c|c|c|c|c|}
\hline $\begin{array}{l}\text { Glyde River Subbasin, } \\
\text { model 3a. }\end{array}$ & $\begin{array}{l}\text { Temperature } \\
\text { range }\left({ }^{\circ} \mathrm{C}\right)\end{array}$ & $\begin{array}{l}\text { Time } \\
\qquad(\mathrm{m} . \mathrm{y} .)\end{array}$ & $\begin{array}{l}\text { Temperature } \\
\text { factor }\end{array}$ & $\begin{array}{l}\text { Interval } \\
\text { TTI }\end{array}$ & $\begin{array}{r}\text { Total } \\
\text { TTI }\end{array}$ \\
\hline Deposition of $3420 \mathrm{~m}$ & $20-30$ & 22.51 & 0.0039 & 0.09 & 0.09 \\
\hline above Barney Ck. & $30-40$ & 22.51 & 0.0078 & 0.18 & 0.27 \\
\hline Fm. from 1690 to & $40-50$ & 22.51 & 0.0156 & 0.35 & 0.62 \\
\hline \multirow[t]{8}{*}{$1459 \mathrm{Ma}$. } & $50-60$ & 22.51 & 0.0313 & 0.70 & 1.32 \\
\hline & $60-70$ & 22.51 & 0.0625 & 1.41 & 2.73 \\
\hline & $70-80$ & 22.51 & 0.125 & 2.81 & 5.54 \\
\hline & $80-90$ & 22.51 & 0.25 & 5.63 & 11.17 \\
\hline & $90-100$ & 22.51 & 0.5 & 11.26 & 22.43 \\
\hline & $100-110$ & 22.51 & 1 & 22.51 & 44.94 \\
\hline & $110-120$ & 22.51 & 2 & 45.02 & 89.96 \\
\hline & $120-130$ & 5.85 & 4 & 23.40 & 113.36 \\
\hline Erosion from & $120-130$ & 0.64 & 4 & 2.56 & 115.92 \\
\hline 1459 to $1449 \mathrm{Ma}$ & $110-120$ & 1.85 & 2 & 3.70 & 119.62 \\
\hline \multirow[t]{5}{*}{ of $1805 \mathrm{~m}$. } & $100-120$ & 1.85 & 1 & 1.85 & 121.47 \\
\hline & $90-100$ & 1.85 & 0.5 & 0.93 & 122.40 \\
\hline & $80-90$ & 1.85 & 0.25 & 0.46 & 122.86 \\
\hline & $70-80$ & 1.85 & 0.125 & 0.23 & 123.09 \\
\hline & $60-70$ & 0.29 & 0.0625 & 0.02 & 123.11 \\
\hline Deposition of $600 \mathrm{~m}$ & $60-70$ & 1.72 & 0.0625 & 0.11 & 123.22 \\
\hline Roper Group from & $70-80$ & 11.11 & 0.125 & 1.39 & 124.61 \\
\hline 1449 to $1429 \mathrm{Ma}$. & $80-90$ & 7.17 & 0.25 & 1.79 & 126.40 \\
\hline Erosion to top of & $80-90$ & 83.34 & 0.25 & 20.84 & 147.24 \\
\hline Barney Ck. Fm. from & $70-80$ & 129.19 & 0.125 & 16.15 & 163.39 \\
\hline \multirow[t]{5}{*}{1429 to $570 \mathrm{Ma}$. } & $60-70$ & 129.19 & 0.0625 & 8.07 & 171.46 \\
\hline & $50-60$ & 129.19 & 0.0313 & 4.04 & 175.50 \\
\hline & $40-50$ & 129.10 & 0.0156 & 2.01 & 177.51 \\
\hline & $30-40$ & 129.10 & 0.0078 & 1.01 & 178.52 \\
\hline & $20-30$ & 129.10 & 0.0039 & 0.50 & 179.02 \\
\hline $\begin{array}{l}\text { Deposition and erosion } \\
\text { of Cambrian and } \\
\text { Cretaceous sediments, } \\
570 \mathrm{Ma} \text { to present. }\end{array}$ & n $20-30$ & 570.00 & 0.0039 & 2.22 & 181.24 \\
\hline
\end{tabular}

Rv\% for a total TTI of 181 is 1.4 ;

Price's (1983) method:

maximum burial $=3420 \mathrm{~m}$, maximum temperature $=122.6^{\circ} \mathrm{C}, \mathrm{Rv} \%=0.6$

Observed equivalent Rv\% for the top of the Barney Creek Fm. in the Glyde River Subbasin is 0.5 to 0.7 .

Appendix M5. Calculations following Waples' (1981) method and Price's (1983) method, assuming a constant geothermal gradient of $30 \mathrm{C}^{\circ} / \mathrm{km}$ with a zero intercept of $20^{\circ} \mathrm{C}$. Near top of Barney Creek Formation, Glyde River Subbasin, depositional-erosional model 3a. 


\begin{tabular}{|c|c|c|c|c|c|}
\hline $\begin{array}{l}\text { Glyde River Subbasin, } \\
\text { model } 3 \mathrm{~b} \text {. }\end{array}$ & $\begin{array}{l}\text { Temperature } \\
\text { range }\left({ }^{\circ} \mathrm{C}\right)\end{array}$ & $\begin{array}{l}\text { Time } \\
(\mathrm{m.y.})\end{array}$ & $\begin{array}{l}\text { Temperature } \\
\text { factor }\end{array}$ & $\begin{array}{l}\text { Interval } \\
\text { TTI }\end{array}$ & $\begin{array}{r}\text { Total } \\
\text { TTI }\end{array}$ \\
\hline $\begin{array}{l}\text { Deposition of } 3420 \mathrm{~m} \\
\text { above Barney Ck. Fm. } \\
\text { deposited over } 231 \mathrm{my} \\
\text { plus } 820 \mathrm{~m} \text { of } \\
\text { Barney Ck. Fm. } \\
\text { deposited over } 2 \mathrm{my} \text {. } \\
\text { A total of } 4240 \mathrm{~m} \\
\text { deposited from } 1692 \\
\text { to } 1459 \mathrm{Ma} \text {. }\end{array}$ & $\begin{array}{l}20-30 \\
30-40 \\
40-50 \\
50-60 \\
60-70 \\
70-80 \\
80-90 \\
90-100 \\
100-110 \\
110-120 \\
120-130 \\
130-140 \\
140-150\end{array}$ & $\begin{array}{r}0.81 \\
0.81 \\
12.78 \\
22.51 \\
22.51 \\
22.51 \\
22.51 \\
22.51 \\
22.51 \\
22.51 \\
22.51 \\
22.51 \\
16.21\end{array}$ & $\begin{array}{l}0.0039 \\
0.0078 \\
0.0156 \\
0.0313 \\
0.0625 \\
0.125 \\
0.25 \\
0.5 \\
1 \\
2 \\
4 \\
8 \\
16\end{array}$ & $\begin{array}{r}0.00 \\
0.01 \\
0.20 \\
0.70 \\
1.41 \\
2.81 \\
5.63 \\
11.26 \\
22.51 \\
45.02 \\
90.04 \\
180.08 \\
259.36\end{array}$ & $\begin{array}{r}0.00 \\
0.01 \\
0.21 \\
0.91 \\
2.32 \\
5.13 \\
10.76 \\
22.02 \\
44.53 \\
89.55 \\
179.59 \\
359.67 \\
619.03\end{array}$ \\
\hline $\begin{array}{l}\text { Erosion from } \\
1670-1449 \mathrm{Ma} \\
\text { of } 1805 \mathrm{~m} .\end{array}$ & $\begin{array}{l}140-150 \\
130-140 \\
120-130 \\
110-120 \\
100-120 \\
90-100\end{array}$ & $\begin{array}{l}1.33 \\
1.85 \\
1.85 \\
1.85 \\
1.85 \\
1.28\end{array}$ & $\begin{array}{l}16 \\
8 \\
4 \\
2 \\
1 \\
0.5\end{array}$ & $\begin{array}{r}21.28 \\
14.80 \\
7.40 \\
3.70 \\
1.85 \\
0.64\end{array}$ & $\begin{array}{l}640.31 \\
655.11 \\
662.51 \\
666.21 \\
668.06 \\
668.70\end{array}$ \\
\hline $\begin{array}{l}\text { Deposition of } 600 \mathrm{~m} \\
\text { Roper Group from } \\
1449 \text { to } 1429 \mathrm{Ma} \text {. }\end{array}$ & $\begin{array}{l}90-100 \\
100-110 \\
110-120\end{array}$ & $\begin{array}{r}7.72 \\
11.11 \\
1.16\end{array}$ & $\begin{array}{l}0.5 \\
1 \\
2\end{array}$ & $\begin{array}{r}3.86 \\
11.11 \\
2.32\end{array}$ & $\begin{array}{l}672.56 \\
683.67 \\
685.99\end{array}$ \\
\hline $\begin{array}{l}\text { Erosion to top of } \\
\text { Barney Ck. Fm. from } \\
1429 \text { to } 570 \mathrm{Ma} \text {. }\end{array}$ & $\begin{array}{l}110-120 \\
100-110 \\
90-100 \\
80-90 \\
70-80 \\
60-70 \\
50-60 \\
40-50\end{array}$ & $\begin{array}{r}13.56 \\
129.20 \\
129.20 \\
129.20 \\
129.20 \\
129.20 \\
129.20 \\
69.77\end{array}$ & $\begin{array}{l}2 \\
1 \\
0.5 \\
0.25 \\
0.125 \\
0.0625 \\
0.0313 \\
0.0156\end{array}$ & $\begin{array}{r}27.12 \\
129.20 \\
64.60 \\
32.30 \\
16.15 \\
8.08 \\
4.04 \\
1.09\end{array}$ & $\begin{array}{l}713.11 \\
842.31 \\
906.91 \\
939.21 \\
955.36 \\
963.43 \\
967.47 \\
968.56\end{array}$ \\
\hline $\begin{array}{l}\text { Deposition of } 300 \mathrm{~m} \text { of } \\
\text { Bukalara Sst. from } \\
570 \text { to } 560 \mathrm{Ma} \text {. }\end{array}$ & $\begin{array}{l}40-50 \\
50-60\end{array}$ & $\begin{array}{l}6.00 \\
4.00\end{array}$ & $\begin{array}{l}0.0156 \\
0.0313\end{array}$ & $\begin{array}{l}0.09 \\
0.13\end{array}$ & $\begin{array}{l}968.65 \\
968.78\end{array}$ \\
\hline $\begin{array}{l}\text { Erosion of } 100 \mathrm{~m} \text { of } \\
\text { Bukalara Sst. from } \\
560 \text { to } 510 \mathrm{Ma} \text {. }\end{array}$ & $50-60$ & 50 & 0.0313 & 1.57 & 970.34 \\
\hline $\begin{array}{l}\text { Deposition of } 100 \mathrm{~m} \text { of } \\
\text { Top Springs Lmst. } \\
\text { from } 510 \text { to } 508 \mathrm{Ma} \text {. }\end{array}$ & $50-60$ & 2.00 & 0.0313 & 0.06 & 970.40 \\
\hline
\end{tabular}




\begin{tabular}{|c|c|c|c|c|c|}
\hline Erosion of Top Springs & $50-60$ & 228.57 & 0.0313 & 7.15 & 977.55 \\
\hline $\begin{array}{l}\text { Lmst. and Bukalara } \\
\text { Sst. }(200 \mathrm{~m}) \text { to Cret. } \\
\text { unconformity from } \\
508 \text { to } 100 \mathrm{Ma} \text {. }\end{array}$ & $40-50$ & 181.43 & 0.0156 & 2.83 & 980.38 \\
\hline $\begin{array}{l}\text { Deposition of } 200 \mathrm{~m} \\
\text { of Cretaceous } \\
\text { Mullaman Beds from } \\
100-90 \mathrm{Ma} .\end{array}$ & $\begin{array}{l}40-50 \\
50-60\end{array}$ & $\begin{array}{l}4.00 \\
6.00\end{array}$ & $\begin{array}{l}0.0156 \\
0.0313\end{array}$ & $\begin{array}{l}0.06 \\
0.19\end{array}$ & $\begin{array}{l}980.44 \\
980.63\end{array}$ \\
\hline $\begin{array}{l}\text { Erosion from } 90 \mathrm{Ma} \\
\text { to present. }\end{array}$ & $\begin{array}{l}50-60 \\
40-50 \\
30-40 \\
20-30\end{array}$ & $\begin{array}{r}9.64 \\
26.79 \\
26.79 \\
26.79\end{array}$ & $\begin{array}{l}0.0313 \\
0.0156 \\
0.0078 \\
0.0039\end{array}$ & $\begin{array}{l}0.30 \\
0.42 \\
0.21 \\
0.10\end{array}$ & $\begin{array}{l}980.93 \\
981.35 \\
981.56 \\
981.66\end{array}$ \\
\hline
\end{tabular}

Rv\% for a total TTI of

Rv\% for a total TTI of 882 is 2.0 ;

Price's (1983) method:

maximum burial $=4240 \mathrm{~m}$, maximum temperature $=147^{\circ} \mathrm{C}, \mathrm{Rv} \%=0.7$

Observed equivalent Rv\% for near the base of the Barney Creek Fm. in the Glyde River Subbasin $(\mathrm{DDH}$ GR7 at $854 \mathrm{~m})=1.0$.

Appendix M6. Calculations following Waples' (1981) method and Price's (1983) method, assuming a constant geothermal gradient of $30 \mathrm{C} / \mathrm{km}$ with a zero intercept of $20^{\circ} \mathrm{C}$. Near base of DDH GR7, Barney Creek Formation, Glyde River Subbasin, depositionalerosional model $3 \mathrm{~b}$. 


\begin{tabular}{|c|c|c|c|c|c|}
\hline $\begin{array}{l}\text { Glyde River Subbasin, } \\
\text { model } 4 a \text {. }\end{array}$ & $\begin{array}{l}\text { Temperature } \\
\text { range }\left({ }^{\circ} \mathrm{C}\right)\end{array}$ & $\begin{array}{l}\text { Time } \\
(m . y .)\end{array}$ & $\begin{array}{l}\text { Temperature } \\
\text { factor }\end{array}$ & $\begin{array}{l}\text { Interval } \\
\text { TTI }\end{array}$ & $\begin{array}{r}\text { Total } \\
\text { TTI }\end{array}$ \\
\hline $\begin{array}{l}\text { Deposition of } 3420 \mathrm{~m} \\
\text { above Barney } \mathrm{Ck} \text {. } \\
\text { Fm. from } 1690 \text { to } \\
1459 \mathrm{Ma} \text {. }\end{array}$ & $\begin{array}{l}20-30 \\
30-40 \\
40-50 \\
50-60 \\
60-70 \\
70-80 \\
80-90 \\
90-100 \\
100-110 \\
110-120 \\
120-130\end{array}$ & $\begin{array}{r}22.51 \\
22.51 \\
22.51 \\
22.51 \\
22.51 \\
22.51 \\
22.51 \\
22.51 \\
22.51 \\
22.51 \\
5.85\end{array}$ & $\begin{array}{l}0.0039 \\
0.0078 \\
0.0156 \\
0.0313 \\
0.0625 \\
0.125 \\
0.25 \\
0.5 \\
1 \\
2 \\
4\end{array}$ & $\begin{array}{r}0.09 \\
0.18 \\
0.35 \\
0.70 \\
1.41 \\
2.81 \\
5.63 \\
11.26 \\
22.51 \\
45.02 \\
23.40\end{array}$ & $\begin{array}{r}0.09 \\
0.27 \\
0.62 \\
1.32 \\
2.73 \\
5.54 \\
11.17 \\
22.43 \\
44.94 \\
89.96 \\
113.36\end{array}$ \\
\hline $\begin{array}{l}\text { Erosion from } \\
1459 \text { to } 1449 \mathrm{Ma} \\
\text { of } 240 \mathrm{~m} .\end{array}$ & $\begin{array}{l}120-130 \\
110-120\end{array}$ & $\begin{array}{l}3.58 \\
6.42\end{array}$ & $\begin{array}{l}4 \\
2\end{array}$ & $\begin{array}{l}14.32 \\
12.84\end{array}$ & $\begin{array}{l}127.68 \\
140.52\end{array}$ \\
\hline $\begin{array}{l}\text { Deposition of } 600 \mathrm{~m} \\
\text { Roper Group from } \\
1449 \text { to } 1429 \mathrm{Ma} \text {. }\end{array}$ & $\begin{array}{l}110-120 \\
120-130 \\
130-140\end{array}$ & $\begin{array}{l}5.11 \\
1.11 \\
3.78\end{array}$ & $\begin{array}{l}2 \\
4 \\
8\end{array}$ & $\begin{array}{r}10.22 \\
4.44 \\
30.24\end{array}$ & $\begin{array}{l}150.74 \\
155.18 \\
185.42\end{array}$ \\
\hline $\begin{array}{l}\text { Erosion to top of } \\
\text { Barney Ck. Fm. from } \\
1429 \text { to } 570 \mathrm{Ma} \text {. }\end{array}$ & $\begin{array}{l}130-140 \\
120-130 \\
110-120 \\
100-120 \\
90-100 \\
80-90 \\
70-80 \\
60-70 \\
50-60 \\
40-50 \\
30-40 \\
20-30\end{array}$ & $\begin{array}{l}25.77 \\
75.75 \\
75.75 \\
75.75 \\
75.75 \\
75.75 \\
75.75 \\
75.75 \\
75.75 \\
75.75 \\
75.75 \\
75.75\end{array}$ & $\begin{array}{l}8 \\
4 \\
2 \\
1 \\
0.5 \\
0.25 \\
0.125 \\
0.0625 \\
0.0313 \\
0.0156 \\
0.0078 \\
0.0039\end{array}$ & $\begin{array}{r}206.16 \\
303.00 \\
151.50 \\
75.75 \\
37.88 \\
18.94 \\
9.47 \\
4.73 \\
2.37 \\
1.18 \\
0.59 \\
0.30\end{array}$ & $\begin{array}{l}391.58 \\
694.58 \\
846.08 \\
921.83 \\
959.71 \\
978.65 \\
988.12 \\
992.85 \\
995.22 \\
996.40 \\
996.99 \\
997.29\end{array}$ \\
\hline $\begin{array}{l}\text { Deposition and erosi } \\
\text { of Cambrian and }\end{array}$ & $1-30$ & 570.00 & 0.0039 & 2.22 & 999.51 \\
\hline
\end{tabular}

of Cambrian and

Cretaceous sediments.

$\mathrm{Rv} \%$ for a total TTI of 1000 is 2.0 ;

Price's (1983) method:

maximum burial $=3780 \mathrm{~m}$, maximum temperature $=133.4^{\circ} \mathrm{C}, \mathrm{Rv} \%=0.7$.

Observed equivalent Rv\% for the top of the Barney Creek Fm. in the Glyde River Subbasin is 0.5 to 0.7 .

Appendix M7. Calculations following Waples' (1981) method and Price's (1983) method, assuming a constant geothermal gradient of $30 \mathrm{C}^{\circ} / \mathrm{km}$ with a zero intercept of $20^{\circ} \mathrm{C}$. Near top of Barney Creek Formation, Glyde River Subbasin, depositional-erosional model 4a. 


\begin{tabular}{|c|c|c|c|c|c|}
\hline $\begin{array}{l}\text { Glyde River Subbasin, } \\
\text { model } 4 \mathrm{~b} \text {. }\end{array}$ & $\begin{array}{l}\text { Temperature } \\
\text { range }\left({ }^{\circ} \mathrm{C}\right)\end{array}$ & $\begin{array}{l}\text { Time } \\
\text { (m.y.) }\end{array}$ & $\begin{array}{l}\text { Temperature } \\
\text { factor }\end{array}$ & $\begin{array}{l}\text { Interval } \\
\text { TTI }\end{array}$ & $\begin{array}{r}\text { Total } \\
\text { TTI }\end{array}$ \\
\hline $\begin{array}{l}\text { Deposition of } 3420 \mathrm{~m} \\
\text { above Barney Ck. Fm. } \\
\text { deposited over } 231 \mathrm{my} \\
\text { plus } 820 \mathrm{~m} \text { of } \\
\text { Barney Ck. Fm. } \\
\text { deposited over } 2 \mathrm{my} \text {. } \\
\text { A total of } 4240 \mathrm{~m} \\
\text { deposited from } 1692 \\
\text { to } 1459 \mathrm{Ma} \text {. }\end{array}$ & $\begin{array}{l}20-30 \\
30-40 \\
40-50 \\
50-60 \\
60-70 \\
70-80 \\
80-90 \\
90-100 \\
100-110 \\
110-120 \\
120-130 \\
130-140 \\
140-150\end{array}$ & $\begin{array}{r}0.81 \\
0.81 \\
12.78 \\
22.51 \\
22.51 \\
22.51 \\
22.51 \\
22.51 \\
22.51 \\
22.51 \\
22.51 \\
22.51 \\
16.21\end{array}$ & $\begin{array}{l}0.0039 \\
0.0078 \\
0.0156 \\
0.0313 \\
0.0625 \\
0.125 \\
0.25 \\
0.5 \\
1 \\
2 \\
4 \\
8 \\
16\end{array}$ & $\begin{array}{r}0.00 \\
0.01 \\
0.20 \\
0.70 \\
1.41 \\
2.81 \\
5.63 \\
11.26 \\
22.51 \\
45.02 \\
90.04 \\
180.08 \\
259.36\end{array}$ & $\begin{array}{r}0.00 \\
0.01 \\
0.21 \\
0.91 \\
2.32 \\
5.13 \\
10.76 \\
22.02 \\
44.53 \\
89.55 \\
179.59 \\
359.67 \\
619.03\end{array}$ \\
\hline $\begin{array}{l}\text { Erosion from } \\
1459 \text { to } 1449 \mathrm{Ma} \\
\text { of } 240 \mathrm{~m} .\end{array}$ & $140-150$ & 10.00 & 16 & 160.00 & 779.03 \\
\hline $\begin{array}{l}\text { Deposition of } 600 \mathrm{~m} \\
\text { Roper Group from } \\
1449 \text { to } 1429 \mathrm{Ma} \text {. }\end{array}$ & $\begin{array}{l}140-150 \\
130-140\end{array}$ & $\begin{array}{r}11.11 \\
8.99\end{array}$ & $\begin{array}{l}16 \\
8\end{array}$ & $\begin{array}{r}177.76 \\
71.92\end{array}$ & $\begin{array}{r}956.78 \\
1028.71\end{array}$ \\
\hline $\begin{array}{l}\text { Erosion to top of } \\
\text { Barney Ck. Fm. from } \\
1429 \text { to } 570 \mathrm{Ma} \text {. }\end{array}$ & $\begin{array}{l}140-150 \\
130-140 \\
120-130 \\
110-120 \\
100-110 \\
90-100 \\
80-90 \\
70-80 \\
60-70 \\
50-60 \\
40-50\end{array}$ & $\begin{array}{l}60.61 \\
75.76 \\
75.76 \\
75.76 \\
75.76 \\
75.76 \\
75.76 \\
75.76 \\
75.76 \\
75.76 \\
40.91\end{array}$ & $\begin{array}{l}16 \\
8 \\
4 \\
2 \\
1 \\
0.5 \\
0.25 \\
0.125 \\
0.0625 \\
0.0313 \\
0.0156\end{array}$ & $\begin{array}{r}969.76 \\
606.08 \\
303.04 \\
151.52 \\
75.76 \\
37.88 \\
18.94 \\
9.47 \\
4.74 \\
2.37 \\
0.64\end{array}$ & $\begin{array}{l}1998.47 \\
2604.55 \\
2907.59 \\
3059.11 \\
3135.87 \\
3173.75 \\
3192.69 \\
3202.16 \\
3206.90 \\
3209.27 \\
3209.91\end{array}$ \\
\hline $\begin{array}{l}\text { Deposition of } 300 \mathrm{~m} \text { of } \\
\text { Bukalara Sst. from } \\
570-560 \mathrm{Ma} \text {. }\end{array}$ & $\begin{array}{l}40-50 \\
50-60\end{array}$ & $\begin{array}{l}6.00 \\
4.00\end{array}$ & $\begin{array}{l}0.0156 \\
0.0313\end{array}$ & $\begin{array}{l}0.09 \\
0.13\end{array}$ & $\begin{array}{l}3210.00 \\
3210.13\end{array}$ \\
\hline rosion of $100 \mathrm{~m}$ of & $50-60$ & 50.00 & 0.0313 & 1.57 & 3211.69 \\
\hline
\end{tabular}

Bukalara Sst. from

560-510 Ma.

Deposition of $100 \mathrm{~m}$ of $\quad 50-60 \quad 2.00 \quad 0.0313 \quad 0.06 \quad 3211.75$

Top Springs Lmst.

from 510-508 Ma. 


$\begin{array}{lrrrrr}\text { Erosion of Top Springs } & 50-60 & 228.57 & 0.0313 & 7.15 & 3218.90 \\ \text { Lmst. and Bukalara } & 40-50 & 181.43 & 0.0156 & 2.83 & 3221.73 \\ \begin{array}{l}\text { Sst. (200m) to Cret. } \\ \text { unconformity from }\end{array} & & & & & \\ 508 \text { to } 100 \mathrm{Ma} \text {. } & & & & & \\ & & & & & \\ \begin{array}{l}\text { Deposition of } 200 \mathrm{~m} \\ \text { of Cretaceous }\end{array} & 40-50 & 4.00 & 0.0156 & 0.06 & 3221.79 \\ \text { Mullaman Beds from } & 50-60 & 6.00 & 0.0313 & 0.19 & 3221.98 \\ 100 \text { to 90 Ma. } & & & & & \\ & 50-60 & 9.64 & 0.0313 & 0.30 & 3222.28 \\ \text { Erosion from 90 Ma } & 40-50 & 26.79 & 0.0156 & 0.42 & 3222.70 \\ \text { to present. } & 30-40 & 26.79 & 0.0078 & 0.21 & 3222.91 \\ & 20-30 & 26.79 & 0.0039 & 0.10 & 3223.01\end{array}$

Rv\% for a total TTI of 3223 is 2.6 ;

Price's (1983) method:

maximum burial $=4460 \mathrm{~m}$, maximum temperature $=158^{\circ} \mathrm{C}, \mathrm{Rv} \%=0.8$

Observed equivalent Rv\% for near the base of the Barney Creek Fm. in the Glyde River Subbasin (DDH GR7 at $854 \mathrm{~m})=1.0$.

Appendix M8. Calculations following Waples' (1981) method and Price's (1983) method, assuming a constant geothermal gradient of $30 \mathrm{C}^{\circ} / \mathrm{km}$ with a zero intercept of $20^{\circ} \mathrm{C}$. Near base of DDH GR7, Barney Creek Formation, Glyde River Subbasin, depositionalerosional model $4 \mathrm{~b}$. 


\begin{tabular}{|c|c|c|c|c|c|}
\hline $\begin{array}{l}\text { Glyde River Subbasin, } \\
\text { model } 5 a .\end{array}$ & $\begin{array}{l}\text { Temperature } \\
\text { range }\left({ }^{\circ} \mathrm{C}\right)\end{array}$ & $\begin{array}{l}\text { Time } \\
\text { (m.y.) }\end{array}$ & $\begin{array}{l}\text { Temperature } \\
\text { factor }\end{array}$ & $\begin{array}{l}\text { Interval } \\
\text { TTI }\end{array}$ & $\begin{array}{r}\text { Total } \\
\text { TTI }\end{array}$ \\
\hline \multirow{6}{*}{$\begin{array}{l}\text { Deposition of } 2000 \mathrm{~m} \\
\text { above Barney Ck. } \\
\text { Fm. from } 1690 \text { to } \\
1670 \mathrm{Ma} \text {. }\end{array}$} & $20-30$ & 3.33 & 0.0039 & 0.01 & 0.01 \\
\hline & $30-40$ & 3.33 & 0.0078 & 0.03 & 0.04 \\
\hline & $40-50$ & 3.33 & 0.0156 & 0.05 & 0.09 \\
\hline & $50-60$ & 3.33 & 0.0313 & 0.10 & 0.19 \\
\hline & $60-70$ & 3.33 & 0.0625 & 0.21 & 0.40 \\
\hline & $70-80$ & 3.33 & 0.125 & 0.42 & 0.82 \\
\hline \multirow{6}{*}{$\begin{array}{l}\text { Erosion from } \\
1670-1449 \mathrm{Ma} \\
\text { of } 1805 \mathrm{~m} .\end{array}$} & $70-80$ & 40.85 & 0.125 & 5.11 & 5.93 \\
\hline & $60-70$ & 40.85 & 0.0625 & 2.55 & 8.48 \\
\hline & $50-60$ & 40.85 & 0.0313 & 1.28 & 10.28 \\
\hline & $40-50$ & 40.85 & 0.0156 & 0.64 & 10.92 \\
\hline & $30-40$ & 40.85 & 0.0078 & 0.32 & 11.24 \\
\hline & $20-30$ & 16.70 & 0.0039 & 0.07 & 11.31 \\
\hline Deposition of $600 \mathrm{~m}$ & $20-30$ & 4.60 & 0.0039 & 0.02 & 11.33 \\
\hline Roper Group from & $30-40$ & 11.11 & 0.0078 & 0.09 & 11.42 \\
\hline 1449 to $1429 \mathrm{Ma}$. & $40-50$ & 4.29 & 0.0156 & 0.07 & 11.49 \\
\hline Erosion to top of & $40-50$ & 138.06 & 0.0156 & 2.15 & 13.64 \\
\hline Barney $\mathrm{Ck}$. Fm. from & $30-40$ & 358.42 & 0.0078 & 2.80 & 16.44 \\
\hline 1429 to $570 \mathrm{Ma}$. & $20-30$ & 358.42 & 0.0039 & 1.40 & 17.84 \\
\hline $\begin{array}{l}\text { Deposition and erosion } \\
\text { of Cambrian and } \\
\text { Cretaceous sediments, } \\
570 \mathrm{Ma} \text { to present. }\end{array}$ & $20-30$ & 570.00 & 0.0039 & 2.22 & 20.06 \\
\hline
\end{tabular}

Rv\% for a total TTI of 20 is 0.7 ;

Price's (1983) method:

maximum burial $=2000 \mathrm{~m}$, maximum temperature $=80^{\circ} \mathrm{C}, \mathrm{Rv} \%=0.4$.

Observed equivalent Rv\% for the top of the Barney Creek Fm. in the Glyde River Subbasin is 0.5 to 0.7 .

Appendix M9. Calculations following Waples' (1981) method and Price's (1983) method, assuming a constant geothermal gradient of $30 \mathrm{C}^{\circ} / \mathrm{km}$ with a zero intercept of $20^{\circ} \mathrm{C}$. Near top of Barney Creek Formation, Glyde River Subbasin, depositional-erosional model 5a. 


\begin{tabular}{|c|c|c|c|c|c|}
\hline $\begin{array}{l}\text { Glyde River Subbasin, } \\
\text { model } 5 \mathrm{~b} \text {. }\end{array}$ & $\begin{array}{l}\text { Temperature } \\
\text { range }\left({ }^{\circ} \mathrm{C}\right)\end{array}$ & $\begin{array}{l}\text { Time } \\
(\mathrm{m} . \mathrm{y.})\end{array}$ & $\begin{array}{l}\text { Temperature } \\
\text { factor }\end{array}$ & $\begin{array}{l}\text { Interval } \\
\text { TTI }\end{array}$ & $\begin{array}{r}\text { Total } \\
\text { TTI }\end{array}$ \\
\hline $\begin{array}{l}\text { Deposition of } 2000 \mathrm{~m} \\
\text { above Bamey Ck. Fm. } \\
\text { deposited over } 20 \mathrm{my} \\
\text { plus } 820 \mathrm{~m} \text { of } \\
\text { Barney Ck. Fm. } \\
\text { deposited over } 2 \mathrm{my} \text {. } \\
\text { A total of } 2820 \mathrm{~m} \\
\text { deposited from } 1692 \\
\text { to } 1670 \mathrm{Ma} \text {. }\end{array}$ & $\begin{array}{l}20-30 \\
30-40 \\
40-50 \\
50-60 \\
60-70 \\
70-80 \\
80-90 \\
90-100 \\
100-110\end{array}$ & $\begin{array}{l}0.81 \\
0.81 \\
3.17 \\
3.30 \\
3.30 \\
3.30 \\
3.30 \\
3.30 \\
1.80\end{array}$ & $\begin{array}{l}0.0039 \\
0.0078 \\
0.0156 \\
0.0313 \\
0.0625 \\
0.125 \\
0.25 \\
0.5 \\
1\end{array}$ & $\begin{array}{l}0.00 \\
0.01 \\
0.05 \\
0.10 \\
0.21 \\
0.41 \\
0.83 \\
1.65 \\
1.80\end{array}$ & $\begin{array}{l}0.00 \\
0.01 \\
0.06 \\
0.16 \\
0.37 \\
0.78 \\
1.60 \\
3.25 \\
5.05\end{array}$ \\
\hline $\begin{array}{l}\text { Erosion from } \\
1670-1449 \mathrm{Ma} \\
\text { of } 1805 \mathrm{~m} .\end{array}$ & $\begin{array}{l}100-110 \\
90-100 \\
80-90 \\
70-80 \\
60-70 \\
50-60\end{array}$ & $\begin{array}{l}18.78 \\
40.80 \\
40.80 \\
40.80 \\
40.80 \\
38.96\end{array}$ & $\begin{array}{l}1 \\
0.5 \\
0.25 \\
0.125 \\
0.0625 \\
0.0313\end{array}$ & $\begin{array}{r}18.78 \\
20.40 \\
10.20 \\
5.10 \\
2.55 \\
1.22\end{array}$ & $\begin{array}{l}23.83 \\
44.23 \\
54.43 \\
59.53 \\
62.08 \\
63.30\end{array}$ \\
\hline $\begin{array}{l}\text { Deposition of } 600 \mathrm{~m} \\
\text { Roper Group from } \\
1449 \text { to } 1429 \mathrm{Ma} \text {. }\end{array}$ & $\begin{array}{l}50-60 \\
60-70\end{array}$ & $\begin{array}{r}10.61 \\
9.39\end{array}$ & $\begin{array}{l}0.0313 \\
0.0625\end{array}$ & $\begin{array}{l}0.33 \\
0.59\end{array}$ & $\begin{array}{l}63.63 \\
64.22\end{array}$ \\
\hline $\begin{array}{l}\text { Erosion to top of } \\
\text { Barney Ck. Fm. from } \\
1429 \text { to } 570 \mathrm{Ma} \text {. }\end{array}$ & $\begin{array}{l}60-70 \\
50-60 \\
40-50\end{array}$ & $\begin{array}{l}302.90 \\
358.39 \\
193.54\end{array}$ & $\begin{array}{l}0.0625 \\
0.0313 \\
0.0156\end{array}$ & $\begin{array}{r}18.93 \\
11.22 \\
3.02\end{array}$ & $\begin{array}{l}83.15 \\
94.37 \\
97.39\end{array}$ \\
\hline $\begin{array}{l}\text { Deposition of } 300 \mathrm{~m} \text { of } \\
\text { Bukalara Sst. from } \\
570 \text { to } 560 \mathrm{Ma} \text {. }\end{array}$ & $\begin{array}{l}40-50 \\
50-60\end{array}$ & $\begin{array}{l}6.00 \\
4.00\end{array}$ & $\begin{array}{l}0.0156 \\
0.0313\end{array}$ & $\begin{array}{l}0.09 \\
0.13\end{array}$ & $\begin{array}{l}97.48 \\
97.61\end{array}$ \\
\hline $\begin{array}{l}\text { Erosion of } 100 \mathrm{~m} \text { of } \\
\text { Bukalara Sst. from } \\
560 \text { to } 510 \mathrm{Ma} \text {. }\end{array}$ & $50-60$ & 50.00 & 0.0313 & 1.57 & 99.17 \\
\hline $\begin{array}{l}\text { Deposition of } 100 \mathrm{~m} \text { of } \\
\text { Top Springs Lmst. } \\
\text { from } 510 \text { to } 508 \mathrm{Ma} \text {. }\end{array}$ & $50-60$ & 2.00 & 0.0313 & 0.06 & 99.23 \\
\hline $\begin{array}{l}\text { Erosion of Top Springs } \\
\text { Lmst. and Bukalara } \\
\text { Sst. (200m) to Cret. } \\
\text { unconformity from } \\
508 \text { to } 100 \mathrm{Ma} \text {. }\end{array}$ & $\begin{array}{l}50-60 \\
40-50\end{array}$ & $\begin{array}{l}228.57 \\
181.43\end{array}$ & $\begin{array}{l}0.0313 \\
0.0156\end{array}$ & $\begin{array}{l}7.15 \\
2.83\end{array}$ & $\begin{array}{l}106.38 \\
109.21\end{array}$ \\
\hline
\end{tabular}




$\begin{array}{lrrrrr}\begin{array}{l}\text { Deposition of 200 m } \\ \text { of Cretaceous }\end{array} & \begin{array}{l}40-50 \\ \text { Mullaman Beds from }\end{array} & 4.00 & 0.0156 & 0.06 & 109.27 \\ 100 \text { to } 90 \mathrm{Ma} \text {. } & & 6.00 & 0.0313 & 0.19 & 109.46 \\ & & & & & \\ \text { Erosion from 90 Ma } & 50-60 & 9.64 & 0.0313 & 0.30 & 109.76 \\ \text { to present. } & 40-50 & 26.79 & 0.0156 & 0.42 & 110.18 \\ & 30-40 & 26.79 & 0.0078 & 0.21 & 110.39 \\ & 20-30 & 26.79 & 0.0039 & 0.10 & 110.49\end{array}$

Rv\% for a total TTI of 110 is 1.2 ;

Price's (1983) method:

maximum burial $=2820 \mathrm{~m}$, maximum temperature $=105^{\circ} \mathrm{C}, \mathrm{Rv} \%=0.5$

Observed equivalent Rv\% for near the base of the Barney Creek Fm. in the Glyde River Subbasin (DDH GR7 at $854 \mathrm{~m})=1.0$.

Appendix M10. Calculations following Waples' (1981) method and Price's (1983) method, assuming a constant geothermal gradient of $30 \mathrm{C} / \mathrm{km}$ with a zero intercept of $20^{\circ} \mathrm{C}$. Near base of DDH GR7, Barney Creek Formation, Glyde River Subbasin, depositionalerosional model $5 b$. 


\begin{tabular}{|c|c|c|c|c|c|}
\hline $\begin{array}{l}\text { Glyde River Subbasin, } \\
\text { model } 6 a\end{array}$ & $\begin{array}{l}\text { Temperature } \\
\text { range }\left({ }^{\circ} \mathrm{C}\right)\end{array}$ & $\begin{array}{l}\text { Time } \\
\text { (m.y.) }\end{array}$ & $\begin{array}{l}\text { Temperature } \\
\text { factor }\end{array}$ & $\begin{array}{l}\text { Interval } \\
\text { TTI }\end{array}$ & $\begin{array}{l}\text { Total } \\
\text { TTI }\end{array}$ \\
\hline $\begin{array}{l}\text { Deposition of } 2000 \mathrm{~m} \\
\text { above Barney Ck. } \\
\text { Fm. from } 1690 \text { to } \\
1670 \mathrm{Ma} \text {. }\end{array}$ & $\begin{array}{l}20-30 \\
30-40 \\
40-50 \\
50-60 \\
60-70 \\
70-80\end{array}$ & $\begin{array}{l}3.33 \\
3.33 \\
3.33 \\
3.33 \\
3.33 \\
3.33\end{array}$ & $\begin{array}{l}0.0039 \\
0.0078 \\
0.0156 \\
0.0313 \\
0.0625 \\
0.125\end{array}$ & $\begin{array}{l}0.01 \\
0.03 \\
0.05 \\
0.10 \\
0.21 \\
0.42\end{array}$ & $\begin{array}{l}0.01 \\
0.04 \\
0.09 \\
0.19 \\
0.40 \\
0.82\end{array}$ \\
\hline $\begin{array}{l}\text { Erosion from } \\
1670 \text { to } 1449 \mathrm{Ma} \\
\text { of } 240 \mathrm{~m} .\end{array}$ & $70-80$ & 221.00 & 0.125 & 27.63 & 28.44 \\
\hline $\begin{array}{l}\text { Deposition of } 600 \mathrm{~m} \\
\text { Roper Group from } \\
1449 \text { to } 1429 \mathrm{Ma} \text {. }\end{array}$ & $\begin{array}{l}70-80 \\
80-90 \\
90-100\end{array}$ & $\begin{array}{r}8.00 \\
11.10 \\
0.89\end{array}$ & $\begin{array}{l}0.125 \\
0.25 \\
0.5\end{array}$ & $\begin{array}{l}1.00 \\
2.78 \\
0.45\end{array}$ & $\begin{array}{l}29.44 \\
32.21 \\
32.66\end{array}$ \\
\hline $\begin{array}{l}\text { Erosion to top of } \\
\text { Barney Ck. Fm. from } \\
1429 \text { to } 570 \mathrm{Ma} \text {. }\end{array}$ & $\begin{array}{l}90-100 \\
80-90 \\
70-80 \\
60-70 \\
50-60 \\
40-50 \\
30-40 \\
20-30\end{array}$ & $\begin{array}{r}9.70 \\
121.21 \\
121.21 \\
121.21 \\
121.21 \\
121.21 \\
121.21 \\
121.21\end{array}$ & $\begin{array}{l}0.5 \\
0.25 \\
0.125 \\
0.0625 \\
0.0313 \\
0.0156 \\
0.0078 \\
0.0039\end{array}$ & $\begin{array}{r}4.85 \\
30.30 \\
15.15 \\
7.58 \\
3.79 \\
1.89 \\
0.95 \\
0.47\end{array}$ & $\begin{array}{l}37.51 \\
67.81 \\
82.96 \\
90.54 \\
94.33 \\
96.22 \\
97.17 \\
97.64\end{array}$ \\
\hline $\begin{array}{l}\text { Deposition and erosion } \\
\text { of Cambrian and } \\
\text { Cretaceous sediments. }\end{array}$ & $20-30$ & 570.00 & 0.0039 & 2.22 & 99.86 \\
\hline
\end{tabular}

Price's (1983) method:

maximum burial $=2360 \mathrm{~m}$, maximum temperature $=90.8^{\circ} \mathrm{C}, \mathrm{Rv} \%=0.5$

Observed equivalent Rv\% for the top of the Barney Creek Fm. in the Glyde River Subbasin is 0.5 to 0.7 .

Appendix M11. Calculations following Waples' (1981) method and Price's (1983) method, assuming a constant geothermal gradient of $30 \mathrm{C} / \mathrm{km}$ with a zero intercept of $20^{\circ} \mathrm{C}$. Near top of Barney Creek Formation, Glyde River Subbasin, depositional-erosional model 6a. 


\begin{tabular}{|c|c|c|c|c|c|}
\hline $\begin{array}{l}\text { Glyde River Subbasin, } \\
\text { model } 6 \mathrm{~b} \text {. }\end{array}$ & $\begin{array}{l}\text { Temperature } \\
\text { range }\left({ }^{\circ} \mathrm{C}\right)\end{array}$ & $\begin{array}{l}\text { Time } \\
(m . y .)\end{array}$ & $\begin{array}{l}\text { Temperature } \\
\text { factor }\end{array}$ & $\begin{array}{l}\text { Interval } \\
\text { TTI }\end{array}$ & $\begin{array}{r}\text { Total } \\
\text { TTI }\end{array}$ \\
\hline $\begin{array}{l}\text { Deposition of } 2000 \mathrm{~m} \\
\text { above Barney Ck. Fm. } \\
\text { deposited over } 20 \mathrm{my} \\
\text { plus } 820 \mathrm{~m} \text { of } \\
\text { Bamey Ck. Fm. } \\
\text { deposited over } 2 \mathrm{my} \text {. } \\
\text { A total of } 2820 \mathrm{~m} \\
\text { deposited from } 1692 \\
\text { to } 1670 \mathrm{Ma} \text {. }\end{array}$ & $\begin{array}{l}20-30 \\
30-40 \\
40-50 \\
50-60 \\
60-70 \\
70-80 \\
80-90 \\
90-100 \\
100-110\end{array}$ & $\begin{array}{l}0.81 \\
0.81 \\
3.17 \\
3.30 \\
3.30 \\
3.30 \\
3.30 \\
3.30 \\
1.80\end{array}$ & $\begin{array}{l}0.0039 \\
0.0078 \\
0.0156 \\
0.0313 \\
0.0625 \\
0.125 \\
0.25 \\
0.5 \\
1\end{array}$ & $\begin{array}{l}0.00 \\
0.01 \\
0.05 \\
0.10 \\
0.21 \\
0.41 \\
0.83 \\
1.65 \\
1.80\end{array}$ & $\begin{array}{l}0.00 \\
0.01 \\
0.06 \\
0.16 \\
0.37 \\
0.78 \\
1.60 \\
3.25 \\
5.05\end{array}$ \\
\hline $\begin{array}{l}\text { Erosion from } \\
1670 \text { to } 1449 \mathrm{Ma} \\
\text { of } 240 \mathrm{~m} .\end{array}$ & $\begin{array}{l}100-110 \\
90-100\end{array}$ & $\begin{array}{r}153.40 \\
86.60\end{array}$ & $\begin{array}{l}1 \\
0.5\end{array}$ & $\begin{array}{r}153.40 \\
43.30\end{array}$ & $\begin{array}{l}158.45 \\
201.75\end{array}$ \\
\hline $\begin{array}{l}\text { Deposition of } 600 \mathrm{~m} \\
\text { Roper Group from } \\
1449 \text { to } 1429 \mathrm{Ma}\end{array}$ & $\begin{array}{l}90-100 \\
100-110 \\
110-120\end{array}$ & $\begin{array}{r}2.89 \\
11.11 \\
6.00\end{array}$ & $\begin{array}{l}0.5 \\
1 \\
2\end{array}$ & $\begin{array}{r}1.45 \\
11.11 \\
12.00\end{array}$ & $\begin{array}{l}203.20 \\
214.31 \\
226.31\end{array}$ \\
\hline $\begin{array}{l}\text { Erosion to top of } \\
\text { Barney Ck. Fm. from } \\
1429 \text { to } 570 \mathrm{Ma} \text {. }\end{array}$ & $\begin{array}{l}110-120 \\
100-110 \\
90-100 \\
80-90 \\
70-80 \\
60-70 \\
50-60 \\
40-50\end{array}$ & $\begin{array}{r}65.45 \\
121.21 \\
121.21 \\
121.21 \\
121.21 \\
121.21 \\
121.21 \\
65.45\end{array}$ & $\begin{array}{l}2 \\
1 \\
0.5 \\
0.25 \\
0.125 \\
0.0625 \\
0.0313 \\
0.0156\end{array}$ & $\begin{array}{r}130.90 \\
121.21 \\
60.61 \\
30.30 \\
15.15 \\
7.58 \\
3.79 \\
1.02\end{array}$ & $\begin{array}{l}357.21 \\
478.42 \\
539.02 \\
569.32 \\
584.47 \\
592.05 \\
595.84 \\
596.86\end{array}$ \\
\hline $\begin{array}{l}\text { Deposition of } 300 \mathrm{~m} \text { of } \\
\text { Bukalara Sst. from } \\
570 \text { to } 560 \mathrm{Ma} \text {. }\end{array}$ & $\begin{array}{l}40-50 \\
50-60\end{array}$ & $\begin{array}{l}6.00 \\
4.00\end{array}$ & $\begin{array}{l}0.0156 \\
0.0313\end{array}$ & $\begin{array}{l}0.09 \\
0.13\end{array}$ & $\begin{array}{l}596.95 \\
597.08\end{array}$ \\
\hline $\begin{array}{l}\text { Erosion of } 100 \mathrm{~m} \text { of } \\
\text { Bukalara Sst. from } \\
560 \text { to } 510 \mathrm{Ma} \text {. }\end{array}$ & $50-60$ & 50.00 & 0.0313 & 1.57 & 598.64 \\
\hline $\begin{array}{l}\text { Deposition of } 100 \mathrm{~m} \text { of } \\
\text { Top Springs Lmst. } \\
\text { from } 510 \text { to } 508 \mathrm{Ma} \text {. }\end{array}$ & $50-60$ & 2.00 & 0.0313 & 0.06 & 598.70 \\
\hline $\begin{array}{l}\text { Erosion of Top Springs } \\
\text { Lmst. and Bukalara } \\
\text { Sst. (200m) to Cret. } \\
\text { unconformity from } \\
508 \text { to } 100 \mathrm{Ma} \text {. }\end{array}$ & $\begin{array}{l}50-60 \\
40-50\end{array}$ & $\begin{array}{l}228.57 \\
181.43\end{array}$ & $\begin{array}{l}0.0313 \\
0.0156\end{array}$ & $\begin{array}{l}7.15 \\
2.83\end{array}$ & $\begin{array}{l}605.85 \\
608.68\end{array}$ \\
\hline
\end{tabular}




$\begin{array}{llrlll}\begin{array}{l}\text { Deposition of } 200 \mathrm{~m} \\ \text { of Cretaceous }\end{array} & 40-50 & 4.00 & 0.0156 & 0.06 & 608.74 \\ \begin{array}{l}\text { Mullaman Beds from } \\ 100 \text { to } 90 \mathrm{Ma} \text {. }\end{array} & 50-60 & 6.00 & 0.0313 & 0.19 & 608.93 \\ & & & & & \\ \text { Erosion from 90 Ma } & 50-60 & 9.64 & 0.0313 & 0.30 & 609.23 \\ \text { to present. } & 40-50 & 26.79 & 0.0156 & 0.42 & 609.65 \\ & 30-40 & 26.79 & 0.0078 & 0.21 & 609.86 \\ & 20-30 & 26.79 & 0.0039 & 0.10 & 609.96\end{array}$

Rv\% for a total TTI of 610 is 1.8 ;

Price's (1983) method:

maximum burial $=3180 \mathrm{~m}$, maximum temperature $=115^{\circ} \mathrm{C}, \mathrm{Rv} \%=0.6$

Observed equivalent Rv\% for near the base of the Barney Creek Fm. in the Glyde River Subbasin (DDH GR7 at $854 \mathrm{~m})=1.0$.

Appendix M12. Calculations following Waples' (1981) method and Price's (1983) method, assuming a constant geothermal gradient of $30 \mathrm{C}^{\circ} / \mathrm{km}$ with a zero intercept of $20^{\circ} \mathrm{C}$. Near base of DDH GR7, Barney Creek Formation, Glyde River Subbasin, depositionalerosional model $6 \mathrm{~b}$. 


\begin{tabular}{|c|c|c|c|c|c|}
\hline $\begin{array}{l}\text { Glyde River Subbasin, } \\
\text { model } 7 \mathrm{a} .\end{array}$ & $\begin{array}{l}\text { Temperature } \\
\text { range }\left({ }^{\circ} \mathrm{C}\right)\end{array}$ & $\begin{array}{l}\text { Time } \\
\text { (m.y.) }\end{array}$ & $\begin{array}{l}\text { Temperature } \\
\text { factor }\end{array}$ & $\begin{array}{c}\text { Interval } \\
\text { TTI }\end{array}$ & $\begin{array}{l}\text { Tota } \\
\text { TTI }\end{array}$ \\
\hline $\begin{array}{l}\text { Deposition of } 2000 \mathrm{~m} \\
\text { above Barney Ck. } \\
\text { Fm. from } 1690 \text { to } \\
1459 \mathrm{Ma} .\end{array}$ & $\begin{array}{l}20-30 \\
30-40 \\
40-50 \\
50-60 \\
60-70 \\
70-80\end{array}$ & $\begin{array}{l}40.16 \\
40.16 \\
40.16 \\
40.16 \\
40.16 \\
40.16\end{array}$ & $\begin{array}{l}0.0039 \\
0.0078 \\
0.0156 \\
0.0313 \\
0.0625 \\
0.125\end{array}$ & $\begin{array}{l}0.16 \\
0.31 \\
0.63 \\
1.26 \\
2.51 \\
5.02\end{array}$ & $\begin{array}{l}0.16 \\
0.47 \\
1.10 \\
2.36 \\
4.87 \\
9.89\end{array}$ \\
\hline $\begin{array}{l}\text { Erosion from } \\
1459-1449 \mathrm{Ma} \\
\text { of } 1805 \mathrm{~m} .\end{array}$ & $\begin{array}{l}70-80 \\
60-70 \\
50-60 \\
40-50 \\
30-40 \\
20-30\end{array}$ & $\begin{array}{l}1.85 \\
1.85 \\
1.85 \\
1.85 \\
1.85 \\
0.77\end{array}$ & $\begin{array}{l}0.125 \\
0.0625 \\
0.0313 \\
0.0156 \\
0.0078 \\
0.0039\end{array}$ & $\begin{array}{l}0.23 \\
0.12 \\
0.06 \\
0.03 \\
0.01 \\
0.00\end{array}$ & $\begin{array}{l}10.12 \\
10.24 \\
10.30 \\
10.33 \\
10.34 \\
10.34\end{array}$ \\
\hline $\begin{array}{l}\text { Deposition of } 600 \mathrm{~m} \\
\text { Roper Group from } \\
1449 \text { to } 1429 \mathrm{Ma} \text {. }\end{array}$ & $\begin{array}{l}20-30 \\
30-40 \\
40-50\end{array}$ & $\begin{array}{r}4.61 \\
11.11 \\
4.28\end{array}$ & $\begin{array}{l}0.0039 \\
0.0078 \\
0.0156\end{array}$ & $\begin{array}{l}0.02 \\
0.09 \\
0.07\end{array}$ & $\begin{array}{l}10.36 \\
10.45 \\
10.52\end{array}$ \\
\hline $\begin{array}{l}\text { Erosion to top of } \\
\text { Barney Ck. Fm. from } \\
1429 \text { to } 570 \mathrm{Ma} \text {. }\end{array}$ & $\begin{array}{l}40-50 \\
30-40 \\
20-30\end{array}$ & $\begin{array}{l}138.06 \\
358.42 \\
358.42\end{array}$ & $\begin{array}{l}0.0156 \\
0.0078 \\
0.0039\end{array}$ & $\begin{array}{l}2.15 \\
2.80 \\
1.40\end{array}$ & $\begin{array}{l}12.67 \\
15.47 \\
16.87\end{array}$ \\
\hline $\begin{array}{l}\text { Deposition and erosion } \\
\text { of Cambrian and } \\
\text { Cretaceous sediments, } \\
570 \mathrm{Ma} \text { to present. }\end{array}$ & $20-30$ & 570.00 & 0.0039 & 2.22 & 19.09 \\
\hline
\end{tabular}

Rv\% for a total TTI of 19 is 0.7 ;

Price's (1983) method:

maximum burial $=2000 \mathrm{~m}$, maximum temperature $=80^{\circ} \mathrm{C}, \mathrm{Rv} \%=0.4$

Observed equivalent Rv\% for the top of the Barney Creek Fm. in the Glyde River Subbasin is 0.5 to 0.7 .

Appendix M13. Calculations following Waples' (1981) method and Price's (1983) method, assuming a constant geothermal gradient of $30 \mathrm{C}^{\circ} / \mathrm{km}$ with a zero intercept of $20^{\circ} \mathrm{C}$. Near top of Barney Creek Formation, Glyde River Subbasin, depositional-erosional model $7 \mathrm{a}$. 


\begin{tabular}{|c|c|c|c|c|c|}
\hline $\begin{array}{l}\text { Glyde River Subbasin, } \\
\text { model } 7 \mathrm{~b} \text {. }\end{array}$ & $\begin{array}{l}\text { Temperature } \\
\text { range }\left({ }^{\circ} \mathrm{C}\right)\end{array}$ & $\begin{array}{l}\text { Time } \\
\text { (m.y.) }\end{array}$ & $\begin{array}{l}\text { Temperature } \\
\text { factor }\end{array}$ & $\begin{array}{l}\text { Interval } \\
\text { TTI }\end{array}$ & $\begin{array}{r}\text { Total } \\
\text { TTI }\end{array}$ \\
\hline $\begin{array}{l}\text { Deposition of } 2000 \mathrm{~m} \\
\text { above Barney Ck. Fm. } \\
\text { deposited over } 231 \mathrm{my} \\
\text { plus } 820 \mathrm{~m} \text { of } \\
\text { Barney Ck. Fm. } \\
\text { deposited over } 2 \mathrm{my} \text {. } \\
\text { A total of } 2820 \mathrm{~m} \\
\text { deposited from } 1692 \\
\text { to } 1459 \mathrm{Ma} \text {. }\end{array}$ & $\begin{array}{l}20-30 \\
30-40 \\
40-50 \\
50-60 \\
60-70 \\
70-80 \\
80-90 \\
90-100 \\
100-110\end{array}$ & $\begin{array}{r}0.81 \\
0.81 \\
21.16 \\
38.49 \\
38.49 \\
38.49 \\
38.49 \\
38.49 \\
27.71\end{array}$ & $\begin{array}{l}0.0039 \\
0.0078 \\
0.0156 \\
0.0313 \\
0.0625 \\
0.125 \\
0.25 \\
0.5 \\
1\end{array}$ & $\begin{array}{r}0.00 \\
0.01 \\
0.33 \\
1.20 \\
2.41 \\
4.81 \\
9.62 \\
19.25 \\
27.71\end{array}$ & $\begin{array}{r}0.00 \\
0.01 \\
0.34 \\
1.54 \\
3.95 \\
8.76 \\
18.38 \\
37.63 \\
65.34\end{array}$ \\
\hline $\begin{array}{l}\text { Erosion from } \\
1459-1449 \mathrm{Ma} \\
\text { of } 1805 \mathrm{~m} .\end{array}$ & $\begin{array}{l}100-110 \\
90-100 \\
80-90 \\
70-80 \\
60-70 \\
50-60\end{array}$ & $\begin{array}{l}0.85 \\
1.84 \\
1.84 \\
1.84 \\
1.84 \\
0.08\end{array}$ & $\begin{array}{l}1 \\
0.5 \\
0.25 \\
0.125 \\
0.0625 \\
0.0313\end{array}$ & $\begin{array}{l}0.85 \\
0.92 \\
0.46 \\
0.23 \\
0.12 \\
0.00\end{array}$ & $\begin{array}{l}66.19 \\
67.11 \\
67.57 \\
67.80 \\
67.92 \\
67.92\end{array}$ \\
\hline $\begin{array}{l}\text { Deposition of } 600 \mathrm{~m} \\
\text { Roper Group from } \\
1449 \text { to } 1429 \mathrm{Ma}\end{array}$ & $\begin{array}{l}50-60 \\
60-70\end{array}$ & $\begin{array}{r}10.61 \\
9.39\end{array}$ & $\begin{array}{l}0.0313 \\
0.0625\end{array}$ & $\begin{array}{l}0.33 \\
0.59\end{array}$ & $\begin{array}{l}68.15 \\
68.84\end{array}$ \\
\hline $\begin{array}{l}\text { Erosion to top of } \\
\text { Barney Ck. Fm. from } \\
1429 \text { to } 570 \mathrm{Ma} \text {. }\end{array}$ & $\begin{array}{l}60-70 \\
50-60 \\
40-50\end{array}$ & $\begin{array}{r}302.9 \\
358.39 \\
193.54\end{array}$ & $\begin{array}{l}0.0625 \\
0.0313 \\
0.0156\end{array}$ & $\begin{array}{r}18.93 \\
11.22 \\
3.02\end{array}$ & $\begin{array}{r}87.77 \\
98.99 \\
102.01\end{array}$ \\
\hline $\begin{array}{l}\text { Deposition of } 300 \mathrm{~m} \text { of } \\
\text { Bukalara Sst. from } \\
570 \text { to } 560 \mathrm{Ma} \text {. }\end{array}$ & $\begin{array}{l}40-50 \\
50-60\end{array}$ & $\begin{array}{l}6.00 \\
4.00\end{array}$ & $\begin{array}{l}0.0156 \\
0.0313\end{array}$ & $\begin{array}{l}0.09 \\
0.13\end{array}$ & $\begin{array}{l}102.10 \\
102.23\end{array}$ \\
\hline $\begin{array}{l}\text { Erosion of } 100 \mathrm{~m} \text { of } \\
\text { Bukalara Sst. from } \\
560 \text { to } 510 \mathrm{Ma} \text {. }\end{array}$ & $50-60$ & 50.00 & 0.0313 & 1.57 & 103.79 \\
\hline $\begin{array}{l}\text { Deposition of } 100 \mathrm{~m} \text { of } \\
\text { Top Springs Lmst. } \\
\text { from } 510-508 \mathrm{Ma} .\end{array}$ & $50-60$ & 2.00 & 0.0313 & 0.06 & 103.85 \\
\hline $\begin{array}{l}\text { Erosion of Top Springs } \\
\text { Lmst. and Bukalara } \\
\text { Sst. (200m) to Cret. } \\
\text { unconformity from } \\
508 \text { to } 100 \mathrm{Ma} \text {. }\end{array}$ & $\begin{array}{l}50-60 \\
40-50\end{array}$ & $\begin{array}{l}228.57 \\
181.43\end{array}$ & $\begin{array}{l}0.0313 \\
0.0156\end{array}$ & $\begin{array}{l}7.15 \\
2.83\end{array}$ & $\begin{array}{l}111.00 \\
113.83\end{array}$ \\
\hline
\end{tabular}




$\begin{array}{llrlll}\begin{array}{l}\text { Deposition of } 200 \mathrm{~m} \\ \text { of Cretaceous }\end{array} & 40-50 & 4.00 & 0.0156 & 0.06 & 113.89 \\ \begin{array}{l}\text { Mullaman Beds from } \\ 100 \text { to } 90 \mathrm{Ma} \text {. }\end{array} & & 6.00 & 0.0313 & 0.19 & 114.08 \\ & & & & & \\ \text { Erosion from } 90 \mathrm{Ma} & 50-60 & 9.64 & 0.0313 & 0.30 & 114.38 \\ \text { to present. } & 40-50 & 26.79 & 0.0156 & 0.42 & 114.80 \\ & 30-40 & 26.79 & 0.0078 & 0.21 & 115.01 \\ & 20-30 & 26.79 & 0.0039 & 0.10 & 115.11\end{array}$

Rv\% for a total TTI of 115 is 1.2 ;

Price's (1983) method:

maximum burial $=2820 \mathrm{~m}$, maximum temperature $=105^{\circ} \mathrm{C}, \mathrm{Rv} \%=0.5$

Observed equivalent Rv\% for near the base of the Barney Creek Fm. in the Glyde River Subbasin (DDH GR7 at $854 \mathrm{~m})=1.0$.

Appendix M14. Calculations following Waples' (1981) method and Price's (1983) method, assuming a constant geothermal gradient of $30 \mathrm{C}^{\circ} / \mathrm{km}$ with a zero intercept of $20^{\circ} \mathrm{C}$. Near base of DDH GR7, Barney Creek Formation, Glyde River Subbasin, depositionalerosional model $7 \mathrm{~b}$. 


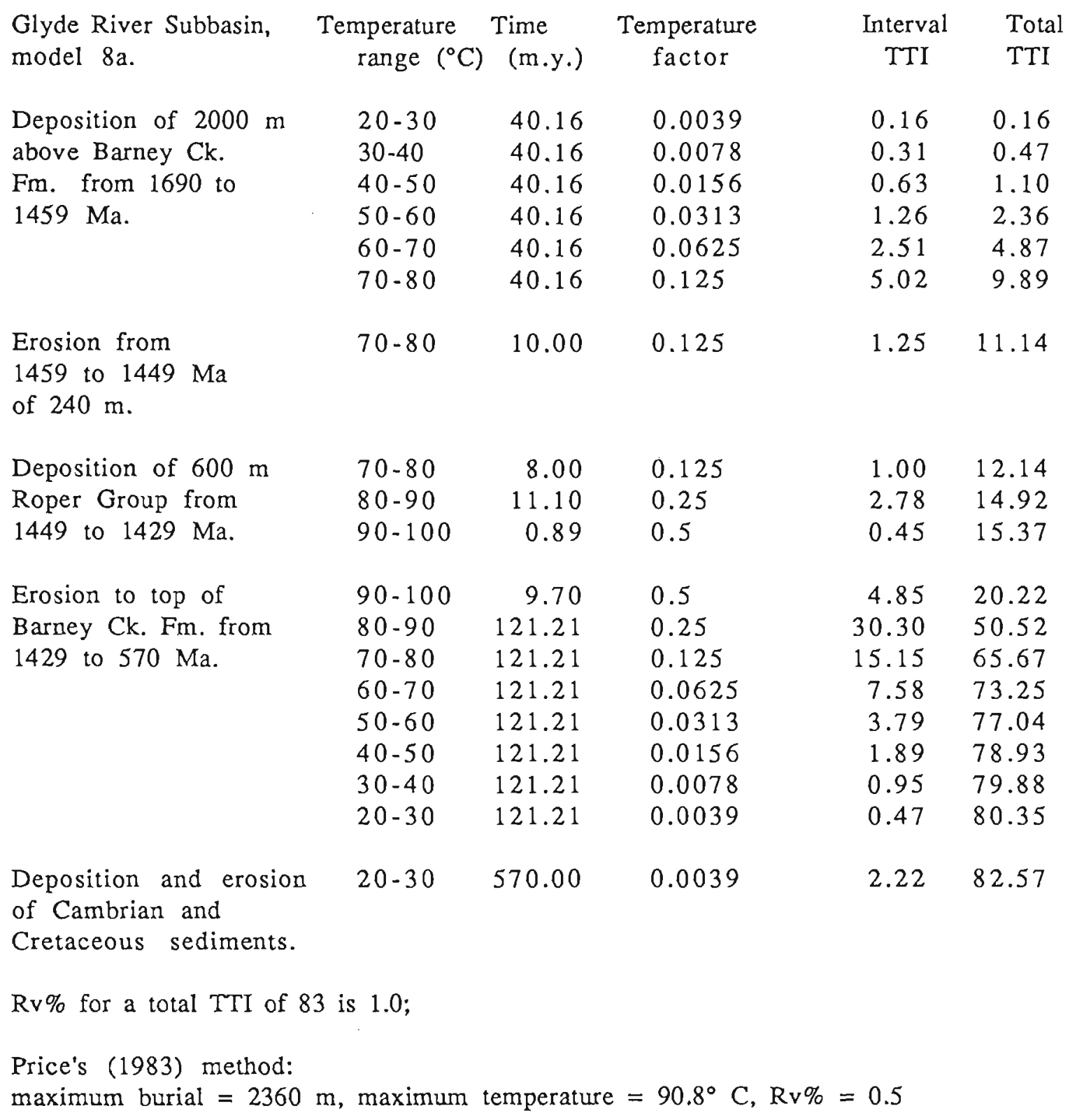

Observed equivalent Rv\% for the top of the Barney Creek Fm. in the Glyde River Subbasin is 0.5 to 0.7 .

Appendix M15. Calculations following Waples' (1981) method and Price's (1983) method, assuming a constant geothermal gradient of $30 \mathrm{C}^{\circ} / \mathrm{km}$ with a zero intercept of $20^{\circ} \mathrm{C}$. Near top of Barney Creek Formation, Glyde River Subbasin, depositional-erosional model 8a. 


\begin{tabular}{|c|c|c|c|c|c|}
\hline $\begin{array}{l}\text { Glyde River Subbasin, } \\
\text { model } 8 \text { b. }\end{array}$ & $\begin{array}{l}\text { Temperature } \\
\text { range }\left({ }^{\circ} \mathrm{C}\right)\end{array}$ & $\begin{array}{l}\text { Time } \\
\text { (m.y.) }\end{array}$ & $\begin{array}{c}\text { Temperature } \\
\text { factor }\end{array}$ & $\begin{array}{l}\text { Interval } \\
\text { TTI }\end{array}$ & $\begin{array}{r}\text { Total } \\
\text { TTI }\end{array}$ \\
\hline Deposition of $2000 \mathrm{~m}$ & $20-30$ & 0.81 & 0.0039 & 0.00 & 0.00 \\
\hline above Barney Ck. Fm. & $30-40$ & 0.81 & 0.0078 & 0.01 & 0.01 \\
\hline deposited over $231 \mathrm{my}$ & $40-50$ & 21.16 & 0.0156 & 0.33 & 0.34 \\
\hline plus $820 \mathrm{~m}$ of & $50-60$ & 38.49 & 0.0313 & 1.20 & 1.54 \\
\hline Barney Ck. Fm. & $60-70$ & 38.49 & 0.0625 & 2.41 & 3.95 \\
\hline deposited over 2 my. & $70-80$ & 38.49 & 0.125 & 4.81 & 8.76 \\
\hline A total of $2820 \mathrm{~m}$ & $80-90$ & 38.49 & 0.25 & 9.62 & 18.38 \\
\hline deposited from 1692 & $90-100$ & 38.49 & 0.5 & 19.25 & 37.63 \\
\hline to $1459 \mathrm{Ma}$. & $100-110$ & 27.71 & 1 & 27.71 & 65.34 \\
\hline Erosion from & $100-110$ & 6.39 & 1 & 6.39 & 71.73 \\
\hline $\begin{array}{l}1459-1449 \mathrm{Ma} \\
\text { of } 240 \mathrm{~m} .\end{array}$ & $90-100$ & 3.61 & 0.5 & 1.81 & 73.53 \\
\hline Deposition of $600 \mathrm{~m}$ & $90-100$ & 2.89 & 0.5 & 1.45 & 74.98 \\
\hline Roper Group from & $100-110$ & 11.11 & 1 & 11.11 & 86.09 \\
\hline 1449 to $1429 \mathrm{Ma}$ & $110-120$ & 6.00 & 2 & 12.00 & 98.09 \\
\hline Erosion to top of & $110-120$ & 65.45 & 2 & 130.90 & 228.99 \\
\hline Barney Ck. Fm. from & $100-110$ & 121.21 & 1 & 121.21 & 350.20 \\
\hline 1429 to $570 \mathrm{Ma}$. & $90-100$ & 121.21 & 0.5 & 60.61 & 410.80 \\
\hline & $80-90$ & 121.21 & 0.25 & 30.30 & 441.10 \\
\hline & $70-80$ & 121.21 & 0.125 & 15.15 & 456.25 \\
\hline & $60-70$ & 121.21 & 0.0625 & 7.58 & 463.83 \\
\hline & $50-60$ & 121.21 & 0.0313 & 3.79 & 467.62 \\
\hline & $40-50$ & 65.45 & 0.0156 & 1.02 & 468.64 \\
\hline Deposition of $300 \mathrm{~m}$ of & $40-50$ & 6.00 & 0.0156 & 0.09 & 468.73 \\
\hline $\begin{array}{l}\text { Bukalara Sst. from } \\
570-560 \text { Ma. }\end{array}$ & $50-60$ & 4.00 & 0.0313 & 0.13 & 468.86 \\
\hline $\begin{array}{l}\text { Erosion of } 100 \mathrm{~m} \text { of } \\
\text { Bukalara Sst. from } \\
560 \text { to } 510 \mathrm{Ma} \text {. }\end{array}$ & $50-60$ & 50.00 & 0.0313 & 1.57 & 470.42 \\
\hline $\begin{array}{l}\text { Deposition of } 100 \mathrm{~m} \text { of } \\
\text { Top Springs Lmst. } \\
\text { from } 510 \text { to } 508 \mathrm{Ma} \text {. }\end{array}$ & $50-60$ & 2.00 & 0.0313 & 0.06 & 470.48 \\
\hline $\begin{array}{l}\text { Erosion of Top Springs } \\
\text {-mst. and Bukalara }\end{array}$ & $\begin{array}{l}50-60 \\
40-50\end{array}$ & $\begin{array}{l}228.57 \\
181.43\end{array}$ & $\begin{array}{l}0.0313 \\
0.0156\end{array}$ & $\begin{array}{l}7.15 \\
2.83\end{array}$ & $\begin{array}{l}477.63 \\
480.46\end{array}$ \\
\hline
\end{tabular}

Sst. (200m) to Cret. unconformity from 508 to $100 \mathrm{Ma}$. 


\begin{tabular}{|c|c|c|c|c|c|}
\hline $\begin{array}{l}\text { Deposition of } 200 \mathrm{~m} \\
\text { of Cretaceous } \\
\text { Mullaman Beds from } \\
100 \text { to } 90 \mathrm{Ma} \text {. }\end{array}$ & $\begin{array}{l}40-50 \\
50-60\end{array}$ & $\begin{array}{l}4.00 \\
6.00\end{array}$ & $\begin{array}{l}0.0156 \\
0.0313\end{array}$ & $\begin{array}{l}0.06 \\
0.19\end{array}$ & $\begin{array}{l}480.52 \\
480.71\end{array}$ \\
\hline $\begin{array}{l}\text { Erosion from } 90 \mathrm{Ma} \\
\text { to present. }\end{array}$ & $\begin{array}{l}50-60 \\
40-50 \\
30-40 \\
20-30\end{array}$ & $\begin{array}{r}9.64 \\
26.79 \\
26.79 \\
26.79\end{array}$ & $\begin{array}{l}0.0313 \\
0.0156 \\
0.0078 \\
0.0039\end{array}$ & $\begin{array}{l}0.30 \\
0.42 \\
0.21 \\
0.10\end{array}$ & $\begin{array}{l}481.01 \\
481.43 \\
481.64 \\
481.74\end{array}$ \\
\hline
\end{tabular}

Rv\% for a total TTI of 481 is 1.7 ;

Price's (1983) method:

maximum burial $=3180 \mathrm{~m}$, maximum temperature $=115^{\circ} \mathrm{C}, \mathrm{Rv} \%=0.6$

Observed equivalent Rv\% for near the base of the Barney Creek Fm. in the Glyde River Subbasin (DDH GR7 at $854 \mathrm{~m})=1.0$.

Appendix M16. Calculations following Waples' (1981) method and Price's (1983) method, assuming a constant geothermal gradient of $30 \mathrm{C}^{\circ} / \mathrm{km}$ with a zero intercept of $20^{\circ} \mathrm{C}$. Near base of DDH GR7, Barney Creek Formation, Glyde River Subbasin, depositionalerosional model $8 b$. 
BROADMERE 1, base of well, Mainoru Formation.

Deposition from 1529 to $1429 \mathrm{Ma}$ of $2174 \mathrm{~m}$ observed thickness of Roper Group at Broadmere 1 plus an additional estimated $1548 \mathrm{~m}$ of Maiwok Sub-Group.

\begin{abstract}
Erosion of an estimated $500 \mathrm{~m}$ of Roper Group from 1429-1280 Ma.

Intrusion of a total of $300 \mathrm{~m}$ of dolerite sills at $1280 \mathrm{Ma}$ followed by erosion of $1248 \mathrm{~m}$ of Roper Group to 570 Ma.
\end{abstract}

Deposition of $300 \mathrm{~m}$ of Bukalara

Sandstone from 570 to $560 \mathrm{Ma}$.

Erosion of Bukalara Sandstone of $100 \mathrm{~m}$ from 560 to $510 \mathrm{Ma}$.

Deposition of $100 \mathrm{~m}$ of Top Springs Limestone from 510 to $508 \mathrm{Ma}$.

Erosion of Top Springs Limestone
Bukalara Sandstone and Roper Group
of $370 \mathrm{~m}$ from 508 to $100 \mathrm{Ma}$
(present top of well is $30 \mathrm{~m}$ below
the Cretaceous unconformity).

Deposition of $200 \mathrm{~m}$ of Cretaceous Mullaman Beds from 100 to $90 \mathrm{Ma}$.

Erosion of $200 \mathrm{~m}$ of Mullaman Beds and $30 \mathrm{~m}$ of Roper Group from 90 Ma to present.

$\begin{array}{cc}\begin{array}{c}\text { Temperature } \\ \text { Interval }\left({ }^{\circ} \mathrm{C}\right)\end{array} & \begin{array}{c}\text { Time } \\ (\mathrm{my})\end{array} \\ 20-30 & 8.95 \\ 30-40 & 8.95 \\ 40-50 & 8.95 \\ 50-60 & 8.95 \\ 60-70 & 8.95 \\ 70-80 & 8.95 \\ 80-90 & 8.95 \\ 90-100 & 8.95 \\ 100-110 & 8.95 \\ 110-120 & 8.95 \\ 120-130 & 8.95 \\ 130-140 & 1.48\end{array}$

$130-140$

16.37

99.21

32.58

$\begin{array}{cc}130-120 & 159.09 \\ 120-110 & 189.39 \\ 110-100 & 189.39 \\ 100-90 & 189.39 \\ 90-80 & 57.17\end{array}$

$\begin{array}{cc}80-90 & 1.14 \\ 90-100 & 8.86\end{array}$

$90-100$

50.00

$90-100$

2.00

$90-100$

219.01

188.99

0.50

109.55

47.25

0.0039
0.0078
0.0156
0.0313
0.0625
0.125
0.25
0.5
1
2
4
8

0.03

0.07

0.14

0.28

0.56

1.12

2.24

4.48

8.95

17.90

35.80

11.84

130.96

396.84

65.16

14.37

611.21

676.37

636.36

1312.73

378.78

189.39

1691.51

1880.90

$94.70 \quad 1975.60$

$14.29 \quad 1989.89$

$0.29 \quad 1990.18$

$4.43 \quad 1994.61$

$25.00 \quad 2019.61$

1.00

2020.61

2130.16

2177.41

TTI of $2258=2.4 \mathrm{Rv} \%$;

Price's (1983) method: maximum burial $=3722 \mathrm{~m}$; maximum temperature $=132^{\circ} \mathrm{C}$; $\mathrm{Rv} \%=0.6$. Observed equivalent $\mathrm{Rv}$ near base of well $=3.5 \%$.

Appendix M17. Calculations following Waples' (1981) method and Price's (1983) method, assuming a constant geothermal gradient of $30 \mathrm{C} / \mathrm{km}$ with a zero intercept of $20^{\circ} \mathrm{C}$. Mainoru Formation, Roper Group, Broadmere 1 well, depositional-erosional model 1. 
BROADMERE 1, base of well, Mainoru Formation.

Deposition from 1449 to $1429 \mathrm{Ma}$ of $2174 \mathrm{~m}$ observed thickness of Roper Group at Broadmere 1 plus an additional estimated $1548 \mathrm{~m}$ of Maiwok Sub-Group.

$\begin{array}{cc}\begin{array}{c}\text { Temperature } \\ \text { range }\left({ }^{\circ} \mathrm{C}\right)\end{array} & \begin{array}{c}\text { Time } \\ \text { (m.y. }\end{array} \\ & \\ 20-30 & 1.79 \\ 30-40 & 1.79 \\ 40-50 & 1.79 \\ 50-60 & 1.79 \\ 60-70 & 1.79 \\ 70-80 & 1.79 \\ 80-90 & 1.79 \\ 90-100 & 1.79 \\ 100-110 & 1.79 \\ 110-120 & 1.79 \\ 120-130 & 1.79 \\ 130-140 & 0.30\end{array}$

\section{Erosion of an estimated $500 \mathrm{~m}$ \\ of Roper Group from 1429-1280 \\ Intrusion of a total of $300 \mathrm{~m}$ of dolerite sills at $1280 \mathrm{Ma}$ \\ followed by erosion of $1248 \mathrm{~m}$ of Roper Group to $570 \mathrm{Ma}$.}

$130-140$

16.37

Ma. 120

99.21

32.58

$\begin{array}{cc}130-120 & 159.09 \\ 120-110 & 189.39 \\ 110-100 & 189.39 \\ 100-90 & 189.39 \\ 90-80 & 57.17\end{array}$

Deposition of $300 \mathrm{~m}$ of Bukalara

Sandstone from 570 to $560 \mathrm{Ma}$.

Erosion of Bukalara Sandstone of $100 \mathrm{~m}$ from 560 to $510 \mathrm{Ma}$.

Deposition of $100 \mathrm{~m}$ of Top Springs 90-100 Limestone from 510 to $508 \mathrm{Ma}$.

Erosion of Top Springs Limestone Bukalara Sandstone and Roper Group of $370 \mathrm{~m}$ from 508 to $100 \mathrm{Ma}$ (present top of well is $30 \mathrm{~m}$ below the Cretaceous unconformity).

\section{Deposition of $200 \mathrm{~m}$ of Cretaceous} Mullaman Beds from 100 to $90 \mathrm{Ma}$.

Erosion of $200 \mathrm{~m}$ of Mullaman Beds and $30 \mathrm{~m}$ of Roper Group from 90 Ma to present.

$90-100 \quad 50.00$

2.00

$\begin{array}{ccccc}80-90 & 6.47 & 0.25 & 1.62 & 2112.54 \\ 90-100 & 3.53 & 0.50 & 1.77 & 2114.31 \\ & & & & \\ 90-100 & 70.7 & 0.50 & 35.35 & 2149.66 \\ 80-90 & 129.3 & 0.25 & 42.33 & 2191.99\end{array}$

$\begin{array}{ccc}0.0039 & 0.01 & 0.01 \\ 0.0078 & 0.01 & 0.02 \\ 0.0156 & 0.03 & 0.05 \\ 0.0313 & 0.06 & 0.11 \\ 0.0625 & 0.11 & 0.22 \\ 0.125 & 0.22 & 0.44 \\ 0.25 & 0.45 & 0.89 \\ 0.5 & 0.90 & 1.79 \\ 1 & 1.79 & 3.58 \\ 2 & 3.58 & 7.16 \\ 4 & 7.16 & 14.32 \\ 8 & 2.40 & 16.72\end{array}$

$130.96 \quad 147.68$

$396.84 \quad 544.52$

$65.16 \quad 609.68$

$636.36 \quad 1246.04$

$378.78 \quad 1624.82$

$189.39 \quad 1814.21$

$94.70 \quad 1908.91$

$14.29 \quad 1923.20$

$\begin{array}{ccccc}80-90 & 1.14 & 0.25 & 0.29 & 1923.69 \\ 90-100 & 8.86 & 0.5 & 4.43 & 1928.12\end{array}$

0.5

25.00

1953.12

0.5

1.00

1954.12

109.55

2063.67

$\begin{array}{lll}0.50 & 109.55 & 2063.67 \\ 0.25 & 47.25 & 2110.92\end{array}$

0.25

47.25

TTI of $2191=2.4 \mathrm{Rv} \%$;

Price's (1983) method: maximum burial $=3722 \mathrm{~m}$; maximum temperature $=132^{\circ} \mathrm{C}$; $\mathrm{Rv} \%=0.6$. Observed equivalent $\mathrm{Rv}$ near base of well $=3.5 \%$.

Appendix M18. Calculations following Waples' (1981) method and Price's (1983) method, assuming a constant geothermal gradient of $30 \mathrm{C} / \mathrm{km}$ with a zero intercept of $20^{\circ} \mathrm{C}$. Mainoru Formation, Roper Group, Broadmere 1 well, depositional-erosional model 2. 
BROADMERE 1, base of

Cobanbarini Fm.

Deposition from 1439.74 to 1429

$\mathrm{Ma}$ of $452 \mathrm{~m}$ observed thickness

Cobanbarini Fm. plus

an additional estimated $1548 \mathrm{~m}$

of Maiwok Sub-Group.

Erosion of an estimated $500 \mathrm{~m}$

of Roper Group from 1429-1280 Ma.

Intrusion of a total of $126 \mathrm{~m}$ of

dolerite sills at $1280 \mathrm{Ma}$

followed by erosion of $1248 \mathrm{~m}$

of Roper Group to $570 \mathrm{Ma}$.

Deposition of $300 \mathrm{~m}$ of Bukalara

Sandstone from 570 to $560 \mathrm{Ma}$.

Erosion of Bukalara Sandstone of

$100 \mathrm{~m}$ from 560 to $510 \mathrm{Ma}$.

Deposition of $100 \mathrm{~m}$ of Top Springs

Limestone from 510 to $508 \mathrm{Ma}$.

Erosion of Top Springs Limestone

Bukalara Sandstone and Roper Group

of $370 \mathrm{~m}$ from 508 to $100 \mathrm{Ma}$

(present top of well is $30 \mathrm{~m}$ below

the Cretaceous unconformity).

\section{Deposition of $200 \mathrm{~m}$ of Cretaceous}

Mullaman Beds from 100 to $90 \mathrm{Ma}$.

Erosion of $200 \mathrm{~m}$ of Mullaman Beds

and $30 \mathrm{~m}$ of Roper Group from

$90 \mathrm{Ma}$ to present.

$\begin{array}{ccccc}\text { Temperature } & \text { Time } & \text { Temperature } & \text { Interval } & \text { Total } \\ \text { range }\left({ }^{\circ} \mathrm{C}\right) & \text { (m.y.) } & \text { factor } & \text { TTI } & \text { TTI }\end{array}$

$\begin{array}{lllll}20-30 & 1.79 & 0.0039 & 0.01 & 0.01 \\ 30-40 & 1.79 & 0.0078 & 0.01 & 0.02 \\ 40-50 & 1.79 & 0.0156 & 0.03 & 0.05 \\ 50-60 & 1.79 & 0.0313 & 0.06 & 0.11 \\ 60-70 & 1.79 & 0.0625 & 0.11 & 0.22 \\ 70-80 & 1.79 & 0.125 & 0.22 & 0.44\end{array}$

$\begin{array}{lllll}80-70 & 99.21 & 0.125 & 12.40 & 12.84\end{array}$

$\begin{array}{lllll}70-60 & 49.79 & 0.0625 & 3.11 & 15.95\end{array}$

$\begin{array}{ccccc}70-60 & 192.76 & 0.0625 & 12.05 & 28.00 \\ 60-50 & 219.30 & 0.0313 & 6.86 & 34.86 \\ 50-40 & 219.30 & 0.0156 & 3.42 & 38.18 \\ 40-30 & 78.64 & 0.0078 & 0.61 & 38.79\end{array}$

$\begin{array}{lllll}30-40 & 3.95 & 0.0078 & 0.03 & 38.82\end{array}$

$\begin{array}{lllll}40-50 & 6.05 & 0.0156 & 0.09 & 38.91\end{array}$

$\begin{array}{lllll}40-50 & 50.00 & 0.0156 & 0.78 & 39.69\end{array}$

$\begin{array}{lllll}40-50 & 2.00 & 0.0156 & 0.03 & 39.72\end{array}$

$\begin{array}{lllll}40-50 & 199.30 & 0.0156 & 3.11 & 42.83\end{array}$

$\begin{array}{lllll}30-40 & 208.70 & 0.0078 & 1.63 & 44.46\end{array}$

$\begin{array}{ccccc}30-40 & 9.43 & 0.0078 & 0.07 & 44.53 \\ 40-50 & 0.57 & 0.0156 & 0.01 & 44.54 \\ 40-50 & 4.45 & 0.0156 & 0.07 & 44.61 \\ 30-40 & 85.55 & 0.0078 & 0.67 & 45.28\end{array}$

TTI of $45=0.9$ Rv\%;

Price's (1983) method: maximum burial $=2000 \mathrm{~m}$; maximum temperature $=80^{\circ} \mathrm{C}$; $\mathrm{Rv} \%=0.5$. Observed equivalent $\mathrm{Rv}$ at the base of the Cobanbarini Fm. $=1.4 \%$.

Appendix M19. Calculations following Waples' (1981) method and Price's (1983) method, assuming a constant geothermal gradient of $30 \mathrm{C}^{\circ} / \mathrm{km}$ with a zero intercept of $20^{\circ} \mathrm{C}$. Cobanbarini Formation, Roper Group, Broadmere 1 well, depositional-erosional model 3. 
BROADMERE 1, base of

Cobanbarini Fm.

Deposition from 1439.74 to 1429

$\mathrm{Ma}$ of $452 \mathrm{~m}$ observed thickness

Cobanbarini Fm. plus

an additional estimated $2548 \mathrm{~m}$

of Maiwok Sub-Group

Erosion of an estimated $500 \mathrm{~m}$

of Roper Group from 1429-1280 Ma.

Intrusion of a total of $126 \mathrm{~m}$ of

dolerite sills at $1280 \mathrm{Ma}$

followed by erosion of $1248 \mathrm{~m}$

of Roper Group to $570 \mathrm{Ma}$.

Deposition of $300 \mathrm{~m}$ of Bukalara

Sandstone from 570 to $560 \mathrm{Ma}$.

Erosion of Bukalara Sandstone of

$100 \mathrm{~m}$ from 560 to $510 \mathrm{Ma}$.

Deposition of $100 \mathrm{~m}$ of Top Springs
Limestone from 510 to $508 \mathrm{Ma}$.

Erosion of Top Springs Limestone

Bukalara Sandstone and Roper Group

from 508 to $100 \mathrm{Ma}$ to $482 \mathrm{~m}$

(present top of well is $30 \mathrm{~m}$ below

the Cretaceous unconformity.)

Deposition of $200 \mathrm{~m}$ of Cretaceous

Mullaman Beds from 100 to $90 \mathrm{Ma}$.

Erosion of $200 \mathrm{~m}$ of Mullaman Beds

and $30 \mathrm{~m}$ of Roper Group from

$90 \mathrm{Ma}$ to present.
$60-70$

Temperature range $\left({ }^{\circ} \mathrm{C}\right)$

$$
\begin{gathered}
20-30 \\
30-40 \\
40-50 \\
50-60 \\
60-70 \\
70-80 \\
80-90 \\
90-100 \\
100-110
\end{gathered}
$$

$110-100$

$100-90$

$100-90$

$90-80$

$80-70$

$70-60$

$60-70$

$70-60$

50.00

2.00

99.21

49.79

192.76

219.30

219.30

78.64

10.00

0.0625

0.0625

3.13

0.13

0.0625

114.94

0.0625

7.18

3.59

1.79

0.50

63.98

0.0156

$40-30$

$30-40$

40-50

$40-50$

$30-40$

114.94

0.0313

0.0078

9.43

0.0078

0.57

0.0156

0.07

0.01

4.45

0.0156

85.55

0.0078

0.07

0.67

349.57

349.65

350.32

TTI of $350=1.6 \mathrm{Rv} \%$;

Price's (1983) method: maximum burial $=3000 \mathrm{~m}$; maximum temperature $=110^{\circ} \mathrm{C}$; $\mathrm{Rv} \%=0.6$. Observed equivalent $\mathrm{Rv}$ at the base of the Cobanbarini Fm. $=1.4 \%$.

Appendix M20. Calculations following Waples' (1981) method and Price's (1983) method, assuming a constant geothermal gradient of $30 \mathrm{C}^{\circ} / \mathrm{km}$ with a zero intercept of $20^{\circ} \mathrm{C}$. Cobanbarini Formation, Roper Group, Broadmere 1 well, depositional-erosional model 4. 


\section{APPENDIX N}

\section{ROCK-EVAL AND ORGANIC CARBON ANALYSES}

\section{Abbreviations:}

$\mathrm{S} 1=$ free hydrocarbons released on heating to $300^{\circ} \mathrm{C}$

$\mathrm{S} 2$ = hydrocarbons released on pyrolysis

S3 = carbon dioxide released on pyrolysis

Tmax = temperature of maximum release of hydrocarbons

released on pyrolysis

$\mathrm{PI}=$ Production Index

$\mathrm{HI}=$ Hydrogen Index

$\mathrm{Ol}=$ Oxygen Index

TOC = Total Organic Carbon

Full well and formation names are given in Appendices $A$ and $B$

Note: Wells are organised in this appendix, alphabetically. 


\section{5}

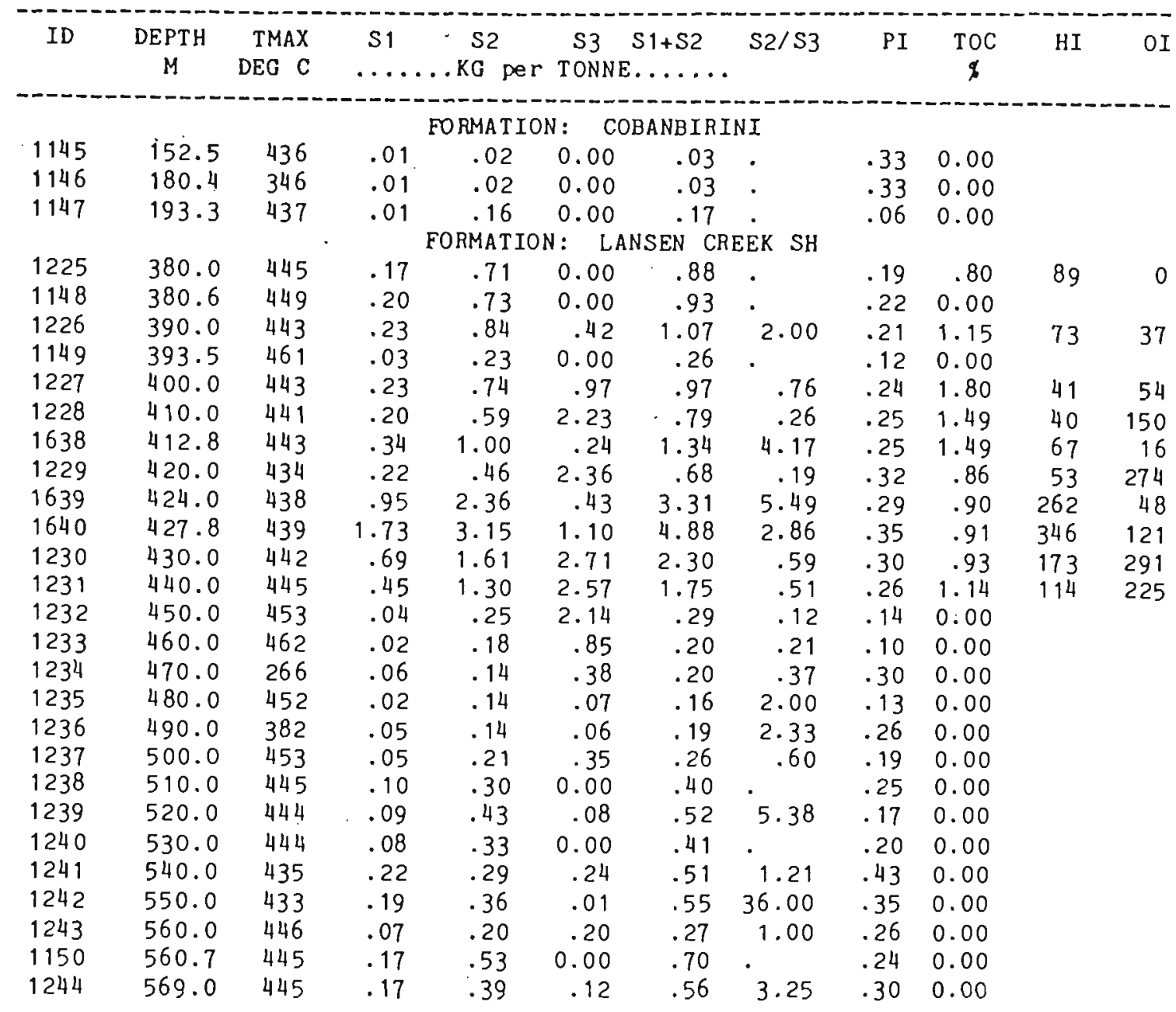

BASIN/AREA : MCARTHUR

WELL/LOCALITY : $\quad 82 / 2$

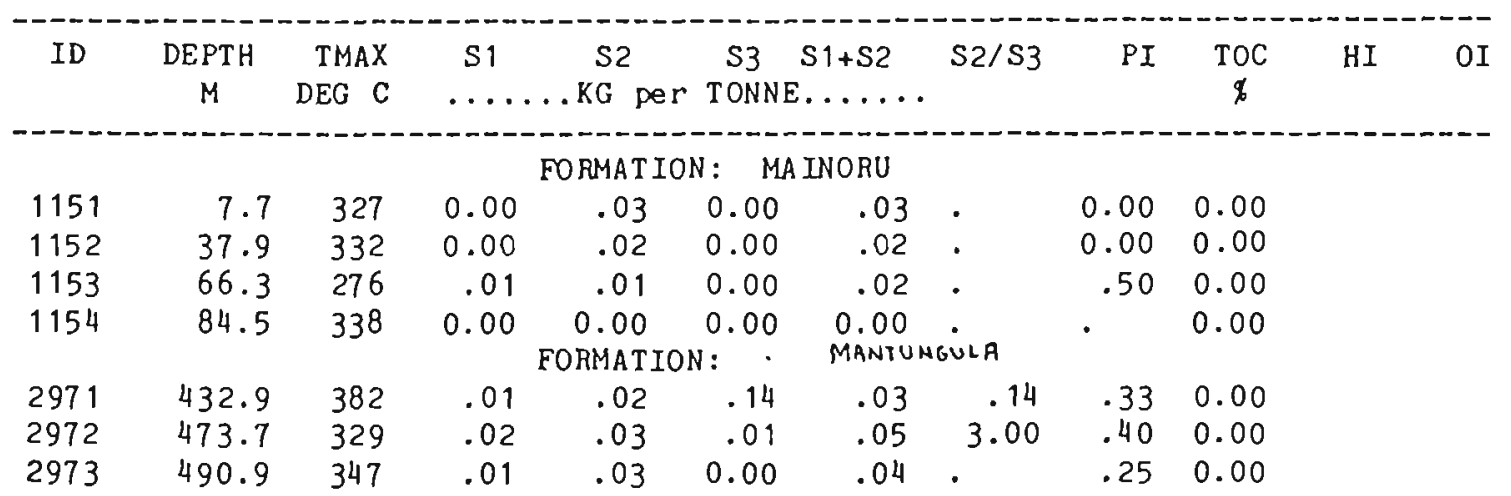


BASIN/AREA: MCARTHUR

WELL/LOCALITY: $\quad 82 / 3$

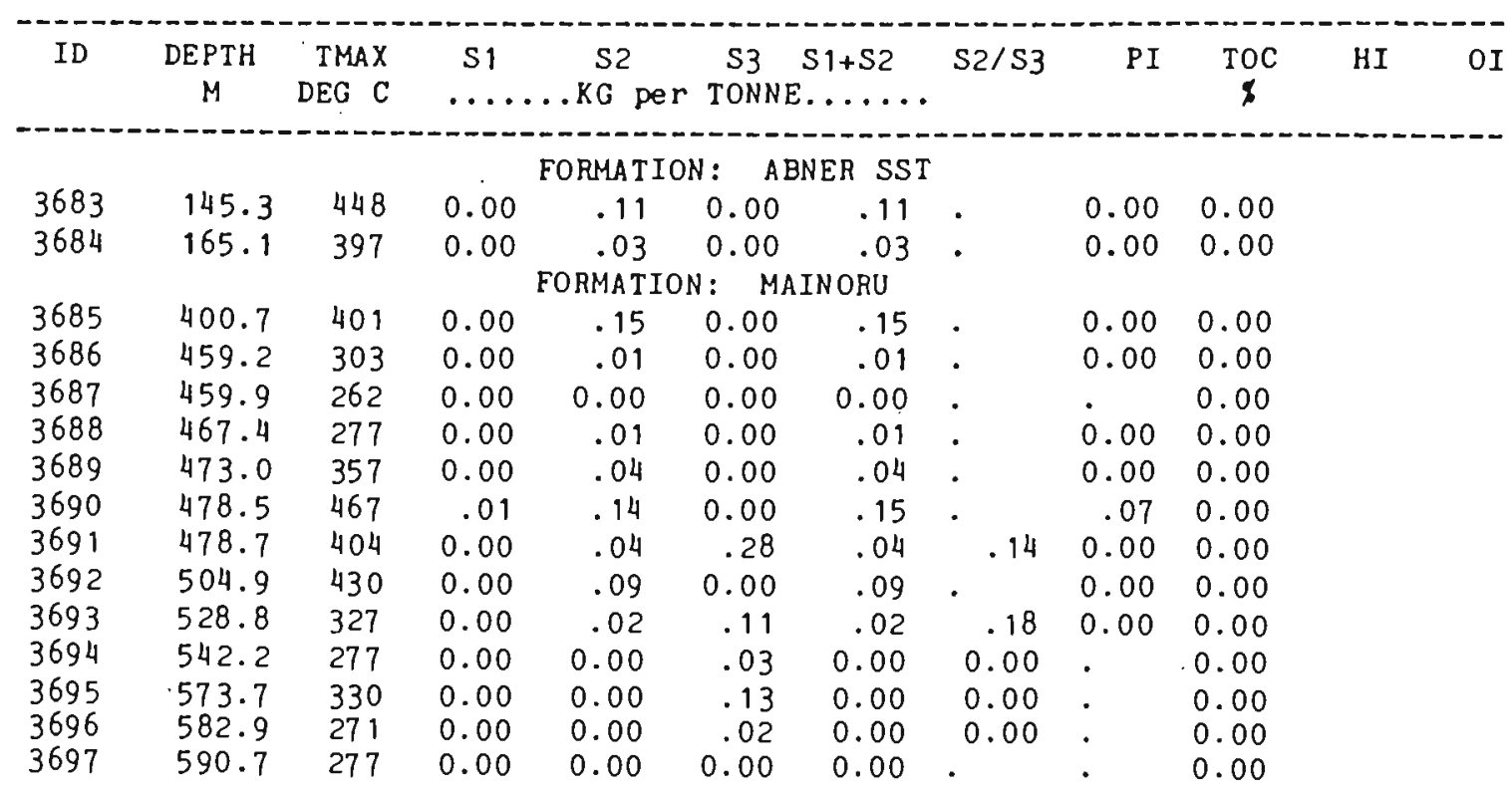

BASIN/AREA : MCARTHUR

WELL/LOCALITY : $\quad 82 / 4$

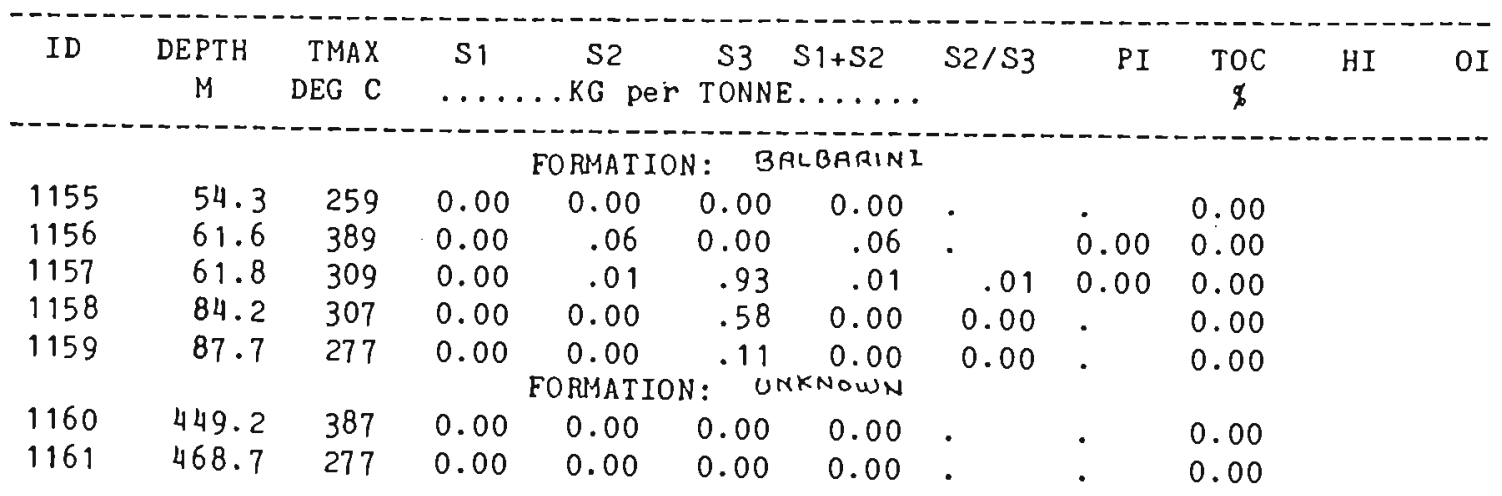




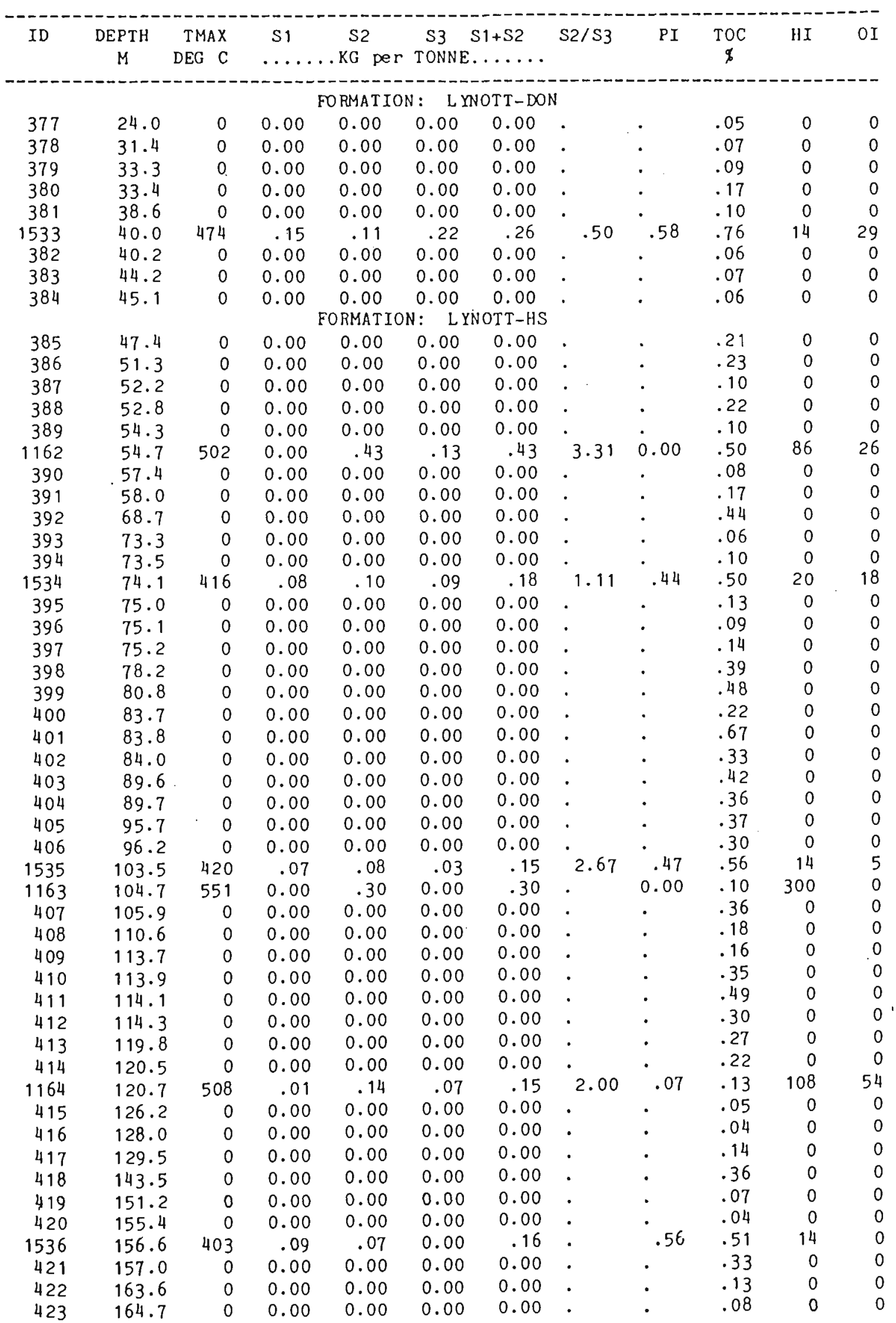




\begin{tabular}{|c|c|c|c|c|c|c|c|c|c|c|c|}
\hline 1538 & 165.3 & 509 & .11 & .09 & .14 & .20 & .64 & .55 & .69 & 13 & 20 \\
\hline 424 & 165.5 & 0 & 0.00 & 0.00 & 0.00 & 0.00 & $\cdot$ & . & 1.46 & 0 & 0 \\
\hline 1165 & 191.7 & 512 & 0.00 & .28 & .01 & .28 & 28.00 & 0.00 & .34 & 82 & 3 \\
\hline 1539 & 316.2 & 427 & .10 & .04 & 0.00 & .14 & . & .71 & .76 & 5 & 0 \\
\hline 1166 & 324.9 & 508 & .01 & .28 & .19 & .29 & 1.47 & .03 & .16 & 175 & 119 \\
\hline 1540 & 382.5 & 261 & 0.00 & 0.00 & 0.00 & 0.00 & . & . & .55 & 0 & 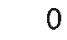 \\
\hline 1167 & 421.9 & 507 & .02 & .19 & .11 & .21 & 1.73 & .10 & .45 & 42 & 24 \\
\hline 1543 & 452.2 & 470 & $.10^{\circ}$ & .04 & .19 & .14 & .21 & .71 & 1.21 & 3 & 16 \\
\hline 1168 & 453.6 & 503 & .02 & .32 & .13 & .34 & 2.46 & .06 & 1.18 & 27 & 11 \\
\hline
\end{tabular}

BASIN/AREA : MCARTHUR

WELL/LOCALITY: $\quad 82 / 6$

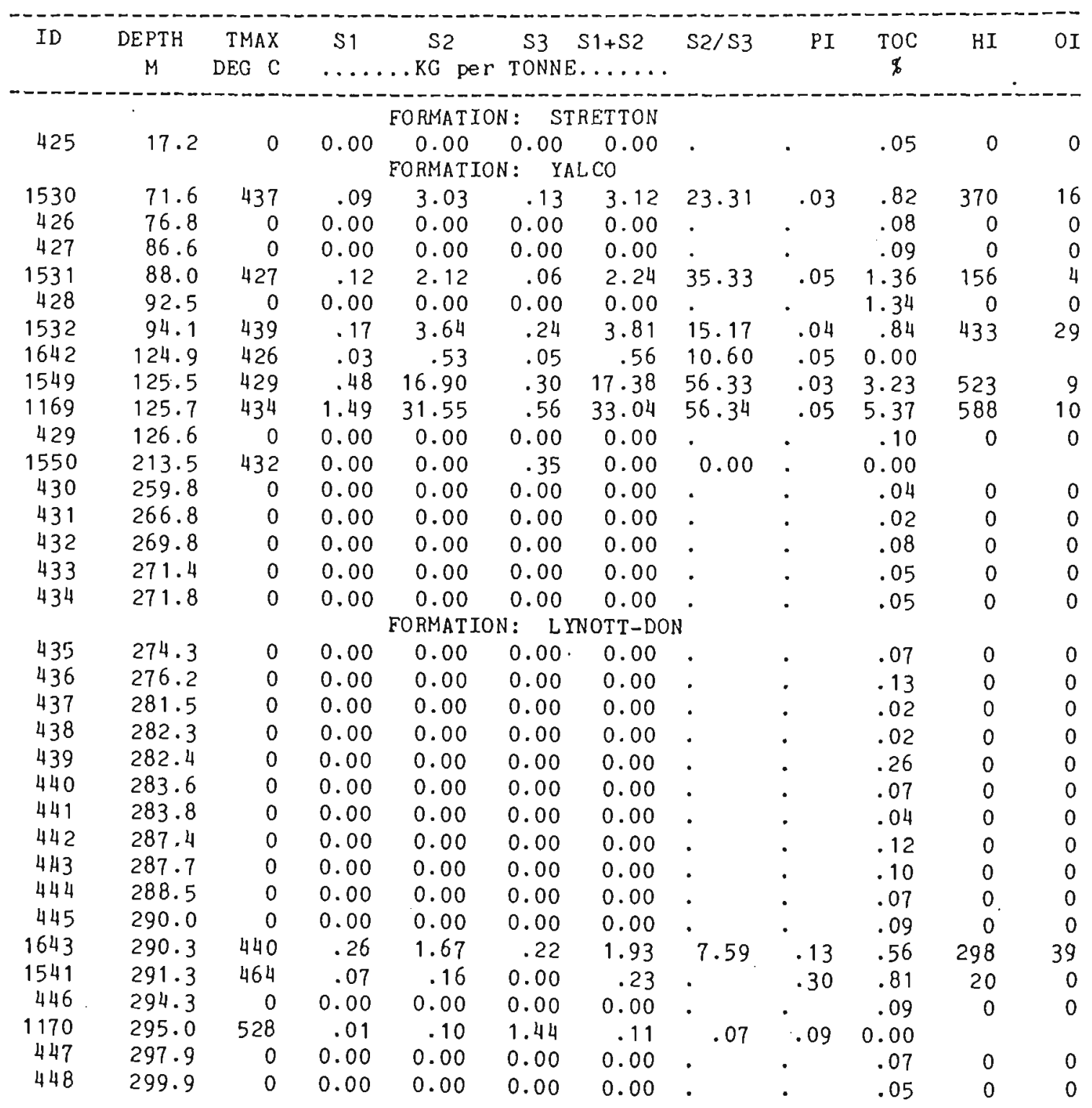




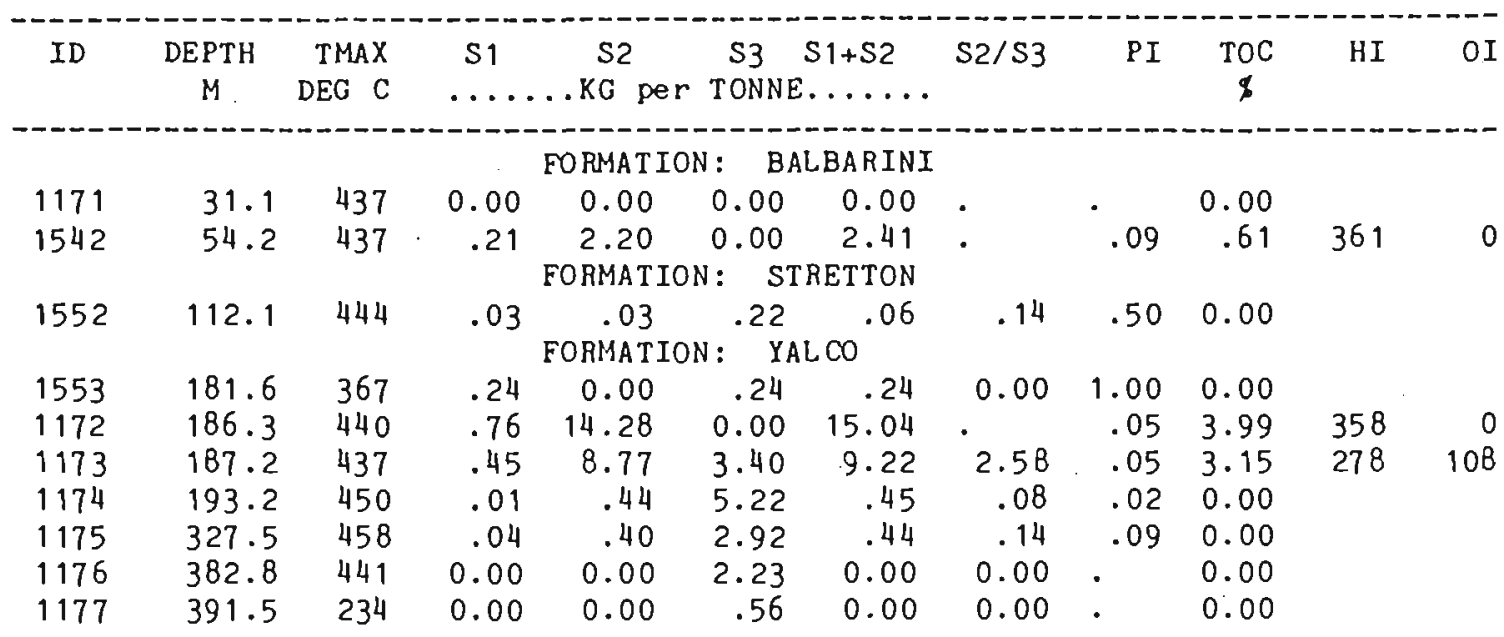

BASIN/AREA: MCARTHUR

WELL/LOCALITY: $\quad 82 / 8$

\begin{tabular}{|c|c|c|c|c|c|c|c|c|c|c|c|}
\hline ID & $\begin{array}{c}\text { DEPTH } \\
M\end{array}$ & $\begin{array}{r}\text { TMAX } \\
\text { DEG C }\end{array}$ & $\begin{array}{c}\text { s1 } \\
\ldots .\end{array}$ & $\begin{array}{c}\mathrm{S} 2 \\
. K G \text { per }\end{array}$ & $\begin{array}{c}\text { S3 } \\
\text { TONNE }\end{array}$ & $\begin{array}{l}s 1+s 2 \\
. \ldots \ldots\end{array}$ & $\mathrm{s} 2 / \mathrm{s} 3$ & PI & $\begin{array}{c}\text { TOC } \\
\not\end{array}$ & $\mathrm{HI}$ & OI \\
\hline & & & & ORMATIOH & & EN CRI & EK SH & & & & \\
\hline 1217 & 30.0 & 439 & .09 & 1.98 & 0.00 & 2.07 & - & .04 & .99 & 200 & 0 \\
\hline 1218 & 40.0 & 439 & 1.03 & .77 & 0.00 & .80 & - & .04 & .58 & 133 & 0 \\
\hline 1219 & 50.0 & 444 & .01 & .03 & 0.00 & .04 & - & .25 & 0.00 & & \\
\hline 1220 & 60.0 & 437 & 0.00 & .06 & .26 & .06 & .23 & 0.00 & 0.00 & & \\
\hline 1641 & 67.4 & 441 & .02 & .32 & 1.00 & .34 & .32 & .06 & .42 & 76 & 238 \\
\hline 1221 & 70.0 & 441 & .01 & .47 & 0.00 & .48 & . & .02 & .42 & 112 & 0 \\
\hline 1222 & 80.0 & 441 & 0.00 & .10 & 0.00 & .10 & - & 0.00 & 0.00 & & \\
\hline 1223 & 90.0 & 441 & .01 & .68 & 0.00 & .69 & - & .01 & .58 & 117 & 0 \\
\hline 1224 & 100.0 & 2 & 0.00 & .53 & 0.00 & .53 & . & 0.00 & .60 & 88 & 0 \\
\hline
\end{tabular}




\begin{tabular}{rrrrrrrrrrrr} 
ID & $\begin{array}{c}\text { DEPTH } \\
M\end{array}$ & TMAX & \multicolumn{1}{c}{ S1 } & S2 & S3 & S1+S2 & S2/S3 & PI & TOC & HI & OI \\
3122 & 17.4 & 439 & 1.28 & .13 .34 & .25 & 14.62 & 53.36 & .09 & 2.96 & 451 & 8 \\
3123 & 22.6 & 440 & .78 & 9.14 & .23 & 9.92 & 39.74 & .08 & 2.11 & 433 & 11 \\
3348 & 22.8 & 440 & .08 & .99 & .39 & 1.07 & 2.54 & .07 & .82 & 121 & 48 \\
3349 & 25.4 & 421 & .41 & 1.55 & .22 & 1.96 & 7.05 & .21 & .30 & 517 & 73 \\
3124 & 33.2 & 438 & .36 & 4.49 & .26 & 4.85 & 17.27 & .07 & 1.83 & 245 & 14 \\
3125 & 38.1 & 458 & .02 & .52 & .23 & .54 & 2.26 & .04 & .75 & 69 & 31 \\
3350 & 40.0 & 464 & .04 & .37 & .66 & .41 & .56 & .10 & .78 & 47 & 85 \\
3351 & 43.4 & 468 & 0.00 & .17 & .48 & .17 & .35 & 0.00 & .64 & 27 & 75 \\
3126 & 50.9 & 466 & .03 & .03 & .06 & .06 & .50 & .50 & 0.00 & & \\
3127 & 59.4 & 436 & .14 & 2.54 & 6.14 & 2.68 & .41 & .05 & 1.06 & 240 & 579 \\
3128 & 64.0 & 436 & .11 & 2.30 & 7.21 & 2.41 & .32 & .05 & 1.11 & 207 & 650 \\
3129 & 68.6 & 440 & .01 & .02 & .01 & .03 & 2.00 & .33 & 0.00 & &
\end{tabular}

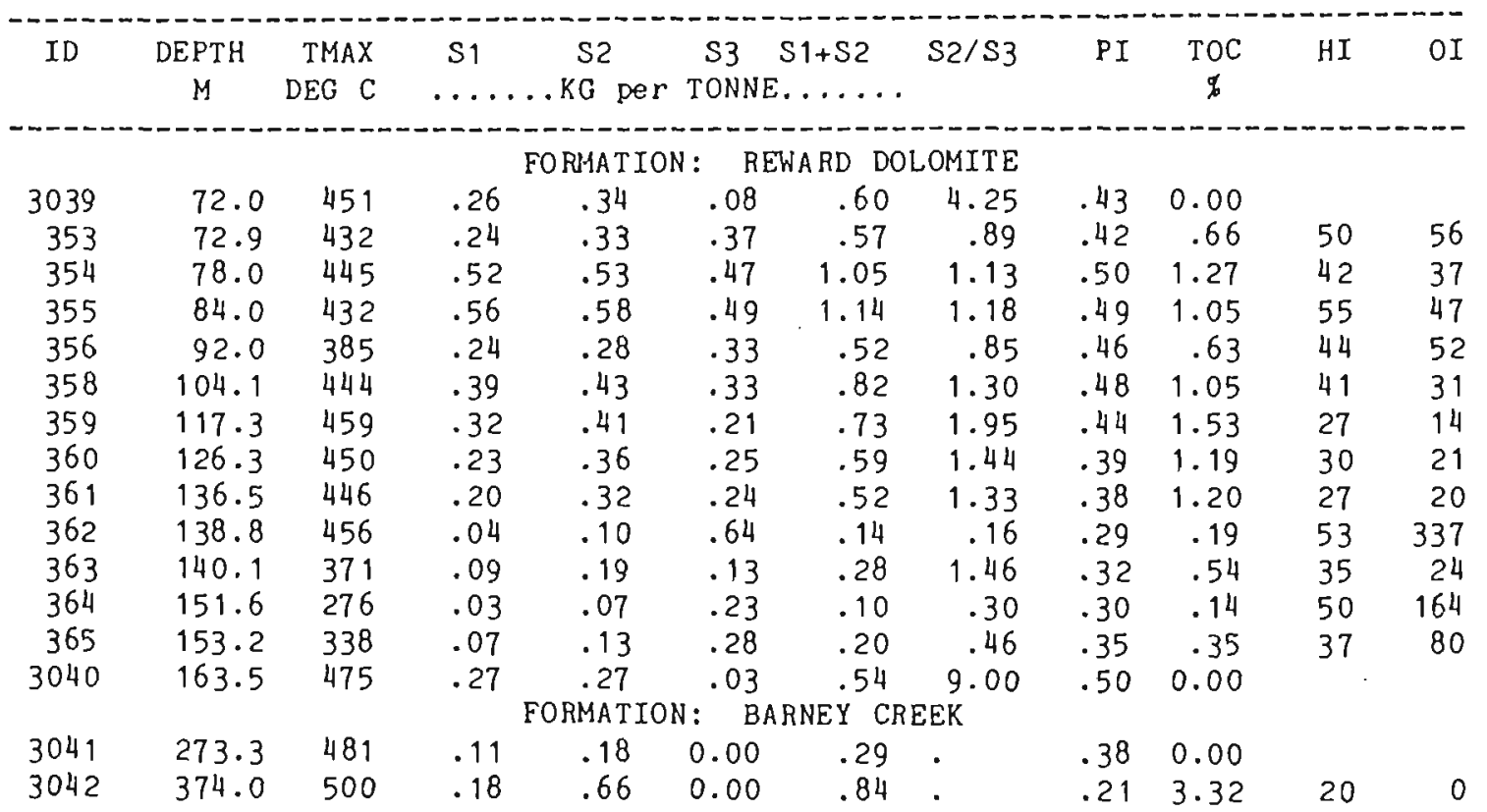


BASIN/AREA: MCARTHUR - WELL/LOCALITY: BB5

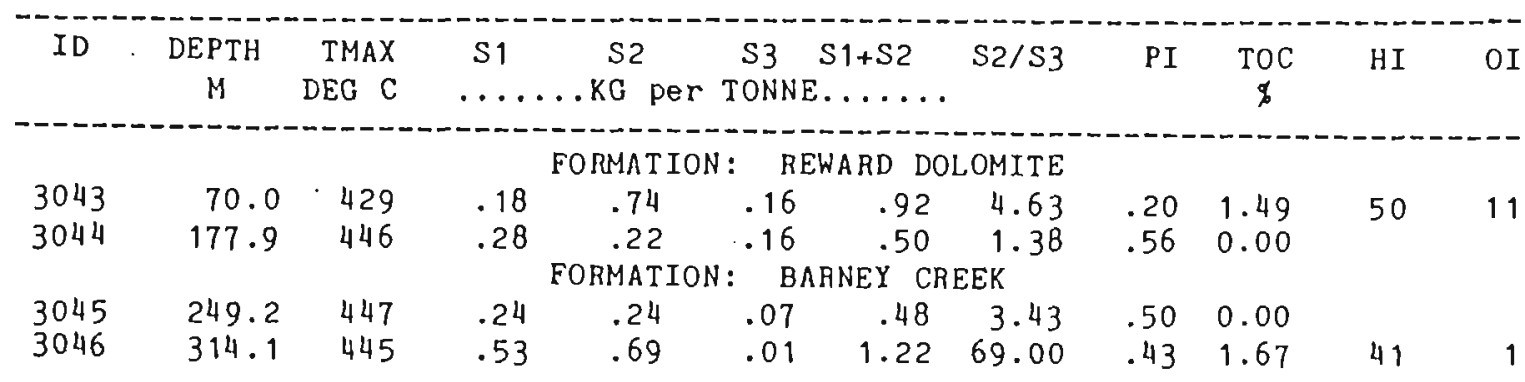

BASIN/AREA: MCARTHUR WELL/LOCALITY: BC3

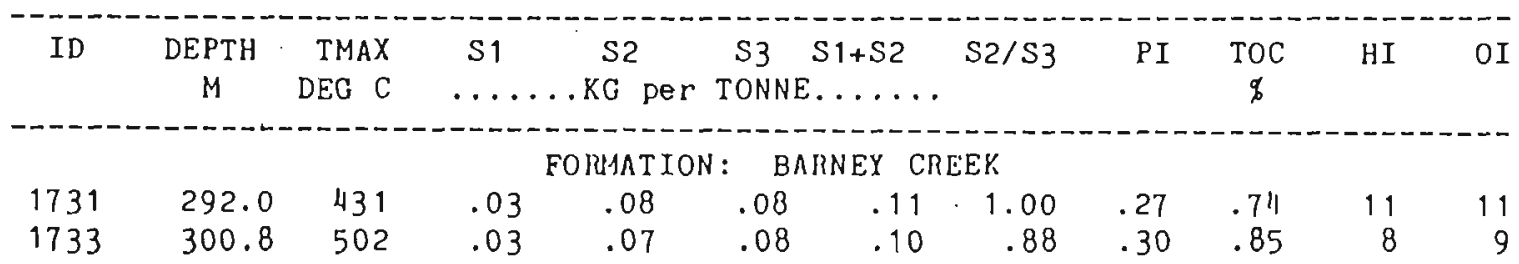

BASIN/AREA: MCARTHUR

WELL/LOCALITY: BJ1

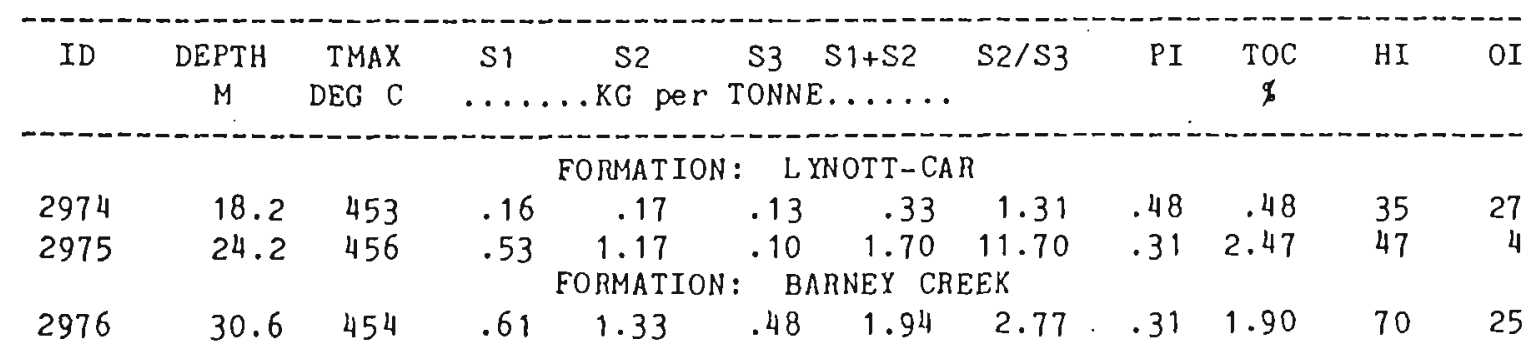




\begin{tabular}{|c|c|c|c|c|c|c|c|c|c|c|c|}
\hline ID & $\begin{array}{c}\text { DEPTH } \\
M\end{array}$ & $\begin{array}{l}\text { TMAX } \\
\text { DEG C }\end{array}$ & $\begin{array}{l}\mathrm{s} 1 \\
\ldots \ldots\end{array}$ & $\begin{array}{l}S 2 \\
K G \text { per }\end{array}$ & $\begin{array}{c}\text { S3 } \\
\text { TONNE }\end{array}$ & $\begin{array}{l}1+\mathrm{S} 2 \\
\ldots \ldots\end{array}$ & $\mathrm{S} 2 / \mathrm{S} 3$ & PI & $\begin{array}{c}\text { TOC } \\
6\end{array}$ & HI & OI \\
\hline \multicolumn{12}{|c|}{ FOPOATION: LYNOTT-CAR } \\
\hline 2977 & 26.5 & 458 & 2.08 & 3.53 & 1.15 & 5.61 & 3.07 & $\cdot 37$ & 4.57 & 77 & 25 \\
\hline 177 & 40.3 & 415 & .19 & .22 & .81 & .41 & .27 & .46 & .29 & 76 & 279 \\
\hline 179 & 44.6 & 444 & .34 & .64 & .62 & .98 & 1.03 & $\cdot 35$ & 2.04 & 31 & 30 \\
\hline 2978 & 45.9 & 464 & .39 & .58 & .98 & .97 & .59 & .40 & 1.54 & 38 & 64 \\
\hline 180 & 49.4 & 435 & .40 & .50 & 1.18 & .90 & .42 & .44 & .83 & 60 & 142 \\
\hline 184. & 51.7 & 416 & .02 & .06 & .78 & .08 & .08 & .25 & .32 & 19 & 244 \\
\hline \multicolumn{12}{|c|}{ FORMATION: REWARD DOLOMITE } \\
\hline 186 & $55 \cdot 3$ & 418 & .83 & .52 & .82 & 1.35 & .63 & .61 & .56 & 93 & 146 \\
\hline 187 & 55.9 & 425 & .70 & .91 & .84 & 1.61 & 1.08 & .43 & 1.05 & 87 & 0 \\
\hline 188 & 56.6 & 417 & 1.21 & .60 & .79 & 1.81 & .76 & .67 & .51 & 118 & 155 \\
\hline \multicolumn{12}{|c|}{ FORMATION: BARNEY CREEK } \\
\hline 190 & 60.0 & 455 & 19 & .34 & .60 & .53 & .57 & $\cdot 36$ & .76 & 45 & 79 \\
\hline 191 & 61.7 & 442 & .23 & .41 & .41 & .64 & 1.00 & .36 & 2.08 & 20 & \\
\hline 2979 & 62.8 & 454 & .48 & 1.50 & .82 & 1.98 & 1.83 & .24 & 2.89 & 52 & 28 \\
\hline 192 & 64.0 & 451 & .06 & .14 & .71 & .20 & .20 & .30 & .29 & 48 & 245 \\
\hline 193 & 71.2 & 460 & .01 & .01 & .56 & .02 & .02 & .50 & .03 & 33 & 1867 \\
\hline 194 & 73.7 & 432 & .23 & .43 & .61 & .66 & .70 & .35 & .44 & 98 & 139 \\
\hline
\end{tabular}

\begin{tabular}{|c|c|c|c|c|c|c|c|c|c|c|c|}
\hline ID & $\begin{array}{c}\text { DEPTH } \\
M\end{array}$ & $\begin{array}{l}\text { TMAX } \\
\text { DEG C }\end{array}$ & $\begin{array}{l}\text { s1 } \\
\ldots .\end{array}$ & $\begin{array}{l}\text { S2 } \\
K G \text { per }\end{array}$ & $\begin{array}{l}\text { S3 } \\
\text { TONNE }\end{array}$ & $\begin{array}{l}S 1+s 2 \\
\ldots \ldots . .\end{array}$ & $\mathrm{S}_{2} / \mathrm{S} 3$ & PI & TOC & $H I$ & $O I$ \\
\hline & \multicolumn{11}{|c|}{ FORMATION: BARNEY CREEK } \\
\hline 2980 & 171.1 & 442 & .06 & .06 & .76 & .12 & .08 & .50 & 0.00 & & \\
\hline 2981 & 194.0 & 398 & .07 & .08 & .69 & .15 & .12 & .47 & .81 & 10 & \\
\hline
\end{tabular}




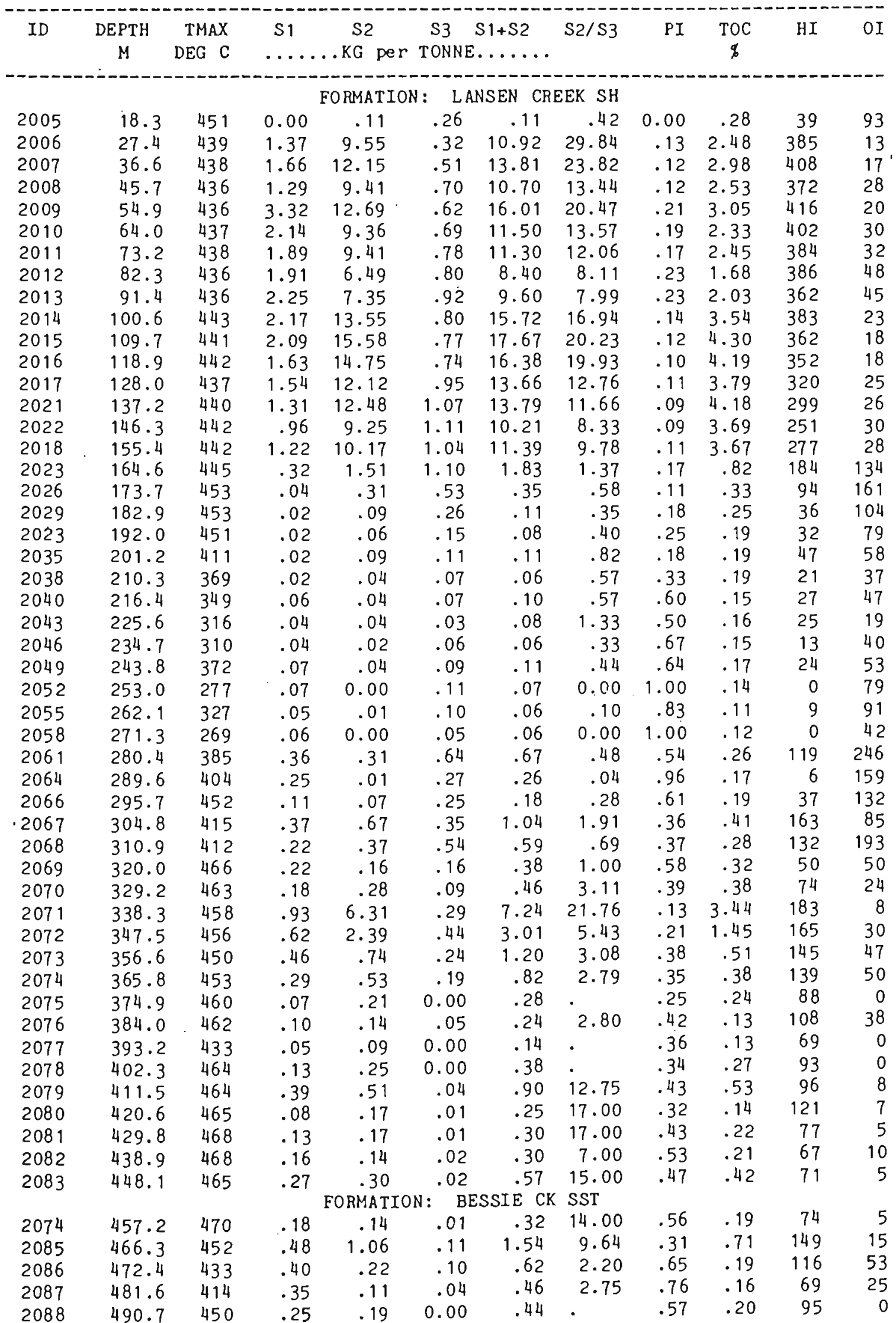




\begin{tabular}{|c|c|c|c|c|c|c|c|c|c|c|c|}
\hline 2089 & 499.9 & 381 & .11 & .05 & 0.00 & .16 & . & .69 & .13 & 38 & 0 \\
\hline 2090 & 509.0 & 469 & .11 & .16 & 0.00 & .27 & . & .41 & .22 & 73 & 0 \\
\hline 2091 & 518.2 & 462 & .31 & .06 & 0.00 & .37 & . & .84 & .14 & 43 & 0 \\
\hline 2092 & $527 \cdot 3$ & 467 & .26 & .12 & .02 & .38 & 6.00 & .68 & .19 & 63 & 11 \\
\hline 2093 & 536.4 & 450 & .24 & .15 & .03 & .39 & 5.00 & .62 & .21 & 71 & 14 \\
\hline 2094 & 545.6 & 417 & .17 & .09 & .01 & .26 & 9.00 & .65 & .18 & 50 & 6 \\
\hline 2095 & 554.7 & 451 & .20 & .13 & 0.00 & .33 & . & .61 & .17 & 76 & 0 \\
\hline 2096 & 563.9 & 457 & .12 & .11 & 0.00 & .23 & . & .52 & .13 & 85 & 0 \\
\hline 2097 & 573.0 & 399 & .22 & .10 & .02 & .32 & 5.00 & .69 & .15 & 67 & 13 \\
\hline 2098 & 582.2 & 417 & .10 & .12 & 0.00 & .22 & . & .45 & .14 & 86 & 0 \\
\hline 2099 & 591.3 & 356 & .09 & .04 & 0.00 & .13 & . & .69 & .10 & 40 & 0 \\
\hline 2100 & 600.5 & 382 & .19 & .12 & .01 & .31 & 12.00 & .61 & .14 & 86 & 7 \\
\hline 2101 & 609.6 & 357 & .12 & .03 & 0.00 & .15 & . & .80 & .07 & 43 & 0 \\
\hline 2102 & 618.7 & 317 & .09 & .02 & 0.00 & .11 & . & .82 & .09 & 22 & 0 \\
\hline 2103 & 627.9 & 270 & .06 & .01 & 0.00 & .07 & . & .86 & .09 & 11 & 0 \\
\hline 2104 & 637.0 & 319 & .15 & .04 & 0.00 & .19 & . & .79 & .11 & 36 & 0 \\
\hline 2105 & 646.2 & 242 & .06 & 0.00 & 0.00 & .06 & . & 1.00 & .05 & 0 & 0 \\
\hline 2106 & 655.3 & 249 & .13 & 0.00 & 0.00 & .13 & . & 1.00 & .05 & 0 & 0 \\
\hline 2107 & 664.5 & 228 & .03 & 0.00 & 0.00 & .03 & . & 1.00 & .06 & 0 & 0 \\
\hline 2108 & 673.6 & 228 & .04 & 0.00 & 0.00 & .04 & . & 1.00 & .03 & 0 & 0 \\
\hline 2109 & 682.8 & 228 & .11 & 0.00 & 0.00 & .11 & . & 1.00 & .05 & 0 & 0 \\
\hline 2110 & 691.9 & 228 & .06 & 0.00 & 0.00 & .06 & . & 1.00 & .04 & 0 & 0 \\
\hline 2111 & 701.0 & 228 & .04 & 0.00 & 0.00 & .04 & . & 1.00 & .04 & 0 & 0 \\
\hline 2112 & 710.2 & 269 & .05 & 0.00 & 0.00 & .05 & . & 1.00 & .06 & 0 & 0 \\
\hline 2113 & 719.3 & 437 & .02 & .02 & 0.00 & .04 & . & .50 & .03 & 67 & 0 \\
\hline 2114 & 728.5 & 354 & .01 & .02 & 0.00 & .03 & . & .33 & .02 & 100 & 0 \\
\hline 2115 & 737.6 & 277 & .01 & .02 & 0.00 & .03 & . & .33 & .04 & 50 & 0 \\
\hline 2116 & 746.8 & 277 & .02 & .02 & 0.00 & .04 & . & .50 & .01 & 200 & 0 \\
\hline 2117 & 755.9 & 277 & .02 & .02 & 0.00 & .04 & . & .50 & .02 & 100 & 0 \\
\hline 2118 & 765.0 & 216 & .03 & .02 & 0.00 & .05 & . & .60 & .01 & 200 & 0 \\
\hline 2119 & 774.2 & 216 & .01 & .02 & 0.00 & .03 & . & .33 & 0.00 & & \\
\hline 2120 & 783.3 & 216 & .01 & .01 & 0.00 & .02 & . & .50 & .01 & 100 & 0 \\
\hline 2121 & 792.5 & 237 & .01 & 0.00 & 0.00 & .01 & . & 1.00 & .01 & 0 & 0 \\
\hline 2122 & 801.6 & 210 & .02 & .03 & 0.00 & .05 & . & .40 & 0.00 & & \\
\hline 2123 & 810.8 & 210 & .03 & 0.00 & .01 & .03 & 0.00 & 1.00 & .01 & 0 & 100 \\
\hline \multicolumn{12}{|c|}{ FORMATION: CORCORAN } \\
\hline 2124 & 819.9 & 210 & .01 & 0.00 & 0.00 & .01 & . & 1.00 & .03 & 0 & 0 \\
\hline 21.25 & 829.1 & 210 & 0.00 & 0.00 & 0.00 & 0.00 & . & . & .06 & 0 & 0 \\
\hline 2126 & 838.2 & 210 & 0.00 & 0.00 & 0.00 & 0.00 & . & . & .08 & 0 & 0 \\
\hline 2127 & 847.3 & 210 & 0.00 & 0.00 & 0.00 & 0.00 & . & - & .07 & 0 & 0 \\
\hline 2128 & 856.5 & 210 & 0.00 & 0.00 & 0.00 & 0.00 & . & . & .08 & 0 & 0 \\
\hline 2132 & 877.8 & 210 & .02 & 0.00 & 0.00 & .02 & . & 1.00 & .16 & 0 & 0 \\
\hline 2129 & 865.6 & 210 & .01 & 0.00 & 0.00 & .01 & . & 1.00 & .05 & 0 & 0 \\
\hline 2130 & 874.8 & 210 & .01 & 0.00 & 0.00 & .01 & . & 1.00 & .07 & 0 & 0 \\
\hline 2131 & 883.9 & 210 & .01 & 0.00 & 0.00 & .01 & . & 1.00 & .08 & 0 & 0 \\
\hline 2133 & 902.2 & 210 & .03 & 0.00 & 0.00 & .03 & . & 1.00 & .12 & 0 & 0 \\
\hline 2134 & 911.4 & 210 & .03 & 0.00 & 0.00 & .03 & . & 1.00 & .10 & 0 & 0 \\
\hline 2135 & 920.5 & 210 & .08 & 0.00 & 0.00 & .08 & . & 1.00 & .10 & 0 & 0 \\
\hline 2136 & 929.6 & 210 & .02 & 0.00 & 0.00 & .02 & - & 1.00 & .04 & 0 & 0 \\
\hline 2137 & 938.8 & 210 & .01 & 0.00 & 0.00 & .01 & . & 1.00 & .02 & 0 & 0 \\
\hline 2138 & 947.9 & 216 & .02 & 0.00 & 0.00 & .02 & . & 1.00 & .03 & 0 & 0 \\
\hline 2139 & 957.1 & 216 & .03 & .02 & 0.00 & .05 & . & .60 & .02 & 100 & 0 \\
\hline 2140 & 966.2 & 216 & .01 & .01 & 0.00 & .02 & . & .50 & .01 & 100 & 0 \\
\hline \multicolumn{12}{|c|}{ FORMATION: DIORITE SILL } \\
\hline 2141 & 975.4 & 216 & .01 & .01 & 0.00 & .02 & . & .50 & .01 & 100 & 0 \\
\hline 2142 & 984.5 & 216 & .01 & .01 & 0.00 & .02 & . & .50 & .03 & 33 & 0 \\
\hline 2143 & 993.6 & 216 & .03 & .02 & 0.00 & .05 & . & .60 & .01 & 200 & 0 \\
\hline 2144 & 1002.8 & 216 & .02 & .01 & 0.00 & .03 & . & $.6 \%$ & .02 & 50 & 0 \\
\hline 2145 & 1011.9 & 203 & .09 & 0.00 & 0.00 & .09 & . & 1.00 & .01 & 0 & 0 \\
\hline 2146 & 1021.1 & 216 & .02 & .01 & 0.00 & .03 & . & .67 & .01 & 100 & 0 \\
\hline 2147 & 1030.2 & 203 & .02 & 0.00 & 0.00 & .02 & • & 1.00 & .03 & 0 & 0 \\
\hline 2148 & 1039.4 & 216 & .04 & 0.00 & 0.00 & .04 & . & 1.00 & .01 & 0 & 0 \\
\hline
\end{tabular}




\begin{tabular}{|c|c|c|c|c|c|c|c|c|c|c|c|}
\hline 2149 & 1048.5 & 216 & .06 & 0.00 & 0.00 & .06 & - & 1.00 & .01 & 0 & 0 \\
\hline 2150 & 1057.7 & 216 & .01 & .01 & 0.00 & .02 & - & .50 & .02 & 50 & 0 \\
\hline 2151 & 1066.8 & 438 & 0.00 & 0.00 & .03 & 0.00 & 0.00 & . & .04 & 0 & 75 \\
\hline 2152 & 1075.9 & 359 & .01 & 0.00 & .02 & .01 & 0.00 & 1.00 & .05 & 0 & 40 \\
\hline 2153 & 1085.1 & 222 & .01 & 0.00 & .02 & .01 & 0.00 & 1.00 & .05 & 0 & 40 \\
\hline 2154 & 1094.2 & 276 & .01 & 0.00 & 0.00 & .01 & - & 1.00 & .05 & 0 & 0 \\
\hline 2155 & 1103.4 & $258^{\circ}$ & .01 & 0.00 & .01 & .01 & 0.00 & 1.00 & .04 & 0 & 25 \\
\hline 2156 & 1112.5 & 222 & .05 & 0.00 & .02 & .05 & 0.00 & 1.00 & .06 & 0 & 33 \\
\hline 2157 & 1121.7 & 276 & .05 & 0.00 & .02 & .05 & 0.00 & 1.00 & .06 & 0 & 33 \\
\hline 2158 & 1130.8 & 259 & .01 & 0.00 & .04 & .01 & 0.00 & 1.00 & .03 & 0 & 133 \\
\hline 2159 & 1140.0 & 248 & .04 & 0.00 & .07 & .04 & 0.00 & 1.00 & .04 & 0 & 175 \\
\hline \multicolumn{12}{|c|}{ FORMATION: CORCORAN } \\
\hline 2160 & 1149.1 & 246 & .05 & 0.00 & .02 & .05 & 0.00 & 1.00 & .04 & 0 & 50 \\
\hline 2161 & 1158.2 & 250 & .02 & 0.00 & 0.00 & .02 & . & 1.00 & .06 & 0 & 0 \\
\hline 2162 & 1167.4 & 222 & .02 & 0.00 & 0.00 & .02 & . & 1.00 & .05 & 0 & 0 \\
\hline 2163 & 1176.5 & 276 & .03 & 0.00 & 0.00 & .03 & . & 1.00 & .05 & 0 & 0 \\
\hline 2164 & 1185.7 & 267 & .03 & 0.00 & 0.00 & .03 & - & 1.00 & .05 & 0 & 0 \\
\hline 2165 & 1194.8 & 251 & .03 & 0.00 & 0.00 & .03 & . & 1.00 & .05 & 0 & 0 \\
\hline 2166 & 1204.0 & 222 & .09 & 0.00 & 0.00 & .09 & . & 1.00 & .07 & 0 & 0 \\
\hline 2167 & 1213.1 & 303 & .07 & 0.00 & 0.00 & .07 & - & 1.00 & .06 & 0 & 0 \\
\hline 2168 & 1222.2 & 222 & .10 & 0.00 & 0.00 & .10 & . & 1.00 & .08 & 0 & 0 \\
\hline 2169 & 1231.4 & 276 & .12 & 0.00 & 0.00 & .12 & . & 1.00 & .09 & 0 & 0 \\
\hline 2170 & 1240.5 & 222 & .05 & 0.00 & 0.00 & .05 & . & 1.00 & .06 & 0 & 0 \\
\hline 2171 & 1249.7 & 276 & .06 & 0.00 & .05 & .06 & 0.00 & 1.00 & .07 & 0 & 71 \\
\hline 2172 & 1258.8 & 222 & .07 & 0.00 & .01 & .07 & 0.00 & 1.00 & .10 & 0 & 10 \\
\hline 2173 & 1268.0 & 334 & .07 & .02 & .63 & .09 & .03 & .78 & .15 & 13 & 420 \\
\hline 2174 & 1277.1 & 261 & .11 & 0.00 & .08 & .11 & 0.00 & 1.00 & .15 & 0 & 53 \\
\hline 2175 & $1286 \cdot 3$ & 223 & .07 & 0.00 & .35 & .07 & 0.00 & 1.00 & .15 & 0 & 233 \\
\hline 2176 & 1295.4 & 301 & .07 & 0.00 & .13 & .07 & 0.00 & 1.00 & .16 & 0 & 81 \\
\hline 2177 & 1304.5 & 223 & .04 & 0.00 & .65 & .04 & 0.00 & 1.00 & .14 & 0 & 464 \\
\hline 2178 & 1313.7 & 293 & .04 & 0.00 & .47 & .04 & 0.00 & 1.00 & .12 & 0 & 392 \\
\hline \multicolumn{12}{|c|}{ FORMATION: AGNER SST } \\
\hline 2179 & 132 & 223 & .06 & 0.00 & 0.00 & .06 & - & 1.00 & .05 & 0 & 0 \\
\hline 2180 & .0 & 293 & .06 & 0.00 & 0.00 & .06 & . & 1.00 & .05 & 0 & 0 \\
\hline 2181 & 1341.1 & 223 & .07 & 0.00 & .02 & .07 & 0.00 & 1.00 & .04 & 0 & 50 \\
\hline 2182 & 135 & 293 & .02 & 0.00 & 0.00 & .02 & - & 1.00 & .04 & 0 & 0 \\
\hline 2183 & 1359.4 & 223 & .03 & 0.00 & 0.00 & .03 & - & 1.00 & .04 & 0 & 0 \\
\hline 2184 & 1368.6 & 302 & .04 & 0.00 & 0.00 & .04 & . & 1.00 & .04 & 0 & 0 \\
\hline 2185 & 1377.7 & 223 & .05 & 0.00 & 0.00 & .05 & . & 1.00. & .04 & 0 & 0 \\
\hline 2186 & 1386.8 & 302 & .06 & 0.00 & 0.00 & .06 & - & 1.00 & .07 & 0 & 0 \\
\hline 2187 & 1396.0 & 223 & .06 & 0.00 & 0.00 & .06 & - & 1.00 & .05 & 0 & 0 \\
\hline 2188 & 1405.1 & 297 & .07 & 0.00 & 0.00 & .07 & . & 1.00 & .04 & 0 & 0 \\
\hline 2189 & 1414.3 & 223 & .06 & 0.00 & .02 & .06 & 0.00 & 1.00 & .03 & 0 & 67 \\
\hline 2190 & 1423.4 & 280 & .02 & 0.00 & 0.00 & .02 & - & 1.00 & .03 & 0 & 0 \\
\hline 2191 & 1432.6 & 222 & .04 & 0.00 & 0.00 & .04 & - & 1.00 & .03 & 0 & 0 \\
\hline 2192 & 1441.7 & 280 & .06 & 0.00 & 0.00 & .06 & - & 1.00 & .04 & 0 & 0 \\
\hline 2193 & 1450.8 & 222 & .07 & 0.00 & .0 & .07 & 0.00 & 1.00 & .04 & 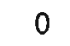 & 50 \\
\hline 2194 & 1460.0 & 374 & .37 & .07 & .10 & .44 & .70 & .84 & .09 & 78 & 111 \\
\hline 2195 & 1469.1 & 434 & .01 & 0.00 & 0.00 & .01 & - & 1.00 & .03 & 0 & 0 \\
\hline 2196 & 1478.3 & 370 & 0.00 & 0.00 & .01 & 0.00 & 0.00 & - & .03 & 0 & 33 \\
\hline 2197 & 1487.4 & 220 & .01 & 0.00 & 0.00 & .01 & • & 1.00 & .03 & 0 & 0 \\
\hline 2198 & 1496.6 & 288 & .02 & 0.00 & 0.00 & .02 & - & 1.00 & .02 & 0 & 0 \\
\hline 2199 & 1505.7 & 333 & 6.98 & 2.61 & 5.52 & 9.59 & .47 & .73 & 1.44 & 181 & 383 \\
\hline 2200 & 1514.9 & 337 & .10 & .03 & 1.47 & .13 & .02 & .77 & .10 & 30 & 1470 \\
\hline 2201 & 1524.0 & 264 & 0.00 & 0.00 & 0.00 & 0.00 & - & - & .03 & 0 & 0 \\
\hline 2202 & 1533.1 & 172 & 0.00 & 0.00 & 0.00 & 0.00 & - & . & .03 & 0 & 0 \\
\hline 2203 & 1542.3 & 257 & .03 & 0.00 & .12 & .03 & 0.00 & 1.00 & .05 & 0 & 240 \\
\hline 2204 & 1551.4 & 248 & .02 & 0.00 & .02 & .02 & 0.00 & 1.00 & .04 & 0 & 50 \\
\hline 2205 & 1560.6 & 184 & .01 & 0.00 & 0.00 & .01 & • & 1.00 & .03 & 0 & 0 \\
\hline 2206 & 1569.7 & 211 & .01 & 0.00 & .07 & .01 & 0.00 & 1.00 & .03 & 0 & 233 \\
\hline 2207 & 1578.9 & 184 & .01 & 0.00 & .03 & .01 & 0.00 & 1.00 & .03 & 0 & 100 \\
\hline 2208 & 1588.0 & 211 & .03 & .01 & .01 & .04 & 1.00 & .75 & .02 & 50 & 50 \\
\hline
\end{tabular}




\begin{tabular}{|c|c|c|c|c|c|c|c|c|c|c|c|}
\hline 2209 & 1597.2 & 184 & .03 & 0.00 & .01 & .03 & 0.00 & 1.00 & .03 & 0 & 33 \\
\hline 2210 & $1606 \cdot 3$ & 250 & .06 & .02 & .65 & .08 & .03 & .75 & .27 & 7 & 241 \\
\hline 2211 & 1615.4 & 255 & .04 & .02 & .29 & .06 & .07 & .67 & .04 & 50 & 725 \\
\hline 2212 & 1624.6 & 272 & .01 & 0.00 & 0.00 & .01 & . & 1.00 & .03 & 0 & 0 \\
\hline 2213 & 1633.7 & 255 & .05 & 0.00 & .01 & .05 & 0.00 & 1.00 & .06 & 0 & 17 \\
\hline 2214 & 1642.9 & 251 & .04 & 0.00 & .01 & .04 & 0.00 & 1.00 & .03 & 0 & 33 \\
\hline 2215 & 1652.0 & 238 & .05 & 0.00 & .01 & .05 & 0.00 & 1.00 & .03 & 0 & 33 \\
\hline 2216 & 1661.2 & 238 & .10 & 0.00 & .03 & .10 & 0.00 & 1.00 & .05 & 0 & 60 \\
\hline 2217 & 1670.3 & 238 & .03 & 0.00 & 0.00 & .03 & . & 1.00 & .03 & 0 & 0 \\
\hline 2218 & 1679.4 & 238 & .04 & 0.00 & 0.00 & .04 & - & 1.00 & .05 & 0 & 0 \\
\hline 2219 & 1688.6 & 238 & .04 & 0.00 & 0.00 & .04 & . & 1.00 & .02 & 0 & 0 \\
\hline 2220 & 1697.7 & 238 & .10 & 0.00 & .01 & .10 & 0.00 & 1.00 & .05 & 0 & 20 \\
\hline 2221 & 1706.9 & 238 & .04 & 0.00 & 0.00 & .04 & - & 1.00 & .03 & 0 & 0 \\
\hline 2222 & 1716.0 & 268 & .15 & 0.00 & .03 & .15 & 0.00 & 1.00 & .04 & 0 & 75 \\
\hline 2223 & 1725.2 & 264 & .04 & 0.00 & 0.00 & .04 & . & 1.00 & .04 & 0 & 0 \\
\hline 2224 & $1734 \cdot 3$ & 255 & .03 & 0.00 & 0.00 & .03 & - & 1.00 & .03 & 0 & 0 \\
\hline 2225 & 1743.5 & 270 & .02 & 0.00 & 0.00 & .02 & . & 1.00 & .03 & 0 & 0 \\
\hline 2226 & 1752.6 & 238 & .04 & 0.00 & .05 & .04 & 0.00 & 1.00 & .04 & 0 & 125 \\
\hline 2227 & 1761.7 & 264 & .07 & 0.00 & .01 & .07 & 0.00 & 1.00 & .04 & 0 & 25 \\
\hline 2228 & 1770.9 & 257 & .06 & 0.00 & 0.00 & .06 & ${ }^{\circ}$ & 1.00 & .03 & 0 & 0 \\
\hline 2229 & 1780.0 & 255 & .10 & 0.00 & .02 & .10 & 0.00 & 1.00 & .05 & 0 & 40 \\
\hline 2230 & 1792.2 & 379 & .03 & .02 & .14 & .05 & .14 & .60 & .05 & 40 & 280 \\
\hline 2231 & 1801.4 & 320 & .10 & .06 & 1.06 & .16 & .06 & .63 & .11 & 55 & 964 \\
\hline 2232 & 1810.5 & 222 & .04 & 0.00 & .02 & .04 & 0.00 & 1.00 & .04 & 0 & 50 \\
\hline 2233 & 1819.7 & 265 & .02 & 0.00 & .04 & .02 & 0.00 & 1.00 & .03 & 0 & 133 \\
\hline 2234 & 1828.8 & 362 & .03 & .03 & .22 & .06 & .14 & .50 & .04 & 75 & 550 \\
\hline 2235 & 1837.9 & 336 & .92 & .51 & 1.83 & 1.43 & .28 & .64 & .03 & 1700 & 6100 \\
\hline 2236 & 1847.1 & 339 & .04 & 0.00 & .06 & .04 & 0.00 & 1.00 & .04 & 0 & 150 \\
\hline 2237 & 185 & 301 & .01 & 0.00 & 0.00 & .01 & . & 1.00 & .03 & 0 & 0 \\
\hline 2238 & 1865.4 & 425 & .31 & .23 & .45 & .54 & .51 & .57 & .11 & 209 & 409 \\
\hline 2239 & 1874.5 & 387 & .09 & .11 & .15 & .20 & .73 & .45 & .07 & 157 & 214 \\
\hline 2240 & 1880.6 & 261 & .03 & .01 & 0.00 & .04 & - & .75 & .05 & 20 & 0 \\
\hline 2241 & 1889.8 & 269 & .04 & .01 & .19 & .05 & .05 & .80 & .03 & 33 & 633 \\
\hline 2242 & 1898.9 & 247 & .03 & .01 & .01 & .04 & 1.00 & .75 & .03 & 33 & 33 \\
\hline 2243 & 1908.0 & 242 & 0.00 & 0.00 & 0.00 & 0.00 & • & - & .02 & 0 & 0 \\
\hline \multicolumn{12}{|c|}{ FORMATION: CRAWFORD } \\
\hline 2244 & 1917.2 & 276 & .01 & 0.00 & .36 & .01 & 0.00 & 1.00 & .04 & 0 & 900 \\
\hline 2245 & $1926 \cdot 3$ & 261 & .01 & 0.00 & .04 & .01 & 0.00 & 1.00 & .03 & 0 & 133 \\
\hline 2246 & 1935.5 & 242 & .01 & 0.00 & 0.00 & .01 & 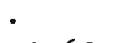 & 1.00 & .05 & 0 & 0 \\
\hline 2247 & 1944.6 & 372 & .09 & .13 & .08 & .22 & 1.63 & .41 & .15 & 87 & 53 \\
\hline 2248 & 1953.8 & 233 & 0.00 & 0.00 & 0.00 & 0.00 & - & r & .06 & 0 & 0 \\
\hline 2249 & 1962.9 & 267 & .02 & 0.00 & 0.00 & .02 & . & 1.00 & .09 & 0 & 0 \\
\hline 2250 & 1972.1 & 348 & .06 & .14 & .12 & .20 & 1.17 & .30 & .16 & 88 & 75 \\
\hline 2251 & 1981.2 & 246 & .01 & 0.00 & 0.00 & .01 & . & 1.00 & .10 & 0 & 0 \\
\hline 2252 & 1990.3 & 343 & .45 & .59 & 1.49 & 1.04 & .40 & .43 & .47 & 126 & 317 \\
\hline 2253 & 1999.5 & 383 & .23 & .31 & 1.10 & .54 & .28 & .43 & .29 & 107 & 379 \\
\hline 2254 & 2008.6 & 333 & .79 & .57 & 1.94 & 1.36 & .29 & .58 & .52 & 110 & 373 \\
\hline 2255 & 2017.8 & 339 & .07 & .09 & .19 & .08 & .05 & .88 & .13 & 8 & 146 \\
\hline 2256 & 2026.9 & 264 & .18 & .04 & .29 & .22 & .14 & .82 & .15 & 27 & 193 \\
\hline 2257 & 2036.1 & 222 & .04 & 0.00 & .05 & .04 & 0.00 & 1.00 & .15 & 0 & 33 \\
\hline 2258 & 2045.2 & 176 & .05 & 0.00 & 0.00 & .05 & - & 1.00 & .08 & 0 & 0 \\
\hline \multicolumn{12}{|c|}{ FORMATION: MAINORU } \\
\hline 2260 & 2063.5 & 182 & .05 & 0.00 & .05 & .05 & 0.00 & 1.00 & .12 & 0 & 42 \\
\hline 2261 & 2072.6 & 217 & .06 & 0.00 & .02 & .06 & 0.00 & 1.00 & .12 & 0 & 17 \\
\hline 2262 & 2081.8 & 333 & 1.72 & 1.39 & 2.53 & 3.11 & .55 & .55 & .86 & 162 & 294 \\
\hline 2263 & 2090.9 & 338 & .07 & .03 & .21 & .10 & .14 & .70 & .24 & 13 & 88 \\
\hline 2264 & 2100.1 & 307 & .06 & .03 & .14 & .09 & .21 & .67 & .16 & 19 & 88 \\
\hline 2265 & 2109.2 & 204 & .05 & 0.00 & .05 & .05 & 0.00 & 1.00 & .22 & 0 & 23 \\
\hline 2266 & 2118.4 & 200 & .16 & 0.00 & .05 & .16 & 0.00 & 1.00 & .13 & 0 & 38 \\
\hline 2267 & $2127 \cdot 5$ & 198 & .44 & 0.00 & .10 & .44 & 0.00 & 1.00 & .13 & 0 & 77 \\
\hline 2268 & 2136.6 & 172 & .87 & 0.00 & .15 & .87 & 0.00 & 1.00 & .14 & 0 & 107 \\
\hline
\end{tabular}




$\begin{array}{llllllllllll}2269 & 2145.8 & 257 & .31 & 0.00 & .08 & .31 & 0.00 & 1.00 & .14 & 0 & 57 \\ 2270 & 2154.9 & 244 & .15 & 0.00 & .02 & .15 & 0.00 & 1.00 & .13 & 0 & 15 \\ 2271 & 2164.1 & 172 & .58 & 0.00 & .12 & .58 & 0.00 & 1.00 & .15 & 0 & 80 \\ 2272 & 2173.2 & 257 & .25 & 0.00 & .03 & .25 & 0.00 & 1.00 & .14 & 0 & 21\end{array}$

BASIN/AREA: MCARTHUR

WELL/LOCALITY: CA 1

\begin{tabular}{|c|c|c|c|c|c|c|c|c|c|c|c|}
\hline ID & $\begin{array}{c}\text { DEPTH } \\
M\end{array}$ & $\begin{array}{l}\text { TMAX } \\
\text { DEG C }\end{array}$ & $\begin{array}{l}s_{1} \\
\ldots .\end{array}$ & $\stackrel{S 2}{K G \text { per }}$ & $\begin{array}{l}\text { S3 } \\
\text { TONNE }\end{array}$ & $\begin{array}{l}s 1+s 2 \\
\ldots \ldots \ldots\end{array}$ & $\mathrm{S}_{2} / \mathrm{S} 3$ & PI & $\underset{\mathscr{T}}{\mathrm{TOC}}$ & $H I$ & OI \\
\hline & & & & FORMATIOH & $\mathrm{RE}$ & WARD DC & OMITE & & & & \\
\hline 1654 & 253.7 & 474 & .17 & .23 & .11 & .40 & 2.09 & .43 & 1.29 & 18 & 9 \\
\hline 1655 & 288.8 & 355 & .10 & .03 & .16 & .13 & .19 & .77 & 0.00 & & \\
\hline 1656 & 295.8 & 334 & .07 & .05 & .07 & .12 & .71 & .58 & 0.00 & & \\
\hline & & & & FORMA T ION & N: & RNEY CR & EEK & & & & \\
\hline 1657 & 337.6 & 539 & .15 & .67 & .30 & .82 & 2.23 & .18 & 9.08 & 7 & 3 \\
\hline 1658 & 390.0 & 331 & 0.00 & .01 & .16 & .01 & .06 & 0.00 & 0.00 & & \\
\hline 1659 & 573.1 & 297 & 0.00 & 0.00 & 0.00 & 0.00 & . & . & 0.00 & & \\
\hline 1660 & 787.3 & 275 & 0.00 & .01 & .14 & .01 & .07 & 0.00 & 0.00 & & \\
\hline 1661 & 889.3 & 412 & 0.00 & .01 & .25 & .01 & .04 & 0.00 & 0.00 & & \\
\hline
\end{tabular}

BASIN/AREA: MCARTHUR

WELL/LOCALITY: CA2

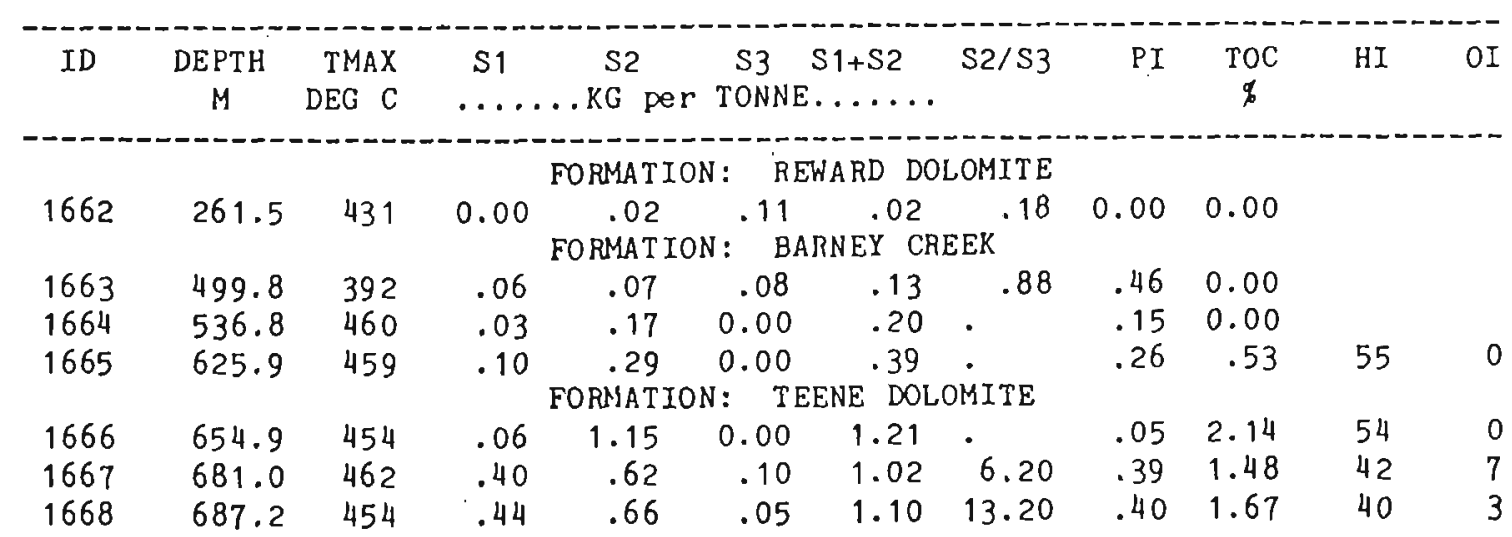




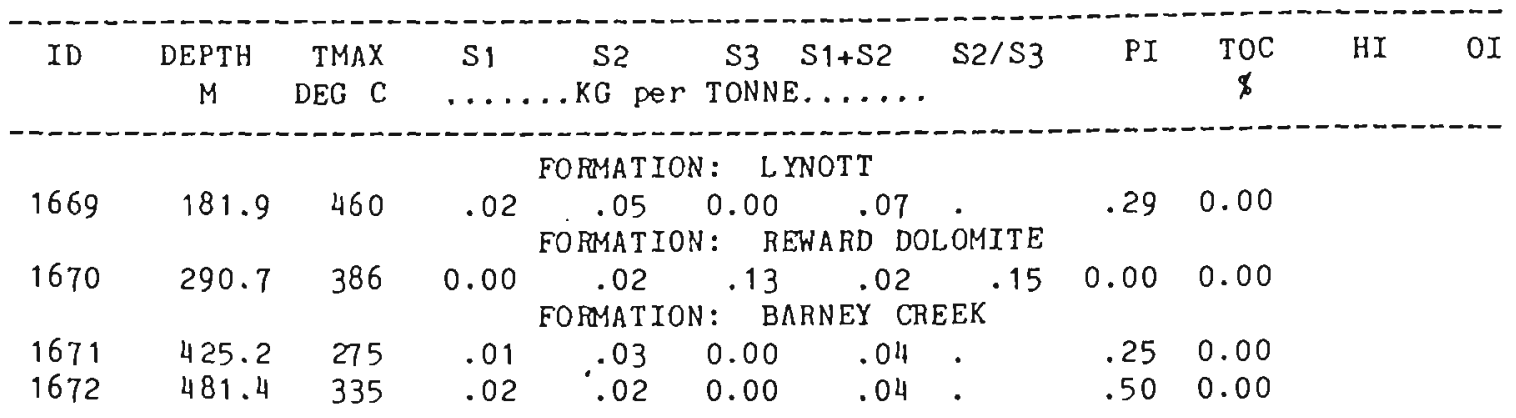

BASIN/AREA: MCARTHUR

WELL/LOCALITY: F15/90

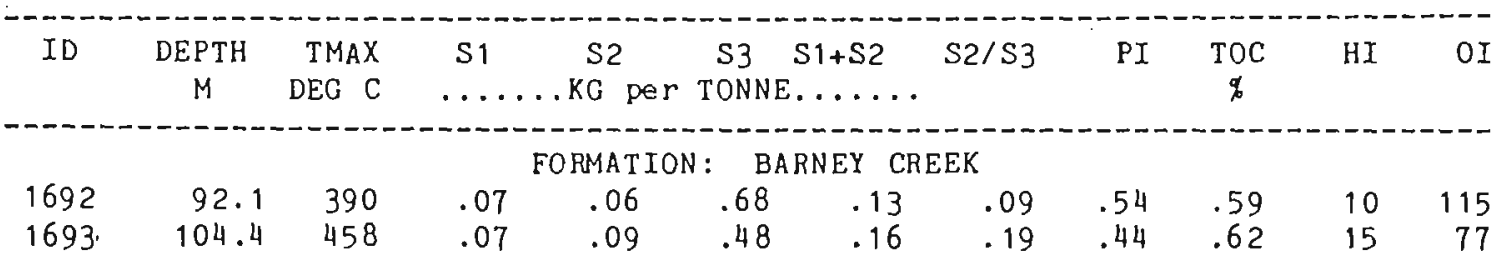

BASIN/AREA: MCARTHUR

HELL/LOCALITY: GR1

\begin{tabular}{|c|c|c|c|c|c|c|c|c|c|c|c|}
\hline ID & $\begin{array}{c}\text { DEPTH } \\
M\end{array}$ & $\begin{array}{r}\text { TMAX } \\
\text { DEG C }\end{array}$ & $\begin{array}{c}\text { S1 } \\
\ldots\end{array}$ & ${ }^{\mathrm{S} 2}$ & $\begin{array}{l}\text { S3 } \\
\text { TONNE }\end{array}$ & $\begin{array}{l}\mathrm{S} 1+\mathrm{s} 2 \\
\ldots .\end{array}$ & $\mathrm{S} 2 / \mathrm{S} 3$ & PI & $\begin{array}{c}\text { TOC } \\
\%\end{array}$ & $\mathrm{HI}$ & Or \\
\hline & & & & FOPMAT & Bf & $N E Y \quad C l$ & EEK & & & & \\
\hline 2810 & 17.8 & 439 & .19 & 3.63 & .15 & 3.82 & 24.20 & .05 & .92 & 395 & 16 \\
\hline 2811 & 26.5 & 439 & .82 & 10.30 & .43 & 11.12 & 23.95 & .07 & 1.69 & 609 & 25 \\
\hline 2812 & 45.2 & 437 & 2.16 & 27.52 & .70 & 29.68 & 39.31 & .07 & 4.22 & 652 & 17 \\
\hline 2813 & 50.8 & 438 & .71 & 7.42 & .60 & 8.13 & 12.37 & .09 & 1.33 & 558 & 45 \\
\hline 2814 & 92.2 & 439 & 1.48 & 17.25 & .62 & 18.73 & 27.82 & .08 & 2.92 & 591 & 21 \\
\hline 2815 & 125.6 & 436 & .88 & 5.80 & .67 & 6.68 & 8.66 & .13 & 1.38 & 420 & 49 \\
\hline 28 & 151.5 & 437 & .78 & 7.41 & .66 & 8.19 & 11.23 & .10 & 1.68 & 441 & 39 \\
\hline 2817 & 170.0 & 438 & .16 & .53 & .55 & .69 & .96 & .23 & .35 & 151 & 157 \\
\hline 2818 & 194.1 & 441 & 1.24 & 10.56 & .65 & 11.80 & 16.25 & .11 & 2.41 & 438 & 27 \\
\hline 2819 & 223.4 & 428 & .05 & .12 & .43 & .17 & .28 & .29 & 0.00 & & \\
\hline 2820 & 256.5 & 438 & .26 & .90 & .22 & 1.16 & 4.09 & .22 & .51 & 176 & 43 \\
\hline 2821 & 279.5 & 437 & .64 & 2.26 & .34 & 2.90 & 6.65 & .22 & .94 & 240 & 36 \\
\hline 2822 & 295.8 & 435 & $\cdot 36$ & 1.16 & .30 & 1.52 & 3.87 & .24 & .61 & 190 & 49 \\
\hline 2823 & 320.2 & 437 & .61 & 1.83 & .28 & 2.44 & 6.54 & .25 & .88 & 208 & 3 \\
\hline 2824 & 331.8 & 441 & .44 & .85 & .24 & 1.29 & 3.54 & .34 & .64 & 133 & 38 \\
\hline 2825 & 350.9 & 446 & .02 & 0.00 & .09 & .02 & 0.00 & 1.00 & 0.00 & & \\
\hline
\end{tabular}


BASIN/AREA: MCARTHUR

WELL/LOCALITY: GR2

\begin{tabular}{|c|c|c|c|c|c|c|c|c|c|c|c|}
\hline ID & $\begin{array}{c}\text { DEPTH } \\
M\end{array}$ & $\begin{array}{r}\text { TMAX } \\
\text { DEG C }\end{array}$ & $\begin{array}{c}\mathrm{s} 1 \\
\ldots .\end{array}$ & $\begin{array}{c}\mathrm{S} 2 \\
\mathrm{KG} \text { per }\end{array}$ & $\begin{array}{l}\text { S3 } \\
\text { TONN }\end{array}$ & $\begin{array}{l}S 1+S 2 \\
\ldots \ldots \ldots\end{array}$ & $\mathrm{S} 2 / \mathrm{S} 3$ & PI & $\begin{array}{c}\text { TOC } \\
\%\end{array}$ & $\mathrm{HI}$ & 01 \\
\hline & & & & FORMATI & 1: & RNEY CR & EEK & & & & \\
\hline 2826 & 45.5 & 437 & .76 & 12.45 & .34 & 13.21 & 36.62 & .06 & 2.10 & 593 & \\
\hline $\begin{array}{l}2827 \\
2828\end{array}$ & 62.9 & 437 & 4.90 & 66.39 & 1.15 & 71.29 & 57 & .07 & 10.38 & 640 & \\
\hline 28 & 86.1 & 438 & 1.35 & 16 & .83 & 18.09 & 20. & .07 & 2.61 & 641 & \\
\hline 2829 & 111.1 & 437 & 1.08 & 19.01 & .81 & 20.09 & 23. & .05 & $3 \cdot 10$ & 613 & \\
\hline 28 & 147.0 & 439 & 1.26 & $17 \cdot 52$ & .81 & 18.78 & 21.63 & .07 & 3.06 & 573 & \\
\hline 2831 & 180.5 & 439 & 1.24 & 13.84 & .87 & 15.08 & 15.91 & .08 & 2.68 & 516 & \\
\hline 2832 & 202.2 & 434 & 1.04 & 8.28 & .28 & 9.32 & 29.57 & .11 & 2.00 & 414 & \\
\hline 2833 & 220.7 & 437 & .48 & 3.01 & .54 & 3.49 & 5.57 & .14 & .97 & 310 & \\
\hline 2834 & 238.2 & 439 & .74 & 4.74 & .66 & 5.48 & 7.18 & .14 & 1.35 & 351 & \\
\hline
\end{tabular}

BASIN/AREA: MCARTHUR

WELL/LOCALITY: GR3

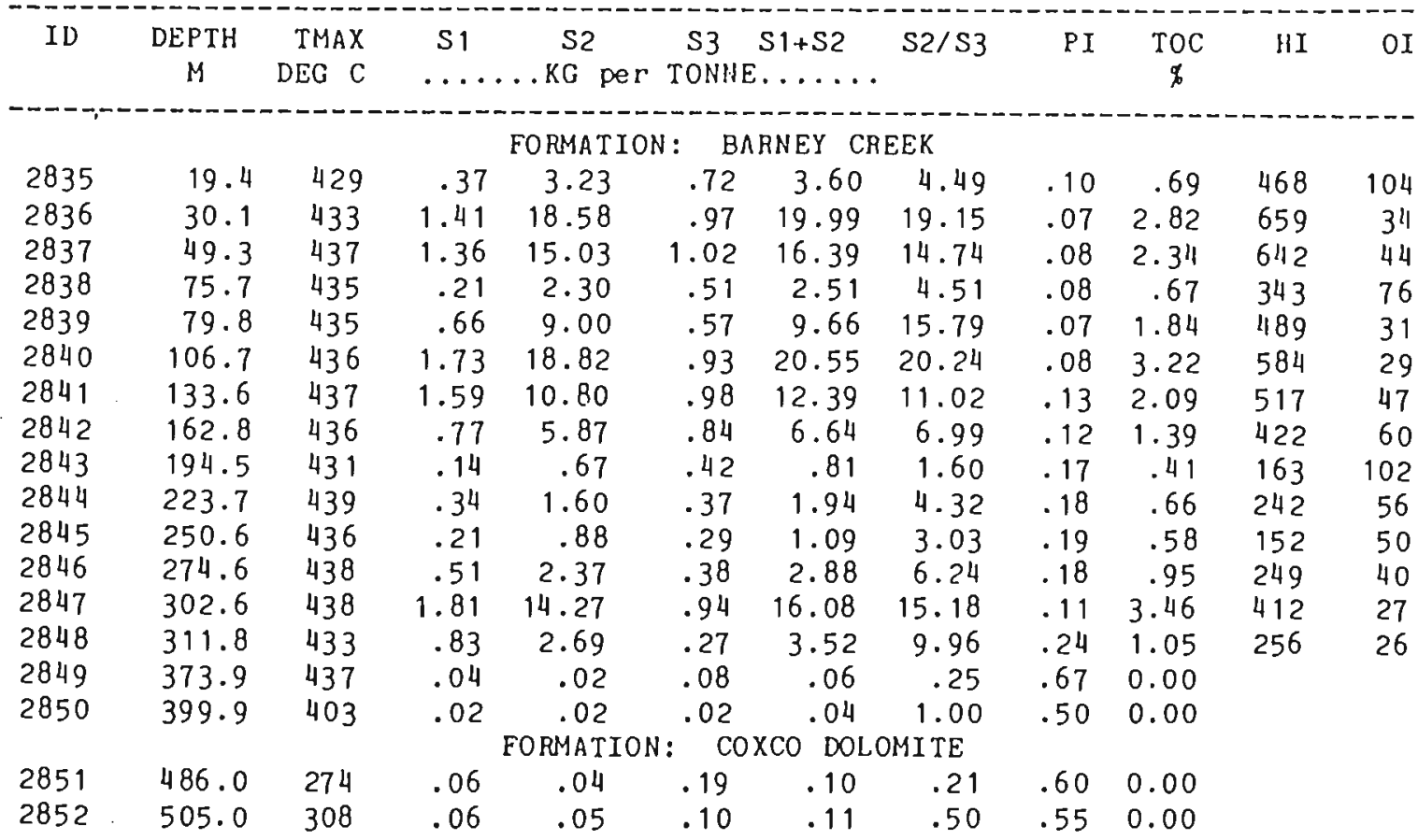

BASIN/AREA： MCARTHUR

WELL/LOCALITY: GRI

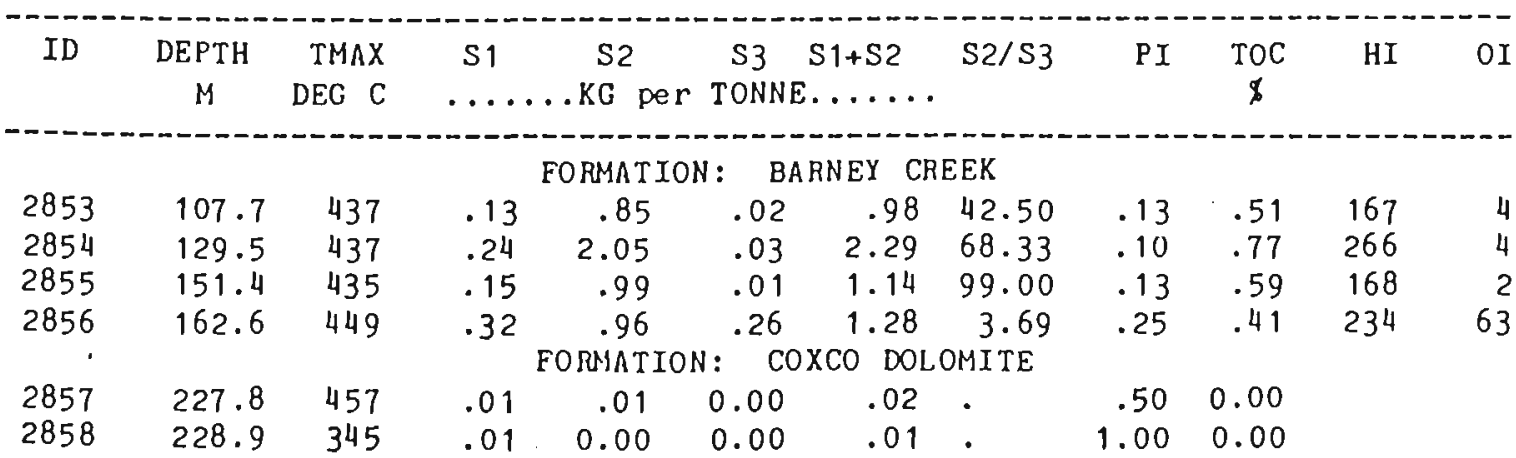


BASIN/AREA : MCARTHUR

WELL/LOCALITY: GR5

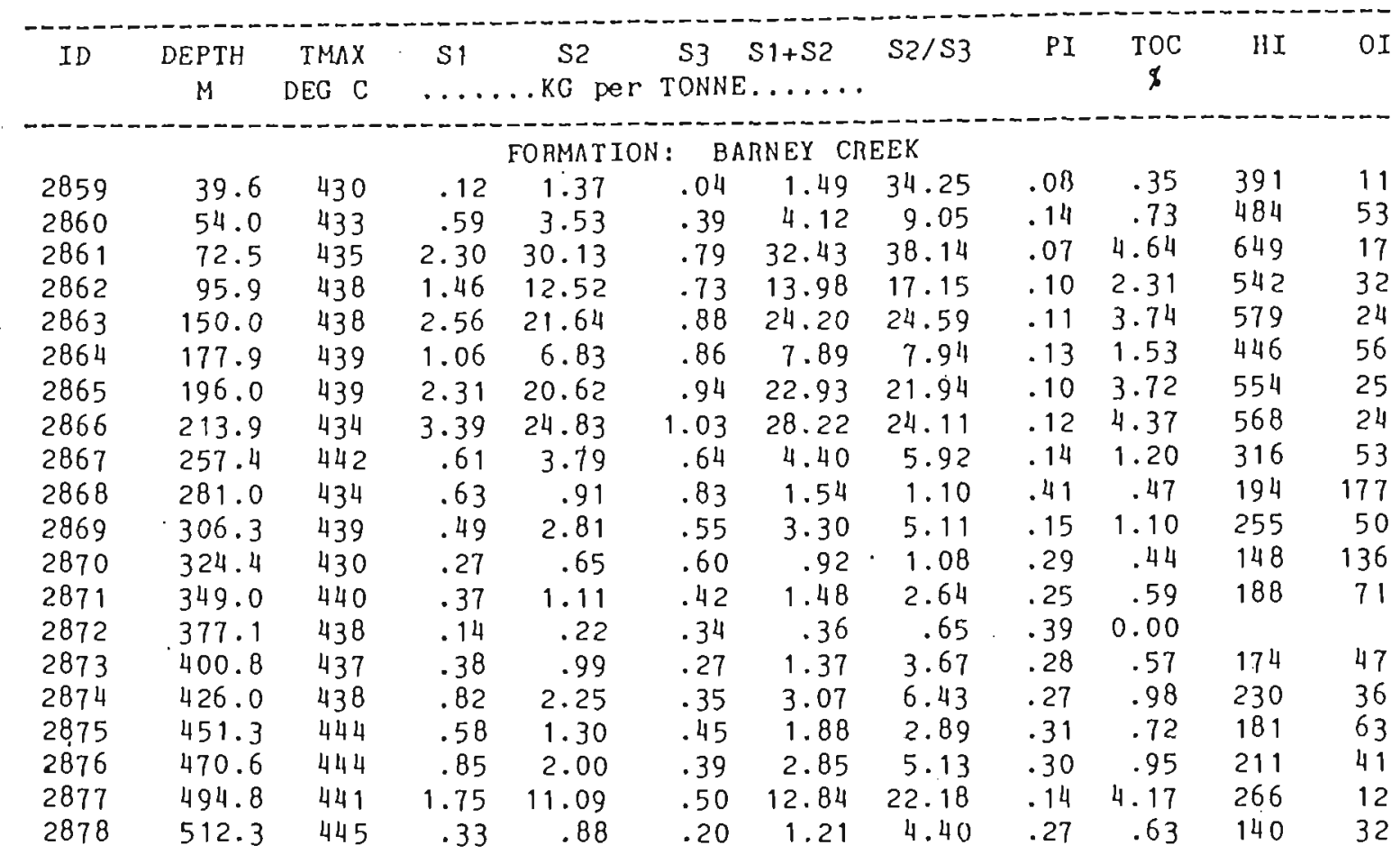

BASIN/AREA: MCARTHUR

WELL/LOCNLITY: GR6

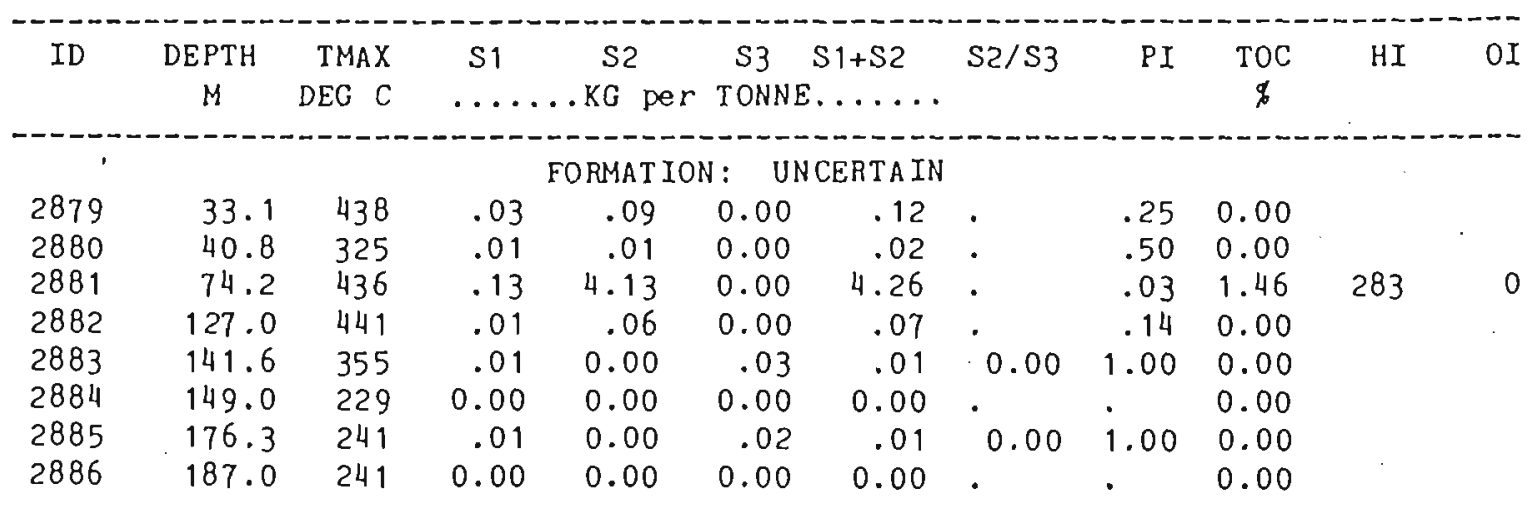




\begin{tabular}{|c|c|c|c|c|c|c|c|c|c|c|c|}
\hline ID & $\begin{array}{c}\text { DEPTH } \\
M\end{array}$ & $\begin{array}{r}\text { TMAX } \\
\text { DEG C }\end{array}$ & $\begin{array}{l}S 1 \\
\ldots .\end{array}$ & $\ldots$..KG per & $\begin{array}{c}\text { S3 } \\
\text { TONNE }\end{array}$ & $S 1+S 2$ & $\mathrm{~S}_{2} / \mathrm{S}_{3}$ & $P I$ & $\begin{array}{c}\text { TOC } \\
\mathscr{q}\end{array}$ & $H I$ & $O I$ \\
\hline & & & & FORMATI & BA & NEY CR & EKK & & & & \\
\hline 2887 & 38.7 & 436 & .53 & 6.72 & .09 & 7.25 & 74.67 & .07 & 1.15 & 584 & \\
\hline 2888 & 41.8 & 439 & .40 & 4.08 & .15 & 4.48 & 27.20 & .09 & .86 & 474 & 17 \\
\hline 2889 & 50.3 & 439 & 3.07 & 36.38 & .69 & 39.45 & 52.72 & .08 & 4.97 & 732 & 14 \\
\hline 2890 & 77.2 & 437 & .92 & 13.65 & .46 & 14.57 & 29.67 & .06 & 2.26 & 604 & 20 \\
\hline 2891 & 101.6 & 436 & 2.03 & 24.00 & .72 & 26.03 & 33.33 & .08 & 3.69 & 650 & 20 \\
\hline 2892 & 116.0 & 438 & 4.68 & 40.76 & .62 & 45.44 & 65.74 & .10 & 5.67 & 719 & 11 \\
\hline 2893 & 126.4 & 438 & 1.83 & 10.14 & .59 & 11.97 & 17.19 & .15 & 1.69 & 600 & 35 \\
\hline 2894 & 151.1 & 438 & 2.85 & 26.49 & .72 & 29.34 & 36.79 & .10 & 3.87 & 684 & 19 \\
\hline 2895 & 180.0 & 442 & 4.85 & 53.27 & .70 & 58.12 & 76.10 & .08 & $7 \cdot 34$ & 726 & 10 \\
\hline 2896 & 209.6 & 440 & 1.27 & 15.07 & .51 & 16.34 & 29.55 & .08 & 2.34 & 644 & 22 \\
\hline 2897 & 238.8 & 441 & 3.54 & 33.17 & .73 & 36.71 & 45.44 & .10 & 5.17 & 642 & 4 \\
\hline 2898 & 252.9 & 441 & 2.51 & 22.70 & .58 & 25.21 & 39.14 & .10 & 3.50 & 649 & 17 \\
\hline 2899 & 276.9 & 440 & .68 & 3.96 & .64 & 4.64 & 6.19 & .15 & 1.09 & 363 & 0 \\
\hline 2900 & 293.5 & 438 & 1.13 & 10.88 & .74 & 12.01 & 14.70 & .09 & 2.10 & 518 & 35 \\
\hline 2901 & 351.8 & 440 & .26 & 1.78 & .41 & 2.04 & 4.34 & .13 & .76 & 234 & 54 \\
\hline 2902 & 377.0 & 442 & .38 & 1.92 & .51 & 2.30 & 3.76 & .17 & .78 & 246 & 65 \\
\hline 2903 & 400.9 & 444 & .13 & .42 & .42 & .55 & 1.00 & .24 & 0.00 & & \\
\hline 2904 & 426.7 & 443 & .36 & 1.50 & .37 & .1 .86 & 4.05 & .19 & .70 & 214 & 53 \\
\hline 2905 & 458.0 & 440 & .20 & .43 & .37 & .63 & 1.16 & .32 & 0.00 & & \\
\hline 2906 & 479.9 & 442 & .45 & 1.44 & .37 & 1.89 & 3.89 & .24 & .72 & 200 & 51 \\
\hline 2907 & 510.1 & 442 & .57 & 1.92 & .48 & 2.49 & 4.00 & .23 & .90 & 213 & 53 \\
\hline 2908 & 524.7 & 441 & .25 & .64 & .33 & .89 & 1.94 & .28 & .46 & 139 & 72 \\
\hline 2909 & 554.0 & 443 & .71 & 1.71 & .40 & 2.42 & 4.28 & .29 & .84 & 204 & 48 \\
\hline 2910 & 581.4 & 444 & .74 & 1.89 & .42 & 2.63 & 4.50 & .28 & .76 & 249 & 55 \\
\hline 2911 & 601.5 & 445 & 1.08 & 2.90 & .54 & 3.98 & 5.37 & .27 & 1.25 & 232 & 43 \\
\hline 2912 & 664.6 & 443 & 1.45 & 3.77 & .42 & 5.22 & 8.98 & .28 & 1.59 & 237 & 26 \\
\hline 2913 & 699.9 & 440 & .72 & 1.02 & .27 & 1.74 & 3.78 & .41 & .59 & 173 & 46 \\
\hline 2914 & 722.8 & 413 & .65 & .64 & .39 & 1.29 & 1.64 & .50 & .30 & 213 & 130 \\
\hline 2915 & 731.6 & 449 & .99 & 2.85 & .40 & 3.84 & 7.13 & .26 & 1.44 & 198 & 28 \\
\hline 2916 & 759.8 & 444 & .94 & 1.49 & .44 & 2.43 & 3.39 & .39 & .86 & 173 & 51 \\
\hline 2917 & 794.6 & 448 & 1.08 & 2.51 & .51 & 3.59 & 4.92 & .30 & 1.54 & 163 & 33 \\
\hline 1673 & 805.9 & 444 & 1.20 & 2.53 & .36 & 3.73 & 7.03 & .32 & 2.12 & 119 & 17 \\
\hline 2918 & 840.8 & 446 & .46 & .71 & .36 & 1.17 & 1.97 & .39 & .58 & 122 & 62 \\
\hline 1674 & 854.0 & 451 & 1.29 & 4.83 & .59 & 6.12 & 8.19 & .21 & 3.67 & 132 & 16 \\
\hline 1675 & 858.7 & 459 & 1.25 & 3.89 & .74 & 5.14 & 5.26 & .24 & 3.38 & 115 & 22 \\
\hline 2919 & 866.5 & 446 & 1.71 & 4.48 & .62 & 6.19 & 7.23 & .28 & 2.81 & 159 & 22 \\
\hline 1676 & 875.8 & 446 & 1.12 & 2.49 & .76 & 3.61 & 3.28 & .31 & 2.57 & 97 & 30 \\
\hline 2921 & 894.6 & 449 & .49 & .54 & .48 & 1.03 & 1.13 & .48 & .70 & 77 & 69 \\
\hline 2922 & 903.0 & 450 & .23 & .38 & .27 & .61 & 1.41 & .38 & 0.00 & & \\
\hline 1677 & 906.2 & 432 & .01 & .03 & .30 & .04 & .10 & .25 & 0.00 & & \\
\hline
\end{tabular}


BASIN/AREA: MCARTHUR

WELL/LOCALITY: GR8

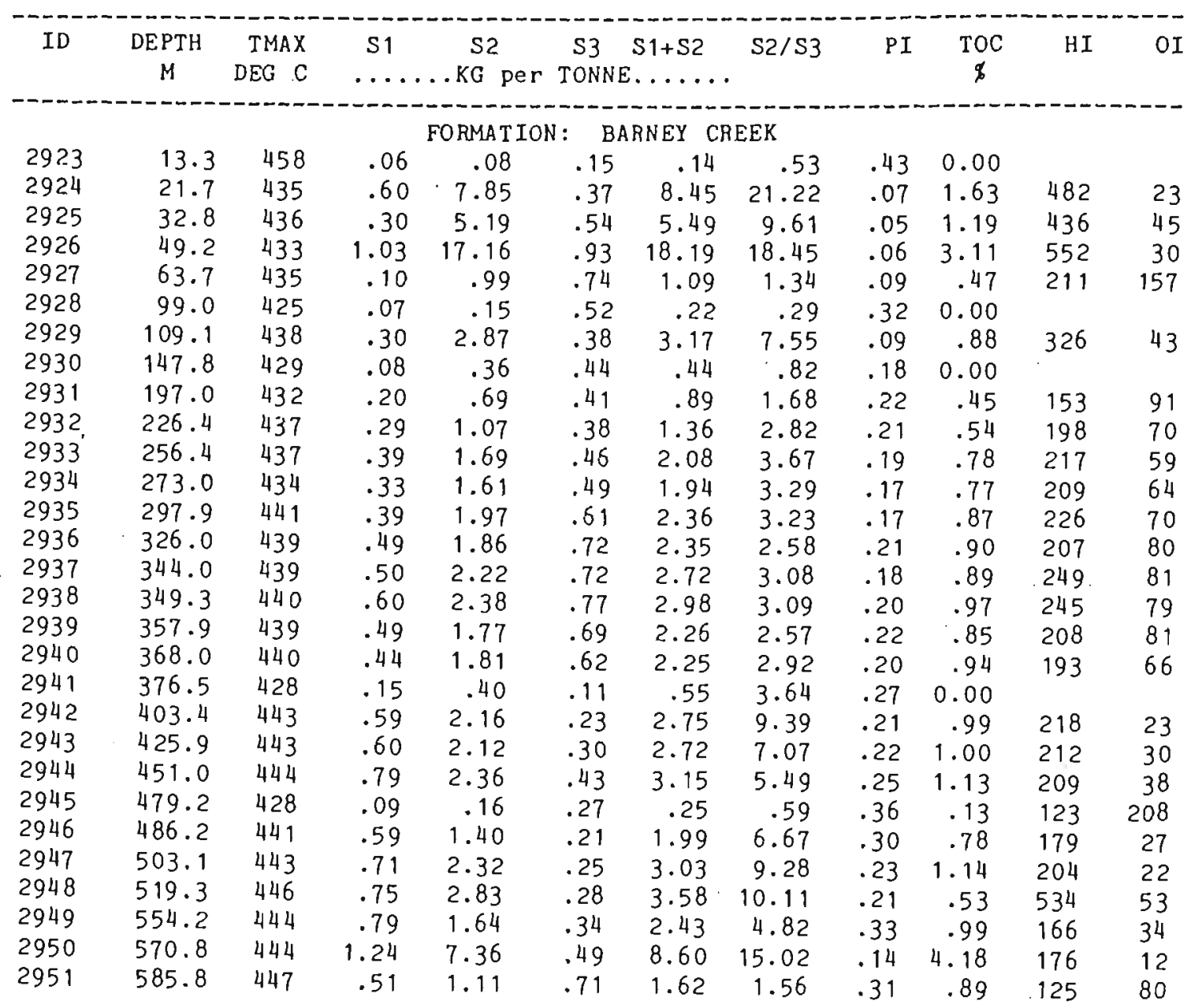


HELL/LOCALITY: GR9

\begin{tabular}{|c|c|c|c|c|c|c|c|c|c|c|c|}
\hline ID & $\begin{array}{c}\text { DEPTH } \\
M\end{array}$ & TMAX & \multicolumn{2}{|c|}{$\ldots . .$. KG per } & \multicolumn{2}{|c|}{$\begin{array}{c}\text { S3 } S i+S 2 \\
\text { TONNE...... }\end{array}$} & $\mathrm{S} 2 / \mathrm{S3}$ & $P I$ & $\underset{\%}{\text { TOC }}$ & $H I$ & OI \\
\hline & & & & FORMAT & $: \quad 8$ & NEY CR & EEK & & & & \\
\hline 2952 & 47.0 & 436 & .48 & 9.31 & .54 & 9.79 & 17.24 & .05 & 1.73 & 538 & 31 \\
\hline 2953 & 55.7 & 435 & .26 & 2.35 & .62 & 2.61 & 3.79 & .10 & .71 & 331 & 87 \\
\hline 2954 & 79.1 & 434 & 1.88 & 28.14 & 1.13 & 30.02 & 24.90 & .06 & 4.27 & 659 & 26 \\
\hline 2955 & 96.3 & 435 & 1.48 & 24.44 & 1.05 & 25.92 & 23.28 & .06 & 3.91 & 625 & 27 \\
\hline 2956 & 124.1 & 437 & .79 & 11.81 & 1.03 & 12.60 & 11.47 & .06 & 2.18 & 542 & 47 \\
\hline 2957 & 151.1 & 432 & 1.78 & 25.05 & 1.28 & 26.83 & 19.57 & .07 & 4.14 & 605 & 31 \\
\hline 2958 & 175.9 & 438 & .61 & 5.45 & 1.16 & 6.06 & 4.70 & .10 & 1.29 & 422 & \\
\hline 2959 & 201.6 & 440 & .23 & 1.86 & .81 & 2.09 & 2.30 & .11 & 0.00 & & \\
\hline 296 & 209.0 & 431 & .07 & .18 & .60 & .25 & .30 & .28 & 0.00 & & \\
\hline 2961 & 227.0 & 434 & .17 & .85 & .57 & 1.02 & 1.49 & .17 & .49 & 173 & 116 \\
\hline 2962 & 251.0 & 431 & .10 & .42 & .42 & .52 & 1.00 & .19 & 0.00 & & \\
\hline 2963 & 277.4 & 435 & .19 & .70 & .40 & .89 & 1.75 & .21 & .46 & 152 & 87 \\
\hline 2964 & 303.0 & 439 & 0.00 & 0.00 & .11 & 0.00 & 0.00 & . & .52 & 0 & 21 \\
\hline 2965 & 337.8 & 436 & .34 & 2.02 & .02 & 2.36 & - & .14 & .79 & 256 & 3 \\
\hline 2966 & 357.9 & 434 & .15 & .61 & .13 & .76 & 4.69 & .20 & .41 & 149 & 32 \\
\hline 2967 & 375.9 & 440 & .18 & .56 & .16 & .74 & 3.50 & .24 & .38 & 147 & 42 \\
\hline 2968 & 401.0 & 441 & .30 & 1.29 & .10 & 1.59 & 12.90 & .19 & .63 & 205 & 16 \\
\hline 1678 & 422.2 & 442 & .24 & 1.69 & .37 & 1.93 & 4.57 & .12 & 1.54 & 110 & 24 \\
\hline 2969 & 464.0 & 444 & .43 & 1.75 & .18 & 2.18 & 9.72 & .20 & .88 & 199 & 20 \\
\hline 1679 & 468.7 & 445 & .32 & 2.51 & .40 & 2.83 & 6.28 & .11 & 1.92 & 131 & 21 \\
\hline 1680 & 469.6 & 443 & .42 & 2.09 & .30 & 2.51 & 6.97 & .17 & 1.37 & 153 & 30 \\
\hline 1681 & 485.5 & 447 & 0.00 & .02 & .35 & .02 & .06 & 0.00 & 0.00 & & \\
\hline 2970 & 494.3 & 435 & .83 & 3.18 & .37 & 4.01 & 8.59 & .21 & 1.19 & 267 & ונ \\
\hline 1682 & 500.1 & 444 & .81 & 6.51 & .45 & $7 \cdot 32$ & 14.47 & .11 & 3.57 & 182 & 17 \\
\hline
\end{tabular}




\begin{tabular}{|c|c|c|c|c|c|c|c|c|c|c|c|}
\hline ID & $\begin{array}{c}\text { DEPTH } \\
M\end{array}$ & $\begin{array}{l}\text { TMAX } \\
\text { DEG C }\end{array}$ & $\begin{array}{c}\text { S1 } \\
\ldots\end{array}$ & ..KG per & $\begin{array}{c}\text { S3 } \\
\text { TONNE }\end{array}$ & $\begin{array}{l}S 1+S 2 \\
\ldots \ldots\end{array}$ & $\mathrm{S} 2 / \mathrm{S} 3$ & $P I$ & $\begin{array}{c}\text { TOC } \\
\%\end{array}$ & HI & 0 \\
\hline & & & & FORMAT I & $N:$ & EY CR & EEK & & & & \\
\hline 3444 & 23.2 & 433 & .06 & .68 & 0.00 & .74 & . & .08 & .26 & 262 & \\
\hline 3445 & 37.4 & 439 & .93 & 16.54 & .03 & 17.47 & . & .05 & 2.18 & 759 & \\
\hline 3049 & 51.9 & 437 & .58 & 9.84 & .34 & 10.42 & 28.94 & .06 & 1.98 & 497 & 17 \\
\hline 3446. & 57.9 & 438 & .54 & 9.83 & .16 & 10.37 & 61.44 & .05 & 1.69 & 582 & \\
\hline 1808 & 80.1 & 435 & 1.83 & 17.82 & .83 & 19.65 & 21.47 & .09 & 2.48 & 719 & 33 \\
\hline 1809 & 88.4 & 438 & 2.81 & 22.12 & 1.44 & 24.93 & $15 \cdot 36$ & .11 & 3.00 & 737 & 48 \\
\hline 3447 & 92.6 & 440 & 2.44 & 21.62 & .93 & 24.06 & 23.25 & .10 & 2.54 & 851 & 37 \\
\hline 3448 & 104.2 & 439 & 1.06 & 8.34 & 1.00 & 9.40 & 8.34 & .11 & 1.34 & 622 & 75 \\
\hline 3449 & 133.8 & 440 & 1.93 & 13.29 & 1.27 & 15.22 & 10.46 & .13 & 1.91 & 696 & 66 \\
\hline 3450 & $137 \cdot 3$ & 442 & 2.88 & 9.90 & 1.34 & 12.78 & 7.39 & .23 & 1.43 & 692 & 94 \\
\hline 3451 & 141.9 & 443 & 2.31 & 40.40 & 1.19 & 42.71 & 33.95 & .05 & 4.27 & 946 & 28 \\
\hline 1810 & 143.3 & 440 & 2.75 & 36.85 & 1.83 & 39.60 & 20.14 & .07 & 4.68 & 787 & 39 \\
\hline 3452 & 146.4 & 443 & 1.42 & 3.91 & 1.29 & 5.33 & 3.03 & .27 & .70 & 559 & 184 \\
\hline 3453 & 155.2 & 440 & 1.25 & 3.58 & 1.14 & 4.83 & 3.14 & .26 & .74 & 484 & 154 \\
\hline 1811 & 170.3 & 438 & .70 & 7.17 & 1.91 & 7.87 & 3.75 & .09 & 1.30 & 552 & 147 \\
\hline 1812 & 182.8 & 438 & 1.56 & 23.13 & 2.06 & 24.69 & 11.23 & .06 & 2.95 & 784 & 70 \\
\hline 3454 & 199.7 & 439 & 1.22 & 14.57 & .75 & 15.79 & 19.43 & .08 & 2.19 & 665 & 34 \\
\hline 1813 & 232.8 & 438 & 2.70 & 30.10 & 2.27 & 32.80 & 13.26 & .08 & 4.50 & 669 & 50 \\
\hline 3455 & 236.9 & 440 & 1.80 & 16.97 & 1.11 & 18.77 & 15.29 & .10 & 2.66 & 638 & 42 \\
\hline 3456 & 242.9 & 440 & 1.32 & 4.67 & 1.32 & 5.99 & 3.54 & .22 & 1.08 & 432 & 122 \\
\hline 1814 & 252.1 & 438 & 2.53 & 27.78 & 2.46 & 30.31 & 11.29 & .08 & 4.50 & 617 & 55 \\
\hline 3457 & 286.1 & 426 & .02 & .13 & .77 & .15 & .17 & .13 & .15 & 87 & 513 \\
\hline 1815 & 291.0 & 433 & 1.28 & 3.09 & 2.45 & 4.37 & 1.26 & .29 & .73 & 423 & 336 \\
\hline 1830 & 297.2 & 441 & .69 & 3.07 & 2.24 & 3.76 & 1.37 & .18 & .90 & 341 & 249 \\
\hline 3458 & 304.9 & 404 & 0.00 & 0.00 & .25 & 0.00 & 0.00 & . & 1.40 & 0 & 18 \\
\hline 1831 & 360.0 & 439 & .12 & .28 & 1.70 & .40 & .16 & .30 & .31 & 90 & 548 \\
\hline 3459 & 397.4 & 230 & 0.00 & 0.00 & .05 & 0.00 & 0.00 & - & .52 & 0 & 10 \\
\hline 1832 & 410.0 & 441 & .24 & .62 & 1.34 & .86 & .46 & .28 & .21 & 295 & 638 \\
\hline 1833 & 443.0 & 444 & .82 & 2.09 & 1.42 & 2.91 & 1.47 & .28 & .80 & 261 & 178 \\
\hline 1834 & 469.8 & 444 & .42 & 1.49 & 1.41 & 1.91 & 1.06 & .22 & .70 & 213 & 201 \\
\hline 3460 & 478.2 & 442 & .72 & 1.07 & .39 & 1.79 & 2.74 & .40 & .44 & 243 & 89 \\
\hline 1835 & 481.4 & 446 & .75 & 2.62 & 1.36 & 3.37 & 1.93 & .22 & 1.04 & 252 & 131 \\
\hline 3461 & 499.0 & 436 & .76 & 2.09 & .32 & 2.85 & 6.53 & .27 & .66 & 317 & 48 \\
\hline 3462 & 499.8 & 400 & 1.52 & 1.75 & .83 & 3.27 & 2.11 & .46 & .39 & 449 & 213 \\
\hline 3463 & 503.9 & 435 & 1.05 & 1.15 & .59 & 2.20 & 1.95 & .48 & .46 & 250 & 128 \\
\hline 1836 & 514.2 & 443 & 1.00 & 3.96 & 1.52 & 4.96 & 2.61 & .20 & 1.46 & 271 & 104 \\
\hline 1837 & 527.7 & 441 & .37 & .70 & 1.15 & 1.07 & .61 & .35 & .52 & 135 & 221 \\
\hline 3464 & 530.2 & 448 & .70 & 3.31 & .25 & 4.01 & 13.24 & .17 & 1.21 & 274 & 21 \\
\hline 1838 & 548.9 & 443 & .63 & .67 & 1.20 & 1.30 & .56 & .48 & .49 & 137 & 245 \\
\hline 1839 & 557.5 & 406 & 1.10 & 1.46 & 1.13 & 2.56 & 1.29 & .43 & .47 & 311 & 240 \\
\hline 1840 & 559.9 & 454 & .69 & .52 & .84 & 1.21 & .62 & .57 & .48 & 108 & 175 \\
\hline 1841 & 571.6 & 446 & .77 & 2.50 & .98 & 3.27 & 2.55 & .24 & 1.22 & 205 & 80 \\
\hline 1842 & 575.3 & 448 & .69 & 2.33 & .97 & 3.02 & 2.40 & .23 & 1.24 & 188 & 78 \\
\hline 1843 & 587.3 & 445 & .74 & 1.34 & 1.03 & 2.08 & 1.30 & .36 & .83 & 161 & 124 \\
\hline 1844 & 597.1 & 443 & 1.05 & 1.93 & .33 & 2.98 & 5.85 & .35 & .96 & 201 & 34 \\
\hline 1845 & 601.9 & 443 & 1.66 & 4.77 & 1.10 & 6.43 & 4.34 & .26 & 2.45 & 195 & 45 \\
\hline 1846 & 602.5 & 443 & 1.58 & 5.94 & .98 & 7.52 & 6.06 & .21 & .76 & 215 & 36 \\
\hline 3465 & 603.9 & 448 & 1.55 & 7.81 & .50 & 9.36 & 15.62 & .17 & 3.27 & 239 & 15 \\
\hline 1847 & 609.5 & 441 & 1.91 & 3.66 & 1.39 & 5.57 & 2.63 & .34 & 1.72 & 213 & 81 \\
\hline 1848 & 621.5 & 442 & .71 & .58 & 1.32 & 1.29 & .44 & .55 & .95 & 61 & 139 \\
\hline 1849 & 630.0 & 447 & .68 & .90 & 1.08 & 1.58 & .83 & .43 & .69 & 130 & 157 \\
\hline 1850 & 638.7 & 446 & 1.49 & 1.45 & .95 & 2.94 & 1.53 & .51 & .48 & 302 & 198 \\
\hline 1851 & 644.1 & 460 & .14 & .11 & .96 & .25 & .11 & .56 & .22 & 50 & 436 \\
\hline 1852 & 645.9 & 454 & .92 & 1.78 & 1.57 & 2.70 & 1.13 & .34 & 1.46 & 122 & 108 \\
\hline 1853 & 646.9 & 459 & .90 & 1.55 & .95 & 2.45 & 1.63 & .37 & 1.02 & 152 & 93 \\
\hline 3466 & 650.4 & 448 & 1.55 & 8.48 & .84 & 10.03 & 10.10 & .15 & 3.21 & 264 & 26 \\
\hline 1854 & 652.5 & 463 & .27 & .47 & .54 & .74 & .87 & .36 & .37 & 127 & 146 \\
\hline 1855 & 662.1 & 466 & .82 & 2.03 & .27 & 2.85 & 7.52 & .29 & .69 & 294 & 39 \\
\hline 856 & 668.5 & 470 & 0.00 & .01 & .09 & .01 & .11 & 0.00 & .06 & 17 & 150 \\
\hline
\end{tabular}




\begin{tabular}{|c|c|c|c|c|c|c|c|c|c|c|c|}
\hline ID & $\underset{M}{\text { DEPTH }}$ & $\begin{array}{r}\text { TMAX } \\
\text { DEG C }\end{array}$ & $\begin{array}{c}\text { s1 } \\
\ldots \ldots\end{array}$ & $\begin{array}{c}\mathrm{S} 2 \\
. \mathrm{KG} \text { per }\end{array}$ & $\begin{array}{c}\text { S3 } \\
\text { TONNE }\end{array}$ & $\begin{array}{l}s 1+s 2 \\
\ldots \ldots \ldots\end{array}$ & $\mathrm{S} 2 / \mathrm{S} 3$ & PI & $\begin{array}{c}\text { TOC } \\
\$\end{array}$ & $\mathrm{HI}$ & OI \\
\hline & & & & RMA T I & $\mathrm{BA}$ & NEY CR & EEK & & & & \\
\hline 1857 & 96.9 & 436 & .20 & 1.25 & 0.00 & 1.45 & . & .14 & 1.22 & 102 & 0 \\
\hline 1858 & 118.3 & 429 & .04 & .18 & 0.00 & .22 & . & .18 & .33 & 55 & j \\
\hline 1859 & 132.0 & 433 & .16 & .50 & 0.00 & .66 & . & .24 & .77 & 65 & 0 \\
\hline 1860 & 178.9 & 438 & .45 & 2.53 & .03 & 2.98 & 84.33 & .15 & 1.90 & 133 & 2 \\
\hline 1861 & 202.8 & 435 & .53 & 2.54 & .32 & 3.07 & 7.94 & .17 & 2.57 & 99 & 12 \\
\hline 1862 & 204.4 & 430 & .23 & .91 & .41 & 1.14 & 2.22 & .20 & 1.32 & 69 & 31 \\
\hline 1863 & 229.6 & 437 & .35 & 1.49 & .50 & 1.84 & 2.98 & .19 & 1.61 & 93 & 31 \\
\hline 1864 & 247.7 & 439 & .59 & 2.81 & .54 & 3.40 & 5.20 & .17 & 2.09 & 134 & 26 \\
\hline 1865 & 253.8 & 442 & .60 & 3.27 & .69 & 3.87 & 4.74 & .16 & 2.15 & 152 & 32 \\
\hline 3467 & 258.7 & 444 & .51 & 3.13 & .85 & 3.64 & 3.68 & .14 & 1.16 & 270 & 73 \\
\hline 1866 & 266.2 & 441 & .38 & 1.64 & .72 & 2.02 & 2.28 & .19 & 1.61 & 102 & 45 \\
\hline 1867 & 272.1 & 437 & .50 & 2.24 & .85 & 2.74 & 2.64 & .18 & 2.14 & 105 & 40 \\
\hline 1869 & 299.2 & 437 & .20 & .93 & 0.00 & 1.13 & . & .18 & 1.09 & 85 & 0 \\
\hline 1870 & 317.8 & 444 & .45 & 1.62 & .11 & 2.07 & 14.73 & .22 & 1.66 & $9 B$ & 7 \\
\hline 1871 & 336.3 & 438 & .28 & 1.36 & 0.00 & 1.64 & . & .17 & 1.35 & 101 & 0 \\
\hline 1872 & 339.4 & 446 & .39 & 1.40 & .16 & 1.79 & 8.75 & .22 & 1.44 & 97 & 11 \\
\hline 1873 & 347.3 & 443 & .77 & 2.34 & .31 & 3.11 & 7.55 & .25 & 1.80 & 130 & 17 \\
\hline 3468 & 347.4 & 445 & .67 & 2.16 & .71 & 2.83 & 3.04 & .24 & .98 & 220 & 72 \\
\hline 1874 & 350.4 & 420 & .28 & 1.11 & .39 & 1.39 & 2.85 & .20 & .60 & 185 & 65 \\
\hline 1875 & 378.3 & 443 & .31 & 1.23 & $.0 B$ & 1.54 & 15.38 & .20 & 1.39 & $8 B$ & 6 \\
\hline 1876 & 382.1 & 446 & .45 & .91 & .12 & 1.36 & 7.58 & .33 & 1.48 & 61 & 8 \\
\hline 1877 & 387.5 & 448 & .59 & 2.21 & .11 & 2.80 & 20.09 & .21 & 1.80 & 123 & 6 \\
\hline 1878 & 410.2 & 442 & .88 & 2.46 & .15 & 3.34 & 16.40 & .26 & 2.71 & 91 & 6 \\
\hline 1879 & 412.8 & 437 & 1.04 & 2.31 & .49 & 3.35 & 4.71 & .31 & 1.87 & 124 & 26 \\
\hline 1880 & 415.2 & 446 & 1.12 & 6.41 & .46 & 7.53 & 13.93 & .15 & 5.38 & 119 & 9 \\
\hline 3469 & 415.7 & 447 & 1.53 & 9.02 & .71 & 10.55 & 12.70 & .15 & 4.47 & 202 & 16 \\
\hline 1881 & 422.2 & 434 & .09 & .11 & .44 & .20 & .25 & .45 & .50 & 22 & 88 \\
\hline 1882 & 424.3 & 446 & .52 & 1.36 & .33 & 1.88 & 4.12 & .28 & 1.64 & 83 & 20 \\
\hline 1883 & 426.1 & 436 & .12 & .18 & .13 & .30 & 1.38 & .40 & .45 & 40 & 29 \\
\hline 1884 & 434.1 & 449 & .61 & 1.17 & .11 & 1.78 & 10.64 & .34 & 0.00 & & \\
\hline 1885 & 437.2 & 449 & .63 & 1.14 & .12 & 1.77 & 9.50 & .36 & 1.60 & 71 & 8 \\
\hline 1886 & 438.2 & 447 & .07 & .11 & 0.00 & .18 & . & .39 & .42 & 26 & 0 \\
\hline 1887 & 441.9 & 452 & .66 & 1.02 & .05 & 1.68 & 20.40 & .39 & 1.70 & 60 & 3 \\
\hline 3470 & 442.0 & 447 & .70 & 1.52 & .94 & 2.22 & 1.62 & .32 & 1.08 & 141 & 87 \\
\hline 1888 & 443.2 & 455 & .19 & .33 & 0.00 & .52 & $\cdot$ & .37 & 1.13 & 29 & 0 \\
\hline
\end{tabular}

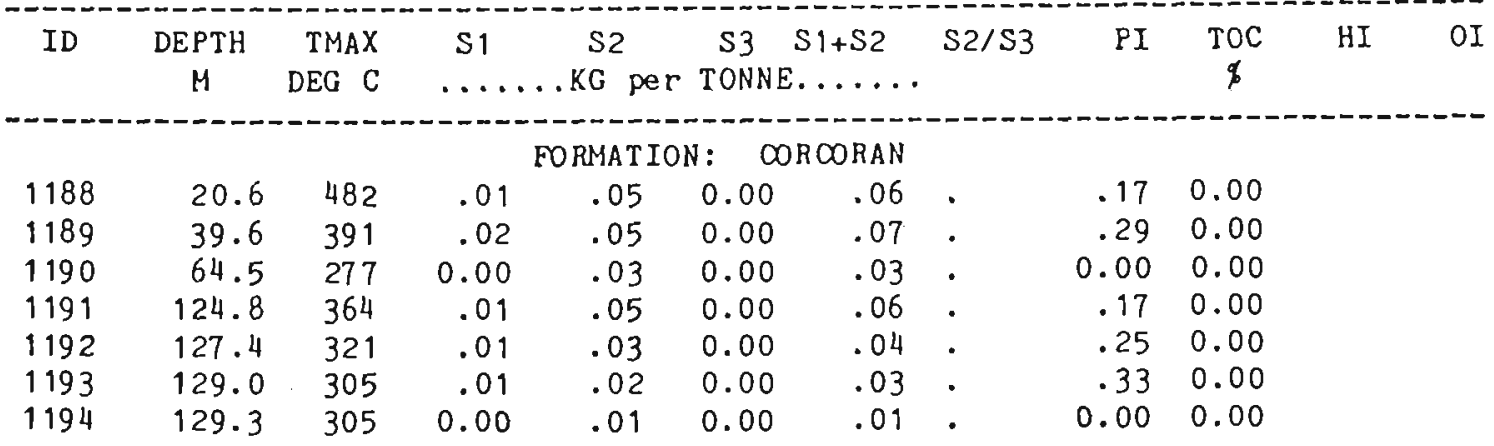




\begin{tabular}{|c|c|c|c|c|c|c|c|c|c|}
\hline 1195 & 130.9 & 301 & .01 & .04 & 0.00 & .05 & - & .20 & 0.00 \\
\hline 1196 & 132.0 & 277 & 0.00 & .01 & 0.00 & .01 & . & 0.00 & 0.00 \\
\hline 1197 & 135.0 & 364 & 0.00 & .02 & 0.00 & .02 & . & 0.00 & 0.00 \\
\hline 1198 & 136.9 & 320 & .01 & .02 & 0.00 & .03 & . & .33 & 0.00 \\
\hline 119 & 142.1 & 302 & .01 & .03 & 0.00 & .04 & . & .25 & 0.00 \\
\hline 1200 & 164.7 & 273 & 0.00 & 0.00 & 0.00 & 0.00 & . & . & 0.00 \\
\hline 1201 & 210.3 & 315 & 0.00 & .03 & 0.00 & .03 & - & 0.00 & 0.00 \\
\hline 1202 & 246.9 & 277 & 0.00 & .03 & 0.00 & .03 & . & 0.00 & 0.00 \\
\hline 1203 & 281.7 & 316 & .01 & .04 & 0.00 & .05 & . & .20 & 0.00 \\
\hline 1204 & 322.8 & 347 & 0.00 & 0.00 & 0.00 & 0.00 & . & . & 0.00 \\
\hline 1205 & 344.4 & 277 & 0.00 & .04 & 0.00 & .04 & 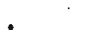 & 0.00 & 0.00 \\
\hline 1206 & 370.0 & 298 & 0.00 & 0.00 & 2.83 & 0.00 & 0.00 & . & 0.00 \\
\hline 1207 & 372.1 & 277 & .01 & .03 & 1.56 & .04 & .02 & .25 & 0.00 \\
\hline 1208 & 372.9 & 389 & .01 & .06 & 0.00 & .07 & . & .14 & 0.00 \\
\hline 1209 & 384.0 & 357 & 0.00 & .02 & 2.10 & .02 & .01 & 0.00 & 0.00 \\
\hline 1210 & 389.8 & 336 & 0.00 & .03 & 0.00 & .03 & . & 0.00 & 0.00 \\
\hline 1211 & 392.6 & 456 & .01 & .06 & .11 & .07 & .55 & .14 & 0.00 \\
\hline
\end{tabular}

\begin{tabular}{|c|c|c|c|c|c|c|c|c|c|c|c|}
\hline ID & $\begin{array}{c}\text { DEPTH } \\
\text { M }\end{array}$ & $\begin{array}{r}\text { TMAX } \\
\text { DEG C }\end{array}$ & $\begin{array}{c}S 1 \\
\ldots\end{array}$ &.${ }^{\mathrm{S} 2}$ per & $\begin{array}{c}\text { S3 } \\
\text { TONNE }\end{array}$ & $\begin{array}{l}\mathrm{s} 1+\mathrm{s} 2 \\
\ldots \ldots\end{array}$ & $\mathrm{S}_{2} / \mathrm{S}_{3}$ & $P I$ & $\begin{array}{c}\text { TOC } \\
\%\end{array}$ & $H I$ & OI \\
\hline & & & & O RMA T IO & : LY & NOTT-HS & & & & & \\
\hline 3020 & 21.4 & 511 & .10 & .15 & .16 & .25 & .94 & .40 & 0.00 & & \\
\hline 7 & 64.7 & 439 & .07 & .06 & .33 & .13 & .18 & .54 & .10 & 60 & 330 \\
\hline 8 & 65.9 & 337 & .02 & .03 & .30 & .05 & .10 & .40 & .02 & 150 & 1500 \\
\hline 9 & 66.7 & 277 & .03 & .09 & .13 & .12 & .69 & .25 & .27 & 33 & 48 \\
\hline 10 & 67.4 & 315 & .03 & .09 & .12 & .12 & .75 & .25 & .45 & 20 & 27 \\
\hline 13 & 84.9 & 224 & .22 & 0.00 & .32 & .22 & 0.00 & 1.00 & .07 & 0 & 457 \\
\hline 17 & 90.0 & 277 & .01 & 0.00 & .23 & .01 & 0.00 & 1.00 & .24 & 0 & 96 \\
\hline 18 & 90.4 & 277 & .01 & .09 & 0.00 & .10 & - & .10 & .17 & 53 & 0 \\
\hline 19 & 95.6 & 277 & .03 & .05 & .27 & .08 & .19 & .38 & .03 & 167 & 900 \\
\hline 23 & 101.6 & 256 & .02 & .02 & .33 & .04 & .06 & .50 & .02 & 100 & 1650 \\
\hline 27 & 113.7 & 225 & .02 & .02 & .28 & .04 & .07 & .50 & 0.00 & & \\
\hline 29 & 118.4 & 238 & .04 & .01 & .45 & .05 & .02 & .80 & .07 & 14 & 643 \\
\hline 30 & 118.9 & 349 & .01 & 0.00 & .23 & .01 & 0.00 & 1.00 & 0.00 & & \\
\hline 31 & $119 \cdot 3$ & 293 & .05 & .08 & .34 & .13 & .24 & .38 & .05 & 160 & 680 \\
\hline 32 & 120.7 & 277 & .03 & .03 & .49 & .06 & .06 & .50 & .30 & 10 & 163 \\
\hline 33 & 121.2 & 292 & .05 & 0.00 & .27 & .05 & 0.00 & 1.00 & .95 & 0 & 28 \\
\hline 34 & 121.5 & 230 & 0.00 & 0.00 & .24 & 0.00 & 0.00 & . & .05 & 0 & 480 \\
\hline 35 & 121.7 & 230 & .01 & 0.00 & .34 & .01 & 0.00 & 1.00 & .03 & 0 & 1133 \\
\hline 36 & 122.6 & 237 & .02 & .01 & .29 & .03 & .03 & .67 & .04 & 25 & 725 \\
\hline 37 & 123.3 & 216 & .04 & .03 & .36 & .07 & .08 & .57 & .09 & 33 & 400 \\
\hline 38 & 123.8 & 230 & 0.00 & .01 & .48 & .01 & .02 & 0.00 & .05 & 20 & 960 \\
\hline 39 & 124.0 & 277 & .02 & .06 & .15 & .08 & .40 & .25 & .28 & 21 & 54 \\
\hline 40 & 129.6 & 230 & .01 & .04 & .39 & .05 & .10 & .20 & .13 & 31 & 300 \\
\hline 41 & 129.8 & 277 & .04 & .17 & .07 & .21 & 2.43 & .19 & .94 & 18 & 7 \\
\hline 43 & 134.5 & 230 & .03 & .03 & .36 & .06 & .08 & .50 & .06 & 50 & 600 \\
\hline 46 & 137.7 & 224 & .02 & .02 & .30 & .04 & .07 & .50 & .05 & 40 & 600 \\
\hline 47 & 148.2 & 230 & 0.00 & .02 & .31 & .02 & .06 & 0.00 & .12 & 17 & 258 \\
\hline 368 & 149.2 & 233 & .02 & .13 & .21 & .15 & .62 & .13 & .16 & 81 & 131 \\
\hline 3021 & 156.8 & 420 & .09 & .06 & .13 & .15 & .46 & .60 & 0.00 & & \\
\hline 57 & 168.6 & 430 & .01 & 0.00 & .08 & .01 & 0.00 & 1.00 & .23 & 0 & 35 \\
\hline 70 & 188.0 & 337 & .01 & 0.00 & .10 & .01 & 0.00 & 1.00 & 0.00 & & \\
\hline 72 & 191.6 & 390 & .04 & .08 & 0.00 & .12 & $\cdot$ & .33 & 1.07 & 7 & 0 \\
\hline 73 & 192.1 & 279 & .02 & .01 & .10 & .03 & .10 & .67 & .04 & 25 & 250 \\
\hline 367 & 196.3 & 206 & .02 & .11 & .32 & .13 & .34 & .15 & .11 & 100 & 291 \\
\hline 77 & 196.4 & 359 & .02 & 0.00 & .12 & .02 & 0.00 & 1.00 & .07 & 0 & 171 \\
\hline
\end{tabular}




\begin{tabular}{|c|c|c|c|c|c|c|c|c|c|c|c|}
\hline 79 & 198.4 & 279 & .26 & .06 & .17 & .32 & .35 & .81 & .11 & 55 & 155 \\
\hline 84 & 208.7 & 416 & .02 & .11 & .08 & .13 & 1.38 & .15 & .50 & 22 & 16 \\
\hline 85 & 209.4 & 300 & .03 & .01 & .04 & .04 & .25 & .75 & .07 & 14 & 57 \\
\hline 86 & 209.8 & 279 & .01 & 0.00 & .03 & .01 & 0.00 & 1.00 & .03 & 0 & 100 \\
\hline 87 & 210.9 & 407 & .02 & .01 & .11 & .03 & .09 & .67 & .13 & 8 & 85 \\
\hline 88 & 211.1 & 319 & .03 & .02 & .03 & .05 & .67 & .60 & .13 & 15 & 23 \\
\hline 89 & 211.5 & 279. & .01 & 0.00 & .13 & .01 & 0.00 & 1.00 & .08 & 0 & 163 \\
\hline 90 & 212.1 & 359 & .01 & 0.00 & .17 & .01 & 0.00 & 1.00 & .08 & 0 & 213 \\
\hline 91 & 212.9 & 327 & .02 & .04 & .10 & .06 & .40 & .33 & .18 & 22 & 56 \\
\hline 92 & 213.1 & 279 & .04 & .03 & .08 & .07 & .38 & .57 & .17 & 18 & 47 \\
\hline 93 & 213.7 & 331 & .01 & .05 & 0.00 & .06 & $\cdot$ & .17 & .57 & 9 & 0 \\
\hline 94 & 214.5 & 324 & .02 & .07 & .05 & .09 & 1.40 & .22 & .39 & 18 & 13 \\
\hline 95 & 215.6 & 384 & .04 & .12 & 0.00 & .16 & . & .25 & .71 & 17 & \\
\hline 100 & 226.9 & 279 & 0.00 & 0.00 & .12 & 0.00 & 0.00 & . & .11 & 0 & 109 \\
\hline 102 & 230.5 & 351 & .02 & .01 & .10 & .03 & .10 & .67 & .04 & 25 & 250 \\
\hline 104 & 234.6 & 413 & .01 & .09 & 0.00 & .10 & . & .10 & .76 & 12 & 0 \\
\hline 366 & 236.5 & 231 & .03 & .10 & .33 & .13 & .30 & .23 & .25 & 40 & 132 \\
\hline 105 & 236.6 & 279 & 0.00 & 0.00 & .02 & 0.00 & 0.00 & • & .10 & 0 & 20 \\
\hline 106 & 239.4 & 416 & 0.00 & .03 & 0.00 & .03 & . & 0.00 & .27 & 11 & 0 \\
\hline 108 & 244.7 & 492 & .02 & .12 & .04 & .14 & 3.00 & .14 & .40 & 30 & 10 \\
\hline 109 & 246.4 & 279 & .01 & 0.00 & .18 & .01 & 0.00 & 1.00 & .04 & 0 & 450 \\
\hline 112 & 253.9 & 416 & .03 & .01 & .10 & .04 & .10 & .75 & .09 & 11 & 111 \\
\hline 369 & 263.7 & 225 & .03 & .14 & .25 & .17 & .56 & .18 & .33 & 42 & 76 \\
\hline & & & & DRMATI & 18 & $\mathrm{TT}-\mathrm{CA}$ & & & & & \\
\hline 119 & 270.7 & 432 & 0.00 & .02 & 0.00 & .02 & . & 0.00 & .30 & 7 & \\
\hline 3022 & 271.4 & 323 & .04 & .02 & 0.00 & .06 & - & .67 & 0.00 & & \\
\hline 120 & 272.5 & 279 & 0.00 & 0.00 & 0.00 & 0.00 & . & 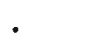 & .08 & 0 & \\
\hline 124 & 274.1 & 416 & .02 & .02 & 0.00 & .04 & - & .50 & .35 & 6 & \\
\hline 125 & 276.4 & 407 & .02 & .05 & .04 & .07 & 1.25 & .29 & .62 & 8 & \\
\hline 126 & 277.4 & 279 & .02 & 0.00 & .03 & .02 & 0.00 & 1.00 & .12 & 0 & 25 \\
\hline 128 & 282.0 & 416 & .01 & 0.00 & .06 & .01 & 0.00 & 1.00 & .25 & 0 & 5 \\
\hline 129 & 283.2 & 403 & .02 & .03 & .09 & .05 & .33 & .40 & .25 & 12 & 36 \\
\hline 136 & 286.6 & 306 & .05 & .03 & 0.00 & .08 & . & .63 & .25 & 12 & \\
\hline 140 & 298.1 & 279 & .02 & 0.00 & 0.00 & .02 & . & 1.00 & .05 & 0 & \\
\hline 141 & 299.5 & 328 & .01 & 0.00 & 0.00 & .01 & . & 1.00 & .08 & 0 & \\
\hline 370 & 305.3 & 225 & .01 & .08 & .02 & .09 & 4.00 & .11. & .16 & 50 & 13 \\
\hline 372 & 307.5 & 244 & .17 & .19 & .40 & .36 & .48 & .47 & 1.26 & 15 & 3 \\
\hline 143 & $312 \cdot 3$ & 318 & .02 & .02 & 0.00 & .04 & . & .50 & .45 & 4 & \\
\hline 146 & 316.6 & 279 & 0.00 & 0.00 & 0.00 & 0.00 & . & . & .34 & 0 & \\
\hline 147 & $317 \cdot 3$ & 428 & 0.00 & 0.00 & .07 & 0.00 & 0.00 & . & .17 & 0 & 41 \\
\hline 371 & 318.3 & 214 & .02 & .10 & .08 & .12 & 1.25 & .17 & .08 & 125 & 100 \\
\hline 149 & 319.9 & 218 & 0.00 & 0.00 & .07 & 0.00 & 0.00 & · & .21 & 0 & 33 \\
\hline 150 & 321.4 & 279 & 0.00 & .02 & .07 & .02 & .29 & 0.00 & .08 & 25 & 88 \\
\hline 155 & 327.1 & 279 & .03 & .09 & .04 & .12 & 2.25 & .25 & 1.74 & 5 & \\
\hline 158 & 332.5 & 244 & 0.00 & 0.00 & .46 & 0.00 & 0.00 & . & .06 & 0 & 767 \\
\hline 159 & 335.6 & 245 & .02 & .04 & .19 & .06 & .21 & .33 & .51 & 8 & 37 \\
\hline 162 & 338.5 & 248 & 0.00 & 0.00 & .13 & 0.00 & 0.00 & . & .51 & 0 & 2 \\
\hline 163 & 341.6 & 311 & .01 & .02 & .11 & .03 & .18 & .33 & 1.26 & 2 & \\
\hline 164 & 344.1 & 342 & .01 & .03 & .18 & .04 & .17 & .25 & 1.15 & 3 & 16 \\
\hline 165 & 351.7 & 304 & .01 & .02 & .14 & .03 & .14 & .33 & 1.14 & 2 & 12 \\
\hline 166 & 355.2 & 299 & .01 & .03 & .22 & .04 & .14 & .25 & 1.16 & 3 & 19 \\
\hline 168 & 358.3 & 341 & 0.00 & .05 & .17 & .05 & .29 & 0.00 & 1.36 & 4 & 1 \\
\hline 169 & 359.2 & 345 & .01 & .05 & .21 & .06 & .24 & .17 & 1.78 & 3 & 1 \\
\hline 170 & 359.5 & 327 & .02 & .04 & .53 & .06 & .08 & .33 & 1.73 & 2 & 3 \\
\hline 171 & 359.8 & 324 & .01 & .03 & .62 & .04 & .05 & .25 & 1.53 & 2 & \\
\hline 172 & 363.6 & 279 & 0.00 & .01 & .75 & .01 & .01 & 0.00 & 1.15 & 1 & 6 \\
\hline 373 & 381.3 & 302 & .03 & .18 & .27 & .21 & .67 & .14 & .56 & 32 & 4 \\
\hline 376 & 397.5 & 357 & .03 & .17 & .37 & .20 & .46 & .15 & .14 & 121 & 26 \\
\hline 374 & 507.5 & 289 & .04 & .17 & .13 & .21 & 1.31 & .19 & 1.10 & 15 & 1 \\
\hline 375 & 545.1 & 250 & .02 & .10 & .27 & .12 & .37 & .17 & .53 & 19 & \\
\hline
\end{tabular}


BASIN/AREA: MCARTHUR

WELL/LOCALITY: M2

\begin{tabular}{|c|c|c|c|c|c|c|c|c|c|c|c|}
\hline ID & $\begin{array}{c}\text { DEPTH } \\
M\end{array}$ & $\begin{array}{l}\text { TMAX } \\
\text { DEG C }\end{array}$ & $\begin{array}{l}\text { s1 } \\
\ldots .\end{array}$ & $\begin{array}{l}\mathrm{S} 2 \\
\mathrm{KG} \text { per }\end{array}$ & $\begin{array}{c}\text { S3 } \\
\text { TONNE }\end{array}$ & $\begin{array}{l}S 1+S 2 \\
\ldots \ldots\end{array}$ & $\mathrm{S} 2 / \mathrm{S} 3$ & PI & $\begin{array}{c}\text { TOC } \\
\%\end{array}$ & $\mathrm{HI}$ & OI \\
\hline & \multicolumn{11}{|c|}{ FORMATION: BARNEY CREEK } \\
\hline 1697 & 125.4 & 444 & .35 & .42 & 1.19 & .77 & .35 & .45 & .97 & 43 & 123 \\
\hline 1699 & $130 \cdot 3$ & 436 & .64 & .72 & .66 & $1 \cdot 36$ & 1.09 & .47 & 1.19 & 61 & 55 \\
\hline 1744 & 339.9 & 470 & .19 & .24 & .10 & .43 & 2.40 & .44 & .91 & 26 & 11 \\
\hline 1746 & 355.2 & 460 & .18 & .19 & .10 & $\cdot 37$ & 1.90 & .49 & .95 & 20 & 11 \\
\hline
\end{tabular}

BASIN/AREA: MCARTHUR WELL/LOCALITY: M3

\begin{tabular}{|c|c|c|c|c|c|c|c|c|c|c|c|}
\hline ID & $\begin{array}{c}\text { DEPTH } \\
M\end{array}$ & $\begin{array}{r}\text { TMAX } \\
\text { DEG C }\end{array}$ & $\begin{array}{c}\mathrm{si} \\
\ldots .\end{array}$ & $\begin{array}{l}S 2 \\
K G \text { per }\end{array}$ & $\begin{array}{c}\text { S3 } \\
\text { TONNE }\end{array}$ & $\begin{array}{l}S 1+S 2 \\
\ldots \ldots \ldots\end{array}$ & $\mathrm{S} 2 / \mathrm{S} 3$ & PI & $\begin{array}{c}\text { TOC } \\
\%\end{array}$ & $\mathrm{HI}$ & or \\
\hline & \multicolumn{11}{|c|}{ FORMATION: BARNEY CREEK } \\
\hline 1701 & 145.1 & 450 & .47 & 3.00 & .51 & 3.47 & 5.88 & .14 & 2.11 & 142 & 4 \\
\hline 1707 & 178.7 & 456 & .23 & .72 & .40 & .95 & 1.80 & .24 & .92 & 78 & \\
\hline 1740 & 334.6 & 464 & .13 & .11 & .13 & .24 & .85 & .54 & .65 & 17 & 0 \\
\hline
\end{tabular}

BASIN/AREA: MCARTHUR

WELL/LOCALITY: M13

\begin{tabular}{rrrrrrrrrrrr} 
ID & $\begin{array}{c}\text { DEPTH } \\
\text { M }\end{array}$ & TMAX & \multicolumn{1}{c}{ S1 } & S2 & S3 $31+S 2$ & S2/S3 & PI & TOC & HI & OI \\
3143 & 20.7 & 442 & 0.00 & .62 & .06 & .62 & 10.33 & 0.00 & .97 & 64 & 6 \\
3144 & 27.4 & 438 & .03 & .82 & .08 & .85 & 10.25 & .04 & .62 & 132 & 13 \\
3145 & 35.7 & 436 & .05 & 1.64 & .16 & 1.69 & 10.25 & .03 & 1.16 & 141 & 14 \\
3146 & 55.2 & 440 & .04 & 3.21 & .19 & 3.25 & 16.89 & .01 & 1.51 & 213 & 13 \\
3147 & 68.6 & 438 & .06 & 3.73 & .59 & 3.79 & 6.32 & .02 & 1.62 & 230 & 36 \\
3148 & 77.1 & 436 & .04 & 3.10 & .24 & 3.14 & 12.92 & .01 & 1.57 & 197 & 15 \\
3149 & 78.9 & 441 & .02 & 1.39 & .10 & 1.41 & 13.90 & .01 & 1.53 & 91 & 7 \\
3150 & 86.6 & 443 & .01 & .16 & .04 & .17 & 4.00 & .06 & 0.00 & &
\end{tabular}


BASIN/AREA : MCARTHUR

WELL/LOCALITY: M17/08

\begin{tabular}{|c|c|c|c|c|c|c|c|c|c|c|c|}
\hline ID & $\begin{array}{c}\text { DEPTH } \\
M\end{array}$ & $\begin{array}{r}\text { TMAX } \\
\text { DEG C }\end{array}$ & $\begin{array}{c}\mathrm{S} 1 \\
\ldots \ldots\end{array}$ & $\begin{array}{c}\mathrm{S} 2 \\
\mathrm{KG} \text { per }\end{array}$ & $\begin{array}{c}\text { S3 } \\
\text { TONNE }\end{array}$ & $\begin{array}{c}S 1+S 2 \\
E \ldots \ldots\end{array}$ & \multicolumn{4}{|c|}{$\$$} & OI \\
\hline & & & & RMAT IOI & & ARNEY CF & EEK & & & & \\
\hline 1695 & 111.9 & 456 & .15 & .23 & .71 & .38 & .32 & .39 & 1.41 & 16 & 50 \\
\hline 1698 & 126.6 & 457 & .23 & .62 & .81 & .85 & .77 & .27 & 3.20 & 19 & 25 \\
\hline 1702 & 147.8 & 453 & .22 & .49 & .37 & .71 & 1.32 & .31 & 2.97 & 16 & 12 \\
\hline 1706 & 173.5 & 397 & .19 & .09 & .43 & .28 & .21 & .68 & 1.00 & 9 & 43 \\
\hline 1711 & 193.9 & 350 & .09 & .06 & .22 & .15 & .27 & .60 & .89 & 7 & 25 \\
\hline 1714 & 242.0 & 322 & .01 & .04 & .04 & .05 & 1.00 & .20 & .62 & 6 & 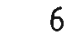 \\
\hline 1716 & 262.6 & 320 & .02 & .05 & .10 & .07 & .50 & .29 & .70 & 7 & 14 \\
\hline 1717 & 269.8 & 537 & .02 & .36 & .19 & .38 & 1.89 & .05 & .55 & 65 & 35 \\
\hline 1720 & 278.6 & 547 & .02 & .19 & .14 & .21 & 1.36 & .10 & .61 & 31 & 23 \\
\hline 1721 & 279.7 & 446 & .01 & .04 & .42 & .05 & .10 & .20 & .35 & 11 & 120 \\
\hline 1723 & 282.1 & 551 & .02 & .36 & .15 & .38 & 2.40 & .05 & .66 & 55 & 23 \\
\hline 1725 & 288.4 & 549 & .02 & .14 & .13 & .16 & 1.08 & .13 & .57 & 25 & 23 \\
\hline 1732 & 300.3 & 552 & .02 & .12 & .09 & .14 & 1.33 & .14 & .60 & 20 & 15 \\
\hline 1735 & 311.5 & 550 & .02 & .88 & .08 & .90 & 11.00 & .02 & .64 & 138 & 13 \\
\hline 1741 & 320.6 & 548 & .02 & .36 & 0.00 & .38 & . & .05 & .70 & 51 & 0 \\
\hline 1738 & 326.9 & 548 & .02 & .33 & .32 & .35 & 1.03 & .06 & .61 & 54 & 52 \\
\hline 1743 & 339.5 & 540 & .02 & .26 & .14 & .28 & 1.86 & .07 & .56 & 46 & 20 \\
\hline 1745 & 351.4 & 394 & 0.00 & .03 & .10 & .03 & .30 & 0.00 & .30 & 10 & 33 \\
\hline
\end{tabular}

BASIN/AREA : MCARTHUR

WELL/LOCALITY: MARINER NO D1

\begin{tabular}{|c|c|c|c|c|c|c|c|c|c|c|c|}
\hline \multirow[t]{2}{*}{ ID } & DEPTH & TMAX & S1 & $\mathrm{S} 2$ & S3 & $1+S 2$ & $\mathrm{~s} 2 / \mathrm{S} 3$ & PI & TOC & \multirow[t]{2}{*}{ HI } & \multirow[t]{2}{*}{ OI } \\
\hline & M & DEG C & $\ldots$ & . KG per & TONNI & ..... & & & & & \\
\hline & & & & OFMATIO & M & NORU & & & & & \\
\hline 1183 & 23.4 & 313 & 0.00 & 0.00 & 0.00 & 0.00 & - & - & 0.00 & & \\
\hline 1184 & 42.0 & 245 & 0.00 & 0.00 & 0.00 & 0.00 & - & - & 0.00 & & \\
\hline 1185 & 85.0 & 304 & 0.00 & 0.00 & 0.00 & 0.00 & . & - & 0.00 & & \\
\hline 1186 & 102.9 & 243 & 0.00 & 0.00 & 0.00 & 0.00 & . & - & 0.00 & & \\
\hline 1187 & 142.2 & 335 & 0.00 & .03 & 0.00 & .03 & - & 0.00 & 0.00 & & \\
\hline
\end{tabular}




\begin{tabular}{|c|c|c|c|c|c|c|c|c|c|c|c|}
\hline ID & $\begin{array}{c}\text { DEPTH } \\
M\end{array}$ & $\begin{array}{r}\text { TMAX } \\
\text { DEG C }\end{array}$ & $\begin{array}{l}S 1 \\
\ldots .\end{array}$ & $\begin{array}{l}S 2 \\
K G \text { per }\end{array}$ & $\begin{array}{l}\text { S3 } \\
\text { TONNE }\end{array}$ & $\begin{array}{l}\mathrm{s} 1+\mathrm{s} 2 \\
\ldots \ldots\end{array}$ & $\mathrm{S} 2 / \mathrm{S} 3$ & PI & $\begin{array}{c}\text { TOC } \\
\$\end{array}$ & $\mathrm{HI}$ & OI \\
\hline & & & & ORMATI & $\operatorname{Ln}$ & VOTT-CAR & & & & & \\
\hline 196 & 208.7 & 498 & .07 & .19 & .42 & .26 & .45 & .27 & .78 & 24 & 54 \\
\hline 197 & 212.2 & 394 & .09 & .11 & .46 & .20 & .24 & .45 & .28 & 39 & 164 \\
\hline 198 & 213.8 & 390 & .04 & .07 & .34 & .11 & .21 & .36 & .51 & 14 & 67 \\
\hline 199 & 214.6 & 441 & .06 & .18 & .74 & .24 & .24 & .25 & .56 & 32 & 132 \\
\hline 200 & 220.5 & 503 & .08 & .23 & .32 & .31 & .72 & .26 & .90 & 26 & 36 \\
\hline 201 & 222.9 & 472 & .17 & .21 & .37 & .38 & .57 & .45 & 1.51 & 14 & 25 \\
\hline 203 & 229.5 & 442 & .07 & .08 & .41 & .15 & .20 & .47 & .38 & 21 & 108 \\
\hline 208 & 244.9 & 348 & .07 & .05 & .35 & .12 & .14 & .58 & .83 & 6 & ${ }_{0}$ \\
\hline 211 & 247.6 & 448 & .12 & .14 & .21 & .26 & .67 & .46 & 1.48 & 9 & \\
\hline 212 & 249.6 & 504 & .08 & .15 & .40 & .23 & .38 & .35 & .93 & 16 & 43 \\
\hline 219 & 266.0 & 340 & .05 & .02 & .45 & .07 & .04 & .71 & .16 & 13 & 281 \\
\hline 220 & 267.8 & 398 & .09 & .09 & .46 & .18 & .20 & .50 & .35 & 26 & 131 \\
\hline 222 & 269.6 & 365 & .07 & .07 & .39 & .14 & .18 & .50 & .69 & 10 & 57 \\
\hline 226 & 275.3 & 504 & .07 & .17 & .27 & .24 & .63 & .29 & 1.07 & 16 & 25 \\
\hline 229 & 286.6 & 430 & 0.00 & 0.00 & .23 & 0.00 & 0.00 & & .07 & 0 & 329 \\
\hline 233 & 294.6 & 358 & .01 & .02 & .29 & .03 & .07 & .33 & .11 & 18 & 264 \\
\hline 239 & 336.1 & 390 & .02 & .09 & .23 & .11 & .39 & .18 & .99 & 9 & 23 \\
\hline 241 & 343.0 & 307 & .02 & .02 & .30 & .04 & .07 & .50 & .11 & 18 & 273 \\
\hline 243 & 349.6 & 353 & .08 & .13 & .27 & .21 & .48 & .38 & 1.06 & 12 & 25 \\
\hline 244 & 351.1 & 348 & .09 & .14 & .22 & .23 & .64 & .39 & .88 & 16 & 25 \\
\hline 245 & 351.4 & 441 & .09 & .23 & .29 & .32 & .79 & .28 & 3.44 & 7 & \\
\hline 246 & 354.0 & 337 & .03 & .08 & .60 & .11 & .13 & .27 & 1.07 & 7 & 56 \\
\hline 250 & 361.4 & 278 & 0.00 & .02 & $\cdot 30$ & .02 & .07 & 0.00 & .14 & 14 & 214 \\
\hline 251 & 364.5 & 415 & .11 & .21 & .49 & .32 & .43 & .34 & 1.23 & 17 & 40 \\
\hline 253 & 378.9 & 340 & .05 & .08 & .44 & .13 & .18 & .38 & .34 & 24 & 129 \\
\hline 254 & 381.3 & 278 & .03 & .10 & .41 & .13 & .24 & .23 & .67 & 15 & 61 \\
\hline 255 & 397.5 & 304 & .05 & .11 & .25 & .16 & .44 & .31 & .54 & 20 & 46 \\
\hline 258 & 411.9 & 271 & .03 & .12 & .25 & .15 & .48 & .20 & .74 & 16 & 34 \\
\hline 259 & 412.3 & 271 & .03 & .17 & .21 & .20 & .81 & .15 & 1.43 & 12 & 15 \\
\hline 260 & 415.5 & 245 & .04 & .11 & .29 & .15 & .38 & .27 & .49 & 22 & 59 \\
\hline 261 & 417.2 & 297 & .03 & .19 & .20 & .22 & .95 & .14 & 1.38 & 14 & 14 \\
\hline 263 & 419.5 & 245 & .05 & .06 & .29 & .11 & .21 & .45 & $\cdot 30$ & 20 & 97 \\
\hline 264 & 421.5 & 254 & .06 & .08 & .23 & .14 & .35 & .43 & .29 & 28 & 79 \\
\hline 267 & 427.1 & 254 & .02 & .08 & .16 & .10 & .50 & .20 & .29 & 28 & 55 \\
\hline 268 & 430.2 & 245 & .04 & .07 & .32 & .11 & .22 & .36 & .27 & 26 & 119 \\
\hline 270 & 440.9 & 245 & .03 & .09 & .28 & .12 & .3 & .25 & .28 & 32 & 100 \\
\hline 271 & 442.2 & 271 & .03 & .13 & .31 & .16 & .42 & .19 & .79 & 16 & 39 \\
\hline 272 & 443.5 & 264 & .03 & .10 & .52 & .13 & .19 & .23 & .07 & 143 & 743 \\
\hline 273 & 445.0 & 290 & .02 & .11 & .33 & .13 & .33 & .15 & .77 & 14 & 43 \\
\hline 274 & 454.0 & 271 & .03 & .14 & .33 & .17 & .42 & .18 & .11 & 127 & 300 \\
\hline 276 & 466.0 & 245 & .01 & .09 & .31 & .10 & .29 & .10 & .13 & 69 & 238 \\
\hline 278 & 470.1 & 271 & .03 & .18 & .23 & .21 & .78 & .14 & 1.56 & 12 & 15 \\
\hline 279 & 478.5 & 254 & .03 & .14 & .37 & .17 & .38 & .18 & 1.57 & 9 & 24 \\
\hline 281 & 484.4 & 483 & .03 & .27 & .39 & .30 & .69 & .10 & 2.34 & 12 & 17 \\
\hline 285 & 504.1 & 277 & .01 & .05 & .61 & .06 & .08 & .17 & .28 & 18 & 218 \\
\hline 286 & 505.4 & 351 & .02 & .17 & .33 & .19 & .52 & .11 & .58 & 29 & 57 \\
\hline 287 & 507.5 & 277 & .01 & .05 & .45 & .06 & .11 & .17 & .58 & 9 & 78 \\
\hline 288 & 518.1 & 36.0 & .01 & .03 & .39 & .04 & .08 & .25 & .23 & 13 & 170 \\
\hline 289 & 536.1 & 277 & .01 & .02 & .50 & .03 & .04 & .33 & .18 & 11 & 278 \\
\hline 293 & 545.1 & 342 & .02 & .04 & .45 & .06 & .09 & .33 & .60 & 7 & 75 \\
\hline 294 & 554.0 & 318 & .02 & .07 & .40 & .09 & .18 & .22 & 1.11 & 6 & 36 \\
\hline 297 & 560.1 & 317 & .01 & .07 & .32 & .08 & .22 & .13 & 1.63 & 4 & 20 \\
\hline 299 & 565.0 & 277 & .02 & .04 & .48 & .06 & .08 & .33 & 1.22 & 3 & 39 \\
\hline 300 & 568.8 & 374 & .02 & .10 & .41 & .12 & .24 & .17 & 1.39 & 7 & 29 \\
\hline 303 & 571.1 & 344 & .03 & .10 & .52 & .13 & .19 & .23 & 1.71 & 6 & 30 \\
\hline
\end{tabular}




$\begin{array}{rrrrrrrrrrrr}305 & 579.5 & 278 & .01 & .02 & .76 & .03 & .03 & .33 & .32 & 6 & 238 \\ 306 & 584.2 & 396 & .01 & .15 & .37 & .16 & .41 & .06 & 2.36 & 6 & 16 \\ 308 & 590.8 & 467 & .02 & .10 & .07 & .12 & 1.43 & .17 & 1.57 & 6 & 4 \\ 309 & 602.0 & 276 & .02 & .10 & .28 & .12 & .36 & .17 & .88 & 11 & 32 \\ 310 & 606.3 & 287 & 0.00 & .01 & .21 & .01 & .05 & 0.00 & .10 & 10 & 210 \\ 313 & 614.9 & 276 & .03 & .07 & .25 & .10 & .28 & .30 & .56 & 13 & 45 \\ 315 & 621.7 & 311 & .02 & .03 & .43 & .05 & .07 & .40 & .26 & 12 & 165 \\ 316 & 625.2 & 276 & .19 & .03 & .41 & .22 & .07 & .86 & .08 & 38 & 513\end{array}$

BASIN/AREA: MCARTHUR

WELL/LOCALITY: MANT 79-3

\begin{tabular}{|c|c|c|c|c|c|c|c|c|c|c|c|}
\hline ID & $\begin{array}{c}\text { DEPTH } \\
M\end{array}$ & $\begin{array}{l}\text { TMAX } \\
\text { DEG C }\end{array}$ & $\begin{array}{l}\text { s1 } \\
\ldots .\end{array}$ & $\begin{array}{l}\text { S2 } \\
\text { KG per }\end{array}$ & $\begin{array}{c}\text { S3 } \\
\text { TONNE }\end{array}$ & $\begin{array}{c}S 1+S 2 \\
E \ldots \ldots\end{array}$ & $\mathrm{S}_{2} / \mathrm{S}_{3}$ & PI & $\begin{array}{c}\text { TOC } \\
\%\end{array}$ & $\mathrm{HI}$ & $O I$ \\
\hline & & & & RMATIO & L) & XNOTT -C & & & & & \\
\hline 3009 & 24.2 & 467 & .23 & .27 & .41 & .50 & .66 & .46 & 1.63 & 17 & 25 \\
\hline 320 & 45.3 & 291 & .22 & .21 & .32 & .43 & .66 & .51 & .51 & 41 & 63 \\
\hline 321 & 46.5 & 353 & .24 & .20 & .23 & .44 & .87 & .55 & 1.12 & 18 & 21 \\
\hline 323 & $57 \cdot 3$ & 468 & .18 & .31 & .24 & .49 & 1.29 & .37 & 2.06 & 15 & 12 \\
\hline 325 & 75.2 & 443 & .10 & .15 & .38 & .25 & .39 & .40 & 1.01 & 15 & 38 \\
\hline 326 & 77.9 & 314 & .06 & .11 & .31 & .17 & .35 & .35 & .44 & 25 & 70 \\
\hline 329 & 99.0 & 300 & .10 & .16 & .29 & .26 & .55 & .38 & .70 & 23 & 41 \\
\hline 331 & 107.2 & 276 & .02 & .05 & .28 & .07 & .18 & .29 & .20 & 25 & 140 \\
\hline 332 & 113.8 & 305 & .03 & .13 & .14 & .16 & .93 & .19 & 1.62 & 8 & 9 \\
\hline 333 & 117.7 & 347 & .04 & .08 & .36 & .12 & .22 & .33 & 1.14 & 7 & 32 \\
\hline 335 & 127.1 & 349 & .03 & .10 & .35 & .13 & .29 & .23 & 1.64 & 6 & 21 \\
\hline 336 & 127.8 & 326 & .05 & .15 & .41 & .20 & .37 & .25 & 1.43 & 10 & 29 \\
\hline 337 & 128.4 & 241 & .06 & .18 & .27 & .24 & .67 & .25 & 1.13 & 16 & 24 \\
\hline 338 & 130.6 & 276 & .04 & .07 & .53 & .11 & .13 & .36 & $\cdot 39$ & 18 & 136 \\
\hline 339 & 134.2 & 318 & .03 & .09 & .48 & .12 & .19 & .25 & .26 & 35 & 185 \\
\hline 340 & 142.6 & 296 & .14 & .25 & .42 & .39 & .60 & $\cdot 36$ & 1.90 & 13 & 22 \\
\hline 341 & 144.2 & 331 & .04 & .17 & .34 & .21 & .50 & .19 & 2.02 & 8 & 17 \\
\hline 343 & 147.9 & 276 & .02 & .07 & .51 & .09 & .14 & .22 & .42 & 17 & 121 \\
\hline 3010 & 151.2 & 469 & .07 & .14 & .16 & .21 & .88 & .33 & 0.00 & & \\
\hline 344 & 156.7 & 341 & .05 & .19 & .30 & .24 & .63 & .21 & .97 & 20 & 31 \\
\hline & & & & RMATI & & D DC & MITE & & & & \\
\hline 345 & 164.6 & 276 & .03 & .05 & .36 & .08 & .14 & $\cdot 38$ & .17 & 29 & 212 \\
\hline 347 & $172 \cdot 3$ & 321 & .04 & .08 & .41 & .12 & .20 & .33 & $\cdot 38$ & 21 & 108 \\
\hline 348 & 174.3 & 276 & .03 & .09 & .33 & .12 & .27 & .25 & .15 & 60 & 220 \\
\hline 349 & 177.0 & 276 & .02 & .02 & .35 & .04 & .06 & .50 & .10 & 20 & 350 \\
\hline 3011 & 279.8 & 449 & .05 & .11 & .24 & .16 & .46 & $\cdot 31$ & 1.07 & 10 & 22 \\
\hline 3012 & 349.8 & 427 & .08 & .11 & .25 & .19 & .44 & .42 & 1.82 & 6 & 14 \\
\hline
\end{tabular}


BASIN/AREA: MCARTHUR

WELL/LOCALITY: MCA5

\begin{tabular}{|c|c|c|c|c|c|c|c|c|c|c|c|}
\hline ID & $\begin{array}{c}\text { DEPTH } \\
M\end{array}$ & $\begin{array}{l}\text { TMAX } \\
\text { DEG C }\end{array}$ & $\begin{array}{l}\text { s1 } \\
\ldots .\end{array}$ & $\begin{array}{c}\mathrm{S} 2 \\
\mathrm{KG} \text { per }\end{array}$ & $\begin{array}{c}\text { S3 } \\
\text { TONN }\end{array}$ & $\begin{array}{l}1+S 2 \\
\ldots \ldots\end{array}$ & $\mathrm{S}_{2} / \mathrm{S}_{3}$ & PI & $\begin{array}{c}\text { TOC } \\
\$\end{array}$ & $H I$ & OI \\
\hline & & & & DMA T I & & NEY CP & EK & & & & \\
\hline 3025 & 59.4 & 446 & .36 & .92 & .09 & 1.28 & 10.22 & .28 & .99 & 93 & 9 \\
\hline 3026 & 74.0 & 449 & .72 & 1.39 & .14 & 2.11 & 9. & .34 & 1.72 & 81 & 8 \\
\hline 3027 & 138.2 & 441 & .10 & .14 & .05 & .24 & 2.80 & .42 & 0.00 & & \\
\hline 3028 & 206.0 & 444 & .15 & .11 & .03 & .26 & 3.67 & .58 & 0.00 & & \\
\hline 3029 & 265.0 & 428 & .79 & .61 & .06 & 1.40 & 10.17 & .56 & .98 & 62 & 6 \\
\hline 3030 & 306.4 & 438 & .54 & .50 & .07 & 1.04 & 7.14 & .52 & 1.22 & 41 & 6 \\
\hline 3031 & 357.4 & 463 & .46 & .36 & 0.00 & .82 & . & .56 & 0.00 & & \\
\hline
\end{tabular}

BASIN/AREA: MCARTHUR WELL/LOCALITY: MCA10

\begin{tabular}{|c|c|c|c|c|c|c|c|c|c|c|c|}
\hline ID & $\begin{array}{c}\text { DEPTH } \\
M\end{array}$ & $\begin{array}{l}\text { TMAX } \\
\text { DEG C }\end{array}$ & $\begin{array}{l}\text { s1 } \\
\ldots .\end{array}$ & $\begin{array}{l}S 2 \\
K G \text { per }\end{array}$ & $\begin{array}{c}\text { S3 } \\
\text { TONNE }\end{array}$ & $\begin{array}{l}31+S 2 \\
\ldots \ldots\end{array}$ & $\mathrm{S} 2 / \mathrm{S} 3$ & PI & $\begin{array}{c}\text { TOC } \\
\mathscr{6}\end{array}$ & $H I$ & OI \\
\hline & & & & ORMAT IOI & & RNEY CR & EEK & & & & \\
\hline 3032 & $\begin{array}{l}27.8 \\
36.6\end{array}$ & $\begin{array}{l}458 \\
445\end{array}$ & $\begin{array}{l}.47 \\
.17\end{array}$ & $\begin{array}{r}1.13 \\
.15\end{array}$ & $\begin{array}{l}.05 \\
.03\end{array}$ & $\begin{array}{r}1.60 \\
.32\end{array}$ & $\begin{array}{r}22.60 \\
5.00\end{array}$ & $\begin{array}{l}.29 \\
.53\end{array}$ & $\begin{array}{l}4.05 \\
0.00\end{array}$ & 28 & 1 \\
\hline
\end{tabular}

BASIN/AREA : MCARTHUR

WELL/LOCALITY: MCARTHUR NO 6

\begin{tabular}{|c|c|c|c|c|c|c|c|c|c|c|c|}
\hline ID & $\begin{array}{c}\text { DEPTH } \\
M\end{array}$ & $\begin{array}{l}\text { TMAX } \\
\text { DEG C }\end{array}$ & $\begin{array}{c}S 1 \\
\ldots .\end{array}$ & $\begin{array}{l}S 2 \\
. K G \text { per }\end{array}$ & $\begin{array}{c}\mathrm{S3} \\
\text { TONN }\end{array}$ & $\begin{array}{l}s 1+s 2 \\
\ldots \ldots\end{array}$ & S2/S3 & PI & $\begin{array}{c}\text { TOC } \\
\%\end{array}$ & HI & $O I$ \\
\hline & & & & ORMA T IOI & & AM BAS & RP & & & & \\
\hline 1178 & 199.0 & 308 & 0.00 & 0.00 & .02 & 0.00 & 0.00 & - & 0.00 & & \\
\hline 1179 & 234.4 & 234 & 0.00 & 0.00 & 0.00 & 0.00 & . & . & 0.00 & & \\
\hline 1180 & 246.8 & 307 & 0.00 & 0.00 & 0.00 & 0.00 & . & . & 0.00 & & \\
\hline 1181 & 247.1 & 234 & 0.00 & 0.00 & 0.00 & 0.00 & . & . & 0.00 & & \\
\hline 1182 & 260.1 & 307 & 0.00 & 0.00 & 0.00 & 0.00 & . & . & 0.00 & & \\
\hline
\end{tabular}


BASIN/AREA : MCARTHUR

WELL/LOCALITY: MY4

\begin{tabular}{|c|c|c|c|c|c|c|c|c|c|c|c|}
\hline ID & $\begin{array}{c}\text { DEPTH } \\
M\end{array}$ & $\begin{array}{r}\text { TMAX } \\
\text { DEG C }\end{array}$ & $\begin{array}{l}\mathrm{s} 1 \\
\ldots .\end{array}$ & $\begin{array}{l}\text { S2 } \\
\text { KG per }\end{array}$ & $\begin{array}{c}\text { S3 } \\
\text { TONNE }\end{array}$ & $\begin{array}{l}1+\$ 2 \\
\ldots \ldots\end{array}$ & $S 2 / S 3$ & PI & $\underset{\mathscr{T}}{\mathrm{TOC}}$ & $H I$ & OI \\
\hline & \multicolumn{11}{|c|}{ FORMATION : BARNEY CREEK } \\
\hline 3013 & 20.4 & 437 & .22 & 1.43 & .11 & 1.65 & 13.00 & .13 & 1.21 & 118 & 9 \\
\hline 3014 & 56.1 & 440 & .56 & 2.56 & .30 & $3 \cdot 12$ & 8.53 & .18 & 1.79 & 143 & 17 \\
\hline 3015 & 79.4 & 445 & .40 & 1.46 & . 39 & 1.86 & 3.74 & .22 & 1.33 & 110 & 29 \\
\hline
\end{tabular}

BASIN/AREA : MCARTHUR

WELL/LOCALITY : MY5

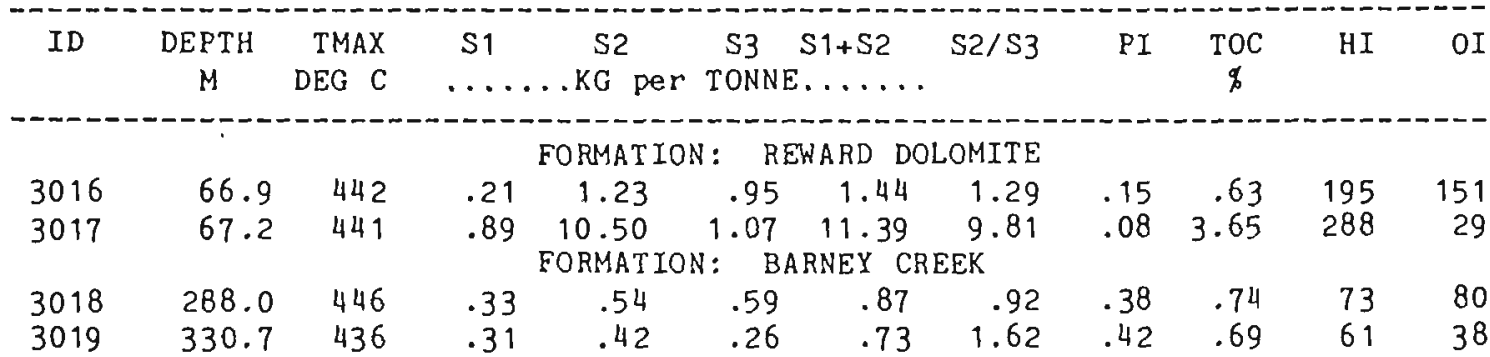

BASIN/AREA: MCARTHUR

WELL/LOCALITY: N27/63

\begin{tabular}{|c|c|c|c|c|c|c|c|c|c|c|c|}
\hline ID & $\begin{array}{c}\text { DEPTH } \\
M\end{array}$ & $\begin{array}{r}\text { TMAX } \\
\text { DEG C }\end{array}$ & $\begin{array}{c}S 1 \\
\ldots \ldots\end{array}$ & $\begin{array}{c}S 2 \\
. K G \text { per }\end{array}$ & $\begin{array}{l}\text { S3 } \\
\text { TONN }\end{array}$ & $\begin{array}{c}S 1+S 2 \\
E \ldots \ldots\end{array}$ & \multicolumn{5}{|c|}{$q$} \\
\hline & & & & ORMATI & B & RNEY CR & EEK & & & & \\
\hline 1690 & 31.8 & 452 & .19 & .13 & .26 & .32 & .50 & .59 & .78 & 17 & 33 \\
\hline 1694 & 105.5 & 465 & .11 & .32 & .54 & .43 & .59 & .26 & 1.98 & 16 & 27 \\
\hline 1696 & 116.4 & 468 & .03 & .05 & .70 & .08 & .07 & .38 & .56 & 9 & 125 \\
\hline 1700 & 145.3 & 445 & .04 & .04 & .06 & .08 & .67 & .50 & 1.18 & 3 & 5 \\
\hline 1703 & 153.0 & 422 & 0.00 & 0.00 & .21 & 0.00 & 0.00 & 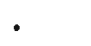 & .71 & 0 & 30 \\
\hline 1704 & 158.7 & 373 & .07 & .07 & .35 & .14 & .20 & .50 & .99 & 7 & 35 \\
\hline 1705 & 172.8 & 455 & .28 & .47 & .42 & .75 & 1.12 & .37 & 2.75 & 17 & 15 \\
\hline 1708 & 188.4 & 400 & .02 & .02 & .28 & .04 & .07 & .50 & .48 & 4 & 58 \\
\hline 1710 & 193.2 & 433 & .03 & .07 & .17 & .10 & .41 & .30 & .75 & 9 & 23 \\
\hline 1713 & 223.2 & 430 & .04 & .09 & .27 & .13 & .33 & .31 & .88 & 10 & 31 \\
\hline 1715 & 244.2 & 303 & .03 & .05 & .29 & .08 & .17 & .38 & .38 & 13 & 76 \\
\hline 1718 & 276.0 & 431 & .02 & $.0 B$ & .11 & .10 & .73 & .20 & .71 & 11 & 15 \\
\hline 1719 & 278.2 & 551 & .01 & .17 & .04 & .18 & 4.25 & .06 & .95 & 18 & 4 \\
\hline 1724 & 289.6 & 550 & .05 & .98 & .08 & 1.03 & 12.25 & .05 & .79 & 124 & 10 \\
\hline 1734 & 308.4 & 536 & .05 & .27 & .07 & .32 & 3.86 & .16 & .58 & 47 & 12 \\
\hline 1736 & 313.0 & 550 & .02 & .53 & .03 & .55 & 17.67 & .04 & .51 & 104 & 6 \\
\hline 1737 & 315.3 & 551 & .02 & .35 & .04 & .37 & 8.75 & .05 & .53 & 66 & 8 \\
\hline 1739 & 329.4 & 550 & .01 & .37 & .07 & .38 & 5.29 & .03 & .58 & 64 & 12 \\
\hline 1742 & 335.1 & 548 & .01 & .49 & 0.00 & .50 & · & .02 & .68 & 72 & 0 \\
\hline 1747 & 355.6 & 534 & .02 & .31 & .03 & .33 & 10.33 & .06 & .47 & 66 & 6 \\
\hline 1749 & 381.0 & 540 & 0.00 & .03 & 0.00 & .03 & . & 0.00 & .34 & 9 & 0 \\
\hline 1750 & 388.9 & 438 & .01 & .04 & .27 & .05 & .15 & .20 & .25 & 16 & 108 \\
\hline
\end{tabular}


BASIN/AREA: MCARTHUR

WELL/LOCALITY: S15/31

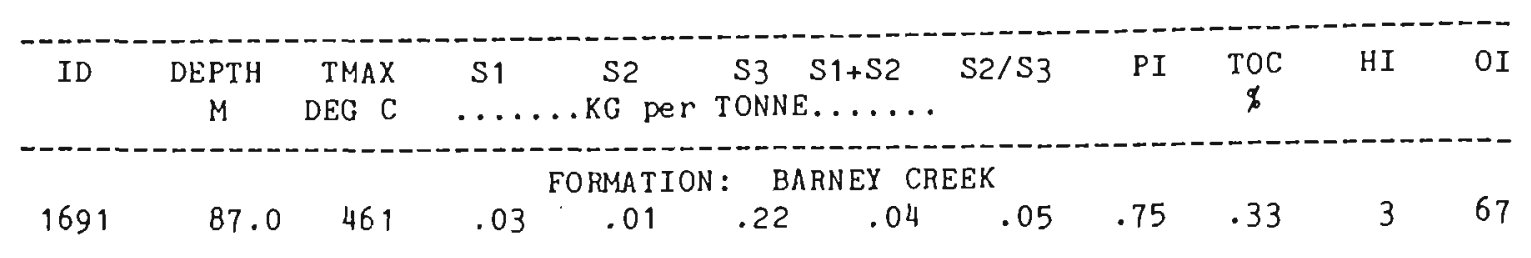

BASIN/AREA: MCARTHUR WELL/LOCALITY: T19

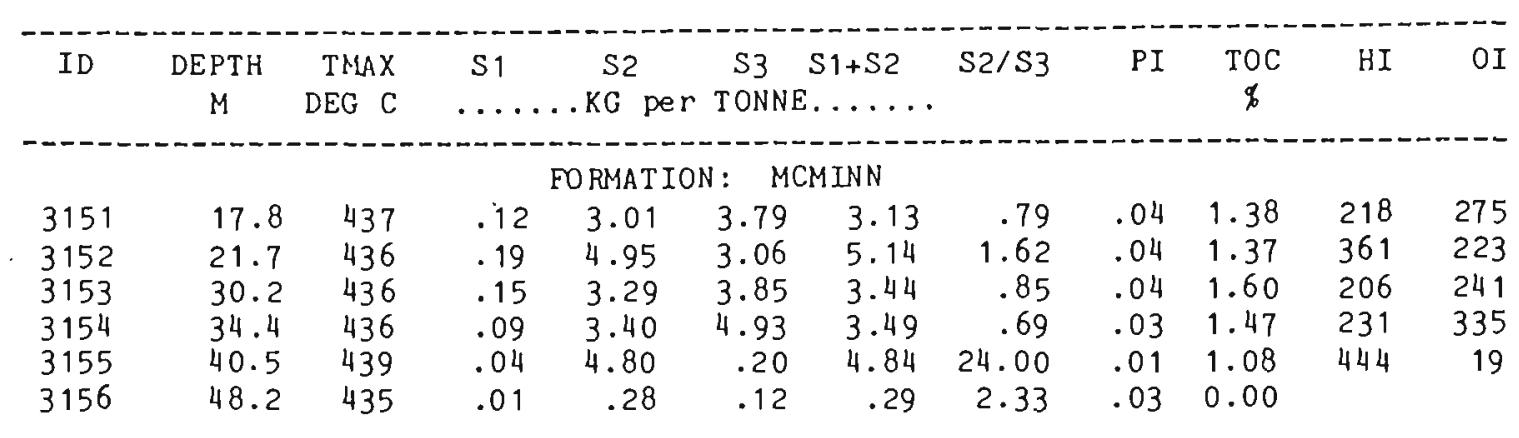

BASIN/AREA : MCARTHUR

WELL/LOCALITY: URAPUNGA NO 1

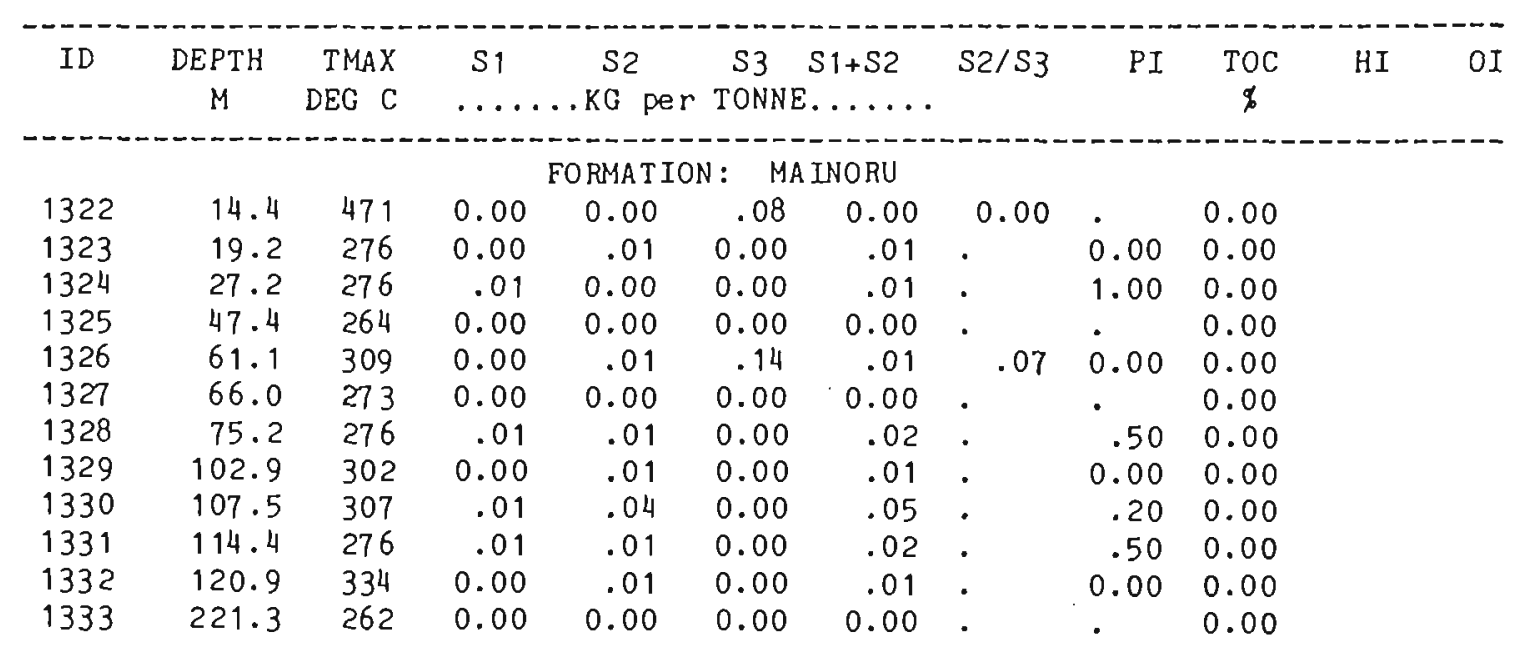

BASIN/AREA : MCARTHUR

WELL/LOCALITY: URAPUNGA NO 2

\begin{tabular}{|c|c|c|c|c|c|c|c|c|c|c|}
\hline ID & $\begin{array}{c}\text { DEPTH } \\
M\end{array}$ & $\begin{array}{r}\text { TMAX } \\
\text { DEG C }\end{array}$ & $\begin{array}{l}\text { s1 } \\
\ldots .\end{array}$ & $\begin{array}{c}\mathrm{S} 2 \\
. \mathrm{KG} \text { per }\end{array}$ & $\begin{array}{c}\text { S3 } \\
\text { TONNE }\end{array}$ & $\begin{array}{l}\mathrm{S} 1+\mathrm{S} 2 \\
\ldots . .\end{array}$ & $\mathrm{S} 2 / \mathrm{S} 3$ & PI & TOC & $\mathrm{HI}$ \\
\hline \multicolumn{11}{|c|}{ FORMATION: CORCORAN } \\
\hline 1334 & 6.4 & 245 & 0.00 & 0.00 & 0.00 & 0.00 & - & & 0.00 & \\
\hline 1335 & 27.6 & 269 & 0.00 & 0.00 & 0.00 & 0.00 & . & , & 0.00 & \\
\hline 1336 & 48.9 & 245 & 0.00 & 0.00 & 0.00 & 0.00 & . & . & 0.00 & \\
\hline 1337 & $67 \cdot 3$ & 276 & 0.00 & 0.00 & 0.00 & 0.00 & - & , & 0.00 & \\
\hline
\end{tabular}


BASIN/AREA: MCARTHUR

WELL/LOCALITY: URAPUNGA NO 3

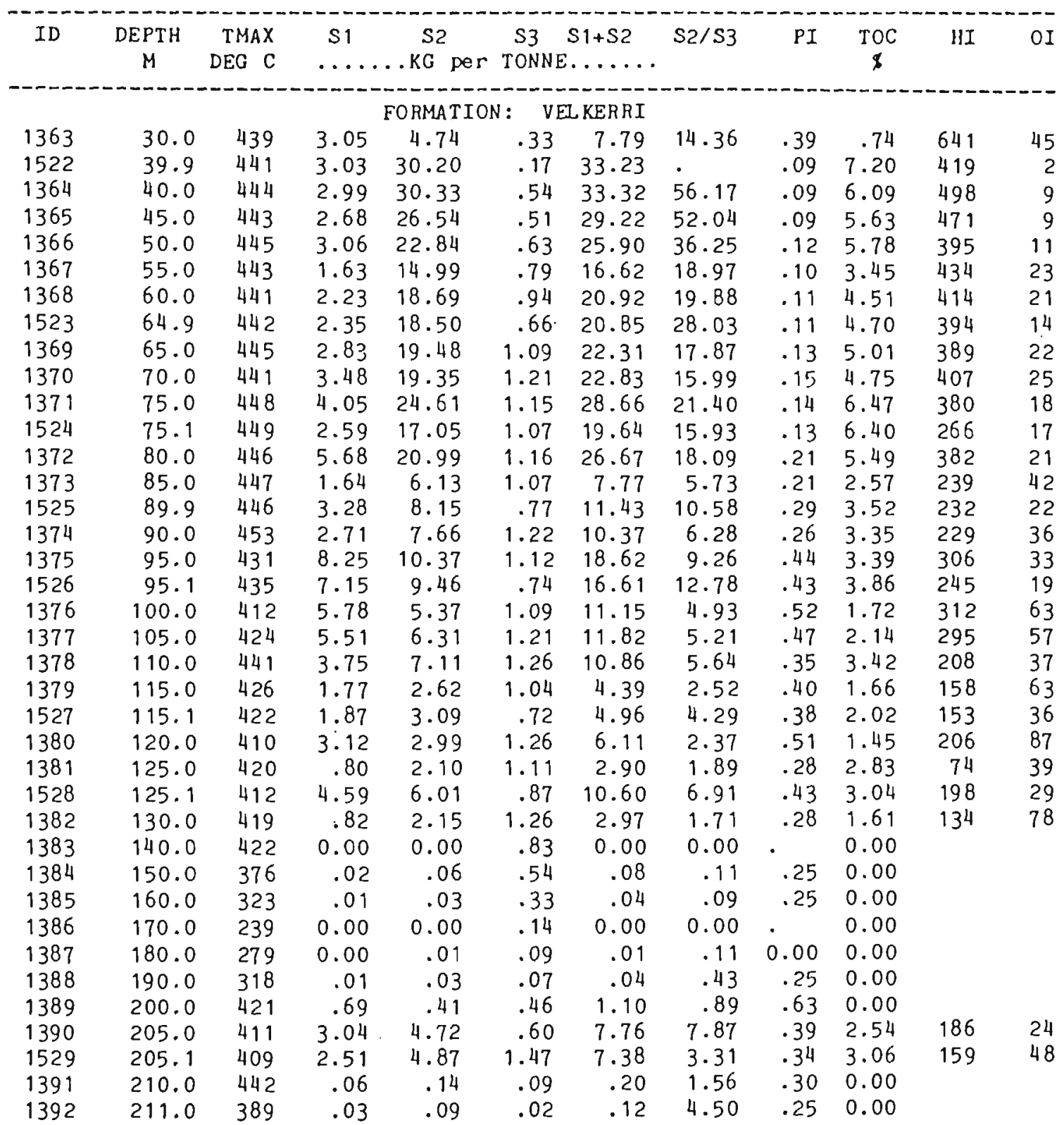




\begin{tabular}{|c|c|c|c|c|c|c|c|c|c|c|c|}
\hline ID & $\begin{array}{c}\text { DEPTH } \\
M\end{array}$ & $\begin{array}{r}\text { TMAX } \\
\text { DEG C }\end{array}$ & $\begin{array}{c}s 1 \\
\ldots\end{array}$ & $\ldots K G^{S 2}$ per & $\begin{array}{c}\text { S3 } \\
\text { TONNE }\end{array}$ & $\begin{array}{l}s 1+s 2 \\
\ldots \ldots \ldots\end{array}$ & $\mathrm{S} 2 / \mathrm{S3}$ & PI & $\underset{6}{\mathrm{TOC}}$ & $\mathrm{HI}$ & OI \\
\hline $\begin{array}{l}3157 \\
3158 \\
3159 \\
3160\end{array}$ & $\begin{array}{l}18.8 \\
26.4 \\
32.3 \\
39.7\end{array}$ & $\begin{array}{l}445 \\
348 \\
488 \\
420\end{array}$ & $\begin{array}{l}.03 \\
.03 \\
.03 \\
.11\end{array}$ & $\begin{array}{r}\text { FORMAT J } \\
.06 \\
.10 \\
.29 \\
.30\end{array}$ & 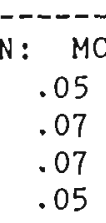 & $\begin{array}{l}N \\
.09 \\
.13 \\
.32 \\
.41\end{array}$ & $\begin{array}{l}1.20 \\
1.43 \\
4.14 \\
6.00\end{array}$ & $\begin{array}{l}.33 \\
.23 \\
.09 \\
.27\end{array}$ & $\begin{array}{l}0.00 \\
0.00 \\
0.00 \\
0.00\end{array}$ & & \\
\hline & & & & FORMATIOI & $V E$ & LKERRIE & & & & & \\
\hline $\begin{array}{l}3161 \\
3162\end{array}$ & 46.9 & 455 & .02 & .14 & .01 & .16 & 14.00 & .13 & 0.00 & & \\
\hline 3162 & 74.4 & 440 & .36 & 1.06 & .01 & 1.42 & . & .25 & .62 & 171 & \\
\hline 3163 & 80.8 & 444 & .46 & .86 & 0.00 & 1.32 & . & .35 & .48 & 179 & \\
\hline 3164 & 92.6 & 442 & .73 & 2.62 & 0.00 & 3.35 & - & .22 & .95 & 276 & \\
\hline 3165 & 132.6 & 439 & 3.85 & 28.18 & .40 & 32.03 & 70.45 & .12 & 6.61 & 426 & \\
\hline 3166 & 134.4 & 439 & 2.83 & 22.97 & .53 & 25.80 & 43.34 & .11 & 5.31 & 433 & 10 \\
\hline 3167 & 137.6 & 440 & 3.69 & 31.57 & .75 & 35.26 & 42.09 & .10 & 7.51 & 420 & \\
\hline 31 & 144.8 & 437 & 2.04 & 11.03 & .86 & 13.07 & 12.83 & .16 & 2.64 & 418 & \\
\hline 31 & 145.6 & 437 & 2.67 & 12.59 & 1.04 & 15.26 & 12.11 & .17 & 3.41 & 369 & \\
\hline 31 & 148.1 & 439 & 3.54 & 19.45 & 1.15 & 22.99 & 16.91 & .15 & 4.61 & 422 & \\
\hline 246 & 155.6 & 443 & 4.88 & 23.73 & .29 & 28.61 & 81.83 & .17 & 5.28 & 449 & \\
\hline 246 & 155.7 & 411 & 1.18 & 1.54 & 0.00 & 2.72 & . & .43 & .67 & 230 & \\
\hline 3171 & $157 \cdot 3$ & 439 & 5.70 & 37.16 & 1.24 & 42.86 & 29.97 & .13 & 8.68 & 428 & 1 \\
\hline 3172 & 160.0 & 440 & 4.04 & 21.95 & 1.08 & 25.99 & 20.32 & .16 & 5.27 & 417 & 20 \\
\hline 3173 & 163.7 & 444 & 3.51 & 24.37 & 1.18 & 27.88 & 20.65 & .13 & 5.87 & 415 & 20 \\
\hline 3174 & 168.1 & 444 & 4.96 & 16.31 & .87 & 21.27 & 18.75 & .23 & 4.15 & 393 & 21 \\
\hline 317 & 173.0 & 444 & 4.78 & 11.70 & 1.04 & 16.48 & 11.25 & .29 & 3.15 & 371 & 33 \\
\hline 3176 & 175.0 & 443 & 4.69 & 12.97 & 1.12 & 17.66 & 11.58 & .27 & 3.54 & 366 & 32 \\
\hline 3177 & 175.5 & 443 & 5.11 & 13.71 & 1.20 & 18.82 & 11.43 & .27 & 3.49 & 393 & 34 \\
\hline 3178 & 206.5 & 448 & 4.05 & 17.93 & 1.18 & 21.98 & 15.19 & .18 & 4.81 & 373 & 25 \\
\hline 3179 & 209.5 & 439 & 3.03 & 12.06 & 1.23 & 15.09 & 9.80 & .20 & 3.82 & 316 & 32 \\
\hline 3180 & 216.9 & 445 & 3.26 & 11.25 & 1.34 & 14.51 & 8.40 & .22 & 3.88 & 290 & 35 \\
\hline 318 & 236.0 & 451 & .01 & .07 & .83 & .08 & .08 & .13 & 0.00 & & \\
\hline 3182 & 258.5 & 385 & .01 & .10 & .51 & .11 & .2 & .09 & 0.00 & & \\
\hline 3183 & 302.7 & 413 & .01 & .12 & .25 & .13 & .48 & .08 & 0.00 & & \\
\hline 318 & 312.0 & 457 & .42 & .84 & .13 & 1.26 & 6.46 & .33 & .70 & 120 & 19 \\
\hline 318 & 320.0 & 448 & .54 & .39 & 0.00 & .93 & . & .58 & 0.00 & & \\
\hline 318 & 324.6 & 449 & 3.65 & 15.83 & .62 & 19.48 & 25.53 & .19 & 5.81 & 272 & 11 \\
\hline 318 & $327 \cdot 5$ & 451 & 4.05 & 15.88 & .90 & 19.93 & 17.64 & .20 & 5.71 & 278 & 16 \\
\hline 318 & 331.5 & 451 & 4.30 & 6.07 & 1.13 & 10.37 & 5.37 & .41 & 2.62 & 232 & 43 \\
\hline 31 & 339.0 & 461 & .28 & .47 & .58 & .75 & .8 & .37 & .48 & 98 & 121 \\
\hline 319 & 342.7 & 427 & 7.60 & 6.68 & .98 & 14.28 & 6.82 & .53 & 2.01 & 332 & 49 \\
\hline 2469 & 346.5 & 416 & 16.79 & 11.41 & .38 & 28.20 & 30.03 & .60 & 2.91 & 392 & 13 \\
\hline 3191 & 348.2 & 447 & 2.60 & 2.72 & .88 & 5.32 & 3.09 & .49 & 3.31 & 82 & 27 \\
\hline 319 & 351.1 & 451 & 2.63 & 3.26 & .49 & 5.89 & 6. & .45 & 1.64 & 199 & 30 \\
\hline 319 & 354.7 & 448 & 3.65 & 4.59 & .67 & 8.24 & 6.85 & .44 & 2.02 & 227 & 33 \\
\hline 31 & 357.0 & 448 & 3.39 & 4.19 & .88 & 7.58 & 4.76 & .45 & 2.23 & 188 & 3 \\
\hline & 360.3 & 447 & 3.09 & 3.64 & 1.06 & 6.73 & 3.4 & .46 & 2.13 & 171 & 50 \\
\hline 390 & 369.5 & 459 & .31 & .57 & .22 & .88 & 2.59 & .35 & .47 & 121 & 47 \\
\hline & & & & ORMAT & & 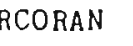 & & & & & \\
\hline 3197 & 410.1 & 453 & 0.00 & .07 & 0.00 & .07 & & 0.00 & 0.00 & & \\
\hline 319 & 421.3 & 396 & .01 & .05 & .06 & .06 & .83 & .17 & 0.00 & & \\
\hline 3198 & 433.4 & 459 & .03 & .15 & .24 & .18 & .63 & .17 & .29 & 52 & 83 \\
\hline 3200 & 463.8 & 346 & 0.00 & .08 & .01 & .08 & 8.00 & 0.00 & 0.00 & & \\
\hline
\end{tabular}


BASIN/AREA: MCARTHUR

WELL/LOCALITY: UAAPUNGA NO 5

\begin{tabular}{|c|c|c|c|c|c|c|c|c|c|c|c|}
\hline \multirow[t]{2}{*}{ ID } & DEPTH & TMAX & S1 & $\mathrm{S} 2$ & \multirow{2}{*}{\multicolumn{2}{|c|}{$\begin{array}{c}\text { S3 } \\
\text { S1 } 1+S 2 \\
\text { TONNE....... }\end{array}$}} & $\mathrm{S} 2 / \mathrm{S} 3$ & PI & TOC & \multirow[t]{2}{*}{$H I$} & \multirow[t]{2}{*}{$O I$} \\
\hline & $M$ & DEG C & \multicolumn{5}{|c|}{$\ldots \ldots \ldots$ KG per TONNE....... } & & & & \\
\hline \multicolumn{12}{|c|}{ FO PMATION: JALBOI MBR } \\
\hline 3211 & 117.4 & 436 & 0.00 & .03 & 0.00 & .03 & - & 0.00 & 0.00 & & \\
\hline 3212 & 119.1 & 382 & 0.00 & .01 & 0.00 & .01 & . & 0.00 & 0.00 & & \\
\hline 3213 & 123.0 & 275 & .02 & .01 & 0.00 & .03 & . & .67 & 0.00 & & \\
\hline 3214 & 123.7 & 300 & 0.00 & .01 & 0.00 & .01 & . & 0.00 & 0.00 & & \\
\hline 3216 & 140.0 & 275 & .01 & .02 & 0.00 & .03 & - & .33 & 0.00 & & \\
\hline \multicolumn{12}{|c|}{ FORNIATION: MAINORU } \\
\hline 3217 & 148.9 & 275 & .03 & .03 & 0.00 & .06 & . & .50 & .27 & 11 & 0 \\
\hline 3219 & 323.5 & 346 & .01 & .03 & 0.00 & .04 & . & .25 & 0.00 & & \\
\hline 3218 & 325.1 & 327 & 0.00 & .02 & 0.00 & .02 & . & 0.00 & 0.00 & & \\
\hline 3220 & 326.1 & 352 & .01 & .03 & 0.00 & .04 & . & .25 & 0.00 & & \\
\hline 3221 & 348.1 & 389 & .01 & .08 & 0.00 & .09 & . & .11 & .32 & 25 & 0 \\
\hline 3222 & 360.1 & 401 & .02 & .07 & 0.00 & .09 & . & .22 & 0.00 & & \\
\hline 3224 & 378.6 & 375 & .01 & .07 & 0.00 & .08 & . & .13 & 0.00 & & \\
\hline 3223 & 387.3 & 409 & .02 & .10 & 0.00 & .12 & - & .17 & .36 & 28 & 0 \\
\hline 3225 & 405.4 & 358 & .01 & .05 & 0.00 & .06 & - & .17 & 0.00 & & \\
\hline 3226 & 408.7 & 389 & .02 & .08 & 0.00 & .10 & . & .20 & 0.00 & & \\
\hline 3227 & 420.0 & 338 & .02 & .04 & 0.00 & .06 & . & .33 & 0.00 & & \\
\hline 3228 & 485.9 & 344 & .01 & .04 & 0.00 & .05 & . & .20 & 0.00 & & \\
\hline 3229 & 536.7 & 377 & .01 & .06 & 0.00 & .07 & . & .14 & 0.00 & & \\
\hline 3230 & 541.1 & 443 & .01 & .09 & 0.00 & .10 & . & .10 & 0.00 & & \\
\hline 3231 & 560.1 & 460 & .15 & .19 & 0.00 & .34 & . & .44 & .56 & 34 & 0 \\
\hline 3232 & 567.6 & 456 & .11 & .13 & 0.00 & .24 & . & .46 & .40 & 33 & 0 \\
\hline 3233 & 569.1 & 420 & .06 & .09 & 0.00 & .15 & . & .40 & 0.00 & & \\
\hline 3234 & 574.0 & 330 & .08 & .08 & 0.00 & .16 & . & .50 & 0.00 & & \\
\hline 3235 & 583.5 & 411 & .12 & .14 & 0.00 & .26 & . & .46 & .45 & 31 & 0 \\
\hline 3236 & 590.1 & 445 & .17 & .17 & 0.00 & .34 & . & .50 & .52 & 33 & 0 \\
\hline 3237 & 599.0 & 406 & .02 & .04 & 0.00 & .06 & . & .33 & 0.00 & & \\
\hline 3238 & 603.8 & 311 & .03 & .06 & 0.00 & .09 & . & .33 & 0.00 & & \\
\hline
\end{tabular}


BASIN/AREA: MCARTHUR

WELL/LOCALITY: WF7

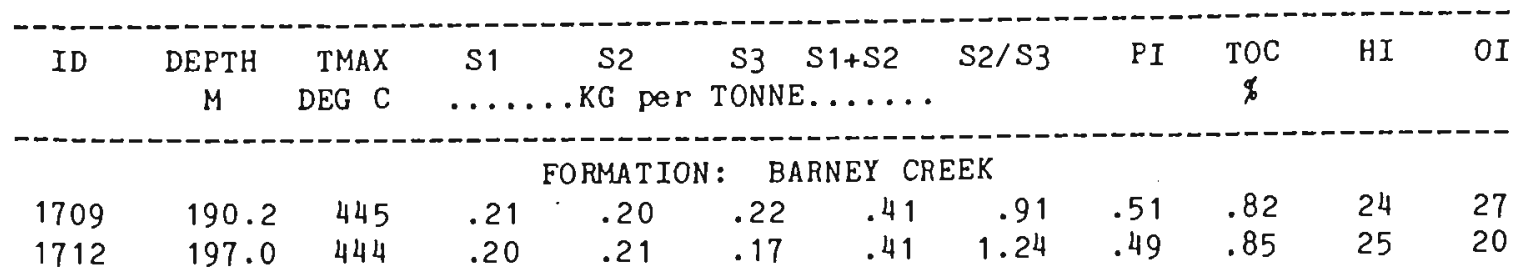

BASIN/AREA: MCARTHUR

WELL/LOCALITY: WMG

\begin{tabular}{|c|c|c|c|c|c|c|c|c|c|c|c|}
\hline ID & $\begin{array}{c}\text { DEPTH } \\
M\end{array}$ & $\begin{array}{l}\text { TMAX } \\
\text { DEG C }\end{array}$ & $\begin{array}{l}s 1 \\
\ldots \ldots\end{array}$ & $\begin{array}{l}\mathrm{S} 2 \\
\mathrm{KG} \text { per }\end{array}$ & $\begin{array}{l}\text { S3 } \\
\text { TONNE }\end{array}$ & $\begin{array}{l}s 1+s 2 \\
\ldots \ldots \ldots\end{array}$ & $\mathrm{s} 2 / \mathrm{s} 3$ & PI & $\begin{array}{c}\text { TOC } \\
\not 6\end{array}$ & HI & OI \\
\hline & \multicolumn{11}{|c|}{ FORMATION: BARNEY CREEK } \\
\hline 3034 & 104.2 & 462 & .61 & .46 & .08 & 1.07 & 5.75 & .57 & 1.22 & 38 & \\
\hline 3035 & 200.8 & 484 & .64 & .50 & .12 & 1.14 & 4.17 & .56 & 1.87 & 27 & \\
\hline 3036 & 294.0 & 450 & .02 & .04 & .03 & .06 & 1.33 & .33 & 0.00 & & \\
\hline 3037 & 423.6 & 415 & .03 & .10 & .01 & .13 & 10.00 & .23 & 0.00 & & \\
\hline 3038 & $519 \cdot 3$ & 334 & .02 & .04 & 0.00 & .06 & & .33 & 0.00 & & \\
\hline
\end{tabular}

BASIN/AREA: MCARTHUR

WELL/LOCALITY : $\quad$ X28

\begin{tabular}{|c|c|c|c|c|c|c|c|c|c|c|c|}
\hline ID & $\begin{array}{c}\text { DEPTH } \\
M\end{array}$ & $\begin{array}{r}\text { TMAX } \\
\text { DEG C }\end{array}$ & $\begin{array}{l}S 1 \\
\ldots\end{array}$ & $\begin{array}{l}\mathrm{S} 2 \\
\mathrm{KG}\end{array}$ & $\begin{array}{c}\text { S3 } \\
\text { TONN }\end{array}$ & $\begin{array}{l}S 1+S 2 \\
\ldots \ldots .\end{array}$ & 23 & PI & $\underset{x}{\text { TOC }}$ & $H I$ & $O I$ \\
\hline & & & & ORMATIO & MC & MINN & & & & & \\
\hline 3130 & 16.9 & 432 & .18 & 4.65 & .37 & 4.83 & 12.57 & .04 & 1.15 & 404 & 32 \\
\hline 3131 & 32.0 & 433 & .36 & 7.08 & 1.46 & 7.44 & 4.85 & .05 & 1.85 & 383 & 79 \\
\hline 3132 & 39.9 & 430 & .18 & 4.13 & .46 & 4.31 & 8.98 & .04 & 1.27 & 325 & 36 \\
\hline 3133 & 50.3 & 432 & .24 & 2.41 & 2.96 & 2.65 & .81 & .09 & 1.00 & 241 & 296 \\
\hline 3134 & 52.4 & 433 & .12 & 2.95 & 6.97 & 3.07 & .42 & .04 & 1.28 & 230 & 545 \\
\hline 3135 & 54.3 & 434 & .12 & 2.23 & 4.82 & 2.35 & .46 & .05 & .91 & 245 & 530 \\
\hline 3136 & 59.4 & 433 & .05 & 1.37 & 1.54 & 1.42 & .89 & .04 & .59 & 232 & 261 \\
\hline 3137 & 60.7 & 435 & .10 & 2.18 & 7.13 & 2.28 & .31 & .04 & 1.03 & 212 & 692 \\
\hline 3138 & 61.0 & 435 & .12 & 2.38 & 7.22 & 2.50 & .33 & .05 & 1.17 & 203 & 617 \\
\hline 3139. & 63.7 & 435 & .07 & 1.86 & 10.21 & 1.93 & .18 & .04 & 1.02 & 182 & 1001 \\
\hline 3140 & 70.7 & 435 & .05 & .65 & .32 & .70 & 2.03 & .07 & .62 & 105 & 52 \\
\hline 3141 & 74.1 & 437 & .05 & 1.28 & .52 & 1.33 & 2.46 & .04 & .72 & 178 & 72 \\
\hline 3142 & 82.9 & 436 & .09 & 1.15 & .24 & 1.24 & 4.79 & .07 & .52 & 221 & 46 \\
\hline 3352 & 83.2 & 440 & .50 & 1.84 & .04 & 2.34 & 46.00 & .21 & .38 & 484 & 11 \\
\hline
\end{tabular}




\title{
APPENDIX O
}

\section{SOLUBLE EXTRACT AND HYDROCARBON YIELDS}

\begin{abstract}
Abbreviations:
$\mathrm{PPM}=$ parts per million

$\mathrm{MG} / \mathrm{G}$ ORG $\mathrm{C}=$ milligrams per gram of organic carbon

SAT/AROM = ratio of saturated to aromatic hydrocarbons

Full well and stratigraphic names are given in Appendices $\mathrm{A}$ and B.
\end{abstract}

Note: wells arranged only in alphabetical order. 
BASIN: MCARTHUR

HELL : $82 / 1$

\begin{tabular}{|c|c|c|c|c|c|c|c|}
\hline \multirow[t]{2}{*}{ ID } & DEPTH & ORG C & EXTRACT & HC'S & \multicolumn{3}{|c|}{ HYDROCARBONS } \\
\hline & $M$ & \% & $\ldots \ldots$ PPM & $\ldots$ & MG/G ORG & $\begin{array}{l}\text { C } \\
\text { EXTRACT }\end{array}$ & SAT/AROM \\
\hline & & & FORMATION: & LANSEN & CREEK SH & & \\
\hline 1638 & 412.8 & 1.49 & 981 & 318 & $21 \cdot 3$ & 32.4 & 1.78 \\
\hline 1639 & 424.0 & .90 & 1655 & 713 & 79.2 & 43.1 & 1.72 \\
\hline 1640 & 427.8 & .91 & 2951 & 1864 & 204.9 & 63.2 & 2.04 \\
\hline
\end{tabular}

BASIN : MCARTHUR

WELL: $\quad 82 / 6$

\begin{tabular}{|c|c|c|c|c|c|c|c|}
\hline \multirow[t]{2}{*}{ ID } & DEPTH & ORG $\mathrm{C}$ & EXTRACT & $\mathrm{HC} ' \mathrm{~S}$ & \multicolumn{3}{|c|}{ HYDROCARBONS } \\
\hline & $M$ & $\%$ & ......PPM. & $\ldots$. & $\mathrm{MG} / \mathrm{G}$ ORG C & $\begin{array}{c}\% \text { IN } \\
\text { EXTRACT }\end{array}$ & SAT/AROR \\
\hline & & & FORMATION : & YALCO & & & \\
\hline 1531 & 88.0 & $1 \cdot 36$ & 692 & 207 & 15.2 & 29.9 & .37 \\
\hline 1532 & 94.1 & .84 & 649 & 226 & 26.8 & 34.8 & .62 \\
\hline 1548 & 124.9 & 1.61 & 467 & 57 & 3.5 & 12.1 & .31 \\
\hline 1169 & 125.7 & 5.37 & $\begin{array}{c}3793 \\
\text { FORMATION }\end{array}$ & $\begin{array}{l}1799 \\
\text { LYNOTT-DON }\end{array}$ & $\begin{array}{r}33.5 \\
\mathrm{~N}\end{array}$ & 47.4 & .39 \\
\hline 1551 & 290.3 & 1.21 & 797 & 288 & 23.8 & 36.1 & 1.56 \\
\hline
\end{tabular}

BASIN: MCARTHUR

WELL: $\quad 82 / 7$

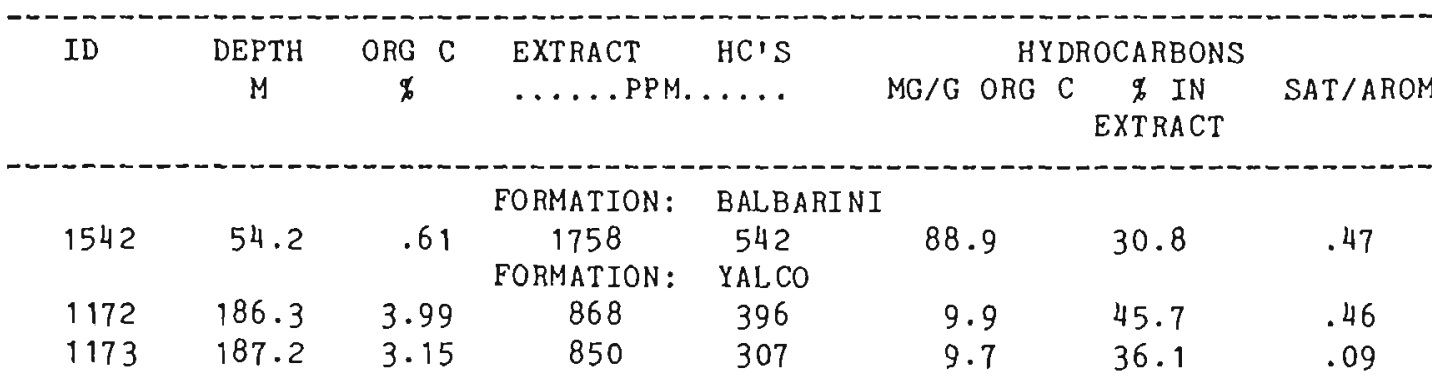

BASIN: MCARTHUR

HELL: $82 / 8$

\begin{tabular}{|c|c|c|c|c|c|c|c|}
\hline \multirow[t]{2}{*}{ ID } & DEPTH & ORG $\mathrm{C}$ & EXTRACT & HC'S & \multicolumn{3}{|c|}{ HYDROCARBONS } \\
\hline & M & 8 & $\ldots . .$. PPM & $\cdots \cdots$ & $\mathrm{MG} / \mathrm{G}$ ORG C & $\begin{array}{c}\$ \text { IN } \\
\text { EXTRACT }\end{array}$ & SAT/AROM \\
\hline 1641 & 67.4 & .42 & FORMATION: & LANSEN & CREEK SH & 157 & 17 \\
\hline & & & 240 & 39 & $9 \cdot 2$ & 15.7 & 1.71 \\
\hline
\end{tabular}


BASIN : MCARTHUR

WELL: B8

\begin{tabular}{|c|c|c|c|c|c|c|c|}
\hline \multirow[t]{2}{*}{ ID } & DEPTH & ORG C & EXTRACT & $\mathrm{HC}$ 'S & \multicolumn{3}{|c|}{ HYDROCARBONS } \\
\hline & FT & 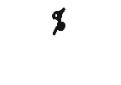 & $\ldots . .$. PPM. & $\cdots$ & $M G / G$ ORG & $\underset{\text { EXTRACT }}{\not \text { IN }}$ & $\mathrm{SAT} / \mathrm{AF}$ \\
\hline & & & FORMATION : & MCMINN & & & \\
\hline 3122 & 57.0 & 2.96 & 2539 & 881 & 29.8 & 34.7 & 3.63 \\
\hline 3127 & 195.0 & 1.06 & 89 & 81 & 7.7 & 91.7 & .57 \\
\hline
\end{tabular}

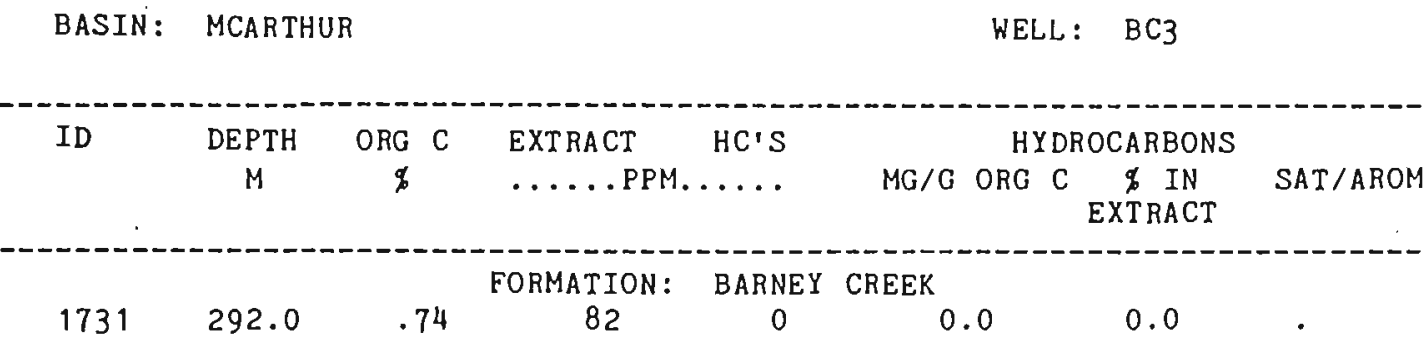

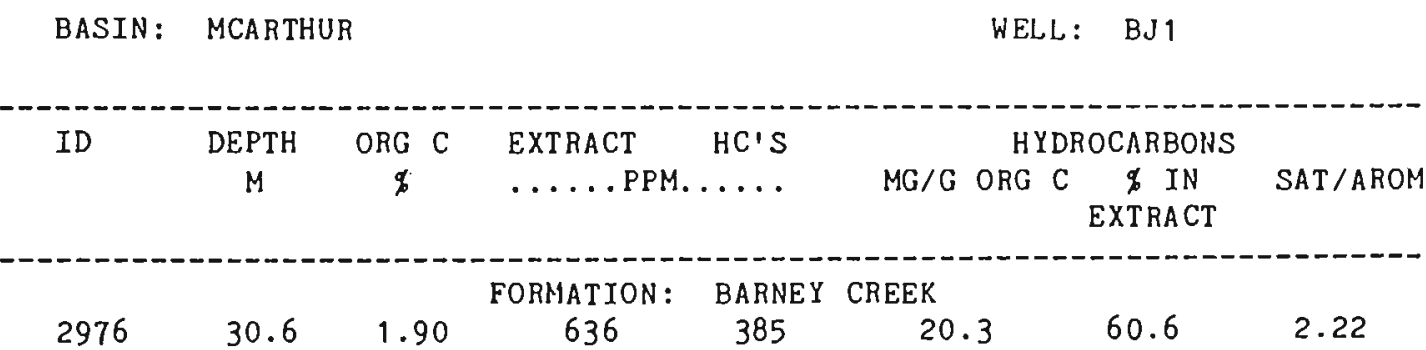

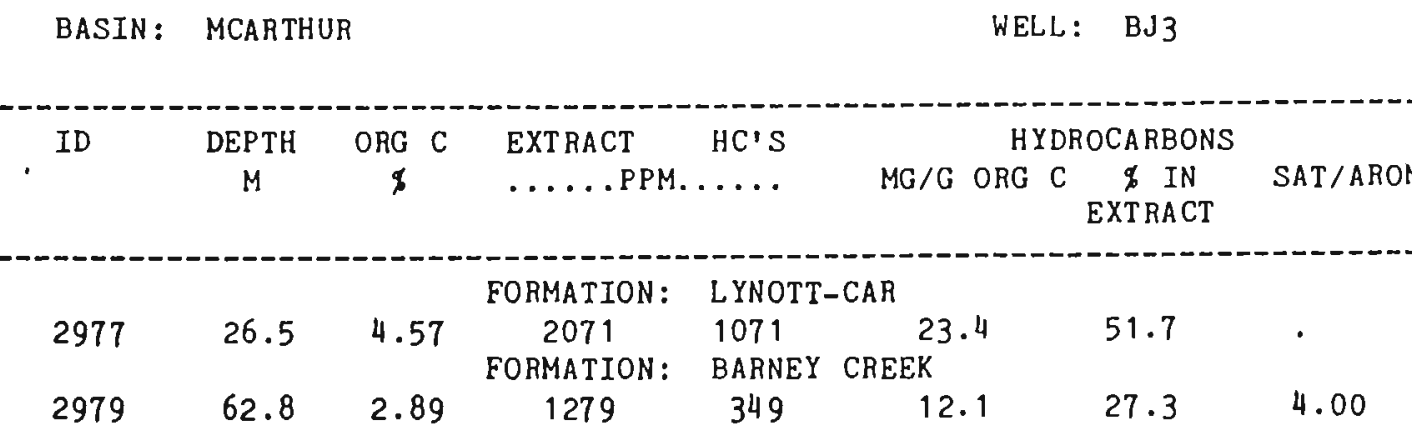


BASIN : MCARTHUR

WELL: BROADMERE NO 1

\begin{tabular}{|c|c|c|c|c|c|c|c|}
\hline \multirow[t]{2}{*}{ ID } & DEPTH & ORG $\mathrm{C}$ & EXTRACT & HC'S & \multicolumn{3}{|c|}{ HYDROCARBONS } \\
\hline & $M$ & 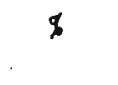 & $\ldots \ldots$ PPM. & $\ldots$ & $\mathrm{MG} / \mathrm{G}$ ORG $\mathrm{C}$ & $\begin{array}{c}\% \text { IN } \\
\text { EXTRACT }\end{array}$ & SAT/AROM \\
\hline & & & FORMATION: & LANSEN & CREEK SH & & \\
\hline 2007 & 36.6 & 2.98 & 1188 & 593 & 19.9 & 49.9 & .63 \\
\hline 2011 & 240.0 & 2.45 & 4188 & 2018 & 82.4 & 48.2 & 1.67 \\
\hline 2014 & 330.0 & 3.54 & 3343 & 1918 & 54.2 & 57.4 & 1.86 \\
\hline 2021 & 450.0 & 4.18 & 2099 & 1318 & 31.5 & 62.8 & $1 \cdot 38$ \\
\hline 2071 & 1110.0 & 3.44 & 1428 & 909 & 26.4 & 63.6 & 3.16 \\
\hline & & & FORMATION: & AGNER & SST & & \\
\hline 2199 & 1505.7 & 1.44 & 91 & 27 & 1.9 & $29 \cdot 3$ & .71 \\
\hline
\end{tabular}

BASIN: MCARTHUR

WELL: CA 9

\begin{tabular}{|c|c|c|c|c|c|c|c|c|}
\hline \multirow{2}{*}{ ID } & DEPTH & ORG C & EXTRACT & HC'S & \multicolumn{4}{|c|}{ HYDROCARBONS } \\
\hline & $M$ & $q$ & $\ldots . . . P P M$ & $\ldots$ & $\mathrm{MG} / \mathrm{G}$ & ORG & $\begin{array}{c}\text { \& IN } \\
\text { EXTRACT }\end{array}$ & SAT / AROM \\
\hline 1657 & 337.6 & 9.08 & $\begin{array}{c}\text { FORMATION: } \\
123\end{array}$ & $\begin{array}{c}\text { BARNE } \\
55\end{array}$ & CREEK & .6 & 45.0 & 1.25 \\
\hline
\end{tabular}

BASIN : MCARTHUR

WELL : CA2

\begin{tabular}{|c|c|c|c|c|c|c|}
\hline \multirow[t]{2}{*}{ ID } & DEPTH & ORG C & EXTRACT & HYD & OROCARBONS & \\
\hline & $M$ & $q$ & $\ldots \ldots$. PPM..... & $M G / G$ ORG C & $\begin{array}{c}\% \text { IN } \\
\text { EXTRACT }\end{array}$ & SAT/AROM \\
\hline
\end{tabular}

$\begin{array}{lcccccc}1665 & 625.9 & .53 & 120 & 59 & 11.1 & 48.9\end{array}$

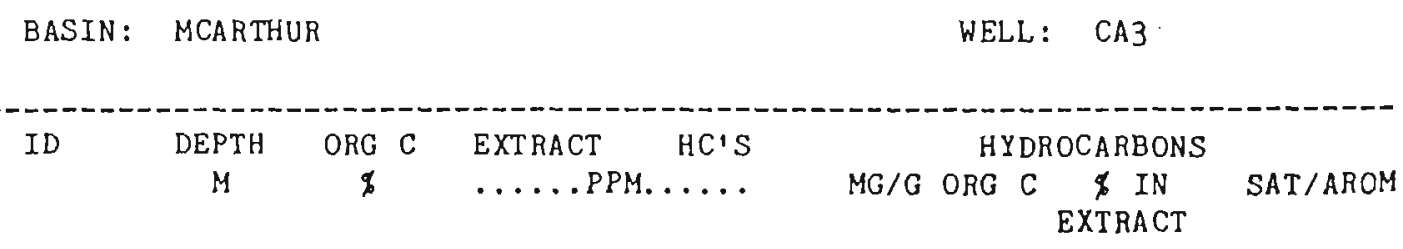

\section{FORMATION: BARNEY CREEK}

$\left.\begin{array}{llllll}1672 & 481.4 & 0.00 & 19 & 0 & .\end{array}\right]$.


BASIN: MCARTHUR

WELL: GA3

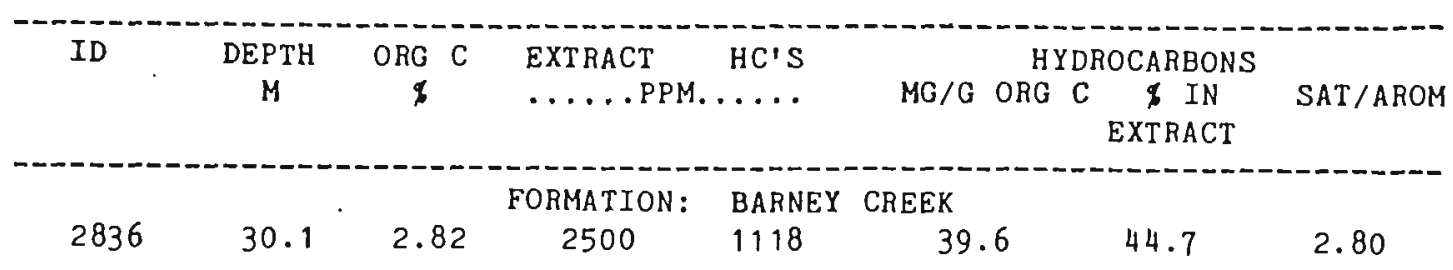

BASIN : MCARTHUR

WELL : GR5

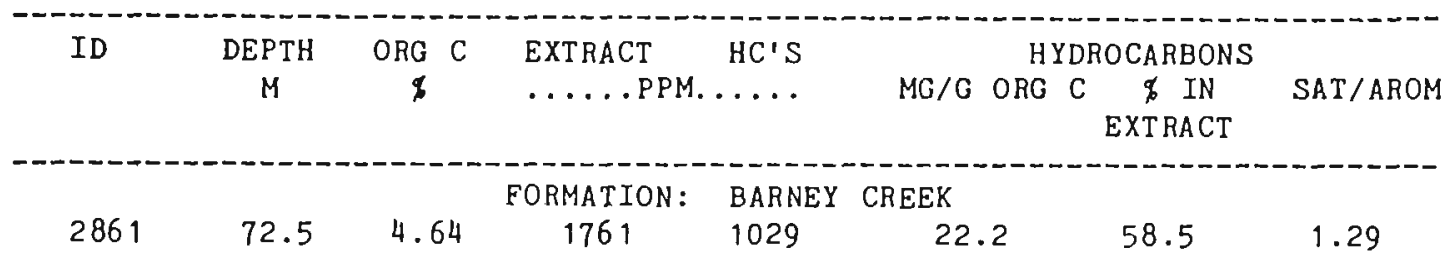

BASIN: MCARTHUR

WELL: GR7

\begin{tabular}{|c|c|c|c|c|c|c|c|}
\hline \multirow[t]{2}{*}{ ID } & DEPTH & ORG C & EXTRACT & $\mathrm{HC}^{\prime} \mathrm{S}$ & \multicolumn{3}{|c|}{ HYDROCARBONS } \\
\hline & $M$ & $\%$ & .....PPM. & 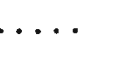 & $M G / G$ ORG $C$ & $\begin{array}{c}\% \text { IN } \\
\text { EXTRACT }\end{array}$ & $\mathrm{SAT} / \mathrm{AR}$ \\
\hline & & & FORMATION: & BARNEY & CREEK & & \\
\hline 2887 & 38.7 & 1.15 & 810 & 327 & 28.5 & 40.4 & 1.47 \\
\hline 2889 & 50.3 & 4.97 & 3698 & 1814 & 36.5 & 49.1 & 1.60 \\
\hline 2897 & 238.8 & 5.17 & 4200 & 1800 & 34.8 & 42.9 & 2.18 \\
\hline 2911 & 601.5 & 1.25 & 2434 & 1379 & 110.3 & 56.7 & 3.06 \\
\hline 2917 & 794.6 & 1.54 & 1525 & 997 & 64.7 & 65.4 & 2.95 \\
\hline 9674 & 854.0 & 3.67 & 1815 & 998 & 27.2 & 55.0 & 1.37 \\
\hline 2919 & 866.5 & 2.81 & 2278 & 1399 & 49.8 & 61.4 & 1.75 \\
\hline 1676 & 875.8 & 2.57 & 1808 & 1023 & 39.8 & 56.6 & 1.08 \\
\hline
\end{tabular}

BASIN : MCARTHUR

WELL : GRO

\begin{tabular}{|c|c|c|c|c|c|c|c|}
\hline \multirow[t]{2}{*}{ ID } & DEPTH & ORG C & EXTRACT & HC'S & \multicolumn{3}{|c|}{ HYDROCARBONS } \\
\hline & M & $q$ & $\ldots \ldots P$ & $\cdots$ & $M G / G$ ORG & $\begin{array}{l}\text { C } \$ \text { IN } \\
\text { EXTRACI }\end{array}$ & SAT / AROM \\
\hline & & & FORMATIO & BARNEY & CREEK & & \\
\hline 2926 & 49.2 & 3.11 & 1926 & 722 & 23.2 & 37.5 & 1.29 \\
\hline 2943 & 425.9 & 1.00 & 1353 & 712 & 71.2 & 52.6 & 2.14 \\
\hline 2950 & 570.8 & 4.18 & 1100 & 647 & 15.5 & 58.8 & 1.15 \\
\hline
\end{tabular}


BASIN : MCARTHUR

WELL: GR9

\begin{tabular}{|c|c|c|c|c|c|c|c|}
\hline \multirow[t]{2}{*}{ ID } & DEPTH & ORC C & EXTRACT & HC'S & \multicolumn{3}{|c|}{ HYDROCARBONS } \\
\hline & M & 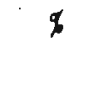 & $\ldots \ldots \mathrm{PPP}$ & $\ldots$ & $M G / G$ ORG & $\begin{array}{l}\text { C IN } \\
\text { EXTRAC }\end{array}$ & SAT/AROH \\
\hline & & & FORMATION : & BARNEY & CREEK & & \\
\hline 1678 & 422.2 & 1.54 & 714 & 326 & 21.2 & 45.7 & 1.45 \\
\hline 1682 & 500.1 & 3.57 & 1145 & 525 & 14.7 & 45.9 & 1.61 \\
\hline
\end{tabular}

BASIN: MCARTHUR

WELL： GR10

\begin{tabular}{|c|c|c|c|c|c|c|c|}
\hline \multirow[t]{2}{*}{$I D$} & DEPTH & ORG C & EXTRACT & HC'S & \multicolumn{3}{|c|}{ HYDROCARBONS } \\
\hline & M & $q$ & $\ldots \ldots P P M$ & $\ldots$. & $M G / G \quad O R G \quad C$ & $\begin{array}{c}q \text { IN } \\
\text { EXTRACT }\end{array}$ & SAT/AROM \\
\hline & & & FORMATION: & BARNEY & CREEK & & \\
\hline 3048 & 37.4 & 1.90 & 2222 & 834 & 43.9 & 37.5 & 1.53 \\
\hline 1809 & 88.4 & 3.00 & 4995 & 2610 & 87.0 & 52.2 & 1.77 \\
\hline 1810 & 143.3 & 4.68 & 1478 & 761 & 16.3 & 51.5 & 1.06 \\
\hline 1811 & $170 \cdot 3$ & 1.30 & 3504 & 2337 & 179.8 & 66.7 & 2.03 \\
\hline 1812 & 182.8 & 2.95 & 1757 & 1157 & 39.2 & 65.9 & 1.71 \\
\hline 1813 & 232.8 & 4.50 & 1964 & 1022 & 22.7 & 52.0 & 1.47 \\
\hline 1830 & 297.2 & .90 & 2370 & 1317 & 146.3 & 55.6 & 1.77 \\
\hline 1831 & 360.0 & .31 & 621 & 287 & 92.7 & 46.3 & 2.29 \\
\hline 1832 & 410.0 & .21 & 590 & 299 & 142.4 & 50.7 & 3.01 \\
\hline 1833 & 443.0 & .80 & 1678 & 894 & 111.7 & 53.3 & 3.88 \\
\hline 1835 & 481.4 & 1.04 & 2000 & 778 & 74.8 & 38.9 & 9.66 \\
\hline 1837 & 527.7 & .52 & 1009 & 617 & 118.7 & 61.2 & 3.76 \\
\hline 1841 & 571.6 & 1.22 & 1628 & 790 & 64.8 & 48.6 & 1.07 \\
\hline 1843 & 587.3 & .83 & 1131 & 798 & 96.1 & 70.5 & 3.12 \\
\hline 1846 & 602.5 & 2.76 & 1657 & 1016 & 36.8 & 61.3 & 3.07 \\
\hline 1849 & 630.0 & .69 & 1956 & 1196 & 173.3 & 61.1 & 9.68 \\
\hline 1855 & 662.1 & .69 & 131 & 97 & 14.1 & 74.3 & 5.82 \\
\hline
\end{tabular}

BASIN: MCARTHUR

WELL: GR11

\begin{tabular}{|c|c|c|c|c|c|c|c|}
\hline \multirow[t]{2}{*}{ ID } & DEPTH & ORG C & EXT RACT & $\mathrm{HC} S \mathrm{~S}$ & \multicolumn{3}{|c|}{ HYDROCARBONS } \\
\hline & $M$ & $\%$ & $\ldots . . . P P M$. & $\cdots$ & $M G / G$ ORG C & $\begin{array}{c}q \text { IN } \\
\text { EXTRACT }\end{array}$ & SAT/AROM \\
\hline & & & FORMATION: & BARNEY & CREEK & & \\
\hline 1860 & 178.9 & 1.90 & 803 & 357 & 18.8 & 44.4 & 1.71 \\
\hline 1865 & 253.8 & 2.15 & 444 & 235 & 10.9 & 52.9 & 2.24 \\
\hline 1873 & $347 \cdot 3$ & 1.80 & 850 & 385 & 21.4 & $45 \cdot 3$ & 1.83 \\
\hline 1880 & 415.2 & $5 \cdot 38$ & 682 & 442 & 8.2 & 64.9 & 1.60 \\
\hline 1887 & 441.9 & 1.70 & 1070 & 1057 & 62.2 & 98.8 & .76 \\
\hline
\end{tabular}


BASIN : MCARTHUR

WELL: M2

\begin{tabular}{|c|c|c|c|c|c|c|c|}
\hline \multirow[t]{2}{*}{ ID } & DEPTH & ORG $\mathrm{C}$ & EXTRACT & HC'S & \multicolumn{3}{|c|}{ HYDROCARBONS } \\
\hline & M & 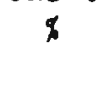 & $\ldots . . . P P M$ & $\ldots$. & $M G / G \quad O R G \quad C$ & $\begin{array}{c}\% \text { IN } \\
\text { EXTRACT }\end{array}$ & SAT/AF \\
\hline & & & FORMATION: & BARNEY & CREEK & & \\
\hline 1699 & 130.3 & 1.19 & 683 & 432 & 36.3 & $63 \cdot 3$ & 3.61 \\
\hline 1746 & 355.2 & .95 & 82 & 30 & 3.2 & 36.9 & 1.58 \\
\hline
\end{tabular}

BASIN: MCARTHUR

WELL: $M 3$

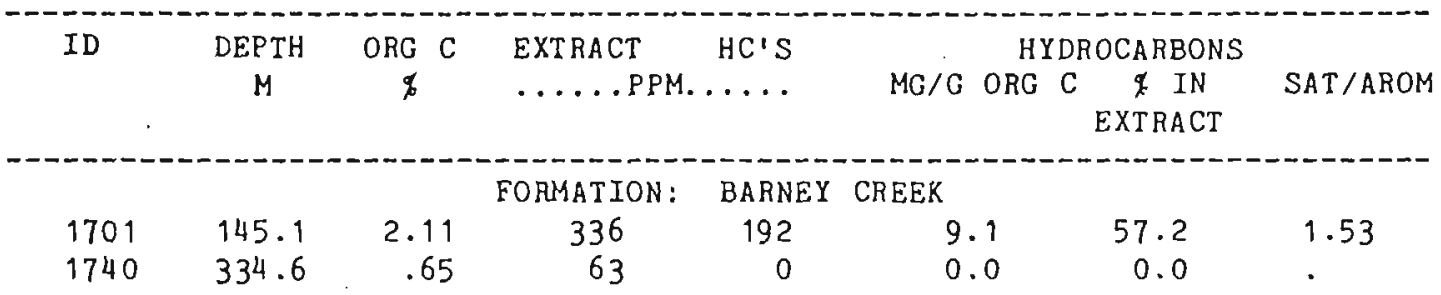

BASIN: MCARTHUR

WELL: M13

\begin{tabular}{|c|c|c|c|c|c|c|c|}
\hline \multirow[t]{2}{*}{ ID } & DEPTH & ORG $\mathrm{C}$ & EXTRACT & HC'S & \multicolumn{3}{|c|}{ HYDROCARBONS } \\
\hline & FT & $\not$ & ..... PPM & $\ldots \ldots$ & $M G / G$ OHG & $\begin{array}{l}\text { C IN } \\
\text { EXTRAC' }\end{array}$ & SAT/AROH \\
\hline & & & FORMATION: & MCMIN & & & \\
\hline 147 & 225.0 & 1.62 & 962 & 236 & 14.6 & 24.5 & .70 \\
\hline 3149 & 259.0 & 1.53 & 229 & 77 & 5.0 & 33.7 & 1.21 \\
\hline
\end{tabular}

BASIN: MCARTHUR

WELL: M17/08

\begin{tabular}{|c|c|c|c|c|c|c|}
\hline \multirow[t]{2}{*}{ ID } & DEPTH & ORG C & EXTRACT & HYD & DROCARBONS & \\
\hline & M & $\not$ & $\ldots \ldots$. РPM..... & $M G / G$ ORG & C $\begin{array}{c}\% \text { IN } \\
\text { EXTRACT }\end{array}$ & SAT / AROM \\
\hline
\end{tabular}

$\begin{array}{lrrrrrrl}1698 & 126.6 & 3.20 & 113 & 22 & .7 & 19.4 & 3.00 \\ 1702 & 147.8 & 2.97 & 37 & 0 & 0.0 & 0.0 & . \\ 1717 & 269.8 & .55 & 43 & 0 & 0.0 & 0.0 & . \\ 1720 & 278.6 & .61 & 39 & 0 & 0.0 & 0.0 & . \\ 1723 & 282.1 & .66 & 33 & 0 & 0.0 & 0.0 & . \\ 1735 & 311.5 & .64 & 46 & 0 & 0.0 & 0.0 & . \\ 1741 & 320.6 & .70 & 10 & 0 & 0.0 & 0.0 & . \\ 1743 & 339.5 & .56 & 30 & 0 & 0.0 & 0.0 & .\end{array}$


BASIN : MCARTHUR

WELL : MCA5

\begin{tabular}{|c|c|c|c|c|c|c|c|}
\hline \multirow[t]{2}{*}{ ID } & DEPTH & ORG C & EXTRACT & HC'S & \multicolumn{3}{|c|}{ HYDROCARBONS } \\
\hline & $M$ & $q$ & $\ldots \ldots$. PPM. & $\ldots$ & $M G / G \quad O R G$ & $\begin{array}{c}\$ \text { IN } \\
\text { EXTRACT }\end{array}$ & SAT /AROM \\
\hline & & & FORMATION : & BARNEY & CREEK & & \\
\hline 3026 & 74.0 & 1.72 & 1216 & 580 & 33.7 & 47.7 & 4.58 \\
\hline 3030 & 306.4 & 1.22 & 577 & 235 & 19.2 & 40.7 & - \\
\hline
\end{tabular}

BASIN : MCARTHUR

WELL: MCA10

\begin{tabular}{|c|c|c|c|c|c|c|c|}
\hline \multirow[t]{2}{*}{ ID } & DEPTH & ORG $\mathrm{C}$ & EXTRACT & HC'S & \multicolumn{3}{|c|}{ HYDROCARBONS } \\
\hline & $M$ & $q$ & $\ldots \ldots P$ & $\ldots$ & $M G / G$ ORG & $\begin{array}{l}\% \text { IN } \\
\text { EXTRACT }\end{array}$ & $\mathrm{SAT} / \mathrm{A}$ \\
\hline 32 & 27.8 & 4.05 & $\begin{array}{c}\text { ORMATIOI } \\
448\end{array}$ & $\begin{array}{c}\text { BARNE } \\
237\end{array}$ & $\begin{array}{r}\text { CREEK } \\
5.9\end{array}$ & 53.0 & 2.05 \\
\hline
\end{tabular}

BASIN : MCARTHUR

WELL: MY4

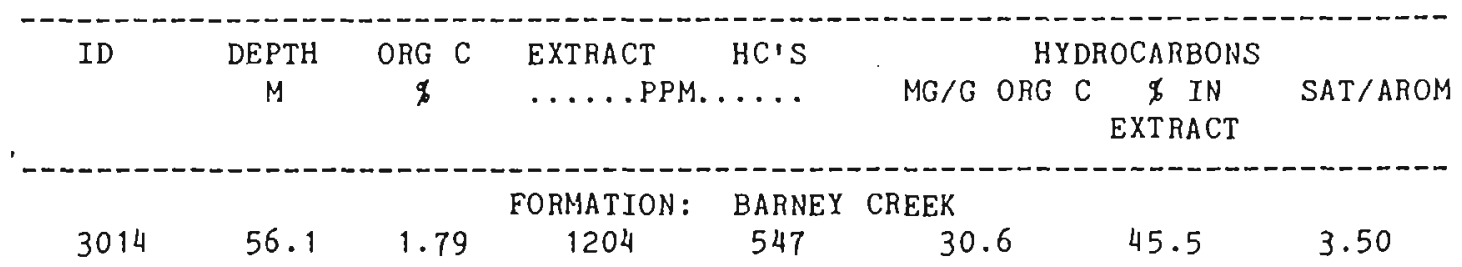

BASIN : MCARTHUR

WELL : MY5

\begin{tabular}{|c|c|c|c|c|c|c|c|}
\hline \multirow[t]{2}{*}{ ID } & DEPTH & ORG $\mathrm{C}$ & EXTRACT & $\mathrm{HC}^{\prime} \mathrm{S}$ & \multicolumn{3}{|c|}{ HYDROCARBONS } \\
\hline & $M$ & $\$$ & $\ldots \ldots$. PPM & $\ldots$ & $M G / G \quad O R G$ & C $\%$ IN & SAT/AROM \\
\hline & & & FORMATION : & REWAR & DOLOMITE & & \\
\hline 3017 & 67.2 & 3.65 & 1921 & 799 & 21.9 & 41.6 & 3.08 \\
\hline
\end{tabular}


BASIN : MCARTHUR

WELL: N27/63

\begin{tabular}{|c|c|c|c|c|c|c|c|}
\hline \multirow[t]{2}{*}{ ID } & DEPTH & ORG C & EXTRACT & HC'S & \multicolumn{3}{|c|}{ HYDROCARBONS } \\
\hline & $M$ & 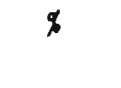 & $\ldots \ldots P P M$ & $\ldots$ & $\mathrm{MG} / \mathrm{G}$ ORG C & $\begin{array}{c}\$ \text { IN } \\
\text { EXTRACT }\end{array}$ & SAT/AROM \\
\hline & & & FORMATION: & BARNEY & CREEK & & \\
\hline 1694 & 105.5 & 1.98 & 247 & 126 & 6.4 & 50.9 & 1.01 \\
\hline 1696 & 116.4 & .56 & 137 & 24 & $4 \cdot 3$ & 17.8 & 2.60 \\
\hline 1705 & 172.8 & 2.75 & 225 & 66 & 2.4 & 29.2 & 1.21 \\
\hline 1713 & 223.2 & .88 & 125 & 29 & $3 \cdot 3$ & 23.0 & 4.00 \\
\hline 1718 & 276.0 & .71 & 313 & 192 & 27.0 & 61.3 & 3.64 \\
\hline 1724 & 289.6 & .79 & 39 & 0 & 0.0 & 0.0 & - \\
\hline 1736 & 313.0 & .51 & 16 & 0 & 0.0 & 0.0 & - \\
\hline 1742 & 335.1 & .68 & 14 & 0 & 0.0 & 0.0 & - \\
\hline 1749 & 381.0 & .34 & 42 & 0 & 0.0 & 0.0 & . \\
\hline
\end{tabular}

BASIN : MCARTHUR

WELL: T19

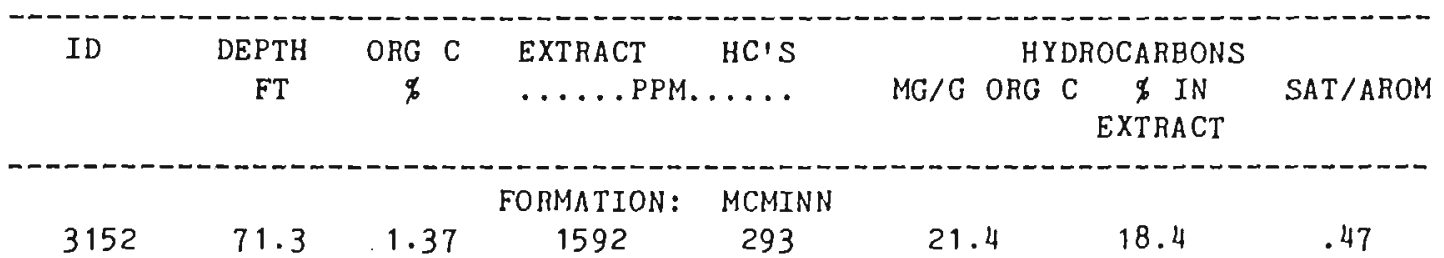

BASIN : MCARTHUR

WELL: URAPUNGA NO 3

\begin{tabular}{|c|c|c|c|c|c|c|c|}
\hline \multirow[t]{2}{*}{ ID } & DEPTH & ORG $\mathrm{C}$ & EXTRACT & HC'S & \multicolumn{3}{|c|}{ HYDROCARBONS } \\
\hline & $M$ & 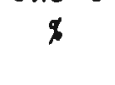 & $\ldots . .$. PPM & $\ldots \ldots$ & $M G / G \quad O R G \quad C$ & $\begin{array}{c}\% \text { IN } \\
\text { EXTRACT }\end{array}$ & SAT/AROM \\
\hline & & & FORMATION: & VELKERRI & & & \\
\hline 1522 & 39.9 & 7.20 & 3355 & 2197 & 30.5 & 65.5 & 2.95 \\
\hline 1523 & 64.9 & 4.70 & 3321 & 2029 & 43.2 & 61.1 & 3.13 \\
\hline 1524 & 75.1 & 6.40 & 3865 & 1733 & 27.1 & 44.8 & 2.54 \\
\hline 1525 & 89.9 & 3.52 & 6729 & 4010 & 113.9 & 59.6 & 3.05 \\
\hline 1526 & 95.1 & 3.86 & 12773 & 7982 & 206.8 & 62.5 & 2.57 \\
\hline 1527 & 115.1 & 2.02 & 2761 & 1440 & 71.3 & 52.1 & 2.23 \\
\hline 1528 & 125.1 & 3.04 & 9143 & 3528 & 116.0 & 38.6 & 1.28 \\
\hline 1529 & 205.1 & 3.06 & 6201 & 3540 & 115.7 & 57.1 & 3.53 \\
\hline
\end{tabular}


BASIN : MCARTHUR

WELL: URAPUNGA NO 4

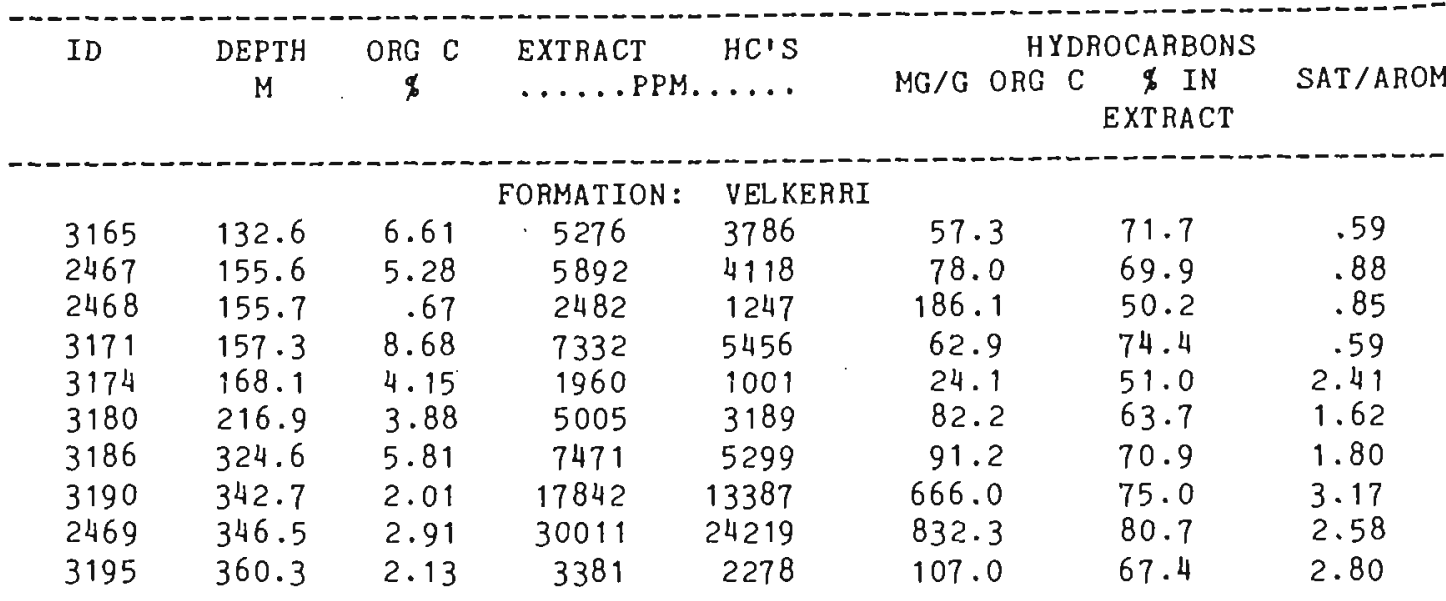

BASIN : MCARTHUR

WELL: WFT

\begin{tabular}{|c|c|c|c|c|c|c|c|}
\hline ID & DEPTH & ORG C & EXTRACT & $\mathrm{HC}^{\prime} \mathrm{S}$ & $H Y L$ & DROCARBON & \\
\hline & M & $q$ & ..... PPM. & $\ldots \ldots$ & $M G / G$ ORG & $\begin{array}{l}\mathscr{I} \text { IN } \\
\text { EXTRACT }\end{array}$ & SAT/AROM \\
\hline 1709 & 190.2 & .82 & $\begin{array}{c}\text { FORMATION: } \\
202\end{array}$ & $\begin{array}{c}\text { BARNEY } \\
0\end{array}$ & $\begin{array}{l}0.0 \\
\text { REEK }\end{array}$ & 0.0 & . \\
\hline
\end{tabular}

BASIN: MCARTHUR

WELL: WM6

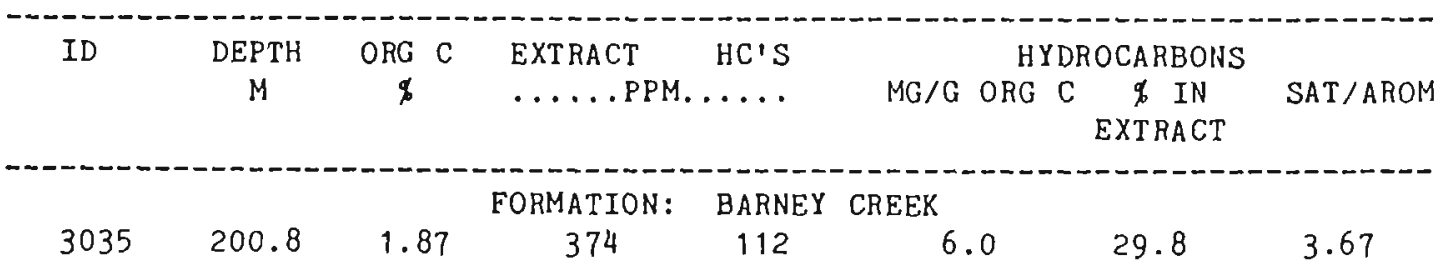

BASIN: MCARTHUR

WELL: $\quad$ X28

\begin{tabular}{|c|c|c|c|c|c|c|c|}
\hline \multirow[t]{2}{*}{ ID } & DEPTH & ORG C & EXTRACT & HC'S & \multicolumn{3}{|c|}{ HYDROCARBONS } \\
\hline & FT & \% & .....PPM & $\ldots$. & $M G / G$ ORG C & $\begin{array}{l}\$ \text { IN } \\
\text { EXTRACI }\end{array}$ & SAT/AROM \\
\hline & & & FORMATION : & MCMIN & & & \\
\hline $\begin{array}{l}3131 \\
3138\end{array}$ & $\begin{array}{l}105.0 \\
200.0\end{array}$ & $\begin{array}{l}1.85 \\
1.17\end{array}$ & $\begin{array}{r}2667 \\
788\end{array}$ & $\begin{array}{l}338 \\
169\end{array}$ & $\begin{array}{l}18.3 \\
14.4\end{array}$ & $\begin{array}{l}12.7 \\
21.4\end{array}$ & $\begin{array}{r}1.37 \\
.39\end{array}$ \\
\hline
\end{tabular}




\section{APPENDIX $P$}

\section{AROMATIC MATURATION INDICES}

\section{Abbreviations:}

\section{DMI = dimethylnapthalene index}

$$
\begin{aligned}
\text { DMI-1 } & =2,6,+2,7, / 1,5 \\
\text { DMI- } 2= & -\log (1,8 / 2,6+2,7+1,3+1,7+1,6+1,4+2,3+1,5 \\
& +1,2+1,8)
\end{aligned}
$$

where the numbers refer to the $1,8-2,6-2,7-1,3-1,7$ $1,6-1,4-2,3-1,5-$ and1,2- dimethylnapthalene isomers.

TNI = trimethyInapthalene index

$\mathrm{TNI}=1,4,6+1,3,5,2,3,6$ where the numbers refer to the $1,4,6-1,3,5,-$ and 2,3,6- trimethylnapthalene isomers.

MPI + methylphenanthrene index

$$
\begin{aligned}
& \text { MPI-1 }=1.5 \times(3,+2,) /(9,+1 .+\mathrm{P}) \\
& \text { MPI-2 }=3 \times 2, /(9,=1,+\mathrm{P})
\end{aligned}
$$

where the numbers refer to the 1-2-3-and 9-methylphenanthrene isomers and $\mathrm{P}=$ phenanthrene.

DPI = dimethylphenanthrene index

$$
\mathrm{DPI}=1+2+3+4+/ \mathrm{P}+5+6+7
$$

where the numbers tefer to unidentified

dimethylphenanthrene isomers figured by Radke and Welte (1983) and $\mathrm{P}=$ phenanthrene.

Full well and stratigraphic names are given in Appendix A.

Note: wells are arranged only in alphabetical order. 


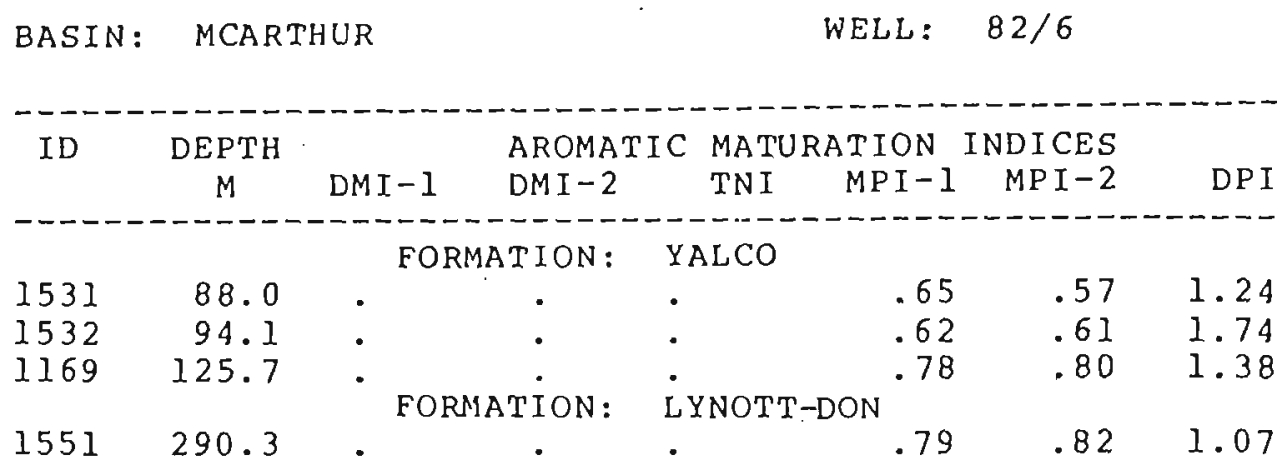

BASIN: MCARTHUR WELL: $82 / 7$

\begin{tabular}{|c|c|c|c|c|c|c|c|}
\hline \multirow[t]{2}{*}{ ID } & \multirow{2}{*}{$\begin{array}{c}\text { DEPTH } \\
M\end{array}$} & \multicolumn{2}{|c|}{ AROMATIC } & \multicolumn{3}{|c|}{ MATURATION INDICES } & \multirow[b]{2}{*}{ DPI } \\
\hline & & DMI -1 & DMI -2 & TN I & $M P I-1$ & MPI -2 & \\
\hline & & FO & ATION: & $\mathrm{BALBA}$ & & & \\
\hline 1542 & 54.2 & - $F O$ & ATION: & YALCO & .26 & .32 & .6 \\
\hline 1172 & 186.3 & - & - & - & .99 & 1.02 & 1.36 \\
\hline
\end{tabular}

BASIN: MCARTHUR WELL: $82 / 8$

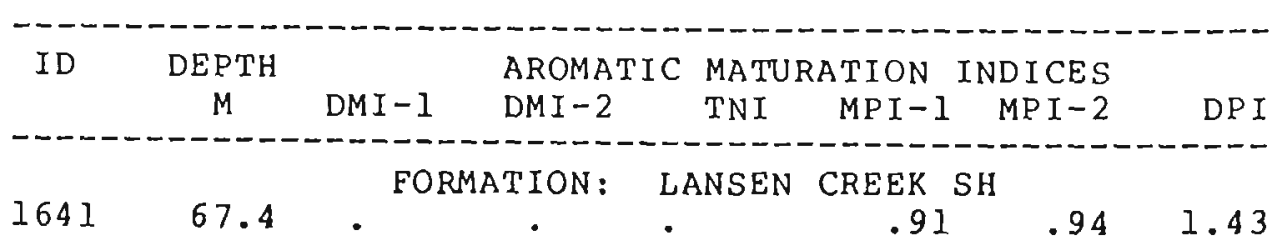


BASIN : MCARTHUR

WELL : GR7

\begin{tabular}{|c|c|c|c|c|c|c|c|}
\hline ID & $\begin{array}{c}\text { DEPTH } \\
M\end{array}$ & DMI I I & $\begin{array}{l}\text { AROMA? } \\
\text { DMI }-2\end{array}$ & $\begin{array}{l}\text { IC } M A T L \\
\text { TNI }\end{array}$ & $\begin{array}{l}\text { RATION } \\
\text { MPI - }\end{array}$ & $\begin{array}{r}\text { INDICES } \\
M P I-2\end{array}$ & DPI \\
\hline & & \multicolumn{2}{|c|}{ FORMATION : } & BARNE & CREEK & & \\
\hline 2887 & 38.7 & 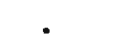 & . & . & .88 & 1.01 & 1.88 \\
\hline 2889 & 50.3 & $\bullet$ & . & . & .63 & .67 & .91 \\
\hline 2897 & 238.8 & . & . & . & .54 & .56 & .68 \\
\hline 2911 & 601.5 & . & . & . & .75 & .79 & .79 \\
\hline 2917 & 794.6 & . & . & . & .76 & .86 & .77 \\
\hline 16 & 854.0 & . & . & . & .87 & .97 & .86 \\
\hline 29 & 866.5 & - & . & . & .89 & .99 & .94 \\
\hline 1676 & 875.8 & . & . & . & .92 & 1.04 & 1.13 \\
\hline
\end{tabular}

BASIN: MCARTHUR

WELL: GRIO

\begin{tabular}{|c|c|c|c|c|c|c|c|}
\hline ID & $\begin{array}{c}\text { DEPTH } \\
M\end{array}$ & \multicolumn{6}{|c|}{ AROMATIC MATURATION INDICES } \\
\hline & & FOR & ITION: & BARNEY & CREEK & & \\
\hline 3048 & 37.4 & - & - & . & .61 & .61 & .87 \\
\hline 1809 & 88.4 & 1.6 & 0.0 & 1.43 & .57 & .57 & .78 \\
\hline 1810 & 143.3 & 2.3 & 3.0 & 1.31 & .60 & .61 & .76 \\
\hline 1812 & 182.8 & 2.3 & 3.2 & . & .58 & .59 & .84 \\
\hline 1813 & 232.8 & 1.7 & 3.2 & 1.85 & .52 & .54 & .71 \\
\hline 1830 & 297.2 & 1.7 & 0.0 & . & .62 & .65 & .83 \\
\hline 1831 & 360.0 & . & . & . & .75 & .82 & 1.06 \\
\hline 1832 & 410.0 & 1.9 & 2.5 & 1.49 & .73 & .82 & 1.20 \\
\hline 1833 & 443.0 & 2.7 & 0.0 & 1.68 & .70 & .74 & .76 \\
\hline 1835 & 481.4 & 1.8 & 0.0 & . & .72 & .77 & .78 \\
\hline 37 & 527.7 & 2.4 & 2.1 & 1.35 & .73 & .80 & .78 \\
\hline 41 & 571.6 & .8 & 2.3 & 1.46 & .73 & .81 & .71 \\
\hline 1843 & 587.3 & 1.8 & 2.3 & 1.18 & .73 & .82 & .72 \\
\hline 1846 & 602.5 & 2.7 & 0.0 & & .77 & .85 & .78 \\
\hline 1849 & 630.0 & 1.4 & 2.1 & 1.35 & .77 & .87 & .77 \\
\hline 1855 & 662.1 & • & • & . & .83 & .92 & 1.11 \\
\hline
\end{tabular}

BASIN : MCARTHUR

WELL: GRIl

\begin{tabular}{|c|c|c|c|c|c|c|c|}
\hline \multirow[t]{2}{*}{ ID } & DEPTH & & AROMAT & \multicolumn{4}{|c|}{ C MATURATION INDICES } \\
\hline & M & $D M I-1$ & DMI -2 & TNI & $M P I-1$ & $M P I-2$ & DPI \\
\hline & & FO & TION : & BARNEY & CREEK & & \\
\hline 1860 & 178.9 & - & - & - & .61 & .63 & .80 \\
\hline 1865 & 253.8 & $\bullet$ & $\bullet$ & - & .66 & .69 & .85 \\
\hline 1873 & 347.3 & • & - & - & .69 & .75 & .81 \\
\hline 1880 & 415.2 & - & - & . & .80 & .87 & .91 \\
\hline 1887 & 441.9 & . & . & . & .85 & .86 & .84 \\
\hline
\end{tabular}


BASIN: MCARTHUR

WELL: $\quad M 2$

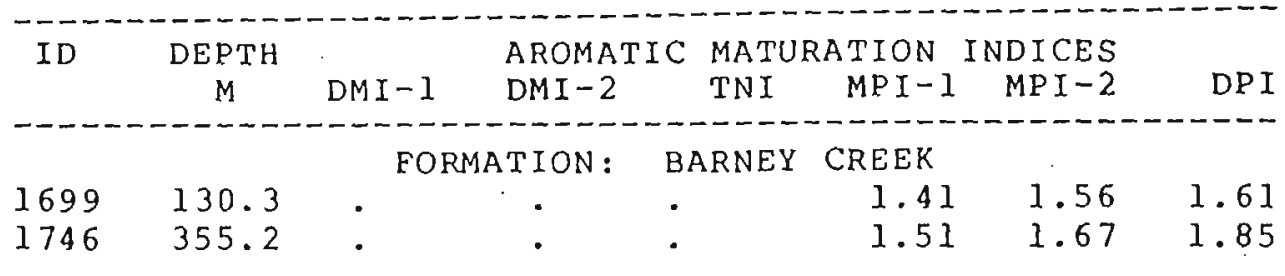

BASIN: MCARTHUR

WELL: M3

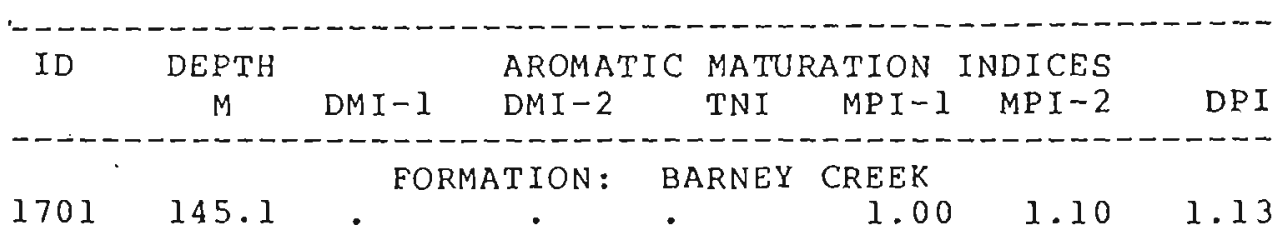

BASIN: MCARTHUR

WELL: MI7/08

\begin{tabular}{|c|c|c|c|c|c|c|}
\hline ID & DEPTH & & AROMATIC & MATURATION & INDICES & \\
\hline & M & DMI -1 & DMI -2 & $M P I-1$ & $M P I-2$ & DPI \\
\hline 8 & 126.6 & D & TION & $\begin{array}{r}\text { ARNEY CREEK } \\
1.93\end{array}$ & 2.25 & 2.48 \\
\hline
\end{tabular}

BASIN: MCARTHUR

WELL: N27/63

\begin{tabular}{|c|c|c|c|c|c|c|c|}
\hline \multirow[t]{2}{*}{ ID } & \multirow{2}{*}{$\begin{array}{c}\text { DEPTH } \\
M\end{array}$} & DM I - 1 & \multirow{2}{*}{$\begin{array}{l}\text { AROMATIC } \\
\text { DMI }-2\end{array}$} & \multicolumn{3}{|c|}{ MATURATION INDICES } & \multirow{2}{*}{ DP I } \\
\hline & & $D M 1-1$ & & & $M P 1-1$ & & \\
\hline & & FO & TION : & BARNEY & CREEK & & \\
\hline 1694 & 105.5 & - & - & • & 1.89 & 2.19 & 2.28 \\
\hline 1696 & 116.4 & • & - & . & 1.99 & 2.30 & 2.32 \\
\hline 1705 & 172.8 & • & - & • & 2.19 & 2.56 & 2.71 \\
\hline 1713 & 223.2 & - & . & . & 2.64 & 3.30 & 3.05 \\
\hline 1718 & 276.0 & - & - & • & 2.39 & 2.87 & 3.06 \\
\hline
\end{tabular}


BASIN : MCARTHUR

WELL: URAPUNGA NO 3

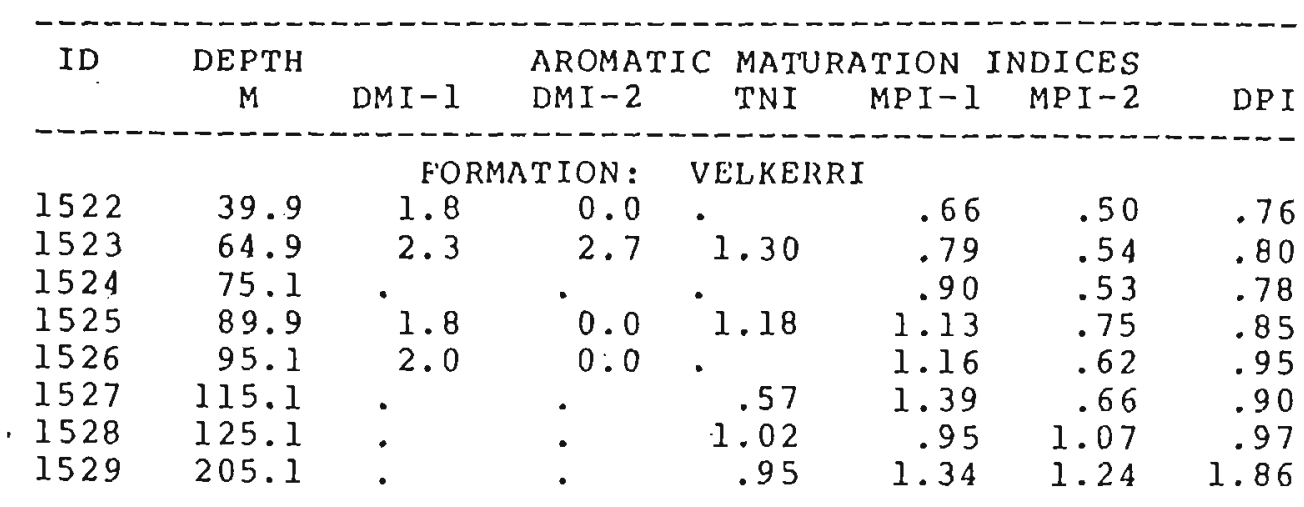

BASIN: MCARTHUR

WELL: URAPUNGA NO 4

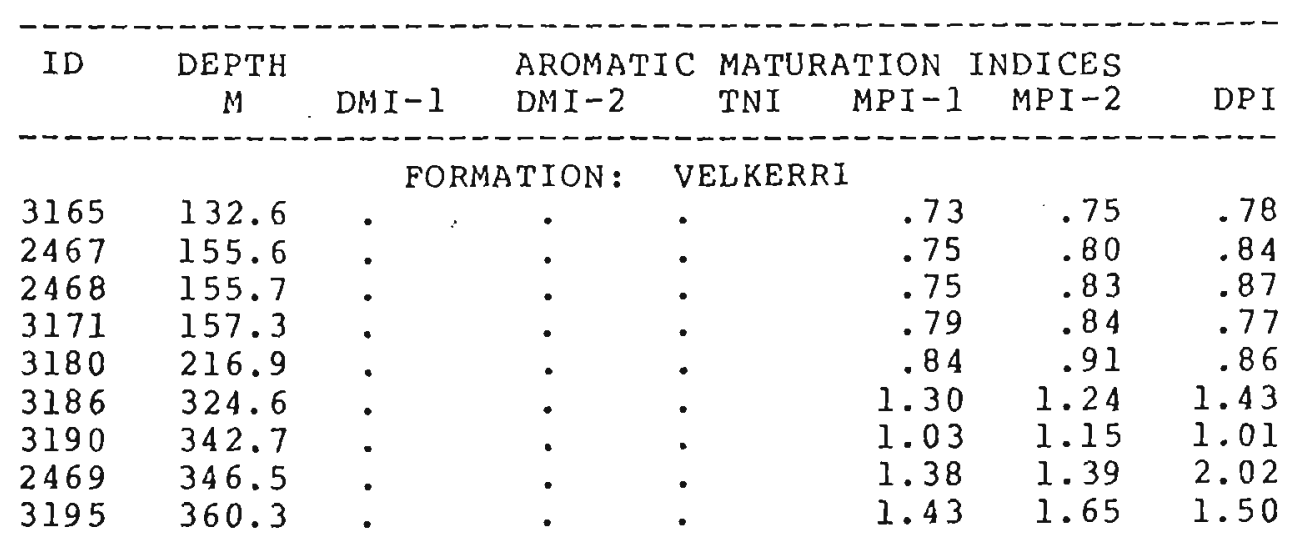


APPENDIX Q

ELEMENTAL ANALYSES OF ISOLATED KEROGENS 


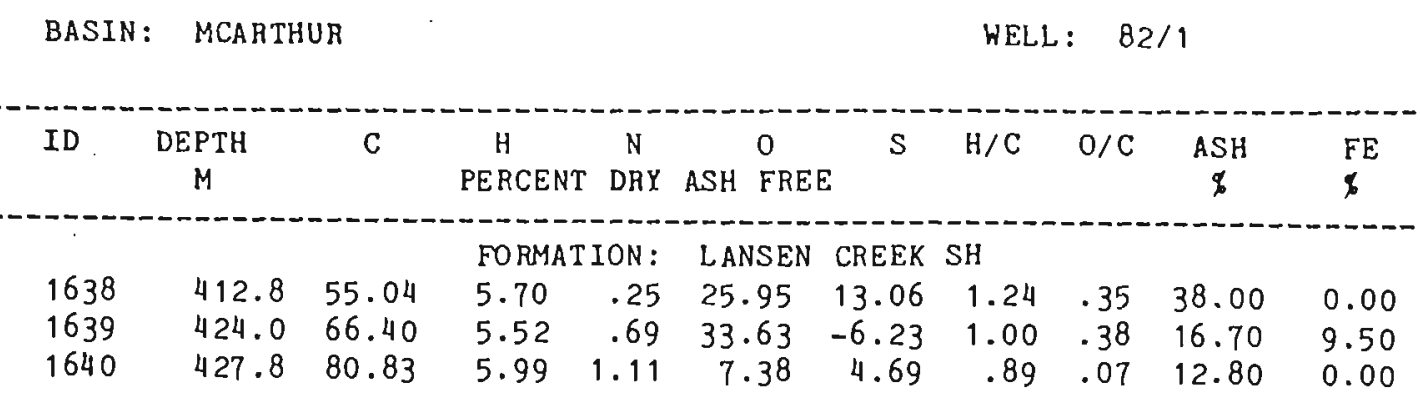

BASIN: MCARTHUR

WELL: $82 / 6$

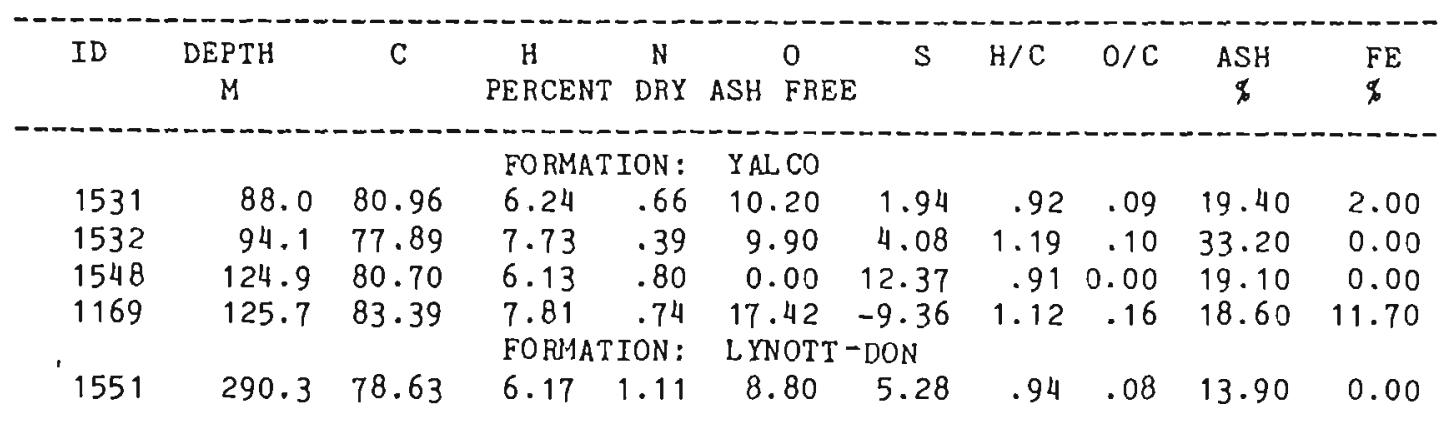

BASIN: MCARTHUR

HELL: $82 / 7$

\begin{tabular}{|c|c|c|c|c|c|c|c|c|c|c|c|}
\hline$I D$ & $\begin{array}{c}\text { DEPTH } \\
M\end{array}$ & C & $\begin{array}{c}H \\
\text { PERCENT }\end{array}$ & $\begin{array}{c}\mathrm{N} \\
\text { DRY }\end{array}$ & $\mathrm{ASH}$ & $\begin{array}{l}0 \\
\text { FRE }\end{array}$ & $S$ & $\mathrm{H} / \mathrm{C}$ & $0 / C$ & $\begin{array}{c}\mathrm{ASH} \\
\varnothing\end{array}$ & $\begin{array}{l}\mathrm{FE} \\
\$\end{array}$ \\
\hline & & & \multicolumn{2}{|c|}{ FORMATION: } & \multicolumn{3}{|c|}{ BALBARINI } & & & & \\
\hline 542 & 54.2 & 86.95 & $\begin{array}{l}7.19 \\
\text { FORMAT }\end{array}$ & $\begin{array}{r}.51 \\
\text { ION: }\end{array}$ & & .27 & -1.92 & .99 & .06 & 8.20 & 3.00 \\
\hline $\begin{array}{l}1172 \\
1172\end{array}$ & 186.3 & 81.00 & 5.98 & $\begin{array}{r}.76 \\
88\end{array}$ & & .96 & 2.31 & .89 & .09 & 17.80 & 3.00 \\
\hline 173 & 187.2 & 80.75 & 6.27 & .88 & & .65 & 3.46 & .93 & .08 & 17.80 & 5.00 \\
\hline
\end{tabular}

BASIN: MCARTHUR

WELL: $82 / 8$

\begin{tabular}{|c|c|c|c|c|c|c|c|c|c|c|c|}
\hline ID & $\begin{array}{c}\text { DEPTH } \\
M\end{array}$ & C & $\begin{array}{c}\mathrm{H} \\
\text { PERCENT }\end{array}$ & $\stackrel{N}{\mathrm{~N}}$ & $\mathrm{ASH}$ & $\begin{array}{l}0 \\
\text { FREE }\end{array}$ & $S$ & $\mathrm{H} / \mathrm{C}$ & $0 / C$ & $\begin{array}{c}\text { ASH } \\
\$\end{array}$ & FE \\
\hline & & & FORMAT & ON: & & & CAEEK & $\mathrm{SH}$ & & & 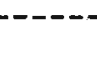 \\
\hline 1641 & 67.4 & 69.41 & 3.47 & .97 & 22. & .90 & 3.25 & .60 & .25 & 34.60 & 0.00 \\
\hline
\end{tabular}


BASIN: MCARTHUR

WELL : GR10

\begin{tabular}{|c|c|c|c|c|c|c|c|c|c|c|}
\hline ID & $\begin{array}{c}\text { DEPTH } \\
M\end{array}$ & C & $\begin{array}{c}\mathrm{H} \\
\text { PERCENI }\end{array}$ & $\stackrel{\mathrm{N}}{\mathrm{DRY}}$ & $\begin{array}{ll} & 0 \\
\text { ASH } & \text { FREE }\end{array}$ & $S$ & $\mathrm{H} / \mathrm{C}$ & $0 / C$ & $\underset{\$}{A S H}$ & $\begin{array}{l}F E \\
q\end{array}$ \\
\hline & & & FORMA & ION : & BARNEI & CREEK & & & & \\
\hline 1809 & 88.4 & 73.68 & 10.19 & 4.17 & 7.63 & 4.34 & 1.66 & .08 & 9.60 & 4.78 \\
\hline 1810 & 143.3 & 78.14 & 10.51 & 3.61 & 9.32 & -1.58 & 1.61 & .09 & 5.80 & 5.00 \\
\hline 1812 & 182.8 & 78.86 & 9.78 & 4.71 & 0.00 & 6.65 & 1.49 & 0.00 & 0.00 & 0.00 \\
\hline 1813 & 232.8 & 77.74 & 10.01 & 3.24 & 6.39 & 2.62 & 1.54 & .06 & 5.51 & 2.70 \\
\hline 1830 & 297.2 & 73.62 & 9.28 & 2.21 & 10.60 & 4.28 & 1.51 & .11 & 19.60 & 10.20 \\
\hline 1831 & 360.0 & 83.89 & 8.62 & 3.74 & 0.00 & 3.75 & 1.23 & 0.00 & 0.00 & 0.00 \\
\hline 1832 & 410.0 & 78.27 & 7.48 & 3.05 & 0.00 & 11.20 & 1.15 & 0.00 & 18.20 & 0.00 \\
\hline 1833 & 443.0 & 83.78 & 6.49 & 3.55 & 0.00 & 6.18 & .93 & 0.00 & 9.10 & 0.00 \\
\hline 1835 & 481.4 & 76.97 & 7.12 & 3.14 & 10.04 & 2.74 & 1.11 & .10 & 7.20 & 3.00 \\
\hline 1837 & 527.7 & 71.71 & 5.81 & 3.51 & 14.06 & 4.91 & .97 & $? 15$ & 16.20 & 0.00 \\
\hline 1841 & 571.6 & 87.66 & 6.68 & 3.89 & 0.00 & 1.78 & .91 & 0.00 & 3.90 & 0.00 \\
\hline 1843 & $587 \cdot 3$ & 75.25 & 6.27 & 2.24 & 9.32 & 6.91 & 1.00 & .09 & 17.00 & 8.00 \\
\hline 1846 & 602.5 & 82.23 & 5.99 & 1.29 & 9.04 & 1.46 & .87 & .08 & 3.60 & 1.26 \\
\hline
\end{tabular}

BASIN: MCARTHUR

WELL: $\quad \mathrm{N} 27 / 63$

\begin{tabular}{|c|c|c|c|c|c|c|c|c|c|c|c|}
\hline ID & $\begin{array}{c}\text { DEPTH } \\
M\end{array}$ & C & $\begin{array}{c}\mathrm{H} \\
\text { PERCENT }\end{array}$ & $\stackrel{N}{D R Y}$ & $\mathrm{ASH}$ & $\begin{array}{l}0 \\
\text { FREE }\end{array}$ & S & $\mathrm{H} / \mathrm{C}$ & $0 / \mathrm{C}$ & $\begin{array}{c}\text { ASH } \\
\not\end{array}$ & $\begin{array}{l}F E \\
q\end{array}$ \\
\hline & & & \multicolumn{2}{|c|}{ FORMATION: } & BAR & RNEY & CREEK & & & & \\
\hline 1694 & 105.5 & 79.32 & 3.92 & .56 & 11. & .24 & 4.96 & .59 & .11 & 10.60 & 4.60 \\
\hline 1696 & 116.4 & 52.67 & 3.41 & .88 & & .00 & 43.04 & .78 & 0.00 & 31.30 & 0.00 \\
\hline 1705 & 172.8 & 75.11 & 5.44 & 1.74 & 19. & .24 & -1.53 & .87 & .19 & 5.90 & 3.40 \\
\hline 1713 & 223.2 & 83.72 & 4.34 & .95 & 13. & .03 & -2.04 & .62 & .12 & 10.60 & 9.00 \\
\hline 1718 & 276.0 & 72.42 & 2.28 & .75 & 13. & .18 & 11.37 & .38 & .14 & 42.80 & 20.00 \\
\hline 1724 & 289.6 & 81.32 & 2.57 & 2.67 & & .00 & 13.44 & .38 & 0.00 & 13.40 & 0.00 \\
\hline 1736 & 313.0 & 4.83 & .81 & .87 & 33. & .70 & 59.79 & 2.02 & 5.23 & 72.00 & .65 \\
\hline 1742 & 335.1 & 15.12 & 1.41 & .63 & 78. & .67 & 4.16 & 1.12 & 3.90 & 5.80 & 1.13 \\
\hline
\end{tabular}

BASIN : MCARTHUR

WELL: URAPUNGA NO 3

\begin{tabular}{|c|c|c|c|c|c|c|c|c|c|c|}
\hline ID & $\begin{array}{c}\text { DEPTH } \\
M\end{array}$ & C & $\begin{array}{c}\mathrm{H} \\
\text { PERCENT }\end{array}$ & $\begin{array}{c}\mathrm{N} \\
\mathrm{DRY}\end{array}$ & $\begin{array}{ll} & 0 \\
\text { ASH } & \text { FREE }\end{array}$ & $S$ & $\mathrm{H} / \mathrm{C}$ & $0 / C$ & $\begin{array}{c}\text { ASH } \\
\$\end{array}$ & $\begin{array}{l}\mathrm{FE} \\
q\end{array}$ \\
\hline & & & FORMAT & ION : & VEL KERR & & & & & \\
\hline 1522 & 39.9 & 86.57 & 7.26 & .74 & 4.52 & .91 & 1.01 & .04 & 7.00 & 3.95 \\
\hline 1523 & 64.9 & 88.98 & 6.52 & .79 & 3.80 & -.09 & .88 & .03 & 5.90 & 1.55 \\
\hline 1524 & 75.1 & 87.79 & 6.28 & .97 & 3.80 & 1.17 & .86 & .03 & 3.80 & 1.73 \\
\hline 1525 & 89.9 & 87.44 & 5.74 & 1.12 & 5.03 & .68 & .79 & .04 & 9.30 & $3 \cdot 35$ \\
\hline 1526 & 95.1 & 89.05 & 5.65 & 1.12 & 4.25 & -.06 & .76 & .04 & 8.80 & 2.05 \\
\hline 1527 & 115.1 & 89.68 & 5.26 & 1.38 & 4.04 & -.35 & .70 & .03 & 5.80 & 2.35 \\
\hline 1528 & 125.1 & 88.57 & 4.81 & .87 & 4.80 & .95 & .65 & .04 & 7.20 & .1 .73 \\
\hline
\end{tabular}


APPENDIX $\mathbf{R}$

PLATE 1 
PLATE 1

(a) The Abner Sandstone (Roper Group) near Beetle Springs, where it forms the eastern escarpment of the Abner Range, $80 \mathrm{~km}$ south-southwest of Borroloola.

(b) Measuring down-hole temperatures of Amoco's DDH 82/7 near Beetle Springs.

(c) Leitz Orthoplan-Pol microscope with MPV1 photometer and associated tranformers in foreground, and a modified Leitz Planphot microscope with zenon lamp and associated transformers in background used for low-power fluorescence microscopy. 


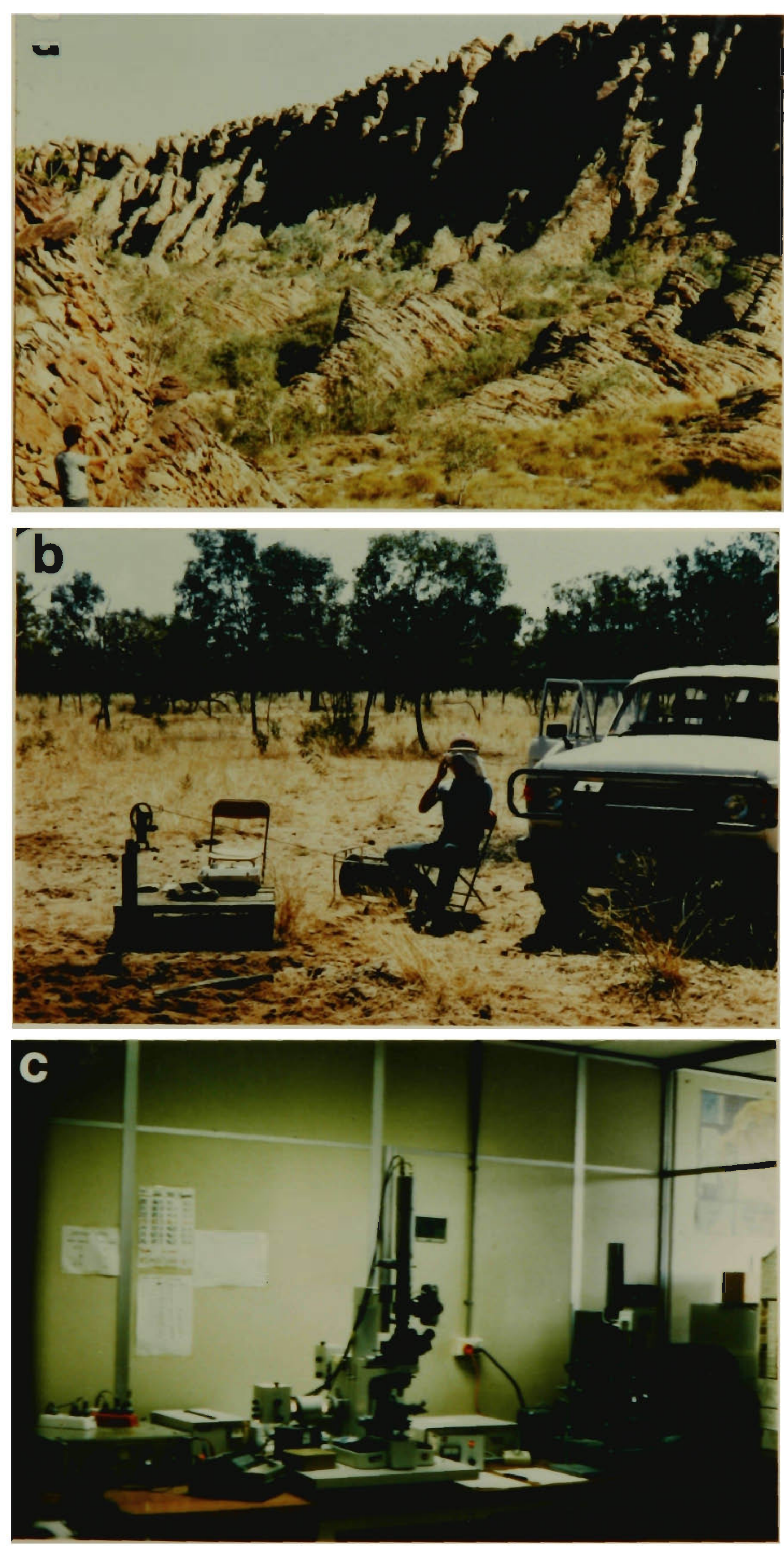

PLATE 1 


\section{PLATE 2}

Probable microfossils, McArthur Basin. 
PLATE 2

Probable microfosslls, McArthur Basin.

a) Roper Group, Mainoru Formation; DDH $82 / 8,66.8 \mathrm{~m}$; a double strand of silvery organic matter which is probably part of a large acritarch; mean maxRo\% $=2.21$; perpendicular to bedding; plane-polarized reflected white light; field-width $=0.10 \mathrm{~mm}$;

b) Roper Group, Corcoran Formation; DDH Urapunga 4, $463.8 \mathrm{~m}$; group of pyritized ?coccoids; perpendicular to bedding; plane-polarized reflected white light; scale bar $=20$ microns;

c) McArthur Group, Barney Creek Formation; DDH M17/08, $351.4 \mathrm{~m}$; pyritized clusters of cells; perpendicular to bedding; plane-polarized reflected white light; field-width = $0.20 \mathrm{~mm}$;

d) McArthur Group, Barney Creek Formation; DDH GR10, $80.1 \mathrm{~m}$; small tetrad of cells within circled area; fluorescence mode; parallel to bedding; scale bar $=20$ microns. 


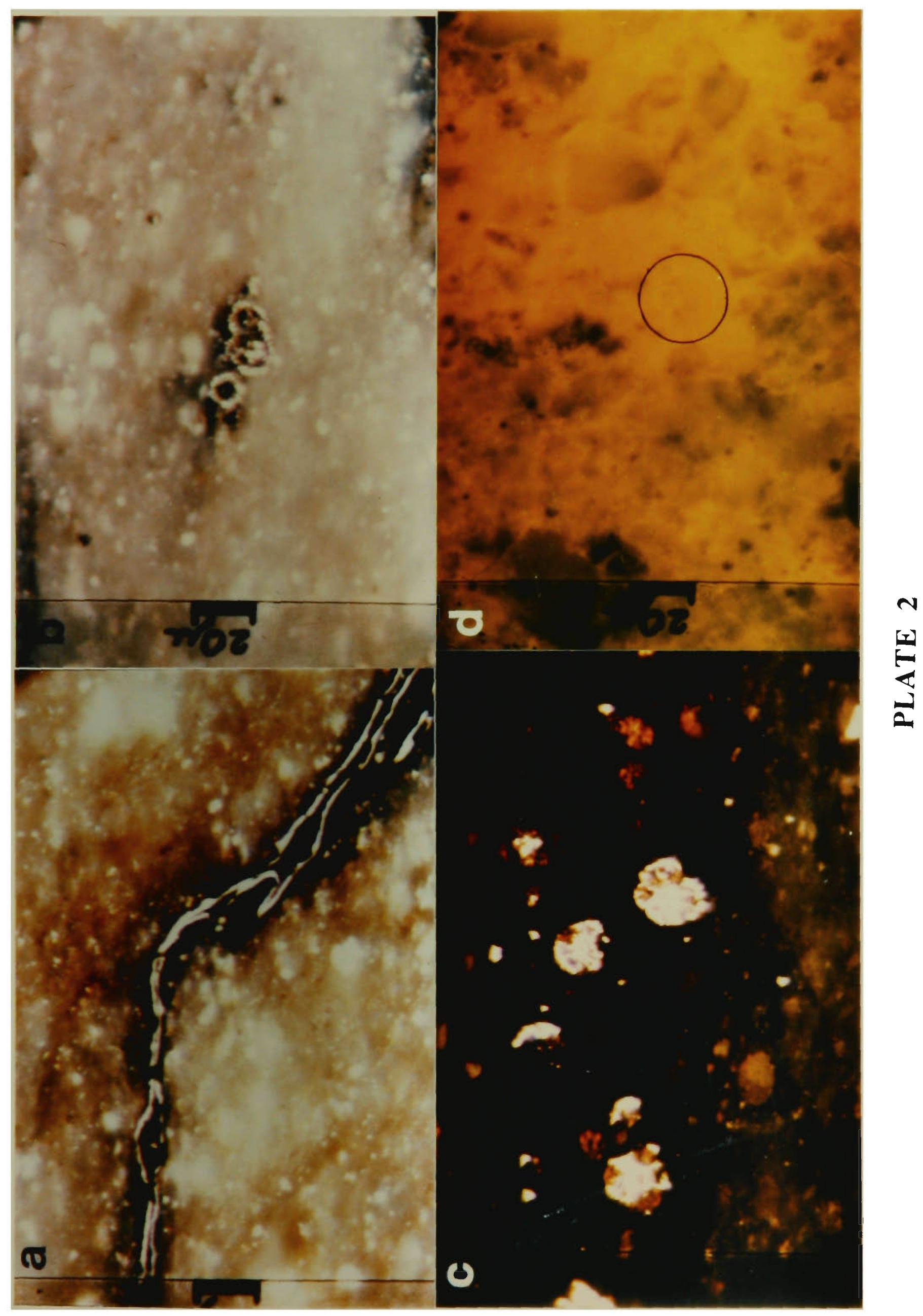




\section{PLATE 3}

Fluorescent lamalginite from the Barney Creek Formation, Glyde River Subbasin, DDH's GR3, 5 \& 7; low magnification photomicrographs. 


\section{PLATE 3}

Fluorescent lamalginite from the Barney Creek Formatlon, Glyde River Subbasin, DDH's GR3, 5 \& 7; low magnitication photomicrographs.

a) A large lenticular lamalginite body in very fine-grained calcarenite underlain by small discrete lamalginite in calcilutite; DDH GR3, $30.1 \mathrm{~m}$; perpendicular to bedding, fluorescence mode, field width $=2.0 \mathrm{~mm}$.

b) A band of wavy filamentous lamalginite in very fine-grained calcarenite, DDH GR5, $213.9 \mathrm{~m}$; perpendicular to bedding, field width $=3.4 \mathrm{~mm}$, plane-polarized white reflected light.

c) As for b) but in fluorescence mode.

d) Part of large body of lamalginite in central area with smaller discrete lamalginite from DDH GR5, $72.5 \mathrm{~m}$, perpendicular to bedding; field width $=2.0 \mathrm{~mm}$; plane-polarized white reflected light; mean maxRo\% $=0.12 \%$.

e) As for d) but in fluorescence mode.

f), g) As for d) and e) but showing one end of the same large body of lamalginite.

h) Small discrete lamalginite bodies from DDH GR7, $180.0 \mathrm{~m}$; field width $=2.0 \mathrm{~mm}$; fluorescence mode; perpendicular to bedding;

i) Small discrete lamalginite in calcilutite overlain by very fine-grained calcarenite showing strong mineral fluorescence, DDH GR7, $238.8 \mathrm{~m}$; fluorescence mode; field-width = $2.0 \mathrm{~mm}$; perpendicular to bedding. 


\section{PLATE 4}

Fluorescent lamalginite from the Barney Creek Formation, Glyde River Subbasin, DDH GR10, low magnification photomicrographs. All photomicrographs are in fluorescence mode. 


\section{PLATE 4}

Fluorescent lamalginlte from the Barney Creek Formation, Glyde Rlver Subbasin, DDH GR10, low magnification photomlcrographs.

All photomicrographs are in fluorescence mode.

a) $23.2 \mathrm{~m}$; discrete lamalginite bodies; perpendicular to bedding; field-width $=2.0 \mathrm{~mm}$;

b) $37.4 \mathrm{~m}$; a large lenticular shaped lamalginite body in central area, discrete lamalginite of varying sizes surrounding it; perpendicular to bedding; field-width $=2.0 \mathrm{~mm}$;

c) $88.4 \mathrm{~m}$; discrete lamalginite bodies of varying sizes, perpendicular to bedding; fieldwidth $=2.0 \mathrm{~mm}$;

d) $88.4 \mathrm{~m}$; parallel to bedding; irregular shaped bodies of lamalginite; field-width $=2.0$ $\mathrm{mm}$;

e) $92.6 \mathrm{~m}$; continuous lamalginite showing soft-sediment deformation and compaction round a carbonate grain; perpendicular to beddding; field-width $=2.0 \mathrm{~mm}$;

f) $137.2 \mathrm{~m}$; lenticular mass of very fine-grained pyrite possibly replacing discoidal gypsum (central dark body) in fluorescing fine-grained calcarenite; perpendicular to bedding, field-width $=0.8 \mathrm{~mm}$;

g) $143.3 \mathrm{~m}$; central discrete lenticular and wavy lamalginite body surrounded by smaller lamalginite bodies; perpendicular to bedding; field-width $=0.8 \mathrm{~mm}$;

h) $143.3 \mathrm{~m}$; parallel to bedding; a single lamalginite body showing an irregular but roughly circular oulline, field-width $=0.8 \mathrm{~mm}$;

i) $232.1 \mathrm{~m}$; thin wavy lamalginite; perpendicular to bedding; field-width $=2.0 \mathrm{~mm}$. 


\section{PLATE 5}

Fluorescent lamalginite from the Barney Creek Formation, Glyde River Subbasin, DDH GR10, $88.4 \mathrm{~m}$ $442.9 \mathrm{~m}$. 


\section{PLATE 5}

Fluorescent lamalginlte from the Barney Creek Formation, Glyde River Subbasin, DDH GR10, $88.4 \mathrm{~m}-442.9 \mathrm{~m}$.

All photomlcrographs are at high magniflcations and perpendicular to bedding.

a) $88.4 \mathrm{~m}$; a strand of lamalginite viewed under plane-polarized reflected light; scale bar $=50$ microns; mean $\operatorname{maxRo} \%=0.12 \%$;

b) as for a) but in fluorescence mode; note thin lamellae in the large strand of lamalginite;

c) $143.3 \mathrm{~m}$; part of a large lamalginite body showing individual lamellae and contained mineral matter, in fluorescence mode; scale bar $=20$ microns;

d) $143.3 \mathrm{~m}$; grey surface of part of a strand of lamalginite; plane-polarized reflected white light; scale bar $=20$ microns; mean $\operatorname{maxRo} \%=0.14 \%$;

e) as for d) but in fluorescence mode; scale bar = 20 microns;

f) $297.2 \mathrm{~m}$; centrally located strand of grey reflecting lamalginite; plane-polarized white reflected light; scale bar $=20$ microns; mean $\operatorname{maxRo} \%=0.24 \%$;

g) as for $f$ ) but in fluorescence mode;

h) $410.0 \mathrm{~m}$; a thin strand of lamalginite; scale bar $=20$ microns; mean $\max R 0 \%=0.27 \%$.

i) as for $f$ ) but in fluorescence mode; note that the prominent mineral fluorescence; scale bar $=20$ microns; 


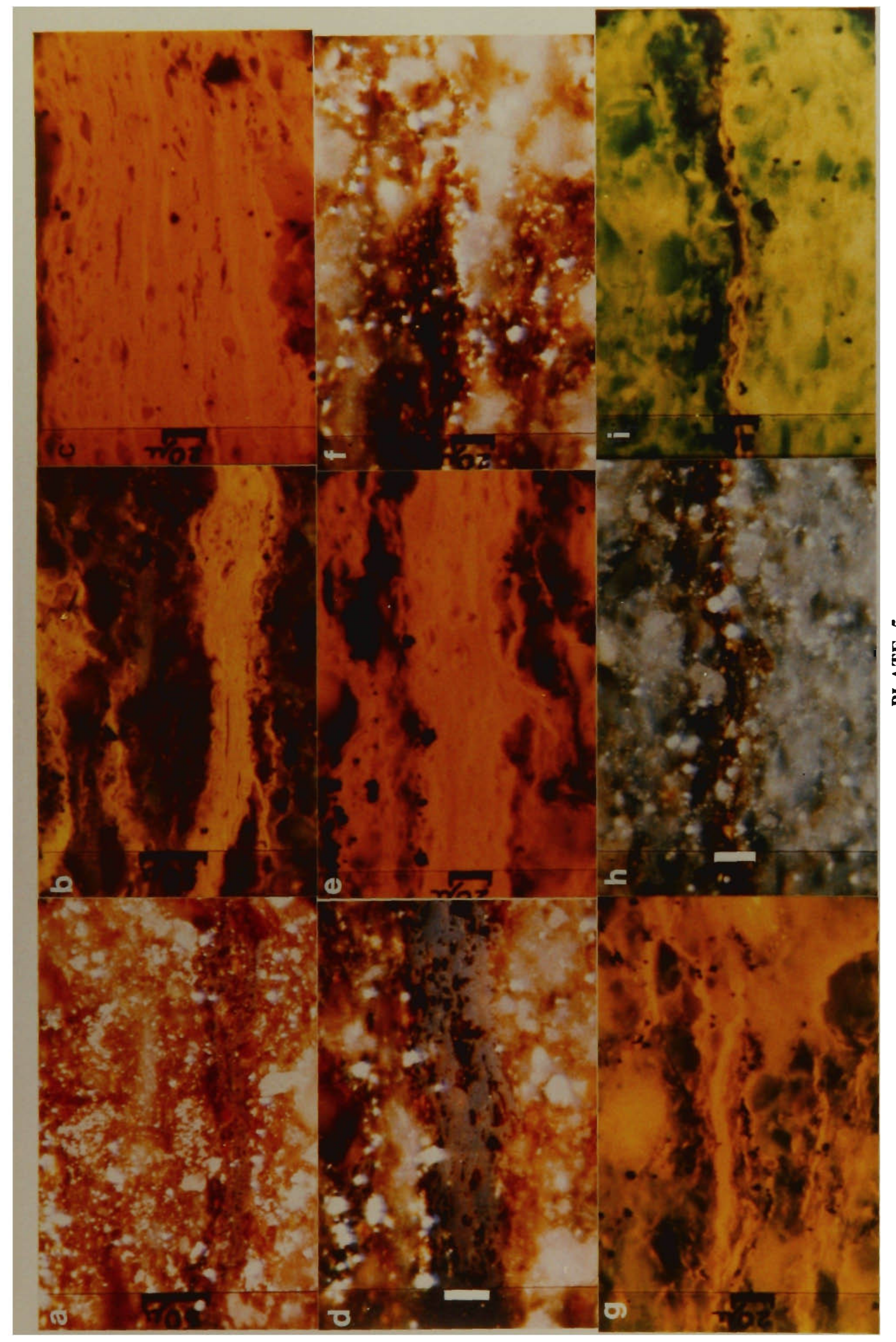




\section{PLATE 6}

Low fluorescent lamalginite and bitumen from the Barney Creek Formation, Glyde River Subbasin, DDH GR $10,575.3 \mathrm{~m}$. 


\section{PLATE 6}

Low-fluorescent lamalginite and bltumen from the Barney Creek Formation, Glyde River Subbasln, DDH GR 10, $575.3 \mathrm{~m}$.

All photos are perpendlcular to bedding.

a) a low-magnification photomicrograph of calcilutite containing diffuse dark organic matter and one thucholite in upper right-hand corner, underlain by layer of relatively organic-matter free very fine grained calcarenite; white reflected light;

b) strand of lamalginite in central area under plane polarized white light; part of a large strand of lamalginite shown in composite photomicrograph $d$; mean maxRo\% for fluorescent lamalginite $=0.40 \%$;

c) same view as for b) but in fluorescence mode;

d) composite photo of a single discontinuous lamalginite body, plane-polarized reflected light.

e) a patch of dispersed bitumen in plane-polarized reflected light; scale bar is 20 microns;

f) the same patch of dispersed bitumen as for e) but in fluorescence mode; note the presence of zoned carbonate rhombs; bright yellow spots within the patch are oil inclusions. 

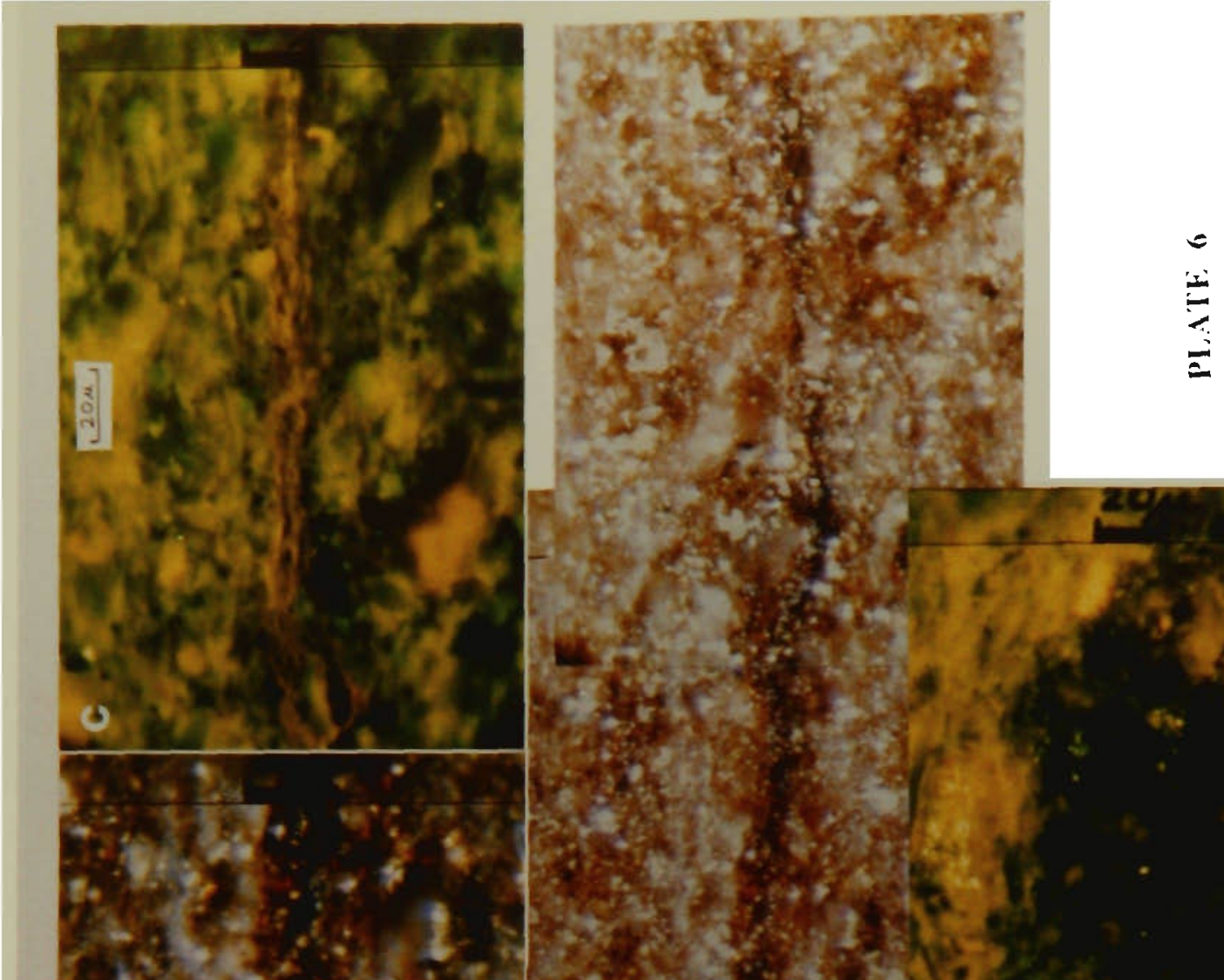

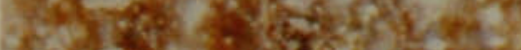

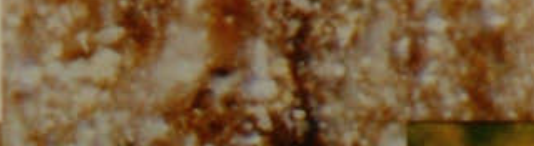

$\underset{1}{2}$ (2)

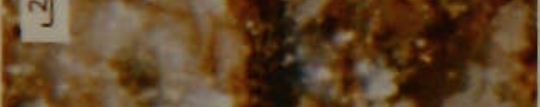

6.

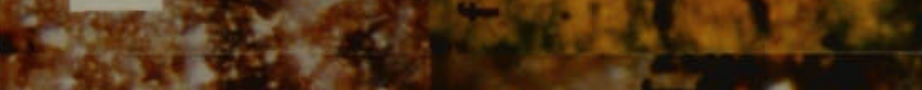

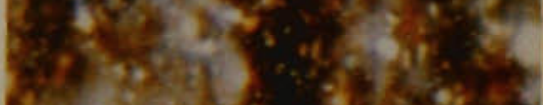

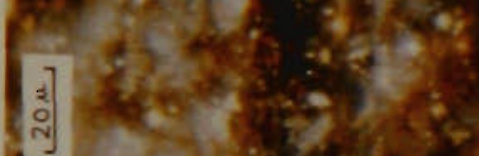

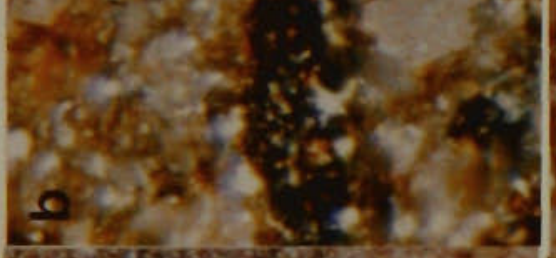

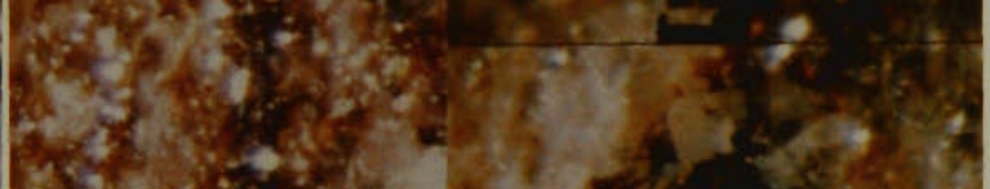
3.5.

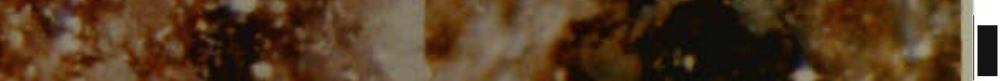

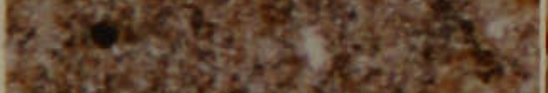

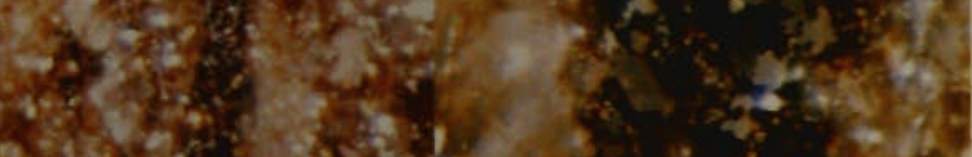

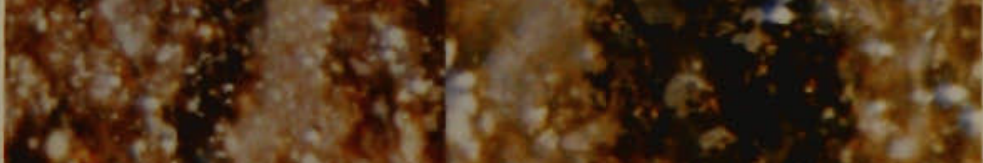
P.

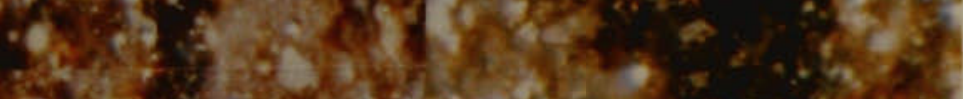

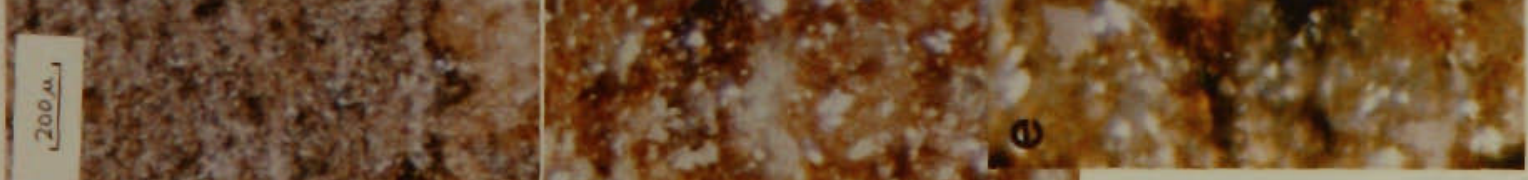

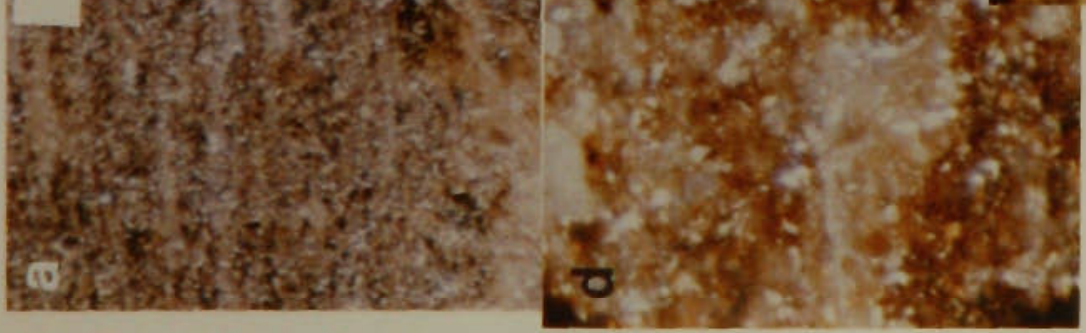


149

\section{PLATE 7}

Bitumen in the Barney Creek Formation, Glyde River Subbasin, DDH GR10. 


\section{PLATE 7}

Bitumen In the Barney Creek Formation, Glyde River Subbasin, DDH GR10; perpendicular to bedding.

a) $443.0 \mathrm{~m}$; bitumen veins, one vein appears to emanate from a slightly darker layer of calcilutite near the bottom of the photo, the layer is upraised at the point of expulsion; reflected white light, field-width $=8 \mathrm{~mm}$;

b) $443.0 \mathrm{~m}$; same specimen as a); small silvery pieces of disseminated bitumen in central and peripheral areas of the photo; plane polarized reflected white light; scale bar $=30$ microns; mean maxRo\% $=0.52 \%$;

c) $443.0 \mathrm{~m}$; same specimen as a); small grey centrally located piece of disseminated bitumen; plane polarized reflected white light; scale bar $=20$ microns;

d) as for c) but in fluorescence mode; note the central dark area which contains the single piece of disseminated bitumen, and bright yellow spots which are oil inclusions;

e) $646.9 \mathrm{~m}$; vein bitumen; plane polarized reflected white light; scale bar $=50$ microns;

f) as for e) but under crossed polarizers;

g) $662.1 \mathrm{~m}$; thin diagonal vein of bitumen; plane polarized reflected white light; scale bar = 20 microns; mean maxRo\% $=0.90 \%$.

h) as for g) but in fluorescence mode; fluorescence appears most intense adjacent to the non-fluorescing bitumen vein;

i) $662.1 \mathrm{~m}$; centrally located bright-yellow fluorescing oil-filled vug just below the surface of the polished block. 


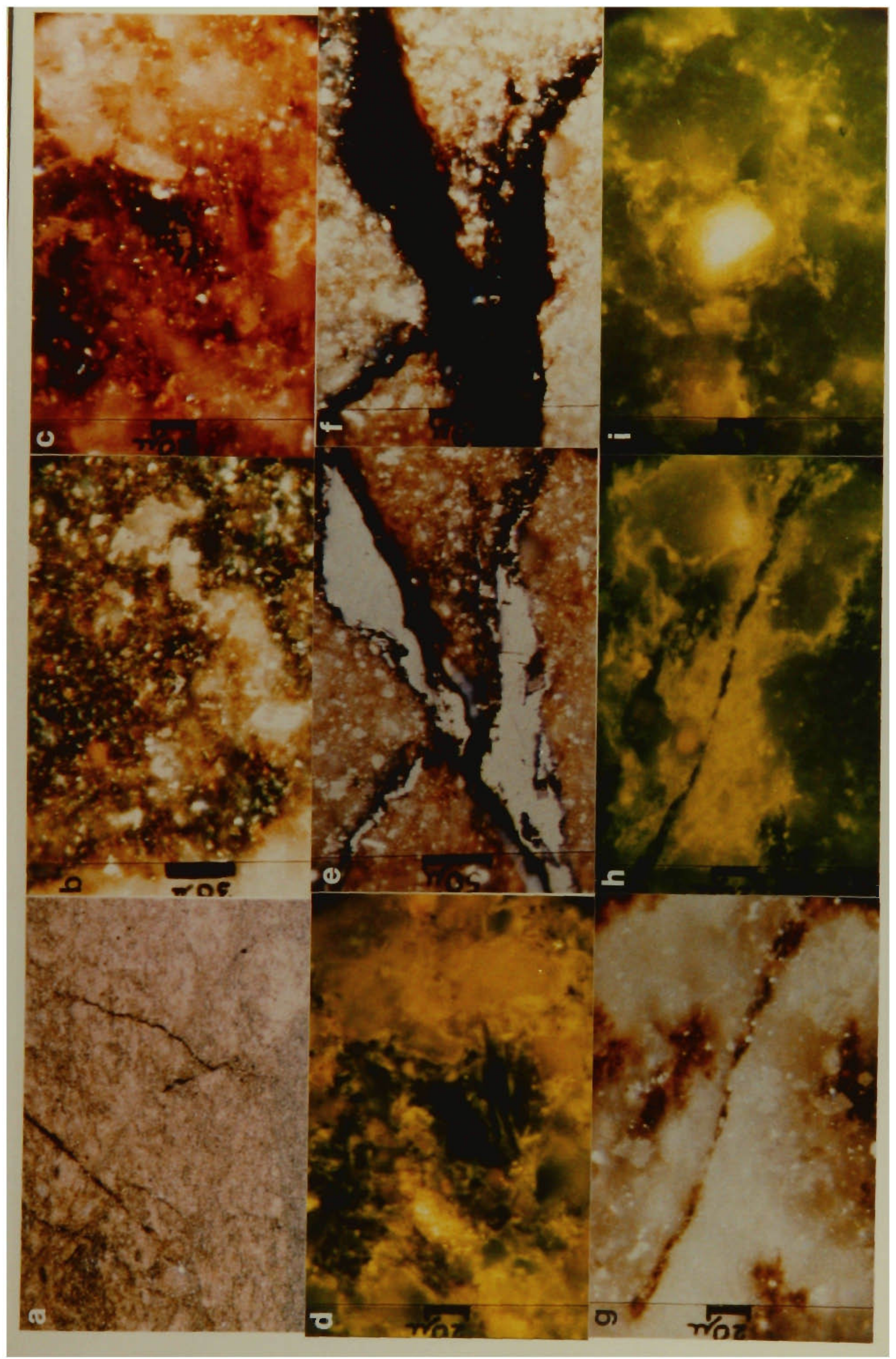


PLATE 8

Thucholite and radiation-affected lamalginite, Barney Creek Formation, Glyde River Subbasin, DDH GR10. 
PLATE 8

Thucholite and radiation-affected lamalginite, Barney Creek Formation, Glyde River Subbasin, DDH GR10; perpendlcular to bedding.

a) $23.2 \mathrm{~m}$; large thucholite in plane polarized reflected white light; scale bar $=20$ microns;

b) as for a) but in fluorescence mode;

c) $37.4 \mathrm{~m}$; thucholite in plane polarized reflected white light; scale bar $=50$ microns;

d) as for c) but in fluorescence mode; note the thucholite has formed within a strand of lamalginite which is slightly displaced by the thucholite;

e) $37.4 \mathrm{~m}$; central white grain, probably zircon, partly surrounded by higher reflecting lamalginite, plane polarized reflected white light, scale bar $=20$ microns;

f) as for e) but in fluorecence mode, note partial loss of fluorescence in the lamalginite adjacent to the grain;

g) $238.2 \mathrm{~m}$; large thucholite grain in plane polarized reflected white light; scale bar $=30$ microns;

h) $392.4 \mathrm{~m}$; centrally located small grey object is probably a saggital section of a large thucholite; plane polarized reflected white light; scale bar $=20$ microns;

i) as for h) but in fluorescence mode; 


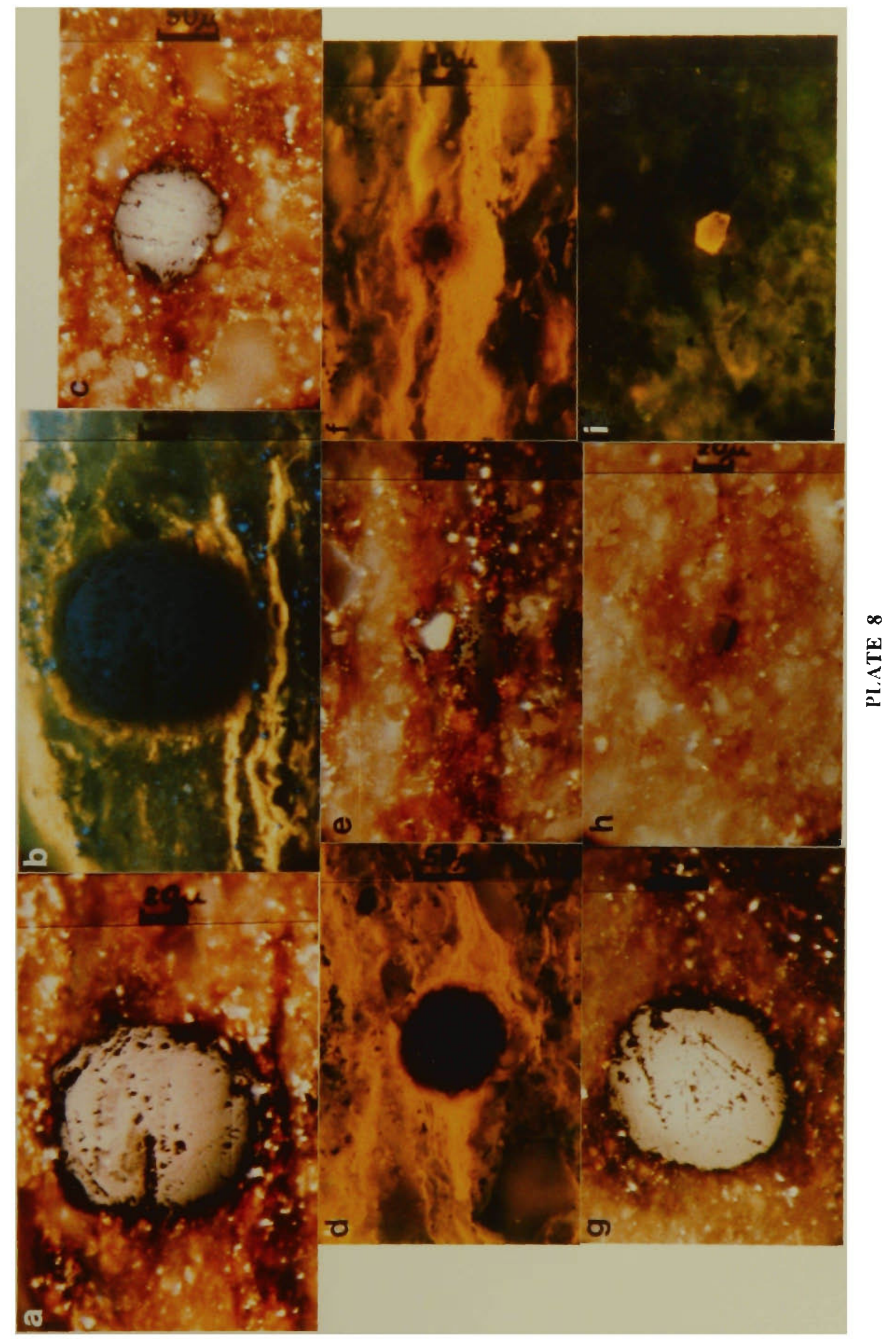




\section{PLATE 9}

Fluorescent lamalginite, matrix and disseminated bitumen, Barney Creek Formation, Glyde River Subbasin, DDH's GR3 \& 7. 


\section{PLATE 9}

Fluorescent lamalginite, matrlx and dlssemlnated bltumen, Barney Creek Formation, Glyde Rlver Subbasin, DDH's GR3 \& 7. Perpendicular to bedding.

a) DDH GR3, $302.6 \mathrm{~m}$; low fluorescing lamalginite; scale bar = 50 microns;

b) as for a) but under reflected plane-polarized white light; note the somewhat dispersed nature of the silvery organic matter on the right side of the photo which has extremely low fluorescence and has been classified as disseminated bitumen; bitumen mean maxRo\% $=0.40 \%$.

c) and d) DDH GR3, $302.6 \mathrm{~m}$; an example of a strand of lamalginite which at its right-hand end is much reduced in fluorescence and under white reflected light (d) appears disrupted; the irregular shaped silvery pieces on the right hand side of d) have been classified as disseminated bitumen; scale bar $=.50$ microns;

e) and f) DDH GR3, $302.6 \mathrm{~m}$; low fluorescing organic matter which under white reflected light $(f)$ has irregular shapes and in places surrounds mineral grains; classified as matrix and disseminated bitumen; scale bars = 50 microns;

g) GR7, $602.7 \mathrm{~m}$; a thin discontinuous orange-yellow fluorescing strand of lamalginite and grains of carbonate showing bright yellow oil inclusions; scale is the same as h) where scale bar $=20$ microns;

h) as for g) but in plane polarized white reflected light;

i) GR9, $79.1 \mathrm{~m}$; wavy thin continuous strands of lamalginite, central circular area has been subjected to 3 hours of continuous UV excitation and shows marked positive alteration; scale bar $=50$ microns. 


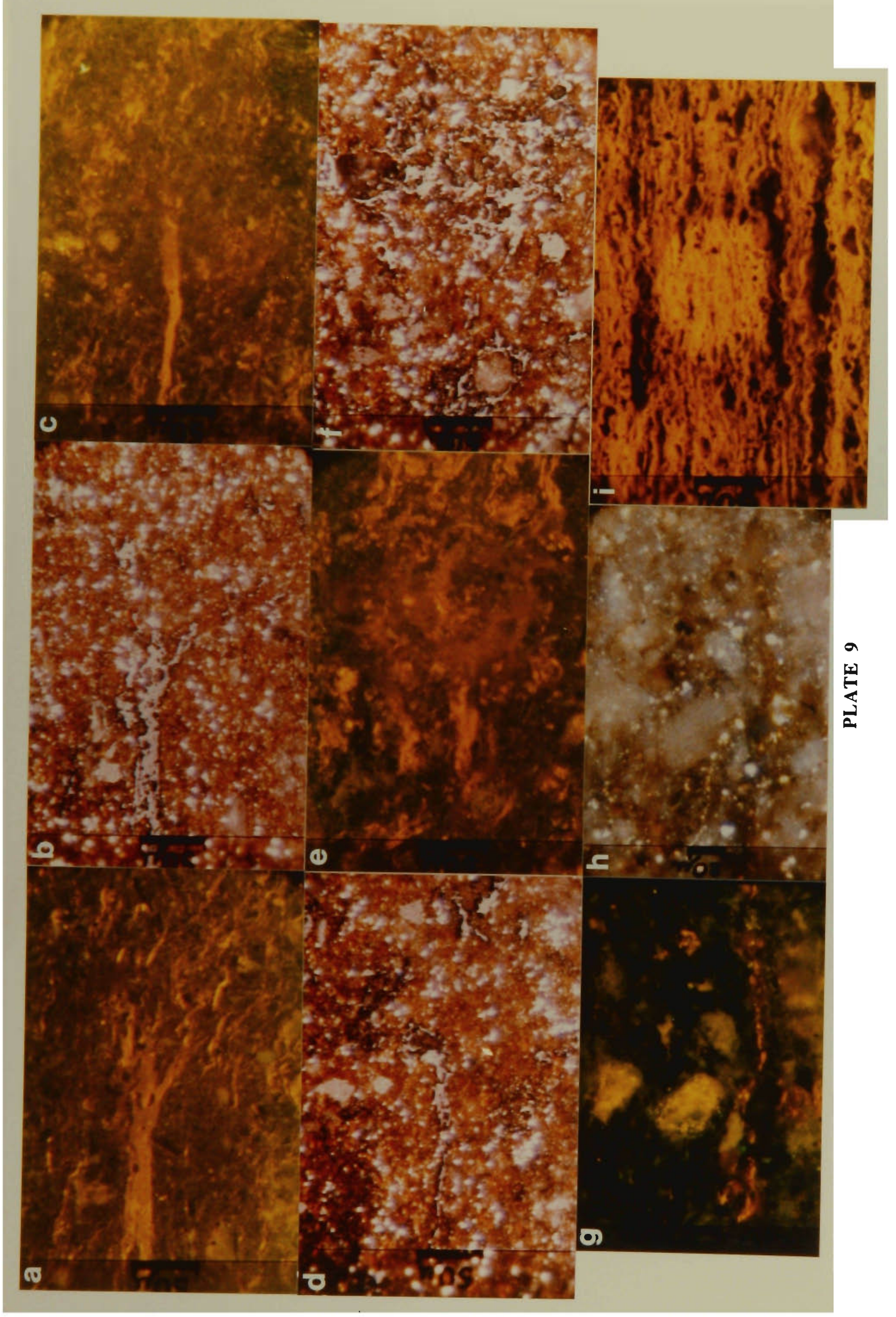


PLATE 10

Kerogen (fluorescent lamalginite) in strew mounts and SEM photographs of fluorescent lamalginite, Barney Creek Formation, Glyde River Subbasin, DDH GR10. 


\section{PLATE 10}

Kerogen (fluorescent lamalginlte) In strew mounts and SEM photographs of kerogen (fluorescent lamalginite), Barney Creek Formatlon, Glyde Rlver Subbasin, DDH GR10.

a) $23.2 \mathrm{~m}$; single large piece of kerogen in transmitted light; black patches are pyrite; scale bar $=20$ microns;

b) as for a) but in fluorescence mode;

c) $23.2 \mathrm{~m}$; as for a);

d) $51.8 \mathrm{~m}$; part of a single large piece of kerogen displaying pseudocellular structure, transmitted light; scale bar $=20$ microns;

e) $51.8 \mathrm{~m}$; SEM of part of a kerogen piece showing plate-like structure; octahedron in lower part is pyrite;

f) $170.3 \mathrm{~m}$ SEM of part of a piece of kerogen also showing its plate-like structure. 


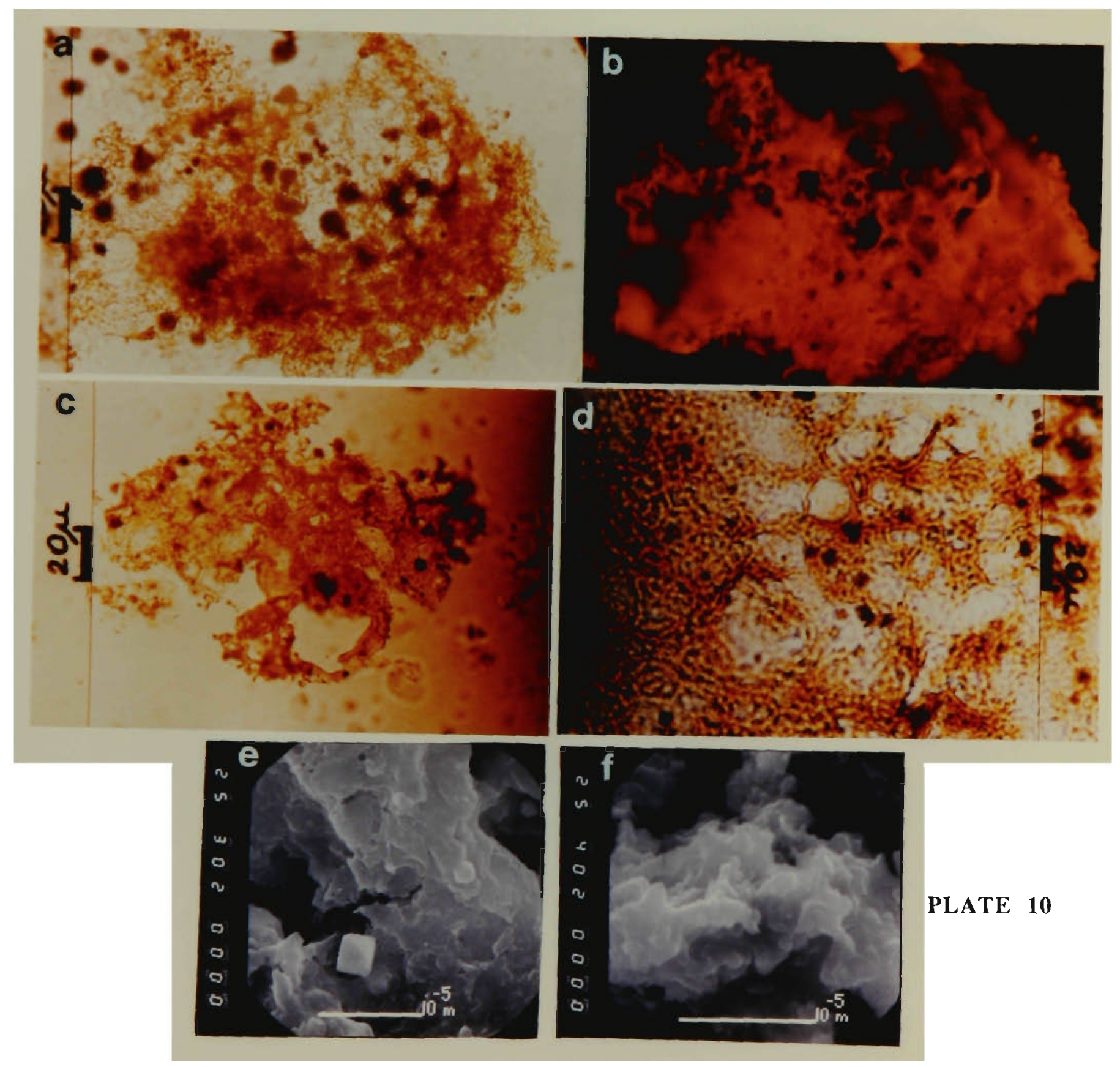


PLATE 11

A titaniferous bitumen nodule, containing possible filamentous microfossils; Barney Creek Formation, Glyde River Subbasin, DDH GR10, $37.4 \mathrm{~m}$; perpendicular to bedding. 


\section{PLATE 11}

\section{A titanlferous bitumen nodule, contalning posslble fllamentous microfosslls; Barney Creek Formation, Glyde River Subbasin, DDH GR10, $37.4 \mathrm{~m}$; perpendicular to bedding.}

a) titaniferous bitumen nodule containing pyritized branching filamentous structures which are possibly microfossils; plane-polarized light; scale bar $=20$ microns;

b) as for a) but in fluorescence mode;

c) SEM image of same nodule as in a); scale bar = 20 microns;

d) X-ray map of c) for Fe; same scale as for c);

e) X-ray map of c) for S; same scale as for c);

f) X-ray map of c) for $\mathrm{Ti}$; same scale as for $\mathrm{C}$ );

g) X-ray map of c) for Si; same scale as for c);

h) X-ray map of c) for Ca; same scale as for c);

i) X-ray map of c) for K; same scale as for c);

h) X-ray map of c) for Ca; same scale as for c);

i) X-ray map of c) for K; same scale as for c);

j) X-ray map of c) for Al; same scale as for c). 

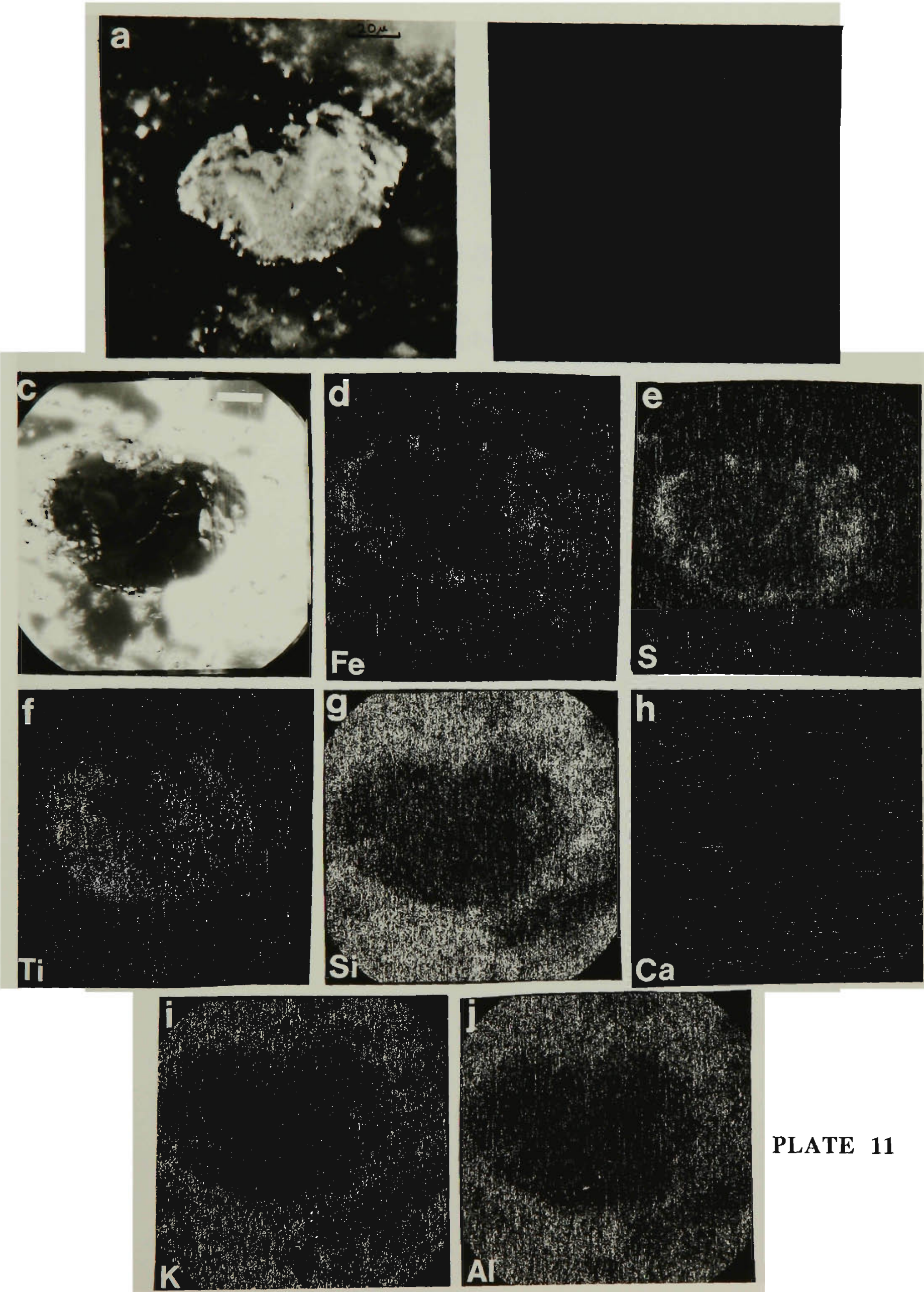

PLATE 11 
PLATE 12

A pyritic nodule containing oil inclusions, Barney Creek Formation, Glyde River Subbasin, DDH GR10, $37.4 \mathrm{~m}$. 


\section{PLATE 12}

A pyritlc nodule contalning oll Inclusions, Barney Creek Formation, Glyde River Subbasin, DDH GR10, $37.4 \mathrm{~m}$; perpendicular to bedding.

a) a large pyritic nodule containing oil inclusions ( $X$ marks the location of three brown inclusions of oil); scale bar $=50$ microns;

b) as in a) but in fluorescence mode, oil in the nodule fluoresces a bright yellow;

c) SEM image of a), slightly rotated, $X$ marks the same oil inclusions as in a); scale bar = 50 microns;

d) Higher power SEM image of area $X$; note cellular structure; scale bar = 10 microns;

e) X-ray map of c) for $\mathrm{Fe}$; scale bar $=50$ microns;

f) X-ray map of c) for $S$; scale bar $=50$ microns. 


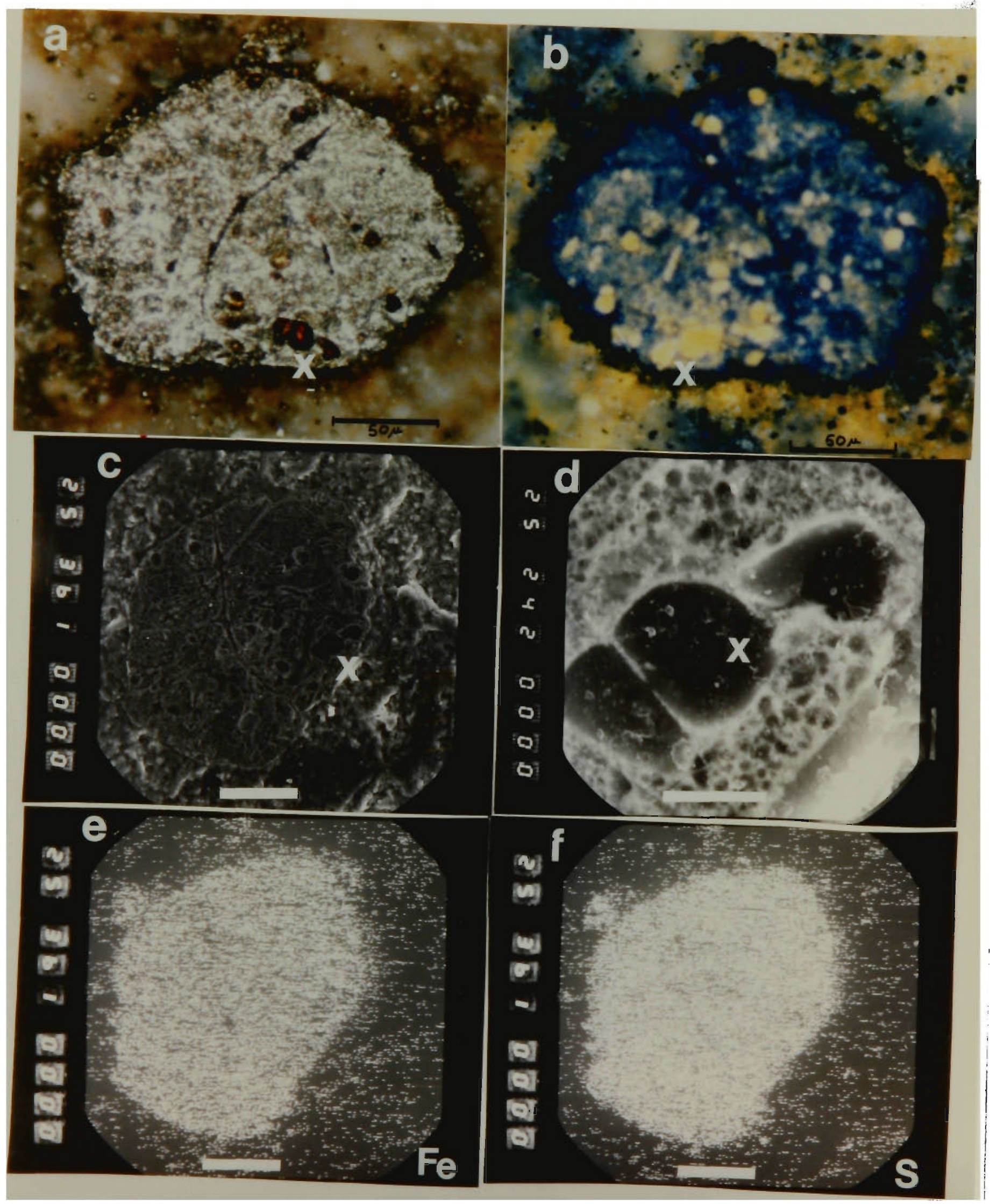

PLATE 12 
PLATE 13

A titaniferous bitumen nodule, Barney Creek Formation, Glyde River Subbasin, DDH GR10, $37.4 \mathrm{~m}$. 


\section{PLATE 13}

A titanlferous bltumen nodule, Barney Creek Formation, Glyde Rlver SubbasIn, DDH GR10, $37.4 \mathrm{~m}$, perpendicular to beddlng.

a) SEM showing a dark lobate bitumen nodule; scale bar = 50 microns;

b) X-ray map for $\mathrm{Fe}$ of a), same scale as for a);

c) X-ray map for $S$ of a); same scale as for a);

d) X-ray map for Ti of a); same scale as for a);

e) X-ray map for Si of a); same scale as for a);

f) X-ray map for $\mathrm{Ca}$ of a); same scale as for a);

g) X-ray map for $\mathrm{K}$ of a); same scale as for a);

h) X-ray map for Al of a); same scale as for a);

i) X-ray map for $\mathrm{Mg}$ of a); same scale as for a). 

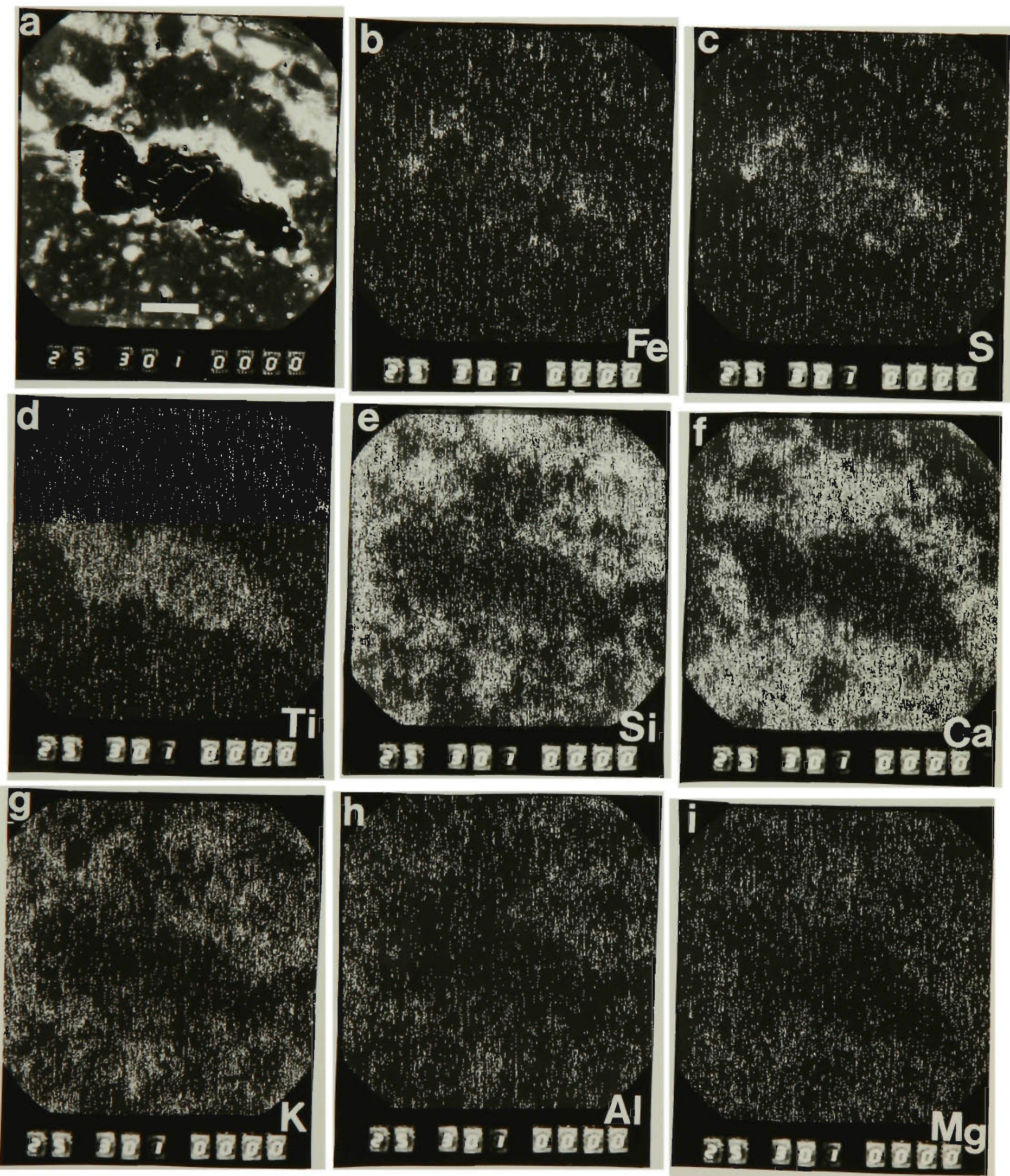
PLATE 14

A titaniferous bitumen nodule, Barney Creek Formation, Glyde River Subbasin, DDH GR10, $37.4 \mathrm{~m}$. 
A titanlferous bltumen nodule, Barney Creek Formatlon, Glyde River Subbasin, DDH GR10, $37.4 \mathrm{~m}$, perpendicular to bedding.

a) large titaniferous bitumen nodule, bright spots are pyrite; plane-polarized white light; scale bar $=20$ microns;

b) as for a) but in fluorescence mode;

c) SEM image of same nodule as in a); scale bar = 5 microns;

d) X-ray map of c) for sulphur which appears to outline individual nodules that that form the larger nodule; scale bar is 5 microns;

e) X-ray map of c) for $\mathrm{Fe}$; scale bar $=5$ microns;

f) X-ray map of c) for Ti; scale bar $=5$ microns;

g) X-ray map of c) for $\mathrm{Si}$; scale bar $=5$ microns;

h) X-ray map of c) for Ca; scale bar $=5$ microns;

i) X-ray map of c) for $K$; scale bar $=5$ microns. 


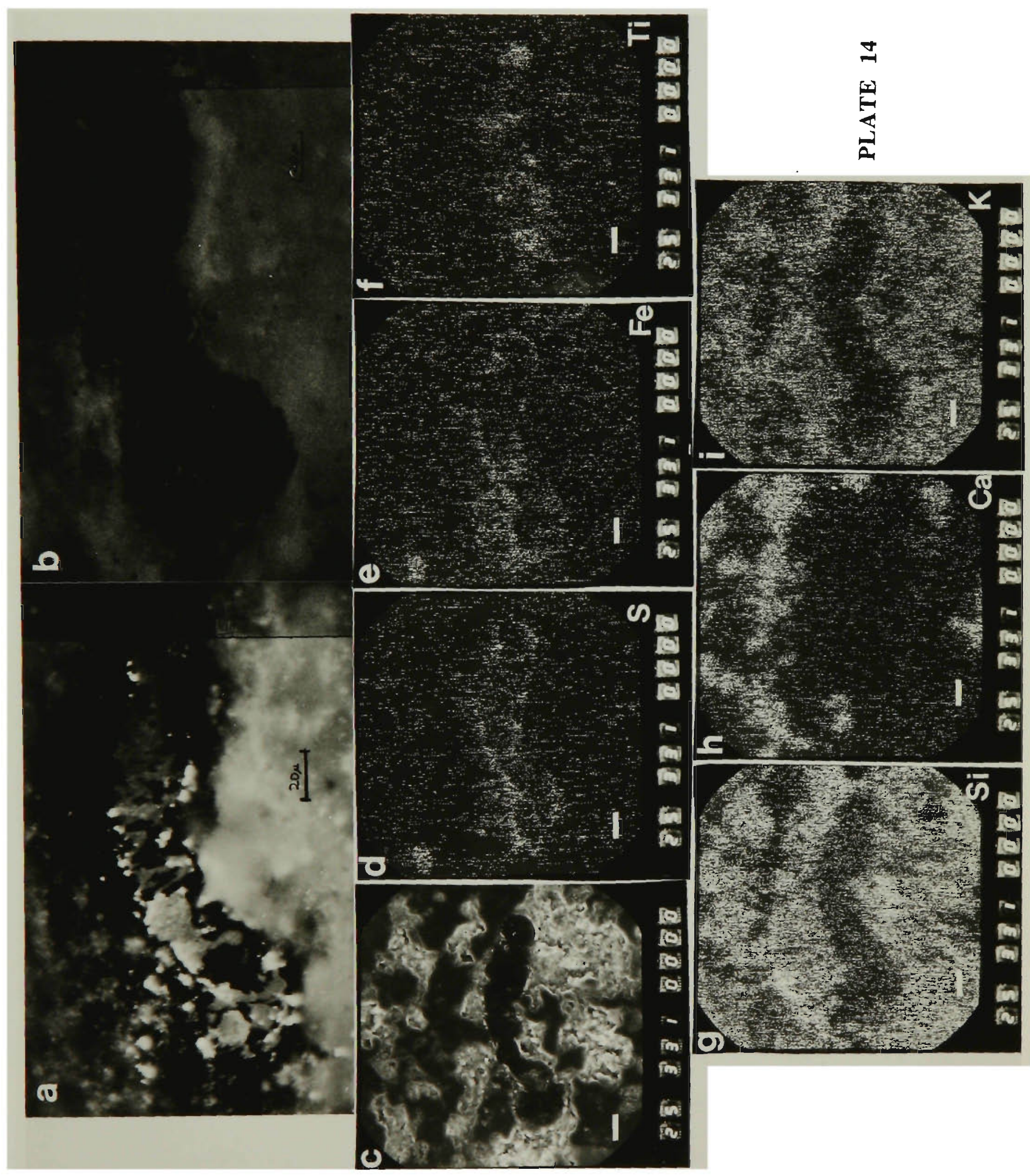




\section{PLATE 15}

SEM X-ray maps of a fluorescent lamalginite body and surrounding mineral matrix, Barney Creek Formation, Glyde River Subbasin, DDH GR10, $92.6 \mathrm{~m}$. 
SEM X-ray maps of a fluorescent lamalginite body and surrounding mineral matrlx, Barney Creek Formation, Glyde River Subbasin, DDH GR10, 92.6 $\mathrm{m}$; perpendlcular to bedding.

a) SEM image showing a large lensoidal body of lamalginite (central black piece) and smaller lamalginite bodies (black), scale bar $=0.1 \mathrm{~mm}$;

b) X-ray map of a) for Ca;

c) X-ray map of a) for Fe;

d) X-ray map of a) for $S$;

e) X-ray map of a) for $\mathrm{Si}$;

f) X-ray map of a) for $K$;

g) X-ray map of a) for $\mathrm{Mg}$;

h) X-ray map of a) for Al. 


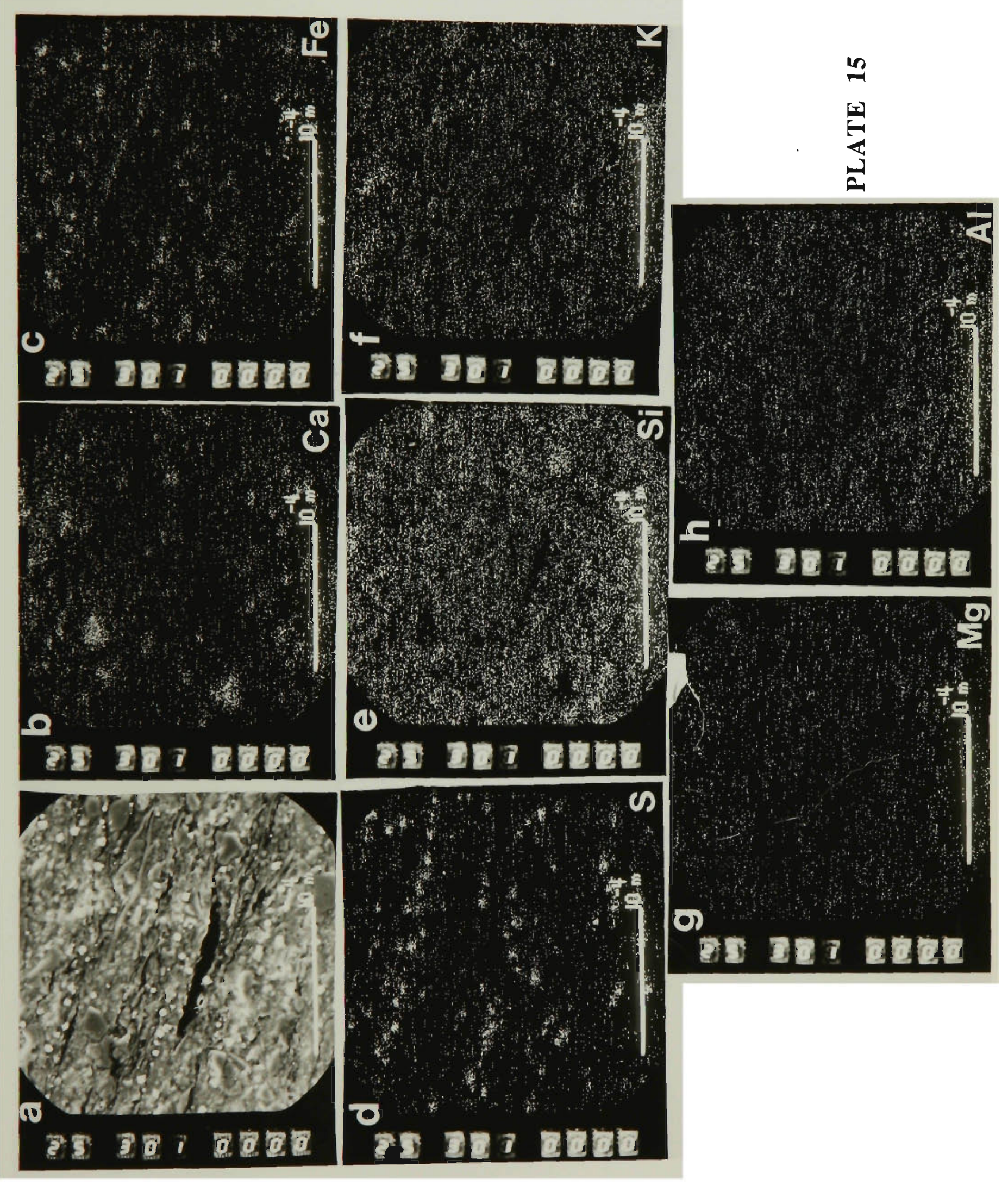


PLATE 16

SEM X-ray maps of a large mat of fluorescent lamalginite, Barney Creek Formation, Glyde River Subbasin, DDH GR5, $72.5 \mathrm{~m}$. 
SEM X-ray maps of a large mat of fluorescent lamalginite, Barney Creek Formation, Glyde Rlver Subbasln, DDH GR5, $72.5 \mathrm{~m}$. Perpendicular to bedding.

a) Central area shows a thick band of lamalginite under white reflected light, scale bar = $0.25 \mathrm{~mm}$;

b) as for a) but in fluorescence mode;

c) SEM image of part of the thick band of lamaginite as shown in a) \& b); scale bar $=0.25 \mathrm{~mm}$;

d) X-ray map of c) for Ca; same scale as for c);

e) X-ray map of c) for Fe; same scale as for c);

f) X-ray map of c) for $S$; same scale as for c);

g) X-ray map of c) for $\mathrm{Mg}$; same scale as for $\mathrm{c}$ );

h) X-ray map of c) for Si; same scale as for c);

i) X-ray map of c) for Al; same scale as for C);

j) X-ray map of c) for $K$; same scale as for $c$ ). 


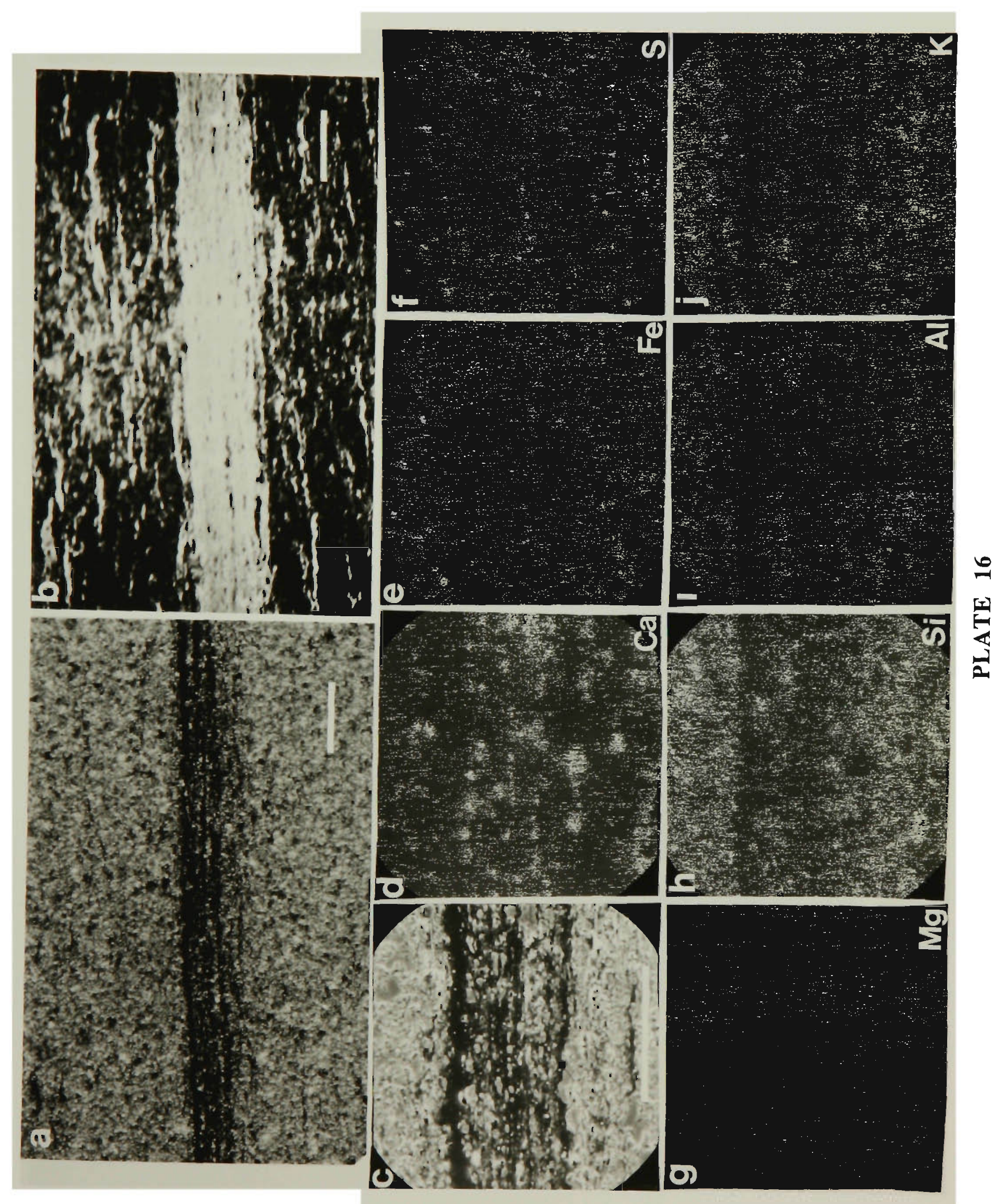


A scoured bed containing phosphate and fluorescent lamalginite, Barney Creek Formation, Glyde River Subbasin, DDH GR7, $180.0 \mathrm{~m}$. 


\section{PLATE 17}

A scoured bed contalning phosphate and fluorescent lamalginite, Barney Creek Formation, Glyde River Subbasln, DDH GR7, $180.0 \mathrm{~m}$; perpendicular to bedding.

1) A composite photo in white reflected light, showing a bed containing dark laminae of lamalginite and phosphate that has been scoured on the right hand side; the brighter band overlying the phosphatic bed is pyrite rich; (a), (b), (c) \& (d) refer to enlarged views of those areas shown in photos below which are all in fluorescence mode; scale bar $=1 \mathrm{~mm}$;

a) Close-up of area (a) in (1); (p) refers to the dark non-fluorescing phosphate; field-width $=2.0 \mathrm{~mm}$;

b) Close-up of area (b) in (1); (p) refers to the dark non-fluorescing phosphate; individual lamalginite lamellae occur within the phosphate lens; field-width $=2.0 \mathrm{~mm}$;

c) Close-up of area (c) in (1) at left-hand edge of the scour; (p) refers to the dark nonfluorescing phosphate; field-width $=2.0 \mathrm{~mm}$;

d) Close-up of area (d) in (1) at the right-hand edge of the scour; (p) refers to the dark non-fluorescing phosphate; field-width $=2.0 \mathrm{~mm}$; 


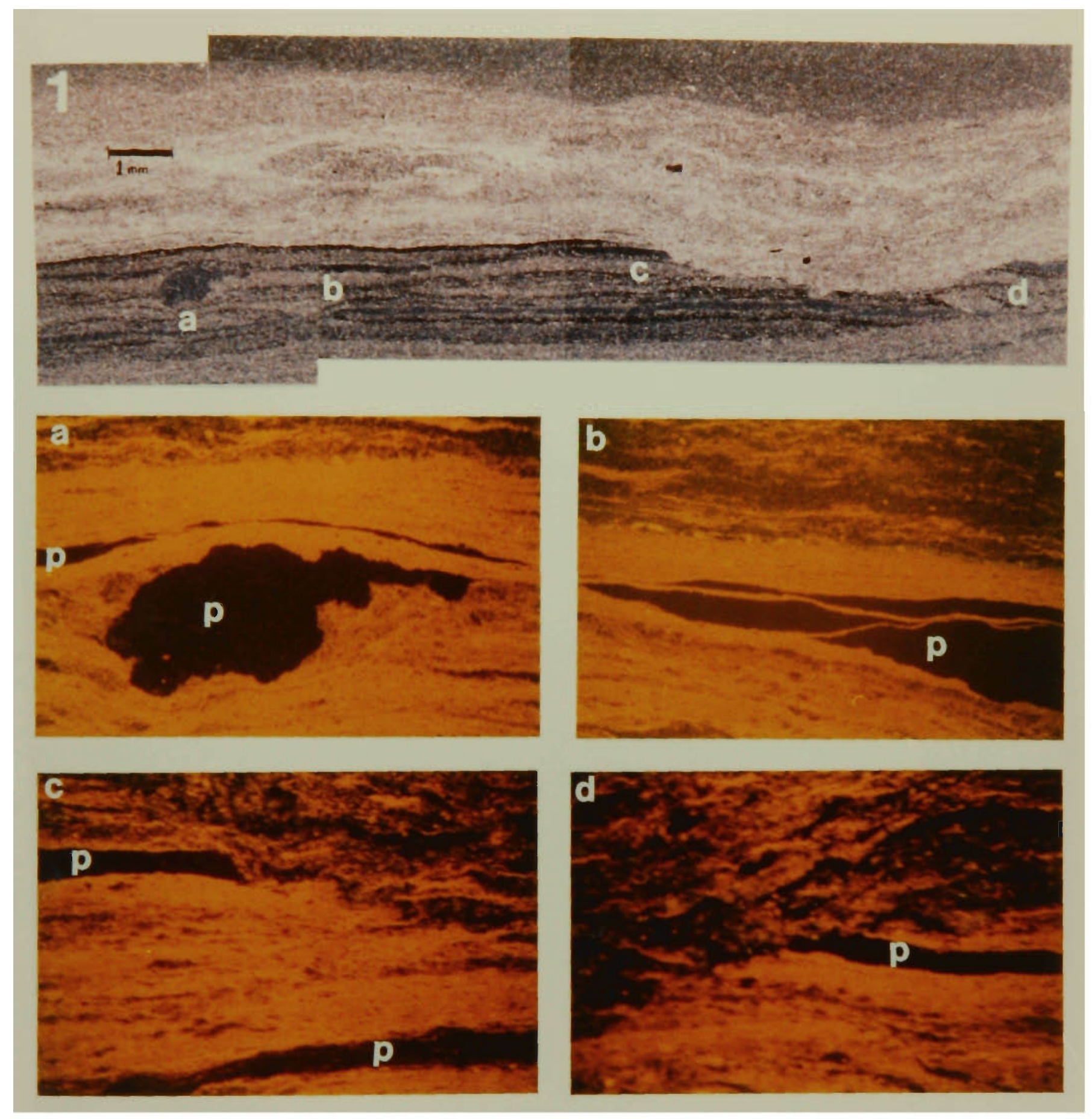

PLATE 17 


\section{PLATE 18}

SEM images of the phosphate nodule shown in Plate 17a from the Barney Creek Formation, Glyde River Subbasin, DDH GR7, $180.0 \mathrm{~m}$. 
SEM Images of the phosphate nodule shown In Plate 17a from the Barney Creek Formation, Glyde Rlver Subbasin, DDH GR7, $180.0 \mathrm{~m}$; perpendicular to bedding.

a) SEM image of the phophate nodule as shown on Plate $17 \mathrm{a}$; scale bar $=0.1 \mathrm{~mm}$;

b) SEM image of same nodule at a higher magnification; scale bar $=50$ microns

c), d) and e) higher magnification SEM photos of the same nodule; scale bar in e) $=10$ microns;

f) hexagonal crystals of phosphate from a lens of phosphate shown partly in Plate 17b; scale bar $=5$ microns. 

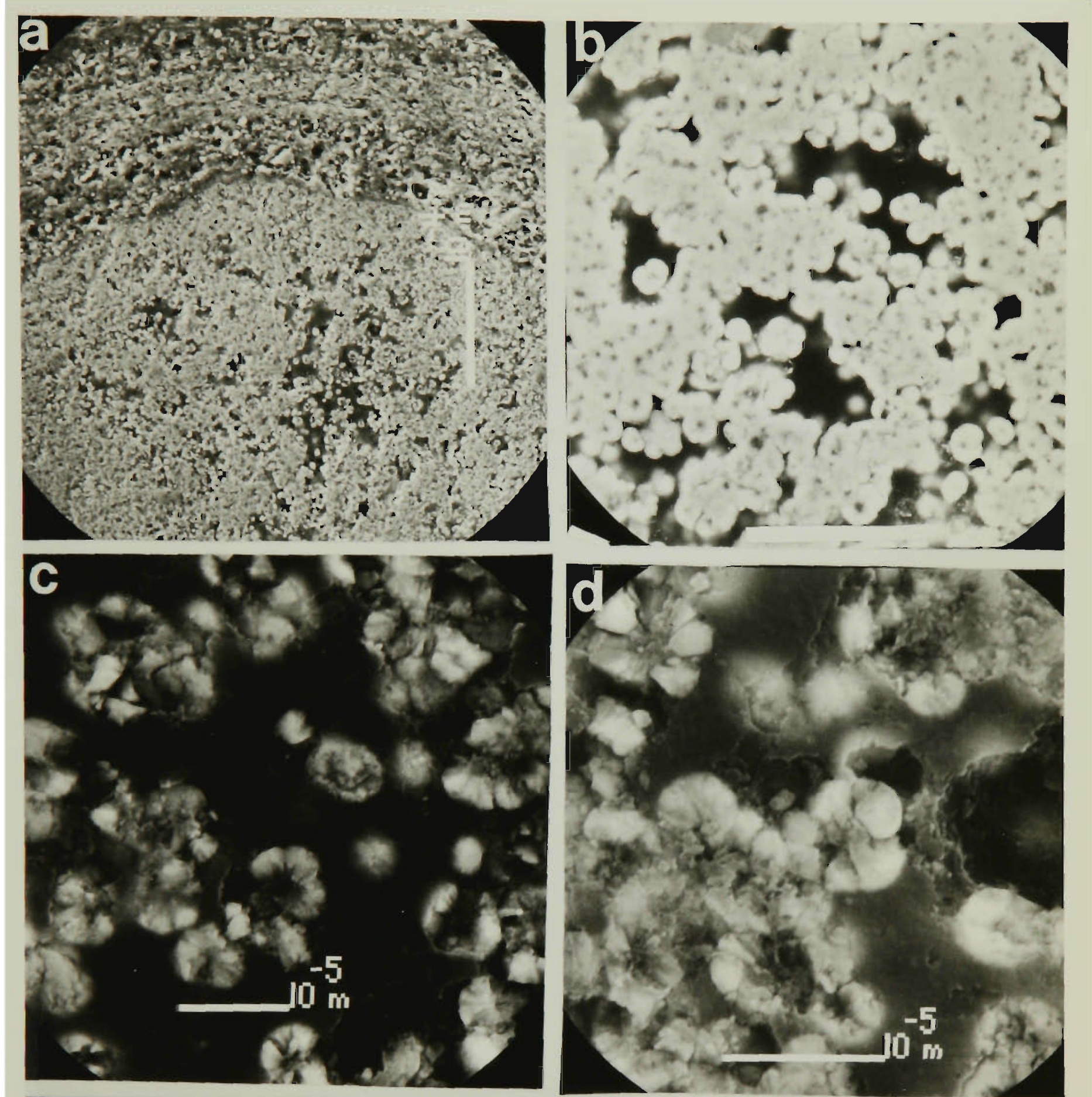

, \\ .}
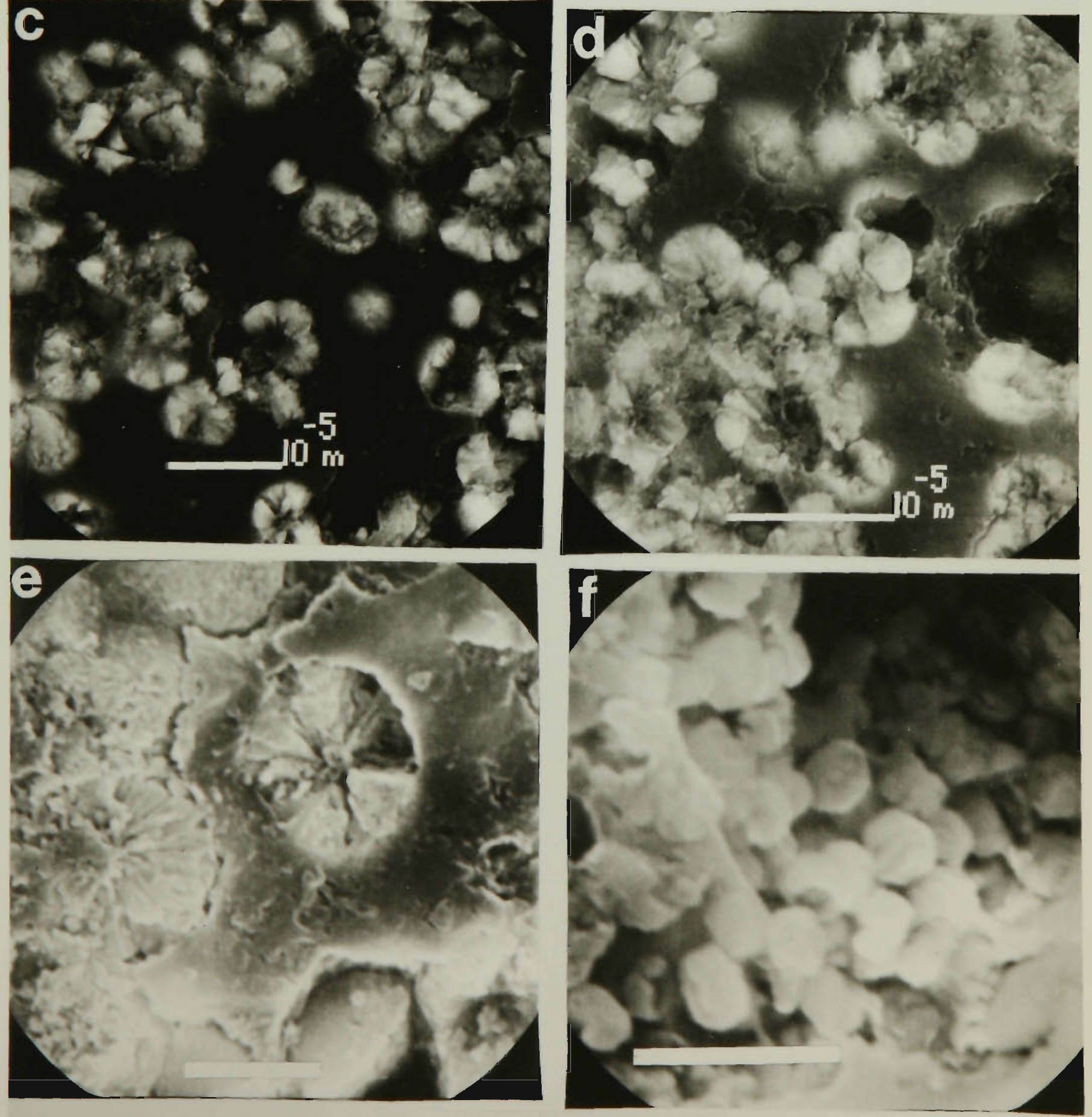

PLATE 18 


\section{PLATE 19}

Phosphate laminae and nodule from the Barney Creek Formation, Glyde River Subbasin, DDH GR7, $180.0 \mathrm{~m}$. 
PLATE 19

Phosphate laminae and nodule from the Barney Creek Formation, Glyde River Subbasln, DDH GR7, $180.0 \mathrm{~m}$.

a) SEM image of phosphate nodule (central area) and lamina (as for Plate 17), bright double line separating the phosphatic-rich layer from the upper pyritic-rich bed is caused by a fissure produced during preparation of this specimen for $X$-ray mapping; scale bar $=1 \mathrm{~mm}$;

b) X-ray map of a) at the same scale, for P;

c) X-ray map of a) at the same scale, for $\mathrm{Ca}$;

d) X-ray map of a) at the same scale, for Si;

e) X-ray map of a) at the same scale, for $\mathrm{Fe}_{\theta}$;

f) X-ray map of a) at the same scale, for $S$;

g) X-ray map of a) at the same scale, for Al;

h) X-ray map of a) at the same scale, for $K$;

i) X-ray map of a) at the same scale, for Ti. 

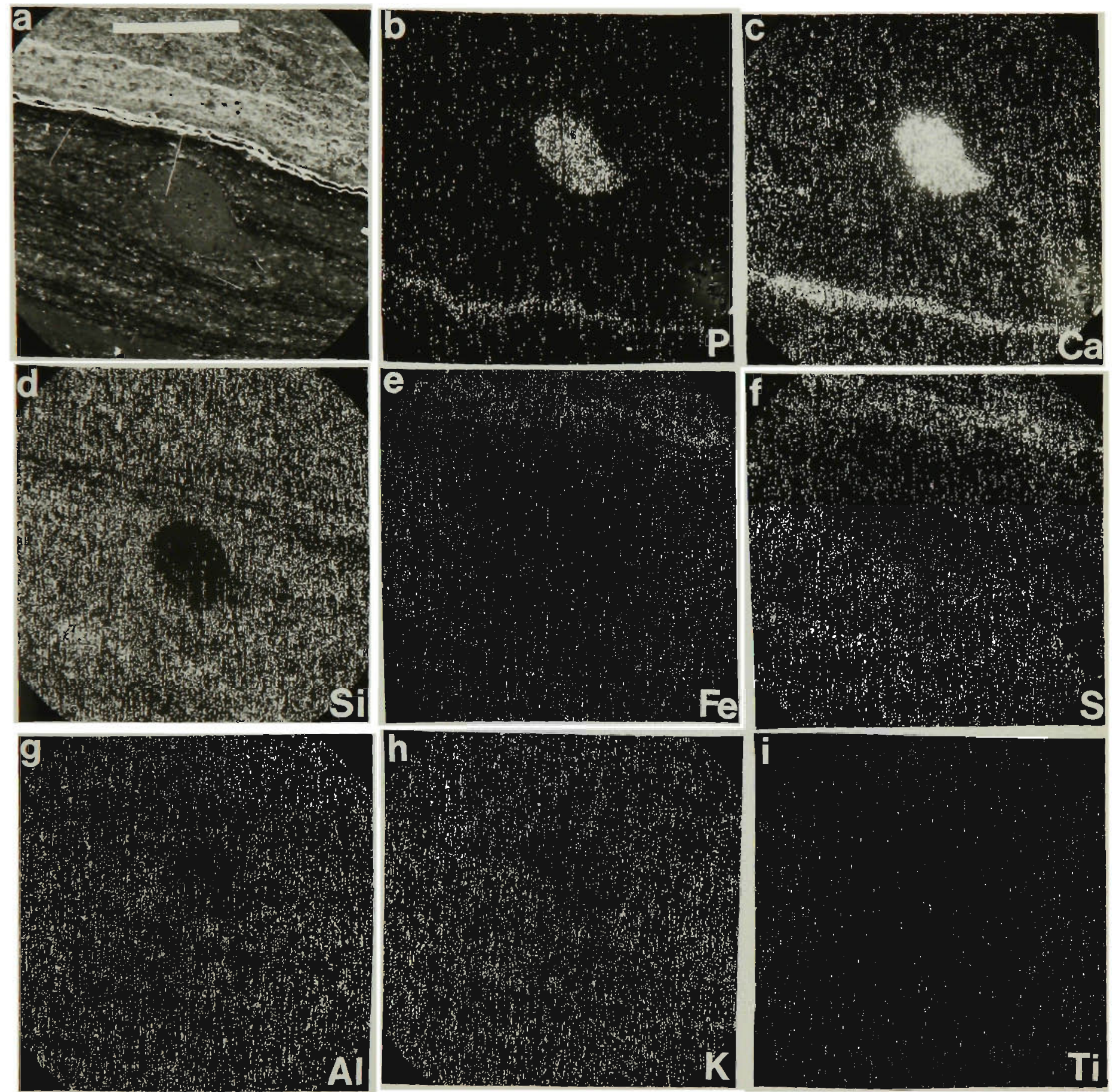

PLATE 19 


\section{PLATE 20}

Phosphate laminae and nodule from the Barney Creek Formation, Glyde River Subbasin, DDH GR7, $180.0 \mathrm{~m}$. 
PLATE 20

Phosphate lamlnae and nodule from the Barney Creek Formation, Glyde River Subbasin, DDH GR7, $180.0 \mathrm{~m}$.

a) X-ray map of lamalginite and phosphate laminae and nodule (as for Plate 17, but a different section to that used for Plate 18) for P;

b) X-ray map of same area as in a) for Ca;

c) X-ray map of phosphate lens (Plate 17b) for P; scale bar = $1 \mathrm{~mm}$;

d) X-ray map of c) for $\mathrm{Ca}$;

e) X-ray map of right-hand side of scour (Plate17-1) for P;

f) as for e) but for Ca;

g) X-ray map of phosphate lens c) enlarged in area of detached laminae of lamalginite (Plate 17b), for $P$; scale bar $=20$ microns;

h) as for g) but for Ca; scale bar $=20$ microns;

i) as for g) but for $\mathrm{Si}$; scale bar $=20$ microns;

j) as for g) but for Fe; scale bar = 20 microns;

k) as for $\mathrm{g}$ ) but for $\mathrm{S}$; scale bar $=20$ microns;

I) as for g) but for $\mathrm{Al}$; scale bar $=20$ microns. 

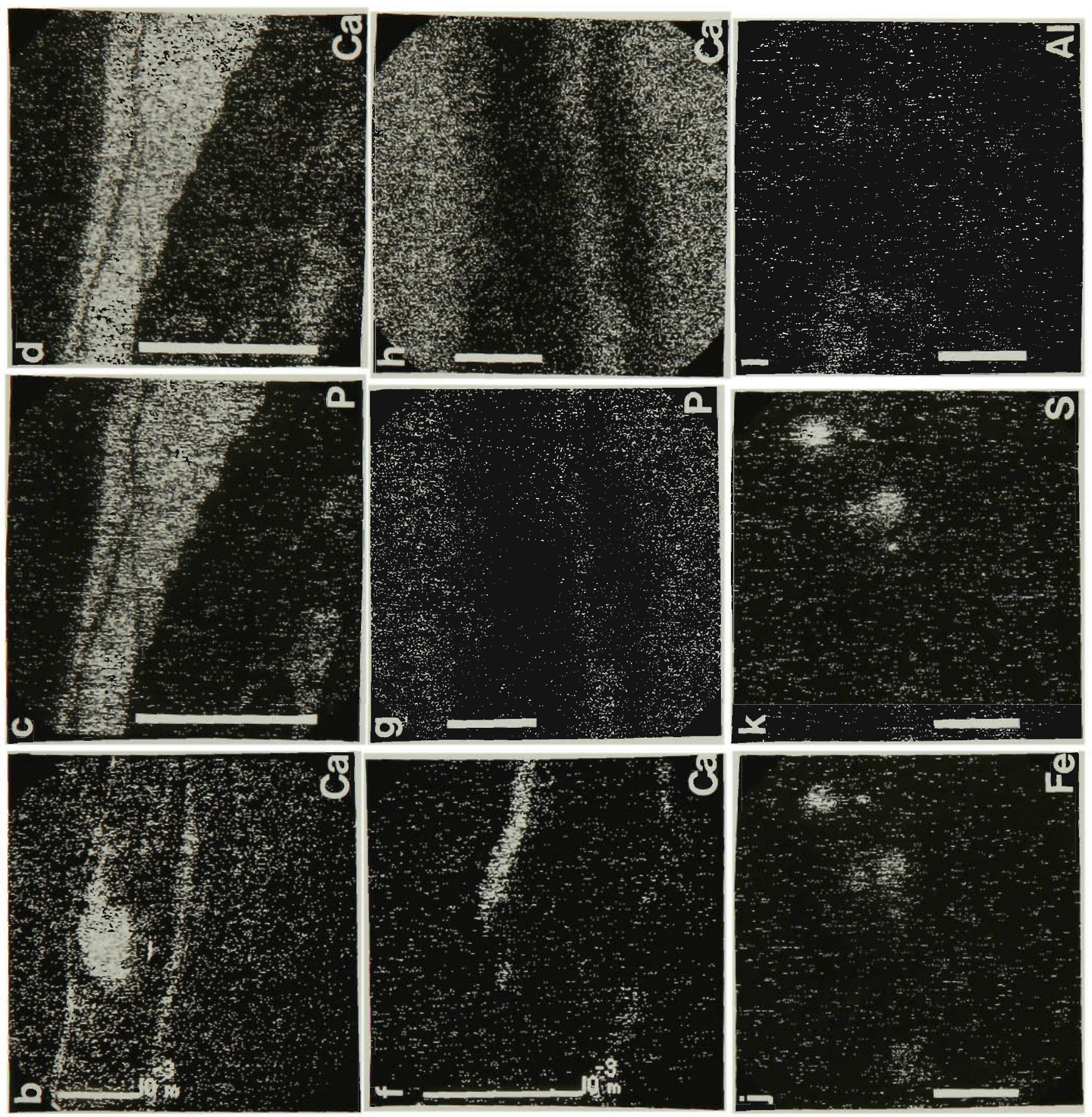

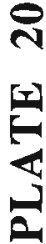
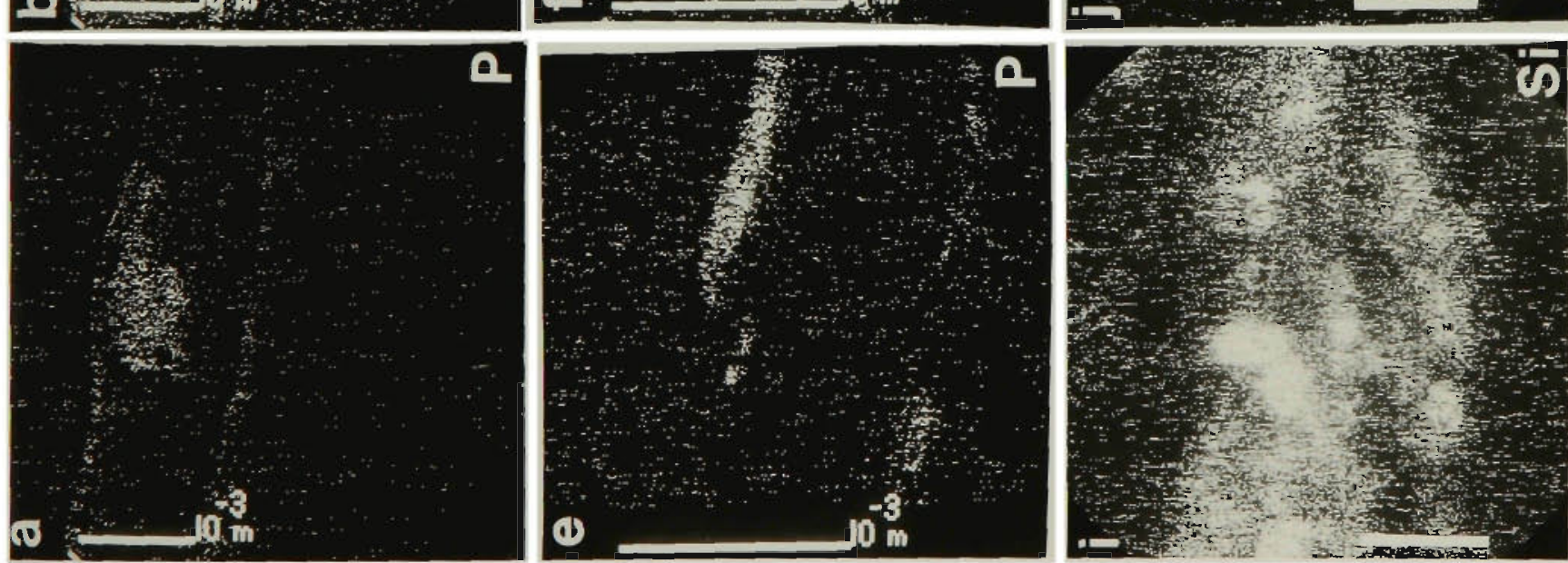


\section{PLATE 21}

SEM X-ray maps of a thucholite grain, Barney Creek Formation, Glyde River Subbasin, DDH GR10, $37.4 \mathrm{~m}$. 
PLATE 21

SEM X-ray maps of a thuchollte graln, Barney Creek Formatlon, Glyde Rlver SubbasIn, DDH GR10, $37.4 \mathrm{~m}$, perpendicular to bedding.

a) SEM of a grain of thucholite, about 200 microns in diameter (round dark central area);

b) X-ray map of a) for Fe; same scale as a);

c) X-ray map of a) for S; same scale as a);

d) X-ray map of a) for Si; same scale as a);

e) X-ray map of a) for Ca; same scale as a);

f) X-ray map of a) for K; same scale as a);

g) X-ray map of a) for Ti; same scale as a);

h) higher magnification X-ray map of central area of thucholite grain a) for Th; scale bar = 50 microns. 

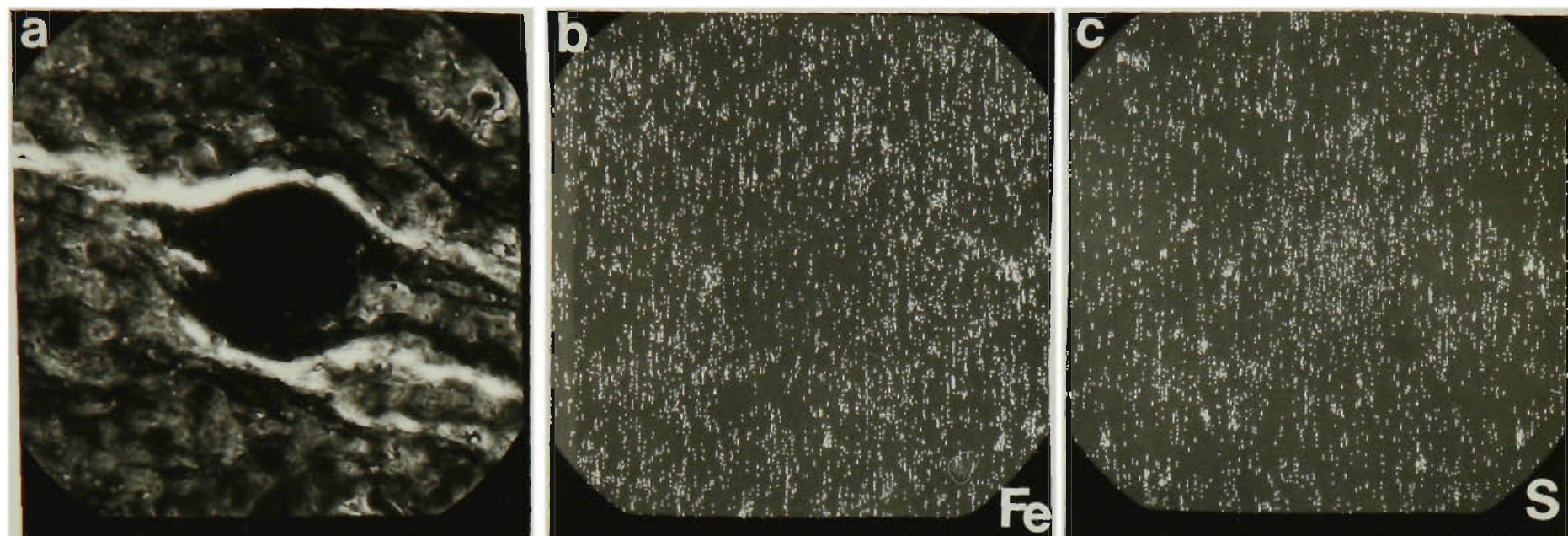

\section{วัร ริ เ}

\section{27 CER}
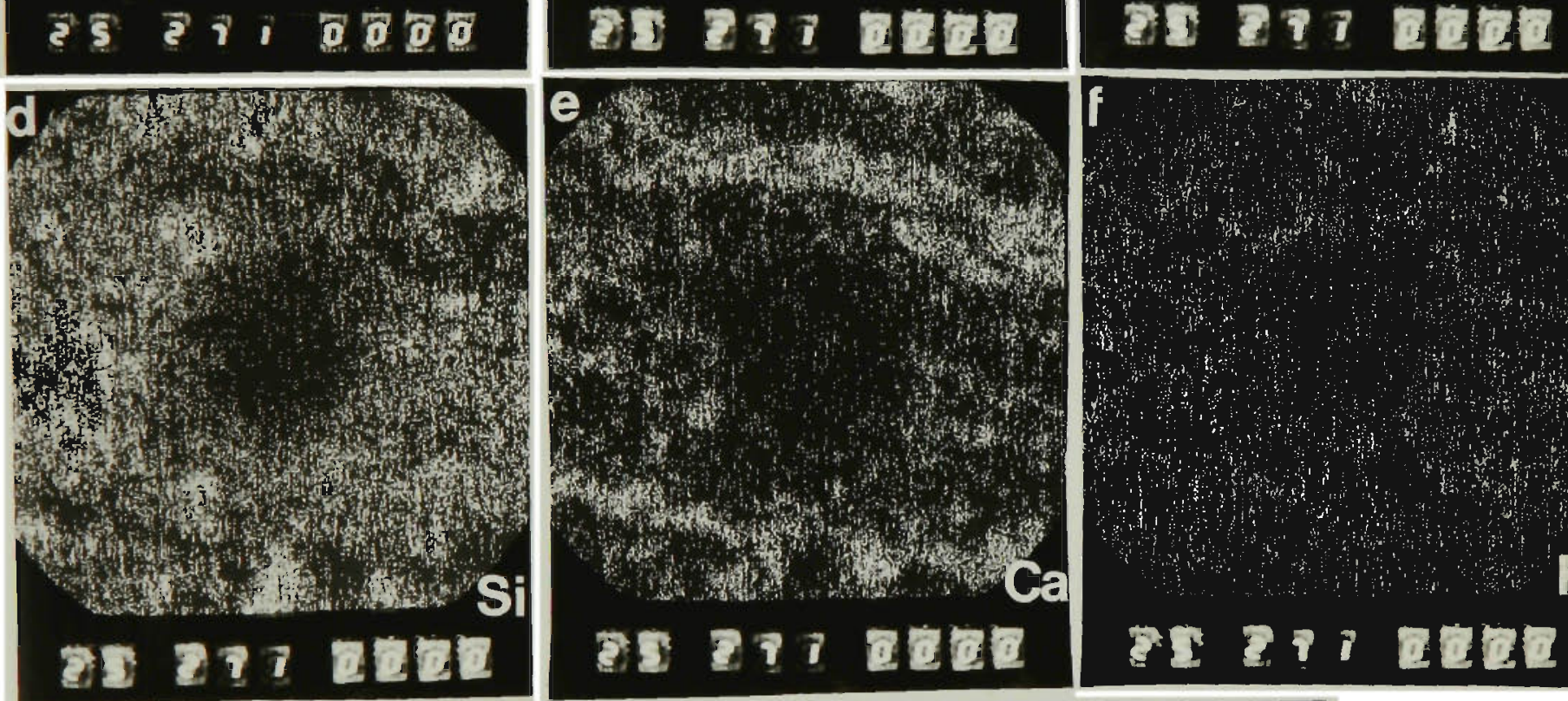

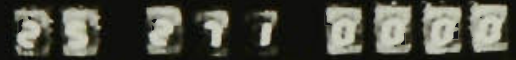
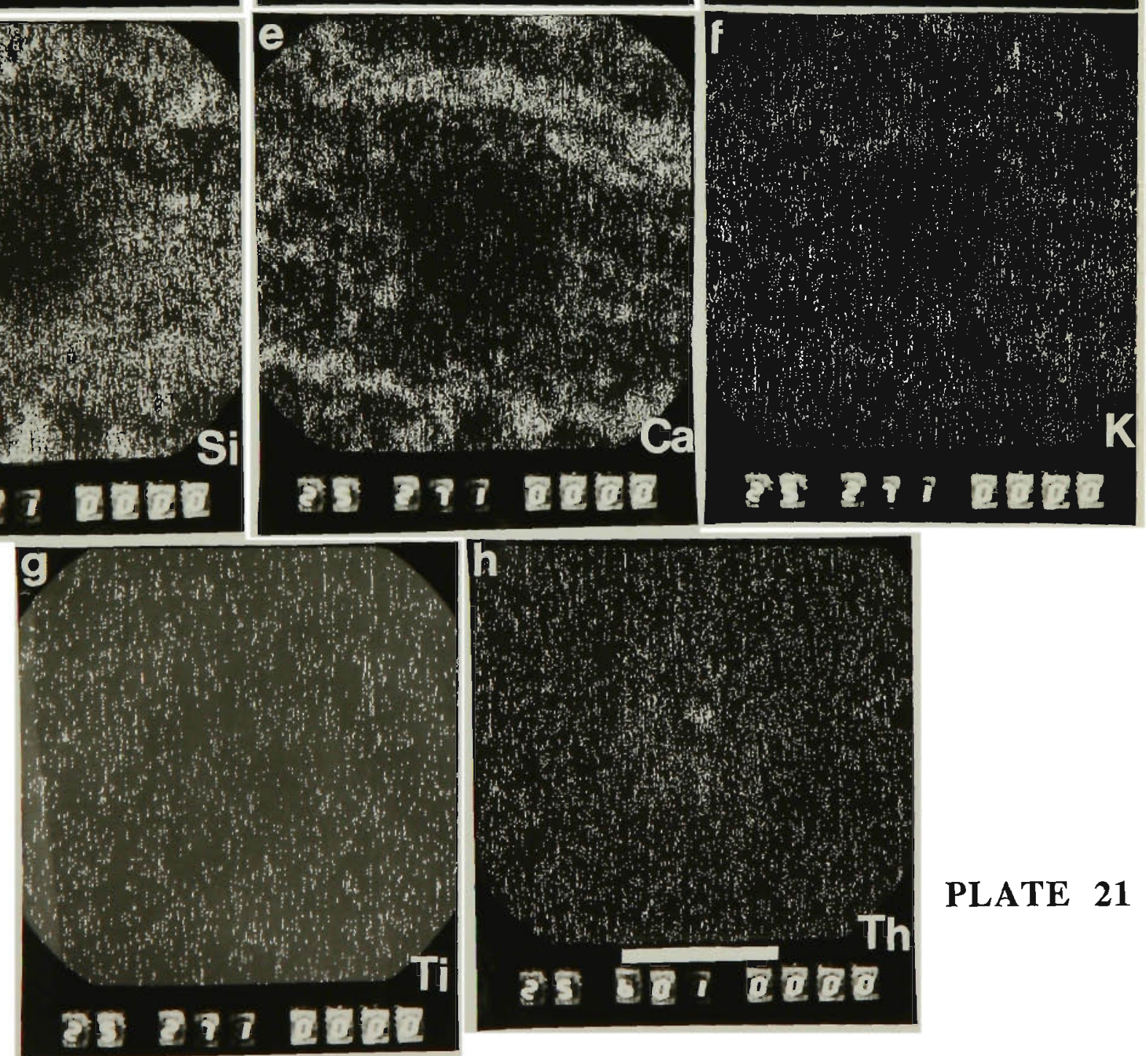

PLATE 21 h<smiles>C1CCCCCCCCCC1</smiles> 


\section{PLATE 22}

SEM X-ray maps of a thucholite grain, Barney Creek Formation, Glyde River Subbasin, DDH GR10, $297.2 \mathrm{~m}$. 
PLATE 22

SEM X-ray maps of a thucholite graln, Barney Creek Formation, Glyde River Subbasin, DDH GR10, $297.2 \mathrm{~m}$, perpendlcular to beddIng; all at the 

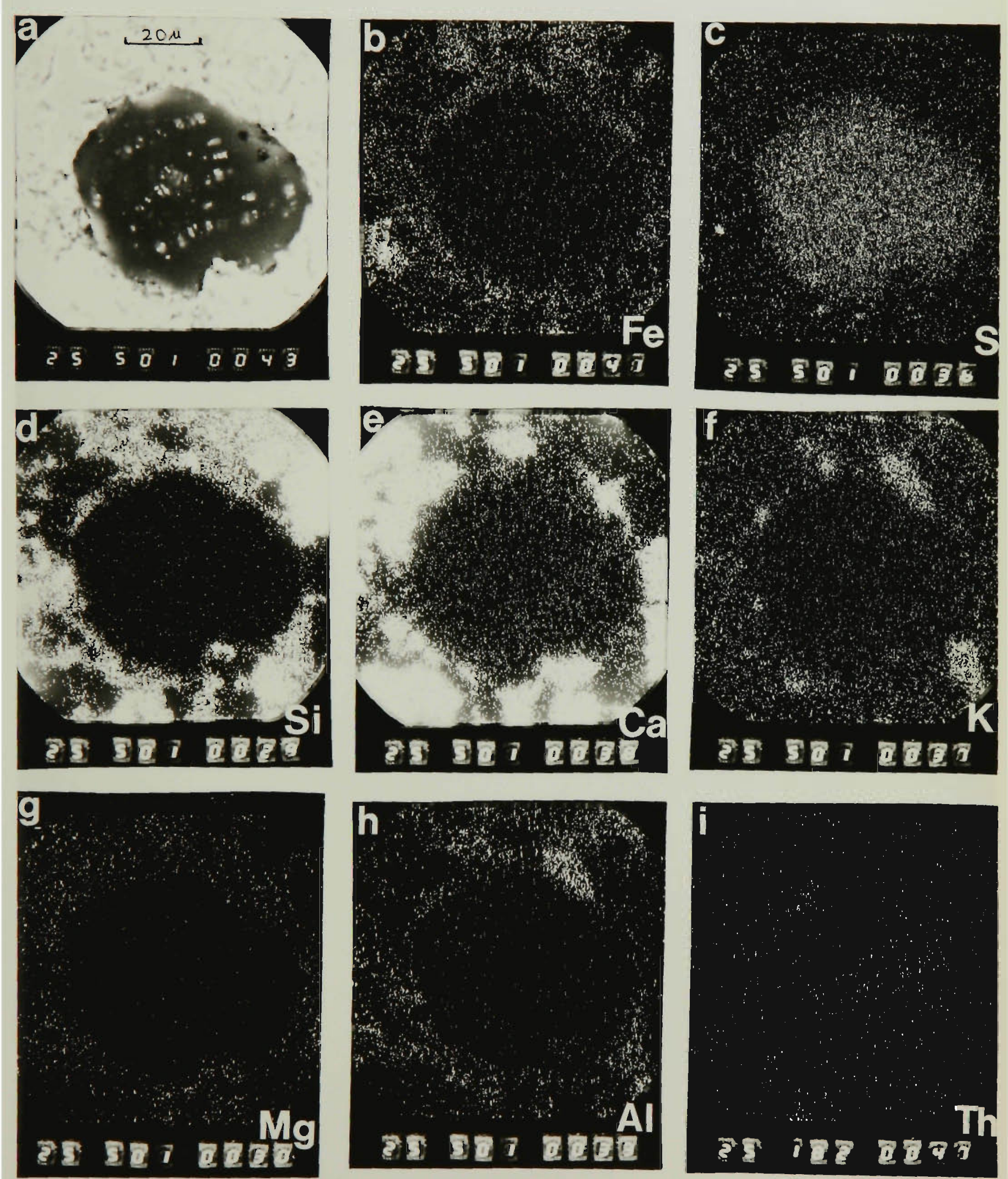


\section{PLATE 23}

SEM X-ray maps of a thucholite grain, Barney Creek Formation, Glyde River Subbasin, DDH GR10, $297.2 \mathrm{~m}$. 
PLATE 23

SEM X-ray maps of a thucholite grain, Barney Creek Formation, Glyde River Subbasin, DDH GR10, $297.2 \mathrm{~m}$, perpendicular to bedding; all at the same scale.
a) SEM of a grain of thucholite; white scale bar at the top of the photo $=50$ microns;
b) X-ray map of a) for Fe;
c) X-ray map of a) for S;
d) X-ray map of a) for Si;
e) X-ray map of a) for $\mathrm{Ca}$;
f) X-ray map of a) for $K$;
g) X-ray map of a) for Al;
h) X-ray map of a) for $\mathrm{Mg}$. 

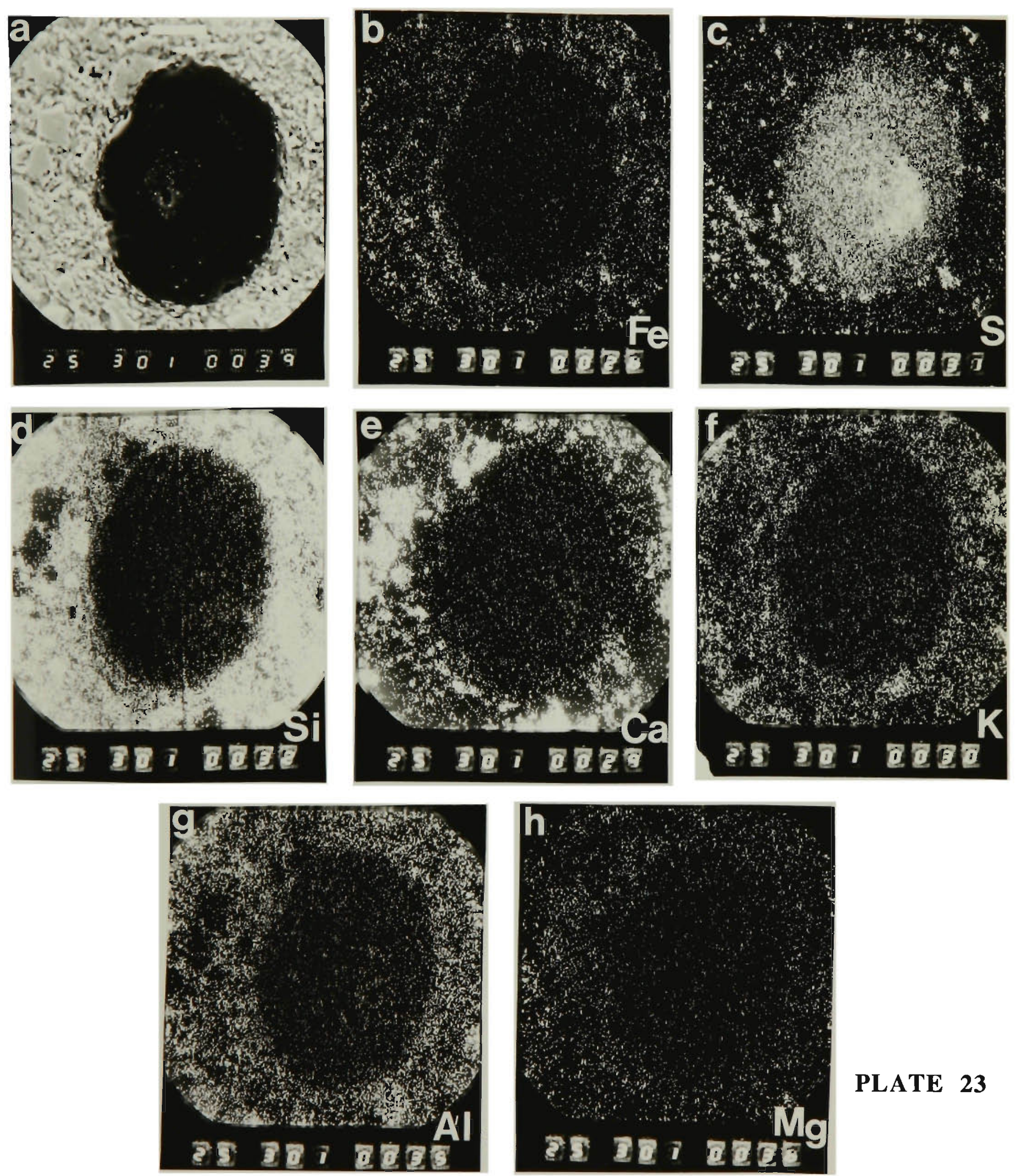

PLATE 23

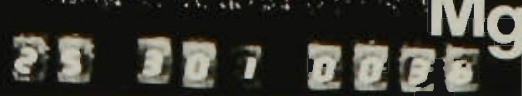




\section{PLATE 24}

Organic matter from the Yalco and Lynott Formations, central Batten Trough, McArthur Group. 


\section{PLATE 24}

Organic matter from the Yalco and Lynott Formatlons, central Batten Trough, McArthur Group; perpendlcular to bedding.

a) Yalco Formation, DDH 82/6, $125.5 \mathrm{~m}$; fluorescent lamalginite disrupted by a sandstone dyke; fluorescence mode; field of view $=2.0 \mathrm{~mm}$;

b) Yalco Formation, $\mathrm{DDH} 82 / 6,125.5 \mathrm{~m}$; cross-bedded fluorescent lamalginite; fluorescence mode; field-width $=2.0 \mathrm{~mm}$;

c) Yalco Formation, DDH 82/6, $125.5 \mathrm{~m}$; fluorescent lamalginite; fluorescence mode; scale bar $=50$ microns;

d) Lynott Formation, DDH $82 / 7,327.5 \mathrm{~m}$; large irregularly shaped bitumen in a bitumencarbonate vein showing zones of lower reflectances; plane-polarised white reflected light; scale bar $=20$ microns;

e) as for d) but showing different zones of lower reflectances after stage has been rotated by 90 degrees;

f) as for d) but under crossed polars;

g) Reward Dolomite, DDH MY5, $67.2 \mathrm{~m}$; an irregular grain of bitumen in a bitumencarbonate vein; plane polarized white reflected light; field-width $=0.2 \mathrm{~mm}$;

h) as for g) but under crossed polars; note fine speckly green, red and yellow appearance;

i) Lynott Formation, Leila Yard 1,21.4 m; a thin vein of bitumen probably formed along a stylolite; plane polarized white reflected light; scale bar $=50$ microns. 


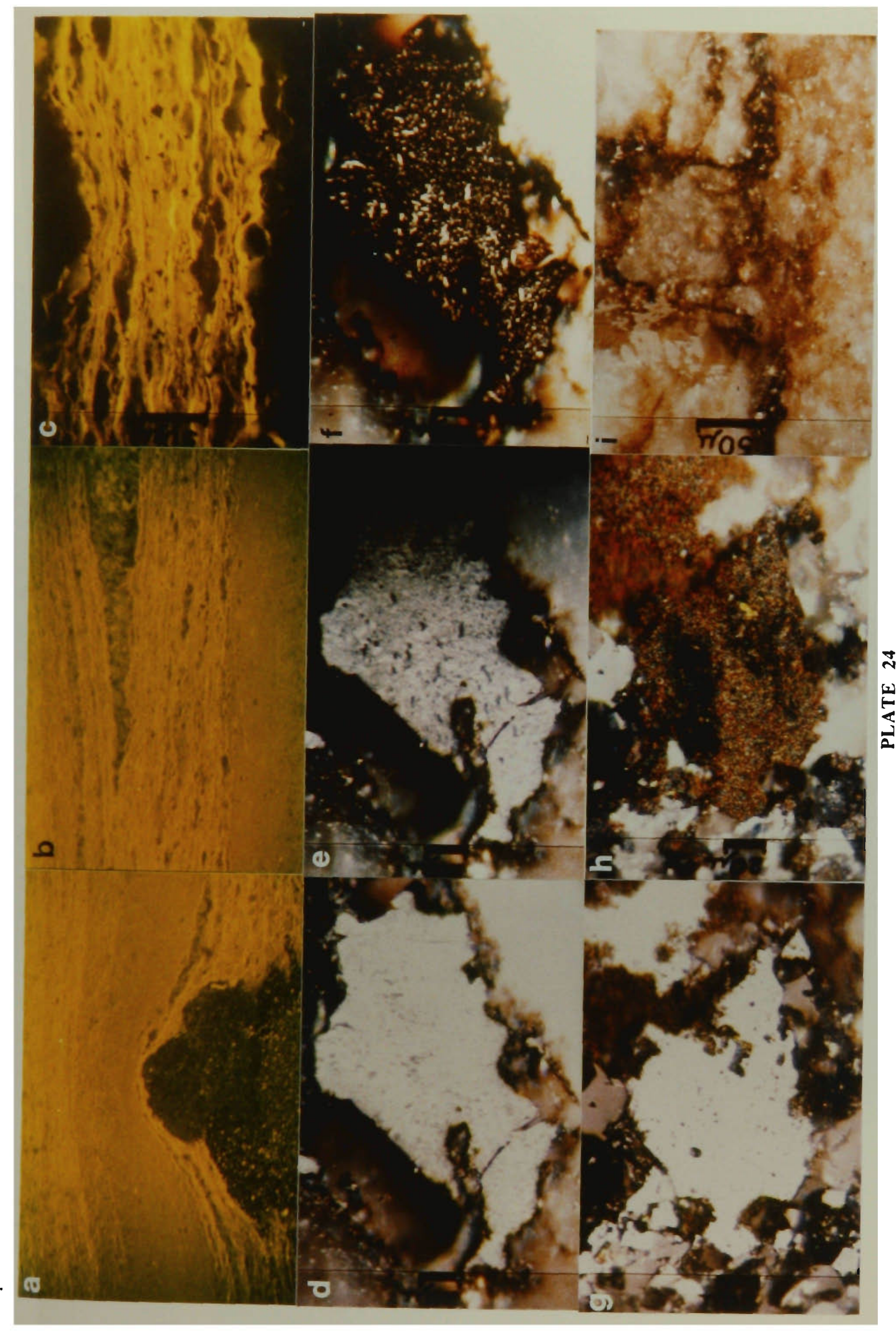




\section{PLATE 25}

Organic matter in the Barney Creek Formation and Emmerugga, Teena and Reward Dolomites from the central and northern parts of the Batten Trough. 
PLATE 25

\begin{abstract}
Organic matter in the Barney Creek Formation and Emmerugga, Teena and Reward Dolomites from the central and northern parts of the Batten Trough; perpendicular to beddling.
\end{abstract}

a) Barney Creek Formation, DDH CA1, $253.7 \mathrm{~m}$; disseminated bitumen (arrows) and a patch of dispersed bitumen (circled) other white patches are mainly pyrite; mean maxRo = $1.90 \%$; plane polarized reflected white light; field-width $=320$ microns;

b) Barney Creek Formation, DDH CA1, $337.6 \mathrm{~m}$; thin strand of nonfluorescent lamalginite in central area; mean maxRo $=2.21 \%$; plane-polarized reflected white light; field-width = 200 microns;

c) Barney Creek Formation, DDH M17/08, $112.0 \mathrm{~m}$; pyritized lamalginite (white strands in lower half of photo) with black strands of lamalginite (non-pyritised) in upper half of the photo; reflected white light; field-width $=0.8 \mathrm{~mm}$;

d) Barney Creek Formation, M17/08, $112.0 \mathrm{~m}$; small piece of nonfluorescent lamalginite in central area; plane-polarized reflected white light; field-width $=200$ microns;

e) Barney Creek Formation, DDH BB2, $374.0 \mathrm{~m}$; matrix bitumen in central area partially surrounding dark carbonate rhomb; mean maxRo\% $=2.77$; plane-polarized reflected white light; field-width $=200$ microns.

f) as for e) but under crossed polars;

g) Reward Dolomite, DDH BB2, $72.0 \mathrm{~m}$; a single rhombic piece of bitumen probably filling a vug; mean max.Ro\% $=1.91$; plane-polarized reflected white light; field-width $=200$ microns.

h) Emmerugga Dolomite, DDH McA10, $160.7 \mathrm{~m}$; part of a bitumen-carbonate vein; mean $\operatorname{maxRo\% }=3.05$; plane-polarized reflected white light; field-width $=320$ microns;

i) Teena Dolomite, DDH McA5, $446.4 \mathrm{~m}$; part of a bitumen-pyrite vein, mean maxRo\% = 1.83; plane- polarized reflected white light; field-width $=200$ microns. 
E)

F.

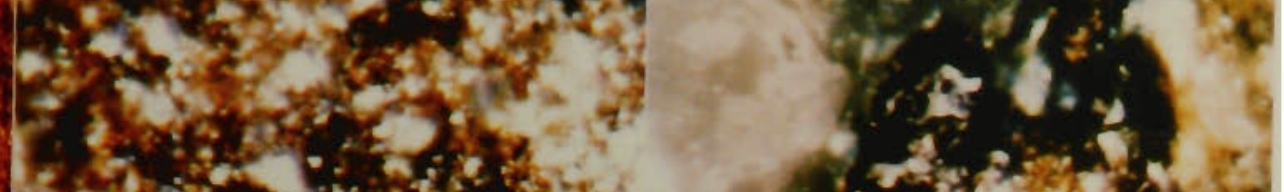

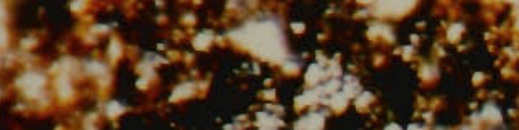

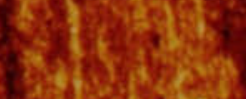

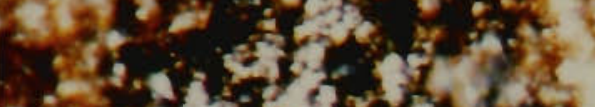

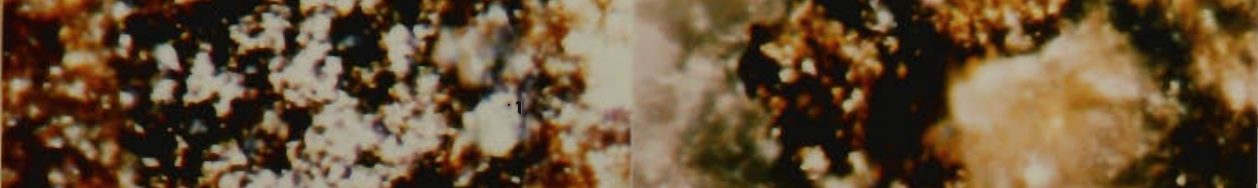

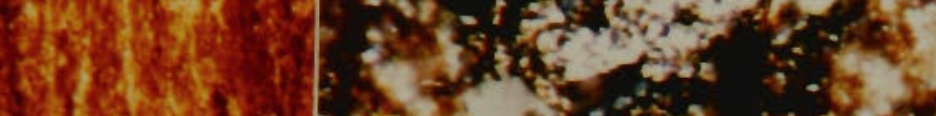

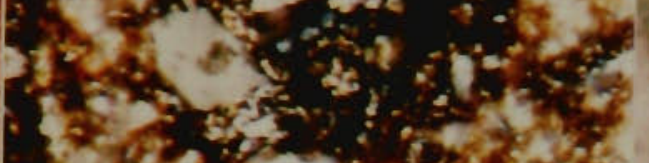

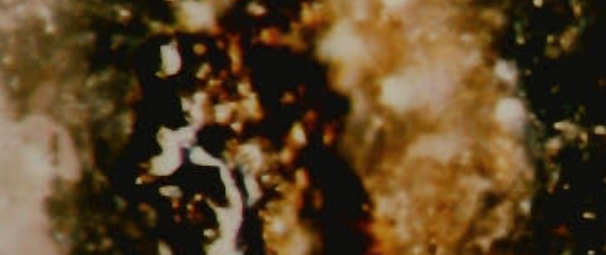
*6)

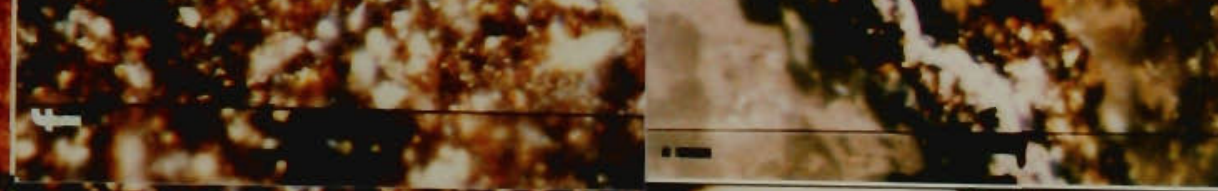

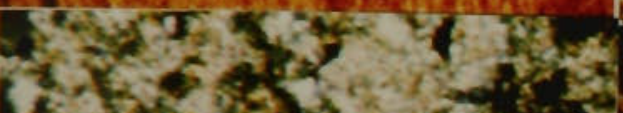
a

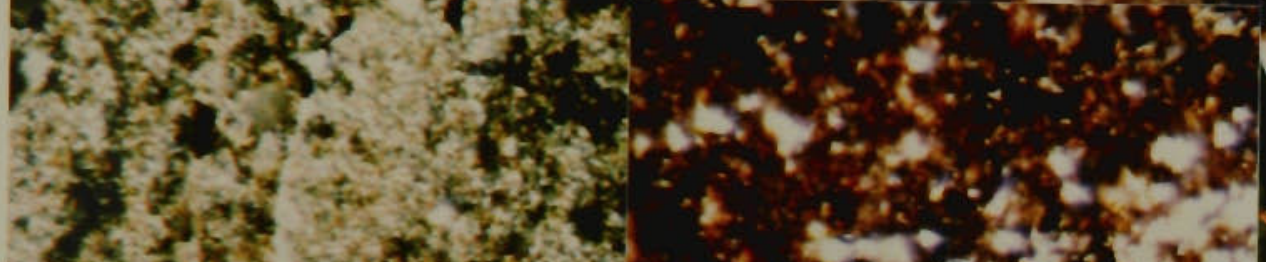

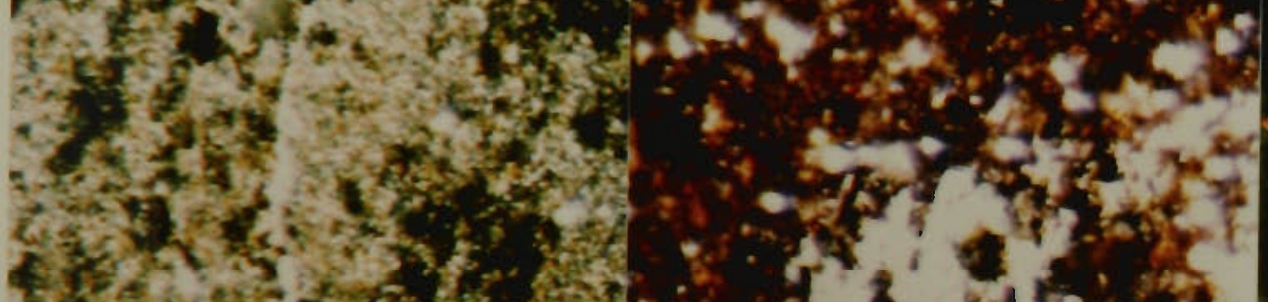

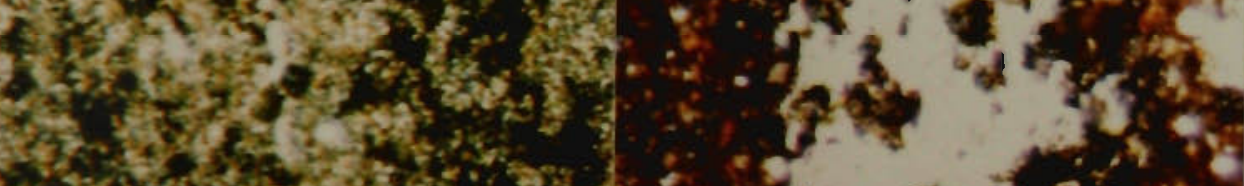

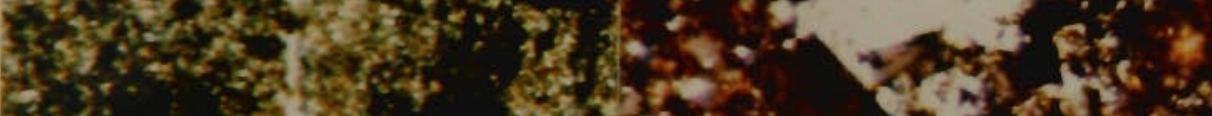

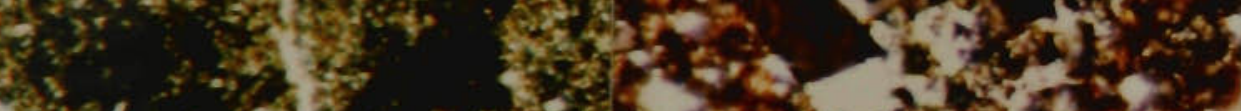
3i: :

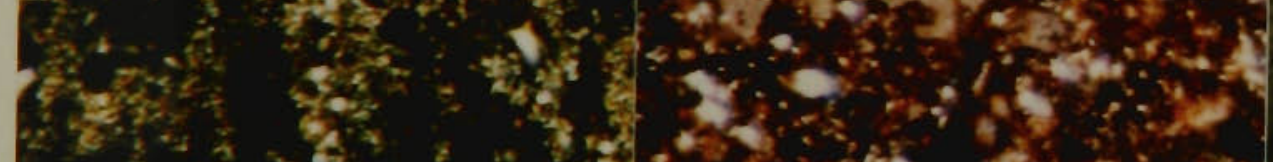
6. $0+x$

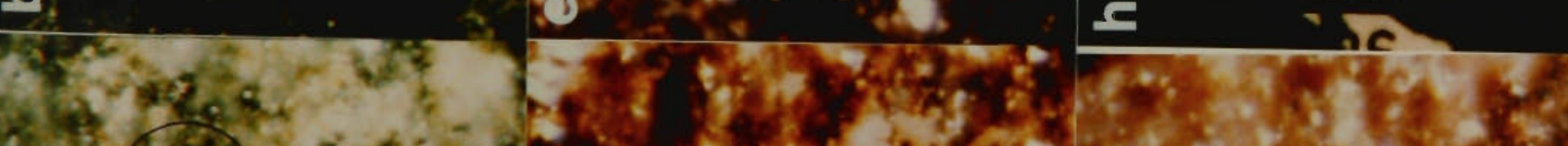

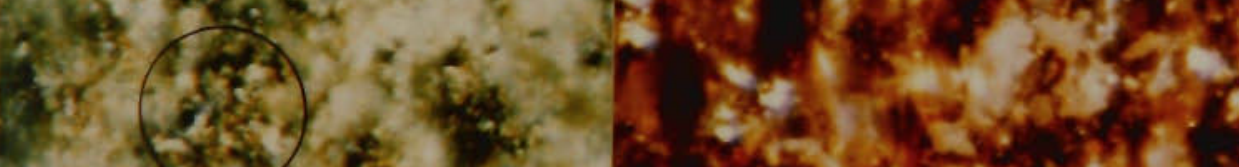

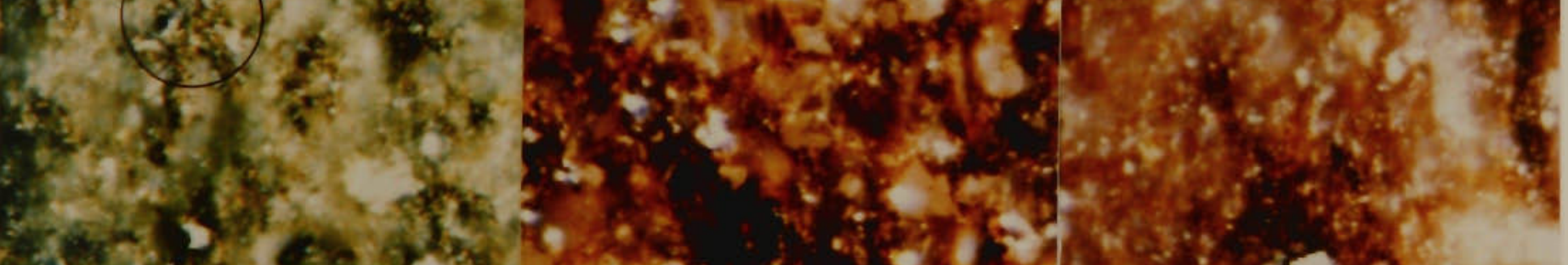

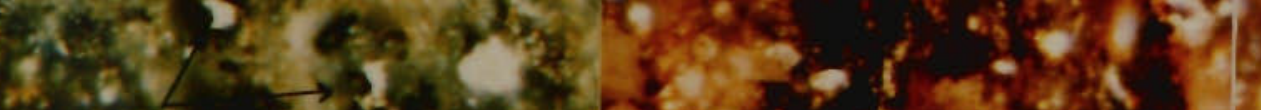

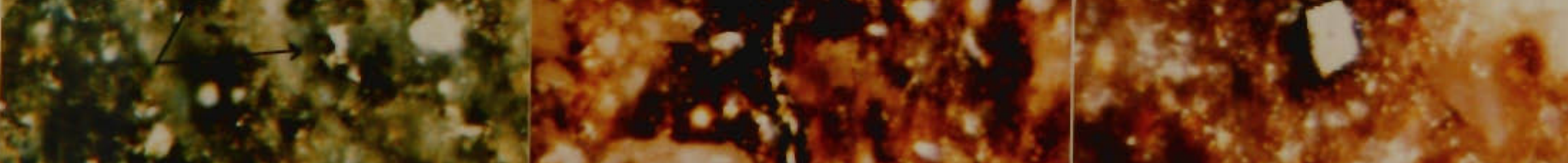

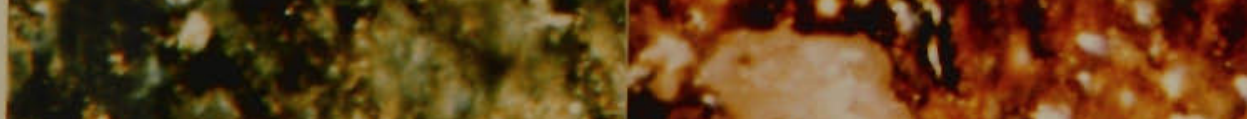

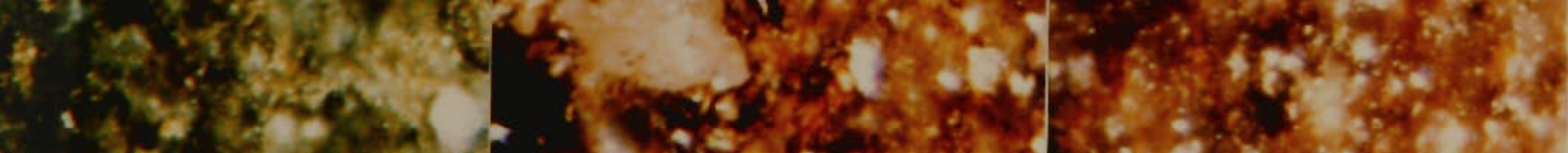

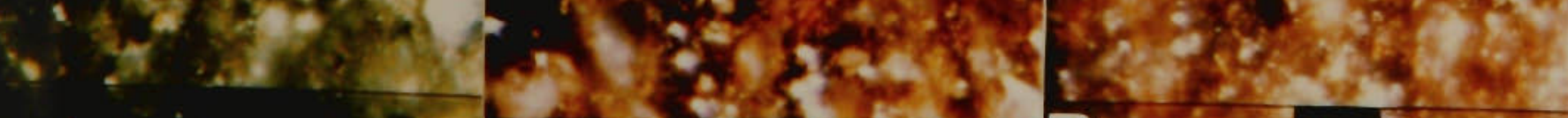




\section{PLATE 26}

Organic matter in the Cobanbarini Formation, "Lansen Creek Shale Member", Roper Group, Broadmere 1 well. 
PLATE 26

Organic matter In the Cobanbarlnl Formation, "Lansen Creek Shale Member", Roper Group, Broadmere 1 well; perpendicular to bedding.

a) $27.4 \mathrm{~m}$; dark strands of lamalginite; plane polarized white reflected light; scale bar = 20 microns;

b) as for a) but in fluorescence mode; both nonfluorescent and fluorescent lamalginite are present; a fluorescent strand is present in the upper right hand corner; mean maxRo for fluorescent lamalginite $=0.27 \%$, for nonfluorescent lamalginite $=0.60 \%$;

c) $109.7 \mathrm{~m}$; a single discontinuous piece of nonfluorescent lamalginite; mean maxRo = $0.73 \%$; plane polarized white reflected light; scale bar $=20$ microns;

d) as for c) but in fluorescence mode;

e) $109.7 \mathrm{~m}$; silvery disseminated and patchy dispersed bitumen showing rounded shapes of some of the bitumen (bitumen microspheres; lower left); plane-polarized white reflected light; scale bar $=20$ microns;

f) as for e) but in fluorescence mode; fluorescing doughnut shapes are phosphate microspheres (see Plate $42 \mathrm{G}-\mathrm{I}$ ), the rounded bitumen shapes adjacent to them do not fluoresce;

g) $335.3 \mathrm{~m}$; nonfluorescent lamalginite and disseminated bitumen; plane polarized reflected white light; mean maxRo(lamalginite + bitumen $)=1.32 \%$; scale bar $=20$ microns;

h) as for g) but in fluorescence mode. 


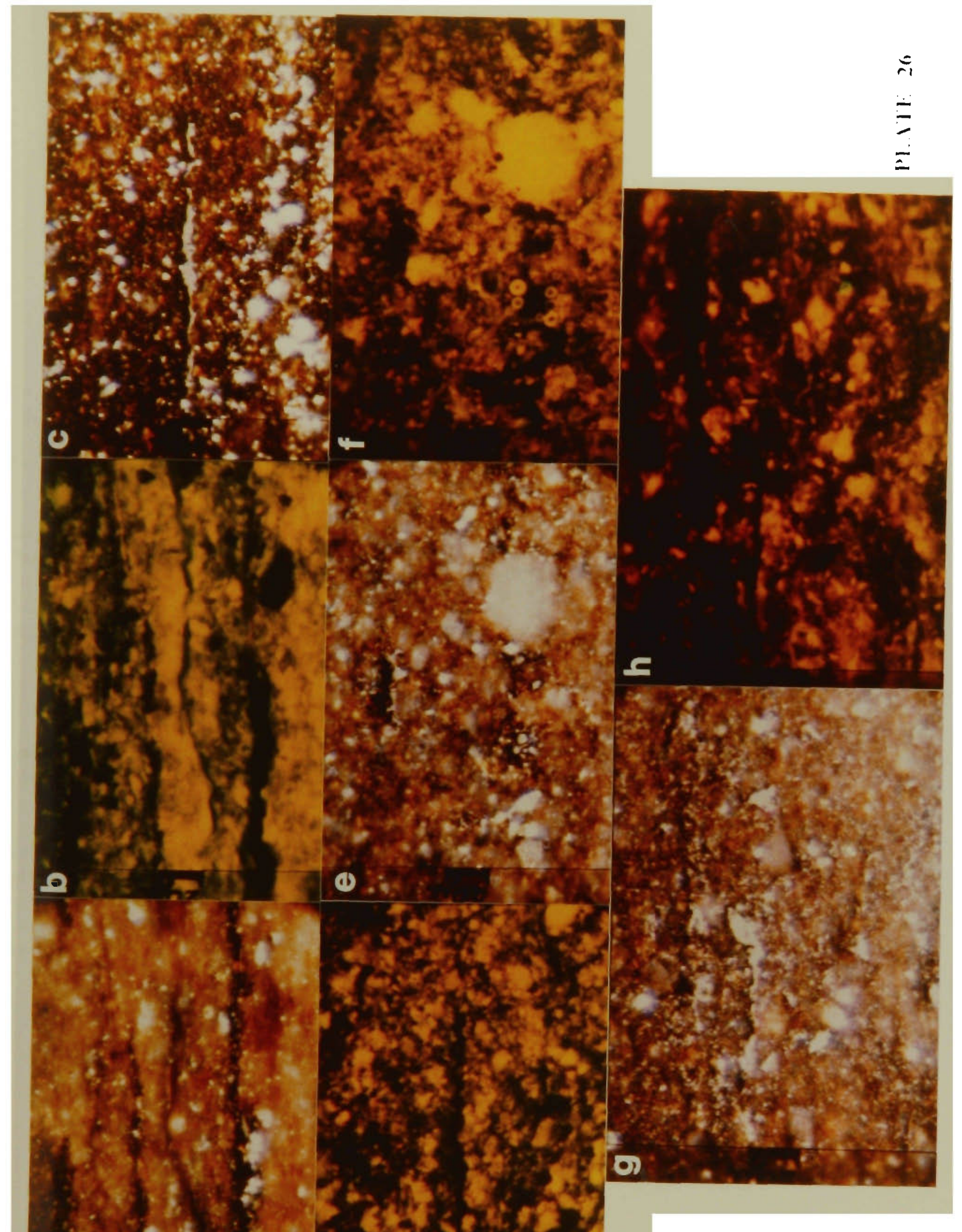

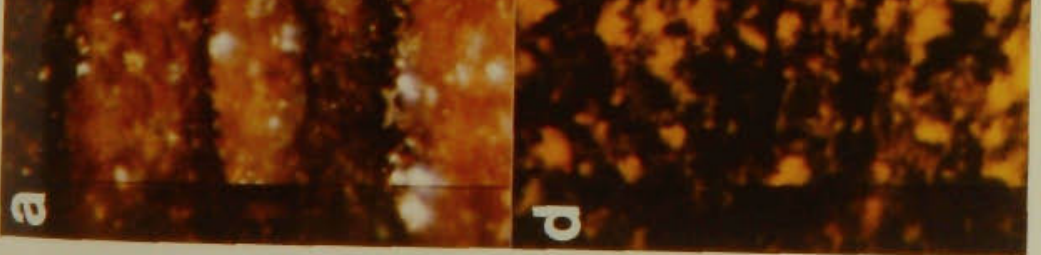




\section{PLATE 27}

Organic matter in the lower Roper Group (Mainoru Formation to Bessie Creek Sandstone), Broadmere 1 well. 


\section{PLATE 27}

\section{Organlc matter in the lower Roper Group (Mainoru Formation to Bessle Creek Sandstone), Broadmere 1 well; perpendlcular to bedding.}

a) $466.3 \mathrm{~m}$. Bessie Creek Sandstone; nonfluorescent lamalginite (central area); planepolarised reflected white light; scale bar $=50$ microns;

b) as for a) but in fluorescence mode;

c) $466.3 \mathrm{~m}$ Bessie Creek Sandstone; patchy dispersed silvery bitumen within black bitumen-impregnated patches and disseminated single bitumen pieces (one piece circled); plane polarized reflected white light; scale bar $=50$ microns;

d) as for c) but in fluorescence mode;

e) $920.5 \mathrm{~m}$, Corcoran Formation; slightly oblique sectlon of nonfluorescent lamaginite in lower central area; plane-polarized reflected white light; scale bar $=20$ microns;

f) $1304.5 \mathrm{~m}$, Hodgson Sandstone Member, Abner Sandstone; bitumen filling pore spaces; plane-polarized reflected white light; scale bar = 50 microns;

g) $2075.7 \mathrm{~m}$, Mainoru Formation; nonfluorescent lamalginite (circled); plane polarized reflected white light; scale bar $=20$ microns;

h) $2106.2 \mathrm{~m}$, Mainoru Formation; nonfluorescent lamalginite in central upper half of the photo; plane polarized reflected white light; scale bar $=20$ microns;

i) $2170.2 \mathrm{~m}$, Mainoru Formation; part of a vein of carbonate (light grey to white patches, one marked " $\mathrm{C}$ ") and bitumen (small speckly silvery shapes) within a quartz arenite (light grey shapes, one marked "q"), dark area at top is resin; plane polarized reflected white light; scale bar $=20$ microns. 
PLATE 28

Organic matter in the Velkerri Formation, Maiwok Subgroup, Roper Group, DDH Urapunga 3. 


\section{PLATE 28}

\section{Organlc matter In the Velkerrl Formatlon, Malwok Subgroup, Roper Group, DDH Urapunga 3 ; perpendlcular to bedding.}

a) $30.3 \mathrm{~m}$; laminated silty mudstone, darker laminae are organic rich and contain lamalginite; reflected white light; field-width $=8 \mathrm{~mm}$;

b) $30.3 \mathrm{~m}$; fluorescent and nonfluorescent lamalginite; a strand of fluorescent lamalginite occurs in the upper central area; carbonate rhomb in lower left contains bright yellow oil inclusions; fluorescence mode; field-width $=200$ microns.

c) as for b) but under plane-polarized white reflected light; mean maxRo for fluorescent lamalginite $=0.30 \%$, for nonfluorescent lamalginite $=0.66 \%$;

d) $54.4 \mathrm{~m}$; vein bitumen, plane-polarized white reflected light; mean maxRo $=0.79 \%$; scale bar $=20$ microns;

e) $54.4 \mathrm{~m}$; edge of a large vein of bitumen showing a thin vein of bitumen parallel to bedding or nonfluorescent lamalginite joining it; plane-polarized white reflected light; field-width $=200$ microns;

f) $54.3 \mathrm{~m}$; discontinuous piece of nonfluorescent lamalginite or possibly a conformable veinlet of bitumen, plane-polarized white reflected light; field-width $=200$ microns;

g) $75.2 \mathrm{~m}$; centrally located patch of carbonate (grey) and associated irregularly shaped silvery grains of bitumen (patchy dispersed bitumen); white grains are pyrite; mean $\operatorname{maxRo}=1.01 \%$; plane-polarized white rellected light; scale bar $=10$ microns;

h) $75.2 \mathrm{~m}$; centrally located patch of carbonate and irregularly shaped grains of silvery bitumen associated with it (patchy dispersed bitumen); plane polarized white reflected light; scale bar = 10 microns;

i) 98.3 ; matrix bitumen surrounding carbonate rhombs; mean maxRo $=1.69 \%$; plane polarized white reflected light; field-width $=0.20 \mathrm{~mm}$; 


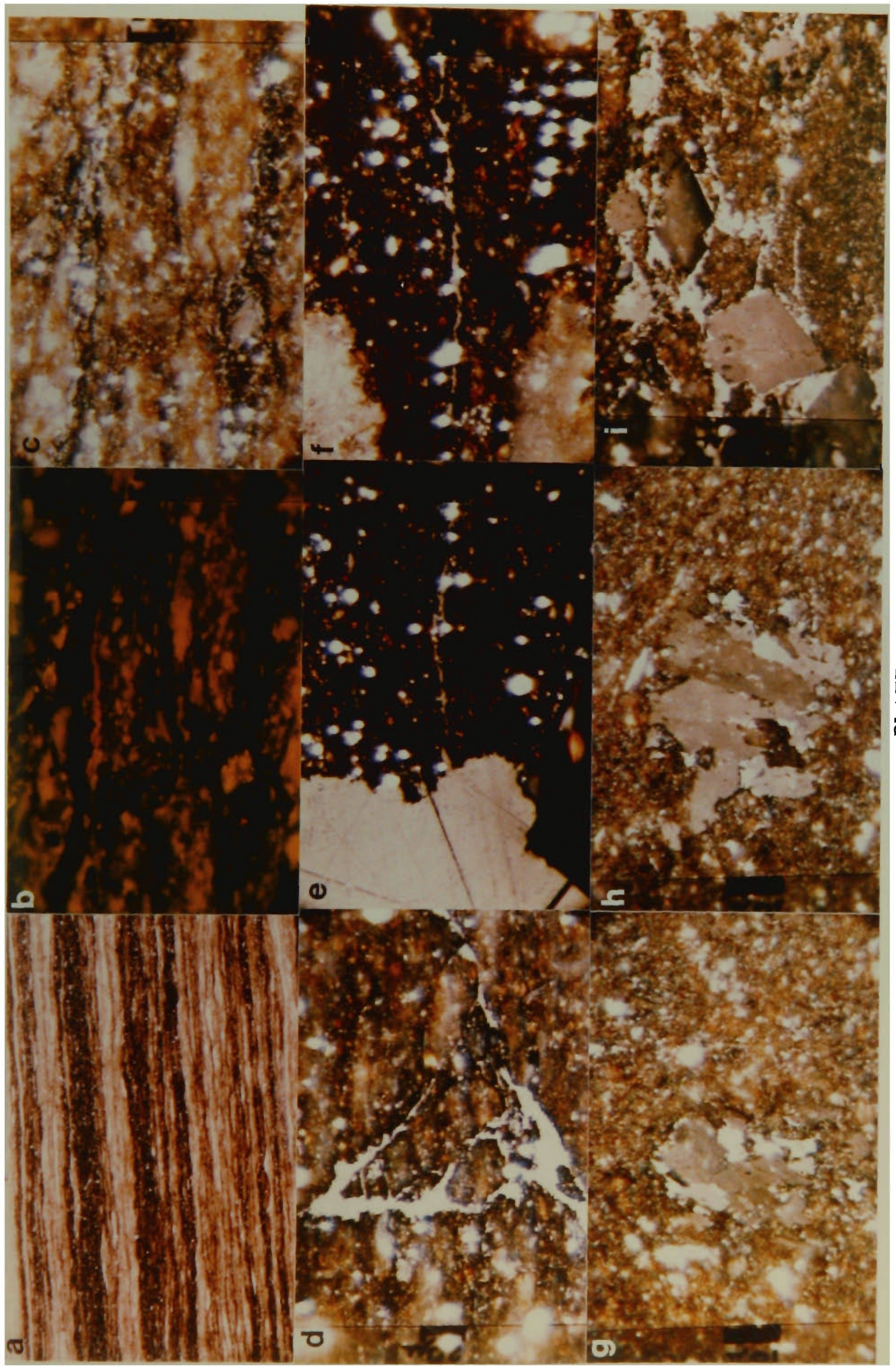




\section{Plate 29}

Vein bitumen, Velkerri Formation, Maiwok Subgroup, Roper Group, DDH Urapunga 3, $98.3 \mathrm{~m}$. 


\section{PLATE 29}

Veln bitumen, Velkerrl Formatlon, Maiwok Subgroup, Roper Grou, DDH Urapunga 3,98.3 $\mathrm{m}$; perpendicular to bedding.

a) vein of cross-cutting and conformable bitumen and carbonate which flowed into the lower darker organic-rich bed containing matrix bitumen (Plate 28i); reflected white light; field-width $=3.4 \mathrm{~mm}$.

b) same vein as a) but a mirror image at a higher magnification, in the area where the vein changes from being conformable to cross-cutting; plane-polarized white reflected light; mean $\operatorname{maxRo}=1.69 \%$; scale bar $=50$ microns;

c) same as b) but under crossed polars; approximately parallel black lines and irregularly shaped black areas in the bitumen indicate zones where lamina and turbulent flow of the bitumen took place; the lamina flow of the bitumen appears disturbed by a small carbonate rhomb trapped within the vein in the central area of the microphotograph indicating the flow of the bitumen is from left to right, ie. into the darker org anic-rich bed shown in Plate 29a.

d) bitumen (b) and carbonate (c) in conformable part of the same vein as a); planepolarized white reflected light; field-width $=200$ microns;

e) as for d) but under crossed polars showing conformable and parallel, black and white, low to highly bireflectant, bands of bitumen indicating that lamina flow of the bitumen took place at one time;

f) part of the same vein as for d) but cross-cutting the bedding; plane-polarized white reflected light; field-width $=200$ microns;

g) as for f) but under crossed polars showing irregularly shaped areas of black and white, low to highly bireflectant zones of bitumen within the vein indicating that non-lamina, or turbulent, flow took place at one time;

h) conformable part of the same vein as for d); the letter "b" marks the bitumen and "c" the carbonate in the vein; plane-polarized white reflected light;

i) as for $h$ ) but in fluorescence mode showing oil inclusions (diffuse white shapes) in the carbonate and lack of fluorescence in the bitumen; scale bar $=20$ microns. 


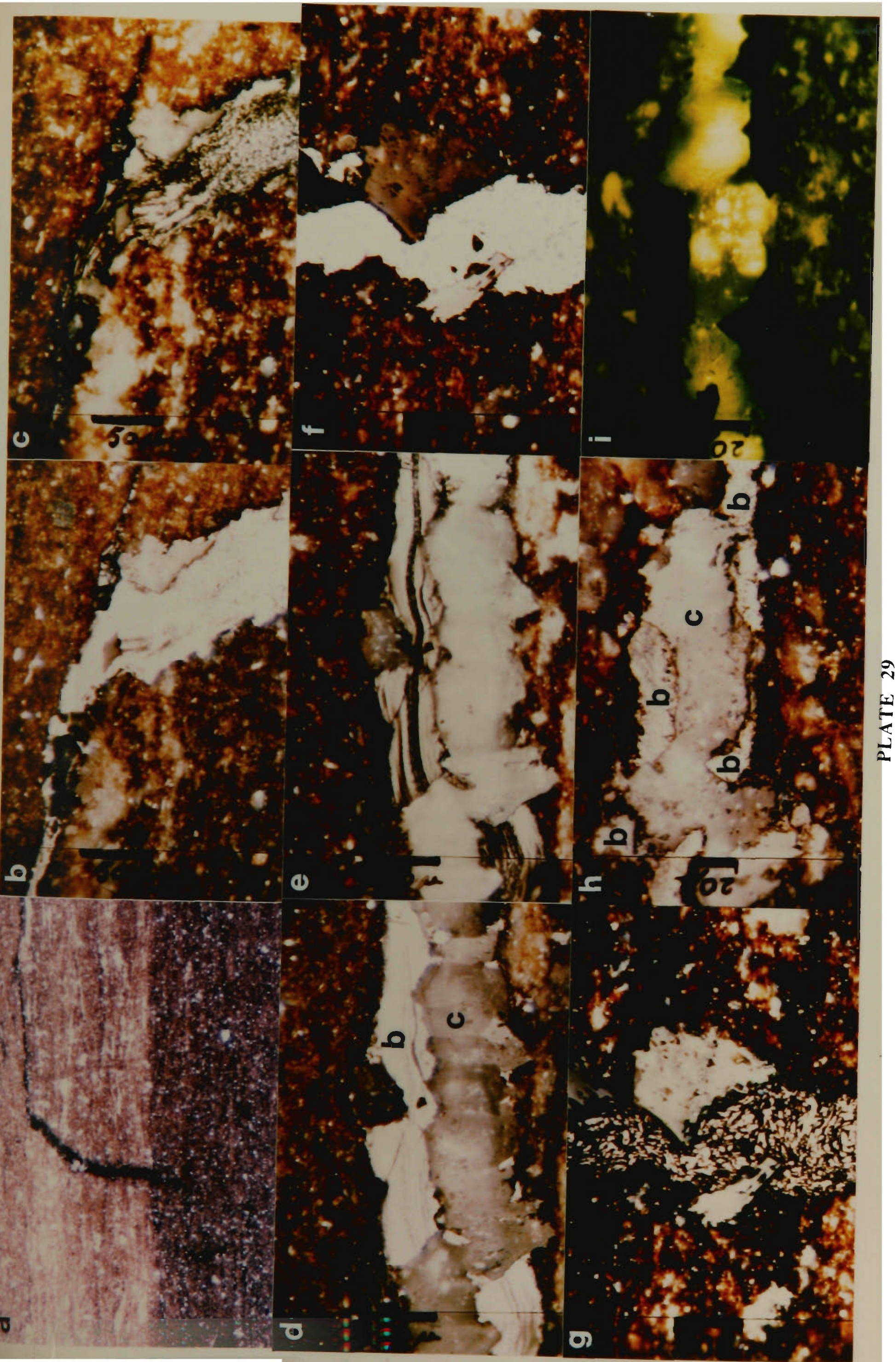




\section{PLATE 30}

Carbonate and pyrite pseudomorphs after gypsum, and organic matter in the Velkerri Formation, Maiwok Subgroup, Roper Group, DDH Urapunga 3, 120.0 to 150.1 $\mathrm{m}$. 


\section{PLATE 30}

Carbonate and pyrlte pseudomorphs after gypsum, and organlc matter in the Velkerrl Formatlon, Malwok Subgroup, Roper Group, DDH Urapunga 3, 120.0 to $150.1 \mathrm{~m}$; perpendicular to bedding.

a) $120.0 \mathrm{~m}$; centrally located single piece of cauliflower bitumen; plane-polarized white reflected light, scale bar $=20$ microns;

b) as for a) but in fluorecence mode;

c) $120.0 \mathrm{~m}$; a large single piece of cauliflower bitumen displaying variable bireflectance; plane-polarized white reflected light, scale bar = 30 microns;

d) a centrally located disrupted strand of silvery nonfluorescent lamalginite containing imbedded grey microspheres of phosphate; plane polarized white reflected light, scale bar $=20$ microns;

e) $130.0 \mathrm{~m}$; randomly orientated discoidal shapes that are mostly carbonate but the one on the lower right is pyrite (bright white shape), which are probably pseudomorphous after gypsum; plane-polarized white reflected light, scale bar $=50$ microns;

f) $137.4 \mathrm{~m}$; a centrally located, cauliflower bitumen piece, and peripheral smaller silvery bitumen pieces; plane-polarized white reflected light, scale bar $=50$ microns;

g) $150.1 \mathrm{~m}$; vein bitumen and pieces of nonfluorescent lamalginite; white reflected light; field-width $=8 \mathrm{~mm}$;

h) $150.1 \mathrm{~m}$; an isolated piece of nonfluorescent lamalginite; mean maxRo\% $=2.10$; plane polarized white reflected light, scale bar $=20$ microns;

i) as for h) but in fluorescence mode. 


\section{(w)}

X 18 or

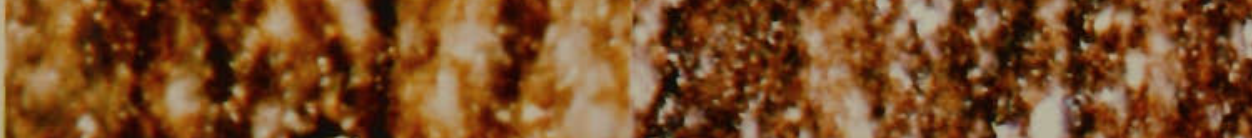
64. 20.5.

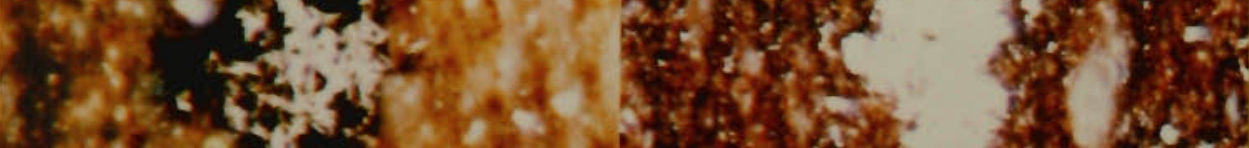

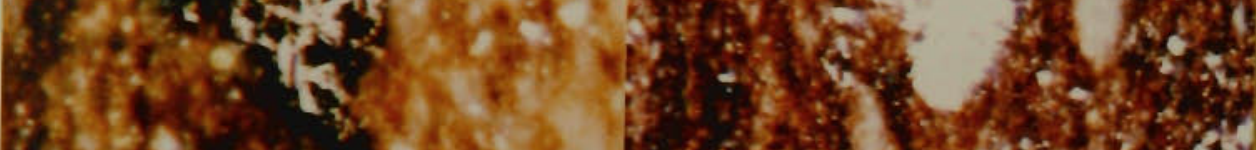
is

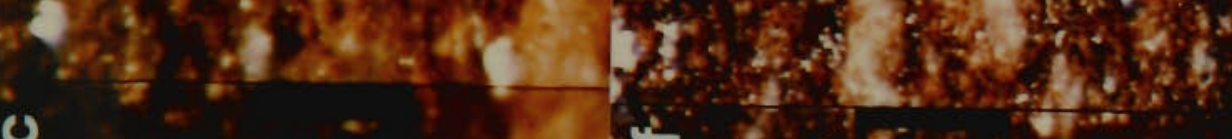

()

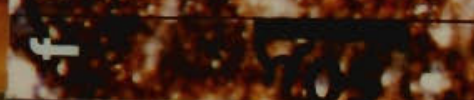

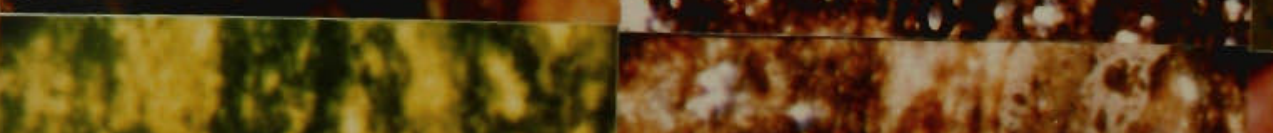

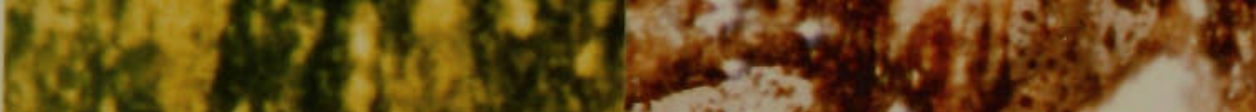
Q

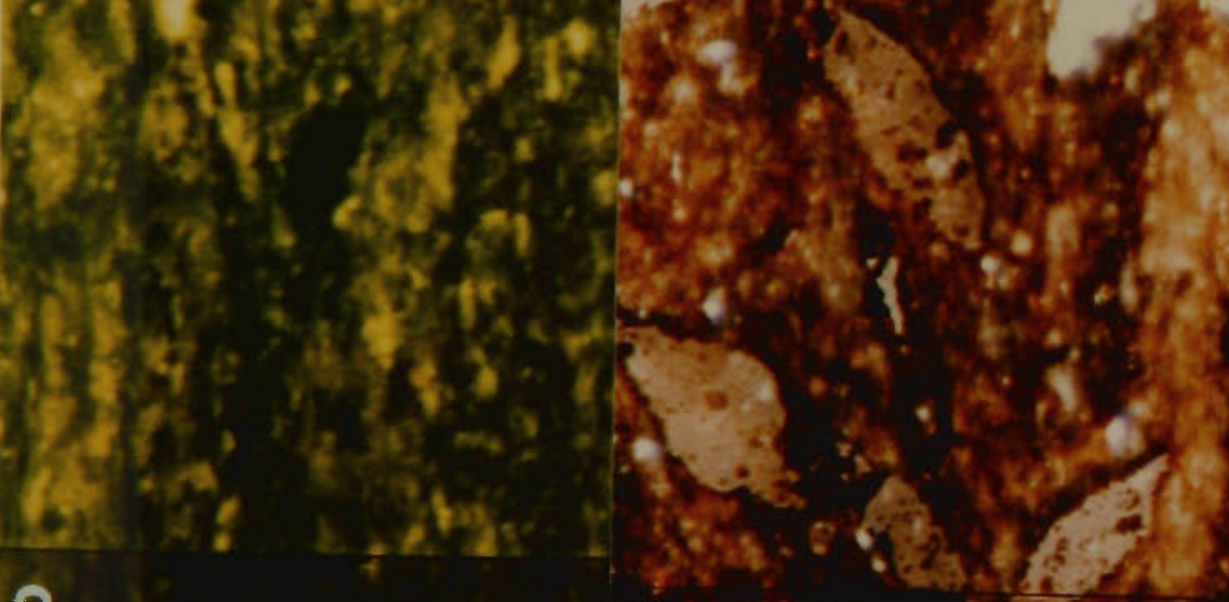

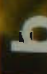

(1)

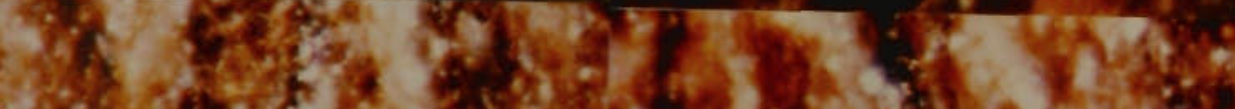

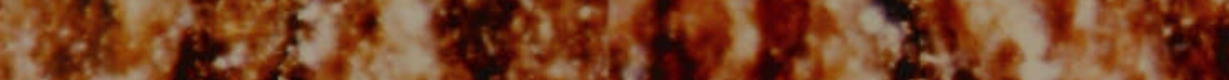

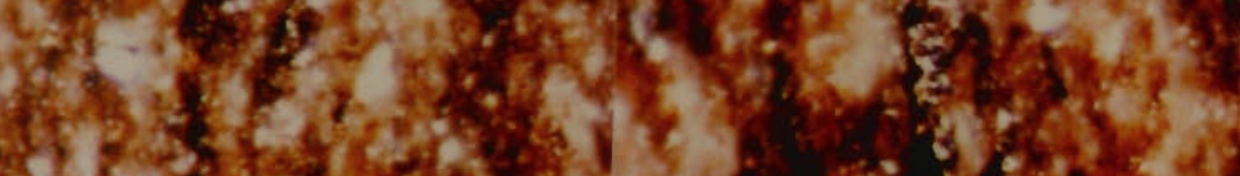

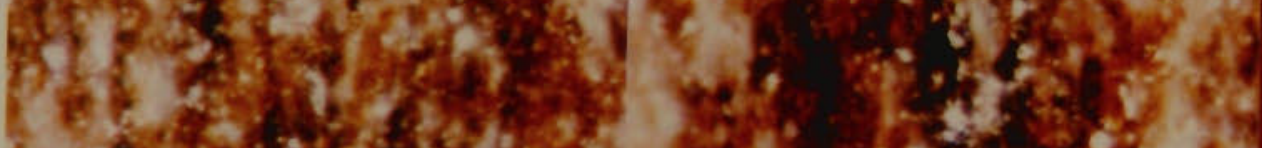

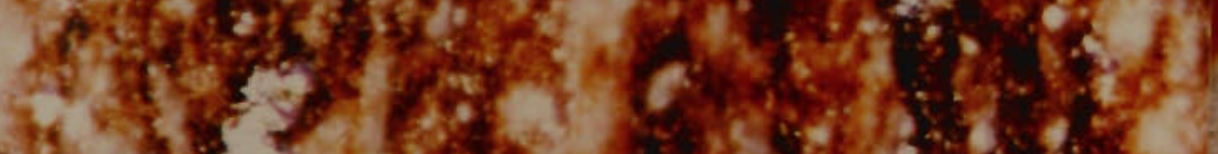

\section{6.}

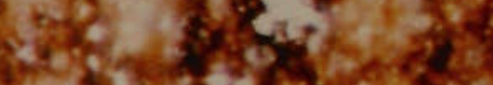

$\frac{1}{6}$

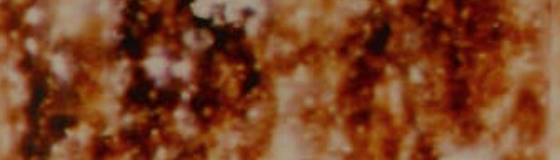

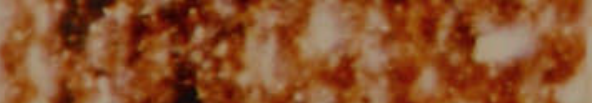

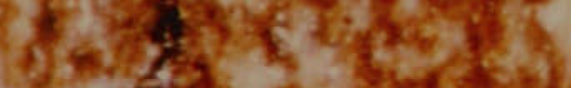
nes 504 ofchentes $20+1,2$

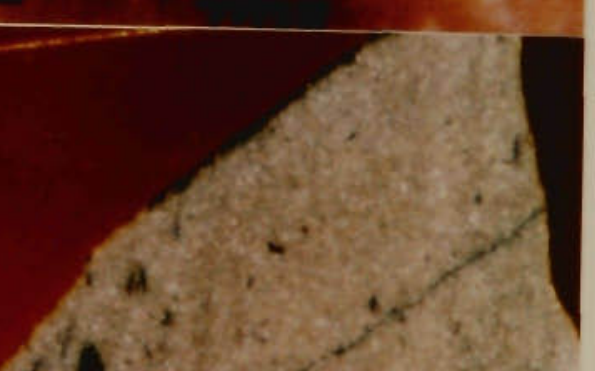




\section{PLATE 31}

Organic matter in the Velkerri Formation, Maiwok Subgroup, Roper Group, DDH Urapunga 3, 150.1 to 210.7. m. 


\section{PLATE 31}

\section{Organlc matter In the Velkerrl Formatlon, Malwok Subgroup, Roper Group, DDH Urapunga 3; perpendlcular to bedding.}

a) $150.1 \mathrm{~m}$, vein bitumen; plane-polarized white reflected light, scale bar $=20$ microns;

b) as for a) but under crossed polars;

c) $172.6 \mathrm{~m}$; randomly orientated pieces of nonfluorescent lamalginite, white reflected light; mean $\operatorname{maxRo}=2.34 \%$; field width $=3.4 \mathrm{~mm}$;

d) $172.6 \mathrm{~m}$; isolated piece of nonfluorescent lamalginite; plane-polarized white reflected light, scale bar $=20$ microns;

e) $172.6 \mathrm{~m}$; several strands of nonfluorescent lamalginite; plane-polarized white reflected light; field-width $=200$ microns;

f) $210.7 \mathrm{~m}$; nonfluorescent lamalginite of varying sizes and differing orientations due to soft-sediment movement; white reflected light; mean maxRo $=3.41 \%$; field-width $=8$ $\mathrm{mm}$;

g) $210.7 \mathrm{~m}$; pieces of nonfluorescent lamalginite, some contorted due to soft sediment movement; white reflected light; field-width $=3.4 \mathrm{~mm}$;

h) $210.7 \mathrm{~m}$; two small pieces of lamalginite, one showing silvery reflecting surface; plane polarized white reflected light, scale bar $=50$ microns;

i) as for h) but in fluorescence mode showing faint mineral fluorescence but no lamalginite fluorescence. 


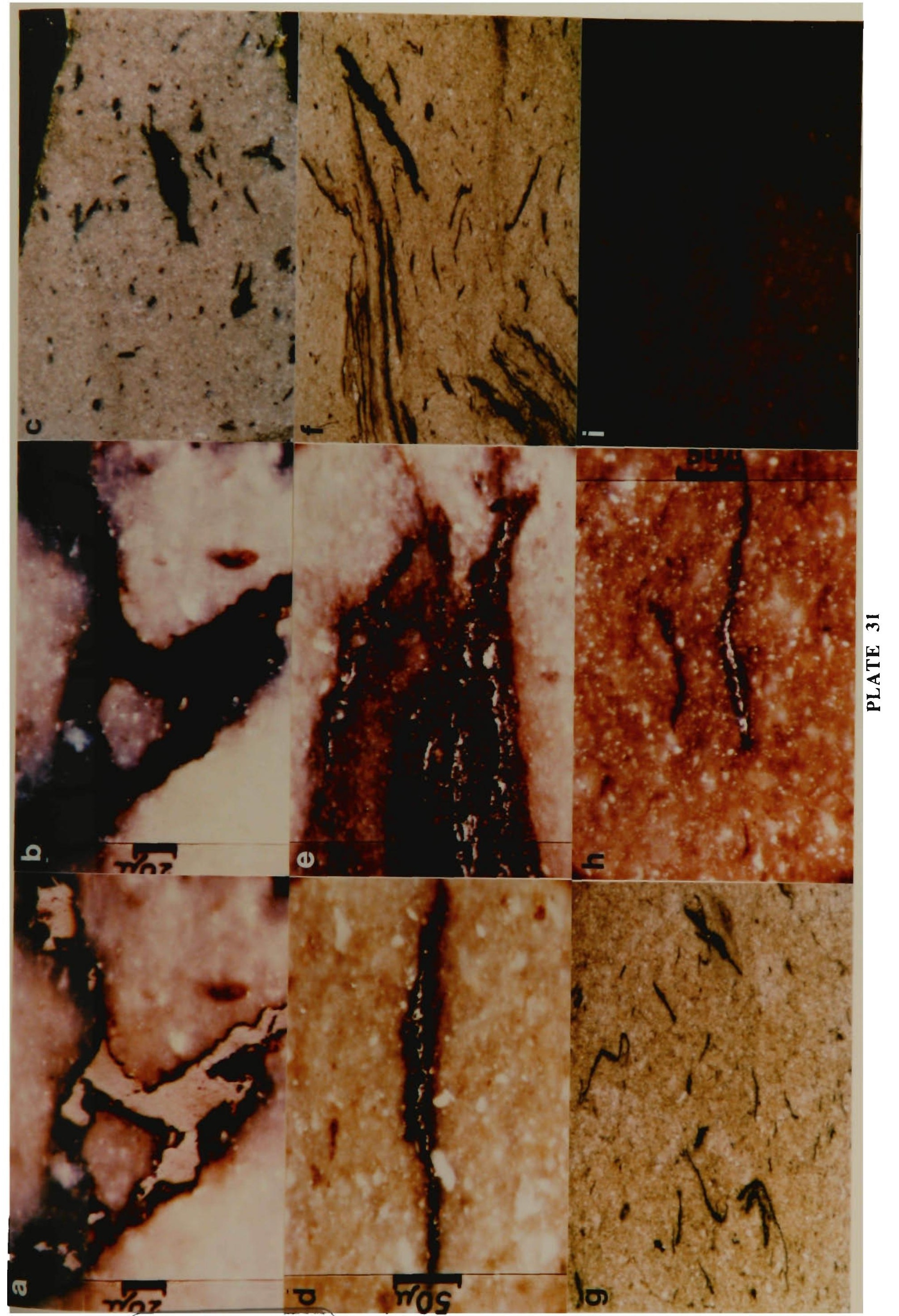




\section{PLATE 32}

Oncolites, McMinn Formation, Maiwok Subgroup, Roper Group; DDH Urapunga 4, 32.3m. 
PLATE 32

Oncolites, McMInn Formation, Maiwok Subgroup, Roper Group; DDH Urapunga 4, $32.3 \mathrm{~m}$; perpendlcular to beddling.

A) A composite photo showing a variety of oncolite shapes, from spheroidal in the central area to lenticular in upper and lower areas. A broken spheroidal oncolite is in an arenite bed in upper half of the photo; white reflected light;

B) a large lenticular oncolite, in the upper half of the photo, that has a nucleus of several mineral grains whereas underlying oncolite has no obvious nucleus and appears partly deformed around an underlying quartz grain; white reflected light; field-width $=3.4 \mathrm{~mm}$;

C) a fluted oncolite, in the central area; the black "tail" of this oncolite is typical of the dark, thin, lenticular oncolites forming much of the lower half in photo A; white reflected light; field-width $=3.4 \mathrm{~mm}$;

D) lenticular oncolites; white reflected light; field-width $=3.4 \mathrm{~mm}$. 

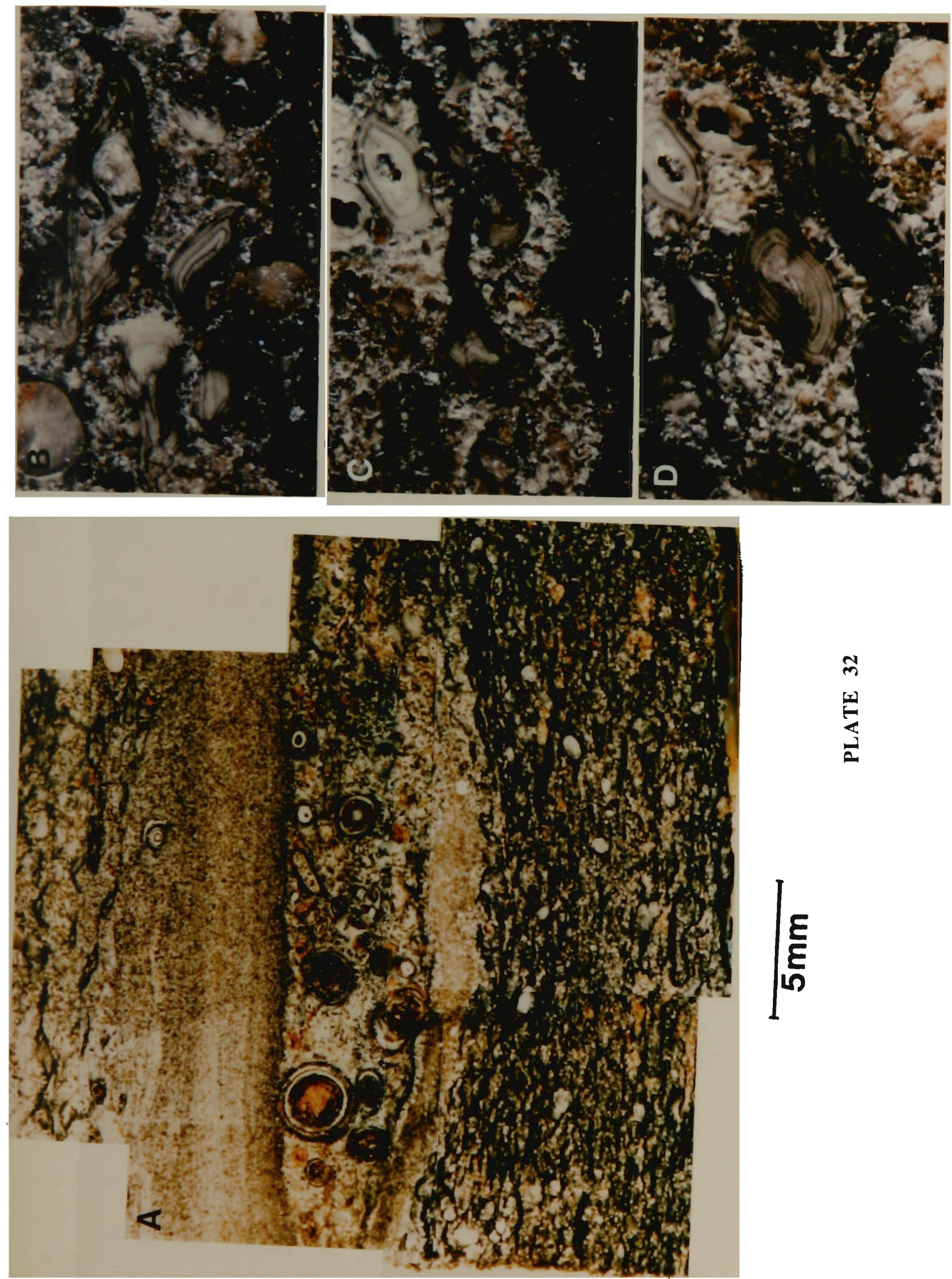


\section{PLATE 33}

Oncalginite and bitumen, McMinn Formation, Maiwok Subgroup, Roper Group, DDH Urapunga 4, $32.3 \mathrm{~m}$. 


\section{PLATE 33}

\section{Oncalginite and bltumen, McMinn Formation, Malwok Subgroup, Roper Group, DDH Urapunga 4, $32.3 \mathrm{~m}$. Perpendlcular to bedding.}

A) Thin silvery laminae of oncalginite diverging and passing around a round quartz grain on the left which forms the nucleus of a lenticular oncolite; plane-polarized white reflected light; scale bar $=50$ microns;

B) thin silvery laminae of oncalginite; plane-polarized white reflected light; scale bar $=50$ microns;

C) matrix bitumen in centre partially surrounding a darker carbonate rhomb, and oncalginite or vein bitumen on the right; plane-polarized white reflected light; mean maxRo (oncalginite + bitumen) $=1.54 \%$; scale bar $=50$ microns;

D) part of a large spherical oncolite showing darker, probably organic rich laminae surrounding a rounded quartz grain nucleus on the right; plane-polarized white reflected light; field-width $=300$ microns;

E) single strands of thin silvery oncalginite; plane polarized white reflected light; scale bar $=50$ microns;

F) as for E) but under crossed polars;

G) a single thin wavy silvery strand of oncalginite following the laminae of a lenticular oncolite; plane polarized white reflected light; field-width $=300$ microns;

H) two parallel thin silvery oncalginite strands which diverge and partially pass around a lens of sphalerite on the left; plane polarized white reflected light; field-width $=300$ microns;

l) as for $\mathrm{H}$ ) but under crossed-polars demonstrating the strong anisotropism of the sphalerite and the lack of anisotropism of the oncalginite. 


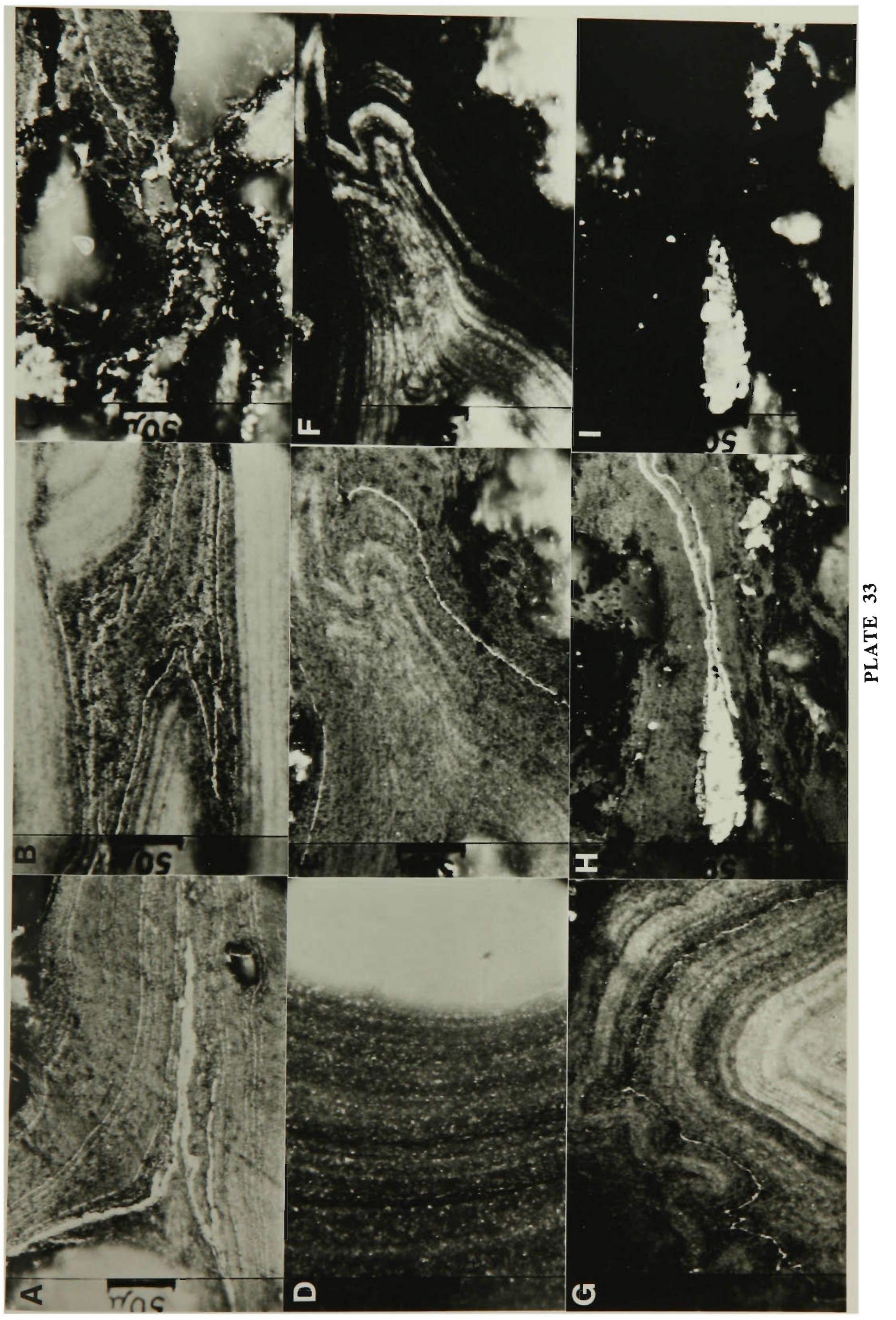




\section{PLATE 34}

\section{Organic matter in the Velkerri Formation, Maiwok Subgroup, Roper Group, DDH Urapunga 4; 157.3 to 209.5 $\mathrm{m}$.}




\section{PLATE 34}

Organic matter In the Velkerrl Formatlon, Malwok Subgroup, Roper Group, DDH Urapunga 4; 157.3 to $209.5 \mathrm{~m}$; perpendlcular to beddling.

A) $157.3 \mathrm{~m}$; a strand of fluorescent lamalginite in the central area; white blurry spots are pyrite; plane-polarized reflected white light; mean maxRo (fluorescent lamalginite) = $0.28 \%$; scale bar $=20$ microns;

B) as for A) but in fluorescence mode, the lamalginite strand is weakly fluorescent;

C) $157.3 \mathrm{~m}$; an isolated piece of nonfluorescent lamalginite in central area; white blurry spots are pyrite; plane polarized reflected white light; mean maxRo (nonfluorescent lamalginite) $=0.50 \%$; scale bar $=20$ microns;

D) as for C) but in fluorescence mode;

E) $209.5 \mathrm{~m}$; a light-grey strand of nonfluorescent lamalginite in the central upper area of the photo and a strand of dark-grey fluorescent lamalginite in the lower half of the photo; white blurry spots are pyrite; mean maxRo (fluorescent lamalginite) $=0.29 \%$, mean maxRo (nonfluorescent lamalginite) $=0.59 \%$; plane polarized reflected white light; scale bar $=20$ microns;

F) as for $E$ ) but in fluorescence mode;

G) $209.5 \mathrm{~m}$, a silvery, broken-up, strand of nonfluorescent lamalginite in the upper half of the photo and irregularly shaped bitumen with imbedded phosphate microspheres in the lower left of the photo; white blurry spots are pyrite; plane polarized reflected white light; scale bar $=20$ microns;

H) as for G) but in fluorescence mode, phosphate microspheres have fluorescent rims;

1) $209.5 \mathrm{~m}$; a lens of carbonate in the central right area of the photo containing bright yellow fluorescent oil inclusions; scale bar $=20$ microns. 


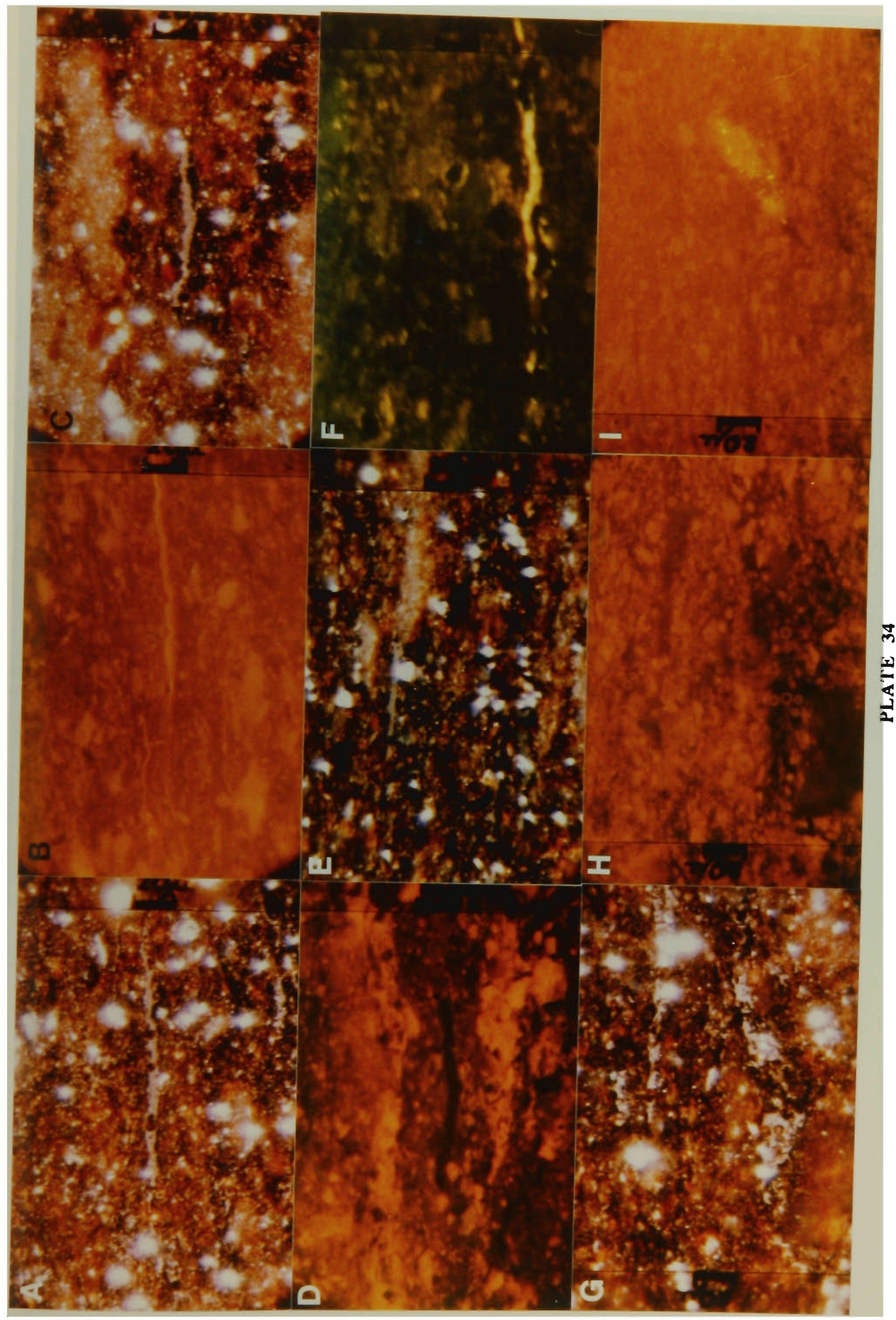


Organic matter in the Velkerri Formation, Maiwok Subgroup, Roper Group, DDH Urapunga $4 ; 258.5$ to 348.2 m. 


\section{PLATE 35}

Organic matter in the Velkerrl Formation, Malwok Subgroup, Roper Group, DDH Urapunga $4 ; 258.5$ to $348.2 \mathrm{~m}$; perpendicular to beddling.

A) $258.5 \mathrm{~m}$; isolated black pieces of lamalginite, different orientations of the lamalginite probably due to soft sediment slumping of the mudstone; white reflected light; field-width $=8 \mathrm{~mm}$;

B) $258.5 \mathrm{~m}$; an isolated strand of lamalginite; plane-polarized white reflected light; scale bar $=30$ microns;

C) as for B) but in fluorescence mode; lamalginite is faintly fluorescent in places;

D) $342.7 \mathrm{~m}$; a strand of nonfluorescent lamalginite in the lower half of the photo and pieces of disseminated bitumen (circled); plane-polarized white reflected light; mean maxRo( nonfluorescent lamalginite) $=0.98 \%$; scale bar $=50$ microns;

E) $342.7 \mathrm{~m}$, part of a vuggy band of lutite containing oil; a small vug appears as a blurry white object in the center of the photo; plane-polarized white reflected light; scale bar = 20 microns;

F) as for E) but in fluorescence mode showing brightly fluorescing oil; free oil was observed bubbling from this core over the interval 345.4 - $346.55 \mathrm{~m}$ (Jackson et al., 1987);

G) an originally non-fluorescing greywacke that has had a drop of oil from Urapunga 4 placed on it; the oil has impregnated the mineral matrix and has produced similar effects as seen in fluorescing mineral matrices in a number of specimens observed from the the McArthur Basin; fluorescence mode; field-width $=0.8 \mathrm{~mm}$;

H) $347.0 \mathrm{~m}$; a brightly fluorescing diagonal fissure containing oil surrounded by patches of fluorescing mineral matter; fluorescence mode; field-width $=0.8 \mathrm{~mm}$;

1) $348.2 \mathrm{~m}$; a broken-up strand of nonfluorescent lamalginite in the central area of the photo; plane-polarized white light; mean maxRo(nonfluorescent lamalginite) $=1.05 \%$; scale bar $=50$ microns. 


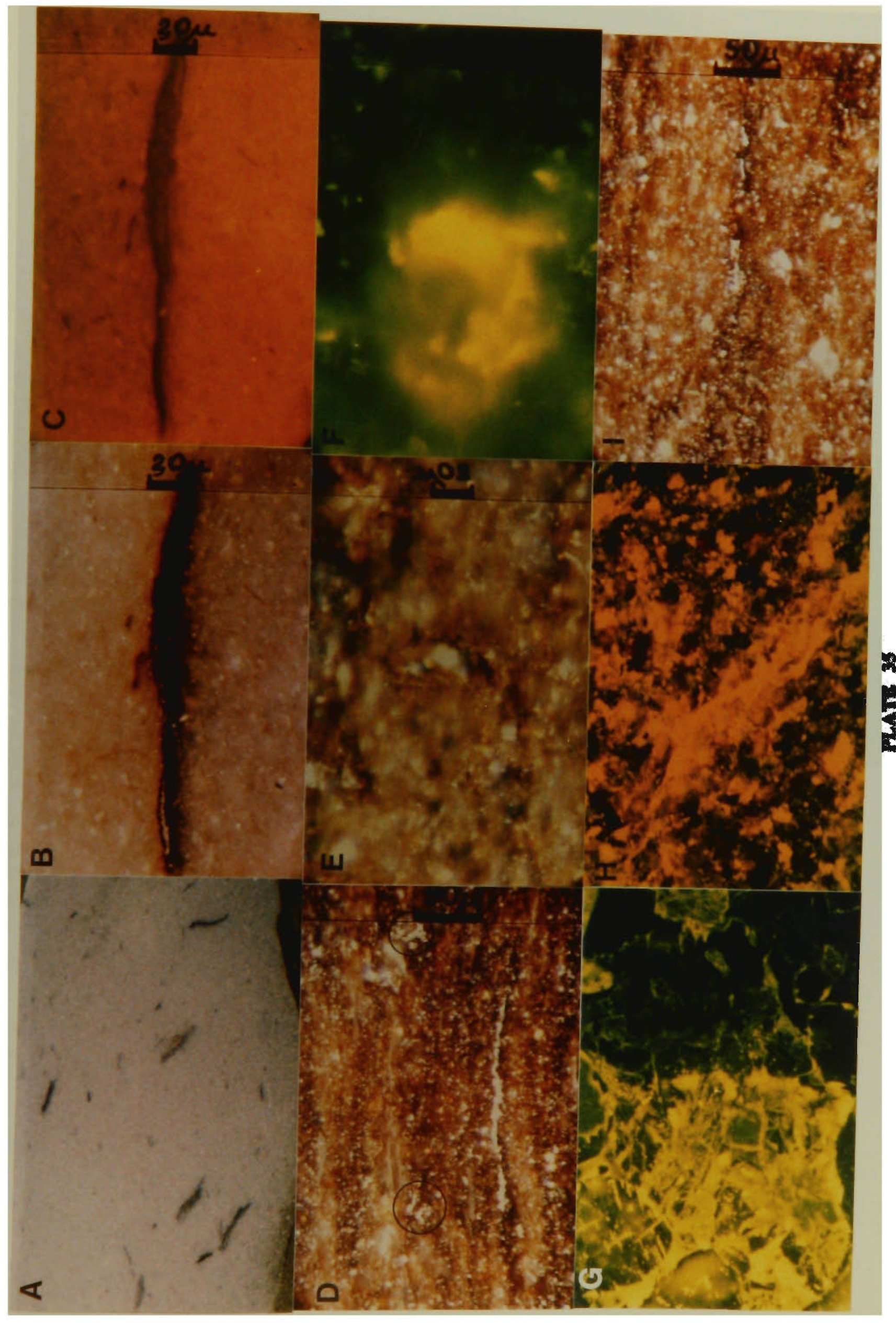




\section{PLATE 36}

Organic matter in the Velkerri and Corcoran Formations, Roper Group, DDH Urapunga 4; 354.7 to $463.8 \mathrm{~m}$. 


\title{
PLATE 36
}

\author{
Organic matter in the Velkerri and Corcoran Formations, Roper Group, DDH \\ Urapunga $4 ; 354.7$ to $463.8 \mathrm{~m}$; perpendicular to bedding.
}

A) $354.7 \mathrm{~m}$; Velkerri Formation; nonfluorescent lamalginite (long thin silvery strand in the central area of the photo, white spots are pyrite); plane-polarized white reflected light; mean $\operatorname{maxRo}($ nonfluorescent lamalginite) $=1.09 \%$; scale bar $=20$ microns;

B) as for A) but in fluorescence mode;

C) $354.7 \mathrm{~m}$; Velkerri Formation; dispersed bitumen (light grey colour, a large piece is at left central area of photo, white spots are pyrite); plane-polarized white reflected light; scale bar $=20$ microns;

D) as for C) but in fluorescence mode;

E) $463.8 \mathrm{~m}$, Corcoran Formation; dark laminae are organic matter; buckled appearance of one laminae in the central area indicates soft-sediment slumping; white reflected light; field-width $=8 \mathrm{~mm}$;

F) 463.8, Corcoran Formation; a silvery piece of disseminated bitumen in the central area of the photo; the dark bands are bitumen-impregnated mineral matter; plane-polarized white reflected light; mean maxRo(nonfluorescent lamalginite + bitumen) $=1.42 \%$; scale bar $=20$ microns;

G) as for F) but in fluorescence mode; the piece of disseminated bitumen and the bitumenimpregnated mineral matter is not fluorescent but mineral matter that is not bitumenimpregnated is strongly fluorescent;

H) 463.8, Corcoran Formation; nonfluorescent lamalginite and nonfluorescing bitumenimpregnated mineral matter and strongly fluorescing mineral matter; fluorescence mode; scale bar $=20$ microns;

l) as for $\mathrm{H}$ ) but in plane-polarized white reflected light mode. 


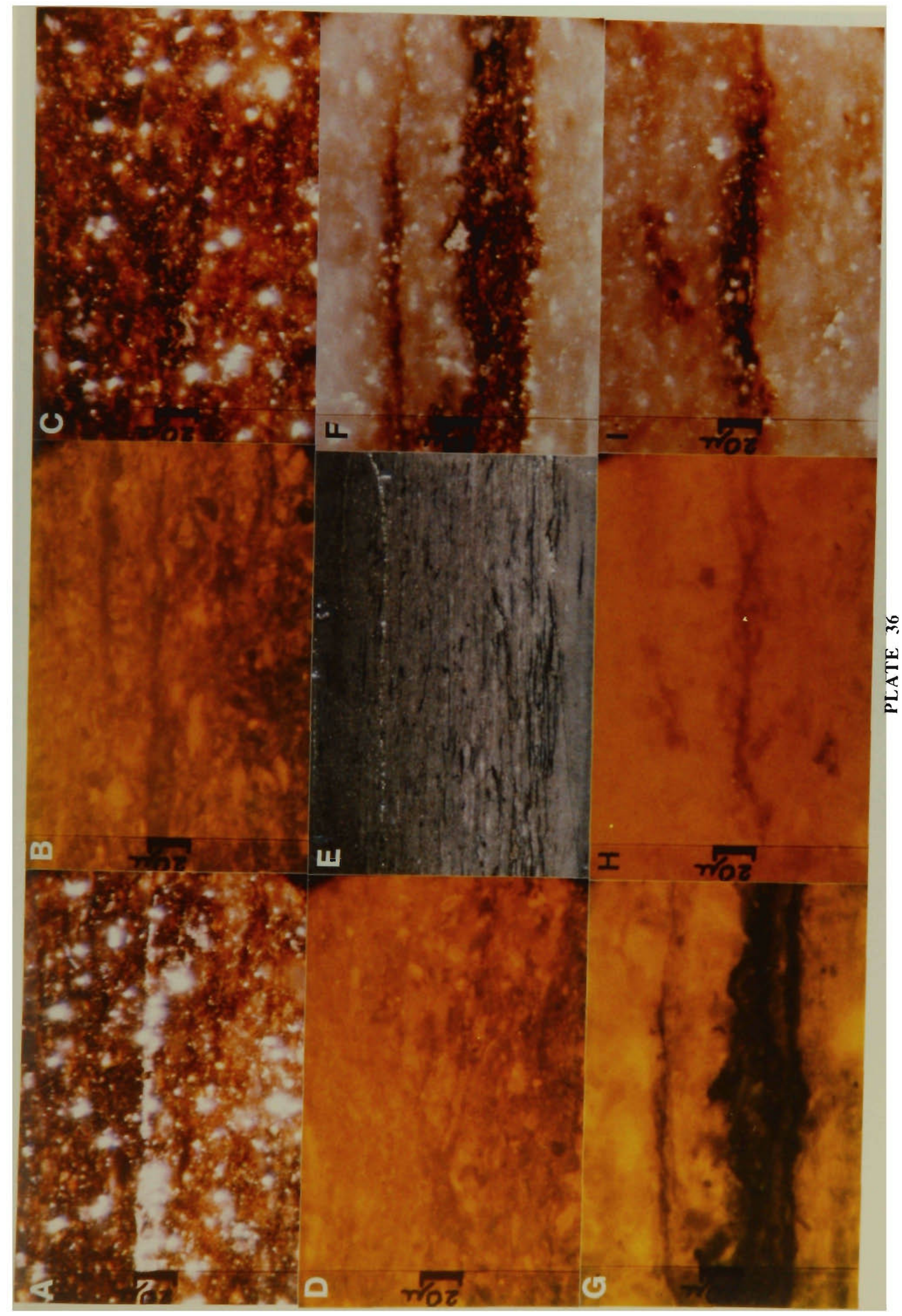




\section{PLATE 37}

Organic matter in the McMinn Formation, Maiwok Subgroup, Roper group, DDH X28. 
PLATE 37

Organlc matter In the McMinn Formation, Malwok Subgroup, Roper group, DDH X28; perpendicular to bedding.

A) $16.9 \mathrm{~m}$; a composite photo of a single large fluorescent lamalginite body and smaller fluorescent lamalginite; plane-polarised reflected white light; mean maxho(fluorescent lamaiginite $)=0.20 \%$; scale bar $=50$ microns;

B) as for A) but in fluorescence mode;

C) $16.9 \mathrm{~m}$; a large lamalginite body composed of a number of lamellae, and smaller lamalginite bodies; fluoresence mode; scale bar = 50 microns;

D) $32.0 \mathrm{~m}$; discontinuous lamalginite bodies of varying sizes; fluorescence mode; fieldwidth $=0.8 \mathrm{~mm}$;

E) $61.0 \mathrm{~m}$; long thin lamalginite bodies; fluorescence mode; field-width $=2.0 \mathrm{~mm}$;

F) $82.9 \mathrm{~m}$; a small discrete lamalginite body; plane-polarized reflected; mean $\operatorname{maxRo}($ fluorescent lamalginite) $=0.40 \%$; white light; scale bar $=50$ microns;

G) as for F) but in fluorescence mode, lamalginite shows faint fluorescence while surrounding mineral matter is strongly fluorescent. 


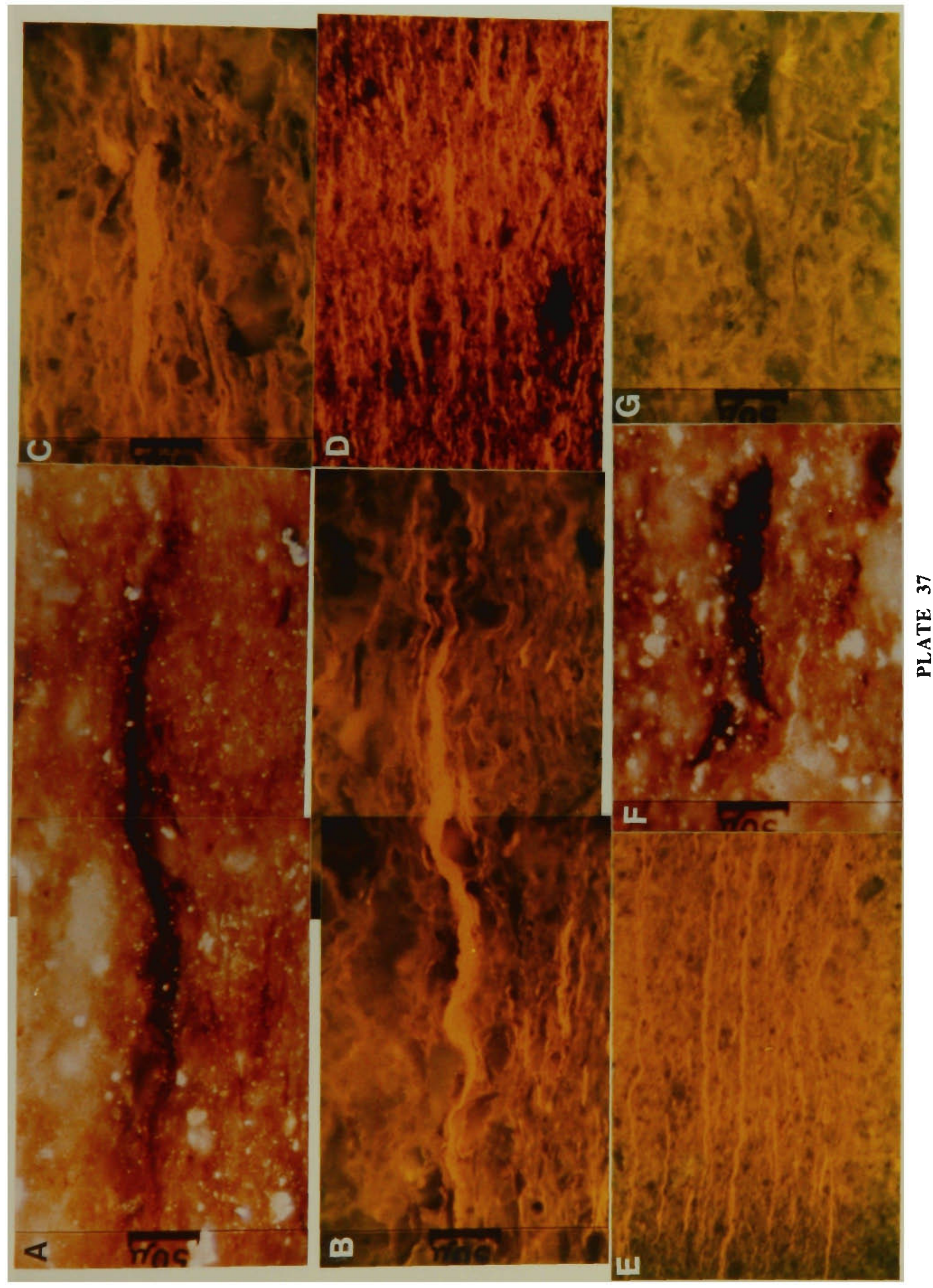




\section{PLATE 38}

Thucholite grains in the Roper Group. 


\section{PLATE 38}

\section{Thucholite grains In the Roper Group; perpendlcular to beddlng.}

a) McMinn Formation, DDH X28, $16.9 \mathrm{~m}$, plane-polarised white reflected light; scale bar $=50$ microns,

b) as for a) but under crossed polars;

c) as for a) but in fluorescence mode;

d) McMinn Formation, DDH X28, $32.0 \mathrm{~m}$, showing thucholitic bitumen formed around a presumably radioactive section in a grain of mica; plane-polarised white light; scale bar $=20$ microns,

e) as for d) but in fluorescence mode;

f) McMinn Formation, DDH X28, $32.0 \mathrm{~m}$, lamalginite appears displaced by the grain of thucholite which has a fluorescent halo; fluorescence mode; field width = $0.8 \mathrm{~mm}$;

g) Velkerri Formation, DDH Urapunga 4, $342.7 \mathrm{~m}$, plane-polarized white reflected light, field width $=0.2 \mathrm{~mm}$,

h) Velkerri Formation, DDH Urapunga 4, $354.7 \mathrm{~m}$, thucholite, plane-polarized reflected white light; scale bar $=20$ microns,

i) as for h) but in fluorescence mode; the thucholite has a large fluorescent halo due to it being almost a tangential section of a larger grain. 


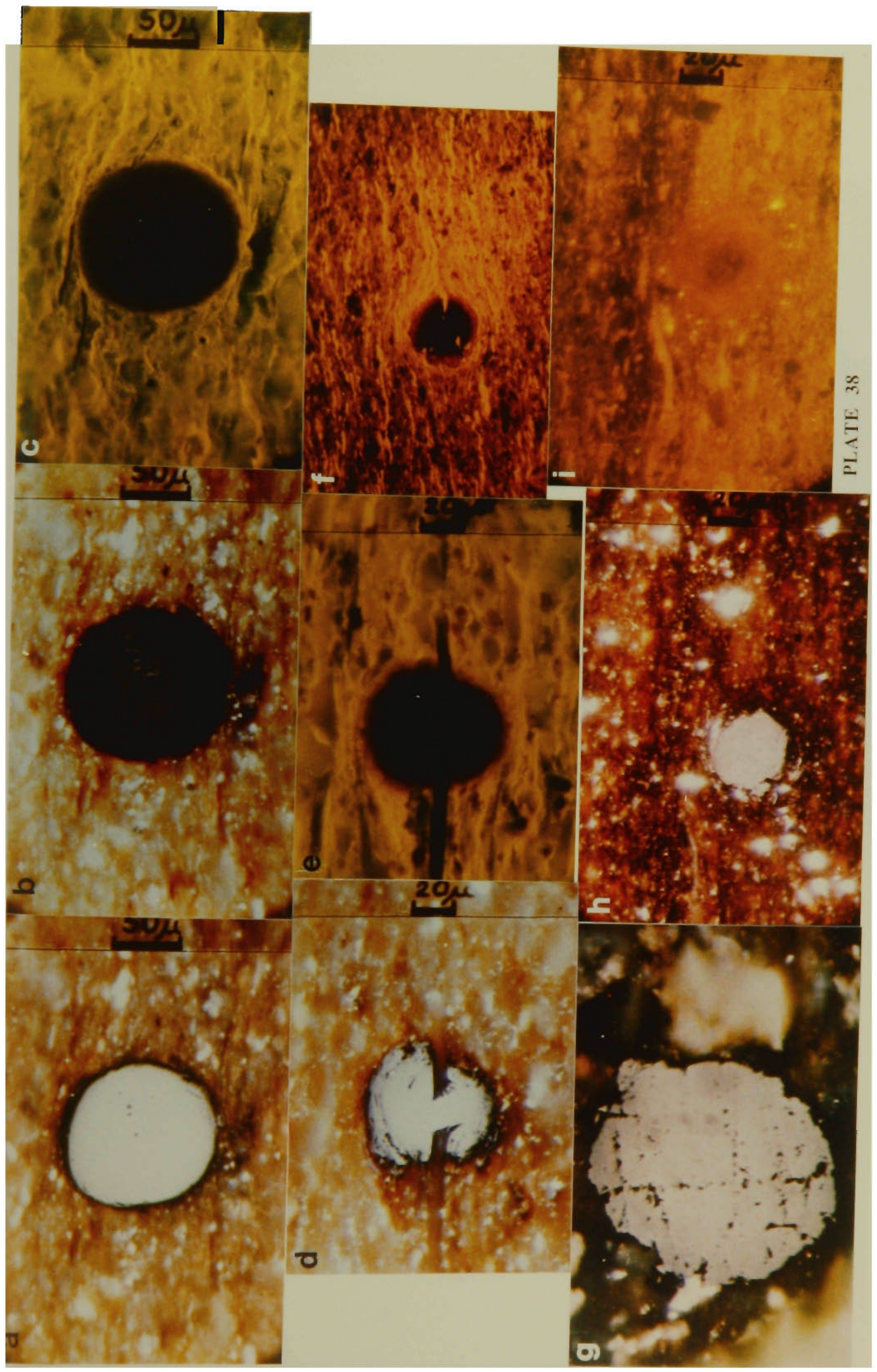




\section{PLATE 39}

Possible pseudomorphs after gypsum in the Velkerri Formation and organic matter in the Velkerri Formation, Abner Sandstone \& Mainoru Formation in DDH's 82/1,2,3 \& 8 . 


\section{PLATE 39}

Probable pseudomorphs after gypsum in the Velkerri Formation and organlc matter in the Velkerrl Formation, Abner Sandstone \& Malnoru Formation in DDH's $82 / 1,2,3$ \& 8 ; perpendicular to beddlng.

A) $\mathrm{DDH} 82 / 1,380.6 \mathrm{~m}$, Velkerri Formation, showing small grains of dark carbonate and light grey pyrite which are probably pseudomorphous after gypsum, in mudstone; white reflected light; field-width $=8 \mathrm{~mm}$;

B) as for A) but at an higher magnification showing a rosette of pyrite and carbonate which is probably pseudomorphous after gypsum.

C) $\mathrm{DDH} 82 / 1,380.6 \mathrm{~m}$; Velkerri Formation; showing part of a relatively large body of fluorescent lamalginite containing pyrite (white spots); mean maxRo\% $=0.47$; plane polarized white reflected light; scale bar $=20$ microns;

D) as for C) but in fluorescence mode;

E) DDH 82/8, $67.4 \mathrm{~m}$, Velkerri Formation, showing an discrete body of fluorescent lamalginite; mean maxRo\%(fluorescent lamalginite) $=0.32$; plane-polarized white reflected light; scale bar $=50$ microns;

F) DDH 82/3, $145.3 \mathrm{~m}$, Jalboi Member, Abner Sandstone, showing a discrete body of nonfluorescent lamalginite; mean $\operatorname{maxRo} \%=2.39$; plane-polarized white reflected light; field-width $=0.20 \mathrm{~mm}$;

G) $\mathrm{DDH}$ 82/2, $66.8 \mathrm{~m}$, Mainoru Formation, showing sandy and silty bands containing discrete bodies of lamalginite; white reflected light; field-width $=3.4 \mathrm{~mm}$;

H) as for G) but at an higher magnification showing a single discrete piece of nonfluorescent lamalginite; mean maxRo\% $=2.21$; plane polarized white reflected light; scale bar = 20 microns;

1) $\mathrm{DDH} 82 / 3478.5 \mathrm{~m}$, Mainoru Formation; plane polarized white reflected light; showing a discrete body of nonfluorescent lamalginite; mean $\operatorname{maxRo\% }=2.01$; scale bar $=20$ microns. 


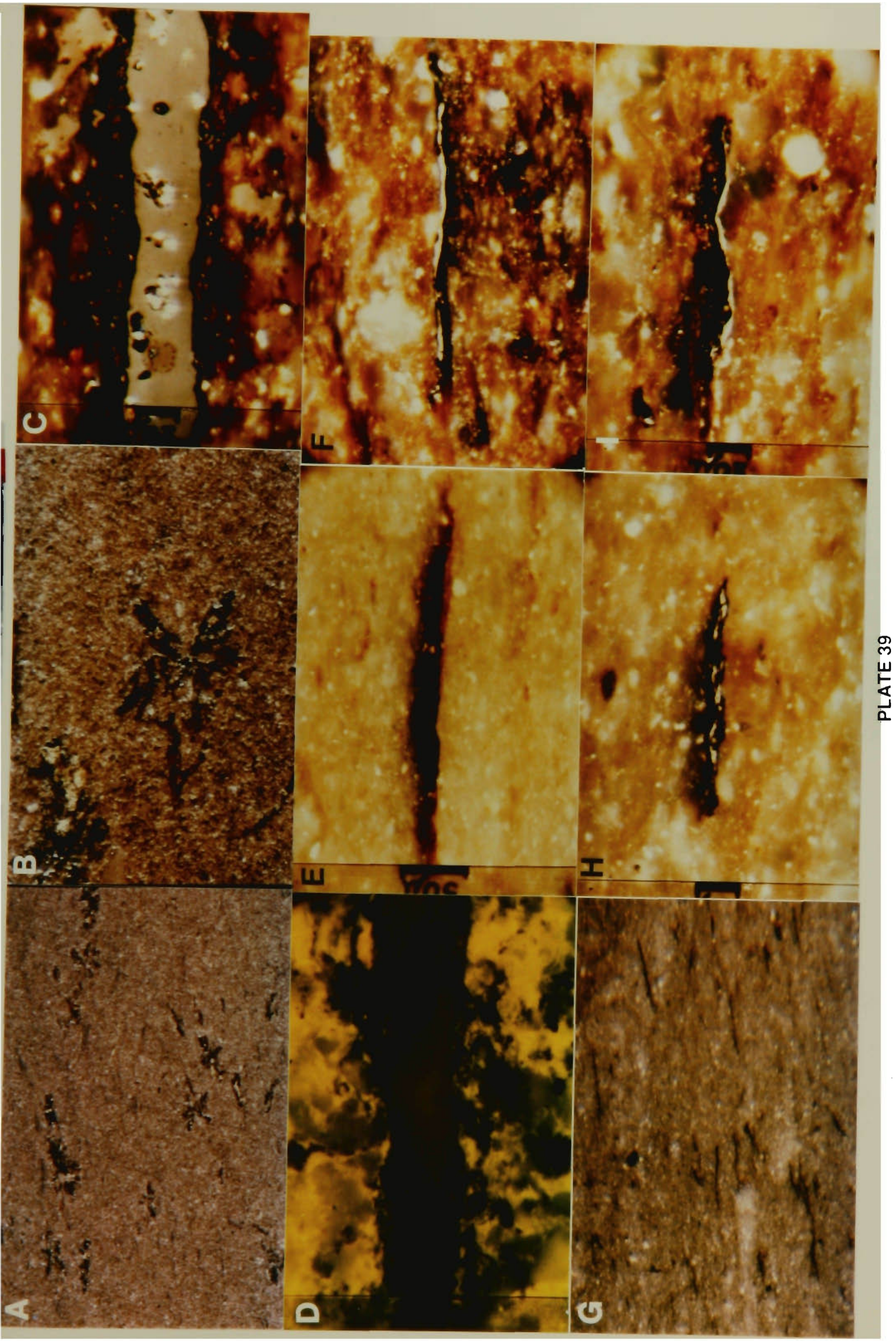


PLATE 40

Organic matter in the Abner Sandstone and Mainoru Formation, Roper Group; DDH's Urapunga 1 \& 5. 


\section{PLATE 40}

Abner Sandstone and Malnoru Formation, Roper Group; DDH's Urapunga 1 \& 5; perpendicular to bedding.

A) Mainoru Formation, Urapunga 1, $120.9 \mathrm{~m}$; a discrete piece of nonfluorescent lamalginite; mean maxRo\% $=2.67$; plane-polarized white reflected light; scale bar $=20$ microns;

B) Jalboi Member, Abner Sandstone, Urapunga 5, $140.0 \mathrm{~m}$; several pieces of nonfluorescent lamalginite; mean maxRo\% $=4.25$; plane-polarized white reflected light; field-width $=200$ microns;

C) Jalboi Member, Abner Sandstone, Urapunga 5, $148.9 \mathrm{~m}$, composite photo showing a coarse arenite bed and organic rich lutites; white reflected light; scale bar $=1 \mathrm{~mm}$;

D) Arnold member, Abner Sandstone, Urapunga 5, $323.5 \mathrm{~m}$; small discrete piece of nonfluorescent lamalginite, mean $\operatorname{maxRo\% }=4.27$; plane-polarized white reflected light; scale bar $=20$ microns;

E) Mainoru Formation, Urapunga 5, $590.1 \mathrm{~m}$; large rectangular piece of bitumen, probably vug bitumen, in the central area of the photo; mean maxRo\% $=2.31$; plane-polarized white reflected light; scale bar $=20$ microns;

F) as for E) but under crossed-polars, showing speckled appearance of the bitumen;

G) Mainoru Formation, Urapunga 5, $590.1 \mathrm{~m}$; showing a patch irregularly shaped pieces of bitumen (circled);

H) as for $G$ ) but under crossed-polars. 


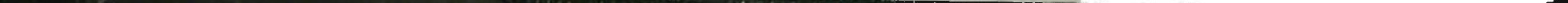


PLATE 41

SEM X-ray maps of bitumen veins in the Velkerri Formation, DDH Urapunga $3,98.3 \mathrm{~m}$. 
SEM X-ray maps of bltumen velns in the Velkerrl Formation, DDH Urapunga $3,98.3 \mathrm{~m}$; all at the same scale; perpendlcular to beddlng.

A) X-ray map for $\mathrm{Si}$; large continuous dark area is a bitumen vein (see also Plate 29 for photomicrographs of this vein);

B) X-ray map for calcium of A);

C) X-ray map for phosphorus of A);

D) SEM photo of conformable and cross-cutting bitumen veins;

E) X-ray map for silica of D);

F) X-ray map for calcium of D);

G) X-ray map for potassium of D);

H) X-ray map for aluminium of D);

J) X-ray map for phosphorus of D). 

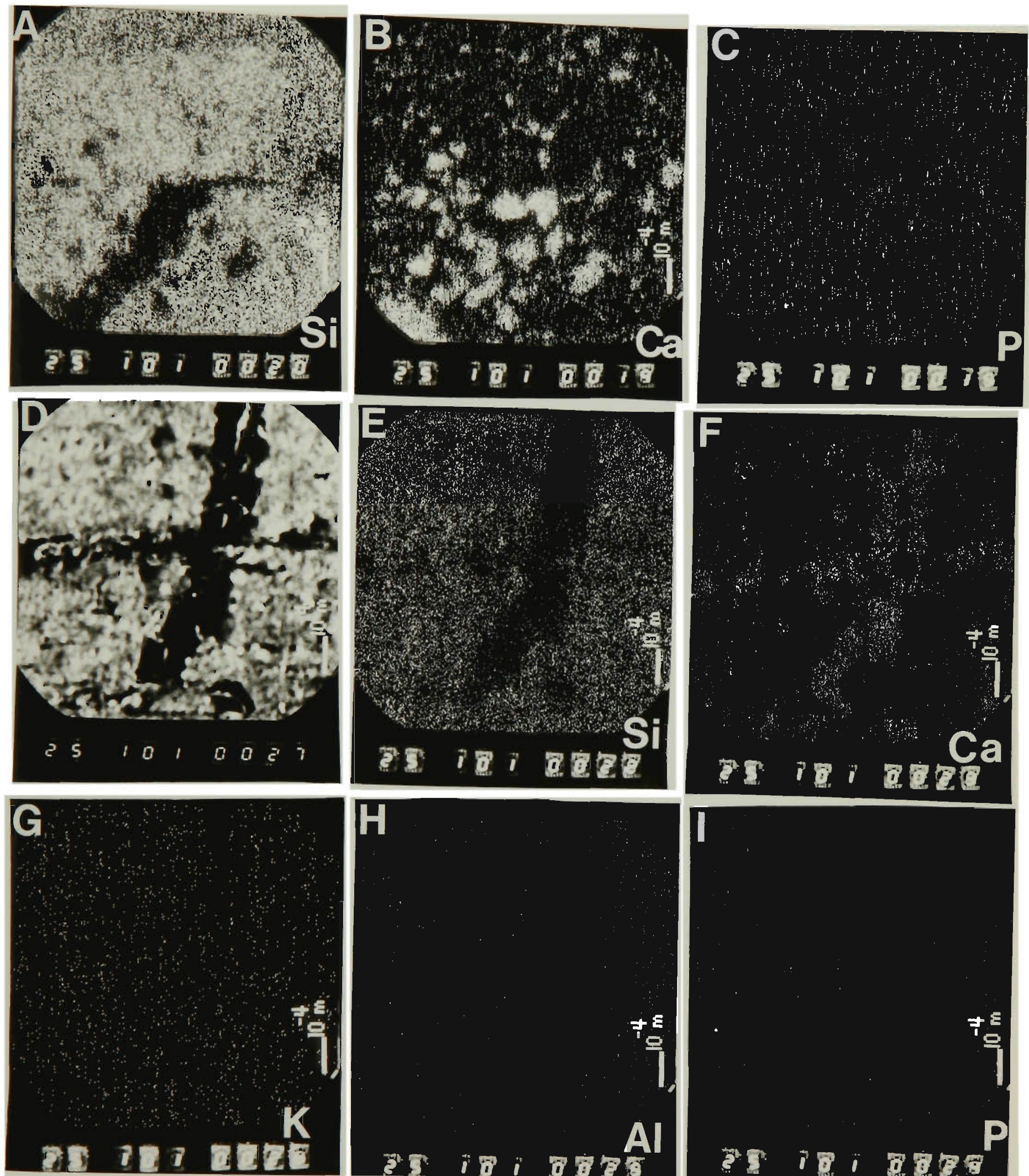

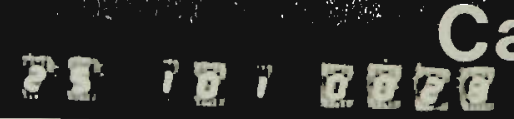

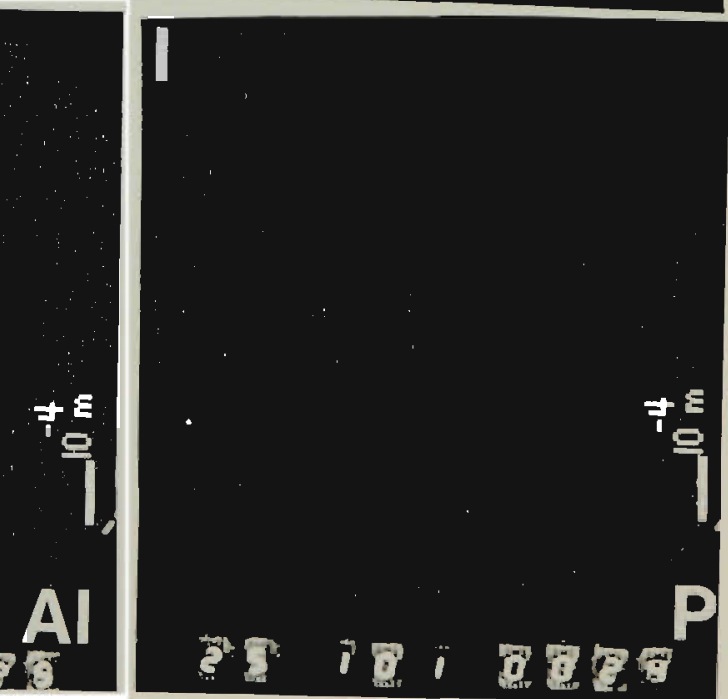




\section{PLATE 42}

SEM images and X-ray maps of phosphates in the Roper Group. 


\section{PLATE 42}

\section{SEM Images and X-ray maps of phosphates in the Roper Group; perpendicular to bedding.}
A) Velkerri Formation, DDH Urapunga 3 at $49.8 \mathrm{~m}$; SEM photo showing central dark area of lamalginite with an imbedded microsphere of phosphate;
B) X-ray map for calcium of A);
C) X-ray map for phosphorus of A);
D) Velkerri Formation, DDH Urapunga 4, $157.3 \mathrm{~m}$; showing dark organic matter and doughnut-shaped phosphate microspheres;
E) X-ray map for calcium of D);
F) X-ray map for phosphorus of D);
G) Cobanbirini Formation, Broadmere 1 well, $109.7 \mathrm{~m}$; SEM photo showing doughnut shaped phosphate microspheres;
H) X-ray map for calcium of $G$ );
I) X-ray map for phosphorus of $G$ ). 

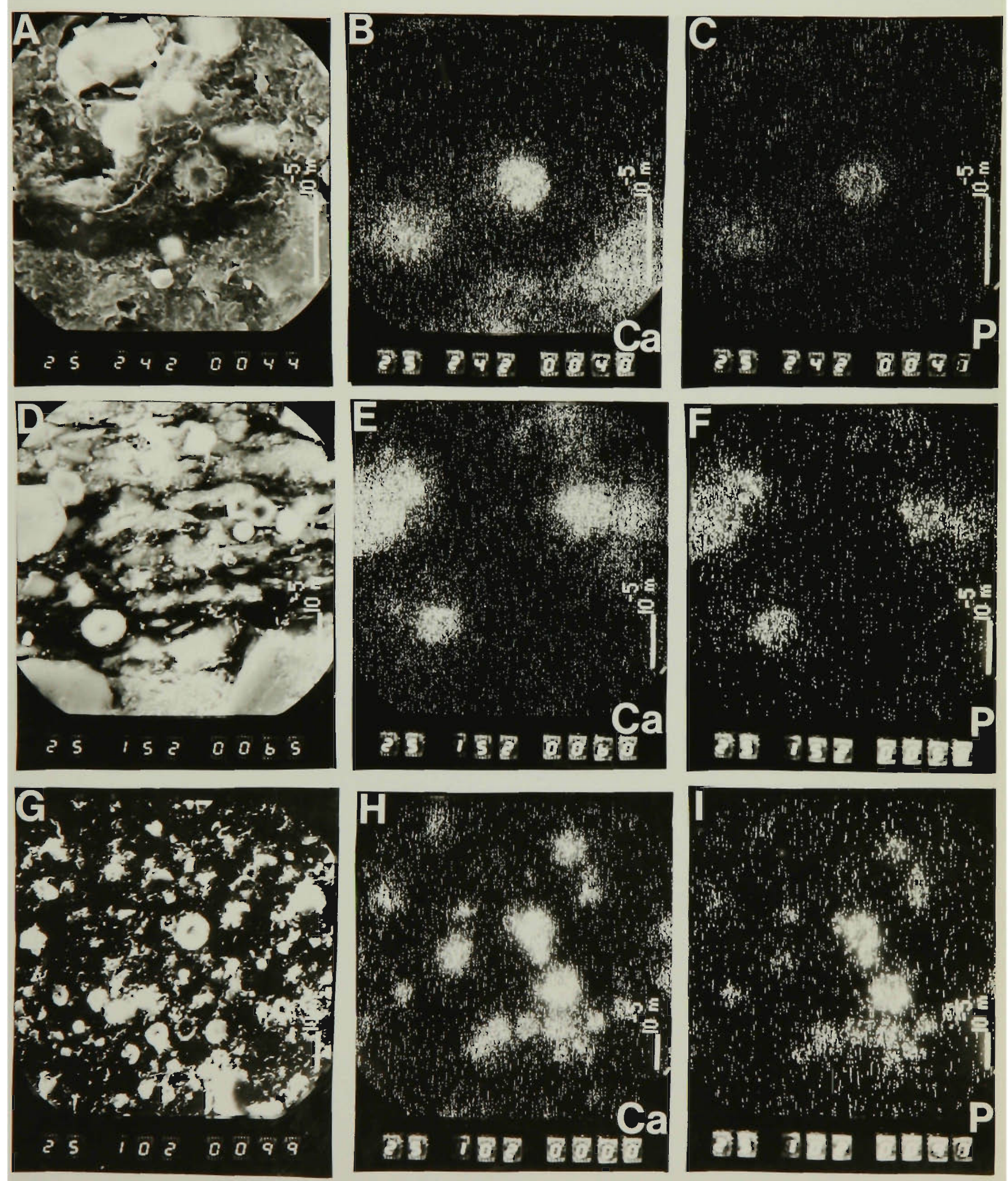

PLATE 42 